Universidade de São Paulo

Instituto de Astronomia, Geofísica e Ciências Atmosféricas

Departamento de Astronomia

Luiz Alberto de Paula

\title{
Elaboração de um modelo para formação planetária dentro do código magneto hidrodinâmico FARGO3D
}

"Versão Corrigida. O original encontra-se disponível na Unidade." 

Luiz Alberto de Paula

\section{Elaboração de um modelo para formação planetária dentro do código magneto hidrodinâmico FARGO3D}

"Versão Corrigida. O original encontra-se disponível na Unidade."

Tese apresentada ao Departamento de Astronomia do Instituto de Astronomia, Geofísica e Ciências Atmosféricas da Universidade de São Paulo como requisito parcial para a obtenção do título de Doutor em Ciências.

Área de Concentração: Astronomia

Orientadora: Prof. ${ }^{a}$ Dr. ${ }^{\text {a }}$ Tatiana Alexandrovna

Michtchenko

São Paulo 

Aos meus pais, José e Sônia, pelo esforço e a dedicação em todos os momentos. Espero que tenham compreendido minha ausência durante a realização desta caminhada.

À minha orientadora, Tatiana Alexandrovna Michtchenko, pelo apoio e a paciência, que não foi pouca, em todos os instantes desta importante etapa de minha vida. Dedico também este trabalho a você leitor, pois espero, sinceramente, que ela possa saciar sua sede de conhecimento ao invés vez da fome das traças da biblioteca. 



\section{Agradecimentos}

Escrever uma tese é uma experiência extremamente enriquecedora. No entanto, é uma tarefa árdua, cujos obstáculos se tornam transponíveis apenas com muito esforço e com a ajuda de muitas pessoas que participam, direta ou indiretamente, e que, muitas vezes, nem se dão conta da enorme contribuição que deram. Meus agradecimentos são direcionados a essas pessoas.

Primeiramente, gostaria de agradecer à minha familía, principalmente meus pais, José Carlos e Sônia dos Anjos, que, mesmo diante de todas as adversidades, puderam me dar a estrutura necessária, sem a qual este trabalho não existiria. Saibam que meu agradecimento é infinito e que nunca poderei recompensá-los à altura.

À minha orientadora e professora, Tatiana A. Michtchenko, por ter me dado a oportunidade que muitos outros negaram, pelas horas de leitura e revisão desta tese, pelo incentivo dado quando eu parecia perdido e desnorteado e, principalmente, por ter exigido maiores aperfeiçoamentos quando necessários. Aos professores e amigos, Pablo Benitez e Octavio M. Guilera, pelos valiosos ensinamentos.

Um agradecimento mais que especial à professora Priscilla Andressa de Sousa Silva pelas dicas fornecidas durante sua leitura técnica.

Aos colegas do grupo de Astronomia Dinâmica: Adrian Rodriguez Colucci, Alan Jorge Alves do Carmo, Eduardo Andrade Inês, Hugo Alberto Folonier, Jorge Alfredo Correa Otto, Levy Scalise Maciel, Marcos Tadeu dos Santos e Natasha Fioretto Aguero, por todas as dicas e contribuições para o desenvolvimento deste trabalho.

A Marilu Maranho Tassetto, pelos apontamentos e as dicas preciosas da língua portuguesa, que melhoraram muito esta tese.

A toda a equipe do Laboratório de Astroinformática, que além de ajudar na manutenção 
e instalação de todo aparato técnico, se dispuseram a esclarecer todas as dúvidas, sem essa contribuição esta tese não teria sido realizada. Essa pesquisa também contou com o auxílio dos recursos de HPC disponibilizados pela Superintendência de Tecnologia da Informação da Universidade de São Paulo. Agradeço imensamente ao professor Francisco Ribacionka pela ajuda com o suporte técnico do cluster.

À FAPESP, pelo apoio financeiro, com o projeto no 2014/00492-3, que possibilitou que eu me dedicasse à pesquisa e à escrita desta tese. Estendo este agradecimento a todos os funcionários do programa de Pós-graduação do Instituto de Astronomia, Geofísica e Ciências Atmosférias da Universidade de São Paulo (IAG-USP), que sempre estiveram à disposição para ajudar nos processos burocráticos que envolvem um curso de doutorado em Ciências.

Esta tese/dissertação foi escrita em $\mathrm{H}_{\mathrm{E}} \mathrm{EX}$ com a classe IAGTESE, para teses e dissertações do IAG. 
"Não vá aonde o caminho o leva; vá aonde não há caminho e deixe seu rastro" Ralph Waldo Emerson (1803-1882), poeta norte-americano

"No que diz respeito ao empenho, ao compromisso, ao esforço, à dedicação, não existe meio-termo, ou você faz uma coisa benfeita ou não faz." Ayrton Senna (1960-1994), piloto de corrida 



\section{Resumo}

De acordo com o modelo sequencial de acreção, os planetas gigantes se formam através de um núcleo sólido a partir da captura de planetesimais. Esse núcleo, atingindo uma determinada massa, é capaz de capturar o gás residual do disco protoplanetário que constituirá o seu envelope, formando, então, um planeta gigante (Mizuno, 1980; Pollack et al., 1996). A parte crítica desse cenário está no ajuste dos tempos de formação do núcleo sólido, de captura do gás e dos processos de migração planetária com o tempo de vida do disco (Mordasini et al., 2010). Resultados numéricos mostram que o tempo necessário para a formação de um planeta gigante é muito alto em relação ao tempo de vida do disco, e, que a migração planetária pode ser muito rápida, levando os planetas a caírem na estrela antes de sua completa formação.

Em geral, os trabalhos sobre formação planetária tratam a migração do planeta utilizando prescrições analíticas (Fortier et al., 2013). No entanto, diversos efeitos associados à termodinâmica do disco de gás fazem com que esses modelos analíticos sejam limitados para lidar com a migração planetária (Paardekooper et al., 2010).

De fato, para lidar com a migração planetária de tipo I, esses resultados analíticos se utilizam de discos de gás fisicamente simples e da linearização das equações da hidrodinâmica (Meyer-Vernet e Sicardy, 1987; Tanaka et al., 2002). Para a migração de tipo II, a situação é ainda mais complicada, já que a alta massa do planeta cria um gap em torno da órbita planetária, que impõe uma quebra da linearidade, impossibilitando a obtenção de uma prescrição analítica (Bryden e Lin, 1999).

Assim, os resultados numéricos obtidos a partir de simuladores hidrodinâmicos, como o FARGO3D (Masset, 2000; Benítez-Llambay e Masset, 2016), ZEUS (Stone e Norman, 1992), PLUTO (Mignone et al., 2012), entre outros, são essenciais para uma análise mais 
robusta dos processos de migração planetária dentro de uma gama maior de condições físicas para o disco de gás.

No entanto, os simuladores hidrodinâmicos que tratam da interação do planeta com o disco de gás, em geral, não possuem um modelo para formação planetária. Em alguns deles, modelos para acreção de gás são construídos com base no regime de runaway dessa acreção (Kley, 1999). Todavia, a acreção de sólidos e a acreção de gás para planetas de baixa massa, na maior parte dos casos, não são levadas em consideração. Boa parte disso se deve ao fato de os modelos de formação planetária usarem simulações N-corpos, que, aliados ao código hidrodinâmico, seriam altamente custosos computacionalmente. Assim, torna-se necessário o uso de modelos alternativos para a formação planetária, que sejam capazes de reproduzir os resultados de uma simulação N-corpos de forma confiável.

Construir um modelo que considera a acreção de sólidos e gás é uma tarefa árdua e ao mesmo tempo desafiadora. Assim, o presente projeto propõe a implementação de um cenário fisicamente plausível para a formação planetária dentro do código magneto hidrodinâmico FARGO3D.

Para modelar a acreção de planetesimais, usamos como base os trabalhos de Guilera et al. (2010) e Fortier et al. (2013), que utilizam um modelo estatístico para determinar a taxa de acreção de planetesimais (Inaba et al., 2001). Esse modelo será implementado pela primeira vez no FARGO3D. Atualmente, sabe-se que a acreção de peebles (material sólido entre cm e mm) tem um impacto importante na formação planetária (Lambrechts e Johansen, 2014; Guilera, 2016; Johansen e Lambrechts, 2017). No entanto, núcleos de poucas massas terrestres possuem um envelope planetário que poderia destruir esses pebbles antes dele alcançar o núcleo (Venturini et al., 2015). Nesta tese, iremos nos preocupar apenas com a acreção de planetesimais, deixando o estudo do pebbles para trabalhos futuros.

Para a acreção de gás, iremos modificar o modelo de Kley (1999) incorporado no FARGO antecessor. Essas modificações visam incorporar o raio de Bondi (Bondi, 1952) para determinar a zona de acreção, o efeito da altura do disco e a mudança na taxa de acreção de gás de acordo com a massa do planeta. As modificações implementadas no modelo de acreção de gás foram realizadas com base nos trabalhos de Dürmann e Kley (2015), Russell (2011) e Fortier et al. (2013). A adaptação no código de acreção de gás para levar em conta uma faixa maior de massas planetárias foi realizada utilizando a escala de tempo de Kelvin-Helmoltz. Para isso, seguimos o trabalho de Ikoma et al. (2000) e Ida 
e Lin (2004b).

Para testar o modelo de formação planetária no FARGO3D, a simulação padrão para o disco de gás utilizada nesta tese adota um disco bidimensional fino com taxa de acreção constante. A razão de aspecto do disco será de $h=0.05$ com um fator de curvatura de $\lambda=0.0$. Esses valores são consistentes com a teoria de discos finos e são usados nas maioria das simulações que envolvem discos de acreção (Bell et al., 1997; Frank et al., 2002). O disco é assumido localmente isotérmico e a viscosidade do disco é dirigida pela prescrição $\alpha$ de Shakura e Sunyaev (1973), com $\alpha=0.03$. O modelo de disco é simplificado e características importantes podem influenciar no processo de formação e migração planetária, como as trocas de energia. No entanto, ele é um ótimo modelo inicial para um teste consistente do modelo de formação planetária implementado, já que possui um resultado analítico conhecido. Casos mais complexos serão explorados em trabalhos futuros.

Com o modelo de formação planetária implementado, foi possível estudar simultâneamente a formação e a migração do planeta dentro do simulador hidrodinâmico. Isto é, analisamos a escala de tempo envolvida no processo de migração em conjunto com a escala de tempo da formação planetária para vários parâmetros físicos envolvidos no modelo. A análise revelou, para nosso modelo de disco, que a escala de crescimento do planeta conseguiu se manter mais baixa que a escala de migração, mesmo quando o planeta atravessou a linha de gelo, local onde há menor quantidade de material disponível para a acreção de sólidos. Assim, para planetesimais pequenos (raio $0.1 \mathrm{~km}$ ), foi possível obter planetas com massas próximas de 5 massas de Júpiter em regiões entre 0.5 e 1 ua, num tempo menor que o tempo de vida do disco.

Vale ressaltar que esta tese conta com uma descrição detalhada de como implementar o modelo dentro do FARGO3D, incluindo um apêndice com o programa comentado linha a linha. O intuito é que o leitor possa usar esse modelo de formação e migração planetária para obter novos resultados e vínculos sobre a formação de sistemas exoplanetários ou do nosso Sistema Solar, assim como usar em qualquer outra aplicação que julgar necessária. 



\section{Abstract}

According to the sequential model of accretion, the giant planets are formed from a solid nucleus by capturing planetesimals. When this nucleus reaches a certain mass, it captures the residual gas of the protoplanetary disc that will constitute its envelope, forming a giant planet (Mizuno, 1980; Pollack et al., 1996). The critical part of this scenario is to adjust the planet formation and migration timescales with the lifetime of the disk (Mordasini et al., 2010). Numerical results show that the time required for the formation of a giant planet is very long compared to the lifetime of the disc, and that planetary migration can be very rapid, causing the planets to fall into the star before their full formation.

In general, works on planetary formation use analytical models to deal with the migration of the planets (Fortier et al., 2013). However, these analytical models are limited given that they do not include several effects associated with the thermodynamics of the gas disc (Paardekooper et al., 2010).

Indeed, in order to deal with planetary migration of type I, these analytical models use physically simple gas discs and rely on the linearization of the hydrodynamic equations (Meyer-Vernet e Sicardy, 1987; Tanaka et al., 2002). For the type II migration, the situation is even more complicated. This is due to the fact that the large mass of the planet creates a gap around the orbit of the planet, causing nonlinearities (Bryden e Lin, 1999).

Thus, the numerical results obtained using hydrodynamic simulators, such as FARGO3D (Masset, 2000; Benítez-Llambay e Masset, 2016), ZEUS (Stone e Norman, 1992), PLUTO (Mignone et al., 2012), among others, are essential for a more robust analysis of the processes of planetary migration considering a wider range of physical conditions for the gas disc.

However, in general, hydrodynamic simulators do not have a model for the planetary 
formation. In some of them, models for gas accretion are built based of the runaway regime of accretion (Kley, 1999). Furthermore, the accretion of solids and the accretion of gas for low mass planets are not considered in most of the cases. This is mainly due to the fact that the models of planetary formation use N-body simulations that are computationally very expensive. Thus, it is necessary to use alternative models for the planetary formation, that are capable of reproducing the same results of an N-body simulation.

Building a complete model that takes into account all these processes is a hard and challenging task. So, this project aims the implementation of a physically plausible scenario for a planetary formation inside the magneto-hydrodynamic code FARGO3D.

For the accretion model we use the works by Guilera et al. (2010) and Fortier et al. (2013), which employ an statistical model to determine the accretion rate of planetesimals (Inaba et al., 2001). This model will be implemented for the first time in the FARGO3D code. It is now known that the accretion of peebles (material with size ranging from mm and $\mathrm{cm}$ ) has a important impact on the planetary formation (Lambrechts e Johansen, 2014; Guilera, 2016; Johansen e Lambrechts, 2017), although cores with a few masses of the Earth have a planetary envelope that could destroy those pebbles, before they reach the nucleus (Venturini et al., 2015). In this thesis, we will only deal with the accretion of planetesimals, leaving the study of pebbles for future work.

For the gas accretion, we use a modified model based on Kley (1999). The modifications aim to incorporate the Bondi radius (Bondi, 1952) to determine the accretion zone, the effect of the height of the disc and the frequency of accretion. The implemented modifications are based on the works by Dürmann e Kley (2015), Russell (2011) and Fortier et al. (2013). The adaptation in the gas accretion code to take into account a wider range of planetary masses was achieved using the Kelvin-Helmoltz timescale, according to the works by Ikoma et al. (2000) and Ida e Lin (2004b).

To test the planetary formation model in FARGO3D, the standard simulation for the gas disc uses a bi-dimensional thin disc. The disc's aspect ratio is $h=0.05$ with a curvature factor of $\lambda=0.0$. These values are consistent with the theory of thin dics and are used in most of the simulations for accretion discs (Bell et al., 1997; Frank et al., 2002). The disc is assumed to be locally isothermal and the viscosity of the disc is driven by the prescription $\alpha$ from Shakura e Sunyaev (1973), with $\alpha=0.03$. The disc model is simplified and important features, such as energy exchanges, may influence the process of planetary formation and 
migration. However, it is a good initial model for a consistent test of the implemented model of planetary formation, which has an known analysical result. More complex cases will be explored in future work.

With the newly implemented model for planetary formation, it was possible to simultaneously study the planet formation and the planet migration using the hydrodynamic simulator. That is, we analyzed both the timescale for planetary formation and the timescale for the migration of the planet, and compared them for the parameters of the model. The analysis revealed that, for our disc model, the timescale of the growth rate of the planet remained lower than the migration timescale, even when the planet crossed the ice line, where there is less material available for solid accretion. Thus, for small planetesimals ( $1 \mathrm{~km}$ radius) it was possible to obtain planets with masses of approximately 5 Jupiter masses in regions between 0.5 and $1 \mathrm{au}$, in nearly the same time as the lifetime of the disc.

It is worth noting that this thesis presents a detailed description of how to implement the model for planetary formation in the FARGO3D, including an appendix with the commented code. The goal is to allow the reader to use this planet formation model to obtain new results both about the formation of exoplanetary systems and our Solar System, as well as use it in any relevant application. 



\section{Lista de Figuras}

2.1 Gráfico da fração de discos protoplanetários em aglomerados jovens em função da estimativa de idade do aglomerado. . . . . . . . . . . . . . 50

2.2 Esboço do perfil da velocidade angular de um disco de gás. . . . . . . . . . 54

2.3 Representação esquemática da focalização gravitacional. . . . . . . . . . . . 59

2.4 Representação de um enxame de planetesimais em torno de um núcleo sólido 61

2.5 Representação esquemática dos estágios da formação de um planeta gigante via modelo de acreção com núcleo sólido. . . . . . . . . . . . . . . . . . 64

2.6 Impressão visual do efeito da migração planetária de tipo I e tipo II no disco

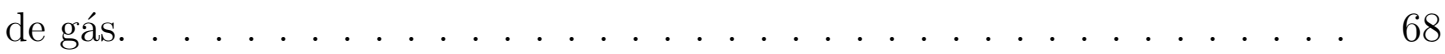

3.1 Representação de um elemento de fluido. . . . . . . . . . . . . . . . . . 81

3.2 Representação de uma célula da malha deslocada. . . . . . . . . . . . . . . 89

3.3 Representação do posicionamento das células no FARGO3D. . . . . . . . . 91

3.4 Representação esquemática de um exemplo de aplicação das condições de borda no FARGO3D. . . . . . . . . . . . . . . . . . . . . 92

3.5 Fluxograma das operações realizadas no FARGO3D durante um passo de tempo. ........................... . . . . . . . . . .

3.6 Formato do cubo de dados no FARGO3D. . . . . . . . . . . . . . . . 121

3.7 Medida do fluxo radial local ao longo do raio do disco após $100 P_{\text {orbital }}$ para um disco de gás sem planetas. . . . . . . . . . . . . . . . . . . . 131

3.8 Gráficos dos principais parâmetros obtidos para o disco de acreção em equilíbrio para uma taxa de acreção de $10^{-7} \mathrm{M}_{\odot} /$ ano após $100 P_{\text {orbital }}$. . . . 132

3.9 Gráficos dos principais parâmetros obtidos para o disco de acreção em equilíbrio para uma taxa de acreção de $10^{-8} \mathrm{M}_{\odot} /$ ano após $100 P_{\text {orbital }}$. . . . 133 
3.10 Gráficos dos principais parâmetros obtidos para o disco de acreção em equilíbrio para uma taxa de acreção de $10^{-9} \mathrm{M}_{\odot} /$ ano após $100 P_{\text {orbital }}$. . . . 134

4.1 Geometria da coordenada de Hill. . . . . . . . . . . . . . . . . . . . . . 143

4.2 Exemplos de movimentos keplerianos em coordenadas de Hill. . . . . . . . . 146

4.3 Síntese da excentricidade e inclinação do movimento relativo a partir das órbitas individuais. . . . . . . . . . . . . . . . . . . . . . . . . . . 148

4.4 Esquema da função densidade de probabilidade $\left\langle n_{2}\right\rangle$ como função de $e$ no caso de $e_{2} \ll e_{1} \simeq e . \ldots \ldots \ldots \ldots \ldots \ldots$. . . . . . . . . . . . . . . . . .

4.5 Exemplo de órbita para um parâmetro de impacto $b$ pequeno. . . . . . . . 153

4.6 Taxa de colisão plotada em função de $b$ para o caso de $(e, i)=(1.0 ; 0.5)$. . 154

4.7 Comparação da probabilidade de colisão média analítica (curvas) com a solução numérica. . . . . . . . . . . . . . . . . . . . 156

4.8 Sistema de coordenadas heliocêntricas equatoriais e coordenadas heliocêntricas orbitais. . . . . . . . . . . . . . . . . . 164

4.9 Separação da força de arrasto em diferentes regimes. . . . . . . . . . . . . . 171

4.10 Comparação dos gráficos da massa em função do tempo para a formação de um planeta com a massa da Terra. . . . . . . . . . . . . . . 184

4.11 Gráfico da excentricidade em função do tempo para a formação de um planeta com a massa da Terra no modelo de Fortier. . . . . . . . . . . . . . 184

4.12 Gráficos da excentricidade em função do tempo para a formação de um planeta com a massa da Terra obtido com o modelo implementado no FARGO3D.185

4.13 Comparação dos gráficos da excentridade em função da massa para a formação de um planeta com a massa da Terra. . . . . . . . . . . . . . . 186

4.14 Comparação dos gráficos da taxa de acreção de sólidos em função da massa para a formação de um planeta da massa da Terra.

4.15 Gráfico da massa do planeta em função do tempo, da excentricidade em função do tempo, da excentricidade em função da massa e da taxa de acreção de gás em função da massa. . . . . . . . . . . . . . . . . . . . . . . . . . 189

4.16 Gráfico da razão e/i em função da massa para a formação de um planeta da ordem da massa da Terra. 
5.1 Perfil da taxa de acreção ao longo do tempo para o disco padrão $(\alpha, \dot{M})=$ $\left(0.003,10^{-7}\right)$ com um planeta de $1 \mathrm{M}_{\mathrm{J}}$ em $r=1 . \ldots \ldots$. . . . . . . 198

5.2 Perfil da média azimutal da densidade superficial de gás para o disco padrão

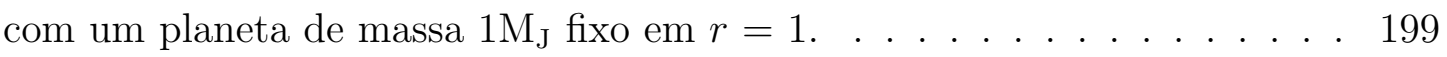

5.3 Gráfico do perfil da média azimutal da densidade superficial do gás para várias massas planetárias e valores de viscosidade. Os gráficos correspondem à versão sem acreção de gás e a um disco de gás cuja taxa de acreção é de $10^{-7} \mathrm{M}_{\odot} /$ ano. . . . . . . . . . . . . . . . .

5.4 Idem à figura anterior para uma taxa de acreção de $10^{-8} \mathrm{M}_{\odot} /$ ano. . . . . . . 201

5.5 Idem à figura anterior para uma taxa de acreção de $10^{-9} \mathrm{M}_{\odot} /$ ano. . . . . . 202

5.6 Gráfico do torque normalizado agindo no planeta numa órbita fixa depois de 5000 órbitas como função da massa do planeta e da viscosidade do disco. O disco usado possui uma taxa de acreção de $10^{-7} \mathrm{M}_{\odot} /$ ano. . . . . . . . . 202

5.7 Gráfico da evolução do semieixo maior dos planetas em função do tempo para várias massas planetárias e valores de viscosidade. Os gráficos correspondem à versão sem acreção de gás e a um disco de gás cuja taxa de acreção é de $10^{-7} \mathrm{M}_{\odot} /$ ano. . . . . . . . . . . . . . . . . . . . . . . 204

5.8 Evolução do perfil da média azimutal da densidade superficial do gás ao longo do tempo para o planeta de massa $0.2 \mathrm{M}_{\mathrm{J}}$ para diferentes viscosidades. A taxa de acreção do disco de gás é de $10^{-7} \mathrm{M}_{\odot} /$ ano e o planeta não acreta gás. . . . . . . . . . . . . . . . . . . . . . . . . . 204

5.9 Evolução do perfil local da média azimutal da densidade superficial do gás em diferentes posições do planeta de massa $0.2 \mathrm{M}_{\mathrm{J}}$ para diferentes viscosidades. A taxa de acreção do disco de gás é de $10^{-7} \mathrm{M}_{\odot} /$ ano e o planeta não acreta gás. . . . . . . . . . . . . . . . . . . . .

5.10 Evolução do perfil local do torque em diferentes posições do planeta de massa $0.2 \mathrm{M}_{\mathrm{J}}$ para diferentes viscosidades. A taxa de acreção do disco de gás é de $10^{-7} \mathrm{M}_{\odot} /$ ano e o planeta não acreta gás.

5.11 Evolução do perfil local do fluxo de gás em diferentes posições do planeta de massa $0.2 \mathrm{M}_{\mathrm{J}}$ para diferentes viscosidades. A taxa de acreção do disco de gás é de $10^{-7} \mathrm{M}_{\odot} /$ ano e o planeta não acreta gás. 
5.12 Evolução do perfil da média azimutal da densidade superficial do gás ao longo do tempo para o planeta de massa $0.5 \mathrm{M}_{\mathrm{J}}$ para diferentes viscosidades. A taxa de acreção do disco de gás é de $10^{-7} \mathrm{M}_{\odot} /$ ano e o planeta não acreta gás. . . . . . . . . . . . . . . . . . . . .

5.13 Evolução do perfil local da média azimutal da densidade superficial do gás em diferentes posições do planeta de massa $0.5 \mathrm{M}_{\mathrm{J}}$ para diferentes viscosidades. A taxa de acreção do disco de gás é de $10^{-7} \mathrm{M}_{\odot} /$ ano e o planeta não acreta gás. . . . . . . . . . . . . . . . . . . . . . .

5.14 Evolução do perfil local do torque em diferentes posições do planeta de massa $0.5 \mathrm{M}_{\mathrm{J}}$ para diferentes viscosidades. A taxa de acreção do disco de gás é de $10^{-7} \mathrm{M}_{\odot} /$ ano e o planeta não acreta gás. . . . . . . . . . . . . .

5.15 Evolução do perfil local do fluxo de gás em diferentes posições do planeta de massa $0.5 \mathrm{M}_{\mathrm{J}}$ para diferentes viscosidades. A taxa de acreção do disco de gás é de $10^{-7} \mathrm{M}_{\odot} /$ ano e o planeta não acreta gás. . . . . . . . . . . . . . . 210

5.16 Evolução do perfil da média azimutal da densidade superficial do gás ao longo do tempo para o planeta de massa $1.0 \mathrm{M}_{\mathrm{J}}$ para diferentes viscosidades. A taxa de acreção do disco de gás é de $10^{-7} \mathrm{M}_{\odot} /$ ano e o planeta não acreta gás. . . . . . . . . . . . . . . . . . . . . .

5.17 Evolução do perfil local da média azimutal da densidade superficial do gás em diferentes posições do planeta de massa $1.0 \mathrm{M}_{\mathrm{J}}$ para diferentes viscosidades. A taxa de acreção do disco de gás é de $10^{-7} \mathrm{M}_{\odot} /$ ano e o planeta não acreta gás. . . . . . . . . . . . . . . . . . . . .

5.18 Evolução do perfil local do torque em diferentes posições do planeta de massa $1.0 \mathrm{M}_{\mathrm{J}}$ para diferentes viscosidades. A taxa de acreção do disco de gás é de $10^{-7} \mathrm{M}_{\odot} /$ ano e o planeta não acreta gás. . . . . . . . . . . . . . . 212

5.19 Evolução do perfil local do fluxo de gás em diferentes posições do planeta de massa $1.0 \mathrm{M}_{\mathrm{J}}$ para diferentes viscosidades. A taxa de acreção do disco de gás é de $10^{-7} \mathrm{M}_{\odot} /$ ano e o planeta não acreta gás. . . . . . . . . . . . . . 212

5.20 Idem à Figura 5.7 para uma taxa de acreção do disco de gás de $10^{-8} \mathrm{M}_{\odot} /$ ano.213

5.21 Idem à figura anterior para uma taxa de acreção do disco de gás de $10^{-9}$ $\mathrm{M}_{\odot} /$ ano. . . . . . . . . . . . . . . . . . 214 
5.22 Evolução do perfil da média azimutal da densidade superficial do gás ao longo do tempo para o planeta de massa $0.2 \mathrm{M}_{\mathrm{J}}$ para diferentes viscosidades. A taxa de acreção do disco de gás é de $10^{-8} \mathrm{M}_{\odot} /$ ano e o planeta não acreta gás. . . . . . . . . . . . . . . . . . . . . . . . . . . . 214

5.23 Evolução do perfil local da média azimutal da densidade superficial do gás em diferentes posições do planeta de massa $0.2 \mathrm{M}_{\mathrm{J}}$ para diferentes viscosidades. A taxa de acreção do disco de gás é de $10^{-8} \mathrm{M}_{\odot} /$ ano e o planeta não acreta gás. . . . . . . . . . . . . . . . . . . . . .

5.24 Evolução do perfil local do torque em diferentes posições do planeta de massa $0.2 \mathrm{M}_{\mathrm{J}}$ para diferentes viscosidades. A taxa de acreção do disco de gás é de $10^{-8} \mathrm{M}_{\odot} /$ ano e o planeta não acreta gás. . . . . . . . . . . . . . 216

5.25 Evolução do perfil local do fluxo de gás em diferentes posições do planeta de massa $0.2 \mathrm{M}_{\mathrm{J}}$ para diferentes viscosidades. A taxa de acreção do disco de gás é de $10^{-8} \mathrm{M}_{\odot} /$ ano e o planeta não acreta gás. . . . . . . . . . . . . . . 216

5.26 Evolução do perfil local do fluxo de gás em diferentes posições do planeta de massa $0.2 \mathrm{M}_{\mathrm{J}}$ para diferentes viscosidades. A taxa de acreção do disco de gás é de $10^{-9} \mathrm{M}_{\odot} /$ ano e o planeta não acreta gás. . . . . . . . . . . . . . . 217

5.27 Evolução do perfil local do torque em diferentes posições do planeta de massa $0.5 \mathrm{M}_{\mathrm{J}}$ para diferentes viscosidades. A taxa de acreção do disco de gás é de $10^{-8} \mathrm{M}_{\odot}$ /ano e o planeta não acreta gás. . . . . . . . . . . . . . . . . 218

5.28 Evolução do perfil local do fluxo de gás em diferentes posições do planeta de massa $0.5 \mathrm{M}_{\mathrm{J}}$ para diferentes viscosidades. A taxa de acreção do disco de gás é de $10^{-8} \mathrm{M}_{\odot} /$ ano e o planeta não acreta gás. . . . . . . . . . . . . . . 218

5.29 Evolução do perfil local do fluxo de gás em diferentes posições do planeta de massa $0.5 \mathrm{M}_{\mathrm{J}}$ para diferentes viscosidades. A taxa de acreção do disco de gás é de $10^{-9} \mathrm{M}_{\odot} /$ ano e o planeta não acreta gás. . . . . . . . . . . . . . . 219

5.30 Evolução do perfil local do torque em diferentes posições do planeta de massa $1.0 \mathrm{M}_{\mathrm{J}}$ para diferentes viscosidades. A taxa de acreção do disco de gás é de $10^{-8} \mathrm{M}_{\odot} /$ ano e o planeta não acreta gás. . . . . . . . . . . . . . . . . . . . 220

5.31 Evolução do perfil local do fluxo de gás em diferentes posições do planeta de massa $1.0 \mathrm{M}_{\mathrm{J}}$ para diferentes viscosidades. A taxa de acreção do disco de gás é de $10^{-8} \mathrm{M}_{\odot} /$ ano e o planeta não acreta gás. . . . . . . . . . . . . . . 
5.32 Evolução do perfil local do fluxo de gás em diferentes posições do planeta de massa $1.0 \mathrm{M}_{\mathrm{J}}$ para diferentes viscosidades. A taxa de acreção do disco de gás é de $10^{-9} \mathrm{M}_{\odot} /$ ano e o planeta não acreta gás. . . . . . . . . . . . . . . 221

5.33 Representação das zonas de acreção no FARGO. . . . . . . . . . . . . . . . 222

5.34 Comparação de resultados para o modelo de acreção de gás do código FARGO antecessor. . . . . . . . . . . . . . . . . . 225

5.35 Representação geométrica do volume de acreção acretado. . . . . . . . . . 229

5.36 Gráfico do perfil da média azimutal da densidade superficial para várias massas planetárias e valores de viscosidade. Os gráficos correspondem a um disco de gás cuja taxa de acreção é de $10^{-7} \mathrm{M}_{\odot} /$ ano . . . . . . . . . . 233

5.37 Idem à figura anterior para uma taxa de acreção $10^{-8} \mathrm{M}_{\odot} /$ ano. . . . . . . 234

5.38 Idem à figura anterior para uma taxa de acreção $10^{-9} \mathrm{M}_{\odot} /$ ano.. . . . . . . 234

5.39 Gráfico da evolução do semieixo maior dos planetas em função do tempo para várias massas planetárias e valores de viscosidade. Os gráficos correspondem à versão com acreção de gás e a um disco de gás cuja taxa de acreção é de $10^{-7} \mathrm{M}_{\odot} /$ ano. . . . . . . . . . . . . . . . . . . . . 235

5.40 Evolução do perfil da média azimutal da densidade superficial do gás ao longo do tempo para o planeta de massa $0.5 \mathrm{M}_{\mathrm{J}}$ para diferentes viscosidades. A taxa de acreção do disco de gás é de $10^{-7} \mathrm{M}_{\odot} /$ ano e o planeta acreta gás. 237

5.41 Evolução do perfil local da média azimutal da densidade superficial do gás em diferentes posições do planeta de massa $0.5 \mathrm{M}_{\mathrm{J}}$ para diferentes viscosidades. A taxa de acreção do disco de gás é de $10^{-7} \mathrm{M}_{\odot} /$ ano e o planeta acreta gás. . . . . . . . . . . . . . . . . . . . .

5.42 Evolução do perfil local do torque em diferentes posições do planeta de massa $0.5 \mathrm{M}_{\mathrm{J}}$ para diferentes viscosidades. A taxa de acreção do disco de gás é de $10^{-7} \mathrm{M}_{\odot} /$ ano e o planeta acreta gás. . . . . . . . . . . . . 238

5.43 Evolução do perfil local do fluxo de gás em diferentes posições do planeta de massa $0.5 \mathrm{M}_{\mathrm{J}}$ para diferentes viscosidades. A taxa de acreção do disco de gás é de $10^{-7} \mathrm{M}_{\odot} /$ ano e o planeta acreta gás. . . . . . . . . . . . 239

5.44 Evolução do perfil da média azimutal da densidade superficial do gás ao longo do tempo para o planeta de massa $1.0 \mathrm{M}_{\mathrm{J}}$ para diferentes viscosidades. A taxa de acreção do disco de gás é de $10^{-7} \mathrm{M}_{\odot} /$ ano e o planeta acreta gás. 240 
5.45 Evolução do perfil local da média azimutal da densidade superficial do gás em diferentes posições do planeta de massa $1.0 \mathrm{M}_{\mathrm{J}}$ para diferentes viscosidades. A taxa de acreção do disco de gás é de $10^{-7} \mathrm{M}_{\odot} /$ ano e o planeta acreta gás. . . . . . . . . . . . . . . . . . . . . . . . . . . . 241

5.46 Evolução do perfil local do torque em diferentes posições do planeta de massa $1.0 \mathrm{M}_{\mathrm{J}}$ para diferentes viscosidades. A taxa de acreção do disco de gás é de $10^{-7} \mathrm{M}_{\odot} /$ ano e o planeta acreta gás.

5.47 Evolução do perfil local do fluxo de gás em diferentes posições do planeta de massa $1.0 \mathrm{M}_{\mathrm{J}}$ para diferentes viscosidades. A taxa de acreção do disco de gás é de $10^{-7} \mathrm{M}_{\odot} /$ ano e o planeta acreta gás. . . . . . . . . . . . . . . 242

5.48 Idem à Figura 5.39 para uma taxa de acreção do disco de gás de $10^{-8} \mathrm{M}_{\odot} /$ ano.243

5.49 Idem à figura anterior para uma taxa de acreção do disco de gás de $10^{-9}$ $\mathrm{M}_{\odot} /$ ano. . . . . . . . . . . . . . . . . . . 244

5.50 Evolução do perfil local da média azimutal da densidade superficial do gás em diferentes posições do planeta de massa $1.0 \mathrm{M}_{\mathrm{J}}$ para diferentes viscosidades. A taxa de acreção do disco de gás é de $10^{-8} \mathrm{M}_{\odot} /$ ano e o planeta acreta gás. . . . . . . . . . . . . . . . . . . . . . . . 245

5.51 Evolução do perfil local da média azimutal da densidade superficial do gás em diferentes posições do planeta de massa $1.0 \mathrm{M}_{\mathrm{J}}$ para diferentes viscosidades. A taxa de acreção do disco de gás é de $10^{-9} \mathrm{M}_{\odot} /$ ano e o planeta acreta gás. . . . . . . . . . . . . . . . . . . . . . . . . 245

5.52 Evolução do perfil local do torque em diferentes posições do planeta de massa $1.0 \mathrm{M}_{\mathrm{J}}$ para diferentes viscosidades. A taxa de acreção do disco de gás é de $10^{-8} \mathrm{M}_{\odot} /$ ano e o planeta acreta gás.

5.53 Evolução do perfil local do torque em diferentes posições do planeta de massa $1.0 \mathrm{M}_{\mathrm{J}}$ para diferentes viscosidades. A taxa de acreção do disco de gás é de $10^{-9} \mathrm{M}_{\odot} /$ ano e o planeta acreta gás.

5.54 Evolução do perfil local do fluxo de gás em diferentes posições do planeta de massa $1.0 \mathrm{M}_{\mathrm{J}}$ para diferentes viscosidades. A taxa de acreção do disco de gás é de $10^{-8} \mathrm{M}_{\odot} /$ ano e o planeta acreta gás. 
5.55 Evolução do perfil local do fluxo de gás em diferentes posições do planeta de massa $1.0 \mathrm{M}_{\mathrm{J}}$ para diferentes viscosidades. A taxa de acreção do disco de gás é de $10^{-9} \mathrm{M}_{\odot} /$ ano e o planeta acreta gás. . . . . . . . . . . . . . . . 247

5.56 Gráfico da massa do planeta em função do tempo, da excentricidade em função do tempo, da excentricidade em função da massa e da taxa de acreção de gás em função da massa. . . . . . . . . . . . . . . . . . . . . 250

5.57 Gráfico da massa do planeta em função do tempo e da posição do planeta em função do tempo para formação planetária com migração. . . . . . . . . 254

5.58 Gráfico da massa do planeta em função da posição do planeta para formação planetária com migração. . . . . . . . . . . . . . . . . . 255

5.59 Gráfico do tempo de escala de crescimento do planeta em função do tempo de escala de migração. . . . . . . . . . . . . . . . . . . . . . 256 25 


\section{Lista de Tabelas}

3.1 Descrição da nomenclatura para as diferentes coordenadas usadas no FARGO3D. 90

3.2 Valores das variáveis transportadas para cada sistema de coordenadas em cada direção. . . . . . . . . . . . . . . . . . . . . . . 101

3.3 Valores das variáveis fontes usados no update da velocidade em cada direção 101

3.4 Valor dos parâmetros usados na simulação padrão. . . . . . . . . . . . . . . 128

3.5 Valores da densidade superficial inicial para cada conjunto de parâmetros. . 128

4.1 Valores de algumas variáveis para teste do modelo de acreção de sólidos. 183 



\section{Lista de Símbolos}

$a_{\mathrm{p}}:$ semieixo maior do planeta.

$a_{\mathrm{m}}$ : semieixo maior do planetesimal.

$b$ : largura da zona de alimentação.

$c_{\mathrm{s}}:$ velocidade do som.

$d_{\text {core }}$ : densidade do núcleo sólido planetário.

$\mathrm{C}_{\mathrm{D}}$ : coeficiente de arrasto.

$e_{\mathrm{p}}:$ excentricidade do planeta.

$e$ : excentricidade dos planetesimais.

$\tilde{e}$ : excentricidade reduzida dos planetesimais.

$i_{\mathrm{p}}$ : inclinação do planeta.

$i$ : inclinação dos planetesimais.

$\tilde{i}$ : inclinação reduzida dos planetesimais.

$G$ : constante gravitacional.

$H$ : escala de altura do disco de acreção.

$h$ : razão entre a altura e o raio do disco de acreção ou razão de aspecto.

$k_{\mathrm{B}}:$ constante de Boltzmann. 
$\dot{M}$ : taxa de acreção do disco de gás.

$M_{\text {core }}:$ massa do núcleo sólido.

$\dot{M}_{\text {core }}$ : taxa de acreção de planetesimais.

$\dot{M}_{\mathrm{KH}}$ : taxa de acreção de gás no regime de Kelvin-Helmholtz.

$\dot{M}_{\text {run }}$ : taxa de acreção de gás no regime de runaway.

$\dot{M}_{\text {gas }}:$ taxa de acreção de gás.

$M_{\mathrm{p}}:$ massa do planeta.

$M_{\mathrm{env}}$ : massa do envelope planetário.

$M_{\text {crit }}^{\text {core }}$ : massa crítica do núcleo sólido.

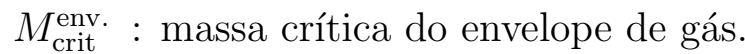

$m$ : massa do planetesimal.

$M_{\text {disk }}:$ massa do disco protoplanetário.

$M_{\star}$ : massa da estrela.

$\mathrm{M}_{\odot}:$ massa do Sol.

$\mathrm{M}_{\mathrm{J}}$ : massa de Jupiter.

$\mathrm{M}_{\otimes}:$ massa da Terra.

$m_{\mathrm{H}}$ : massa da molécula do gás hidrogênio.

$n_{\mathrm{H}_{2}}$ : densidade numérica de moléculas de hidrogênio.

$P_{\text {gas }}:$ pressão do gás.

$P_{\text {orbital }}:$ período orbital do planeta.

$P_{\text {coll }}$ : probabilidade com que os planetesimais são acretados pelo protoplaneta.

$P_{\text {high }}:$ probabilidade com que os planetesimais de alta velocidade são acretados pelo protoplaneta. 
$P_{\text {medium }}:$ probabilidade com que os planetesimais de média velocidade são acretados pelo protoplaneta.

$P_{\text {low }}:$ probabilidade com que os planetesimais de baixa velocidade são acretados pelo protoplaneta.

$r_{\mathrm{p}}$ : distância radial do planeta.

$r_{\mathrm{m}}$ : raio dos planetesimais.

$R_{\text {core }}:$ raio do núcleo planetário.

$R_{\text {cap }}$ : raio de captura.

$R_{\mathrm{p}}$ : raio do planeta.

$R_{\mathrm{H}}$ : raio de Hill.

$R_{\mathrm{B}}$ : raio de Bondi.

Re : número de Reynolds.

$\operatorname{Re}_{\text {mol }}$ : número de Reynolds molecular.

$T_{\text {gas }}:$ temperatura do gás.

$v_{\text {esc }}$ : velocidade de escape de um corpo.

$v_{\text {r,gas }}:$ velocidade radial do gás.

$v_{\text {rel }}:$ velocidade relativa entre dois corpos.

$v_{\theta, \text { gas }}:$ velocidade tangencial do gás.

$v_{\mathrm{K}}:$ velocidade kepleriana.

$\alpha$ : parâmetro de Shakura-Sunyev.

$\gamma$ : parâmetro que define a curvatura do disco.

$\gamma_{\text {gas }}$ : índice adiabático do gás.

$\kappa_{\mathrm{R}}$ : opacidade do gás. 
$\lambda_{\text {gas }}:$ livre caminho médio da molécula de gás.

$\mu$ : massa molecular média.

$\nu_{\text {gas }}:$ viscosidade do gás.

$\nu_{\text {mol }}$ : viscosidade molecular do gás.

$\rho_{\text {gas }}:$ densidade volumétrica do gás.

$\rho_{\mathrm{m}}$ : densidade volumétrica do planetesimal.

$\rho_{\text {bulk }}$ : densidade do bulbo de planetesimais.

$\varphi$ : expoente do perfil da curva de densidade superficial do gás.

$\sigma_{\mathrm{H}_{2}}$ : seção de choque da molécula de hidrogênio.

$\Sigma_{\text {gas }}$ : densidade superficial do gás.

$\Sigma_{\mathrm{m}}$ : densidade superficial de planetesimais.

$\tau_{\text {drag }}$ : tempo de arrasto do planetesimal com o disco de gás.

$\tau_{\mathrm{KH}}:$ tempo de escala de Kelvin-Helmholtz para contração do envelope de gás.

$\Omega_{\mathrm{K}}:$ velocidade angular kepleriana.

$\Omega_{\mathrm{p}}$ : velocidade angular do planeta.

$\Omega_{\mathrm{f}}$ : velocidade angular do referencial sobre um eixo vertical. 


\section{Sumário}

1. Introdução . . . . . . . . . . . . . . . . . . . . . . . 39

2. Fundamentos teóricos . . . . . . . . . . . . . . . . . . . 43

2.1 Discos de acreção . . . . . . . . . . . . . . . . . . . . . 44

2.1.1 Parametrização de Shakura-Sunyaev . . . . . . . . . . . 44

2.1.2 Estrutura vertical . . . . . . . . . . . . . . . . 46

2.1.3 Velocidade tangencial do gás . . . . . . . . . . . . . 48

2.1.4 Evolução de um disco de acreção . . . . . . . . . . . . . . 49

2.1.5 Disco com taxa de acreção constante . . . . . . . . . . . . . 53

2.2 Formação planetária . . . . . . . . . . . . . . . . . . . . 55

2.2.1 Formação dos planetesimais . . . . . . . . . . . . 56

2.2.2 Acreção dos planetesimais . . . . . . . . . . . . 57

2.2 .3 Acreção de gás . . . . . . . . . . . . . . . . . . 63 63

2.3 Migração planetária . . . . . . . . . . . . . . . . . 67

2.3.1 Migração planetária tipo I . . . . . . . . . . . . . . . 69 69

2.3.2 Migração planetária tipo II . . . . . . . . . . . . . . . . . 71

2.4 Raio de Hill . . . . . . . . . . . . . . . . . . . . . . . . . . . . . . 773

2.5 Acreção de Bondi-Hoyle-Lyttleton . . . . . . . . . . . . . . . . . . 74

2.6 Conclusão . . . . . . . . . . . . . . . . . . . 75

3. O código FARGO3D . . . . . . . . . . . . . . . . . . . . . . . . . . 79

3.1 Equações fundamentais . . . . . . . . . . . . . . . . . . . . 80

3.1.1 Equação de continuidade . . . . . . . . . . . . . . . . . 80

3.1 .2 Equação de Euler . . . . . . . . . . . . . . . . . . 82 
3.1 .3 Equação de energia . . . . . . . . . . . . . . . . . . . 855

3.1 .4 Equação de estado . . . . . . . . . . . . . . . . . . . . 86

3.2 Malha deslocada e campos vetoriais . . . . . . . . . . . . . . . 89

3.3 Condições de borda . . . . . . . . . . . . . . . . . . . . . . . . . . . . . 91

3.4 Incluindo novas variáveis . . . . . . . . . . . . . . . . . . 94

3.5 Unidades . . . . . . . . . . . . . . . . . . . . . . . . . . . 95

3.6 Principais parâmetros de entrada ～. . . . . . . . . . . . . . 97

3.7 Descrição do método numérico . . . . . . . . . . . . . . . . . . . . . 99

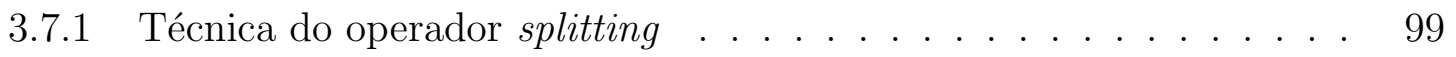

3.7 .2 Resolução da equação fonte . . . . . . . . . . . . . . . . . 102

3.7.3 Resolução da equação de transporte . . . . . . . . . . . . . . . . 104

3.7.4 Estabilidade e a condição CFL . . . . . . . . . . . . . . . . . 107

3.7 .5 Advecção orbital . . . . . . . . . . . . . . . . . . . 108

3.7.6 Integrador orbital para os planetas . . . . . . . . . . 112

3.8 Processo de paralelização no FARGO3D . . . . . . . . . . . . . . . . 114

3.9 Arquivos de saída do FARGO3D . . . . . . . . . . . . . . 120

3.9.1 Arquivos com as variáveis de campo . . . . . . . . . . . . 120

3.9.2 Arquivos com o domínio computacional . . . . . . . . . . . 122

3.9.3 Arquivo com as variáveis . . . . . . . . . . . . . . . . . . 122

3.9.4 Arquivos com o domínio das submalhas . . . . . . . . . . 122

3.9.5 Arquivos com os dados planetários . . . . . . . . . . . 123

3.9 .6 Arquivos de monitoração . . . . . . . . . . . . . . . . . . . . . . . 124

3.10 Simulação padrão utilizada . . . . . . . . . . . . . . . . . . 125

3.10 .1 Parâmetros e módulos de entrada . . . . . . . . . . . . . 125

3.10 .2 Condições iniciais . . . . . . . . . . . . . . . . . . . . . 128

3.10 .3 Condições de borda . . . . . . . . . . . . . . . . . . . 129

3.10 .4 Análise das simulações . . . . . . . . . . . . . . . 129

3.11 Conclusão . . . . . . . . . . . . . . . . . . . . . . . . 135

4. Modelo para acreção de planetesimais . . . . . . . . . . . . . . . . . . 139

4.1 Introdução . . . . . . . . . . . . . . . . . . . . . . 139

4.2 Aproximação de Hill para o problema de três corpos . . . . . . . . . . . . . 141 
4.2 .1 Equações de Hill . . . . . . . . . . . . . . . . . . . . . . . . 141

4.2 .2 Movimento kepleriano . . . . . . . . . . . . . . . . 144

4.2.3 Separação em movimento relativo e movimento do centro de massa 145

4.3 Equação de coagulação estatística . . . . . . . . . . . . . . . . . . . . 147

4.3.1 Função de distribuição dos planetesimais . . . . . . . . . . . . . . . 147

4.3.2 Taxa de colisão total ～. . . . . . . . . . . . . . . . . . . . 150

4.4 Evolução da excentricidade e da inclinação quadrática média dos planetesimais 157

4.4.1 Evolução da excentricidade e da inclinação quadrática média dos planetesimais devido à perturbação gravitacional do protoplaneta . 157

4.4.2 Evolução da excentricidade e da inclinação quadrática média devido ao arrasto do gás . . . . . . . . . . . . . . . . . . 163

4.5 Modelo para acreção de sólidos no FARGO3D . . . . . . . . . . . . . . 172

4.5.1 Modelagem para o crescimento do núcleo sólido . . . . . . . . 172

4.5.2 Densidade superficial inicial de sólidos e a zona de alimentação . . . 174

4.5.3 Modelagem da evolução da excentricidade e da inclinação quadráticas médias . . . . . . . . . . . . . . . . . . 176

4.5.4 Teste do modelo . . . . . . . . . . . . . . . . . . . . 182

4.6 Formação de um planeta de $1 \mathrm{M}_{\otimes} \ldots \ldots \ldots$. . . . . . . . . . . 187

4.7 Conclusão . . . . . . . . . . . . . . . . . . . . . . . . . . . . . 190

5. Modelo para acreção de gás . . . . . . . . . . . . . . . . . . . . . . 195

5.1 Disco standard em equílibrio . . . . . . . . . . . . . . . . . . . 197

5.2 Análise do formato do gap para planetas fixos - cenário sem acreção de gás 199

5.3 Migração de planetas massivos - cenário sem acreção de gás . . . . . . . . 203

5.4 Novo modelo para acreção de gás . . . . . . . . . . . . . . . . 222

5.4 .1 Modelo de acreção de gás do FARGO . . . . . . . . . . . . . 222

5.4.2 Adaptação do tamanho da região de acreção de gás . . . . . . . . . 225

5.4.3 Ajuste da escala de tempo do processo de acreção de gás . . . . . 226

5.4 .4 Efeitos da altura do disco . . . . . . . . . . . . . 228

5.4.5 Acreção de gás fora do regime de runaway . . . . . . . . . . 230

5.5 Análise do formato do gap para planetas fixos - versão com acreção de gás 232

5.6 Migração de planetas massivos - cenário com acreção de gás . . . . . . . 2234 
5.7 Formação de um planeta de $1 \mathrm{M}_{\mathrm{J}} \ldots \ldots \ldots \ldots$

5.8 Formação planetária com migração . . . . . . . . . . . . . . . 252

5.9 Conclusão . . . . . . . . . . . . . . . . . . . . . 257

6. Conclusões. . . . . . . . . . . . . . . . . . . . . . . . . . . 263

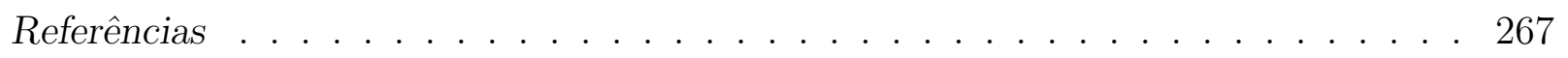

Apêndice 281

A. SETUP da simulação padrão, inclusão de novas variáveis/funções e modificações no código padrão . . . . . . . . . . . . . . . . . . . . . . . . . 283

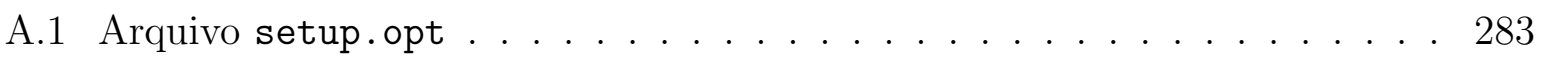

A.1.1 Transcrição do código . . . . . . . . . . . . . . . . . . 283

A.1.2 Comentários gerais . . . . . . . . . . . . . . . 285

A.2 Arquivo condinit.c . . . . . . . . . . . . . . 286

A.2.1 Transcrição do código . . . . . . . . . . . . . . . . . . 286

A.2.2 Comentários gerais . . . . . . . . . . . . . . . . . 294

A.3 Arquivos para as condições de borda . . . . . . . . . . . . . . 297

A.3.1 Arquivo boundaries.txt . . . . . . . . . . . . 297

A.3.1.1 Transcrição do código . . . . . . . . . . . . . . . . 297

A.3.1.2 Comentários gerais . . . . . . . . . . . . . . . . 298

A.3.2 Arquivo setup.bound . . . . . . . . . . . . . . 299

A.3.2.1 Transcrição do código . . . . . . . . . . . . . . . . 299

A.3.2.2 Comentários gerais . . . . . . . . . . . . . . 299

A.3.3 Arquivo centering.txt . . . . . . . . . . . . 300

A.3.3.1 Transcrição do código . . . . . . . . . . . . . . . 300

A.3.3.2 Comentários gerais . . . . . . . . . . . . 300

A.4 Declaração das novas variáveis e funções . . . . . . . . . . . . . . 301

A.4.1 Arquivo global.h . . . . . . . . . . . . . 301

A.4.1.1 Transcrição das modificações no código . . . . . . . . . . 301

A.4.1.2 Comentários gerais . . . . . . . . . . . . . . . 303

A.4.2 Arquivo LowTasks.c . . . . . . . . . . . . . . 305 
A.4.2.1 Transcrição das modificações no código . . . . . . . . . . . 305

A.4.2.2 Comentários gerais . . . . . . . . . . . . . . 307

A.4.3 Arquivo struct.h . . . . . . . . . . . . . 307

A.4.3.1 Transcrição das modificações no código . . . . . . . . . . . 307

A.4.3.2 Comentários gerais . . . . . . . . . . . . . . 310

A.4.4 Arquivo psys.c . . . . . . . . . . . . . . 310

A.4.4.1 Transcrição das modificações no código . . . . . . . . . . . 310

A.4.4.2 Comentários gerais . . . . . . . . . . . . . 319

A.4.5 Arquivo prototypes.h . . . . . . . . . . . . . . 320

A.4.5.1 Transcrição das modificações no código . . . . . . . . . . . 320

A.4.5.2 Comentários gerais . . . . . . . . . . . . 321

A.4.6 Arquivo comm.c . . . . . . . . . . . . . 321

A.4.6.1 Transcrição das modificações no código . . . . . . . . . . . 321

A.4.6.2 Comentários gerais . . . . . . . . . . . . . 322

A.4.7 Arquivo comm_device.c . . . . . . . . . . . . 322

A.4.7.1 Transcrição das modificações no código . . . . . . . . . . . 322

A.4.7.2 Comentários gerais . . . . . . . . . . . . . 322

A.4.8 Arquivo setup.objects . . . . . . . . . . . . 323

A.4.8.1 Transcrição do código . . . . . . . . . . . . . . . . . 323

A.4.8.2 Comentários gerais . . . . . . . . . . . . . 324

A.4.9 Arquivo charge_arch.c . . . . . . . . . . . . . 324

A.4.9.1 Transcrição das modificações no código . . . . . . . . . . . 324

A.4.9.2 Comentários gerais . . . . . . . . . . . . . 327

A.4.10 Arquivo func $a$ arch.cfg . . . . . . . . . . . . 327

A.4.10.1 Transcrição das modificações no código . . . . . . . . . . . 327

A.4.10.2 Comentários gerais . . . . . . . . . . . . . . . 328

A.5 Arquivo output.c . . . . . . . . . . . . . . 328

A.5.0.1 Transcrição das modificações no código . . . . . . . . . . . 328

A.5.0.2 Comentários gerais . . . . . . . . . . . . 333

A.6 Modificação do arquivo foundam.h . . . . . . . . . . . . . . 334

A.6.1 Transcrição das modificações no código . . . . . . . . . . . . . . 334

A.6.2 Comentários gerais . . . . . . . . . . . . 336 
A.7 Arquivo setup.par . . . . . . . . . . . . . . . . . . . . . 337

A.7.1 Transcrição do código . . . . . . . . . . . . . . . . . . 337

A.7.2 Comentários gerais . . . . . . . . . . . . . . 339

A.8 Arquivo setup.units . . . . . . . . . . . . . . . . . . . . 340

A.8.1 Transcrição do código . . . . . . . . . . . . . . . . . . . . . . 340

A.8.2 Comentários gerais . . . . . . . . . . . . . 340

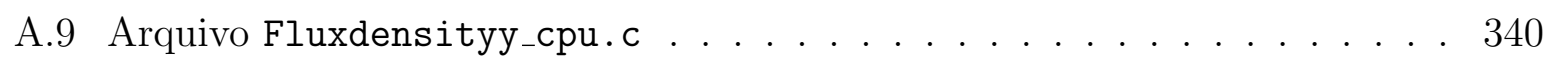

A.9.1 Comentários gerais . . . . . . . . . . . . . . 343

B. Estrutura do programa de formação planetária dentro do FARGO3D . . . . . 345

B.1 Arquivo main.c . . . . . . . . . . . . . . . . . . 345

B.1.1 Transcrição das modificações no código . . . . . . . . . . . . 345

B.1.2 Comentários gerais . . . . . . . . . . . . . . 346

B.2 Arquivo initAccsolids.c . . . . . . . . . . . . . . . . 347

B.2.1 Transcrição do código . . . . . . . . . . . . . . . . . . . . 347

B.2.2 Comentários gerais . . . . . . . . . . . . . . . . . 352

B.3 Arquivo initAccSolidsEquilibrium.c . . . . . . . . . 352

B.3.1 Transcrição do código . . . . . . . . . . . . . . . . . . 352

B.3.2 Comentários gerais . . . . . . . . . . . . . . . . 358

B.4 Arquivo AlgoGas.c . . . . . . . . . . . . . . . . . 358

B.4.1 Transcrição das modificações no código . . . . . . . . . . . 358

B.4.2 Comentários gerais . . . . . . . . . . . . . . . 360

B.5 Arquivo Computerhogas.c . . . . . . . . . . . . . . . . . 361

B.5.1 Transcrição do código . . . . . . . . . . . . . . . . . . 361

B.5.2 Comentários gerais . . . . . . . . . . . . . . . . . 364

B.6 Arquivo computenumol.c . . . . . . . . . . . . . . 364

B.6.1 Transcrição do código . . . . . . . . . . . . . . . . . . . . 364

B.6.2 Comentários gerais . . . . . . . . . . . . . . 367

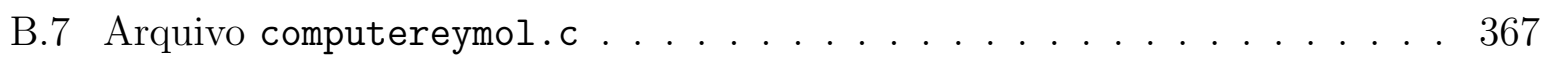

B.7.1 Transcrição do código . . . . . . . . . . . . . . . . . . . . 367

B.7.2 Comentários gerais . . . . . . . . . . . . . . . 370

B.8 Arquivo computegasdragecc.c . . . . . . . . . . . . 371 
B.8.1 Comentários gerais . . . . . . . . . . . . . . . . . 376

B.9 Arquivo computegravecc.c . . . . . . . . . . . . . 377

B.9.1 Comentários gerais . . . . . . . . . . . . . . . 381

B.10 Arquivo updateecc.c . . . . . . . . . . . . . . . . . . . 382

B.10.1 Comentários gerais . . . . . . . . . . . . . . . 385

B.11 Arquivo computegasdraginc.c . . . . . . . . . . . 386

B.11.1 Comentários gerais . . . . . . . . . . . . . . . . 391

B.12 Arquivo computegravinc.c . . . . . . . . . . . . . . 392

B.12.1 Comentários gerais . . . . . . . . . . . . . . 396

B.13 Arquivo updateinc.c . . . . . . . . . . . . . . 397

B.13.1 Comentários gerais . . . . . . . . . . . . . . . . . 401

B.14 Arquivo computeaccretionsolids.c . . . . . . . . . . . . . . 401

B.14.1 Comentários gerais . . . . . . . . . . . . . . . . 411

B.15 Arquivo computeaccretionsolidsequilibrium.c . . . . . . . . 412

B.15.1 Transcrição do código . . . . . . . . . . . . . . . . . . . . . . 4412

B.15.2 Comentários gerais . . . . . . . . . . . . . . . . 422

B.16 Arquivo accretiongas.c . . . . . . . . . . . . . 423

B.16.1 Comentários gerais . . . . . . . . . . . . . . . . 431 

Capítulo 1

\section{Introdução}

Atualmente, já são conhecidos mais que de 3000 exoplanetas detectados por diversas técnicas observacionais (Han et al., 2014). Parte desses planetas, detectados pelo método de velocidade radial e/ou trânsito, são planetas gigantes, isto é, cujas massas são próximas ou maiores que a massa de Júpiter e são encontrados em regiões próximas de sua estrela hospedeira. Por isso, são denominados de Jupiteres quentes.

Essas novas descobertas colocaram em xeque o paradigma atual sobre a formação do nosso Sistema Solar. Sabe-se, por exemplo, que, devido à disponibilidade de material, os planetas gigantes provavelmente se formaram em regiões externas do disco protoplanetário (i.e, além da linha de gelo) e, portanto, devem sofrer algum processo físico responsável por levá-los para regiões próximas de sua estrela hospedeira (Trilling et al., 2002; Baruteau et al., 2014). Esses processos, conhecidos como migração planetária, ocorrem devido à interação gravitacional do planeta com o disco de gás, interação gravitacional com os planetesimais ou outros planetas vizinhos, efeitos de maré etc... No entanto, ainda não se sabe por que os planetas gigantes do nosso Sistema Solar não sofreram um processo de migração planetária tão brusco como os que são inferidos para outros sistemas planetários observados. Uma possibilidade é que Júpiter e Saturno migraram em uma configuração ressonante que cessou ou mesmo reverteu a migração (Masset e Snellgrove, 2001; Pierens e Raymond, 2011). Devido a essa e outras questões em aberto, como a escala de tempo desses fenômenos, os processos de migração ainda são temas frequentes de estudo. Nesta tese, damos atenção especial à migração planetária devido à interação gravitacional com o disco de gás, que será estudada mediante o uso do simulador hidrodinâmico FARGO3D.

A meta principal desta tese é implementar no código FARGO3D, desenvolvido por Masset (2000) sob o nome de FARGO e depois aprimorado por Benítez-Llambay e Masset 
(2016), um modelo bem consistente para formação planetária que envolve a acreção de sólidos e gás. O objetivo é explorar os parâmetros livres do modelo e sua influência nos processos de migração planetária devido ao disco de gás, processo fundamental na evolução dos sistemas planetários. Com isso, espera-se dar um primeiro passo na tentativa de explicar a diversidade de exoplanetas encontrados, assim como fornecer recursos para uma melhor compreensão dos processos de migração e formação planetária. De fato, a migração planetária devido ao disco de gás vem sendo estudada, na maioria dos trabalhos, sem um uso consistente de um modelo para formação planetária. Em geral, utiliza-se apenas a captura de gás através de uma taxa de acreção definida de forma ad-hoc. Por sua vez, os trabalhos de formação planetária utilizam, geralmente, relações analíticas para o tratamento da migração planetária devido ao disco de gás. No entanto, essas relações não possuem toda a abrangência de uma simulação hidrodinâmica. Assim, um modelo para formação planetária dentro do FARGO3D torna-se importante para trazer à tona novos resultados que possam fornecer maior entendimento sobre os processos de formação e migração planetária. Nesta tese, trataremos da formação de um planeta isolado, desse modo, podemos nos concentrar nas escalas de tempo envolvidas nos processos de migração devido à interação com o disco de gás e de formação planetária sem considerar o efeito gravitacional de outros planetas. No entanto, o código foi construído de forma generalizada, e a inclusão de novos planetas pode ser feita de forma automática pelo leitor.

O capítulo 2 traz um resumo das principais características físicas de um disco de gás com taxa de acreção constante, que será o modelo para o disco adotado nesta tese, e uma descrição do processo de formação planetária baseado no modelo de formação com núcleo sólido. Além disso, faremos uma breve sinopse do processo de migração planetária de tipo I, mais rápida, e que ocorre para planetas menos massivos, e a migração planetária de tipo II, mais lenta, que possui como característica a abertura de um gap no disco de gás e que ocorre para planetas massivos. Além disso, vamos explorar o conceito de raio de Hill e acreção de Bondi. Esses conceitos serão importantes e exaustivamente usados durante toda a tese.

No capítulo 3, iremos fazer uma descrição do código numérico FARGO3D. A ideia é fornecer ao leitor menos experiente alguns recursos necessários para a manipulação do código que será implementado ou modificado ao longo do trabalho. O leitor mais experiente, já acostumado com a implementação do FARGO3D, pode ir diretamente para a 
última seção do capítulo 3 (seção 3.10), na qual uma simulação padrão para um disco de gás com taxa de acreção constante é apresentada. Essa simulação servirá como base para todos as outras que serão realizadas na tese. Contudo, ao usuário iniciante, recomendamos ainda a leitura do manual do FARGO3D, que pode ser encontrado em $<$ http://fargo.in2p3.fr/Documentation $>1^{1}$.

Para melhor legibilidade, o nome dos arquivos e das variáveis utilizadas no FARGO3D são descritos usando a fonte COURIER. Os códigos serão descritos usando a formatação usual que aparece nas principais IDEs (do inglês Integrated Development Environment ou Ambiente de Desenvolvimento Integrado) da linguagem de programação C, como mostra o exemplo a seguir:

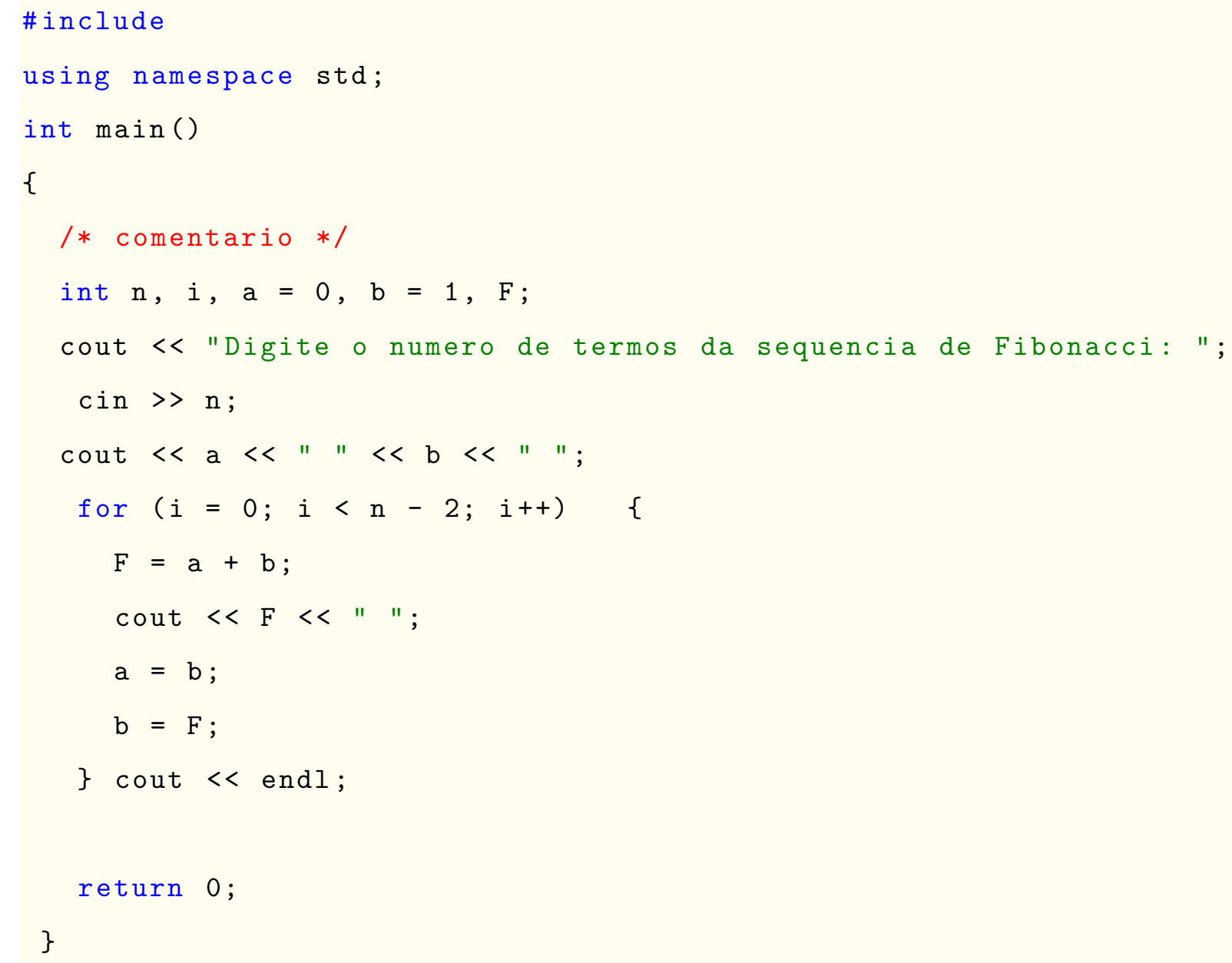

Toda a implementação de um código novo poderá ser encontrada no apêndice ou, em caso de pequenas mudanças, descrito ao longo da tese.

O capítulo 4 conta com uma descrição detalhada do modelo de acreção de sólidos que possui como base o trabalho de Fortier et al. (2013) e Guilera et al. (2010). Esse modelo

\footnotetext{
${ }^{1}$ Acesso em: 9 fev. 2017.
} 
será implementado pela primeira vez no FARGO3D. Com essa implementação, será possível estudar simultaneamente a formação e migração de um núcleo sólido (migração planetária de tipo I) dentro do simulador hidrodinâmico. Isto é, analisaremos a escala de tempo envolvida no processo de migração de tipo I em conjunto com a formação planetária para vários parâmetros físicos envolvidos no modelo.

Já no capítulo 5 , iremos modificar o modelo de acreção de gás que existe para o FARGO (Kley, 1999) e que não foi incorporado ao FARGO3D. Essas modificações serão descritas passo a passo, de modo a deixar claro ao leitor as características físicas que estão sendo incorporadas ao modelo de acreção de gás e sua influência no processo de migração planetária de tipo II sofrida por planetas gigantes. Para isso, vamos analisar a evolução de um gap, produzido por um planeta gigante, dentro de um disco de acreção em equilíbrio, analisando o fluxo de massa através do gap e as escalas de tempo envolvidas nesse processo migratório. As modificações implementadas no modelo de acreção de gás foram realizadas com base nos trabalhos de Dürmann e Kley (2015), Russell (2011) e Fortier et al. (2013).

É importante enfatizar que esta tese foi desenvolvida de modo que o leitor iniciante, através de descrições razoavelmente detalhadas, possa compreender os recursos teóricos envolvidos no modelo implementado. O leitor mais experiente pode optar por um caminho mais curto que descreve diretamente o modelo que foi implementado para formação planetária no FARGO3D e os resultados obtidos. Esse caminho envolve a leitura, na sequência, das seções $3.10,4.5,4.6,5.1,5.4,5.5,5.6,5.7$, 5 5.8, Ao longo dessas seções, e suas respectivas subseções, serão encontradas as referências para os apêndices que contêm as implementações em linguagem $\mathrm{C}$ e as descrições de todos os novos conteúdos implementados no FARGO3D. 
Capítulo 2

\section{Fundamentos teóricos}

Neste capítulo, iremos fazer uma breve recapitulação de alguns fenômenos físicos necessários à compreensão desta tese. Inicialmente, iremos descrever as principais características físicas de um disco de acreção. Essa descrição envolve desde a compreensão da parametrização de Shakura-Sunyaev, usada para tratamento da viscosidade do gás, até a evolução física do disco de gás.

O modelo de disco de gás usado nesta tese é o de um disco com taxa de acreção constante. O intuito foi restringir os parâmetros físicos do disco de gás de modo que o modelo para formação planetária possa ser testado num cenário físico mais comportado. Futuramente, o modelo será analisado em cenários físicos mais complexos e realistas. De todos os modos, esta limitação não é tão restritiva, já que, mesmo dentro deste cenário, será possível obter características extremamente relevantes para melhor compreensão dos mecanismos de formação e migração planetária.

Faremos também uma introdução teórica dos processos físicos envolvidos na acreção com núcleo sólido e na acreção de gás. Esta introdução fornecerá uma base teórica para melhor compreensão do modelo de formação planetária que será implementado numericamente dentro do código FARGO3D.

Também faremos uma breve descrição dos processos de migração planetária de tipo I e de tipo II. O propósito é fornecer ao leitor alguns conceitos que serão importantes em capítulos futuros, assim como são os conceitos de raio de Hill e taxa de acreção de Bondi que também serão explanados neste capítulo.

Conceitos mais avançados, usados ao longo da tese, usarão extensivamente algumas definições descritas neste capítulo. 


\subsection{Discos de acreção}

Os discos de gás e poeira são encontrados ao redor de estrelas jovens e são uma consequência natural do processo de formação estelar que ocorre dentro das nuvens moleculares. Eles surgem devido ao fato de a nuvem molecular possuir muito momento angular para colapsar diretamente numa estrela (Goodman et al. 1993).

Esses discos protoestelares são estruturas compostas, em sua maior parte, de gás em movimento orbital ao redor da estrela. Devido ao efeito da viscosidade entre as camadas do gás, ocorre uma redistribuição do momento angular que faz com que o gás espirale em direção à estrela. Assim, parte da massa do disco é acretada na estrela durante sua evolução enquanto outra parte é perdida em suas fronteiras externas. Além disso, também ocorre a fotoevaporação em que há a destruição do gás por meio da radiação ultravioleta das estrelas. E ventos solares, que podem carregar boa parte do momento algular desse disco.

Os discos protoestrelares, presentes nas etapas iniciais da formação estelar, evoluem para um disco protoplanetário onde são encontradas as condições propícias para formação dos planetas. Os processos que envolvem a formação do disco protoestelar e sua evolução para um disco protoplanetário estão fora do escopo desta tese.

Os discos protoplanetários, também tratados como discos de acreção, possuem um processo de acreção de sua massa pela estrela relativamente lento, entre $10^{-7} \mathrm{M}_{\odot} /$ ano e $10^{-9} \mathrm{M}_{\odot}$ /ano (Hartmann et al., 1998; Li e Xiao, 2016), sendo, portanto, estruturas estáveis cujo tempo de vida, conforme veremos adiante, é estimado, na maioria dos casos, como sendo da ordem de alguns milhões de anos (Williams e Cieza, 2011).

\subsubsection{Parametrização de Shakura-Sunyaev}

A viscosidade é responsável pela redistribuição do momento angular no disco de gás e, portanto, em direcionar a acreção de massa. No entanto, a fonte dessa viscosidade ainda é tema de estudo já que a viscosidade molecular pura não possui ordem de magnitude suficiente para produzir as taxas de acreção observadas. Uma alternativa viável é considerar que essa viscosidade é maior devido aos efeitos de turbulência do gás.

Um mecanismo bastante estudado para a fonte dessa viscosidade turbulenta é conhecido como instabilidade magneto-rotacional (MRI) (Balbus e Hawley, 2002). Nesse modelo, 
além da força da gravidade e das forças de pressão, o elemento de fluido magnetizado sofre ação da força de Lorentz. O campo magnético interage com o disco de gás gerando um acoplamento magnético entre o fluido de uma órbita interna com outro de uma órbita externa, isso faz com que o fluido na órbita interna seja forçado a reduzir sua velocidade angular espiralando para uma órbita interna e que o fluido externo seja empurrado para uma órbita mais externa. No entanto, esse mecanismo ainda não é completamente conhecido e permanece em estudd

Numa forma mais simplificada, o fluxo turbulento pode ser caracterizado pela escala de comprimento $\left(\lambda_{\text {turb }}\right)$ e pela velocidade de rotação $\left(v_{\text {turb }}\right)$ dos vórtices maiores. Assim, a viscosidade turbulenta $\left(\nu_{\text {turb }}\right)$ pode ser escrita como:

$$
\nu_{\text {turb }} \sim \lambda_{\text {turb }} v_{\text {turb }}
$$

Obviamente, o maior valor para escala de comprimento de um vórtice não pode exceder a escala de altura $H$ do disco, de modo que $\lambda_{\text {turb }} \lesssim H$ e a velocidade de rotação é, provavelmente, subsônica, isto é, menor que a velocidade do som $c_{\mathrm{s}}\left(v_{\text {turb }} \lesssim c_{\mathrm{s}}\right)$, já que movimentos supersônicos resultariam em choques e na dissipação dos vórtices. Portanto, a viscosidade do gás pode ser estimada como

$$
\nu_{\text {gas }} \sim \nu_{\text {turb }} \sim \alpha c_{\mathrm{s}} H
$$

onde $\alpha \lesssim 1$. Esta estimativa é conhecida como parametrização de Shakura-Sunyaev (Shakura e Sunyaev, 1973). Neste procedimento, nossa ignorância sobre os mecanismos responsáveis pela viscosidade do disco são parametrizados no fator $\alpha$. Estimativas observacionais para esse parâmetro indicam valores entre $10^{-4}$ e $10^{-2}$ (Hartmann et al., 1998; Mukhopadhyay, 2008).

A parametrização de Shakura-Sunyaev permanece como o modelo mais comumentemente utilizado na análise de discos de acreção. Em geral, o parâmetro $\alpha$ é mantido fixo ao longo do raio do disco de acreção, característica que também usaremos nesta tese. Todavia, há simulações que analisam a dependência teórica desse parâmetro com o raio do

\footnotetext{
${ }^{1}$ Alguns estudos têm mostrado que MRI é provavelmente suprimida, a qualquer distância da estrela devido a efeitos não ideais em magnetohidrodinâmica (Bai e Stone, 2013, Lesur et al., 2014; Turner et al. 2014).
} 
disco (Penna et al., 2013; Lyra et al., 2015). Guilera e Sándor (2017), por exemplo, utilizam um valor de $\alpha$ variável para gerar uma região em que ocorre um acúmulo de material que impacta na formação de planetas gigantes. Essas regiões são conhecidas como zonas da morte. Zonas da morte são criadas quando o gás local é insuficiente ionizado para dar suporte a MRI. Elas podem ocorrer, por exemplo, quando a densidade da coluna de gás é grande o suficiente para proteger as zonas internas do disco da ionização por raios cósmicos.

\subsubsection{Estrutura vertical}

É comum nos trabalhos de formação e migração planetária o uso de modelos de discos protoplanetários com razão de aspecto $(h=H / r)$ da ordem de 0.05 ou menores.

Para inferir a espessura do disco protoplanetário, vamos trabalhar com o conceito de equilíbrio hidrostático na vertical, raciocínio análogo ao empregado por Armitage (2010). Considerando um sistema de coordenadas cilíndricas, fixo no centro do disco, no qual a coordenada $r$ se encontra em seu plano e cujo eixo $z$ é perpendicular e aponta na direção do eixo de rotação, a equação de equilíbrio hidrostático na direção vertical pode ser escrita na forma:

$$
\frac{d P_{\text {gas }}}{d z}=-g_{z} \rho_{\text {gas }}
$$

onde $g_{z}$ é a aceleração gravitacional na direção vertical, $P_{\text {gas }}$ é a pressão do gás e $\rho_{\text {gas }}$ sua densidade volumétrica.

Vamos considerar, como de fato indicam as medidas observacionais (Hartmann et al., 1998), que a massa do disco $\left(M_{\text {disk }}\right)$ seja estritamente menor que a da estrela, isto é, $M_{\text {disk }} \ll M_{\star}$, dessa forma, podemos negligenciar a atração gravitacional do disco sobre si mesmo. Logo, o campo gravitacional numa distância $(r, z)$ será dado por:

$$
g_{z}=\frac{G M_{\star}}{d^{2}} \sin \theta=\frac{G M_{\star} z}{d^{3}}=\frac{G M_{\star} z}{\left(r^{2}+z^{2}\right)^{3 / 2}},
$$

onde $d$ e $(r, z)$ são, respectivamente, a distância e as coordenadas de um ponto em relação ao sistema de referência. Levando em conta que o disco possui uma grande área superficial, obtemos um resfriamento bastante eficiente que implica um disco cujo raio é extremamente 
maior que sua espessura $(r \gg z)$. Logo, a equação 2.4 pode ser escrita na forma simplificada:

$$
g_{z} \approx \Omega_{\mathrm{K}}^{2} z
$$

onde $\Omega_{\mathrm{K}}=\left(G M_{\star}\right)^{1 / 2} r^{-3 / 2}$ é a velocidade angular kepleriana do gás.

Além disso, a pequena espessura do disco em relação a seu raio permite assumir um disco verticalmente isotérmico, de modo que a pressão do gás pode ser descrita pela relação $P_{\text {gas }}=c_{\mathrm{s}}^{2} \rho_{\text {gas }}$, na qual $c_{\mathrm{s}}$ é a velocidade do som que, por sua vez, é dada por:

$$
c_{\mathrm{s}}^{2}=\frac{k_{\mathrm{B}} T_{\mathrm{gas}}}{\mu m_{\mathrm{p}}},
$$

onde $k_{\mathrm{B}}$ é a constante de Boltzmann, $T_{\text {gas }}$ é a temperatura do gás e $\mu$ é a constante molecular média em unidades de massa do próton $m_{\mathrm{p}}$.

Assim, a equação 2.3 para o equilíbrio hidrostático, torna-se:

$$
c_{\mathrm{s}}^{2} \frac{d \rho_{\mathrm{gas}}}{d z}=-\Omega_{\mathrm{K}}^{2} \rho_{\mathrm{gas}} z
$$

A equação acima é uma equação diferencial de primeira ordem, cuja solução é:

$$
\rho_{\text {gas }}=\rho_{0} e^{-z^{2} / 2 H^{2}}
$$

onde $H \equiv \frac{c_{\mathrm{s}}}{\Omega_{\mathrm{K}}}$ é a escala de altura do disco (a distância na qual a densidade volumétrica decai por um fator $e^{-1 / 2}$ ) e $\rho_{0}$ a densidade volumétrica do gás no plano médio do disco. Observe que, usando $\Omega_{\mathrm{K}}=\frac{v_{\theta, \text { gas }}}{r}$, onde $v_{\theta, \text { gas }}$ é a velocidade tangencial kepleriana do gás, podemos escrever que:

$$
\frac{H}{r} \sim \frac{c_{\mathrm{s}}}{v_{\theta, \text { gas }}} .
$$

Note também que $v_{\theta \text {,gas }} \simeq r \Omega_{\mathrm{K}} \sim r^{-1 / 2}$, assim $H \sim \frac{c_{\mathrm{s}} r}{v_{\theta, \text { gas }}} \sim c_{\mathrm{s}} \frac{r}{r^{-1 / 2}} \sim c_{\mathrm{s}} r^{3 / 2}$, ou seja, $H$ aumenta com $r$. No entanto, a velocidade do som $c_{\mathrm{s}}$ depende da temperatura (ver eq. 2.6) que, por sua vez, varia com a distância à estrela $\left(c_{\mathrm{s}}^{2} \propto T_{\text {gas }}(r)\right)$. Considerando a velocidade do som parametrizada na forma $c_{\mathrm{s}} \propto r^{-\beta}$, podemos escrever:

$$
\frac{H}{r} \propto r^{-\beta+1 / 2}
$$


A relação acima mostra que a razão de aspecto do disco obtido pela relação $h=\frac{H}{r}$ depende de $T_{\text {gas }}(r)$, assim, torna-se importante estudar como ocorrem as trocas de energia dentro do disco, de modo a obter a distribuição radial de temperatura. No entanto, nesta tese, nosso foco é adaptar um modelo para formação planetária. Portanto, vamos nos limitar a um disco verticalmente isotérmico cujo perfil radial de temperatura é obtido mediante a equação 2.9, usando uma razão de aspecto constante e igual a $h=H / r=0.05$. Assim, de acordo com a equação 2.10, a velocidade do som varia na forma $c_{\mathrm{s}} \propto r^{-1 / 2}$, portanto, a temperatura em nosso modelo de disco deve variar na forma $T_{\text {gas }}(r) \propto r^{-1}$.

\subsubsection{Velocidade tangencial do gás}

A velocidade orbital do gás no disco pode ser determinada para um dado perfil de densidade e temperatura. Considerando um disco bidimensional, com simetria axial, estacionário e no qual o potencial é dominado pelo potencial da estrela central, a componente radial do momento implica uma velocidade orbital dada pela equação:

$$
\frac{v_{\theta, \mathrm{gas}}^{2}}{r}=\frac{G M_{\star}}{r^{2}}+\frac{1}{\Sigma_{\text {gas }}} \frac{d P_{\mathrm{gas}}}{d r},
$$

onde $v_{\theta \text {,gas }}$ é a velocidade tangencial do gás, $G$ a constante gravitacional, $M_{\star}$ a massa da estrela central e, $\Sigma_{\text {gas }}$ e $P_{\text {gas }}$, respectivamente, a densidade superficial e a pressã $\rrbracket^{1}$ do gás na posição $r$.

Em geral, a pressão próxima do plano médio do disco decai com o aumento de $r$, portanto, o segundo termo do lado direito deve ser negativo. Considerando um disco fino, vimos (ver seção 2.1.2 que a velocidade do som pode ser escrita na forma $c_{\mathrm{s}}=H \Omega_{\mathrm{K}}$. A razão de aspecto do disco $h=H / r$ pode ser parametrizada em termos de um fator $\gamma$ que leva em conta a curvatura do disco, assim:

$$
h(r)=\frac{H}{r}=h_{0}\left(\frac{r}{R_{0}}\right)^{\gamma},
$$

onde $h_{0}$ é a razão de aspecto em $R_{0}$.

Portanto, dado $\Omega_{\mathrm{K}}=\left(G M_{\star}\right)^{1 / 2} r^{-3 / 2}$, podemos escrever a velocidade do som na forma:

$$
c_{\mathrm{s}}=\frac{r^{\gamma-1 / 2} h_{0}\left(G M_{\star}\right)^{1 / 2}}{R_{0}^{\gamma}} .
$$

\footnotetext{
${ }^{1}$ Num disco bidimensional, a pressão obtida é a pressão por unidade de profundidade.
} 
Num disco verticalmente isotérmico e bidimensional, a pressão é dada por $P_{\text {gas }}=$ $c_{\mathrm{s}}^{2} \Sigma_{\text {gas }}$, considerando um perfil de densidade superficial do gás na forma $\Sigma_{\text {gas }}=\Sigma_{0} r^{-\varphi}$ e a equação 2.13, a pressão do gás pode ser escrita como:

$$
P_{\text {gas }}=\frac{r^{2 \gamma-1-\varphi} h_{0}^{2} G M_{\star} \Sigma_{0}}{R_{0}^{2 \gamma}} .
$$

Substituindo a relação acima na equação 2.11, temos que a velocidade tangencial do gás num disco verticalmente isotérmicd ${ }^{2}$ é dada por:

$$
v_{\theta, \text { gas }}=\Omega_{\mathrm{K}} r\left[1+h_{0}^{2}\left(\frac{r}{R_{0}}\right)^{2 \gamma}(2 \gamma-1-\varphi)\right]^{1 / 2} .
$$

Conforme discutimos na seção anterior, usaremos no nosso modelo um disco cuja razão de aspecto é constante e, portanto, $\gamma=0$ o que nos permite escrever a equação 2.15 na forma:

$$
v_{\theta, \text { gas }}=\Omega_{\mathrm{K}}\left[1-h_{0}^{2}(1+\varphi)\right]^{1 / 2} .
$$

É possível perceber, analisando a equação 2.16, que a velocidade tangencial do gás é levemente menor que a velocidade tangencial kepleriana. No entanto, veremos que essa leve diferença é importante, já que resulta no arrasto aerodinâmico responsável pelo decaimento da poeira e dos planetesimais em direção à estrela.

\subsubsection{Evolução de um disco de acreção}

Vimos que a evolução do disco de gás está intrinsecamente ligada ao transporte de momento angular no seu interior, o que leva o gás a espiralar e a ser acretado pela estrela. Esse e outros mecanismos como a fotoevaporação, a acreção de gás pelos planetas etc. fazem com que a massa de gás presente no disco diminua com o tempo (Dullemond et al. 2007). Portanto, o disco de gás possui um tempo de vida que está relacionado com a dissipação do gás.

O vínculo observacional mais forte para o estudo dos discos protoplanetários é o excesso de infravermelho. Analisando a presença desse excesso em aglomerados estelares, é possível fazer uma estimativa do tempo de vida de um disco protoplanetário. A Figura 2.1

\footnotetext{
${ }^{2}$ Num disco adiabático, a velocidade do som em cada ponto não é constante e a velocidade tangencial do gás varia de acordo com a transferência de energia e a consequente mudança de temperatura.
} 
mostra a fração de estrelas jovens, em diferentes aglomerados, que possuem evidência da presença de discos de acreção. Essa fração é plotada junto com a idade estimada para esses aglomerados, obtida da localização dessas estrelas no diagrama H-R, aliado a modelos de evolução. Podemos observar que a frequência de discos é pouco abaixo de $100 \%$ para aglomerados com idade média inferior a 1 milhão de anos, caindo para aproximadamente $50 \%$ para aglomerados com 3 milhões de anos e chegando a 10\% para idades médias próximas de 6 milhões de anos. Não há evidência de discos para aglomerados com mais de 10 milhões de anos. Portanto, podemos estimar o tempo de vida de um disco protoplanetário como sendo da ordem de alguns milhões de anos.

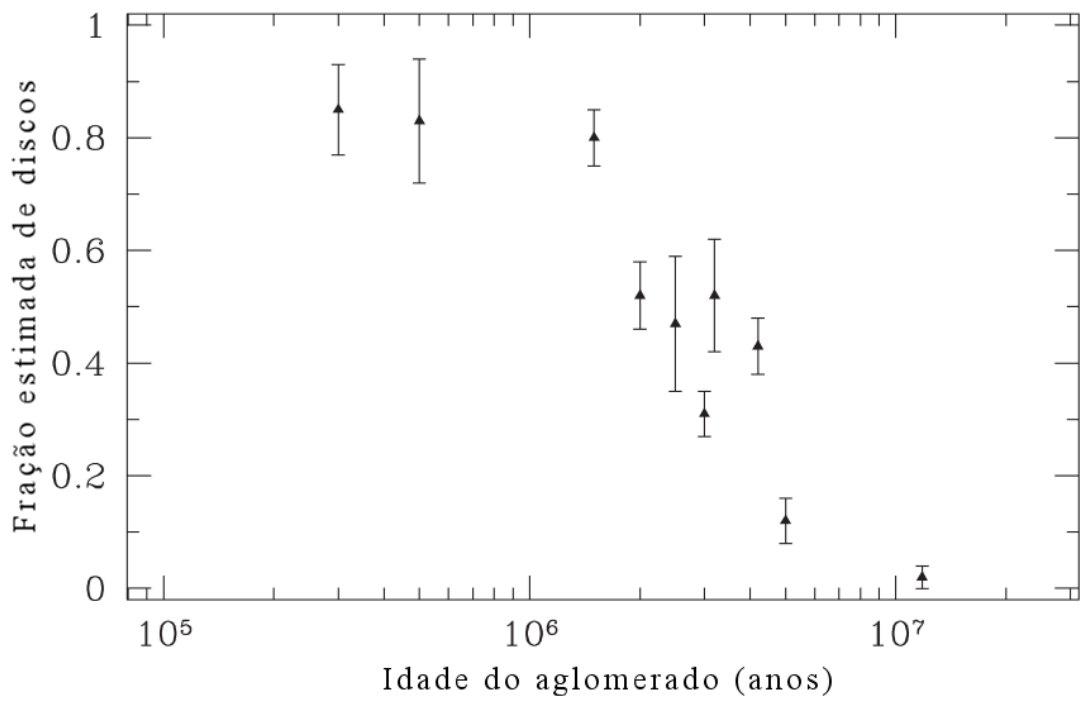

Figura 2.1: Gráfico da fração de discos protoplanetários em aglomerados jovens em função da estimativa de idade do aglomerado. Os aglomerados plotados são: NGC 2024, o Trapézio, NGC 2264, NGC 2362, NGC 133, $\sigma$-Ori, IC 348, Tr 37, NGC 7160 e Chamaeleon. Figura obtida em: Armitage (2010), onde também é possível encontrar as referências do estudo de cada aglomerado.

Acredita-se que essas estrelas, devido à idade do aglomerado, são do tipo T-tauri, que possuem um disco primordial, não sendo estrelas mais velhas com disco de detritos cuja colisão poderia gerar a poeira responsável pelo excesso de infravermelho.

É importante mencionar também que as medidas do excesso de infravermelho são realizadas em regiões internas, próximas de 1 ua, o que nos leva a questionar o tempo de vida do restante do disco. No entanto, algumas evidências levam a acreditar que esse tempo é bastante plausível para todo o corpo do disco. A primeira é a medida espectroscópica que indica a acreção do gás e que decai no tempo numa escala similar (Hartmann et al. 
1998); a segunda é a presença de outros sinais, como o excesso na região millimétrica do espectro eletromagnético, em diferentes regiões. Estas observações indicam que os discos foram dispersados através de uma faixa de distância numa escala de tempo relativamente curta (Andrews e Williams, 2005).

Para estudar a evolução de um disco de acreção, vamos considerar um disco de gás bidimensional e sem campo magnético, cujo perfil de densidade superficial seja dado por $\Sigma_{\text {gas }}(r, t)$, que a velocidade radial do gás seja pequena comparada com sua velocidade orbital e, conforme discutido na seção 2.1 .2 , que o disco seja fino $(H / r \ll 1)$. Nesse caso, o efeito dominante é a atração gravitacional da estrela, o que implica um potencial gravitacional independente do tempo e, portanto, na conservação do momento angular. $\mathrm{Na}$ ausência de mecanismos de transporte desse momento angular, teríamos um disco de gás estático e uma densidade superficial constante ao longo do tempo. No entanto, a viscosidade faz com que uma parte do gás espirale em direção à estrela e, consequentemente, pela conservação do momento angular, outra parte espirale para fora. Outros mecanismos de transporte do momento angular são, por exemplo, a ação de fluxos magnéticos e a ação de ventos estelares, que não serão considerados neste trabalho.

A evolução da densidade superficial de gás $\Sigma_{\text {gas }}(r, t)$ pode ser deduzida considerando a equação de continuidade e a componente azimutal do momento angular (Pringle, 1981). Para isso, vamos considerar a massa $\Delta m$ de um anel do disco de gás entre $r$ e $r+\Delta r$ :

$$
\Delta m=2 \pi r \Delta r \Sigma_{\text {gas }}(r, t)
$$

Assim, a taxa de mudança de massa dentro de um anel de largura $\Delta r$ é dada por:

$$
\frac{\partial}{\partial t}\left(2 \pi r \Delta r \Sigma_{\text {gas }}\right)=2 \pi r \Sigma_{\text {gas }}(r, t) v_{\mathrm{r}, \mathrm{gas}}(r, t)-2 \pi(r+\Delta r) \Sigma_{\mathrm{gas}}(r+\Delta r, t) v_{\mathrm{r}, \mathrm{gas}}(r+\Delta r, t)
$$

onde $v_{\mathrm{r}, \text { gas }}$ é a velocidade radial do gás.

Como $\Sigma_{\text {gas }}(r+\Delta r, t) \simeq \Sigma_{\text {gas }}(r, t)+\left(\frac{\partial \Sigma_{\text {gas }}}{\partial r}\right) \Delta r$, fazendo $\Delta r \rightarrow 0$, encontramos:

$$
r \frac{\partial \Sigma_{\text {gas }}}{\partial t}+\frac{\partial}{\partial r}\left(r \Sigma_{\text {gas }} v_{\text {r,gas }}\right)=0 .
$$

Já o momento angular $\Delta L$ do anel de gás é dado por:

$$
\Delta L=2 \pi r \Delta r \Sigma_{\text {gas }} r^{2} \Omega
$$


onde $\Omega$ é a velocidade angular do gás.

Utilizando o mesmo raciocínio usado para a conservação de massa, a conservação do momento angular fornece:

$$
\begin{array}{r}
\frac{\partial}{\partial t}\left(2 \pi r \Delta r \Sigma_{\text {gas }} r^{2} \Omega\right)=v_{\mathrm{r}, \mathrm{gas}}(r, t) 2 \pi r \Sigma_{\mathrm{gas}}(r, t) r^{2} \Omega-v_{\mathrm{r}, \mathrm{gas}}(r+\Delta r, t) 2 \pi(r+\Delta r) \\
\Sigma_{\mathrm{gas}}(r+\Delta r, t)(r+\Delta r)^{2} \Omega(r+\Delta r)+G(r+\Delta r)-G(r) \approx \\
\approx-2 \pi \Delta r \frac{\partial}{\partial r}\left(r \Sigma_{\text {gas }} v_{\mathrm{r}, \mathrm{gas}} r^{2} \Omega\right)+\frac{\partial G}{\partial r} \Delta r,
\end{array}
$$

onde $G$ é o torque viscoso exercido no anel de massa $\Delta m$ pelo anel externo. A partir da lei de Newton para fricção entre camadas de fluidos laminares, sabemos que a força entre as camadas é dada por $F=\nu A \frac{\partial v}{\partial y}$, onde $\nu$ é a viscosidade, $A$ a área de contato entre as camadas e $\frac{\partial v}{\partial y}$ o gradiente da velocidade. Assim, o torque viscoso $(G=F r)$ entre os anéis do disco pode ser obtido considerando que, no disco bidimensional, a área entre as camadas do fluido é o arco de circunferência e que $\frac{\partial v}{\partial r}=r \frac{d \Omega}{d r}$. Assim, o torque viscoso é dado por:

$$
G=2 \pi r \nu_{\text {gas }} \Sigma_{\text {gas }} r^{2} \frac{d \Omega}{d r}
$$

onde $\nu_{\text {gas }}$ é a viscosidade entre as camadas do gás.

Tomando o limite $\Delta r \rightarrow 0$ na equação 2.21, obtemos:

$$
r \frac{\partial}{\partial r}\left(\Sigma_{\text {gas }} r^{2} \Omega\right)+\frac{\partial}{\partial r}\left(r \Sigma_{\text {gas }} v_{\text {r,gas }} r^{2} \Omega\right)=\frac{1}{2 \pi} \frac{\partial G}{\partial r} .
$$

Eliminando $v_{\text {r,gas }}$ entre as equações 2.19 e 2.23, e especificando um disco kepleriano $\left(\Omega=\Omega_{\mathrm{K}} \propto r^{-3 / 2}\right)$, obtém-se:

$$
\frac{\partial \Sigma_{\mathrm{gas}}}{\partial t}=\frac{3}{r} \frac{\partial}{\partial r}\left[r^{1 / 2} \frac{\partial}{\partial r}\left(\nu_{\mathrm{gas}} \Sigma_{\mathrm{gas}} r^{1 / 2}\right)\right]
$$

que é a equação que rege a evolução da densidade superficial de um disco fino sob a ação do transporte de momento angular interno.

A equação acima é a equação básica para evolução de um disco kepleriano. Uma vez conhecida a densidade superficial em função do tempo, a velocidade radial segue da conservação da massa (ver eq. 2.19), logo:

$$
v_{\mathrm{r}, \mathrm{gas}}=-\frac{3}{\Sigma_{\text {gas }} r^{1 / 2}} \frac{\partial}{\partial r}\left(\nu_{\mathrm{gas}} \Sigma_{\mathrm{gas}} r^{1 / 2}\right)
$$


As equações 2.19 e 2.25 podem ser resolvidas analiticamente para alguns casos especiais. De fato, usaremos essas equações para encontrar o perfil da densidade superficial e da velocidade radial para um disco com taxa de acreção constante, que será o modelo de disco de gás usado nesta tese.

\subsubsection{Disco com taxa de acreção constante}

Devido à complexidade do modelo de formação planetária e ao grande número de parâmetros livres, usaremos nesta tese um disco de gás com solução analítica bem conhecida. Assim, o modelo para formação dos planetas poderá ser testado dentro de um cenário físico para o disco de gás com parâmetros e evolução bem comportados. Escolhemos, portanto, um disco com taxa de acreção constante, cuja solução pode ser obtida impondo $\frac{\partial \Sigma_{\text {gas }}}{\partial t}=0$ na equação 2.19. Integrando a equação obtida, obtemos que a taxa de acreção, $\dot{M}=2 \pi r \Sigma_{\text {gas }} v_{\text {r,gas }}(r, t)$, ao longo do disco é constante. Então, a equação 2.23 para conservação do momento angular, pode ser escrita na forma:

$$
-\dot{M} r^{2} \Omega=2 \pi r^{3} \nu_{\text {gas }} \Sigma_{\text {gas }} \frac{d \Omega}{d r}+\text { constante . }
$$

A constante de integração da equação acima pode ser obtida localizando a posição do disco onde $\frac{d \Omega}{d r}=0$. Nesse ponto, o termo que contém a viscosidade se anula e a constante é simplesmente igual ao fluxo do momento angular

$$
\text { constante }=-\dot{M} r^{2} \Omega
$$

Para isso, podemos considerar que o disco de gás se estende até a superfície de uma estrela que possui baixa velocidade angular. Assim, o disco e a estrela formam um sistema fluido único e a velocidade angular obtida em função do raio seria algo similar à observada na Figura 2.2. Na prática observamos um disco de gás separado da estrela (Romanova e Lovelace, 2006). Trata-se de uma região extremamente complexa e que permanece estudo. No entanto, esse estudo foge do escopo desse trabalho.

Para que ocorra uma transição contínua entre $\Omega \approx 0$ na borda da estrela e $\Omega=\Omega_{\mathrm{K}} \propto$ $r^{-3 / 2}$ dentro do disco de gás, o tensor viscoso precisa se anular em $R_{\star}+r_{\mathrm{bl}}$, onde $r_{\mathrm{bl}}$ é a largura da camada de fronteira que separa a camada próxima da estrela da parte kepleriana do disco. 


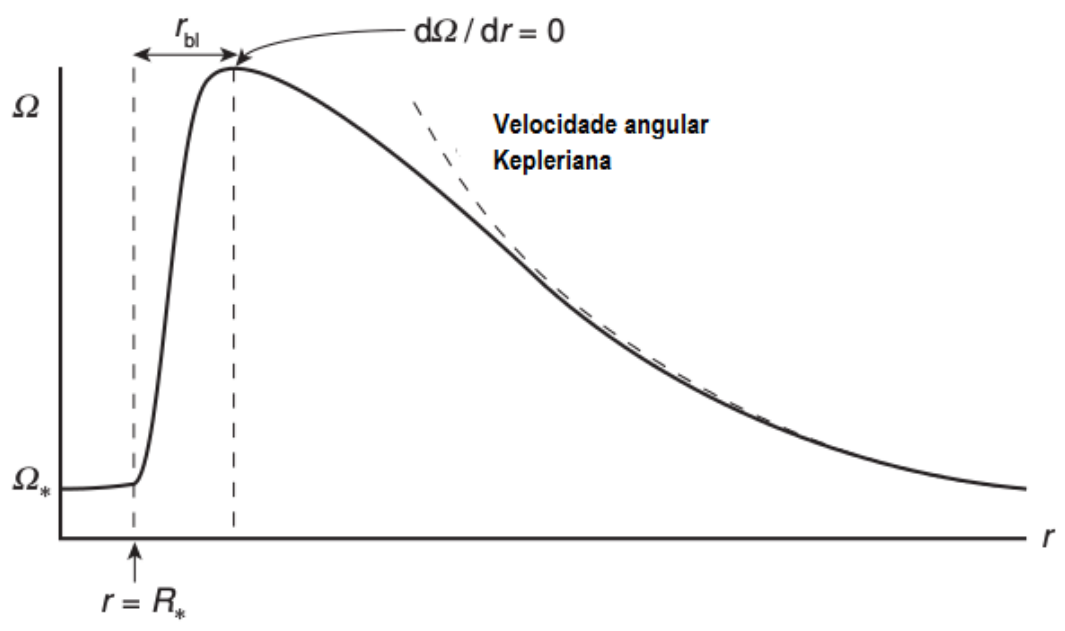

Figura 2.2: Esboço do perfil da velocidade angular de um disco de gás. O raio do disco se estende do equador de uma estrela em baixa rotação até a borda externa do disco. Figura obtida em: Armitage (2010).

A hidrodinâmica e a magneto-hidrodinâmica da região da borda interna são bastante complexas e longe do escopo desta tese. No entanto, argumentos físicos sugerem que a largura dessa camada é uma pequena fração do raio estelar. Logo, podemos utilizar $R_{\star}+r_{\mathrm{bl}} \simeq R_{\star}$, portanto, a constante fica na forma:

$$
\text { constante }=-\dot{M} R_{\star}^{2} \Omega_{\mathrm{K}}=-\dot{M} \sqrt{G M_{\star} R_{\star}} .
$$

Assim, substituindo o valor da constante obtida acima na equação 2.26, o perfil para a densidade superficial de um disco com taxa de acreção constante pode ser descrito por:

$$
\Sigma_{\text {gas }}=\frac{\dot{M}}{3 \pi \nu_{\text {gas }}}\left(1-\sqrt{\frac{R_{\star}}{r}}\right) .
$$

Em geral, o raio do disco que define a região de estudo é estritamente maior que o raio estelar $r>>R_{\star}$, além disso, utilizando a relação $\nu_{\text {gas }}=\alpha c_{\mathrm{s}} H$ (ver eq. 2.2), a velocidade do som $c_{\mathrm{s}}=H \Omega_{\mathrm{K}}$ (ver eq. 2.9) e a razão de aspecto do disco $h=H / r$, podemos escrever a densidade superficial de um disco de acreção em equilíbrio como:

$$
\Sigma_{\text {gas }}=\frac{\dot{M}}{3 \pi \alpha h^{2} r^{2} \Omega_{\mathrm{K}}} .
$$

Além disso, substituindo a relação acima na equação 2.25, temos que o perfil para a velocidade radial do gás é descrito por: 


$$
v_{\mathrm{r}, \mathrm{gas}}=-\frac{3}{2} \frac{\alpha c_{\mathrm{s}} H}{r} .
$$

As equações 2.16, 2.30 e 2.31 serão usadas para descrever as condições iniciais do nosso disco de gás standard implementado no FARGO3D e que será usado ao longo de toda a tese.

\subsection{Formação planetária}

O processo de formação planetária baseado no modelo de acreção com núcleo sólido é costumeiramente dividido em três estágio principais (Lissauer, 1993; Pollack et al., 1996). O primeiro estágio consiste na formação dos planetesimais a partir da aglomeração de poeira. No segundo estágio, esses planetesimais, sob ação da atração gravitacional mútua, são responsáveis pela formação de um núcleo sólido. À medida que esse núcleo cresce torna-se capaz de atrair o gás do disco, entrando no terceiro estágio, a partir do qual é possível a formação de um planeta gigante. Os planetas terrestres são formados de forma similar, no entanto, em razão da região em que se formam e do tempo de vida do disco, não conseguem alcançar uma massa suficiente grande para iniciar a acreção do gás de forma desenfreada (Pollack et al., 1996).

O modelo de acreção com núcleo sólido, devido à distribuição de material do disco e ao tempo de vida do disco, é incapaz de explicar a presença de planetas gigantes em regiões próximas à estrela, os denominados Jupiteres quentes. Para isso, é necessário o estudo dos mecanismos que permitem que o planeta formado em regiões externas do disco seja levado a regiões próximas da estrela. Esses mecanimos são os processos de migração planetária que podem ocorrer em razão da interação planeta-planeta, efeito maré, entre outros. Nesta tese, focaremos na migração planetária que ocorre em decorrência da interação gravitacional do planeta com o disco de gás. Além disso, nosso estudo irá considerar a formação de apenas um planeta, assim, poderemos analisar mais cuidadosamente o modelo de formação planetária sem levar em consideração a interação entre os planetas que poderia mudar radicalmente o cenário (Papaloizou, 2003; Baruteau e Papaloizou, 2013; Baruteau et al. 2014).

Um modelo alternativo, conhecido como formação por via instabilidade gravitacional (Boss, 1997), tem sido usado para explicar a formação de planetas gigantes. Esse modelo 
considera que a formação planetária ocorre de forma similar à formação estelar, isto é, por meio do colapso do gás numa região de maior densidade. O modelo de formação via instabilidade não depende da metalicidade do disco e, em geral, exige a condição de discos mais massivos do que os considerados no modelo de formação com núcleo sólido. Além disso, a formação planetária ocorre em regiões mais afastadas da estrela onde há um resfriamento mais rápido. A massa dos planetas formados são maiores que $2 \mathrm{M}_{\mathrm{J}}$, no entanto, o modelo apresenta dificuldades para formação de planetas com massas menores e em regiões próximas da estrela. Uma discussão entre os dois modelos e suas limitações pode ser vista em Matsuo et al. (2007).

Esses dois processos de formação planetária não são necessariamente excludentes, podendo ocorrer simultaneamente. No entanto, nesta tese, optamos por trabalhar com o modelo de acreção com núcleo sólido, já que ele possui a capacidade de reproduzir uma gama maior de massas planetárias que estão de acordo com os vínculos observacionais. Além disso, ainda há um grande debate sobre qual modelo é mais eficiente em gerar planetas gigantes num tempo hábil, cenários híbridos também se tornam uma opção interessante para resolução deste dilema (Durisen et al., 2007).

\subsubsection{Formação dos planetesimais}

Planetesimal é um corpo rochoso ou de gelo, cujo tamanho varia entre 0.01 até $100 \mathrm{~km}$ e são formados a partir da aglutinação da poeira encontrada no disco protoplanetário.

No primeiro estágio da formação planetária, os grãos de poeira, similares àqueles encontrados no meio interestelar, sofrem um processo de sedimentação em direção ao plano médio do disco e um deslocamento radial em direção à estrela. O gás do disco, devido aos efeitos da pressão que se contrapõe à gravidade, possui uma velocidade sub-kepleriana (ver seção 2.1.3), assim, os grãos, que são rapidament@包 acoplados ao gás devido ao arrasto, atingem uma velocidade menor que sua velocidade orbital kepleriana e realizam um deslocamento radial em direção à estreld $2^{2}$. Ambos os processos, sedimentação e deslocamento radial, ocorrem em conjunto com o processo de coagulação, no qual, os grãos, por meio de

\footnotetext{
${ }^{1}$ Em termos do período orbital em torno da estrela, podemos considerar que o acoplamento é praticamente instantâneo.

${ }^{2}$ A poeira não sofre um efeito significativo das forças de pressão do gás, por isso, espirala em direção à estrela.
} 
colisões entre si, se aglutinam aumentando sua massa.

Esses processos, em conjunto, permitem que os grãos cresçam da ordem de micrometros até metros (Brauer et al., 2008). No entanto, alguns problemas são encontrados para a formação de planetesimais maiores. De fato, a velocidade radial para materiais da ordem de metros, dentro de condições típicas para um disco de gás, alcança um valor muito alto de forma que a escala de tempo para o deslocamento radial é menor que a escala de tempo para o crescimento, assim, os planetesimais migram em direção a estrela e são destruídos pela alta temperatura antes da sua completa formação. Outro problema se refere ao fato de objetos da ordem de metros, em razão do aumento de sua velocidade radial, sofrerem um processo alto de fragmentação causado pelas colisões, o que torna sua taxa de crescimento ainda menor.

Uma das alternativas para contornar esse problema é o modelo de instabilidade para camadas de poeira (Goldreich e Ward, 1973) que envolve a autogravidade em regiões de concentração de poeira. De fato, nos modelos anteriores a única interação física entre as partículas é o processo de colisão, assim, a dinâmica da poeira não tem efeito sobre a evolução do disco de gás. Essas considerações são válidas para pequenas partículas distribuídas uniformemente no disco de gás. No entanto, mudanças físicas nos processos de sedimentação ou de deslocamento radial, e até mesmo processos como a fotoevaporação, podem gerar concentrações diferenciadas de poeira ao longo do disco que favoreçam a formação de planetesimais via mecanismo de instabilidade. O problema é que a turbulência é suficientemente forte para previnir essas regiões de sobredensidade, que são necessárias para alcançar o limite adequado para um colapso da poeira por autogravidade (Johansen et al., 2006; Cuzzi et al., 2008). Logo, as condições para a formação de planetesimais ainda é um tema atual de pesquisa (Dra̧żkowska et al., 2016).

É importante ressaltar que esta tese foca na fase subsequente de formacao planetária, a partir de quando planetesimais já estariam formados. Portanto, nenhum modelo para evolução da poeira será necessário.

\subsubsection{Acreção dos planetesimais}

A partir da formação dos planetesimais, a força dominante no processo de formação planetária passa a ser a força gravitacional mútua, responsável pelo processo de atração e acumulação desses planetesimais num protoplaneta, ou núcleo planetário, cujo raio é da 
ordem de alguns milhares de kilômetros (Levison et al., 2010).

No entanto, o estudo da formação de um núcleo planetário apresenta alguns desafios. O primeiro deles se refere às condições iniciais, já que a distribuição dos planetesimais durante o processo de formação desse núcleo não é bem conhecida. Além disso, a formação desse núcleo exige um grande número de planetesimais. De fato, um planeta do tamanho da Terra consiste de aproximadamente $10^{18}$ planetesimais de raio de $30 \mathrm{~km}$ (Mordasini et al. 2010). Esse grande número de planetesimais torna difícil uma análise baseada numa simulação N-corpos realizada de forma direta. Somado a isso, deve-se levar em conta o fato de o processo de colisão e aglutinação para formação ser lento, isto é, da ordem de milhões de anos.

Os processos físicos envolvidos na formação do núcleo sólido são altamente não lineares, já que dependem de diversas características físicas do disco protoplanetário, que evoluem com o tempo. A complexidade do processo exige algumas simplificações físicas que devem sempre ser inseridas de maneira abalizada e cuidadosa.

Todas essas dificuldades fazem com que essa etapa do processo de formação planetária seja modelada usando diferentes métodos. Nesta tese, usaremos o método estatístico baseado no trabalho de Inaba et al. (2001), descrito no capítulo 4 , outros métodos incluem o método de Monte Carlo (Ormel et al. 2010) e modelos que utilizam simulação N-corpos. Um modelo mais simples, baseado no conceito de foco gravitacional, será descrito a seguir e servirá como base para a compreensão do método estatístico descrito no capítulo 4.

Para o processo de captura do planetesimal, é importante introduzir o conceito de seção de choque $(\Gamma)$, definida como a área que mede a probabilidade de ocorrer uma colisão (interação) entre partículas. A atração gravitacional de um corpo massivo irá defletir a trajetória de um corpo que se move em sua direção resultando em uma seção de choque maior, numa espécie de "focalização gravitacional". Considere a Figura 2.3, na qual dois corpos de massa $m$ movem-se com velocidade relativa $v_{\text {rel }}$ numa trajetória cujo parâmetro de impacto, ou seja, a distância perpendicular entre o vetor velocidade do projétil e o centro do objeto do qual está se aproximando, é $b$.

Definindo o momento de maior aproximação como aquele em que os corpos possuem uma separação $R_{\min }$ e velocidade máxima $v_{\max }$, a equação de conservação de energia, no referencial do centro de massa, fornece: 


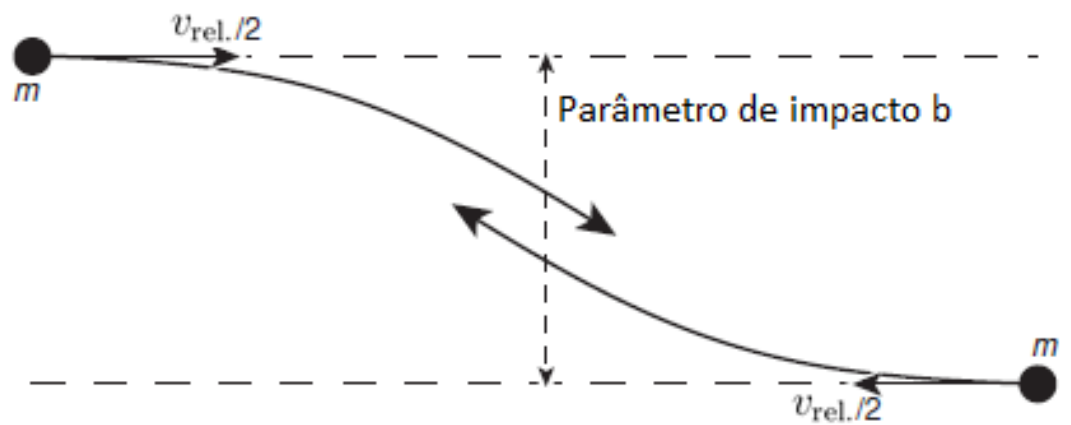

Figura 2.3: Representação esquemática da focalização gravitacional. A atração gravitacional pode tornar a seção de choque maior, desde que a velocidade randômica seja menor que a velocidade de escape de sua superfície. Figura obtida em: Armitage (2010).

$$
2 \cdot \frac{1}{2} m\left(\frac{v_{\mathrm{rel}}}{2}\right)^{2}=2 \cdot m\left(\frac{v_{\max }}{2}\right)^{2}-\frac{G m^{2}}{R_{\min }} .
$$

Como não há componente radial para a velocidade no ponto de maior aproximação, a conservação do momento angular permite escrever:

$$
\frac{1}{2} v_{\max } R_{\min }=\frac{1}{2} b \frac{1}{2} v_{\text {rel }} \Rightarrow v_{\max }=\frac{1}{2} \frac{b}{R_{\min }} v_{\text {rel }} .
$$

Definindo a soma dos raios dos corpos como $R_{\mathrm{s}}$; temos que, se $R_{\min }<R_{\mathrm{s}}$, haverá uma colisão, caso contrário, não. Assim, o maior valor do parâmetro de impacto necessário à colisão ocorre quando $R_{\min }=R_{\mathrm{s}}$, logo:

$$
b_{\max }^{2}=R_{\mathrm{s}}^{2}+\frac{4 G m R_{\mathrm{s}}}{v_{\mathrm{rel}}^{2}}
$$

Expressando em termos da velocidade de escape $v_{\mathrm{esc}}^{2}=\frac{4 G m}{R_{\mathrm{s}}}$, obtemos:

$$
b_{\max }^{2}=R_{\mathrm{s}}^{2}\left(1+\frac{v_{\mathrm{esc}}^{2}}{v_{\mathrm{rel}}^{2}}\right) .
$$

Portanto, a seção de choque é descrita por:

$$
\Gamma=\pi b_{\max }^{2} \Rightarrow \Gamma=\pi R_{\mathrm{s}}^{2}\left(1+\frac{v_{\mathrm{esc}}^{2}}{v_{\mathrm{rel}}^{2}}\right) .
$$

A equação acima só levou em conta a força gravitacinal mútua entre os corpos. No entanto, a atração gravitacional da estrela também pode ser importante e, neste caso, torna-se necessário considerar o problema de três corpos. Uma estimativa para a condição 
no qual o tratamento para o problema de três corpos se torna importante é obtida usando o conceito de esfera de Hill (ver seção 2.4), cujo raio define uma região dentro da qual a gravidade do protoplaneta, com massa $M_{\text {core }}$ e semieixo maior $a_{\mathrm{p}}$, é dominante em relação ao campo gravitacional da estrela de massa $M_{\star}$, sendo seu valor dado por:

$$
R_{\mathrm{H}} \equiv\left(\frac{M_{\text {core }}}{3 M_{\star}}\right)^{1 / 3} a_{\mathrm{p}} .
$$

Dentro da esfera de Hill, o problema de dois corpos é uma aproximação adequada para a dinâmica dos corpos. Usando a equação 2.37, é comum o uso de uma velocidade característica chamada velocidade de Hill $\left(v_{\mathrm{H}}\right)$, definida como a velocidade orbital ao redor do protoplaneta numa distância igual ao raio de Hill, assim:

$$
v_{\mathrm{H}} \equiv \sqrt{\frac{G M_{\text {core }}}{R_{\mathrm{H}}}} .
$$

Se a velocidade relativa randômica $v_{\text {rel }}$ do planetesimal é maior que a velocidade de Hill $\left(v_{\text {rel }}>v_{\mathrm{H}}\right)$, então a taxa com que eles entram na esfera de Hill e colidem é determinada pela dinâmica de dois corpos. No entanto, se $v_{\text {rel }}<v_{\mathrm{H}}$, a atração gravitacional da estrela precisa ser considerada. O tratamento que utiliza a dinâmica de dois corpos falha para planetesimais em baixo regime de velocidade randômica, pois o tempo de interação com o protoplaneta deixa de ser desprezível em relação ao tempo orbital.

Podemos obter uma estimativa para taxa de crescimento de um núcleo sólido no domínio de dois corpos. Considere um núcleo planetário de massa $M_{\text {core }}$ e raio $R_{\text {core }}$, imerso em um enxame de pequenos planetesimais movendo-se com velocidade relativa $v_{\text {rel }}$ (ver Fig. 2.4). A taxa de crescimento do corpo pode ser estimada por meio de um modelo conhecido como "partícula em uma caixa", que descreve a taxa de acreção dos planetesimais como sendo igual ao produto da densidade do enxame de planetesimais $\left(\rho_{\text {bulk }}\right)$, da velocidade relativa entre o núcleo e o planetesimal e da seção de choque (ver eq. 2.36), logo:

$$
\frac{d M_{\mathrm{core}}}{d t}=\rho_{\mathrm{bulk}} v_{\mathrm{rel}} \pi R_{\mathrm{core}}^{2}\left(1+\frac{v_{\mathrm{esc}}^{2}}{v_{\mathrm{rel}}^{2}}\right) .
$$

Podemos obter a densidade do enxame de planetesimais através da relação:

$$
\rho_{\mathrm{bulk}} \approx \frac{\Sigma_{\mathrm{m}}}{2 h_{\mathrm{p}}}
$$




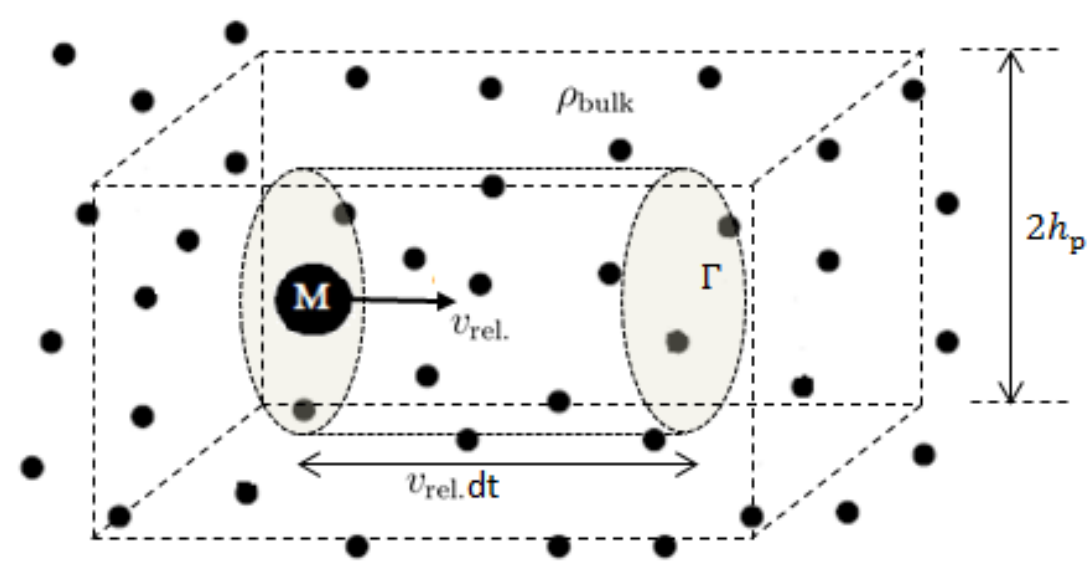

Figura 2.4: Representação de um enxame de planetesimais em torno de um núcleo sólido. O núcleo sólido se move com velocidade relativa $v_{\text {rel }}$ em relação aos planetesimais, numa região cuja a densidade do bulbo de planetesimais é $\rho_{\text {bulk }}$. A seção de choque da colisão é $\Gamma$ e $h_{\mathrm{p}}$ é a escala de altura da região que contêm os planetesimais.

onde $\Sigma_{\mathrm{m}}$ é a densidade superficial de planetesimais (ou densidade superficial de sólidos) e $h_{\mathrm{p}}$ a escala de altura da região que contêm os planetesimais que pode ser aferida como (Greenzweig e Lissauer, 1990:

$$
\frac{h_{\mathrm{p}}}{a_{\mathrm{p}}} \approx \frac{v_{\mathrm{rel}}}{v_{\mathrm{K}}}=\frac{v_{\mathrm{rel}}}{a_{\mathrm{p}} \Omega_{\mathrm{K}}} \Rightarrow h_{\mathrm{p}} \approx \frac{v_{\mathrm{rel}}}{\Omega_{\mathrm{K}}} .
$$

Substituindo as relações 2.40 e 2.41 na equação 2.39, obtém-se:

$$
\frac{d M_{\text {core }}}{d t}=\frac{\sqrt{3}}{2} \Sigma_{\mathrm{m}} \Omega_{\mathrm{K}} \pi R_{\mathrm{s}}^{2}\left(1+\frac{v_{\mathrm{esc}}^{2}}{v_{\mathrm{rel}}^{2}}\right),
$$

onde o pré-fator numérico $\sqrt{3}$ surge porque a velocidade relativa é considerada isotrópica (Lissauer, 1993).

É possível explorar duas soluções simples que podem nos ajudar a compreender modelos mais complexos. A primeira assume que o fator de foco gravitacional $F_{\mathrm{g}}=\left(1+\frac{v_{\mathrm{esc}}^{2}}{v_{\mathrm{rel}}^{2}}\right)$ é constante e que a densidade superficial de planetesimais não muda com o tempo. Usando $M_{\text {core }}=d_{\text {core }} \frac{4 \pi}{3} R_{\text {core }}^{3}$, em que $d_{\text {core }}$ é a densidade do núcleo sólido, a equação 2.42 pode ser escrita na forma:

$$
\frac{d R_{\text {core }}}{d t}=\frac{\sqrt{3}}{8} \frac{\Sigma_{\mathrm{m}} \Omega_{\mathrm{K}}}{d_{\text {core }}} F_{\mathrm{g}},
$$

cuja integral mostra que o raio cresce numa taxa linear $\left(R_{\text {core }} \propto t\right)$, desde que a densidade do protoplaneta seja mantida constante. 
A equação 2.43 descreve um crescimento muito lento, por exemplo, um protoplaneta de densidade $d_{\text {core }}=1 \mathrm{~g} / \mathrm{cm}^{3}$ numa distância de 5.2 ua onde a densidade de planetesimais é próxima de $10 \mathrm{~g} / \mathrm{cm}^{3}$, levaria cerca de 10 milhoes de anos para atingir um tamanho de $100 \mathrm{~km}$, tempo maior que a vida útil do disco (ver seção 2.1.4). Concluímos, então, que a formação de planetas maiores exige maior foco gravitacional e, portanto, uma maior seção de choque.

Assim, o próximo limite a considerar é $v_{\text {esc }} \gg v_{\text {rel }}$, que resulta na maior seção de choque possível, a qual fornece $F_{\mathrm{g}} \approx \frac{v_{\mathrm{esc}}^{2}}{v_{\text {rel }}^{2}}=\frac{2 G M_{\mathrm{p}}}{v_{\text {rel }}^{2} R_{\text {core }}}$, e a taxa de crescimento torna-se:

$$
\frac{d M_{\text {core }}}{d t}=\frac{\sqrt{3} \pi G \Sigma_{\mathrm{m}} \Omega_{\mathrm{K}}}{v_{\text {rel }}^{2}} M_{\text {core }} R_{\text {core }} \simeq \frac{2.5 \pi^{2 / 3} G \Sigma_{\mathrm{m}} \Omega_{\mathrm{K}}}{v_{\text {rel }}^{2} d_{\text {core }}^{1 / 3}} M_{\text {core }}^{4 / 3}=k M_{\text {core }}^{4 / 3},
$$

na qual $k$ será constante desde que as propriedades do enxame de planetesimais sejam mantidas fixas, condição que indica que, o crescimento do protoplaneta não muda a velocidade de dispersão, nem consome uma fração significativa de planetesimais. Em razão da dependência da massa na forma $M_{\text {core }}^{4 / 3}$ percebemos que um corpo mais massivo cresce mais rápido que um menos massivo, fenômeno conhecido como runaway growth, ou crescimento desenfreado. Integrando a equação 2.44, obtém-se:

$$
M_{\text {core }}(t)=\frac{1}{\left(M_{0}^{-1 / 3}-k^{\prime} t\right)^{3}} .
$$

Na equação anterior, podemos observar que o planeta alcança uma massa infinita num tempo finito $\left(t=M_{0}^{-1 / 3} / k^{\prime}\right)$. Na realidade, a taxa de crescimento diminui pelo fato de a velocidade de dispersão dos planetesimais aumentar à medida que ocorre o crescimento, evitando assim essa singularidade.

A análise acima, apesar de bastante simplificada, mostra que um foco gravitacional adequado possibilita obter a formação de núcleos sólidos grandes num tempo menor que o tempo de vida do disco, e nos permite entender a dependência do foco gravitacional com a velocidade relativa dos planetesimais. No capítulo 4, vamos explorar um modelo estatístico para descrever a evolução das excentricidades e inclinações desses planetesimais que, por sua vez, interferem nos valores das velocidades relativas e, consequentemente, na taxa de acreção de planetesimais.

Além disso, vamos incorporar a influência gravitacional do núcleo sólido e o arrasto do gás na velocidade de dispersão média dos planetesimais, características que mudam 
sensivelmente a taxa de acreção e, como resultado, o tempo de formação do núcleo sólido.

\subsubsection{Acreção de gás}

No modelo de acreção com núcleo sólido, a formação de um planeta gigante exige que esse núcleo sólido atinja sua massa crítica num tempo hábil, isto é, antes da dissipação do disco de gás. A massa crítica, da ordem de $10 \mathrm{M}_{\otimes}$, é o limite no qual o núcleo cria uma instabilidade hidrodinâmica a partir da qual passa a acretar massa num regime de runaway, isto é, de forma desenfreada (Mizuno, 1980; Benvenuto e Brunini, 2005). O processo de acreção de gás ainda é tema de estudo. De fato, estudos mais recentes mostram que o envelope planetário não está em equilíbrio hidrostático. Simulações hidrodinâmicas 3D mostram um fluxo de gás intenso nos polos que são enviados para o plano médio do disco (Lambrechts e Lega, 2017). Aqui manteremos o processo de equilíbrio como aproximação para um primeiro modelo. O processo fora do equilíbrio será explorado em trabalhos futuros.

A Figura 2.5 a seguir ilustra as principais etapas do processo de formação planetária.

Na primeira etapa, um núcleo sólido cresce por meio de colisões com o enxame de planetesimais até se tornar suficiente massivo para reter algum envelope planetário. Os conceitos físicos envolvidos são aqueles discutidos na seção 2.2.2. A taxa de acreção de sólidos depende essencialmente da densidade de planetesimais e da extensão do foco gravitacional.

Na segunda etapa, o envelope capturado está em equilíbrio hidrostático. A energia liberada pelo impacto dos planetesimais com o núcleo sólido e a energia gravitacional obtida da contração do envelope é difundida ao longo do envelope por radiação ou convecção. O núcleo sólido e o envelope crescem até que o núcleo atinja a massa crítica. Essa massa crítica depende da taxa de acreção de planetesimais e da opacidade do envelope.

Uma vez atingida a massa crítica, ocorre a terceira etapa na qual o planeta atinge a fase de runaway e começa a acretar gás de forma desenfreada. A taxa de acreção não é mais definida pelas propriedades físicas do envelope, mas pela interação hidrodinâmica entre o planeta e o disco de gás. Grande parte da massa do envelope planetário é acretada durante essa fase, que possui, em média, uma escala de tempo tipica da ordem de $10^{5}$ anos, portanto, um processo rápido dentro da escala de tempo da formação planetária.

Por fim, na quarta etapa, o gás é exaurido como consequência da dissipação do disco, da 


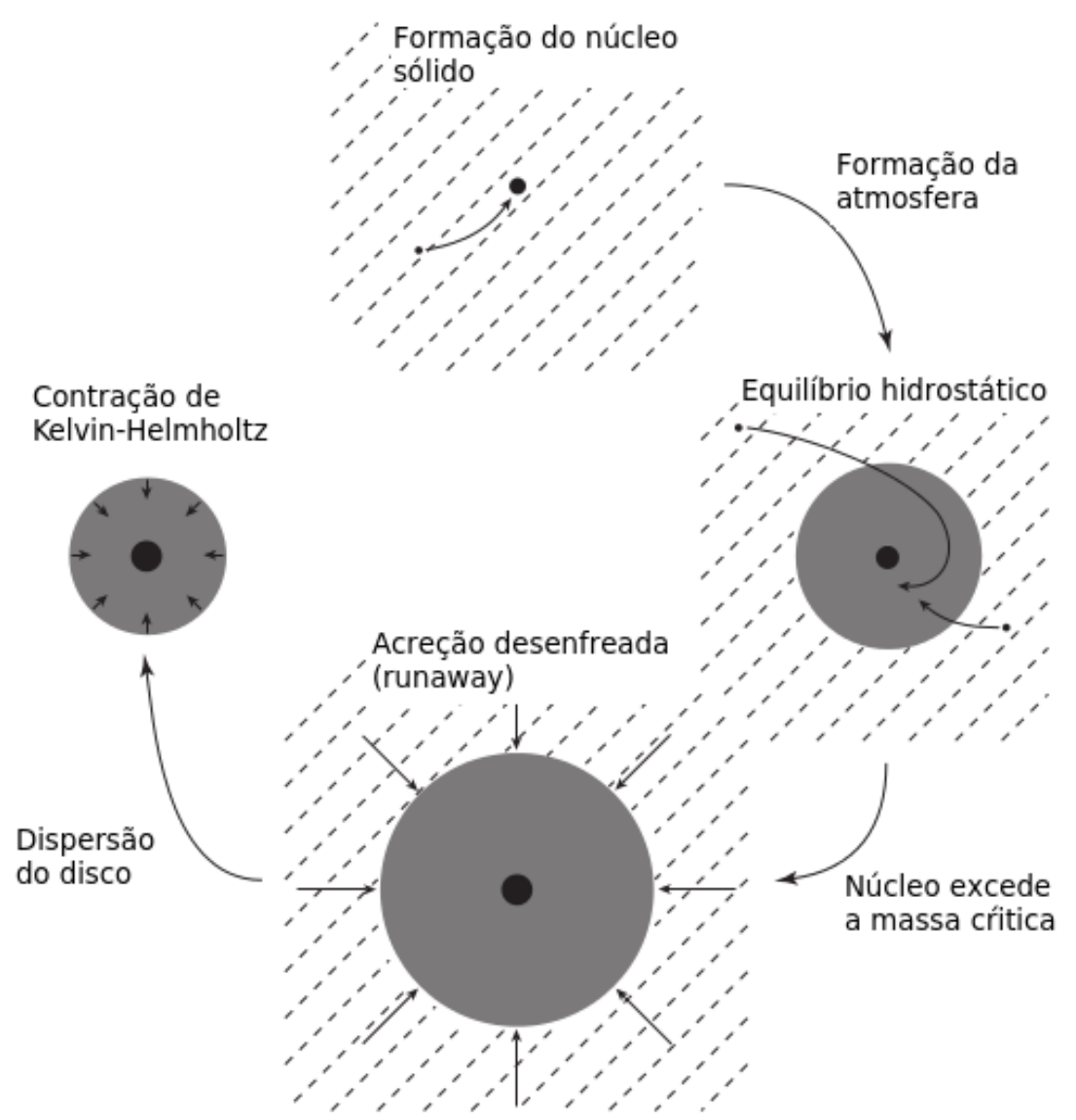

Figura 2.5: Representação esquemática dos estágios da formação de um planeta gigante via modelo de acreção com núcleo sólido. Figura obtida em: Armitage (2010).

acreção do planeta e pela abertura de um gap que surge, conforme veremos mais adiante, devido à interação gravitacional do planeta com o disco de gás. Nessa última fase, a acreção termina e o planeta entra na fase de resfriamento do envelope e contração quase estática. É interessante destacar que o modelo de acreção de núcleo sólido é capaz de explicar a existência de planetas da ordem de dezenas da massa de Júpiter. Planetas mais massivos são obtidos com o modelo de instabilidade gravitacional. No entanto, deve-se ficar atento a massa obtida, analisando a capacidade de fusão do hidrogênio, a partir do qual o objeto se torna uma estrela.

As equações que descrevem a situação de equilíbrio hidrostático (segunda etapa) de um envelope podem ser adaptadas para um modelo que evolui com o tempo, pelo menos até o ponto onde a rápida acreção do envelope começa. O modelo consiste em um conjunto de soluções estáticas, exigindo, assim, que o crescimento da massa planetária seja suficiente lento para que esse equilíbrio seja alcançado. De fato, o tempo característico para estabe- 
lecer o equilíbrio depende do tempo de propagação da velocidade do som entre as camadas, portanto, tempo suficiente para que o modelo seja considerado uma boa aproximação.

Tomando a variável $M_{\mathrm{r}}$, massa do envelope numa distância $r$, como variável independente, as equações que descrevem o equilíbrio do envelope planetário são (Ikoma et al., 2000):

$$
\begin{gathered}
\frac{\partial P}{\partial M_{\mathrm{r}}}=-\frac{G\left(M_{\mathrm{r}}+M_{\text {core }}\right)}{4 \pi r^{4}}, \\
\frac{\partial r}{\partial M_{\mathrm{r}}}=-\frac{1}{4 \pi r^{2} \rho}, \\
\frac{\partial T}{\partial M_{\mathrm{r}}}=\left\{\begin{array}{ll}
-\frac{3 \kappa_{\mathrm{R}}}{64 \pi \sigma r^{2} T^{3}} \frac{L}{4 \pi r^{2}} & \text { se radioativo } \\
\left(\frac{\partial T}{\partial P}\right)_{S}\left(\frac{\partial P}{\partial M_{\mathrm{r}}}\right)_{S} & \text { se convectivo }
\end{array}\right) \\
\frac{\partial L}{\partial M_{\mathrm{r}}}=\epsilon_{a c c}-T \frac{d S}{d T},
\end{gathered}
$$

onde $P$ é a pressão na camada, $T$ é a temperatura na camada, $M_{\text {core }}$ é a massa do núcleo sólido, $\rho$ é a densidade volumétrica de gás, $\kappa$ é a opacidade do envelope, $L$ é a luminosidade, $S$ é a entropia específica do gás e $\epsilon_{a c c}$ a energia liberada no envelope em razão da queda de planetesimais e dada por:

$$
\epsilon_{a c c}=\frac{\partial\left(r-R_{\mathrm{s}}\right)}{4 \pi r^{2} \rho} \dot{M}_{\text {core }} \int_{R_{\mathrm{s}}}^{r_{\mathrm{out}}} \frac{G M_{\mathrm{r}}}{r^{2}} d r .
$$

Na literatura, é possível encontrar algumas variações das equações acima, relacionadas principalmente ao transporte de energia e às condições de borda (Kippenhahn e Weigert, 1990; Hubickyj et al., 2005; Alibert et al., 2005).

Por meio de resultados numéricos das equações anteriores para envelopes planetários em diversas condições físicas, Ikoma et al. (2000) verificaram que a massa crítica do núcleo sólido pode ser aproximada por uma lei de potência que depende da taxa de acreção de planetesimais $\dot{M}_{\text {core }}$ e da opacidade do envelope $\kappa$, essa aproximação é dada por:

$$
M_{\text {crit }}^{\text {core }} \simeq 7\left(\frac{\dot{M}_{\text {core }}}{10^{-7} \mathrm{M}_{\otimes} \mathrm{yr}^{-1}}\right)^{q}\left(\frac{\kappa}{1 \mathrm{~cm}^{2} \mathrm{~g}^{-1}}\right)^{s} \mathrm{M}_{\otimes},
$$

onde as leis de potência $q$ e $s$ são estimadas entre $0.2-0.3$. 
A equação 2.51 fornece alguns resultados interessantes. De fato, a massa crítica obtida pode variar substancialmente do valor padrão adotado de $10 \mathrm{M}_{\otimes}$ dependendo da taxa de acreção e da opacidade. Uma massa crítica de $20 \mathrm{M}_{\otimes}$ pode ser atingida em discos cuja densidade superficial de planetesimais é alta o bastante para aumentar a taxa de acreção. E massa críticas menores, da ordem da massa da Terra, podem ser obtidas em regiões de baixa opacidade. Diminuir a opacidade é a melhor opção para obter massas críticas menores, já que a redução da taxa de acreção dos planetesimais também implicaria o aumento do tempo de formação do núcleo sólido.

Ikoma et al. (2000) também calculou uma escala de tempo para o crescimento percentual do envelope. Definindo uma escala de tempo na forma:

$$
\tau_{\text {grow }} \equiv\left(\frac{1}{M_{\text {env }}} \frac{d M_{\text {env }}}{d t}\right)^{-1},
$$

a partir do qual obteve, por meio de várias simulações numéricas, a expressão:

$$
\tau_{\text {grow }} \sim 10^{8}\left(\frac{M_{\text {core }}}{\mathrm{M}_{\otimes}}\right)^{-2.5}\left(\frac{\kappa_{\mathrm{R}}}{1 \mathrm{~cm}^{2} \mathrm{~g}^{-1}}\right) \text { anos } .
$$

É importante ressaltar que esse tempo foi obtido sem levar em consideração a acreção de planetesimais, que pode ser uma limitação importante para núcleos sólidos menores, já que toda a energia irradiada irá depender essencialmente da contração do envelope.

Embora esse modelo exija uma sequência de passos hidrostáticos, o alcance dos seus resultados estão de acordo com modelos que possuem a dependência temporal implícita (Alibert et al. 2005).

A magnitude de $d M_{\text {env }} / d t$, que vem da contração de Kelvin-Helmholtz, aumenta rapidamente com a massa total do planeta. No entanto, essa taxa de acreção deve ser limitada pela taxa de acreção de Bondi (Bondi, 1952), pelo fluxo interno dentro da região de acreção (Tanigawa e Watanabe, 2002), pela difusão da massa através do disco (Bryden e Lin, 1999) e pela disponibilidade de massa na órbita do planeta. Estes efeitos são importantes quando a massa planetária é da ordem da massa de Júpiter. Nesta tese, a taxa de acreção de gás estará limitada pela taxa de acreção de Bondi.

É importante ressaltar que simulações hidrodinâmicas 3D mostram que a evolução térmica do envelope pode atrasar a entrada no regime de runaway (Lega e Lambrechts, 2016) e alterar as taxas de acreção de gás. Esses efeitos serão investigados em trabalhos 
futuros.

\subsection{Migração planetária}

Conforme vimos na seção 2.2, a teoria clássica de formação de planetas gigantes prediz que planetas desse tipo, devido à disponibilidade de material no disco, devem se formar além da linha de gelo. No entanto, dados observacionais mostram uma enorme quantidade de planetas gigantes em órbitas de período muito curto (Udry e Santos, 2007). Diversos mecanimos são usados para explicar a distribuição dos semieixos encontrados, entre eles a migração planetária causada pela interação com o disco de gás (Benítez-Llambay et al. 2011). Observações de órbitas ressonantes entre sistemas multi planetários mostram uma forte evidência dos processos migratórios, isto é, a migração planetária faz com que os planetas migrem e caiam em determinadas condições ressonantes (Laughlin e Chambers, 2001; Kley et al., 2005).

A interação gravitacional com o disco de gás causa uma mudança na energia orbital e no momento angular dos planetas, ocasionando uma mudança nos seus parâmetros orbitais. Em geral, ocorre um decaimento do semieixo maior do planeta e um amortecimento da excentricidade e da inclinação (Papaloizou et al., 2007). Nenhum torque resultante ocorre entre o planeta e o disco de gás num disco aximétrico, no entanto, a quebra dessa simetria em razão da presença de ondas de densidade espirais que se manifestam no disco de gás gera um torque gravitacional resultante diferente de zero (Goldreich e Tremaine, 1980; Ward, 1986). Essas ondas de densidade ocorrem em decorrência da perturbação do planeta no disco de gás, por isso, é um fenômeno que se torna mais significativo para planetas com massas maiores que a massa de Marte. Em geral, a migração planetária é ignorada no caso da formação dos planetas terrestres, visto que o disco de gás já teria se dissipado até a completa formação do planeta (Touboul et al., 2007; Dauphas e Pourmand, 2011).

A migração planetária devido à interação com o disco de gás ocorre por dois processos principais: a migração de tipo I, que ocorre por meio da perda da energia e do momento angular de planetas de baixa massa para o disco de gás, causando uma rápida migração, ou, pela migração de tipo II, no qual o planeta, nesse caso, mais massivo, também sofre uma migração, porém, através de um processo mais lento. A migração de tipo I, em geral, é duas ordens de magnitude mais rápida que a migração de tipo II. Além desses dois tipos 
característicos, novos processos migratórios decorrentes da interação com o gás estão sendo investigados, como a migração em discos turbulentos (Nelson, 2005) e a migração de tipo III (Papaloizou et al., 2007), que, pode gerar uma migração planetária radialmente para fora ou para dentro e mudar fortemente os parâmetros orbitais do planeta num tempo muito curto. Porém, esses dois processos não serão explorados nesta tese.

A impressão visual dos dois regimes é mostrado na Figura 2.6, que indica a estrutura da densidade superficial do disco de gás para cada regime. Na migração planetária de tipo I, a interação é fraca e, por isso, o disco não apresenta uma perturbação muito grande. No entanto, a migração planetária de tipo II possui como característica uma perturbação bem mais forte, que, em consequência, produz um buraco anelar no disco de gás (gap), fenômeno característico desse tipo de migração.
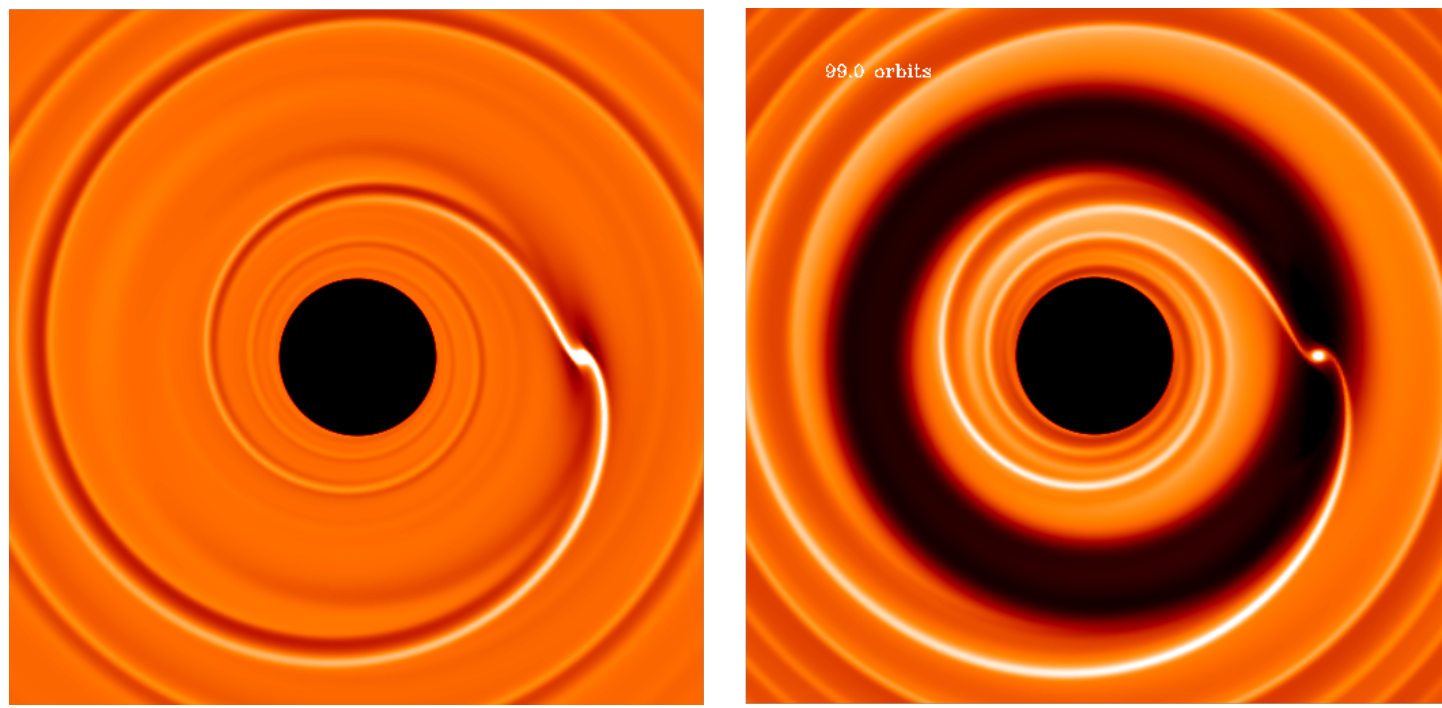

Figura 2.6: Impressão visual do efeito da migração planetária de tipo I e tipo II no disco de gás obtida com o simulador hidrodinâmico FARGO. A figura da esquerda representa uma migração planetária de tipo I que ocorre para planetas de baixa massa e a figura da direita uma migração planetária de tipo II mais relevante para planetas gigantes. Figura obtida em: <http://www.maths.qmul.ac.uk/ masset/moviesmpegs.html>.

A migração planetária é um fator muito importante nos processos de formação planetária. Portanto, os dois processos devem ser investigados em conjunto para que se obtenha melhor compreensão da atual distribuição observacional dos parâmetros encontrados para os planetas extra-solares (Ida e Lin, 2004a, 2008; Mordasini et al., 2009; Miguel et al. 2011; Alibert et al., 2013). 


\subsubsection{Migração planetária tipo I}

A migração planetária de tipo I ocorre quando o semieixo maior do planeta muda rapidamente devido à soma dos torques ressonantes que surgem por causa da interação gravitacional do disco perturbado com o planeta (Ward, 1986; Papaloizou et al., 2007; Paardekooper et al., 2010). O planeta gera uma perturbação no disco de gás, criando uma onda espiral de densidade, isto é, regiões de sobredensidade, que fazem com que o planeta, mediante um torque entre as regiões de sobredensidade e o planeta, ganhe momento angular da parte interior do disco e perca momento angular para a parte externa do disco. Como o torque devido à parte interna do disco tende a ser menor que o torque devido à parte externa, obtém-se um torque resultante negativo (Papaloizou et al., 2007). Consequentemente, a migração planetária de tipo I causa, em gera! 1 um decaimento do semieixo maior do planeta (Ward, 1997).

Em geral, os resultados analíticos obtidos para a migração de tipo I desconsideram efeitos associados com transporte de momento angular devido à turbulência ou campos magnéticos. O torque resultante é calculado somando-se os torques entre o planeta e o disco de gás em regiões ressonantes discretas, conhecidas como ressonâncias de Lindblad, em conjunto com o torque de corrotação (Tanaka et al., 2002).

O modelo analítico para estudo dessa migração consiste, portanto, em decompor o potencial gravitacional do planeta dentro de modos de Fourier, que variam azimutalmente com $\exp \left[i m\left(\phi-\Omega_{\mathrm{p}} t\right)\right]$, onde $m$ é o número de onda azimutal. Em seguida, obtém-se a resposta do disco de gás a essa perturbação linearizando as equações da hidrodinâmica, a partir das quais é possível deduzir o torque. Essa construção teórica foi aplicada ao sistema planeta-disco por Goldreich e Tremaine (1980) e subsequentemente melhorado por Ward (1986), Artymowicz (1993), Artymowicz (1993), Korycansky e Pollack (1993), Ward (1997) e Tanaka et al. (2002), para citar alguns. Um desenvolvimento teórico bastante didático pode ser encontrado em Meyer-Vernet e Sicardy (1987) e em (DePaula, 2014).

A condição de ressonância de corrotação ocorre quando a velocidade orbital do gás é igual à velocidade orbital do planeta, isto é, $\Omega_{\mathrm{K}}(r)=\Omega_{\mathrm{p}}$, ignorando efeitos de pressão e a auto-gravidade do disco, essa ressonância ocorre na região coorbital com o planeta. A condição para ressonância de Lindblad é similar, exceto que ela ocorre quando a frequência

\footnotetext{
${ }^{1}$ Estamos analisando o efeito global. O torque depende da estrutura e do estado termodinâmico do disco de gás. Portanto, é possível obter em determinadas condições uma migração reversa.
} 
epicíclica do gás $\kappa$, que surge por causa da oscilação radial do fluido perturbado, está em ressonância com a frequência orbital do planeta, isto é:

$$
m\left[\Omega_{\mathrm{K}}(r)-\Omega_{\mathrm{p}}\right]= \pm \kappa(r)
$$

onde $m$ é um inteiro.

Na migração planetária de tipo I, a perturbação causada pelo planeta não é suficiente para alterar significamente a estrutura do disco de gás. O problema então consiste em calcular, para um dado perfil de densidade superficial, o torque total $\Gamma$ no planeta para cada ressonância, logo:

$$
\Gamma=\sum_{m=1}^{\infty} \Gamma_{\mathrm{OLR}}(m)+\sum_{m=1}^{\infty} \Gamma_{\mathrm{ILR}}(m)+\Gamma_{\mathrm{CR}},
$$

onde $\Gamma_{\mathrm{OLR}}(m), \Gamma_{\mathrm{ILR}}(m)$ e $\Gamma_{\mathrm{CR}}$ são, respectivamente, o torque devido a ressonância de Lindblad na parte externa do disco, o torque decorrente da ressonância de Lindblad na parte interna do disco e o torque decorrente da ressonância de corrotação.

Tanaka et al. (2002) calcularam o torque no planeta, em regime de migração de tipo I, considerando um disco tridimensional, verticalmente e radialmente isotérmico, utilizando um perfil de densidade superficial para o gás na forma:

$$
\Sigma_{\text {gas }}(r) \propto r^{\varphi}
$$

e um planeta de massa $M_{\mathrm{p}}$ orbitando uma estrela de massa $M_{\star}$ numa órbita circular de raio a com velocidade angular $\Omega_{\mathrm{p}}$. O disco de gás possui uma razão de aspecto $H / r$. Com isso, Tanaka et al. (2002) encontraram a seguinte expressão analítica:

$$
\begin{gathered}
\Gamma_{\mathrm{LR}}=-(2.34-0.10 \varphi)\left(\frac{M_{\mathrm{p}}}{M_{\star}}\right)^{2}\left(\frac{H}{r}\right)^{-2} \Sigma_{\text {gas }} a^{4} \Omega_{\mathrm{K}}^{2}, \\
\Gamma_{\mathrm{CR}}=(0.98-0.64 \varphi)\left(\frac{M_{\mathrm{p}}}{M_{\star}}\right)^{2}\left(\frac{H}{r}\right)^{-2} \Sigma_{\text {gas }} a^{4} \Omega_{\mathrm{K}}^{2}, \\
\Gamma_{\text {Total }}=-(1.36+0.54 \varphi)\left(\frac{M_{\mathrm{p}}}{M_{\star}}\right)^{2}\left(\frac{H}{r}\right)^{-2} \Sigma_{\text {gas }} a^{4} \Omega_{\mathrm{K}}^{2} .
\end{gathered}
$$

onde $\Gamma_{\mathrm{LR}}$ é o torque devido a ressonância de Lindblad, $\Gamma_{\mathrm{CR}}$ o torque de corrotação e $\Gamma_{\text {Total }}$ o torque total. 
Essas expressões são frequentemente empregadas como estimativas para a migração de tipo I para discos isotérmicos. No entanto, a limitação teórica de um disco radialmente isotérmico é um fator que poderia afetar consideravelmente a taxa de migração (Paardekooper et al., 2010, 2011), principalmente, o torque de corrotação, como indica Benítez-Llambay et al. (2015), já que efeitos de aquecimento mudam de forma significativa as forças de pressão e, consequentemente, a estrutura do gás na região de corrotação.

\subsubsection{Migração planetária tipo II}

A migração de tipo II ocorre quando o planeta se torna suficiente massivo a ponto de criar uma perturbação não linear no disco de gás. Como a interação do planeta com o disco adiciona momento angular ao disco exterior e remove do disco interior, o efeito resultante se caracteriza pela abertura de um buraco anelar (gap). A largura desse buraco depende da relação entre o fluxo viscoso do disco, que tende a fechá-lo, e o torque planetário, que tende a abri-lo (Bryden e Lin, 1999).

Para um disco protoplanetário típico e fino, um planeta com massa próxima à de Saturno, já é capaz abrir um buraco considerável no disco de gás (Armitage, 2010).

Um planeta cuja massa permanece próxima da massa limite para abrir o gap, somente irá diminuir a massa de gás dentro da região e não esvazia-lá consideravelmente. Isso gera um problema complicado de lidar, já que o disco de gás está perturbado, e não se pode usar os mecanismos de cálculo utilizados na migração planetária de tipo I, além disso, a região coorbital ainda contém gás, cujo torque pode ter uma influência significativa na migração do planeta.

Um maneira mais simplificada de estudar a migração de tipo II é considerar um modelo teórico cujo planeta, acima da massa limite, da ordem da massa de Júpiter, cria uma descontinuidade na densidade superficial no disco de gás alta o suficiente para que ela atue como uma barreira para o fluxo de gás e o planeta permaneça preso dentro do gap. Dessa maneira, a evolução do planeta fica sujeita à evolução viscosa do próprio disco (Ida e Lin, 2004a). Para dar destaque a essa limitação teórica, a migração de tipo II descrita por esse cenário será chamada nesta tese de migração planetária de tipo II teórica.

A análise da migração de tipo II teórica, nesses moldes, é mais fácil de analisar dado que o torque significativo se deve às primeiras ressonâncias de Linbdlad (baixos valores de $m$ ). Assim, a largura do gap pode ser obtida considerando a região da ressonância que é 
capaz de contrapor o fluxo viscoso do gás para dentro do buraco.

Um modelo didático, proposto por Armitage (2010), pode ser utilizado para entender esse processo. A ideia consiste em imaginar que o gap planetário está envolvido por uma parede de tijolos que define a borda interna e externa do gap dentro do qual se encontra o planeta. Na borda interna, a parede (ou, fisicamente, o torque) remove momento angular do gás o suficiente de modo a não permitir que o fluido passe por cima da parede. Na borda externa, a parede adiciona a quantidade apropriada de momento angular no gás que impede o gás de penetrar na região. Como o fluido que chega à parede externa flui em razão de sua evolução viscosa, ele esbarra na barreira imposta pelo torque planetário; assim, para impedir que o fluido entre no gap, o planeta precisa perder momento angular para o disco externo, que deve ser balanceado pela perda do momento angular do disco interno, com isso, o fluido do disco interno se afasta da barreira interna do gap. Para manter as fronteiras nos locais apropriados, condição ressonante, o planeta precisa se mover para a região mais interna do disco, configurando sua migração.

No cenário teórico descrito acima, o planeta dentro do gap se comporta como um transmissor de momento angular, retirando momento angular do disco interno e fornecendo momento angular ao disco externo. Portanto, a taxa nominal da migração de tipo II teórica é igual à velocidade do fluxo de gás.

A condição para que o planeta migre em conjunto com a evolução viscosa do disco de gás leva em consideração que o gás próximo do planeta contém a maior parte do momento angular, caso essa condição não seja satisfeita, a taxa de migração será diferente. Assim, uma estimativa não rigorosa para saber se a migração está próxima do cenário teórico descrito acima pode ser obtida usando a relação:

$$
f \equiv \frac{M_{\mathrm{p}}}{\pi a_{\mathrm{p}}^{2} \Sigma_{\text {gas }}} \leq 1
$$

onde $a_{\mathrm{p}}$ é a posição do planeta, $M_{\mathrm{p}}$ é a massa do planeta e $\Sigma_{\text {gas }}$ é a densidade superficial que o gás deveria ter caso o planeta não existisse naquela região (Armitage, 2010). Em muitas circunstâncias, o planeta será muito massivo para que a condição acima seja satisfeira. Por exemplo, adotando um perfil de densidade superficial na forma:

$$
\Sigma_{\text {gas }}(r)=1.5 \times 10^{3}\left(\frac{r}{1 \text { ua }}\right)^{-1} \mathrm{~g} \mathrm{~cm}^{-2},
$$

a migração irá ocorrer mais próxima da sua forma teórica para massas 


$$
M_{\mathrm{p}}<0.6\left(\frac{a}{1 \mathrm{ua}}\right) \mathrm{M}_{\mathrm{J}}
$$

isto é, à medida que o planeta migra sua distância à estrela pode ser baixa o suficiente para que a condição teórica deixe de ser satisfeita.

As imposições teóricas descritas acima mostram as dificuldades na construção de um cenário analítico para lidar com a migração tipo II. Simulações numéricas tornam-se, portanto, essenciais para uma melhor compreensão desse processo migratório.

Em geral, simulações numéricas colocam um planeta, sem acreção de gás, em uma órbita fixa e analisam a distribuição da densidade do torque a partir da qual é possível obter a velocidade de migração (Kley e Nelson, 2012), em outros casos, simulações em que se permite que o planeta migre têm sido realizadas em discos isotérmicos bidimensionais (Nelson et al. 2000). Ambos os casos mostram que a taxa da migração planetária de tipo II é muito mais rápida do que o resultado teórico descrito aqui, podendo o planeta migrar 5 ua em aproximadamente $10^{5}$ anos. Em discos radiativos tridimensionais, taxas de migração ainda maiores foram encontradas (Bitsch e Kley, 2010).

No capítulo 5, iremos investigar a migração de tipo II dentro do simulador hidrodinâmico FARGO3D e comparar com o cenário teórico descrito acima. Para isso, vamos medir a taxa de migração do planeta para várias massas planetárias e regimes viscosidades para o disco de gás e comparar com a predição teórica de que os planetas migram a uma taxa próxima da evolução viscosa do disco de gás ou menor. Iremos também implementar um modelo para acreção de gás e comparar como ele afeta os resultados das simulações para a migração planetária de tipo II.

\subsection{Raio de Hill}

Considere um corpo principal de massa elevada e um corpo secundário de menor massa que orbita o corpo principal. O raio de Hill define uma região esférica centrada no corpo secundário dentro da qual um corpo massivo permanece em órbita em torno do corpo secundário sem ser atraído para uma órbita em torno do corpo principal. A esfera de Hill define, portanto, a distância máxima que um corpo massivo pode orbitar um corpo secundário na presença de um corpo principal.

A aproximação para o raio de Hill de um corpo secundário, um planeta de massa $M_{\mathrm{p}}$, 
orbitando um corpo principal, uma estrela de massa $M_{\star}$, é dada por Murray e Dermott, 1999):

$$
R_{\mathrm{H}} \approx a_{\mathrm{p}}\left(1-e_{\mathrm{p}}\right)\left(\frac{M_{\mathrm{p}}}{3 M_{\star}}\right)^{1 / 3},
$$

onde $a_{\mathrm{p}}$ é o semieixo maior do planeta e $e_{\mathrm{p}}$ sua excentricidade.

O raio de Hill de um planeta com órbita excêntrica varia entre um valor mínimo e um valor máximo, que estão, respectivamente, no periapse e no apoapsi. O termo $a_{\mathrm{p}}\left(1-e_{\mathrm{p}}\right)$ na equação 2.63 se refere ao raio de Hill do corpo secundário quando este está no periapse. No apoapsi, o termo deve ser substituído por $a_{\mathrm{p}}\left(1+e_{\mathrm{p}}\right)$.

Nesta tese, a excentricidade orbital do corpo secundário será sempre considerada muito pequena e, portanto:

$$
R_{\mathrm{H}} \approx a_{\mathrm{p}}\left(\frac{M_{\mathrm{p}}}{3 M_{\star}}\right)^{1 / 3} .
$$

A importância do raio de Hill para esta tese reside no fato de que ele delimilita uma região na qual o planetesimal pode orbitar um planeta na presença de um corpo principal, no caso, a estrela.

\subsection{Acreção de Bondi-Hoyle-Lyttleton}

A acreção de Bondi-Hoyle-Lyttleton é geralmente utilizada no contexto de acreção em estrelas de nêutrons e buracos negros. A ideia consiste na acreção gravitacional de material gasoso por um ponto massivo que se move numa nuvem de gás. A nuvem de gás não é auto gravitante e é considerada uniforme (Edgar, 2004).

O raio que delimita a região na qual o gás é acretado por um planeta de massa $M_{\mathrm{p}}$, considerado um ponto massivo, é denominado raio de Bondi e é dado por:

$$
R_{\mathrm{B}}=\frac{2 G M_{\mathrm{p}}}{c_{\mathrm{s}}^{2}},
$$

onde $G$ é a constante gravitacional e $c_{\mathrm{s}}$ a velocidade local do som (Shima et al., 1985).

Considere um planeta que se move através da nuvem de gás uniforme com velocidade $\Delta v$, a velocidade relativa entre o gás e o planeta será:

$$
v_{\text {rel }}=\sqrt{\Delta v^{2}+c_{\mathrm{s}}^{2}}
$$


Se essa velocidade relativa é menor que a velocidade de escape do planeta, dada por:

$$
v_{\mathrm{esc}}=\sqrt{\frac{2 G M_{\mathrm{p}}}{r}}
$$

o gás pode ser considerado gravitacionalmente ligado ao corpo. Igualando as duas equações e isolando $r$, obtemos:

$$
R_{\mathrm{B}}=\frac{2 G M_{\mathrm{p}}}{v_{\mathrm{rel}}^{2}}=\frac{2 G M_{\mathrm{p}}}{\Delta v^{2}+c_{\mathrm{s}}^{2}} .
$$

Assim, o raio de Bondi permite, por exemplo, estimar a taxa de acreção de gás por um planeta que se move através de uma nuvem uniforme. Dada uma nuvem de densidade $\rho$, com velocidade $v_{\text {rel }}$ e dado que o raio de Bondi delimita um seção de choque $\pi R_{\mathrm{B}}^{2}$, a taxa de acreção de gás pode ser estimada como:

$$
\dot{M}_{\mathrm{B}}=\rho\left(\pi R_{\mathrm{B}}^{2}\right) v_{\mathrm{rel}}=\frac{4 \pi G^{2} M_{\mathrm{p}}^{2} \rho}{\left(\Delta v^{2}+c_{\mathrm{s}}^{2}\right)^{3 / 2}},
$$

que é conhecida como taxa de acreção de Bondi Edgar, 2004). É interessante notar que velocidades relativas altas implicam pequenas seções de choque e, portanto, taxas de acreção menores (Lissauer, 1993).

A taxa de acreção de Bondi impõe, portanto, um limite no qual um objeto compacto pode capturar matéria ao seu redor e será usado nesta tese como um limitador para a acreção de gás do planeta.

\subsection{Conclusão}

Este capítulo teve como objetivo fornecer as principais ferramentas teóricas necessárias para a compreensão das simulações realizadas nesta tese. De fato, o modelo de disco de gás que será implementado no FARGO3D tem como base o disco com taxa de acreção constante descrito na seção 2.1.5. Assim, o perfil inicial para a velocidade radial e para a densidade superficial do gás são, respectivamente, descritos pelas equações 2.31 e 2.30. Esse modelo para o disco de gás tem como peculariedade possuir uma taxa de acreção constante ao longo do raio, característica que vamos explorar com mais detalhes no capítulo 5, no qual comparamos a evolução de um planeta sujeito à migração planetária de tipo II com a própria evolução do disco de gás. Um aprofundamento teórico sobre esse modelo de disco de gás pode ser obtido em Lynden-Bell e Pringle (1974) e Pringle (1981). 
Vimos também, por meio do estudo da estrutura vertical de um disco de acreção (ver seção 2.1.2), que esses discos de acreção possuem uma razão de aspecto que varia de acordo com a velocidade do som e, portanto, com a temperatura (ver eq. 2.10), o que nos permite estimar sua espessura como bem pequena em relação à distância radial, principalmente, na região de formação planetária que se encontra em regiões próximas da estrela hospedeira. Assim, nas simulações, usaremos sempre $H / r=0.05$, que é um valor razoável para a razão de aspecto. A influência da temperatura e outros modelos mais complexos podem ser vistos em Armitage (2010).

O estudo da componente radial do momento angular realizado na seção 2.1 .3 nos permitiu obter o perfil inicial para a velocidade tangencial do gás, dado pela equação 2.16 , perfil que será usado para todas as simulações.

Além disso, o modelo para o disco de acreção simulado nesta tese possui sua viscosidade descrita pela parametrização de Shakura-Sunyaev (ver seção 2.1.1). Esse modelo é o mais comumentemente usado na análise de discos de acreção nos quais, em geral, o parâmetro $\alpha$ é mantido fixo ao longo do raio, característica que também usaremos nesta tese. Um estudo do mecanismo responsável por essa viscosidade, a instabilidade magneto-rotacional, foi realizado por Balbus e Hawley (2002) e um modelo de disco de gás com $\alpha$ variável pode ser obtido em Penna et al. (2013).

A opção por um modelo de disco simplificado se deve ao foco da tese ser a implementação de um modelo para formação planetária dentro do código FARGO3D. Isso nos permitirá analisar a formação planetária dentro de um conjunto de parâmetros livres mais restritivo, tornando mais fácil a realização de testes no modelo.

Neste capítulo, também fizemos uma breve descrição do processo de formação planetária (ver seção 2.2), para o qual optamos pelo modelo de formação planetária com núcleo sólido ao invés do modelo de formação in situ. A opção se deve ao fato de o modelo de formação com núcleo sólido fornecer uma maior gama de massas planetárias e, aparentemente, resultados mais consistentes com os dados observacionais que temos para o nosso Sistema Solar. Vale ressaltar que isso não descarta o modelo de formação in situ, dado que um processo não anula o outro. Uma discussão entre os dois modelos e suas limitações pode ser vista em Matsuo et al. (2007).

O modelo de formação planetária com núcleo sólido é dividido em três etapas: a formação dos planetesimais (ver seção 2.2.1), a acreção de planetesimais (ver seção 2.2.2) 
e a acreção de gás (ver seção 2.2.3). Nesta tese, os planetesimais já serão considerados formados. De fato, a alta velocidade radial obtida para os planetesimais, aliada a um rápido processo de sedimentação e coagulação, indica que o processo de formação de planetesimais é um processo rápido e, portanto, não afeta significamente o tempo característico para formação planetária (Brauer et al., 2008)1. No entanto, a acreção de planetemais é um processo mais longo. Isso se deve à diferença física dos processos, já que a formação dos planetesimais depende essencialmente do atrito aerodinâmico do material sólido com o disco de gás, enquanto a formação do núcleo sólido depende da atração gravitacional entre os planetesimais. Uma descrição bastante completa de ambos os processos pode ser vista em Armitage (2010).

Além de um intervalo de tempo alto para a formação do núcleo, existe outra dificuldade inerente ao processo: o alto número de planetesimais. Assim sendo, uma simulação N-corpos é inviável computacionalmente. Por isso, optamos por um modelo estatístico para implementação dessa fase, que será descrito em detalhes no capítulo 4. Esse modelo estatítisco para acreção de sólidos tem como base o trabalho de Inaba et al. (2001). No entanto, alguns detalhes importantes podem ser obtidos com utilização de um modelo mais simples. A seção 2.2 .2 mostra a dependência da taxa de acreção com a velocidade relativa entre o núcleo sólido e o planetesimal, que afeta o foco gravitacional (ver eq. 2.42), permitindo, desde uma taxa de acreção lenta até um regime de runamay, no qual o núcleo cresce rapidamente. O modelo para acreção de planetesimais usado nesta tese leva em conta essa característica, para isso, a velocidade relativa será escrita em função da excentricidade e da inclinação quadrática média de um enxame de planetesimais, e um modelo estatístico será usado para analisar a taxa de acreção do núcleo sólido. A partir do modelo obtido para acreção de sólidos, será possível analisar a migração de tipo I (ver seção 2.3.1) sofrida por esse núcleo conjuntamente com a formação planetária. Uma descrição bastante didática da migração planetária de tipo I pode ser encontrada em Meyer-Vernet e Sicardy (1987).

A acreção de gás implementada nesta tese será realizada a partir do modelo de Kley (1999). No entanto, diversas características serão adaptadas para que o cenário seja fisicamente similar ao descrito na seção 2.2.3. Assim, o modelo de Kley (1999) será modificado para adicionar uma taxa de acreção mais lenta (ver eq. 2.53), que ocorre antes de o núcleo

\footnotetext{
${ }^{1}$ Estamos desconsiderando a formação do planetesimal via colapso gravitacional, cujo tempo de formação pode ser diferente (Johansen et al., 2006, Blum, 2018).
} 
atingir a massa crítica obtida pela equação 2.51. Além disso, vamos acrescentar uma limitação ao regime de runamay imposta pela análise da acreção de Bondi, descrita na seção 2.5. Tanto o modelo de acreção de gás quanto o modelo de acreção de sólidos dependem também do conhecimento do raio de Hill, descrito na seção 2.4. O modelo de acreção de gás implementado nesta tese tem como base os trabalhos de Ikoma et al. (2000), Ida e Lin (2004b) e Russell (2011).

Por fim, o modelo completo será usado no estudo da migração de tipo II, descrito na seção 2.3.2. O estudo teórico simplificado dessa migração indica que o planeta deve migrar numa escala de tempo similar à evolução viscosa do disco. No entanto, simulações computacionais indicam o contrário (Dürmann e Kley, 2015), assim, no capítulo 5 iremos investigar esse processo e as mudanças que ocorrem nesse processo migratório devido ao novo modelo de acreção de gás. 
Capítulo 3

\section{O código FARGO3D}

O FARGO3D é um código magneto-hidrodinâmico (MHD) desenvolvido com ênfase na física da interação de um disco de gás com planetas. Embora seja um código totalmente novo, e inclua novos conceitos, ele foi escrito de modo a preservar algumas característiscas do seu antecessor, o FARGO.

Atualmente, os estudos que envolvem simulações da interação do disco de gás com o planeta durante a formação planetária vêm evoluindo sistematicamente graças ao grande número de experimentos numéricos e ao desenvolvimento de novas ferramentas que possibilitam o aumento do poder computacional.

Parte desse desenvolvimento se deve ao uso de algoritmos cada vez mais eficientes em resolver o problema do movimento do gás em um disco kepleriano como, por exemplo, os algoritmos de advecção orbital. E parte se deve, ao uso de ferramentas computacionais de programação paralela, como MPI (Message Passing Interface) e GPU (Graphics Processing Unit), características que permitem ao FARGO3D um grande poder computacional na resolução da interação do disco de gás com o planeta.

Além disso, o FARGO3D é um código bastante versátil, que utiliza um grande número de variáveis de macrocomando, o que permite desativar ou ativar partes do código dependendo do problema que se queira resolver. Por exemplo, caso se queira trabalhar com um disco de gás em duas dimensões sem MHD, o código não necessita calcular o algoritmo responsável pela MHD, isto é, uma declaração if checa se o usuário necessita ou não dessa parte do código. Essas variáveis, em geral, são definidas no arquivo setup. opt $t^{1}$ em uma variável recipiente chamada FARGO_OPT da seguinte forma:

\footnotetext{
${ }^{1}$ setup é um nome genérico. Outras variáveis são definidas durante o processo make, cujo entendimento não é necessário para esta tese.
} 
FARGO_OPT $+=-$ DVARIABLE

Uma lista dessas variáveis podem ser encontradas no manual do FARGO3D disponível em <http://fargo.in2p3.fr/manuals/html/opt_file.html>. As variáveis de macrocomando usadas nesta tese se encontram no arquivo setup.opt transcrito no apêndice A.1.

Neste capítulo, iremos apresentar as principais características do código, as equações envolvidas na sua implementação e introduzir a notação utilizada no código que, por sua vez, também será usada na tese. Explicaremos como manipular as condições de borda e acrescentar novas variáveis. Descreveremos um fluxograma do código, mostrando passo a passo os métodos numéricos que são empregados para resolução das equações da hidrodinâmica1. Também abordaremos o modo como o programa trabalha com a programação CUDA para uso da GPU.

Por fim, com base na descrição física de um disco de gás com taxa de acreção constante, desenvolveremos uma simulação standard para um disco de gás que será usada durante toda a tese.

\subsection{Equações fundamentais}

O FARGO3D resolve as equações da hidrodinâmica numa malha euleriana. Apresentamos a seguir a dedução de cada uma das equações e algumas características físicas importantes sobre o uso dessas equações dentro do código.

Para dedução das equações, considere um fluido cujo estado é descrito pela distribuição de velocidades $\vec{v}(x, y, t)$ e por duas variáveis termodinâmicas: a pressão $P(x, y, t)$ e a densidade volumétrica $\rho(x, y, t)$.

\subsubsection{Equação de continuidade}

Considere um volume $V$ de fluido, sabemos que a massa total $M$ contida nesse volume é dada por:

\footnotetext{
${ }^{1}$ O FARGO3D resolve as equações da magneto-hidrodinâmica. No entanto, nesta tese, não iremos acrescentar campos magnéticos, portanto, iremos focar na forma com que o FARGO3D resolve o problema puramente hidrodinâmico. Os detalhes da resolução completa das equações pode ser visto em BenítezLlambay e Masset (2016).
} 


$$
M=\int_{V} \rho d V
$$

Seja $d S$ o elemento de superfície que delimita o volume $V$ considerado e $\vec{n}$ o vetor unitário normal ao elemento $d S$ e dirigido para fora do elemento (ver Fig. 3.1). A quantidade de matéria que atravessa $d S$ por unidade de tempo é:

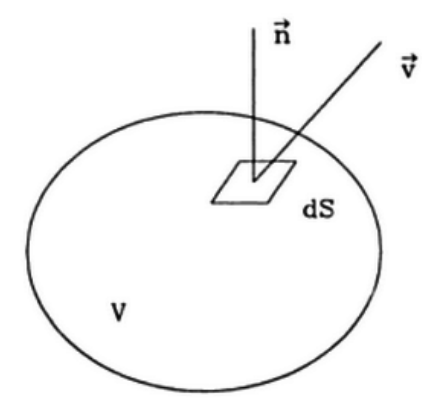

Figura 3.1: Representação de um elemento de fluido de volume $V$ e elemento de superfície $d S$.

$$
\frac{d m}{d t}=\rho \vec{v} \cdot \vec{n} d S
$$

Assim, a massa total de fluido que deixa o volume $V$ por unidade de tempo será descrita por:

$$
\frac{d M}{d t}=\oint \rho \vec{v} \cdot \vec{n} d S
$$

Entretanto, o decréscimo de massa de fluido por unidade de tempo é:

$$
\frac{\partial M}{\partial t}=-\frac{\partial}{\partial t} \int_{V} \rho d V
$$

Assim, para que haja conservação de massa, devemos ter:

$$
\frac{\partial}{\partial t} \int_{V} \rho d V=-\oint \rho \vec{v} \cdot \vec{n} d S
$$

De acordo com o teorema da divergência, podemos escrever:

$$
\oint \rho \vec{v} \cdot \vec{n} d S=\int_{V} \vec{\nabla} \cdot(\rho \vec{v}) d V
$$

Portanto, a equação 3.5 fica na forma: 


$$
\frac{\partial}{\partial t} \int_{V} \rho d V=-\int_{V} \vec{\nabla} \cdot(\rho \vec{v}) d V
$$

o que nos permite escrever:

$$
\int_{V}\left[\frac{\partial \rho}{\partial t}+\vec{\nabla} \cdot(\rho \vec{v})\right] d V=0 .
$$

A igualdade acima prevalece em qualquer volume; portanto, obtemos:

$$
\frac{\partial \rho}{\partial t}+\vec{\nabla} \cdot(\rho \vec{v})=0
$$

A equação acima é denominada equação de continuidade ou equação de conservação da massa.

O fluido considerado aqui é um gás, então, apenas por uma questão de notação, em coordenadas cartesianas, a equaçao 3.9 pode ser escrita na forma:

$$
\frac{\partial \rho_{\text {gas }}}{\partial t}+\frac{\partial}{\partial x}\left(\rho_{\text {gas }} v_{x, \text { gas }}\right)+\frac{\partial}{\partial y}\left(\rho_{\text {gas }} v_{y, \text { gas }}\right)+\frac{\partial}{\partial z}\left(\rho_{\text {gas }} v_{z, \text { gas }}\right)=0
$$

Em coordenadadas cilindrícas $(r, \theta, z)$, na forma:

$$
\frac{\partial \rho_{\text {gas }}}{\partial t}+\frac{1}{r} \frac{\partial}{\partial r}\left(r \rho_{\text {gas }} v_{\mathrm{r}, \text { gas }}\right)+\frac{1}{r} \frac{\partial}{\partial \theta}\left(\rho_{\text {gas }} v_{\theta, \text { gas }}\right)+\frac{\partial}{\partial z}\left(\rho v_{z, \text { gas }}\right)=0 .
$$

E, em coordenadadas esféricas $(r, \theta, \phi)$, na forma:

$$
\frac{\partial \rho_{\text {gas }}}{\partial t}+\frac{1}{r^{2}} \frac{\partial}{\partial r}\left(r^{2} \rho_{\text {gas }} v_{\text {r,gas }}\right)+\frac{1}{r \sin \theta} \frac{\partial}{\partial \theta}\left(\sin \theta \rho_{\text {gas }} v_{\theta, \text { gas }}\right)+\frac{1}{r \sin \theta} \frac{\partial}{\partial \phi}\left(\rho_{\text {gas }} v_{\phi}\right)=0
$$

\subsubsection{Equação de Euler}

Considere um fluido ideal em equilíbrio, ou seja, em que não haja forças tangenciais envolvidas. A força resultante $\vec{F}_{\text {res. }}$, que atua num elemento $V$ do fluido, devido à interação com o restante do fluido, é obtida integrando as força de pressão sobre toda a área superficial. Desse modo, temos:

$$
\vec{F}_{\text {res. }}=-\oint P \vec{n} d S
$$

na qual o sinal (-) indica que a força atua sobre o elemento $V$.

Aplicando o teorema do divergente, encontramos: 


$$
\vec{F}_{\text {res }}=-\oint P \vec{n} d S=-\int_{V} \vec{\nabla} P d V .
$$

Portanto, $-\vec{\nabla} P$ é a força por unidade de volume, ou seja:

$$
\rho \vec{a}=-\vec{\nabla} P .
$$

Como a velocidade do fluido é função da posição e do tempo $\vec{v}=v(x, y, z, t)$, sua diferencial é escrita na forma:

$$
d \vec{v}=\frac{\partial \vec{v}}{\partial t} d t+(d \vec{r} \cdot \vec{\nabla}) \vec{v}
$$

Portanto, a aceleração do fluido pode ser escrita como:

$$
\vec{a}=\frac{d \vec{v}}{d t}=\frac{\partial \vec{v}}{\partial t}+(\vec{v} \cdot \vec{\nabla}) \vec{v}
$$

que substituída na equação 3.15 , fornece:

$$
\rho\left[\frac{\partial \vec{v}}{\partial t}+(\vec{v} \cdot \vec{\nabla}) \vec{v}\right]=-\vec{\nabla} P .
$$

Essa relação é conhecida como equação de Euler. Um caso mais geral ocorre na presença de forças externas. Assim, supondo uma força $\vec{F}_{\text {ext. }}$ atuando num volume unitário, podemos generalizar a equação de Euler na forma:

$$
\frac{\partial \vec{v}}{\partial t}+(\vec{v} \cdot \vec{\nabla}) \vec{v}=-\frac{1}{\rho} \vec{\nabla} P+\frac{1}{\rho} \vec{F}_{\text {ext. }} .
$$

O fluido aqui considerado é um gás e a força externa é a força gravitacional, então, apenas por uma questão de notação, em coordenadas cartesianas, a equação 3.19 pode ser escrita para cada direção na forma:

$$
\begin{gathered}
\rho_{\text {gas }}\left(v_{x, \text { gas }} \frac{\partial v_{x, \text { gas }}}{\partial x}+v_{y, \text { gas }} \frac{\partial v_{x, \text { gas }}}{\partial y}+v_{z, \text { gas }} \frac{\partial v_{x, \text { gas }}}{\partial z}+\frac{\partial v_{x, \text { gas }}}{\partial t}\right)=-\frac{\partial P_{\text {gas }}}{\partial x}+\rho_{\text {gas }} g_{x}, \\
\rho_{\text {gas }}\left(v_{x, \text { gas }} \frac{\partial v_{y, \text { gas }}}{\partial x}+v_{y, \text { gas }} \frac{\partial v_{y, \text { gas }}}{\partial y}+v_{z, \text { gas }} \frac{\partial v_{y, \text { gas }}}{\partial z}+\frac{\partial v_{y, \text { gas }}}{\partial t}\right)=-\frac{\partial P_{\text {gas }}}{\partial y}+\rho_{\text {gas }} g_{y},
\end{gathered}
$$




$$
\rho_{\text {gas }}\left(v_{x, \text { gas }} \frac{\partial v_{z, \text { gas }}}{\partial x}+v_{y, \text { gas }} \frac{\partial v_{z, \text { gas }}}{\partial y}+v_{z, \text { gas }} \frac{\partial v_{z, \text { gas }}}{\partial z}+\frac{\partial v_{z, \text { gas }}}{\partial t}\right)=-\frac{\partial P_{\text {gas }}}{\partial z}+\rho_{\text {gas }} g_{z} .
$$

Em coordenadadas cilindrícas $(r, \theta, z)$, na forma:

$$
\begin{aligned}
& \rho_{\text {gas }}\left(v_{\mathrm{r}, \text { gas }} \frac{\partial v_{\mathrm{r}, \text { gas }}}{\partial r}+\frac{v_{\theta, \text { gas }}}{r} \frac{\partial v_{\mathrm{r}, \text { gas }}}{\partial \theta}+v_{z, \text { gas }} \frac{\partial v_{\text {r,gas }}}{\partial z}-\frac{v_{\theta, \text { gas }}^{2}}{r}+\frac{\partial v_{\text {r,gas }}}{\partial t}\right)= \\
& -\frac{\partial P_{\text {gas }}}{\partial r}+\rho_{\text {gas }} g_{r} \\
& \rho_{\text {gas }}\left(v_{\mathrm{r}, \mathrm{gas}} \frac{\partial v_{\theta, \mathrm{gas}}}{\partial r}+\frac{v_{\theta, \mathrm{gas}}}{r} \frac{\partial v_{\theta, \mathrm{gas}}}{\partial \theta}+v_{z, \mathrm{gas}} \frac{\partial v_{\theta, \mathrm{gas}}}{\partial z}-\frac{v_{\mathrm{r}, \mathrm{gas}} v_{\theta, \mathrm{gas}}}{r}+\frac{\partial v_{\theta, \mathrm{gas}}}{\partial t}\right)= \\
& -\frac{1}{r} \frac{\partial P_{\text {gas }}}{\partial \theta}+\rho_{\text {gas }} g_{\theta} \\
& \rho_{\text {gas }}\left(v_{\mathrm{r}, \mathrm{gas}} \frac{\partial v_{z, \text { gas }}}{\partial r}+\frac{v_{\theta, \text { gas }}}{r} \frac{\partial v_{z, \text { gas }}}{\partial \theta}+v_{z, \text { gas }} \frac{\partial v_{z, \text { gas }}}{\partial z}+\frac{\partial v_{z, \text { gas }}}{\partial t}\right)= \\
& -\frac{\partial P_{\text {gas }}}{\partial z}+\rho_{\text {gas }} g_{z}
\end{aligned}
$$

E, em coordenadadas esféricas $(r, \theta, \phi)$, na forma:

$$
\begin{gathered}
\rho_{\text {gas }}\left(v_{\mathrm{r}, \mathrm{gas}} \frac{\partial v_{\mathrm{r}, \mathrm{gas}}}{\partial r}+\frac{v_{\theta, \mathrm{gas}}}{r} \frac{\partial v_{\mathrm{r}, \mathrm{gas}}}{\partial \theta}+\frac{v_{\phi, \mathrm{gas}}}{r \sin \theta} \frac{\partial v_{\mathrm{r}, \mathrm{gas}}}{\partial \phi}-\frac{v_{\theta, \mathrm{gas}}^{2}+v_{\phi, \mathrm{gas}}^{2}}{r}+\frac{\partial v_{\mathrm{r}, \mathrm{gas}}}{\partial t}\right)= \\
-\frac{\partial P_{\mathrm{gas}}}{\partial r}+\rho_{\mathrm{gas}} g_{r}, \\
\rho_{\mathrm{gas}}\left(v_{\mathrm{r}, \mathrm{gas}} \frac{\partial v_{\theta, \mathrm{gas}}}{\partial r}+\frac{v_{\theta, \mathrm{gas}}}{r} \frac{\partial v_{\theta, \mathrm{gas}}}{\partial \theta}+\frac{v_{\phi, \mathrm{gas}}}{r \sin \theta} \frac{\partial v_{\theta, \mathrm{gas}}}{\partial \phi}+\frac{v_{\mathrm{r}, \mathrm{gas}} v_{\theta, \mathrm{gas}}-v_{\phi, \mathrm{gas}}^{2} \cot \theta}{r}+\frac{\partial v_{\theta, \mathrm{gas}}}{\partial t}\right)= \\
-\frac{1}{r} \frac{\partial P_{\text {gas }}}{\partial \theta}+\rho_{\text {gas }} g_{\theta},
\end{gathered}
$$

$$
\begin{array}{r}
\rho_{\text {gas }}\left(v_{\mathrm{r}, \mathrm{gas}} \frac{\partial v_{\phi, \mathrm{gas}}}{\partial r}+\frac{v_{\theta, \mathrm{gas}}}{r} \frac{\partial v_{\phi, \mathrm{gas}}}{\partial \theta}+\frac{v_{\phi, \mathrm{gas}}}{r \sin \theta} \frac{\partial v_{\phi, \mathrm{gas}}}{\partial \phi}+\frac{v_{\mathrm{r}, \mathrm{gas}} v_{\phi, \mathrm{gas}}+v_{\phi, \mathrm{gas}} v_{\theta, \mathrm{gas}} \cot \theta}{r}+\frac{\partial v_{\phi, \mathrm{gas}}}{\partial t}\right)= \\
-\frac{1}{r \sin \theta} \frac{\partial P_{\mathrm{gas}}}{\partial \phi}+\rho_{\mathrm{gas}} g_{\phi} .
\end{array}
$$

A dedução acima desconsidera as forças viscosas, se incluirmos o tensor viscoso $\vec{T}_{\text {visc. }}$ e a possibilidade de rotação do referencial $\left(\Omega_{\mathrm{f}}\right)$ sobre um eixo vertical, a equação 3.19 é escrita na forma: 


$$
\rho\left(\frac{\partial \vec{v}}{\partial t}+\vec{v} \cdot \vec{\nabla} \vec{v}\right)=-\vec{\nabla} P-\vec{\nabla} \cdot \vec{T}_{\text {visc. }}+\vec{F}_{\text {ext. }}-\left[2 \vec{\Omega}_{\mathrm{f}} \times \vec{v}+\overrightarrow{\Omega_{\mathrm{f}}} \times\left(\overrightarrow{\Omega_{\mathrm{f}}} \times \vec{r}\right)+\dot{\overrightarrow{\Omega_{\mathrm{f}}}} \times \vec{r}\right] \rho
$$

observe que o último termo da equação se deve à possibilidade de rotação do referencial e

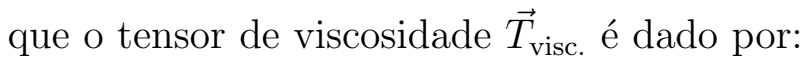

$$
\vec{T}_{\text {visc. }}=\rho \nu\left[\nabla \vec{v}+(\nabla \vec{v})^{T}-\frac{2}{3}(\nabla \cdot \vec{v}) \vec{I}\right]
$$

onde $\nu$ é a viscosidade cinemática e $\vec{I}$ é o tensor unitário de mesma ordem do tensor $\nabla \vec{v} 1$.

As componentes do tensor de viscosidade para cada sistema de coordenadas pode ser encontrada no apêndice do artigo Benítez-Llambay e Masset (2016).

\subsubsection{Equação de energia}

Conside a energia térmica interna específica $e$ e a energia cinética específica $e_{\text {kin. }}=v^{2} / 2$ de um fluido. Utilizando o mesmo raciocínio da seção anterior, podemos escrever a variação temporal da energia total como a derivada no tempo da integral volumétrica de $\rho\left(e+v^{2} / 2\right)$, e a advecção da energia através da superfície do volume de controle como a integral de superfície de $\rho\left(e+v^{2} / 2\right) \vec{v} \cdot \vec{n}$. A variação temporal do trabalho exterior que atua no volume de controle é a integral de superfície de $P \vec{v} \cdot \vec{n}$. Portanto, a partir da primeira lei da termodinâmica $d U=d Q-d W$, podemos escrever:

$$
\frac{\partial}{\partial t} \int \rho\left(e+\frac{1}{2} v^{2}\right) d V=-\int_{\partial V} \rho\left(e+\frac{1}{2} v^{2}\right) \vec{v} \cdot \vec{n} d S-\int_{\partial V} P \vec{v} \cdot \vec{n} d S .
$$

Usando o teorema da divergência, a equação 3.31 pode ser escrita na forma:

$$
\frac{\partial}{\partial t} \int \rho\left(e+\frac{1}{2} v^{2}\right) d V+\int \nabla \cdot\left[\left(\rho e+\frac{1}{2} \rho v^{2}+P\right) \vec{v}\right]=0 .
$$

Como a equação precisa ser válida para todo o volume de controle $V$, a forma diferencial da equação de conservação de energia é:

$$
\frac{\partial}{\partial t} \rho e_{\text {tot. }}+\nabla \cdot\left[\left(\rho e_{\text {tot. }}+P\right) \vec{v}\right]=0
$$

\footnotetext{
${ }^{1}$ A dedução completa da equação de Euler com o tensor de viscosidade pode ser encontrada em $<$ http://web.mit.edu/2.25/www/pdf/viscous_flow_eqn.pdf $>$.
} 
Usando a notação para um gás, podemos escrever a equação 3.33 como:

$$
\frac{\partial}{\partial t} \rho_{\text {gas }} e_{\text {tot. }}+\nabla \cdot\left(\rho_{\text {gas }} e_{\text {tot. }}\right)=-P_{\text {gas }} \nabla \cdot \vec{v}_{\text {gas }} .
$$

É importante ressaltar que o FARGO3D resolve a equação de energia na forma não conservativa. Conforme Benítez-Llambay e Masset (2016), códigos baseados no método de Godunov usam, em geral, o fluxo de energia total e se preocupam com a conservação de energia conforme a acurácia da máquina. Entretanto, códigos baseados em malhas deslocadas, caso do FARGO, consideram o fluxo de energia interna e, portanto, não obtêm a conservação de energia de acordo com a acurácia da máquina. Embora isso pareça uma desvantagem, discos protoplanetários, usualmente, possuem um grande número de Mach, isto é, a energia cinética é de duas a três ordens de magnitude maior que a energia interna. Assim, o cálculo da energia térmica, subtraindo a energia cinética da energia total, se torna impreciso devido a erros de truncamento, especialmente em regiões onde há ondas de choque. Esse problema é conhecido como problema do alto número de Mach, uma análise mais detalhada pode ser encontrada em Ryu et al. (1993) e Trac e Pen (2004). Muitos problemas que envolvem a interação disco-planeta requerem uma acurácia na advecção da entropia na região coorbital do planeta, necessitando, portanto, uma acurácia maior na conservação da energia interna do que na energia total.

\subsubsection{Equação de estado}

Até agora caracterizamos o estado de um fluido genérico usando uma distribuição de velocidades $\vec{v}(x, y, t)$, a pressão $P(x, y, t)$ e a densidade $\rho(x, y, t)$. Assim, o fluido fica caracterizado por cinco grandezas escalares $P, \rho, v_{x}, v_{y}$ e $v_{z}$. As demais quantidades que aparecem nas equações hidrodinâmicas devem ser conhecidas ou relacionadas por meio das propriedades termodinâmicas desse fluido; como o disco protoplanetário é composto em sua maior parte de gás podemos caracterizá-lo usando uma equação de estado para um gás ideal. Para um gás ideal, não degenerado, a equação de estado é:

$$
P_{\text {gas }} V=N k_{\mathrm{B}} T_{\text {gas }}
$$

onde $k_{\mathrm{B}}=1.38064852 \cdot 10^{-23} \frac{\mathrm{J}}{\mathrm{K}}$ é a constante de Boltzman e $N$ é o número de moléculas do gás. Usando a densidade numérica de partículas $d_{\mathrm{n}}=\frac{N}{V}$, podemos escrever a equação 
3.35 na forma:

$$
P_{\text {gas }}=d_{\mathrm{n}} k_{\mathrm{B}} T_{\text {gas }}
$$

Sabemos que a massa molecular média $\mu$ para um gás composto por diversas partículas é dada por:

$$
\mu=\frac{1}{m_{\mathrm{H}}} \frac{\sum n_{\mathrm{i}} m_{\mathrm{i}}}{\sum n_{\mathrm{i}}}
$$

onde $n_{\mathrm{i}}$ e $m_{\mathrm{i}}$ são, respectivamente, a quantidade e a massa de partículas de um determinado tipo. Nessa tese, trabalharemos com um gás de hidrogênio neutro. Assim, a equação 3.37 pode ser escrita na forma:

$$
\mu=\frac{m}{m_{\mathrm{H}}} .
$$

Isso permite escrever a densidade numérica de partículas como $d_{\mathrm{n}}=\frac{\rho_{\text {gas }}}{\mu m_{\mathrm{H}}}$. Assim a equação de estado (ver eq. 3.36) para um gás homogêneo pode se escrita como:

$$
P_{\text {gas }}=\frac{k_{\mathrm{B}} \rho_{\mathrm{gas}} T_{\mathrm{gas}}}{\mu m_{\mathrm{H}}}
$$

Além disso, sabemos que a velocidade de propagação de uma onda sonora é dada por:

$$
c_{\mathrm{s}}^{2}=\frac{\partial P_{\mathrm{gas}}}{\partial \rho_{\text {gas }}} .
$$

Portanto, usando a equação 3.39 para um fluido isotérmico, obtemos:

$$
c_{\mathrm{s}}^{2}=\left(\frac{\partial P_{\text {gas }}}{\partial \rho_{\text {gas }}}\right)_{T}=\frac{k_{\mathrm{B}} T_{\text {gas }}}{\mu m_{\mathrm{H}}}=\frac{P_{\text {gas }}}{\rho_{\text {gas }}} .
$$

Isso permite escrever a equação de estado para um fluido isotérmico na forma:

$$
P_{\text {gas }}=\rho_{\text {gas }} c_{\mathrm{s}}^{2}
$$

Para o caso adiabático, podemos escrever a pressão do gás em termos da energia interna de um gás ideal dada por:

$$
E_{\text {int. }}=\frac{N f k_{\mathrm{B}} T_{\text {gas }}}{2}
$$


onde $N$ é o número de moléculas e $f$ o número de graus de liberdade de uma molécula. Sabendo que o número de móleculas é o número de mols $n$ vezes o número de Avogadro $\left(N=n N_{\mathrm{A}}\right)$, obtemos que a energia volumétrica, isto é, a energia por unidade de volume é:

$$
e=\frac{E_{\text {int. }}}{V}=\frac{n N_{\mathrm{A}} f k_{\mathrm{B}} T_{\mathrm{gas}}}{2 V}=\frac{n R f T_{\mathrm{gas}}}{2 V}
$$

onde $R=k_{\mathrm{B}} N_{\mathrm{A}}$ é a constante universal dos gases perfeitos e possui valor de $8.31 \mathrm{~J} / \mathrm{mol}$.K.

Usando a relação $R=k_{\mathrm{B}} N_{\mathrm{A}}$ e $N=n N_{\mathrm{A}}$, obtemos $N k_{\mathrm{B}}=n R$, que, substituído na equação 3.35 , fornece:

$$
P_{\mathrm{gas}} V=n R T_{\mathrm{gas}} \Rightarrow P_{\mathrm{gas}}=\frac{n R T_{\mathrm{gas}}}{V} \Rightarrow P_{\mathrm{gas}}=\frac{m R T_{\mathrm{gas}}}{M V} \Rightarrow P_{\mathrm{gas}}=\frac{\rho_{\mathrm{gas}} R T_{\mathrm{gas}}}{M}
$$

onde usamos $n=m / M$, isto é, o número de mols é a massa $m$ dividido pela massa molar $M$.

Isolando $R T_{\text {gas }}$ da equação 3.44 e substituindo na equação 3.45 , obtemos:

$$
P_{\text {gas }}=\frac{2 e}{f} .
$$

O número de graus de liberdade $f$ da molécula pode ser escrito em função do índice adiabático $\gamma_{\text {gas }}$ (razão entre os calores específicos sob pressão e volume constante) como $f=\frac{2}{\gamma_{\text {gas }}-1}$, logo, a equação de estado para um gás adiábatico fica na forma:

$$
P_{\text {gas }}=\left(\gamma_{\text {gas }}-1\right) e
$$

O algoritmo do FARGO3D é construído de forma a usar a equação de estado 3.42 no caso de o módulo ISOTHERMAL estar acionado no arquivo SETUP. opt, por isso, para o caso de um disco localmente isotérmico, como o que será usado nesta tese, devemos informar no arquivo condinit.c um perfil inicial para a velocidade do som, em geral, descrito pela equação 2.13 (ver seção 2.1.3). Nesse caso, a equação para a energia não é resolvida.

No caso adiabático, o módulo ADIABATIC acionado no arquivo SETUP.opt, em geral, informa-se um perfil inicial para a energia do gás, descrita pela equação 3.47, em que a pressão inicial, em geral, é a mesma obtida do caso isotérmico. 


\subsection{Malha deslocada e campos vetoriais}

A solução numérica das equações deduzidas nas seções anteriores envolve uma discretização espacial e temporal, para isso, é necessário construir uma malha que contenha os pontos nos quais as variáveis serão calculadas. É possível escolher nessa malha a posição em que cada variável será armazenada. Quando essas variavéis estão armazenadas em posições diferentes, obtemos a chamada malha deslocada (staggered grid). Esse tipo de malha permite utilizar discretizações de segunda ordem sem o risco de campos oscilatórios (Fortuna, 2012).

O FARGO3D utiliza o mesmo conceito de malha utilizada por Harlow e Welch (1965), no qual as grandezas vetoriais (ex.: velocidade, campo magnético etc.) são guardadas no centro das arestas, ou faces, de comprimento $\Delta x$ e $\Delta y$, e as grandezas escalares (ex.: densidade, pressão, energia etc.) são alocadas no centro da célula. A Figura 3.2 a seguir mostra um esboço de uma célula bidimensional com essas características. A extensão para uma célula em três dimensões é imediata.

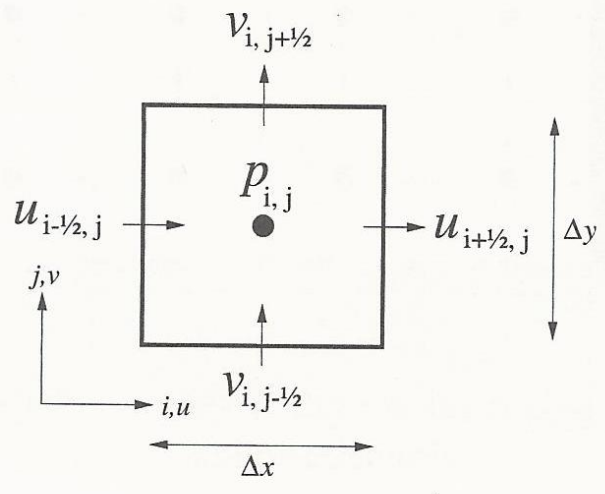

Figura 3.2: Representação de uma célula da malha deslocada. A pressão (grandeza escalar) é armazenada no centro da célula, enquanto as velocidades (grandeza vetorial) são armazenadas no centro da face. Figura adaptada de Fortuna (2012).

Para as quantidades definidas no centro da célula de posição $(i, j, k)$, usaremos a notação $Q_{i, j, k}$, já para as definidas no centro da face usaremos uma notação fracionária que depende da face onde está localizada $\left(Q_{i, j+1 / 2, k}\right)$.

O FARGO3D trabalha em diferentes sistemas de coordenadas. Por meio da seleção da variável de macrocomando adequada no arquivo SETUP .opt, é possível escolher entre a geometria cartesiana (CARTESIAN), cilíndrica (CYLINDRICAL) ou esférica (SPHERICAL). A 
Tabela 3.1 a seguir resume a nomenclatura utilizada.

\begin{tabular}{c|ccc} 
Nomenclatura & Cartesiana & Cilindrica & Esférica \\
\hline $\mathrm{x}$ & $\mathrm{x}$ & $\theta$ & $\theta$ \\
$\mathrm{y}$ & $\mathrm{y}$ & $\mathrm{r}$ & $\mathrm{r}$ \\
$\mathrm{z}$ & $\mathrm{z}$ & $\mathrm{z}$ & $\varphi$
\end{tabular}

Tabela 3.1 - Descrição da nomenclatura para as diferentes coordenadas usadas no FARGO3D. O ângulo $\theta$ no sistema de coordenadas cilindricas e esférica é o ângulo azimutal. O ângulo $\varphi$ no sistema de coordenadas esféricas é a colatitude.

A malha euleriana criada no programa consiste de NX células na direção $x, \mathrm{NY}+2 * \mathrm{NGHY}$ células na direção $y$ e NZ $+2 *$ NGHZ células na direção $z$, onde NGHY e NGHZ são o número de células fantasmas, respectivamente, na direção $x$ e $y$ (ver seção 3.3). O número de dimensões deve ser especificado no arquivo SETUP.opt com as variáveis de macrocomando DX, DY e DZ, e o número de células em cada direção (NX, NY e NZ) no arquivo SETUP.par, que, quando não especificado, recebe o valor nulo. O número de células é importante para aferir a resolução necessária para o problema em estudo.

A informação sobre a posição das células é guardada em arrays 1D com a nomenclatura [xyz]min(index) e [xyz]med(index), na qual o min se refere à posição do canto inferior da célula (em $x, y$ ou $z$ ) e med à posição do centro da célula (em $x, y$ ou $z$ ). O índice index refere-se à localização da célula, assim, utilizando um índice, no FARGO3D denominado de 1 , é possível localizar uma determinada célula de posição $(i, j, k)$, e usando o índice lxp/lxm, a célula posterior/anterior à célula de índice 1 na direção $x$, o mesmo vale para $y$ e $z$ ( lyp/lym e lzp/lzm). Todos esses índices estão definidos no arquivo src/define.h. A Figura 3.3 a seguir resume algumas notações usadas para localização da célula. A notação deve ser usual aos usuários do FARGO.

O uso dos índices facilita muito o trabalho de implementação do código já que não é necessário realizar nenhuma álgebra sofisticada. Portanto, essa notação será amplamente usada neste trabalho.

Diversos outros índices podem ser encontrados no manual, principalmente para análise 3D. Nesta tese, nos limitamos a uma malha bidimensional cilindrica. Caso algum índice ou variável usada nos programas descritos no apêndice não pareçam triviais ao leitor, sugerimos a leitura do manual no capítulo Mesh and Fields. 


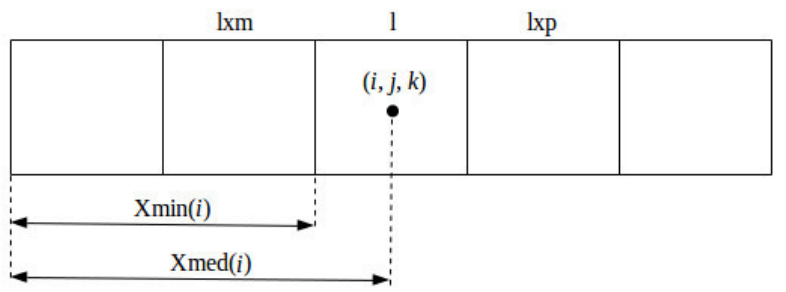

Figura 3.3: Representação do posicionamento das células no FARGO3D. A variável xmed(i) é a posição do centro da célula 1 na direção $x$, a variável xmin(i) é a posição do canto inferior da célula 1 na direção x. Os índices lxm e lxp são usados para designar a célula anterior e posterior à célula 1 na direção x. O mesmo raciocínio pode ser usado para as outras dimensões.

\subsection{Condições de borda}

O processo de discretização das equações no FARGO3D vale para pontos internos do domínio computacional, portanto, células adjacentes às fronteiras podem exigir informações sobre pontos fora do dominío computacional, que são descritos pelas condições de borda. O número de células fora do dominío computacional, depende do problema em estudo e do processo de discretização. No FARGO3D, são utilizados, por padrão, três células para condições de borda ( $\mathrm{NGHY}=\mathrm{NGHZ}=3)$, esse valor está definido em src/define.h.

As condições de borda podem ser aplicadas somente nas direções $y$ e $z$, já que a direção $x$ é assumida, na sua implementação, como periódica. Isso ocorre porque o tratamento de um disco azimultamente periódico gera um algoritmo efetivo para o tratamento do problema da advecção orbital (ver seção 3.7.5).

A Figura 3.4 mostra, esquematicamente, um exemplo de como as células que estão no domínio computacional podem ser mapeadas para as células fantasmas nas bordas.

As condições de borda são manipuladas através de uma metalinguagem traduzida por um script descrito no arquivo boundparser . py que traduz um arquivo texto numa linguagem C, subsequentemente convertida em CUDA. Por isso, as condições de borda devem ser aplicadas a todas as variáveis primitivas. Todas essas condições são manipuladas pela rotina FillGhosts dentro do código src/algogas.c.

$\mathrm{O}$ arquivo boundparser . py funciona com base na leitura de quatro arquivos. Primeiramente, ele lê a informação dentro de setup.bound e compara com as informações em boundaries.txt e centering.txt. Esses dois arquivos podem ser copiados no diretório scr/SETUP para manter a reusabilidade do código. No arquivo centering.txt, descre- 


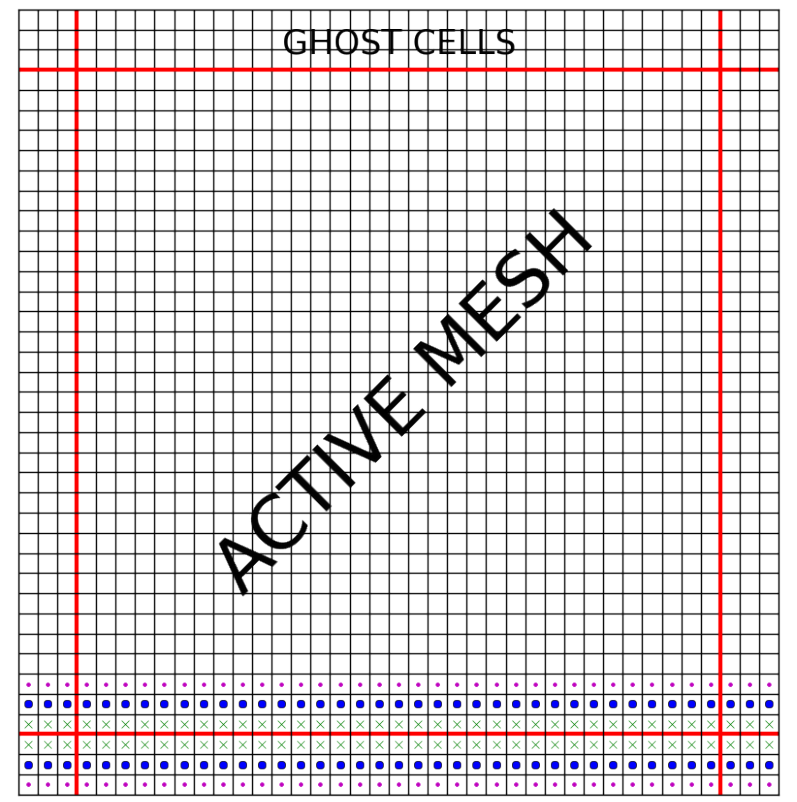

Figura 3.4: Representação esquemática de um exemplo de aplicação das condições de borda no FARGO3D. A última célula fantasma é preenchida com a terceira célula do domínio computacional (círculo menor vermelho), a segunda célula fantasma com a segunda célula do domínio (círculo maior azul) e, finalmente, a primeira célula fantasma é preenchida com o valor da primeira célula do domínio (cruz verde). <Figura obtida em: http://fargo.in2p3.fr/manuals/html/boundaries.html>.

vemos se a variável está definida na borda (ex. Vx: Staggering: x) ou no centro da célula (ex. Density: Staggering: C). Já no arquivo boundaries.txt o usuário define como as condições de borda serão aplicadas. Por fim, o arquivo boundary_template.c gera um arquivo $C([\mathrm{y} / \mathrm{z}][\mathrm{min} / \mathrm{max}]$ _boundary.c) que constrói as condições de borda.

Considere, por exemplo, a variável Density, que guarda o valor da densidade do gás, e a variável Vx, que guarda o valor da velocidade do gás na direção $x$. Como a densidade é definida no centro da célula e a velocidade na borda das células na direção $x$, essas variáveis devem ser declaradas no arquivo centering.txt como:

Density: Staggering: C

Vx: Staggering: $x$

O arquivo centering.txt irá, portanto, conter a descrição de como a variável está implementada no código. Todas as condições de borda seguem a mesma formatação.

O arquivo boundaries.txt apresenta a descrição da operação que será aplicada na condição de borda. Vamos supor que queiramos copiar os valores das células da fronteira para as condições de borda. Vamos atribuir o nome, SYMMETRIC a essa condição. O código 
ficaria na forma:

SYMMETRIC :

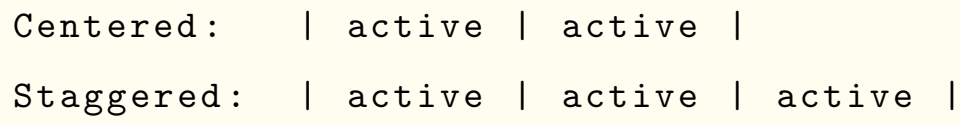

Essa representação considera, para a variável do tipo Centered, a coluna da esquerda como a célula fantasma e a coluna da direita como a célula ativa, isto é, a célula na fronteira do domínio computacional. A string active pode ser substituída por qualquer outra string, isto é, qualquer string usada na célula ativa será "linkada" com a mesma string descrita na célula fantasma. Uma string entre aspas é sempre convertida em maiúsculas, assim é possível atribuir variáveis usadas no algoritmo dentro das condições de borda. Valores numéricos também são aceitos.

No caso da variável do tipo Staggered, a descrição envolve três colunas. As colunas, nesse caso, descrevem os valores nas bordas de duas células lado a lado.

Também é possível trabalhar com índices para as células fantasmas e ativas, usando, por exemplo, jgh/kgh para a localização da células fantasmas em y ou $z$ e jact/kact para localização da célula ativa em $y$ ou $z$.

O exemplo acima descreve uma situação na qual queremos definir um gradiente nulo para a densidade e a velocidade na direção $x$. Exemplos mais complexos podem ser encontrados no próprio arquivo boundaries.txt.

Por fim, para a condição de borda ser aplicada basta especificar no arquivo SETUP. bound nossa construção chamada SYMMETRIC, construída em boundaries . txt, da seguinte forma:

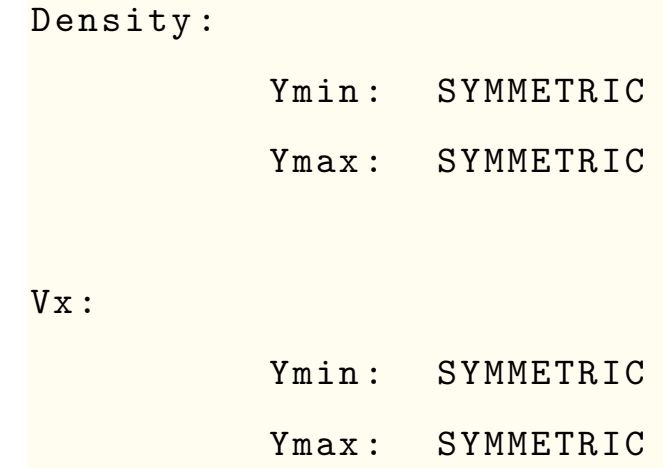

Essa sintaxe é a mesma usada para as demais condições de borda.

Além das condições de borda usuais do FARGO3D, usaremos o módulo STOCKHOLM no arquivo SETUP.opt (ver apêndice A.1). Essa condição definida por de Val-Borro et al. (2006) evita a reflexão das ondas nas bordas. No entanto, faremos uma leve modificação 
nesse módulo, que será descrita mais adiante (ver seção 3.10.3).

Um exemplo de aplicação das condições de borda pode ser encontrado no apêndice A.3. Esse exemplo foi usado em algumas simulações desta tese.

\subsection{Incluindo novas variáveis}

Ao longo desta tese, foram incluídas novas variáveis no programa FARGO3D, assim, o leitor deve ficar atento e incluí-las cuidadosamente no código para conseguir reproduzir os dados obtidos.

O FARGO3D utiliza um pacote de variáveis, um registro, que em linguagem C é conhecido como struct. Quando as variáveis são guardadas em uma array 1D, elas são chamadas de variáveis de campo. Abaixo, temos um exemplo de uma struct, chamada field, escrita no padrão do FARGO3D para variável de campo.

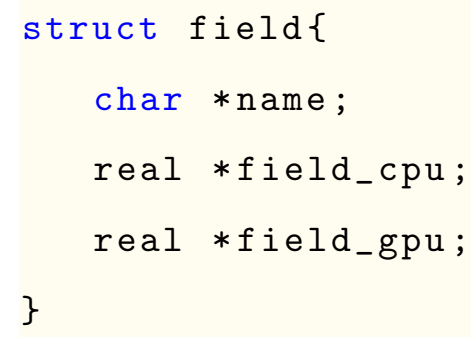

O exemplo acima mostra apenas as linhas mais relevantes. A string name é usada para determinar o nome do arquivo de saída; field_cpu é um apontador para um array 1D, double ou float, e é devidamente alocado na memória RAM antes de qualquer uso no código.

Da mesma forma, field_gpu é um apontador para um array 1D, double ou float, que é devidamente alocado na memória RAM de vídeo antes de qualquer uso no código. Esse tipo de variável nunca é invocada no código, pois o FARGO3D é programado para lidar diretamente com a transformação dessa variável para uso na linguagem CUDA.

Podemos encontrar uma lista de variáveis de campos no arquivo src/global.h, arquivo no qual devemos declarar nossas novas variáveis de campo. Além disso, devemos implementar essas novas variáveis de campo na função CreatedFields (), encontrada no arquivo src/LowTasks. c. Essa função é responsável por criar as variáveis de campo no FARGO3D. O apêndice A.4 contém parte dos arquivos src/global.h e src/LowTasks.c, onde é possível encontrar a declaração das novas variáveis usadas para o modelo de formação 
planetária implementado nesta tese.

Essas novas variáveis serão usadas nos programas para guardar valores ao longo do domínio computacional. Considere, por exemplo, uma variável chamada Density. No código, se quisermos atribuir um valor para essa variável ao longo de cada ponto da malha devemos fazer:

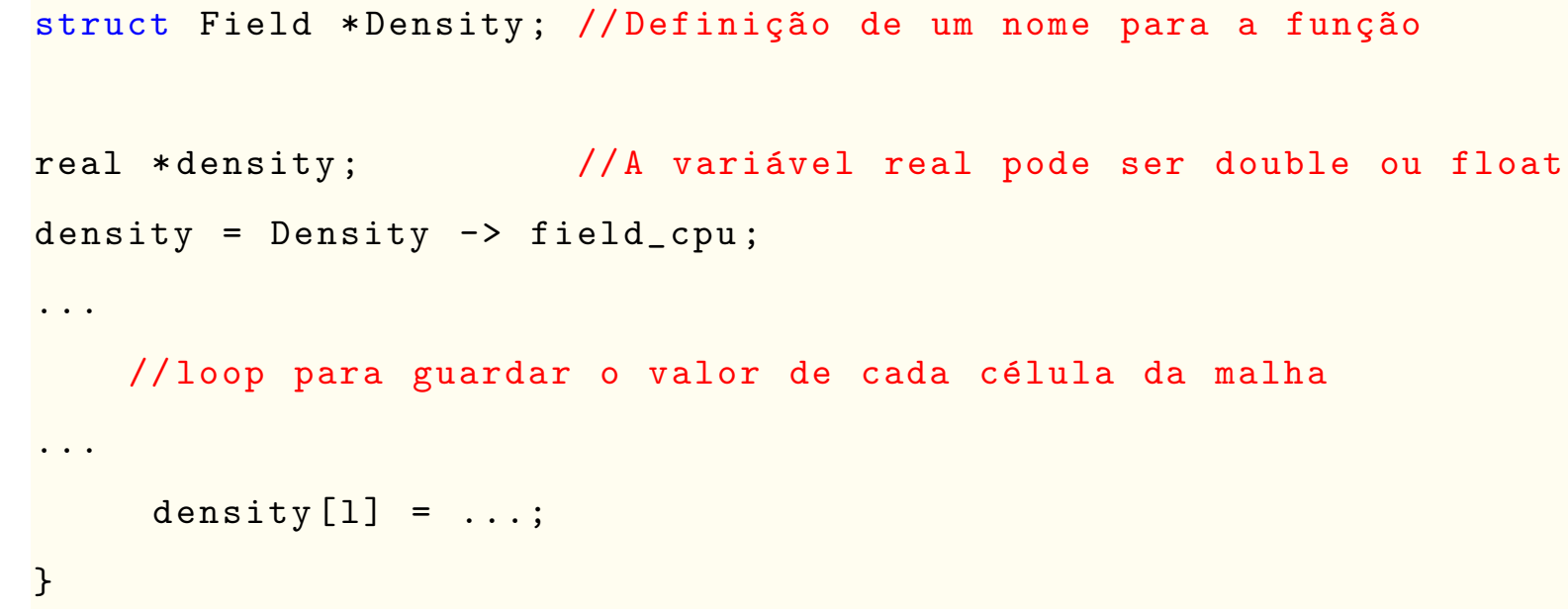

Essa será a estrutura usada em todo código novo inserido no FARGO3D.

Nesta tese, além de trabalharmos com novos arrays, iremos modificar uma struct já programada no FARGO3D, a struct planetary_system, que é encontrada no arquivo struct.h. Iremos acrescentar variáveis para guardar alguns valores do modelo de formação planetária para cada planeta. As variáveis, inseridas de forma direta, são chamadas pela função InitPlanetarySystem, que se encontra no arquivo psyc.c, e necessitam ser adaptadas nesse arquivo. A programação segue a mesma rotina das outras variáveis da mesma struct que estão na mesma função. Essa modificação pode ser encontrada no apêndice A.4.

Vale ressaltar que, para imprimirmos o valor das novas variáveis num arquivo de saída, algumas modificações no arquivo output . c foram necessárias. Para isso, seguimos o mesmo padrão que já existe para as outras variáveis do código. Parte do arquivo modificado pode ser encontrado no apêndice A.5.

\subsection{Unidades}

Ao contrário do seu antecessor, no FARGO3D, é possível mudar o sistema de unidades. Essa característica oferece algumas vantagens. A primeira delas, a mais óbvia, é a possibilidade de conferir os resultados de maneira mais prática. Além disso, isso permite comparar 
resultados gerados com diferentes sistemas de coordenadas para testar se a implementação do código está correta. De fato, a razão entre os resultados obtidos com diferentes sistemas de coordenadas deve ser uma reta (dentro da precisão da máquina).

Outra característica importante é a possibilidade de usar os resultados em outras aplicações, como códigos de transferência radiativa, que exigem a entrada de dados num sistema de unidades específico.

Os diferentes sistemas de unidades estão descritos no arquivo foundam.h e podem ser acessados a partir de variáveis de pré-processamento ativadas pelo comando make UNITS=MKS para o sistema MKS, make UNITS=CGS para o sistema CGS ou make UNITS=0 para o sistema adimensional, já conhecido pelos usuários do FARGO. No sistema adimensional, a massa da estrela, o raio do planeta e a constante gravitacional são tomados como 1. O período orbital é, portanto, $2 \pi$ em $r=R_{0}$.

Para uso no modelo de formação planetária, acrescentamos outras unidades no arquivo foundam.h. Essa modificação pode ser encontrada no apêndice A.6.

No FARGO3D, é possível manipular o arquivo de saída para um sistema de unidade específico sem necessidade de alterar as unidades no arquivo de parâmetros (setup.par). Para isso, basta ativar a variável de pré-processamento RESCALE pelo comando make RESCALE $=1$.

Durante o processo make, o script python scripts/unitparser.py é rodado e lê todas as variáveis reais de entrada do código, isto é, as variáveis do arquivo setup.par. Para as regras de conversão de unidades, esse script faz a leitura do arquivo std/standard.units. No caso de uma variável nova ser acrescentada no arquivo de parâmetros, o script faz a leitura do arquivo setup.units, no qual o usuário define a regra para transformação das novas variáveis. Essa regra é copiada automaticamente para um arquivo chamado rescale.c, que contém todas as transformações de unidades necessárias para execução do código. As unidades adimensionais, que não possuem descrição de transformação no código, aparecem com um Warning durante o processo de compilação ou através da execução direta do próprio script python, como mostra o exemplo abaixo:

Warning ! Scanling rule not found for FLARINGINDEX. Is it dimensionless ? 
O arquivo setup.units com a transformação de unidades para as novas variáveis do arquivo setup.par podem ser encontradas no apêndice A.8.

É importante ressaltar que, após a compilação do código, o usuário precisa remover o arquivo rescale.c do diretório .. /bin deixado pelo script. Caso contrário, por razões de dependência, o makefile pode não apagar a nova variável em outra simulação que não a utilize.

\subsection{Principais parâmetros de entrada}

Os parâmetros de entrada no FARGO3D são descritos no arquivo setup.par e são essencialmente os mesmos daqueles usados no FARGO antecessor. Segue abaixo a descrição dos principais parâmetros:

- AspectRatio - $h(r e a l)$ : atribui um valor para a razão de aspecto do disco em $R_{0}$, onde $R_{0}$ é um comprimento característico definido em src/fondam.h. Fisicamente, esse valor está relacionado com a velocidade do som (ver seção 2.1.2) por meio da relação:

$$
h=\frac{H}{r}=\frac{c_{\mathrm{s}}}{\Omega_{\mathrm{K}} r} .
$$

Portanto, esse parâmetro pode ser usado para inicializar o valor da velocidade do som no disco de gás no arquivo condinit.c.

- Sigma0 - $\Sigma_{0}(r e a l)$ : atribui um valor para a densidade superficial do gás em $r=R_{0}$.

- SigmaSlope - $\varphi$ (real): atribui um valor para o expoente do perfil de densidade superficial do gás, descrito pela equação:

$$
\Sigma(r)=\Sigma_{0}\left(\frac{r}{R_{0}}\right)^{-\varphi} .
$$

- FlaringIndex - $\gamma($ real $)$ : atribui um valor para a curvatura do disco de gás. Caso seja nulo, o disco de gás tem um perfil constante, isto é, a altura do disco aumenta linearmente com o raio. A dependência da razão de aspecto do disco com a variável $\gamma$ é dada por:

$$
h(r)=\frac{H}{r}=h\left(\frac{r}{R_{0}}\right)^{\gamma} .
$$

- PlanetConfig (string): nome do arquivo que contém os dados sobre o(s) planeta(s). O caminho é relativo ao local onde será executado o código. 
- ThicknessSmoothing - $\epsilon$ (real): parâmetro de suavização do potencial para todos os planetas para levar em conta o fato de ser 3D. O uso desse parâmetro é mutualmente exclusivo com o RocheSmoothing. O comprimento de suavização do potencial é dado por:

$$
s=h\left(\frac{r}{R_{0}}\right)^{\gamma} \times r \times \epsilon .
$$

Assim, o potencial do planeta de massa $M_{\mathrm{p}}$ numa distância $r_{\mathrm{p}}$ será descrito pela função potencial:

$$
\phi=-\frac{G M_{\mathrm{p}}}{\sqrt{r_{\mathrm{p}}^{2}+s^{2}}} .
$$

- RocheSmoothing - $\epsilon$ (real): possui a mesma função do ThicknessSmoothing. No entanto, o comprimento de suavização do potencial é calculado usando o raio de Hill do planeta:

$$
s=\epsilon \times r \times\left(\frac{M_{\mathrm{p}}}{3 M_{\star}}\right)^{1 / 3} .
$$

- Eccentricity - $e_{\mathrm{p}}($ real): valor inicial para a excentricidade dos planetas.

- IndirectTerm (boolean): seleciona se o cálculo do potencial envolverá termos indiretos que surgem devido à aceleração primária decorrente da gravidade do planeta. Esses termos surgem em razão da escolha da origem do sistema de coordenadas. No FARGO3D, a origem do sistema de coordenadas está na estrela, portanto, esse termo sempre estará designado como YES. Quanto mais próximo o centro de massa estiver da estrela, menos influência teremos dos termos indiretos.

- Frame (string): seleciona o referencial que pode ser F (fixo), C (corrotação) e G (guiding center). No primerio caso $(\mathrm{F})$, o referencial roda com velocidade constante definida pela variável OmegaFrame. No referencial de corrotação (C), o referencial roda com o planeta de número 0. Quando G é acionado, o referencial roda com o guiding center do planeta de número 0.

- OmegaFrame - $\Omega_{\mathrm{f}}($ real $)$ : define um valor para a velocidade angular do referencial. Ela terá sentido apenas se a variável Frame receber o valor F.

Outras variáveis foram usadas no modelo de formação planetária. O arquivo setup.par completo e uma descrição de todas as novas variáveis podem ser encontrados no apêndice 


\subsection{Descrição do método numérico}

O FARGO3D resolve as equações diferenciais da hidrodinâmica em uma malha euleriana com um método explícito no tempo usando a técnica do operador splitting e a técnica upwind. A discretização de algumas dessas equações diferenciais ocorre via método de diferenças finitas, enquanto em outras, utiliza-se o método de volumes finitos.

A Figura 3.5 representa um fluxograma correspondente a um passo completo de tempo no FARGO3D. As equações são resolvidas atráves de uma sucessão de diferentes subpassos que serão explicados a seguir.

\subsubsection{Técnica do operador splitting}

O FARGO3D utiliza um método de passos para a resolução das equações da hidrodinâmica conhecido como método splitting, no qual a resolução das equações diferenciais parciais são divididas em duas partes. Este é o mesmo método empregado no código ZEUS (Stone e Norman, 1992).

Para entendermos o processo, vamos supor que queiramos resolver a equação diferencial

$$
\frac{\partial x}{\partial t}+f(x)=0 \quad x(0)=x_{0}
$$

tal que $f(x) \equiv f_{1}(x)+f_{2}(x)$. A solução da equação 3.54 pode ser obtida pela combinação linear das soluções:

$$
\begin{aligned}
& \frac{\partial x_{1}}{\partial t}+f_{1}\left(x_{1}\right)=0, \\
& \frac{\partial x_{2}}{\partial t}+f_{2}\left(x_{2}\right)=0,
\end{aligned}
$$

desde que as duas equações obtidas sejam integráveis. No cenário numérico, usando o método de diferenças finitas, podemos escrever:

$$
\begin{aligned}
& \frac{x^{1}-x^{0}}{\Delta t}=-f_{1}\left(x_{0}\right), \\
& \frac{x^{2}-x^{1}}{\Delta t}=-f_{2}\left(x_{1}\right) .
\end{aligned}
$$




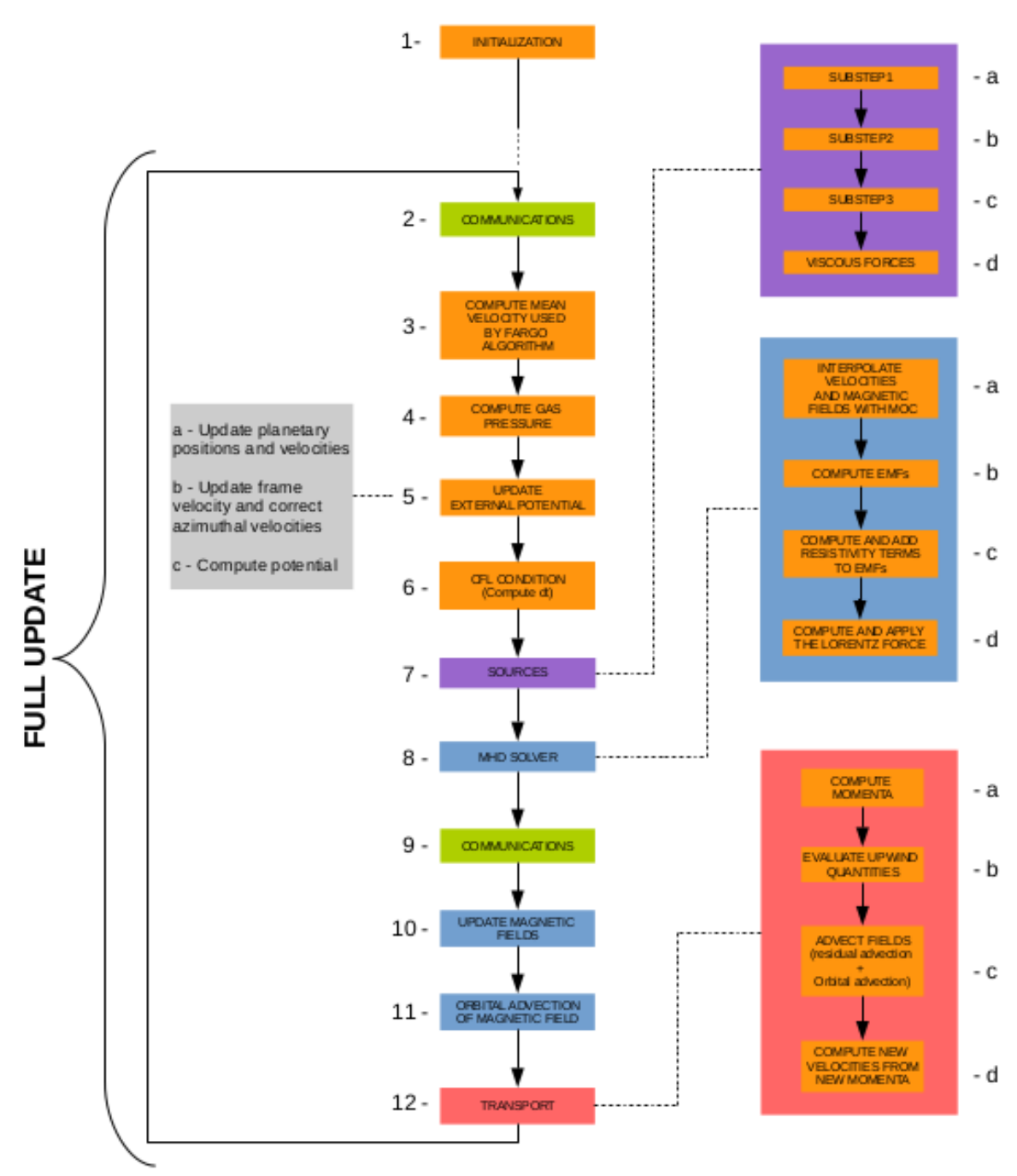

Figura 3.5: Fluxograma das operações realizadas no FARGO3D durante um passo de tempo. Os boxes azuis são específicos para o caso MHD, que não serão abordados nesta tese. Os processos de comunicação MPI e GPU, indicados pelas células 2 e 9, são vistos na seção 3.8 . O cálculo da velocidade média devido ao algoritmo de advecção orbital, indicado na célula 3 , é discutido na seção 3.7.5 A pressão do gás na célula 4 é obtida por meio da equação 3.42 ou 3.47. O cálculo relativo ao potencial externo (célula 5) é discutido na seção 3.7.6. O passo de tempo que envolve a condição CFL será detalhado nas seções 3.7.4 e 3.7.5. Os detalhes referentes aos passos fontes da célula 7 são apresentados na seção 3.7.2 e os de transporte (célula 12) na seção 3.7.3. Os algoritmos específicos da MHD (célula 8, 10 e 11) podem ser encontrados em Benítez-Llambay e Masset (2016). Figura obtida em: Benítez-Llambay e Masset (2016).

Com um pouco de álgebra, podemos colocar todas as equações diferenciais parciais resolvidas no FARGO3D (referentes à parte hidrodinâmica) na forma geral:

$$
\frac{\partial Q}{\partial t}+\nabla \cdot(Q \vec{v})=S(Q, \vec{v}, t)
$$


onde $Q$ é a variável transportada e $S(Q, \vec{v}, t)$, o termo fonte.

A Tabela 3.2 indica as variáveis transportadas em cada sistema de coordenadas para cada direção.

\begin{tabular}{c|ccc} 
Geometria & $X$ & $Y$ & $Z$ \\
\hline Cartesiana & $\rho v_{x}$ & $\rho v_{y}$ & $\rho v_{z}$ \\
Cilíndrica & $\rho\left(r v_{\phi}+r^{2} \Omega_{f}\right)$ & $\rho v_{r}$ & $\rho v_{z}$ \\
Esférica & $\rho\left(r v_{\phi} \sin \theta+r^{2} \sin ^{2} \theta \Omega_{f}\right)$ & $\rho v_{r}$ & $\rho r v_{\theta}$
\end{tabular}

Tabela 3.2 - Valores das variáveis transportadas para cada sistema de coordenadas em cada direção.

A Tabela 3.3 a seguir mostra os termos fontes usados no update da velocidade em cada direção.

\begin{tabular}{c|ccc} 
Geometria & $X$ & $Y$ & $Z$ \\
\hline Cartesiana & $-\frac{1}{\rho} \frac{\partial P}{\partial x}-\frac{\partial \Phi}{\partial x}$ & $-\frac{1}{\rho} \frac{\partial P}{\partial y}-\frac{\partial \Phi}{\partial y}$ & $-\frac{1}{\rho} \frac{\partial P}{\partial z}-\frac{\partial \Phi}{\partial z}$ \\
Cilíndrica & $-\frac{1}{r \rho} \frac{\partial P}{\partial \phi}-\frac{1}{r} \frac{\partial \Phi}{\partial \phi}$ & $-\frac{1}{\rho} \frac{\partial P}{\partial r}-\frac{\partial \Phi}{\partial r}+\frac{\left(v_{\phi}^{t}\right)^{2}}{r}$ & $-\frac{1}{\rho} \frac{\partial P}{\partial z}-\frac{\partial \Phi}{\partial z}$ \\
Esférica & $-\frac{1}{r \rho \sin \theta} \frac{\partial P}{\partial \phi}-\frac{1}{r \sin \theta} \frac{\partial \Phi}{\partial \phi}$ & $-\frac{1}{\rho} \frac{\partial P}{\partial r}-\frac{\partial \Phi}{\partial r}+\frac{\left(v_{\phi}^{t}\right)^{2}+v_{\theta}^{2}}{r}$ & $-\frac{1}{r \rho} \frac{\partial P}{\partial \theta}-\frac{1}{r} \frac{\partial \Phi}{\partial \theta}+\frac{\left(v_{\phi}^{t}\right)^{2} \cot \theta}{r}$
\end{tabular}

Tabela 3.3 - Valores das variáveis fontes usados no update da velocidade em cada direção.

Assim, aplicando o método splitting (ver eq. 3.55 e 3.56 na equação 3.59, podemos escrever:

$$
\begin{gathered}
f_{1}=-S, \\
f_{2}=\nabla \cdot(Q \vec{v}) .
\end{gathered}
$$

As equações correspondentes são, portanto:

$$
\begin{gathered}
\frac{\partial Q}{\partial t}=S(Q, \vec{v}, t), \\
\frac{\partial Q}{\partial t}+\nabla \cdot(Q \vec{v})=0 .
\end{gathered}
$$

A técnica do operador splitting dividiu o problema em duas equações diferenciais parciais, chamadas, respectivamente, de equação fonte e equação de transporte. Portanto, 
o passo de tempo completo é composto da resolução da equação fonte $Q\left(t_{0}\right)=Q^{0} \rightarrow Q^{1}$, dada pela equação 3.62 , seguido pela resolução da equação de transporte $Q^{1} \rightarrow Q^{2}=$ $Q\left(t_{0}+\Delta t\right)$, dada pela equação 3.63 .

\subsubsection{Resolução da equação fonte}

Seguindo o mesmo procedimento de Stone e Norman (1992), a resolução da equação fonte (ver eq. 3.62) ocorre em três subpassos.

No subpasso 1, ocorre o update no campo de velocidade devido ao gradiente de pressão e do potencial gravitacional, esse subpasso corresponde à célula 7a do fluxograma mostrado na Figura 3.5 e pode ser encontrado nos arquivos substep1_x.c, substep_1y.c e substep_1z.c.

O subpasso 2 adiciona a viscosidade artificial de Von Neumann-Richtmyer e as correspondentes fontes de aquecimento. A formulação da viscosidade artificial é baseada na análise de ondas de choques planares em uma dimensão. O método é estendido a outras dimensões através da definição de coeficientes de viscosidade em cada direção de forma independente, esses coeficientes são então usados para computar separadamente uma pressão escalar artificial adicional $(P)$ para um update em cada direção. O triunfo da análise de Von Neumann e Richtmyer (1950) foi a constatação de que uma pressão adicional não linear, sensível somente à compressão, poderia resultar numa correta entropia e velocidade de propagação, enquanto tem um pequeno efeito longe do choque. Assim, Von Neumann e Richtmyer (1950) propuseram:

$$
P=\left\{\begin{array}{l}
l^{2} \rho\left(\frac{\partial v}{\partial x}\right)^{2} \quad \text { se } \quad \frac{\partial v}{\partial x}<0 \\
0 \quad \text { se } \quad \frac{\partial v}{\partial x} \geq 0
\end{array}\right.
$$

onde $l$ é a constante com dimensão de comprimento que determina a força da viscosidade artificial. Para uma implementação multidimensional, a pressão adicional para cada direção é dada por:

$$
P_{x i, j, k}=\left\{\begin{array}{l}
C_{2}^{2} \rho_{\operatorname{gas}_{i, j, k}}\left(v_{x i+1, j, k}-v_{x i, j, k}\right)^{2} \quad \text { se } \quad\left(v_{x i+1, j, k}-v_{x i, j, k}\right)<0 \\
0 \quad \text { se } \quad\left(v_{x i+1, j, k}-v_{x i, j, k}\right)>0
\end{array}\right.
$$




$$
\begin{aligned}
& P_{y_{i, j, k}}=\left\{\begin{array}{l}
C_{2}^{2} \rho_{\operatorname{gas}_{i, j, k}}\left(v_{y_{i, j+1, k}}-v_{y_{i, j, k}}\right)^{2} \quad \text { se } \quad\left(v_{y_{i, j+1, k}}-v_{y_{i, j, k}}\right)<0, \\
0 \quad \text { se } \quad\left(v_{y_{i, j+1, k}}-v_{y_{i, j, k}}\right)>0,
\end{array}\right. \\
& P_{z i, j, k}=\left\{\begin{array}{l}
C_{2}^{2} \rho_{\operatorname{gas}_{i, j, k}}\left(v_{z i, j, k+1}-v_{z i, j, k}\right)^{2} \quad \text { se } \quad\left(v_{z i, j, k+1}-v_{z i, j, k}\right)<0 \\
0 \quad \text { se } \quad\left(v_{z i, j, k+1}-v_{z i, j, k}\right)>0,
\end{array}\right.
\end{aligned}
$$

Note que a grandeza $l$ foi substituida pela grandeza adimensional $C_{2}=l / \Delta x$. Fisicamente, $C_{2}$ mede o número de zonas sobre o qual a viscosidade artificial irá espalhar um choque, em geral, $C_{2} \approx 2$. Dada a pressão adicional, um update para o campo de velocidades é realizado em cada direção e um termo dissipativo é adicionado à equação de energia, estes updates são dados, respectivamente, por:

$$
\begin{aligned}
& \frac{v_{x i, j, k}^{n+b}-v_{x i, j, k}^{n+a}}{\Delta t}=-\frac{P_{x i, j, k}-P_{x i-1, j, k}}{d x\left(\left(\rho_{\operatorname{gas}_{i, j, k}}^{n}+\rho_{\operatorname{gas}_{i-1, j, k}^{n}}^{n}\right) / 2\right)}, \\
& \frac{v_{y_{i, j, k}}^{n+b}-v_{y_{i, j, k}}^{n+a}}{\Delta t}=-\frac{P_{y_{i, j, k}}-P_{y_{i, j-1, k}}}{d y\left(\left(\rho_{\operatorname{gas}_{i, j, k}}^{n}+\rho_{\operatorname{gas}_{i, j-1, k}}^{n}\right) / 2\right)}, \\
& \frac{v_{z i, j, k}^{n+b}-v_{z_{i, j, k}}^{n+a}}{\Delta t}=-\frac{P_{z i, j, k}-P_{z i, j, k-1}}{d z\left(\left(\rho_{\operatorname{gas}_{i, j, k}^{n}}^{n}+\rho_{\operatorname{gas}_{i, j, k-1}}^{n}\right) / 2\right)}, \\
& \frac{e_{i, j, k}^{n+b}-e_{i, j, k}^{n}}{\Delta t}=-P_{x i, j, k}\left(\frac{v_{x i+1, j, k}-v_{x i, j, k}}{d x}\right)-P_{y_{i, j, k}}\left(\frac{v_{y_{i, j+1, k}}-v_{y_{i, j, k}}}{d y}\right)-P_{z i, j, k}\left(\frac{v_{z i, j, k+1}-v_{z i, j, k}}{d z}\right),
\end{aligned}
$$

onde $d x, d y, d z$ são as distâncias entre as faces das células e dependem do sistema de coordenadas utilizado.

Esse subpasso correspondente à célula $7 \mathrm{~b}$ do fluxograma, mostrado na Figura 3.5, e pode ser encontrado nos arquivos substep2_a.c e substep_2b.c.

De acordo com Stone e Norman (1992), essa extensão multidimensional é ad hoc. Um tratamento rigoroso envolveria definir um tensor viscoso artificial isotrópico e, então, usar as componentes deste tensor nos termos pseudoviscosos nas equações de evolução.

No subpasso 3, adiciona-se o trabalho realizado pelas forças de pressão, isto só ocorre se a equação de energia for resolvida. 
No caso da equação de um gás ideal, um update implícito envolvendo a pressão $P_{\text {gas }}^{n+1 / 2}$ pode ser usado para melhorar a conservação de energia. Assim:

$$
\frac{e^{n+1}-e^{n}}{\Delta t}=-P_{\text {gas }}^{n+1 / 2} \nabla \cdot \vec{v},
$$

onde $P_{\text {gas }}^{n+1 / 2}=\left(P_{\text {gas }}^{n}+P_{\text {gas }}^{n+1}\right) / 2$. Usando a equação de estado, $P_{\text {gas }}=(\gamma-1) e$, podemos rearranjar a equação de energia para obter uma expressão explícita para $e^{n+1}$, dada por:

$$
e_{i, j, k}^{n+1}=\left[\frac{1-(\Delta t / 2)(\gamma-1)(\nabla \cdot \vec{v})_{i, j, k}}{1+(\Delta t / 2)(\gamma-1)(\nabla \cdot \vec{v})_{i, j, k}}\right] e_{i, j, k}^{n} .
$$

Este subpasso corresponde à célula 7c da Figura 3.5e se encontra no arquivo substep3.

\subsubsection{Resolução da equação de transporte}

Conforme vimos na subseção 3.7.1, a equação de transporte consiste na equação 3.63 , que funciona como uma lei de conservação para a quantidade $Q$, correspondente às quantidades mostradas na Tabela 3.2 .

A forma integral da equação 3.63 é dada por:

$$
\frac{\partial}{\partial t} \iiint Q d V+\iiint \nabla \cdot(Q \vec{v}) d V=0
$$

Usando o teorema do divergente, podemos escrever:

$$
\iiint \nabla \cdot(Q \vec{v}) d V=\iint_{\partial V} Q \vec{v} \cdot \vec{n} d S
$$

Portanto, a equação de transporte fica na forma:

$$
\frac{\partial}{\partial t} \iiint Q d V+\iint_{\partial V} Q \vec{v} \cdot \vec{n} d S=0
$$

Com a equação acima, vemos que a variação temporal de $Q$ dentro do volume de controle ocorre, exclusivamente, devido ao fluxo nas faces do volume de controle. No caso de $Q$ ser uma variável escalar, isto é, definida no centro da célula, a representação por diferenças finitas da equaçao 3.76 fica na forma:

$\frac{Q_{i, j, k}^{n+1}-Q_{i, j, k}^{n}}{\Delta t} V=-\left[F_{x_{i+\frac{1}{2}, j, k}}-F_{x_{i-\frac{1}{2}, j, k}}+F_{y_{i, j+\frac{1}{2}, k}}-F_{y_{i, j-\frac{1}{2}, k}}+F_{z i, j, k+\frac{1}{2}}-F_{z i, j, k-\frac{1}{2}}\right]^{n+1 / 2}$, 
onde $V$ é o volume de controle e $F$ é o fluxo de $Q$ através das faces da célula. O FARGO3D divide a resolução da equação 3.77 usando passos intermediários $n \rightarrow n+a, n+a \rightarrow n+b$ e $n+b \rightarrow n+1$. Esse procedimento resulta em três equações unidimensionais, descritas por:

$$
\begin{aligned}
& {\left[Q_{i, j, k}^{n+a}-Q_{i, j, k}^{n}\right] V=-\Delta t\left[F_{x_{i+\frac{1}{2}, j, k}}-F_{X_{i-\frac{1}{2}, j, k}}\right]^{n+\frac{1}{2}}} \\
& {\left[Q_{i, j, k}^{n+b}-Q_{i, j, k}^{n+a}\right] V=-\Delta t\left[F_{y_{i, j+\frac{1}{2}, k}}-F_{y_{i, j-\frac{1}{2}, k}}\right]^{n+\frac{1}{2}}} \\
& {\left[Q_{i, j, k}^{n+1}-Q_{i, j, k}^{n+b}\right] V=-\Delta t\left[F_{z i, j, k+\frac{1}{2}}-F_{z i, j, k-\frac{1}{2}}\right]^{n+\frac{1}{2}} .}
\end{aligned}
$$

As operações acima correspondem à célula 12c da Figura 3.5 e são aplicadas a todos os termos da Tabela 3.2 .

O cálculo do fluxo é realizado através do método upwind inferindo um valor para a quantidade $Q^{*}$ no centro da face em meio passo de tempo. Assim, na direção $x$, por exemplo, temos:

$$
F_{x_{i+1 / 2, j, k}}^{n+1 / 2}=v_{x i+1 / 2, j, k}\left[Q_{i+1 / 2, j, k}^{* x}\right]^{n+1 / 2} S_{i+1 / 2, j, k},
$$

onde o subscrito $x$ indica a direção normal à face, ao longo da qual o fluxo é calculado, e $Q_{i+1 / 2, j, k}^{* x}$ é o valor da quantidade centrada $Q$ interpolada na face $i+1 / 2$ de área $S_{i+1 / 2, j, k}$, na metade do passo de tempo. Raciocínio análogo é usado para as outras direções e faces.

Seguindo o mesmo procedimento de Stone e Norman (1992), o FARGO3D interpola o valor de $Q$ utilizando uma função linear $\bigsqcup^{1}$ para calcular os valores dentro da célula com coeficientes lineares obtidos do modelo de Van Leer van Leer, 1977) $)^{2}$. Assim, o valor interpolado é obtido usando:

$$
Q_{i+1 / 2}^{*}=\left\{\begin{array}{lll}
Q_{i}+a_{i}\left(\Delta X_{i}-v_{x i+1 / 2, j, k} \Delta t\right) / 2 & \text { se } & v_{x i+1 / 2, j, k} \geq 0, \\
Q_{i+1}-a_{i+1}\left(\Delta X_{i}+v_{x i+1 / 2, j, k} \Delta t\right) / 2 & \text { se } & v_{x i+1 / 2, j, k}<0,
\end{array}\right.
$$

\footnotetext{
${ }^{1}$ Uma exceção ocorre no cálculo da velocidade residual do algoritmo de advecção orbital que utiliza uma função parabólica de forma similar ao código PLUTO.

${ }^{2}$ Uma explicação bastante didática da interpolação dos valores dentro da célula usando diferentes métodos pode ser encontrada em <http://www2.mpia-hd.mpg.de/ dullemon/lectures/fluiddynamics08/chap_4_advection_II.pdf $>$.
} 
onde $\Delta X_{i}$ é a distância entre as faces na mesma direção e $a_{i}$ é dado por:

$$
a_{i}=\left\{\begin{array}{lll}
0 & \text { se } & \Delta Q_{i+1 / 2} \Delta Q_{i-1 / 2}<0, \\
2 \frac{\Delta Q_{i+1 / 2} \Delta Q_{i-1 / 2}}{\Delta Q_{i+1 / 2}+\Delta Q_{i-1 / 2}} & \text { se } & \Delta Q_{i+1 / 2} \Delta Q_{i-1 / 2} \geq 0
\end{array}\right.
$$

onde $\Delta Q_{i+1 / 2}=\left(Q_{i+1}-Q_{i}\right) / \Delta X_{i}$. Esse cálculo é realizado em meio espaço de tempo e corresponde à célula $12 \mathrm{~b}$ da Figura 3.5. Os arquivos que contêm a programação referente a esses passos são vanleer_x_a.c, vanleer_x_b.c, vanleer_y_a.c, vanleer_y_b.c, vanleer_z_a.c e vanleer_z_b.c.

É importante destacar que as quantidades momento envolvem o produto de grandezas definidas em diferentes posições da malha. Nesse caso, o FARGO3D trabalha com a definição de momento esquerdo e direito, definidos por:

$$
\begin{aligned}
& \Pi_{i}^{-}=\rho_{i} v_{i-1 / 2, j, k}, \\
& \Pi_{i}^{+}=\rho_{i} v_{i+1 / 2, j, k},
\end{aligned}
$$

que são transportados como quantidades centradas. As grandezas acima envolvem o produto de uma quantidade centrada com uma quantidade definida na face. Elas são calculadas antes de serem transportadas, portanto, no passo 12a da Figura 3.5 nos arquivos momenta_x.c,momenta_y.c e momenta_z.c. Após a conclusão dos subpassos de transporte, a nova velocidade é inferida dos novos momentos e da nova densidade usando:

$$
v_{i-1 / 2, j, k}^{n+1}=\frac{\Pi_{i-1}^{+}(n+1)}{{ }^{(n+1}+\Pi_{i}^{-(n+1)}} .
$$

Essa operação é realizada na célula $12 \mathrm{~d}$ da Figura 3.5 nos arquivos newvel_x · c, newvel_y ·c e newvel_z.c. A relação acima é usada no caso cartesiano, para as outras geometrias é necessário escrever os momentos com base na Tabela 3.2. Esse procedimento assegura a conservação do momento direito e esquerdo de acordo com acurácia da máquina e, portanto, a média aritmética dos dois.

Além disso, outro detalhe importante é o upgrade da velocidade angular devido ao referencial, passo 5b da Figura 3.5, que não é realizado entre o começo e o fim dos passos responsáveis pela resolução da equação de transporte. Assim, deve-se ficar atento à 
correção das velocidades. Em coordenadas esféricas, por exemplo, essa correção é feita usando:

$$
v_{\phi_{i, j, k}}^{c}=v_{\phi_{i, j, k}}^{b}-\left(\Omega_{f}^{\prime}-\Omega_{f}\right) r \sin \theta
$$

onde $\Omega_{f}$ é a rotação antiga do referencial, $\Omega_{f}^{\prime}$ a nova rotação e o sobescrito $b$ e $c$ denotam respectivamente o valor da velocidade azimutal no começo da célula 5b e 5c da Figura 3.5 , que são também os valores no começo e no fim da rotina de correção da velocidade. Este subpasso também conserva o momento angular conforme a acurácia da máquina.

\subsubsection{Estabilidade e a condição $C F L$}

O passo de tempo $\Delta t$ para resolução das equações deve ser limitado de modo a assegurar a estabilidade do método explícito, esse procedimento é conhecido como condição de Courant-Friedrichs-Levy ou condição CFL. Embora em alguns casos seja possível determinar com exatidão um critério de estabilidade com a análise de Von Neumann, em geral, como ocorre no FARGO3D, é necessário um método heurístico para determinar o maior passo de tempo permitido. A ideia do método consiste no fato de que a informação não pode percorrer mais de uma célula durante um passo de tempo. O FARGO3D utiliza o mesmo critério usado por Stone e Norman (1992), no qual o maior passo de tempo é determinado por:

$$
\Delta t=C \min \left[\left(\sum_{i} \Delta t_{i}^{-2}\right)^{-1 / 2}\right],
$$

onde $C<1$ é um parâmetro real chamado número de Courant. No FARGO3D, é utilizado o valor $C=0.44$ obtido por meio de testes de estabilidade e velocidade em algumas simulações modelos. O cálculo de $\Delta t$ é obtido com base nos dados de toda a malha, com exceção das células fantasmas, e corresponde ao procedimento da célula 6 da Figura 3.5 . que pode ser encontrado no arquivo cfl.c. Durante o teste da condição, são obtidos alguns valores de $\Delta t_{i}$ com base em diferentes processos:

1. velocidade da onda sonora ou magnetosônica: $\Delta t_{1}=\Delta_{j} / c_{\mathrm{w}}$, onde $c_{\mathrm{w}}$ é a velocidade máxima das ondas que se propagam no meio e $\Delta_{j}$ o tamanho da célula na direção $j=$ $(x, y, z)$. No caso MHD, temos $c_{\mathrm{w}}=c_{\mathrm{s}}+v_{\mathrm{A}}$ para a velocidade da onda magnetosônica, 
onde $c_{\mathrm{s}}$ é a velocidade do som e $v_{\mathrm{A}}=\left(B^{2} /\left(\mu_{0} \rho_{\text {gas }}\right)\right)^{0.5}$ é a velocidade de Alfvén. No caso puramente hidrodinâmico, $c_{\mathrm{w}}$ é a própria velocidade do som;

2. movimento do fluido: $\Delta t_{2}=\Delta_{j} /\left|v_{\mathrm{j}}\right|$, onde $v_{\mathrm{j}}$ é a velocidade do fluido na direção $j$;

3. viscosidade artificial: $\Delta t_{3}=C_{2}\left|\Delta_{j} / \Delta v_{\mathrm{j}}\right|$, onde $C_{2}=4 \sqrt{2}$ é uma constante arbitrária e $\Delta v_{\mathrm{j}}$ a diferença entre valores sucessivos de $v_{j}$ na direção $j$;

4. viscosidade: $\Delta t_{4}=\Delta_{j}^{2} /\left(4 \nu_{\text {gas }}\right)$ onde $\nu_{\text {gas }}$ é a viscosidade cinemática do gás;

5. resistividade: $\Delta t_{5}=\Delta_{j}^{2} /(4 \eta)$ onde $\eta$ é a resistividade.

Obtidos os valores de tempos $\Delta t_{i}$, a equação 3.88 fornece o passo de tempo usado durante a simulação até o processo de update depois do qual se calcula novamente o próximo passo de tempo.

\subsubsection{Advecção orbital}

A resolução da equação de transporte, apresentada na seção 3.7.3. possui, como característica, alguns problemas:

1. Grandes velocidades azimutais que limitam severamente o passo de tempo (seção 3.7 .4 .

2. Erros de truncamento que dependem do sistema de referência (Robertson et al. 2010).

Para evitar esses problemas, o FARGO3D utiliza o mesmo método do seu antecessor (Masset, 2000), exceto pelo uso de outro limitador de fluxo, o método Piecewise Parabolic Advection, para realizar o deslocamento fracional. A ideia do método consiste em decompor, para cada anel da célula em um dado raio e colatitude, a velocidade azimutal em uma velocidade maior uniforme e em uma velocidade menor residual, que equivale a trabalhar em um referencial aproximadamente corrotante em cada anel. Assim:

$$
v=v^{0}+\partial v
$$

onde $v \equiv v_{\phi}$ em coordenadas esféricas e cilíndricas e $v \equiv v_{x}$ em cartesianas. 
Para entender esse processo, vamos considerar, por exemplo, a equação de transporte a seguir:

$$
\frac{\partial J}{\partial t}+\frac{1}{r} \frac{\partial\left(v_{\theta} J\right)}{\partial \theta}+\frac{1}{r} \frac{\partial\left(r v_{r} J\right)}{\partial r}=\text { termos fontes }
$$

onde $J=\rho r v_{\theta}$. Podemos escrever, sem perda de generalidade, a equação anterior na forma:

$$
\frac{\partial J}{\partial t}+\frac{1}{r} \frac{\partial\left[\left(v_{\theta}-u\right) J\right]}{\partial \theta}+\frac{u}{r} \frac{\partial J}{\partial \theta}+\frac{1}{r} \frac{\partial\left(r v_{r} J\right)}{\partial r}=\text { termos fontes }
$$

onde $u$ pode ser qualquer quantidade que não dependa de $\theta$. Portanto, ao usar a técnica do operador splitting na equação acima, vamos obter:

- uma equação fonte;

- uma equação de transporte;

- uma equação de transporte azimutal com $v_{\theta}-u$, chamada de velocidade residual;

- uma equação adicional descrita por $\frac{\partial J}{\partial t}+\frac{u}{r} \frac{\partial J}{\partial \theta}=0$.

Assim, dada a relação 3.89, a equação de transporte na direção azimutal fica na forma:

$$
\partial_{t} Q+\partial_{x}(v Q)=0
$$

onde $\partial_{x} \equiv(1 / r) \partial_{\phi}$ em coordenadas cilíndricas e $\partial_{x} \equiv(1 / r \sin \theta) \partial_{\phi}$ em coordenadas esféricas. A equação anterior pode ser resolvida em dois passos usando a técnica do operador splitting, logo:

$$
\begin{gathered}
\partial_{t} Q+\partial_{x}(\partial v Q)=0 \\
\partial_{t} Q+v^{0} \partial_{x}(\partial Q)=0 .
\end{gathered}
$$

No FARGO3D, a velocidade $v^{0}$ é obtida de forma que a velocidade residual tenha o menor vetor norma 11 possível (arquivo compute_vmed.c), usando a relação:

\footnotetext{
${ }^{1}$ Dado um vetor $\vec{x}=\left(x_{1}, x_{2}, \ldots, x_{n}\right)$, o vetor norma $|\vec{x}|_{\infty}$ é definido por $|\vec{x}|_{\infty}=\max _{i}\left|x_{i}\right|$. Até o término dessa tese o FARGO3D foi aperfeiçoado, a versão atual utilza somente a velocidade kepleriana e não mais o vetor norma.
} 


$$
v_{j k}^{0}=\frac{1}{2}\left[\max \left(v_{i j k}\right)+\min \left(v_{i j k}\right)\right],
$$

para $j$ e $k$ fixos.

A equação 3.94 é resolvida usando o método discutido na seção 3.7 .3 . Já a equação 3.94 equivale a um deslocamento do perfil inicial:

$$
Q(x, t+\Delta t)=Q\left(x-v^{0} \Delta t, t\right)
$$

Como este deslocamento não necessariamente representa um número inteiro de células, nós usamos o método splitting mais uma vez em dois subpassos. Assim, decompomos $v^{0}$ como:

$$
v^{0} \equiv v_{\text {shift }}+v_{\text {shift }}^{R}
$$

onde

$$
v_{\text {shift }}=N \frac{\Delta X}{\Delta t}
$$

com $N=E\left(v^{0} \frac{\Delta t}{\Delta X}\right), E(X)$ sendo o inteiro mais próximo de $X$. Então, usando novamente o operador splitting na equação 3.94, temos:

$$
\begin{aligned}
& \partial_{t} Q+v_{\text {shift }} \partial_{x} Q=0, \\
& \partial_{t} Q+v_{\text {shift }}^{R} \partial_{x} Q=0 .
\end{aligned}
$$

De forma didática, podemos considerar que o material em dado raio sofreu um deslocamento de 4.7 células. Assim, o que as equações acima fazem é decompor esse deslocamento num inteiro mais próximo e um resto, no caso, 5 - 0.3. No primeiro subpasso, o material é deslocado levando em conta o resto, realizado pelo método de transporte clássico. O segundo subpasso corresponde a um número inteiro de células, copiando o conteúdo da célula $j$ para $j+5$. O deslocamento interior é obtido no arquivo advect_shift.c e a velocidade residual em compute_residual.c. Os diferentes subpassos estão no arquivo transport.c.

Assim, a solução da equação 3.99 é dada por: 


$$
\begin{array}{r}
Q_{i}^{n+1}=Q\left(x_{i}, t+\Delta t\right)=Q\left(x-v_{\text {shift }} \Delta t, t\right) \\
=Q\left(x_{i}-N \Delta X, t\right)=Q_{i-N}^{n},
\end{array}
$$

que é simplesmente uma permutação circular dos valores da zona dentro do anel em consideração.

Já a equação 3.100 pode ser reformulada como:

$$
\partial_{t} Q+\partial_{x}\left(v_{\text {shift }}^{R} Q\right)=0
$$

e, portanto, pode ser tratada usando a mesmo mecanismo da seção 3.7.3. A única diferença, ocorre para a interpolação onde se usa um método de ordem maior (Piecewise Parabolic Advection). Assim, os valores na interface são dados por:

$$
Q_{i+1 / 2}^{* x}=\left\{\begin{array}{l}
Q_{R, i}+\xi\left(Q_{i}-Q_{R, i}\right)+\xi(1-\xi)\left(2 Q_{i}-Q_{R, i}-Q_{L, i}\right) \quad \text { se } \quad v_{x i+1 / 2} \geq 0 \\
Q_{L, i}+\xi\left(Q_{i+1}-Q_{L, i+1}\right)+\xi(1-\xi)\left(2 Q_{i+1}-Q_{R, i+1}-Q_{L, i+1}\right) \quad \text { se } \quad v_{x i+1 / 2}<0
\end{array}\right.
$$

onde $\xi=v_{i+1 / 2} \Delta t / \Delta x$ e $Q_{L / R}$ são os valores de $Q$ nas interfaces direita/esquerda monotonizadas conforme definido abaixo. Dado $\partial Q_{i}=\left(Q_{i+1}-Q_{i-1}\right) / 2$, nós definimos, primeiramente, os coeficientes (slopes) centrados monotonizados em cada célula como:

$$
\partial_{m} Q_{i}=\left\{\begin{array}{l}
0 \quad \text { se } \quad\left(Q_{i+1}-Q_{i}\right)\left(Q_{i}-Q_{i-1}\right) \leq 0 \\
\min \left(2\left|Q_{i}-Q_{i-1}\right|, 2\left|Q_{i+1}-Q_{i}\right|,\left|\partial Q_{i}\right|\right) \times \operatorname{sgn}\left(\partial Q_{i}\right), \text { caso contrário } .
\end{array}\right.
$$

Este procedimento corresponde ao mesmo usado por Colella e Woodward (1984) com células de tamanho uniforme. Em um segundo estágio, interporlações parabólicas são usadas para reconstruir a quantidade nas interfaces da forma:

$$
Q_{i+1}^{L}=Q_{i}^{R}+\frac{1}{2}\left(Q_{i+1}-Q_{i}\right)-\frac{1}{6}\left(\partial_{m} Q_{i+1}-\partial_{m} Q_{i}\right)
$$

Além disso, testes finais são usados para remover os extremos locais potencialmente criados pelo procedimento acima, da seguinte forma: 


$$
\left\{\begin{array}{lcc}
Q_{i}^{L}=Q_{i}^{R}=Q_{i} \quad \text { se } \quad & \left(Q_{i+1}-Q_{i}\right)\left(Q_{i}-Q_{i-1}\right) \leq 0, \\
Q_{i}^{L}=3 Q_{i}-2 Q_{i}^{R} \quad \text { se } & \Delta_{i} C_{i}>\Delta_{i}^{2} / 6, \\
Q_{i}^{R}=3 Q_{i}-2 Q_{i}^{L} & \text { se } & -\Delta_{i}^{2} / 6>\Delta_{i} C_{i},
\end{array}\right.
$$

onde $\Delta_{i}=Q_{i}^{R}-Q_{i}^{L}$ e $C_{i}=Q_{i}-\left(Q_{i}^{L}+Q_{i}^{R}\right) / 2$. O uso deste método requer uma camada extra de células fantasmas além da estabelecida pela interpolação de Van Leer. O método aqui descrito foi empregado no FARGO3D exclusivamente para o transporte do resíduo uniforme fracionário da advecção orbital, da mesma forma que Mignone et al. (2012). Todo esse processo de interpolação pode ser visualizado nos arquivos fargo_ppa_a.c, fargo_ppa_b.c, fargo_ppa_c.c e fargo_ppa_d.c.

É interessante destacar que o usuário pode escolher usar a opção da advecção orbital ou não através da variável de macrocomando DSTANDARD no arquivo setup.opt.

A permutação circular devido a equação 3.101 não introduz erros numéricos, e $v_{\text {shift }}$ não tem que ser incluído na análise da estabilidade: ele não contribui com a condição de Courant. Assim, a condição de Courant é determinada da mesma forma que descrevemos na seção 3.7.4, substituindo-se $v$ por $\partial v$. Mais detalhes sobre a condição CFL podem ser obtidos em Benítez-Llambay e Masset (2016).

\subsubsection{Integrador orbital para os planetas}

O FARGO3D, assim como seu antecessor, possibilita colocar alguns pontos massivos ao redor da estrela central. O método numérico usado para tratar a evolução do sistema planetário é o método de Cash-Karp (Cash e Karp, 1990), que consiste num método de Runge-Kutta de passo fixo, no caso, governado pela condição CFL.

É importante ressaltar que, como o passo é independente da interação entre os corpos, esse método não assegura uma boa solução no caso de corpos muito próximos. Para levar em conta essa situação, seria necessário acrescentar um sub-passo desacoplado da condição CFL, como realizado por Morbidelli e Nesvorny (2012), que implementaram o integrador SYMBA (Duncan et al., 1998) para detectar encontros próximos e colisões.

O algoritmo que rege a evolução do sistema planetário no FARGO3D consiste em resolver equações diferenciais da forma: 


$$
\frac{d \vec{y}}{d t}=f(t, \vec{y})
$$

onde $\vec{y}$ é um vetor das $6 N$ componentes que envolvem a posição e a velocidade dos $N$ planetas. O método de Cash-Karp consiste em estimar $\vec{y}$ a partir de um Runge-Kutta de quarta ordem, logo:

$$
\vec{y}_{i+1}=\vec{y}_{i}+\left(\frac{37}{378} \overrightarrow{k_{1}}+\frac{250}{621} \overrightarrow{k_{3}}+\frac{125}{594} \overrightarrow{k_{5}}+\frac{512}{1771} \overrightarrow{k_{6}}\right) h
$$

onde

$$
\begin{gathered}
\vec{k}_{1}=f\left(t_{i}, \vec{y}_{i}\right) \\
\vec{k}_{2}=f\left(t_{i}+\frac{1}{5} h, \vec{y}_{i}+\frac{1}{5} \overrightarrow{k_{1}} h\right), \\
\vec{k}_{3}=f\left(t_{i}+\frac{3}{10} h, \overrightarrow{y_{i}}+\frac{3}{40} \overrightarrow{k_{1}} h+\frac{9}{40} \overrightarrow{k_{2}} h\right), \\
\vec{k}_{4}=f\left(t_{i}+\frac{3}{5} h, \overrightarrow{y_{i}}+\frac{3}{10} \overrightarrow{k_{1}} h-\frac{9}{10} \overrightarrow{k_{2}} h+\frac{6}{5} \overrightarrow{k_{3}} h\right), \\
\vec{k}_{5}=f\left(t_{i}+h, \overrightarrow{y_{i}}-\frac{11}{54} \overrightarrow{k_{1}} h+\frac{5}{2} \overrightarrow{k_{2}} h-\frac{70}{27} \overrightarrow{k_{3}} h+\frac{35}{27} \overrightarrow{k_{4}} h\right), \\
\left.\frac{7}{8} h, \vec{y}_{i}+\frac{1631}{55296} \overrightarrow{k_{1} h}+\frac{175}{512} \overrightarrow{k_{2}} h+\frac{575}{13824} \overrightarrow{k_{3}} h+\frac{44275}{110592} \overrightarrow{k_{4}} h+\frac{253}{4096} \overrightarrow{k_{5}} h\right) .
\end{gathered}
$$

A força exercida pelo gás no planeta é calculada a cada passo hidrodinâmico e usada para calcular a nova velocidade do planeta. Essa força pode ser calculada pela soma direta exercida por cada célula ou pela remoção de todo o gás, antes da soma, correspondente à parte aximétrica do disco, já que não há torque em um planeta coplanar em um disco de gás aximétrico. A primeira opção é o padrão do FARGO3D. A segunda opção é ativada por meio do macrocomando BM08 no arquivo setup.opt. Maiores detalhes podem ser encontrados no manual do FARGO3D. 


\subsection{Processo de paralelização no FARGO3D}

O FARGO3D é um código escrito em C e paralelizado usando MPI (Message Passing Interface), em que se decompõem as direções $Y$ e $Z$, já a direção $X$ é resolvida em um único processador. Isso inclui também as células fantasmas (ver seção 3.3). O número de células fantasmas depende do problema físico em estudo e da frequência de comunicação, isto é, o número de passos dentro de um intervalo de tempo. Quanto maior a frequência, maior o número de células fantasmas necessárias. Essa relação deve ser tal que o resultado da simulação não dependa do número de processadores. No FARGO3D, a comunicação é realizada duas vezes por passo (células 2 e 9 da Figura 3.5) e possui três camadas de células fantasmas em cada direção, que são definidas pela variável de pré-processamento NHGY e NHGZ, que se encontram no arquivo define.h. É importante ressaltar que o número de células fantasmas pode ser alterado caso um nova condição física programada apresente essa exigência.

Além disso, o FARGO3D possui uma característica muito peculiar que é o uso da programação CUDA (Compute Unified Device Architecture) para uso da GPU (Graphics Processing Unit). De fato, o código possui algumas rotinas que transformam automaticamente a programação para uso da CPU para a de uso na GPU, sem que o usuário tenha necessidade de conhecer a programação CUDA. É usual a denominação kernel para denominar as funções na programação CUDA, estas funções começam com o especificador _global_ e sempre deve retornar void. Outra denominação bastante usual na programação CUDA é a palavra device para a GPU e a palavra host para a CPU, assim, quando usamos o termo memória do host, estamos nos referindo à memória RAM do CPU, enquanto memória do device trata da memória RAM de vídeo.

Para que as funções, em geral dentro do loop hidrodinâmico, possam ser transformadas de funções (em C) para kernels (funções CUDA), o usuário precisa seguir um determinado script, essas funções são conhecidas como funções mesh. Uma função mesh usa certos parâmetros e os processa na malha usando loops aninhados.

A função mesh retorna sempre um void e possui os seguintes componentes que são implementados em blocos específicos:

- Header.

- Nome e tipo da função. 
- Argumentos.

- Variáveis globais.

- Variável locais.

- Loop sobre a malha.

Há um conjunto de regras (script) para que as rotinas já programadas no FARGO3D possam transformar cada parte dos componentes acima em um kernel. Isso evita que o usuário tenha que se preocupar com o gerenciamento de memória e a logística de transferência de dados entre a CPU e a GPU. Além disso, há dois comandos no FARGO3D, o INPUT e o OUTPUT, que automaticamente realizam a transferência de dados entre a GPU e CPU. O comando INPUT é usado para disparar a transferência de dados enquanto o comando OUTPUT disponibiliza o campo para armazenagem. Vamos considerar como exemplo a seguinte situação: suponha que seja de interesse computar a pressão isotérmica do gás na $\operatorname{GPU}\left(P_{\text {gas }}=c_{\mathrm{s}}^{2} \rho_{\text {gas }}\right)$, mas nós temos as condições iniciais na CPU. Nós precisamos enviar para a GPU os campos de velocidade do som e de densidade do gás, mas sem enviar todos os outros campos, já que isso seria muito custoso computacionalmente. Assim, usamos o comando INPUT para que o programa automaticamente verifique se as variáveis velocidade do som e densidade do gás estão aptas para serem enviadas a GPU e o comando OUTPUT para verificar o lugar apropriado para armazenagem do campo de pressão.

Para explicar como o script funciona, vamos transformar a situação descrita acima, que calcula a pressão isotérmica do gás, numa função apta a ser traduzida automaticamente para um kernel. Primeiramente, considere o programa a seguir:

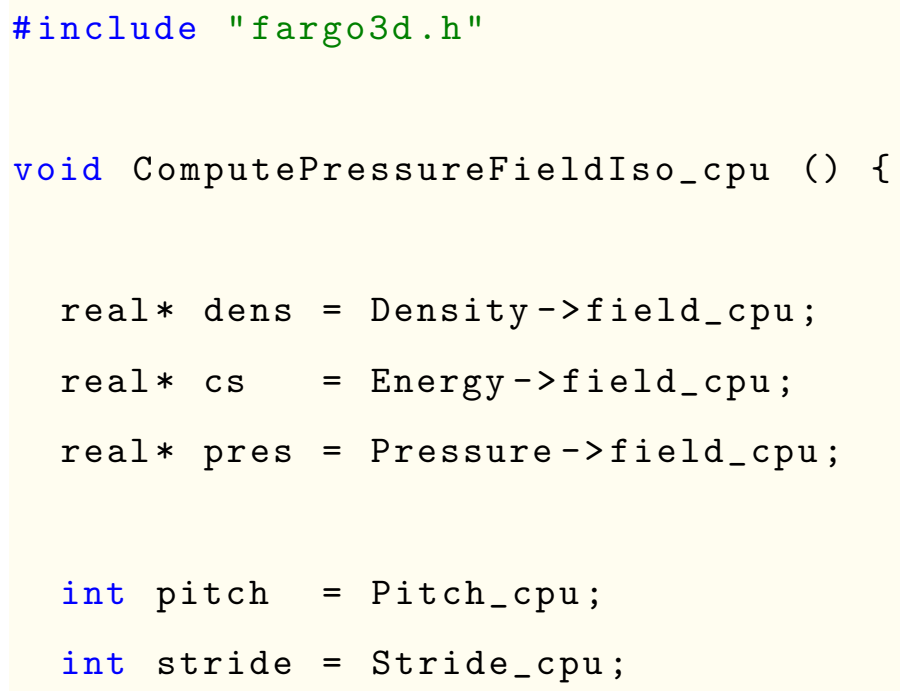


A função acima pode ser executada na CPU, para que essa função seja transformada num kernel pelas rotinas do FARGO3D, precisamos separar o código em blocos usando identificadores $(/ /<$ IDENTIFICADOR $>$ e $/ /<\backslash$ IDENTIFICADOR $>)$ para cada bloco específico da função.

No programa abaixo, escrevemos a função anterior na formatação correta, isto é, seguindo o script, para que possa ser interpretada pelos conversores. Os comentários com // são obrigatórios, os comentários com * devem ser ignorados e são usados apenas para explicar o conteúdo de cada bloco.

\section{$/ /\langle$ FLAGS $>$}

* Nesse bloco são definidas as variáveis de pré-processamento.

Elas devem ser definidas com duas barras. As variáveis _GPU e _NOPROTO são obrigatórias. A variável _GPU pode ser usada dentro da função mesh para alguma tarefa específica que deva rodar apenas em GPU, para isso basta utilizar o comando \# ifdef _GPU ... \# \#ndif* 


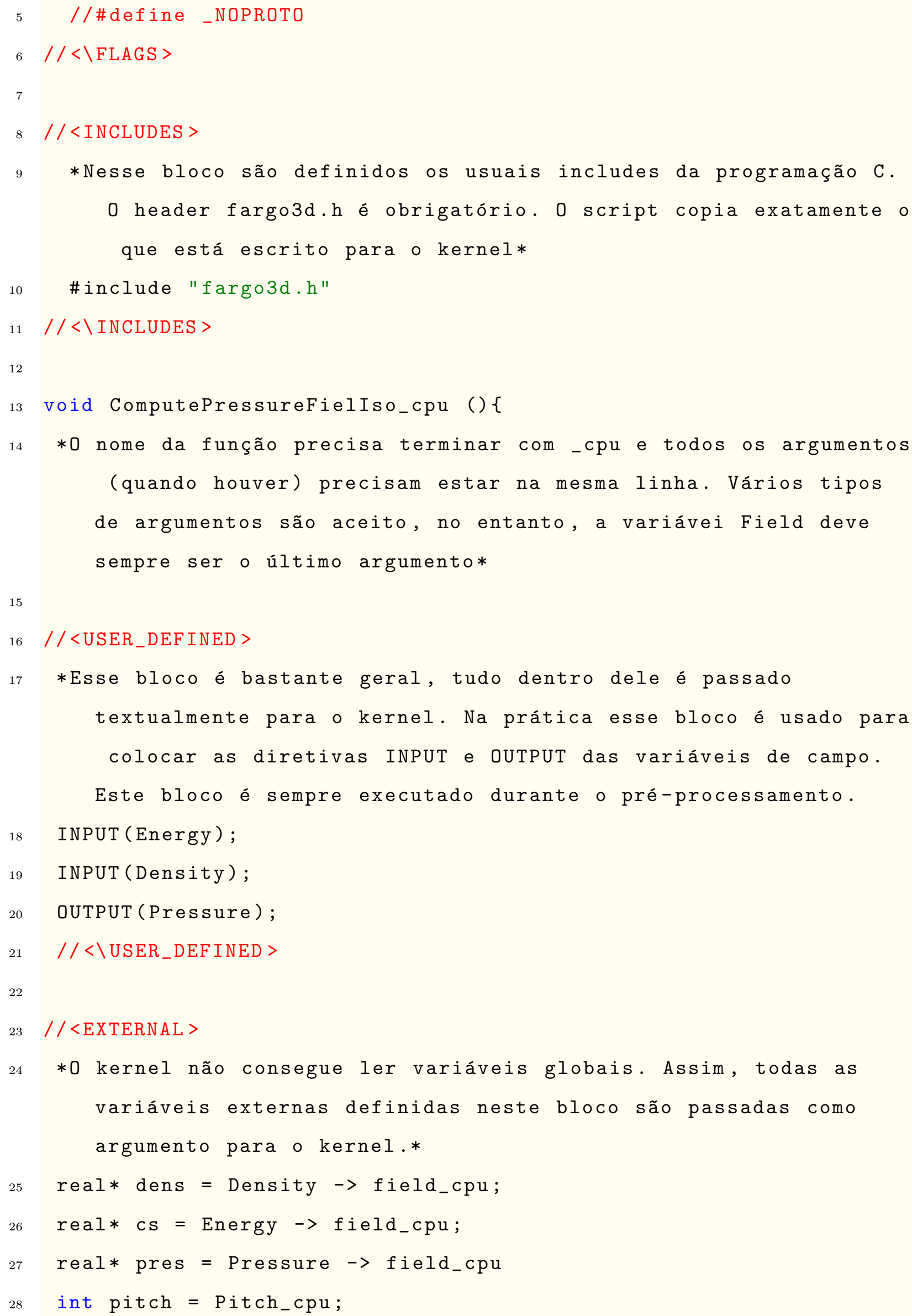




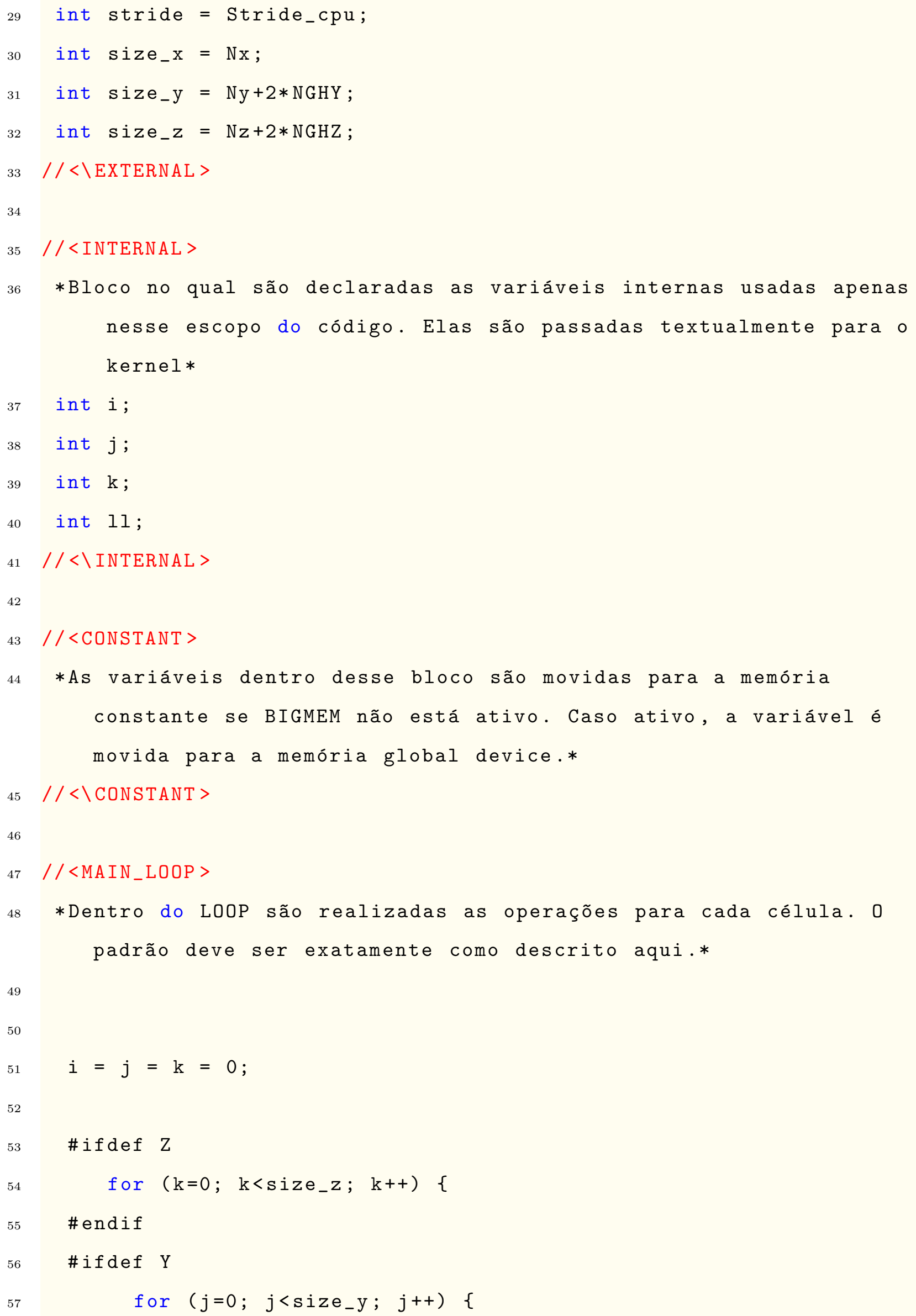




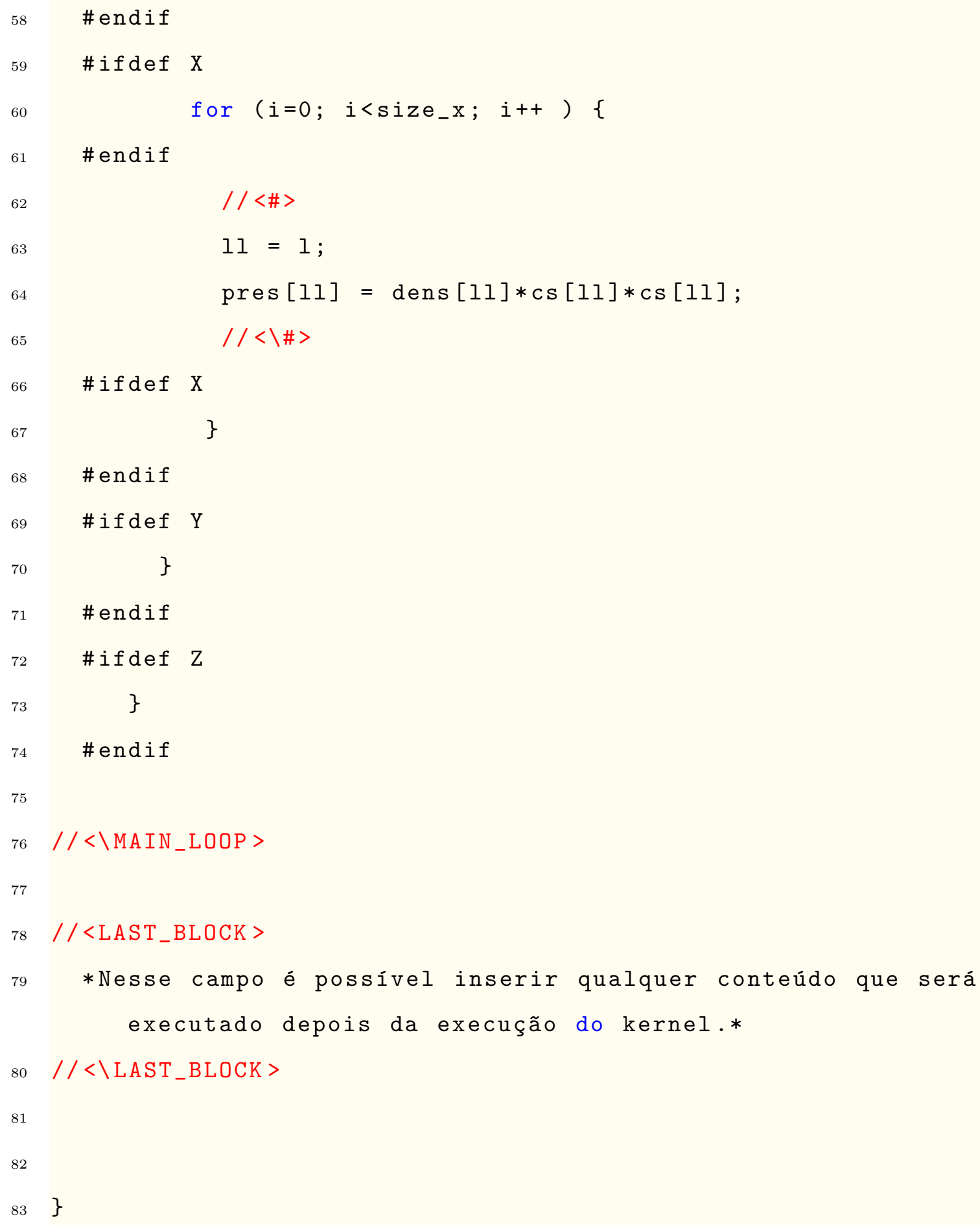

As novas funções acrescentadas nesta tese para lidar com a formação planetária no FARGO3D serão escritas com base no script acima. No entanto, após escrita, a função deve ser acrescentada no FARGO3D. Para isso, deve-se seguir o seguinte procedimento:

1. Criar o arquivo setups . objects no diretório do seu setup e incluir nesse arquivo o nome do arquivo da função;

2. Copiar os arquivos std/fun_arch.cfg e src/change_arch.cfg para seu setup; 
3. Adicionar a função no arquivo src/prototypes.h;

4. Adicionar o ponteiro da nova função no arquivo src/global.h;

5. Modificar o arquivo change_arch. cfg do seu diretório seguindo o mesmo padrão das outras funções já programadas;

6. Adicionar a função no arquivo fun_arch.cfg e colocar o caminho desse arquivo no arquivo de parâmetros setup.par;

7. Validar seu novo kernel usando FARGO_DEBUG.

A lista acima é apenas um resumo dos procedimentos, os detalhes podem ser consultados no manual do FARGO3D no capítulo Developing a complex setup, que pode ser encontrado em <http://fargo.in2p3.fr/Documentation $>1$.

\subsection{Arquivos de saída do FARGO3D}

O FARGO3D produz diferentes tipos de arquivos em sua saída. Todos os arquivos desta tese foram lidos usando o programa ipython notebook, a partir do qual todos os gráficos foram gerados. No entanto, o usuário pode optar por qualquer outra forma de leitura desses dados.

Além disso, é importante destacar que no arquivo setup. par o usuário define o intervalo de tempo no qual o programa gerará os arquivos de saída. As variáveis são DT e Ninterm, a maioria dos arquivos são gerados após DT * Ninterm enquanto outros possuem uma saída mais fina, gerada a cada DT. Nesta tese, usamos DT $=1 / 20 P_{\text {jup }}$ e Ninterm de acordo com a conveniência de cada simulação.

A seguir iremos descrever cada tipo de arquivo separadamente.

\subsubsection{Arquivos com as variáveis de campo}

Esses arquivos possuem a extensão .dat, portanto, são arquivos binários não formatados. A estrutura de cada arquivo é uma sequência de dados doubles (8 bytes) ou floats (4 bytes) (caso a a opçao FLOAT esteja ativada no arquivo .opt). Assim, o número de bytes guardados em cada arquivo será:

\footnotetext{
${ }^{1}$ Acesso em: 9 fev. 2017.
} 
- $8 \times \mathrm{NX} \times \mathrm{NY} \times \mathrm{NZ}$

- 4 x NX x NY x NZ, se a opção FLOAT está ativada

onde NX, NY e NZ são o número de células em cada direção (ver seção 3.2).

Para uma correta leitura desses arquivos, deve-se tomar cuidado com a ordem dos dados. A Figura 3.6 a seguir ilustra como eles são guardados em cada arquivo no caso 2D (o caso 3D segue o mesmo raciocínio).

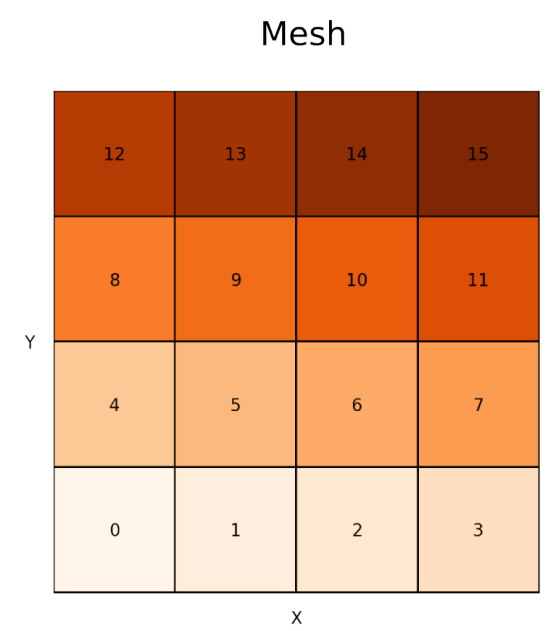

Binary file

\begin{tabular}{|l|l|l|l|l|l|l|l|l|l|l|l|l|l|l|l|}
\hline 0 & 1 & 2 & 3 & 4 & 5 & 6 & 7 & 8 & 9 & 10 & 11 & 12 & 13 & 14 & 15 \\
\hline
\end{tabular}

Figura 3.6: Formato do cubo de dados no FARGO3D. O cubo de dados é guardado da esquerda para a direita e de cima para baixo, conforme ilustrado na figura.

Note, portanto, que essse arquivo não contém qualquer informação sobre as coordenadas, sendo somente um array de dados, sem qualquer informação adicional. No caso da implementação MPI, a situação é mais complexa, porque cada processador escreve um pedaço da malha. Se quisermos juntar os arquivos manualmente precisaremos da informação dos arquivos das malhas (ver seção 3.9.2). Na prática, usamos a flat -m durante a execução do programa para que isso ocorra de forma automática. Caso o cluster não possua um repositório global, o usuário terá que fazer isso manualmente 2 .

Esses arquivos também podem ser escritos no formato VTK.

\footnotetext{
${ }^{2}$ Para os clusters utilizados no IAG-USP, somente a máquina UV30 possui repositório global, portanto, para uso no ALPHACRUCIS, deve-se utilizar apenas 1 nodo (24 processadores) ou juntar os arquivos de saída na formatação correta após a simulação.
} 


\subsubsection{Arquivos com o domínio computacional}

Estes arquivos são criados durante a primeira rodada e guardam os valores da coordenadas da primeira face de cada célula ([xyz]min). Eles são impressos com as células fantasmas. O formato é ASCII (American Standard Code for Information Interchange) e o número total de linhas é:

- domain_x.dat: NX linhas

- domain_y.dat: NY + 2NGHY linhas

- domain_z.dat: NZ + 2NGHZ linhas

onde NGHY = NGHZ = 3 por padrão (ver seção 3.2). Caso se queira usar um espaçamento logarítmico, basta mudar o parâmetro Spacing para log no arquivo setup.par.

É possível incluir no diretório de saída arquivos com o nome domain_[xyz].dat com coordenadas específicas, que permitem que se manipule manualmente o tamanho de zonas não constantes.

\subsubsection{Arquivo com as variáveis}

Após rodar a simulação, dois arquivos chamados variables . par e IDL . var são criados. Esses arquivos são arquivos ASCII e contêm a mesma informação em dois diferentes formatos: o nome e os valores de todos os parâmetros usados. O arquivo IDL.var é formatado para simplificar o processo de leitura em um script IDL/GDL.

\subsubsection{Arquivos com o domínio das submalhas}

Um arquivo de malha é criado por processador. Dentro de cada arquivo, há informação guardada sobre cada submalha relativa a cada processador. O formato padrão é em 7 colunas, com os dados:

- CPU_Rank: índice do CPU (Central Processing Unit).

- Yo: Índice inicial Y da submalha.

- YN: Índice final Y da submalha.

- Z0: Índice inicial Z da submalha. 
- ZN: Índice final Z da submalha.

- IndexY: Índice Y do processador em uma malha 2D de processadores.

- IndexZ: Índice Z do processador em uma malha 2D de processadores.

\subsubsection{Arquivos com os dados planetários}

Estes arquivos são gerados quando um setup inclui um ou mais planetas. Há três arquivos por planeta, são eles: planet [i] .dat, bigplanet [i] .dat e orbit [i] .dat, onde i é o número do planeta especificado pelo parâmetro PLANETCONFIG. Este número começa com 0. Os últimos dois arquivos correspondem a uma impressão mais fina, isto é, realizada a cada DT. Em contraste, planet [i] .dat é impresso a cada vez que as variáveis de campo são plotadas. O arquivo, portanto, é um subconjunto de bigplanet [i] .dat.

A cada update, uma nova linha é adicionada a cada um desses arquivos. Nos arquivos planet [i] .dat e biplanet [i] .dat, uma linha contém as seguintes colunas:

1. Um inteiro que corresponde ao número da saída.

2. A coordenada $x$ do planeta.

3. A coordenada $y$ do planeta.

4. A coordenada $z$ do planeta.

5. A coordenada $x$ da velocidade do planeta.

6. A coordenada y da velocidade do planeta.

7. A coordenada $z$ da velocidade do planeta.

8. A massa do planeta.

9. A data.

10. A rotação instantânea do referencial.

No arquivo orbit [i] .dat, uma linha contém as seguintes colunas:

1. A data $t$. 
2. A excentricidade $e$.

3. O semi-eixo maior $a$.

4. A anomalia média $M$ (em radianos).

5. A anomalia verdadeira $V$ (em radianos).

6. O argumento do periastro $\psi$ (em radianos, medido a partir do nodo ascendente).

7. O ângulo $\varphi$ entre a posição atual e inicial do eixo $x$ (em radianos).

8. A inclinação da órbita $i$ (em radianos).

9. A longitude $\omega$ do nodo ascendente (com relação ao eixo $x$ atual).

10. A posição angular $\alpha$ do periélio (o ângulo da projeção do periélio na direção do plano $x-y$, com relação ao eixo $x$ atual).

Em nossas simulações, acrescentamos alguns dados extras no arquivo planet [i] .dat correspondente ao modelo de formação planetária, esses novos dados correspondem às novas variáveis presentes na struct alterada, que está no apêndice A.4.3.

\subsubsection{Arquivos de monitoração}

A monitoração de uma quantidade pode ser feita de maneiras diferentes.

Para as grandezas escalares, uma soma (ou média) da quantidade é realizada ao longo do domínio computacional. O arquivo de saída é único, duas colunas, no qual a coluna da esquerda é o tempo, e a da direita a soma ou a média da quantidade. A nova linha é impressa a cada DT.

As grandezas vetoriais podem ser monitoradas em 1D ou 2D. No caso 1D, a soma ou média é realizada sobre duas dimensões, assim obtemos um perfil radial ou vertical em cada saída através de mapas. O arquivo impresso pode estar no formato .raw, no qual uma fila de bytes é adicionada a cada DT, ou num formato .dat em duas colunas, nas quais a primeira representa o valor de $y$ ou $z$, e a segunda coluna o valor da soma ou média.

No caso 2D, a soma ou média é realizada exclusivamente em $x$, de modo que o mapa 2D em y e $z$ é produzido. Neste caso, uma linha no arquivo de formato raw é impressa a cada DT. 
Para entender mais pormenores e saber quais quantidades podem ser monitoradas e como o programa realiza essa tarefa, recomendamos a leitura do manual do FARGO3D no capítulo OUTPUTS.

\subsection{Simulação padrão utilizada}

\subsubsection{Parâmetros e módulos de entrada}

A simulação padrão utilizada nesta tese utiliza um disco de gás bidimensional fino, isto é, $h=H / r<<1$. A razão de aspecto do disco será de $h=0.05$ com um fator de curvatura de $\lambda=0.0$. Esses valores são consistentes com a teoria de discos finos (ver seção 2.1.2) e são usados nas maioria das simulações que envolvem discos de acreção (Bell et al., 1997; Frank et al. 2002).

Além disso, o disco é assumido localmente isotérmico mediante a inserção, no arquivo setup.opt, do módulo ISOTHERMAL. As implicações do uso desse módulo nas equações resolvidas pelo FARGO3D podem ser vistas na seção 3.1.4. Obviamente, um disco realista não poderia ser considerado verticalmente isotérmico e a resolução da equação de energia poderia gerar novos resultados. No entanto, o foco desta tese é a inserção de um modelo de formação planetária dentro do código, portanto, a escolha de um disco mais simples é mais recomendável para um estudo inicial do modelo.

A viscosidade do disco é dirigida pela prescrição $\alpha$ de Shakura e Sunyaev (1973), por meio da inserção do módulo ALPHAVISCOSITY. As condições teóricas impostas por essa condição podem ser vistas na seção 2.1.1

A estrela, de $1 \mathrm{M}_{\odot}$, está no centro de um sistema de coordenadas cilíndrica, obtido com a inserção do módulo CYLINDRICAL, e cobre a distância radial de 1.56 até 15.6 ua, que corresponde a 0.3 até 3.0 unidades de comprimento do código. A unidade de comprimento padrão do código é $R_{0}=5.2$ ua. Em nossa simulação padrão, a resolução utilizada será de 388 células radiais e 904 células azimutais (388 x 904). Essa resolução foi escolhida para que as células possuam espaçamentos iguais nas direções radial e azimutal. Em algumas outras simulações iremos especificar outros valores para resolução. Maiores detalhes sobre a estrutura da malha no FARGO3D e seus sistemas de coordenadas podem vistos na seção 3.2 .

O arquivo setup.opt com todos os módulos usados nesta tese pode ser encontrado no 
apêndice A.1.

Os dados dos planetas inseridos nas simulações, arquivo planet.cfg, serão modificados de acordo com a conveniência. Todavia, estes dados sempre serão especificados para cada simulação. Para o potencial gravitacional, nós usaremos $\varepsilon=0.6 H$ (Müller et al., 2012) na variável ThicknessSmoothing no arquivo setup.par. O torque gerado dentro da região próxima do raio de Hill do planeta foi reduzido utilizando o módulo HILLCUT. No entanto, nós fizemos uma modificação no arquivo computeforce.c trocando a função padrão pela função:

$$
f_{\text {taper }}=\frac{1}{1+\exp \left(-\frac{r_{\text {cell }}-f_{\mathrm{t}}}{0.1 f_{\mathrm{t}}}\right)},
$$

onde $r_{\text {cell }}$ é a distância da célula ao planeta e $f_{\mathrm{t}}=0.8 R_{\mathrm{H}}$. Essa função foi escolhida de modo que pudéssemos comparar nossos resultados com Dürmann e Kley (2017) e também com base no estudo de Crida et al. (2009). Conforme indicam Crida et al. $(2009)$, há uma diferença no tempo de migração planetária de acordo com o tamanho da região desconsiderada para o torque. Seguindo Dürmann e Kley (2017) nós fizemos a opção por $f_{\mathrm{t}}=0.8 R_{\mathrm{H}}$, porque estávamos interessados na forma com que o fluxo de gás dentro do gap afeta a migração planetária de tipo II, portanto, utilizamos uma região maior para desconsiderar efeitos gravitacionais do gás preso em torno do ponto massivo. Mais detalhes serão discutidos no capítulo 5 .

Uma breve descrição sobre os parâmetros de entrada do arquivo setup.par pode ser encontrada na seção 3.6 e um exemplo desse arquivo com os dados dessa simulação padrão no apêndice A.7.

Em geral, o perfil de densidade supercial do gás em um disco protoplanetário não é uma função contínua simples, indo de $\Sigma_{\text {gas }} \propto r^{-1 / 2}$ até $\Sigma_{\text {gas }} \propto r^{-1}$ na parte interna do disco, e $\Sigma_{\text {gas }} \propto r^{-3 / 2}$, na parte mais externa (Wetherill, 1996). No entanto, para melhor compararmos os resultados, iremos utilizar apenas o perfil de $\Sigma_{\text {gas }} \propto r^{-1 / 2}$, que é obtido quando consideramos um disco de gás com taxa de acreção local constante, conforme demonstraremos abaixo. Para isso, considere uma taxa de acreção dada por:

$$
\dot{M}=-2 \pi r \Sigma_{\text {gas }} v_{\text {r,gas }}
$$

Essa taxa depende, portanto, da densidade superficial, $\Sigma_{\text {gas }}$, e da velocidade radial, 
$v_{\text {r,gas }}$, do gás. Considerando a situação em equilíbrio, na qual a taxa de acreção viscosa $\dot{M}$ é constante (ver seção 2.1.5), a velocidade de acreção viscosa do gás é dada por:

$$
v_{\mathrm{r}, \mathrm{gas}}=-\frac{3}{2} \frac{\nu_{\mathrm{gas}}}{r}
$$

onde $\nu_{\text {gas }}$ é a viscosidade cinemática do gás e $r$ a distância radial da estrela central. Considerando um disco isotérmico e usando a prescrição $\alpha$ de Shakura e Sunyaev (1973), podemos escrever $\nu_{\text {gas }}=\alpha c_{\mathrm{s}} H$, onde $H=h r$ é a escala de altura do disco $(h=0.05)$. Como a velocidade do som, no caso isotérmico, é $c_{\mathrm{s}}=H \Omega_{\mathrm{K}}$, a velocidade viscosa do gás pode ser escrita como:

$$
v_{\mathrm{r}, \mathrm{gas}}=-\frac{3}{2} \frac{\alpha c_{\mathrm{s}} H}{r}=-\frac{3}{2} \alpha h^{2} r \Omega_{\mathrm{K}}
$$

onde $\Omega_{\mathrm{K}}=\sqrt{G M_{\star} / r^{3}}$ é a velocidade angular kepleriana do gás. Portanto, dada uma taxa de acreção com $\dot{M}$ e $\alpha$ constante e, substituindo a equação 3.118 na equação 3.116 , obtemos o perfil da densidade superficial do gás na forma:

$$
\Sigma_{\text {gas }}=\frac{1}{3 \pi} \frac{\dot{M}}{\alpha h^{2} r^{2} \Omega_{\mathrm{K}}}=\frac{\dot{M}}{3 \pi \alpha h^{2} \sqrt{G M_{\star}}} r^{-1 / 2}=\Sigma_{0} r^{-1 / 2} .
$$

O parâmetro de Shakura-Sunyaev da simulação padrão será $\alpha=3.0 \times 10^{-3}$, uma boa estimativa baseada em dados observacionais, que sugerem que esse valor deve se manter em uma escala de $10^{-4}$ e $10^{-2}$ (Hartmann et al., 1998; Mukhopadhyay, 2008).

Para o disco padrão $\left(\alpha=0.003\right.$ e $\dot{M}=10^{-7} \mathrm{M}_{\odot} /$ ano $)$, obtemos $\Sigma_{0}=874 \mathrm{~g} / \mathrm{cm}^{2}$ esse é um valor maior que o obtido a partir do modelo da Nebulosa Solar Mínima (Hayashi, 1981) para o valor da densidade superficial em 5.2 ua $\left(\Sigma_{0}=143 \mathrm{~g} / \mathrm{cm}^{2}\right)$. Isto é, o disco da simulação padrão é bem mais massivo do que o obtido para o modelo da Nebulosa Solar Mínima.

A Tabela 3.4 resume alguns parâmetros da simulação padrão.

Além da simulação padrão aqui descrita, também usaremos outros valores para $\alpha$ e $\dot{M}$. A Tabela 3.5 a seguir mostra os valores de $\Sigma_{0}$ obtidos em cada caso e que devem ser ajustados no arquivo setup.par de acordo com a simulação realizada.

Esses dados produzem um disco de gás cuja massa total da região perpassa uma grande faixa de valores, entre $10^{-2} \mathrm{M}_{\odot}$ e $10^{-4} \mathrm{M}_{\odot}$, que são condizentes com os valores observacionais (Hartmann et al., 1998; Andrews e Williams, 2005). 


\begin{tabular}{c|cc} 
Nome da variável & Representação & Valor \\
\hline Sigma0 & $\Sigma_{0}$ & $878 \mathrm{~g} / \mathrm{cm}^{2}$ \\
SigmaSlope & $\varphi$ & 0.5 \\
Alpha & $\alpha$ & $3.0 \times 10^{-3}$ \\
AspectRatio & $h$ & 0.05 \\
FlaringIndex & $\lambda$ & 0.0 \\
ThicknessSmoothing & $\varepsilon$ & 0.6 \\
Rmin & $R_{\min }$ & $1.56 \mathrm{UA}$ \\
Rmax & $R_{\max }$ & $15.6 \mathrm{UA}$
\end{tabular}

Tabela 3.4 - Valor dos parâmetros usados na simulação padrão.

\begin{tabular}{c|c|c|c|}
$\dot{M} \backslash \alpha$ & 0.001 & 0.003 & 0.015 \\
\hline $10^{-7} \mathrm{M}_{\odot} /$ ano & $2626.3 \mathrm{gcm}^{-2}$ & $874.3 \mathrm{gcm}^{-2}$ & $262.6 \mathrm{gcm}^{-2}$ \\
$10^{-8} \mathrm{M}_{\odot} /$ ano & $262.6 \mathrm{gcm}^{-2}$ & $87.4 \mathrm{gcm}^{-2}$ & $26.3 \mathrm{gcm}^{-2}$ \\
$10^{-9} \mathrm{M}_{\odot} /$ ano & $26.3 \mathrm{gcm}^{-2}$ & $8.7 \mathrm{gcm}^{-2}$ & $2.6 \mathrm{gcm}^{-2}$
\end{tabular}

Tabela 3.5 - Valores da densidade superficial inicial $\Sigma_{0}$ para cada conjunto de parâmetros $(\dot{M}, \alpha)$.

\subsubsection{Condições iniciais}

O valor obtido para a densidade superficial inicial do gás Sigma0, denotado por $\Sigma_{0}$, é combinado com o valor de SigmaSlope, denotado por $\varphi$, para definir o perfil da densidade superficial inicial do gás implementado no arquivo condinit.c e reproduzido no apêndice A.2, logo:

$$
\Sigma_{\text {gas }}=\Sigma_{0} \cdot\left(\frac{r}{5.2 \mathrm{UA}}\right)^{-\varphi}
$$

Neste arquivo, também especificamos o perfil inicial para a velocidade radial, dado pela equação 3.118, e o perfil inicial para a velocidade azimutal (ver seção 2.1.3), dada por:

$$
v_{\theta, \text { gas }}=\Omega_{\mathrm{K}} r\left[1-h^{2}(1+\varphi)\right]^{1 / 2} .
$$

Vimos na seção 3.1 .4 que, para o caso isotérmico, o algoritmo não resolve a equação de energia, e a equação de estado para o gás dependerá do perfil inicial para a velocidade do som, dado por:

$$
c_{\mathrm{s}}=h \Omega_{\mathrm{K}} r
$$


essa função também foi incorporada no arquivo condinit.c.

Nesta tese, iremos trabalhar apenas com o caso isotérmico, já que nosso foco é a implementação de um modelo para formação planetária. No entanto, vale destacar que efeitos importantes relacionados à transferência de energia podem ocasionar mudanças nas taxas de migração planetária conforme indicam Benítez-Llambay et al. (2015).

\subsubsection{Condições de borda}

As condições de borda foram implementadas de modo que, na borda externa, o gás entra no domínio computacional com velocidade $v_{\mathrm{r}, \mathrm{g}}$ e densidade superficial $\Sigma_{\text {gas }}$, dadas, respectivamente, pelas equações 3.118 e 3.119 , esses valores precisam ser ajustados de acordo com os valores de $\alpha$ e $\dot{M}$.

$\mathrm{Na}$ borda interna, somente a velocidade radial é fixa de acordo com a equação 3.118 , O material pode, portanto, deixar a malha com a mesma densidade superficial local obtida em Rmin.

A velocidade tangencial é fixa em ambas as bordas de acordo com a equação 3.121 .

Para previnir os efeitos de flutuações geradas pela reflexão das ondas nas bordas, usamos, no arquivo setup.opt, o módulo STOCKHOLM, que já está implementando no FARGO3D. No entanto, fizemos uma modificação, usamos o amortecimento na velocidade radial e azimutal e excluímos do código o amortecimento na densidade superficial do gás. Isso foi realizado para permitir um fluxo de massa na borda interna mais condizente com o esperado. No entanto, esse efeito de borda não ocasionará diferenças significativas nos resultados numéricos obtidos nesta tese, podendo o leitor que desejar reproduzir os dados manter o módulo conforme implementado originalmente.

Uma descrição de como as condições de borda são implementadas no FARGO3D pode ser encontrada na seção 3.3 e os arquivos para as condições de borda da simulação padrão são reproduzidos no apêndice A.3.

\subsubsection{Análise das simulações}

Antes de introduzir os planetas, realizamos as simulações apenas com a evolução do disco de gás. É importante destacar que, caso o leitor deseje reproduzir os resultados aqui obtidos, além das condições acima (parâmetros, módulos, condições iniciais e de borda), 
deve utilizar o referêncial fixo, impondo F na variável Frame do arquivo setup.opt. Como se trata de simulações simples, a resolução utilizada foi mais baixa (251 x 583).

Nosso primeiro teste foi verificar se o disco de equilíbrio foi atingido numericamente, isto é, dados os parâmetros e as condições iniciais, devemos, após determinado tempo de estabilização, obter uma taxa de acreção local constante ao longo de todo o disco. Para isso, construímos um programa que guarda os valores do fluxo na direção radial para cada célula e o colocamos logo depois do cálculo numérico responsável pelas equações de transporte da direção radial. As regras para incorporação dessa função no FARGO3D podem ser encontradas no final da seção 3.8 e sua transcrição se encontra no apêndice A.9. Em seguida, usando uma função em python, os valores encontrados para cada célula foram somados ao longo da direção azimutal, obtendo-se então o fluxo radial para cada raio. A Figura 3.7 a seguir mostra os resultados obtidos para um disco com $\alpha=0.003$ após $100 P_{\text {orbital }}$. Lembrando que no FARGO3D o valor de $P_{\text {orbital }}$ é uma unidade adimensional (ver seção 3.5), em MKS, equivale ao período órbital de Júpiter.

Os resultados mostram um excelente acordo com o resultado teórico esperado, uma taxa de acreção constante (reta horizontal). De fato, só seria possível visualizar a diferença da reta em uma escala muito menor para o eixo $y$, da ordem de centesímos. A estabilização do disco ocorre de forma razoavelmente rápida, mesmo após $50 P_{\text {orbital }}$, já temos um disco bem próximo da situação estacionária com uma diferença do resultado teórico da ordem de décimos. Os gráficos obtidos para $\alpha=0.001$ e $\alpha=0.015$ geraram resultados similares aos da Figura 3.7, portanto, não foram reproduzidos aqui.

Dado que a solução teórica foi obtida numericamente com excelente precisão, o próximo passo foi analisar os valores de saída obtidos (ver seção 3.9). A Figura 3.8 a seguir mostra os valores da densidade superficial, da densidade volumétrica, da temperatura, da velocidade tangencial e radial ao longo do raio para um disco de gás cuja taxa de acreção é de $10^{-7} \mathrm{M}_{\odot} /$ ano.

Vale destacar que a densidade volumétrica não é um valor de saída (disco bidimensional). No entanto, essa variável será utilizada no modelo de formação planetária, portanto, vamos utilizar uma estimativa baseada na integração da equação 2.8 obtida para um disco isotérmico Armitage, 2010), da qual obtemos:

$$
\rho_{\text {gas }}=\frac{1}{\sqrt{2 \pi}} \frac{\sum_{\text {gas }}}{h r} .
$$



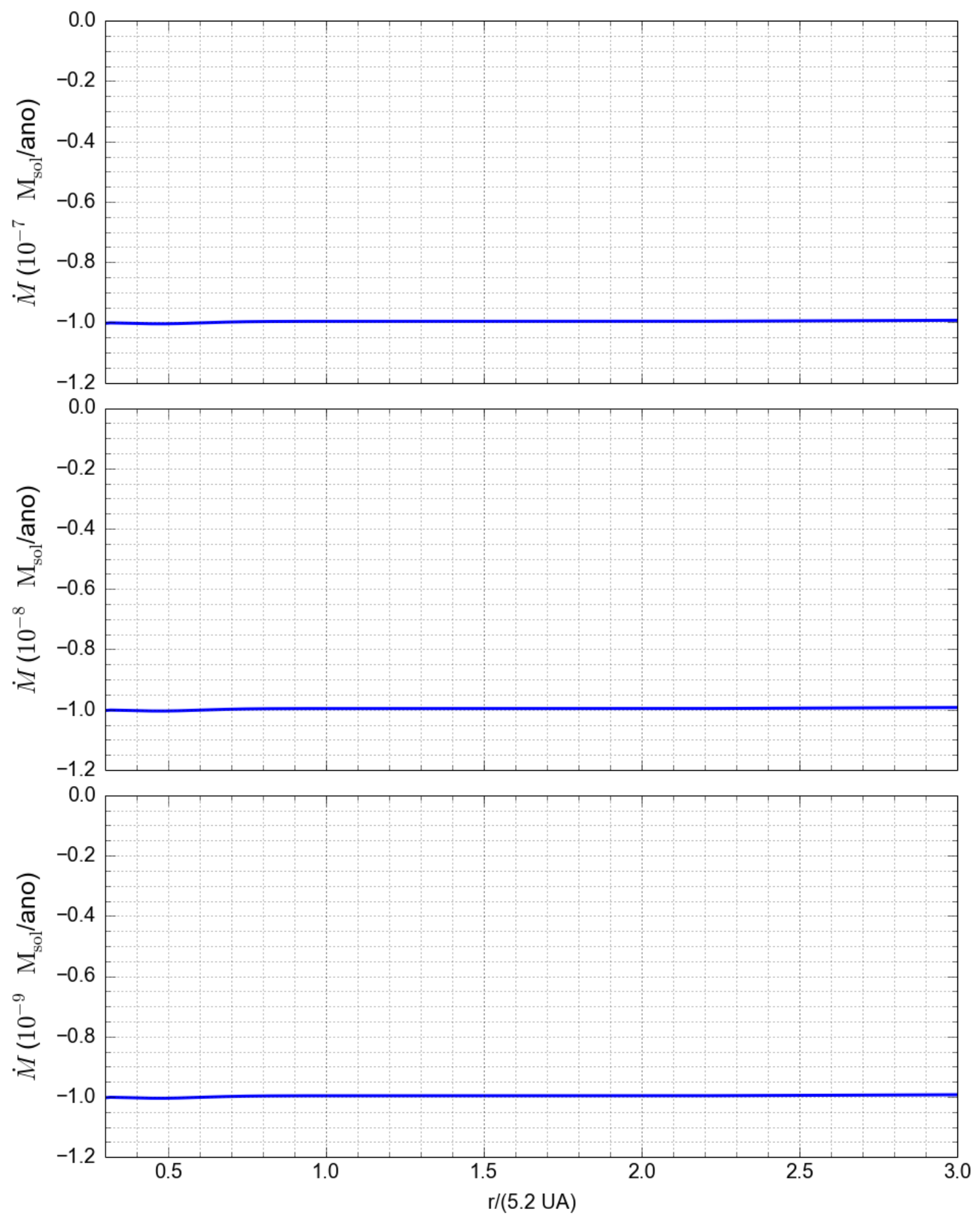

Figura 3.7: Medida do fluxo radial local ao longo do raio do disco após $100 P_{\text {orbital }}$ para um disco de gás sem planetas. Disco com $\alpha=0.003$. O arquivo de parâmetros e de borda são ajustados de acordo com a taxa de acreção do disco. 

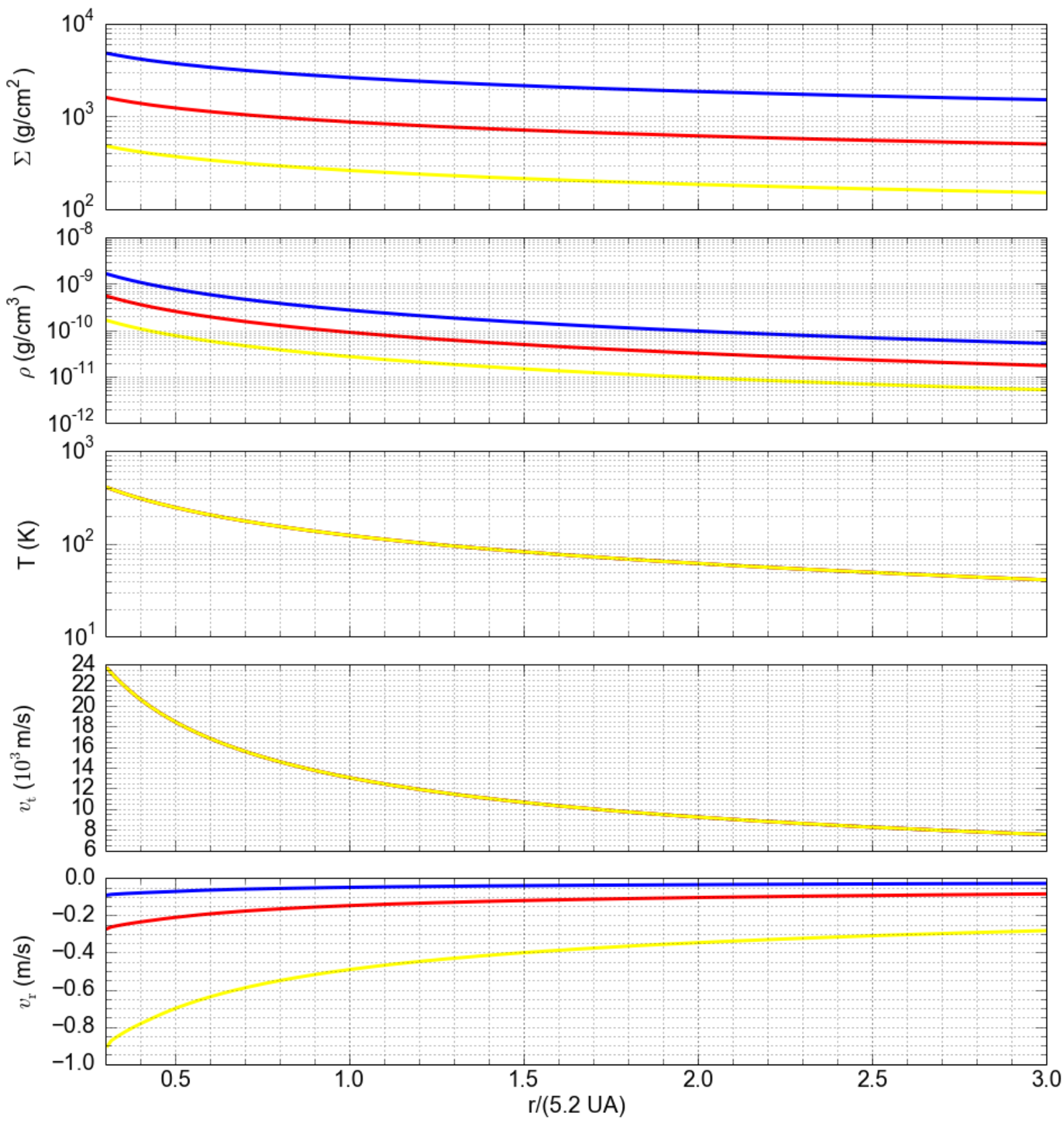

Figura 3.8: Gráficos dos principais parâmetros obtidos para o disco de acreção em equilíbrio para uma taxa de acreção de $10^{-7} \mathrm{M}_{\odot} /$ ano após $100 P_{\text {orbital. }}$. De cima para baixo: densidade superficial, densidade volumétrica, temperatura, velocidade tangencial e velocidade radial ao longo do raio. As cores são usadas para designar as diferentes viscosidades: azul para $\alpha=0.001$, vermelho para $\alpha=0.003$ e amarelo para $\alpha=0.010$.

Essa estimativa gera um valor de densidade volumétrica cerca de 10 vezes menor do que os obtidos usando outras simulações para discos protoplanetários (Papaloizou e Terquem, 1999a). Essa diferença não afeta o tempo de formação planetária, conforme veremos no capítulo 4. Vale ressaltar que essa estimativa não é necessária no caso de uma simulação 

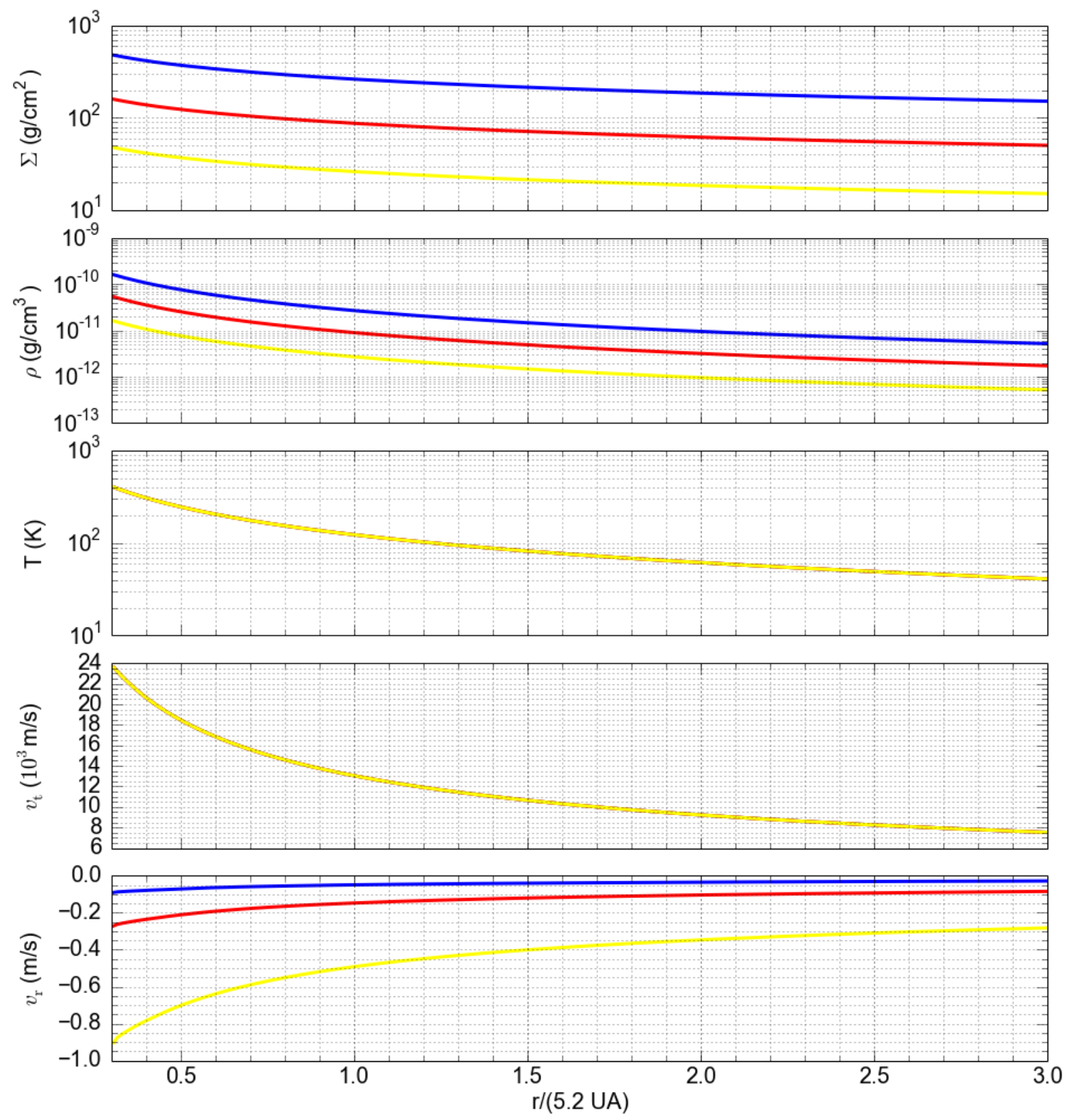

Figura 3.9: Gráficos dos principais parâmetros obtidos para o disco de acreção em equilíbrio para uma taxa de acreção de $10^{-8} \mathrm{M}_{\odot} /$ ano após $100 P_{\text {orbital }}$. De cima para baixo: densidade superficial, densidade volumétrica, temperatura, velocidade tangencial e velocidade radial ao longo do raio. As cores são usadas para designar as diferentes viscosidades: azul para $\alpha=0.001$, vermelho para $\alpha=0.003$ e amarelo para $\alpha=0.010$.

3D, que não efetuaremos aqui devido ao alto custo computacional.

Ainda na Figura 3.8, note que, para o modelo de disco utilizado nessa tese, os valores obtidos na curva de densidade superficial ao longo do raio diminuem com o aumento do valor de $\alpha$. Isso ocorre devido à equação 3.119 , que fornece o valor da distribuição da den- 

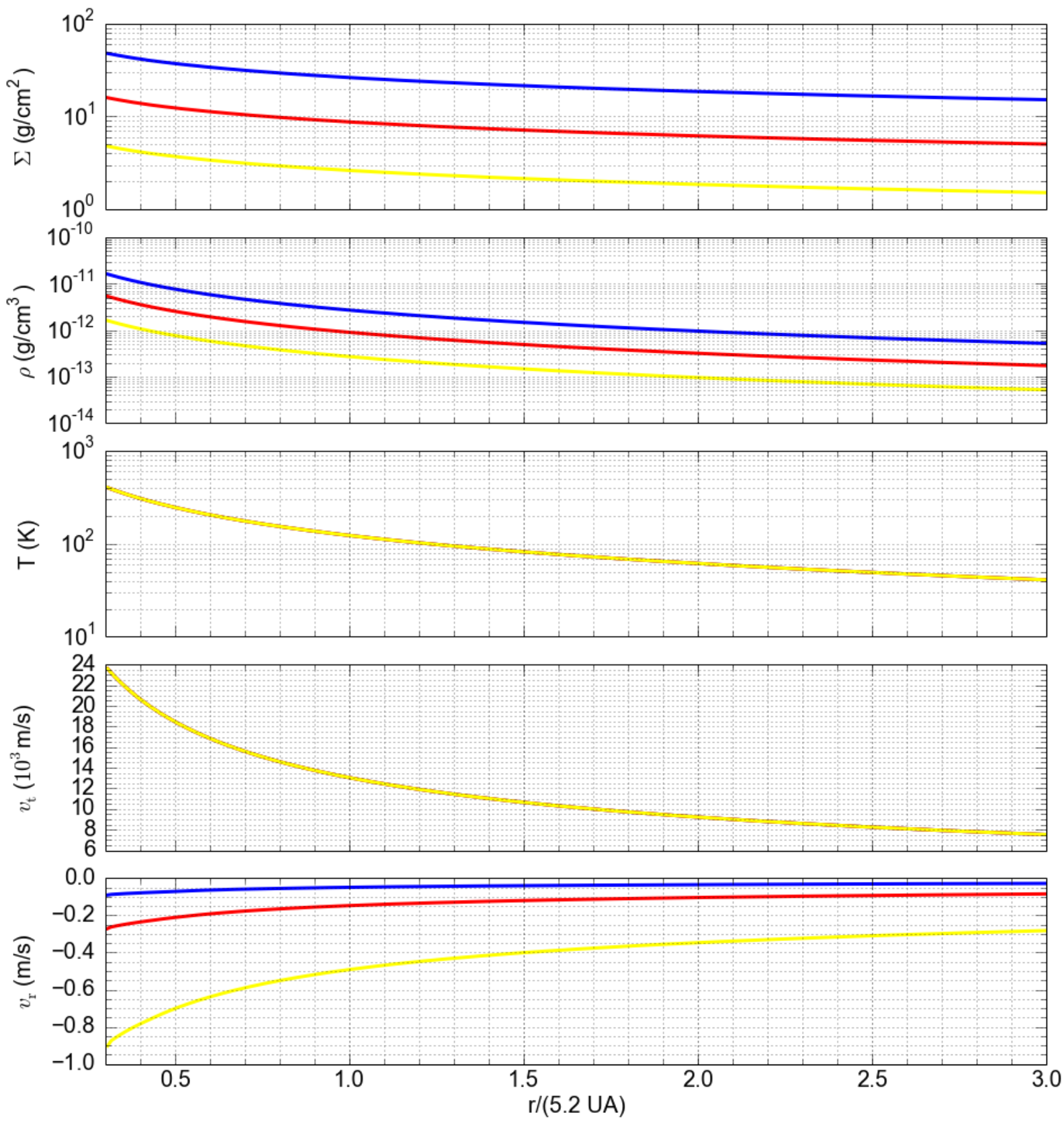

Figura 3.10: Gráficos dos principais parâmetros obtidos para o disco de acreção em equilíbrio para uma taxa de acreção de $10^{-9} \mathrm{M}_{\odot} /$ ano após $100 P_{\text {orbital }}$. De cima para baixo: densidade superficial, densidade volumétrica, temperatura, velocidade tangencial e velocidade radial ao longo do raio. As cores são usadas para designar as diferentes viscosidades: azul para $\alpha=0.001$, vermelho para $\alpha=0.003$ e amarelo para $\alpha=0.010$.

sidade superficial inicial, que se mantém ao longo da simulação; observe que a distribuição da densidade superficial é inversamente proporcional a $\alpha$. Assim, da curva azul $(\alpha=0.001)$ para a curva amarela $(\alpha=0.010)$, a distribuição da densidade superficial deverá ser 10 vezes menor para cada raio. Além disso, a equação 3.119 indica a proporcionalidade com 
$\dot{M}$, isto é, para uma taxa de acreção de $10^{-8} \mathrm{M}_{\odot} /$ ano, vamos obter uma distribuição de densidade superficial 10 vezes menor. De fato, essa proporcionalidade pode ser observada comparando a Figura 3.8 com as Figuras 3.9 e 3.10 , que reproduzem os mesmos gráficos para as taxas de acreção de $10^{-8} \mathrm{M}_{\odot} /$ ano e $10^{-9} \mathrm{M}_{\odot} /$ ano, respectivamente.

Os gráficos da temperatura e da velocidade tangencial ao longo do raio do disco (gráficos 3 e 4 das Figuras 3.8 , 3.9 e 3.10 mostram que os valores para as três viscosidades estão sobrepostos. Isso é esperado já que a distribuição de temperatura depende da curva para a velocidade do som (ver final da seção 2.1.2) e a velocidada tangencial, do expoente da curva de densidade superficial (ver eq. 3.121). Ademais, como esperado, obtemos os mesmos valores da potência para o perfil de temperatura para todas as taxas de acreção para o disco de gás, como mostram as Figuras 3.9 e 3.10. Portanto, como era esperado para nosso modelo, a temperatura e a velocidade tangencial são independentes dos valores de $\alpha$ e $\dot{M}$. Além disso, os valores obtidos para a temperatura são próximos daqueles alcançados em discos mais complexos (Papaloizou e Terquem, 1999a).

A curva de velocidade radial obtida no gráfico 5 da Figura 3.8 mostra sua dependência com a viscosidade. De fato, a partir da equação 3.118, notamos que a velocidade radial é diretamente proporcional ao valor de $\alpha$, assim, os valores obtidos para $\alpha=0.010$ devem ser 10 vezes maiores que os obtidos para a curva para $\alpha=0.001$. Também é possível notar a independência da velocidade radial com $\dot{M}$ comparando-se as Figuras 3.8, 3.9 e 3.10.

Os resultados obtidos revelam a concordância com o cenário teórico esperado. É claro que a presença de um planeta irá perturbar esse cenário e a situação de equilíbrio será diferente da obtida acima. Esse ponto será discutido com mais detalhes no capítulo 5 .

\subsection{Conclusão}

Neste capítulo, nós fizemos uma descrição do código FARGO3D dentro do qual iremos implementar o modelo de formação planetária. Vimos que o FARGO3D é um código magneto-hidrodinâmico e que, nesta tese, usaremos somente a parte hidrodinâmica, cujas equações resolvidas são mostradas na seção 3.1 .

Também fizemos uma descrição na seção 3.2 sobre como o FARGO3D discretiza o dominínio computacional e como o valor das variavéis são calculados em pontos específicos da célula. No caso de grandezas vetoriais, os valores são armazenados nas bordas das 
células, enquanto, as grandezas escalares, são armazenadas no centro da célula. Ainda nesta seção vimos algumas nomenclaturas, chamadas índices, utilizadas pelo programa para localização das células e, também, os diferentes sistemas de coordenadas usados no FARGO3D. Essas nomenclaturas são importantes e serão usadas largamente na construção das funções responsáveis pela formação planetária que serão implementadas no código.

Em seguida, descrevemos como o FARGO3D aplica as condições de borda (seção 3.3) e como o usuário deve manipular os arquivos para que essas condições sejam aplicadas corretamente.

O modelo de formação planetária exigirá a inclusão de novas variáveis no código. A forma como essas variáveis são incluídas, e como o programa as manipula, é descrito na seção 3.4 .

Vimos também que uma das novas caracteristísca do FARGO3D, em relação ao seu antecessor, é a manipulação dos sistemas de unidades, podendo-se optar pelo uso do sistema CGS, MKS ou adimensional. A descrição de como ocorre essa escolha está na seção 3.5 .

O FARGO3D, assim como seu antecessor, possui um arquivo responsável pela entrada de parâmetros que definem o disco de gás utilizado. Esses parâmetros envolvem desde a curvatura e a razão de aspecto do disco até sua viscosidade e distribuição de densidade. A descrição de algumas dessas variáveis pode ser encontrada na seção 3.6 .

Pelo fato de o FARGO3D ser nossa principal ferramenta, optamos por um estudo completo da forma como ele resolve as principais equações da hidrodinâmica. Um resumo do procedimento é descrito pelo fluxograma da Figura 3.5, obtida em Benítez-Llambay e Masset (2016). Estudamos, na seção 3.7.1, a técnica do operador splitting, que é utilizada para transformar uma equação diferencial em duas outras equações, a equação fonte e a equação de transporte, que são resolvidas numericamente em passos de tempo intermediários. Esse método é o mesmo empregado por Stone e Norman (1992) no código hidrodinâmico ZEUS.

A resolução da equação fonte, descrita na seção 3.7 .2 , ocorre através de 3 subpassos. No primeiro subpasso, ocorre a resolução das equações com os termos de pressão e de potencial. O segundo subpasso é responsável pela viscosidade artificial de Von Neumann que adiciona uma pressão artificial responsável por fornecer um método simples para lidar de forma aproximada com ondas de choque, isto é, quando há descontinuidades no problema. Por fim, no terceiro subpasso, resolve-se a equação de energia. No caso desta tese, o terceiro subpasso não ocorre, dado que estamos trabalhando com um disco isotérmico. 
No entanto, a grande vantagem do algoritmo FARGO3D está na resolução da equação de transporte. De fato, o uso do algoritmo de advecção orbital, explicado na seção 3.7.5. permite aos algoritmos do tipo FARGO evitar a limitação de tempo imposta pelo alto valor da velocidade tangencial do gás e os erros de truncamento que dependem do sistema de referência. A limitação do passo de tempo é uma consequência da condição CFL, descrita na seção 3.7.4. que possui como base o tempo necessário para o gás em alta velocidade cruzar a célula. O algoritmo de advecção orbital consiste em usar a técnica do operador splitting na resolução da equação de transporte na direção X do código, no qual se obtém uma equação que permite um deslocamento do material através de uma permutação das células. Os detalhes de todo o algoritmo de transporte e dos termos fontes estão na seção 3.7.

Outra grande vantagem do FARGO3D é a possibilidade de trabalhar com a linguagem CUDA para uso da GPU mediante o uso de scripts. Os detalhes para utilização desses scripts e como o programa manipula algumas condições para comunicação GPU - CPU podem ser lidos na seção 3.8 .

Para manipulação dos resultados obtidos no FARGO3D, o usuário deve conhecer os arquivos de saída gerados pelo programa, para isso, fizemos uma descrição de alguns desses arquivos na seção 3.9 .

Apesar de um pouco extenso, o intuito deste capítulo foi fornecer ao usuário um conhecimento básico de como o código funciona e recursos para que possa implementar e compreender a forma como o modelo de formação planetária foi incorporado no código. Espera-se que o usuário, lendo este capítulo, o apêndice desta tese e o manual do programa, possa implementar por si só o modelo que será descrito nos próximos capítulos.

Por fim, para lidar com o modelo de formação planetária precisamos definir algumas características físicas para o disco de gás. De fato, como o modelo de formação planetária fornece um grande número de parâmetros livres, optamos por um disco de gás simples e com um resultado teórico bem estabelecido. Escolhemos, então, um disco de acreção com taxa de acreção constante (ver seção 2.1.5). Assim, com base nessas condições, descrevemos um disco de gás padrão na seção 3.10, que será utilizado ao longo de toda a tese. Nessa seção, o leitor pode encontrar toda a descrição dos módulos, parâmetros e condições de borda utilizados. Os resultados obtidos são descritos na seção 3.10 .4 . 
Capítulo 4

\section{Modelo para acreção de planetesimais}

\subsection{Introdução}

A acreção de planetesimais, em geral, pode ser investigada por meio de duas técnicas: a utilização de uma simulação N-corpos ou através de um método estatístico. Na simulação N-corpos, a evolução orbital dos planetesimais é obtida via integração numérica das equações que descrevem a interação gravitacional entre os corpos. O crescimento, portanto, ocorre quando dois corpos colidem e se juntam em um só. Este método, na maior parte dos casos, descreve o processo de acumulação de planetesimais com a condição imposta de que as colisões devem ser perfeitamente inelásticas. Isto é, quando ocorre uma colisão, os corpos se unem independentemente da velocidade relativa entre eles Kokubo e Ida, 1998). No entanto, uma simulação N-corpos requer um custo computacional muito alto para descrever o processo de crescimento de um planeta, já que o número de corpos necessários, nos primeiros estágios de crescimento, costuma ser maior que $10^{18}$ planetesimais. Vale destacar que resultados muito bons vêm sendo obtidos com novos integradores, como o código REBOUND (Rein e Tamayo, 2016).

O método estatístico torna-se, portanto, uma ferramenta importante no estudo da acreção de um grande número de planetesimais, já que não utiliza as quantidades físicas individuais de cada planetesimal, optando pelo uso de quantidades médias. Como resultado, o tempo computacional é muito mais curto do que o obtido numa simulação $\mathrm{N}$-corpos. Entretanto, o método estatístico apresenta algumas desvantagens, devido o fato de as quantidades obtidas serem valores médios e a acreção de sólidos ser um fenômeno não linear, se a média não é realizada corretamente a solução pode ser fortemente afetada e gerar resultados incorretos. Além disso, após a entrada num regime de crescimento de- 
senfreado (runaway growth), o número de planetesimais pode ser baixo o suficiente para não descrever corretamente um cenário estatístico confiável.

Por esses motivos, é importante que o modelo estatístico seja desenvolvido de forma a gerar os dados mais próximos possível de uma simulação N-corpos.

Vale ressaltar que os dois métodos não são excludentes, numa situação ideal, ambos seriam necessários para investigar o processo de acumulação de planetesimais.

Nesta tese, iremos trabalhar com um modelo semianalítico para o crescimento oligárquico de um planeta, no qual calcula-se explicitamente a mudança da excentricidade e da inclinação quadrática média dos planetesimais em razão do arrasto do gás e da perturbação do embrião planetário. O modelo estatístico usado nesta tese ainda é simplificado e alguns fenômenos importantes, como a fragmentação durante a colisão e a migração radial, não foram incluídos no processo. Isso se deve ao fato de o processo de formação planetária ser bastante complexo, devendo-se acrescentar e analisar os processos físicos cuidadosamente, assim, no futuro, espera-se que este trabalho seja usado para incluir outros fenômenos, a fim de que seja possível tratar a formação planetária de forma tão realista quanto possível.

Este capítulo inicia com uma revisão sobre o modelo de Hill, que será utilizado para obter as equações necessárias para estudar a interação do protoplaneta com o planetesimal. Em seguida, vamos descrever o modelo estatístico que usaremos especificando as principais condições e vínculos teóricos utilizados. Por fim, vamos adaptar esse código ao FARGO3D. O modelo será testado tendo como base o trabalho de Guilera et al. (2010) e Fortier et al. (2013). Esses dois trabalhos utilizam um modelo de disco que não é hidrodinâmico, isto é, não tratam da resolução das equações da hidrodinâmica, como ocorre no FARGO3D, ao invés disso, utilizam um modelo de disco baseado na resolução da equação de equilíbrio hidrostático, dissipação viscosa e fluxo de energia (Papaloizou e Terquem, 1999b). No entanto, veremos que, mesmo utilizando um modelo de disco diferente, foi possível, impondo algumas condições locais, a reprodução dos resultados de forma muito satisfatória.

Esse modelo será usado com o modelo de acreção de gás para estudo do processo de migração planetária em paralelo com a formação planetária. Neste capítulo, focaremos nossa atenção no modelo de acreção de sólidos. Para isso, vamos analisar o crescimento de um protoplaneta de massa $0.01 \mathrm{M}_{\otimes}$ fixo numa órbita de 6 ua no nosso modelo padrão para o disco de gás (ver seção 3.10), e comparar nossos resultados com os obtidos na literatura. 


\subsection{Aproximação de Hill para o problema de três corpos}

Os planetesimais que orbitam a estrela hospedeira experimentam atração gravitacional mútua e colisões até finalmente coalescerem e se tornarem um núcleo sólido. Assim, a descrição matemática do processo de aglutinação é formulada tendo como base o problema de três corpos: uma estrela, um núcleo sólido (protoplaneta) e um planetesimal, todos sob ação gravitacional mútua. No entanto, as massas do planetesimal e do núcleo sólido são estritamente menores que a massa da estrela hospedeira, além disso, podemos considerar que o protoplaneta e o planetesimal orbitam o centro de massa do sistema (estrela, protoplaneta e planetesimal) numa órbita aproximadamente circular. Essas considerações possibilitam o estudo do movimento do planetesimal em torno da vizinhança do protoplaneta através das equações de Hill, originalmente propostas para estudo da órbita lunar (Hill, 1878).

A análise do problema por meio das equações de Hill oferece algumas vantagens. A primeira delas é que o movimento relativo e do centro de massa podem ser separados. Assim, a equação para o movimento do centro de massa pode ser obtida analiticamente. Ademais, veremos que a solução do movimento relativo e do centro de massa são aplicáveis a qualquer par de massas com razões de massas arbirtrárias. Essas características tornam o cenário de Hill muito útil ao estudo do espalhamento gravitacional e das colisões dos planetesimais com o núcleo sólido.

Nas seções a seguir, iremos fazer uma breve descrição sobre o problema de Hill para que o leitor possa entender o desenvolvimento do modelo estatístico para acreção de sólidos. Mais detalhes sobre esse desenvolvimento podem ser obtidos em Henon e Petit (1986).

\subsubsection{Equações de Hill}

Suponhamos um núcleo sólido com massa $m_{1}$ e um planetesimal com massa $m_{2}$ orbitando uma estrela de massa $M_{\star}$, o sistema de referência é cartesiano e centrado no baricentro do sistema. No caso geral, suas órbitas são descritas por soluções complicadas do problema de três corpos. Entretanto, vamos introduzir algumas condições para simpli-

ficar esse problema e reduzir as equações de movimento às equações de Hill (Hill, 1878), essas condições são: 


$$
\left\{\begin{array}{l}
m_{j} \ll M_{\star}, \\
e_{j}, i_{j} \ll 1, \\
\left|a_{j}-a_{0}\right| \ll a_{0},
\end{array}\right.
$$

onde $j=1$ e $2, e_{j}$ e $i_{j}$ são, respectivamente, a excentricidade e a inclinação da $j$-ésima partícula. Além disso, $a_{j}$ é o semieixo maior da $j$-ésima partícula e $a_{0}$ um semieixo maior de referência. É interessante notar que o problema de Hill não deve ser visto como um caso particular do problema restrito de três corpos, dado que o problema restrito exige que uma massa seja extritamente pequena; já o problema de Hill exige que as duas massas sejam menores que o corpo principal, não importando a razão entre elas.

Considere agora um sistema de coordenadas cilindricas girante $(\tilde{r}, \tilde{\theta}, \tilde{z})$, onde o eixo $\tilde{z}$ é perpendicular ao plano da eclíptica. A origem do sistema de coordenadas coincide com o baricentro do sistema. O sistema de coordenadas gira ao redor do eixo $\tilde{z}$ com velocidade angular dada por:

$$
\Omega_{0}^{2}=G\left(M_{\star}+m_{1}+m_{2}\right) / a_{0}^{3},
$$

onde $a_{0}$ é um semieixo maior de referência e $\tilde{\theta}$ é escolhido de tal forma que a estrela está sempre em $\tilde{\theta}=\pi$.

Em seguida, vamos transformar o sistema de coordenadas $(\tilde{r}, \tilde{\theta}, \tilde{z})$ em um novo sistema de coordenadas $(x, y, z)$, chamado de coordenadas de Hill (ver Fig. 4.1):

$$
\left\{\begin{array}{l}
\tilde{r}=a_{0}(1+h x), \\
\tilde{\theta}=h y \\
\tilde{z}=a_{0} h z
\end{array}\right.
$$

onde $h$ é o raio de Hill reduzido e definido por:

$$
h=\left[\frac{\left(m_{1}+m_{2}\right)}{3 M_{\star}}\right]^{1 / 3} .
$$

Expandindo, no novo sistema de coordenadas, a equação do movimento em séries de potência em torno de $h$ e mantendo os termos de primeira ordem, nós obtemos as equações de Hill para a partícula $j$, dadas por: 


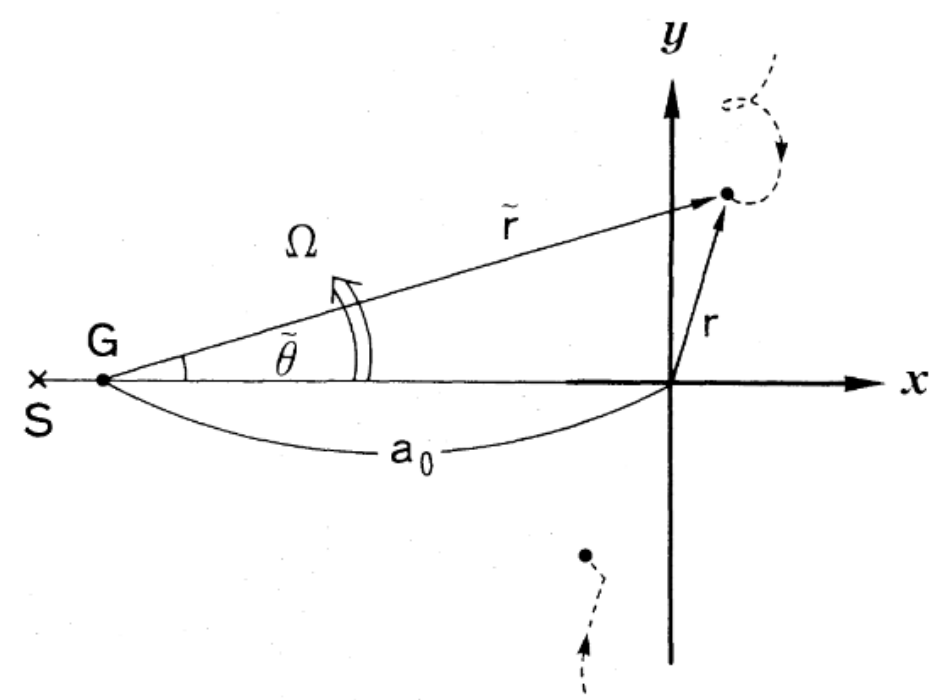

Figura 4.1: Geometria da coordenada de Hill. A estrela é denotada por $S$ e o centro de massa do sistema por $G$. Figura obtida em Nakazawa et al. (1989a).

$$
\left\{\begin{array}{l}
x_{j}^{\prime \prime}-2 y_{j}^{\prime}=3 x_{j}+\frac{3 \nu_{i}}{r^{3}}\left(x_{i}-x_{j}\right), \\
y_{j}^{\prime \prime}+2 x_{j}^{\prime}=\frac{3 \nu_{i}}{r^{3}}\left(y_{i}-y_{j}\right), \\
z_{j}^{\prime \prime}=-z_{j}+\frac{3 \nu_{i}}{r^{3}}\left(z_{i}-z_{j}\right),
\end{array}\right.
$$

onde $i=1$ (ou 2) para $j=2$ (ou 1 ) e as variáveis com apóstrofo denotam a derivada com relação ao tempo $t$. O tempo é normalizado por $\Omega^{-1}$. Além disso, $\nu_{j}$ é fração de massa dada por:

$$
\nu_{j}=\frac{m_{j}}{\left(m_{1}+m_{2}\right)},
$$

e $r$ é a distância entre as duas partículas dada por:

$$
r^{2}=\left(x_{1}-x_{2}\right)^{2}+\left(y_{1}-y_{2}\right)^{2}+\left(z_{1}-z_{2}\right)^{2} .
$$

$\mathrm{Na}$ equação 4.5, o primeiro termo do lado direito denota a soma da força gravitacional da estrela central com a força centrífuga, e o segundo termo do lado direito, a força de atração gravitacional mútua. O segundo termo do lado esquerdo é devido à força de Coriolis. 


\subsubsection{Movimento kepleriano}

Quando a distância relativa $(r)$ é muito grande, o termo responsável pela atração gravitacional mútua pode ser negligenciado. Assim, a equação 4.5 pode ser resolvida exatamente e descrita em termos dos parâmetros orbitais (Henon e Petit, 1986), essa solução é dada por:

$$
\left\{\begin{array}{l}
x_{j}(t)=\tilde{b}_{j}-\tilde{e}_{j} \cos \left(t-\tau_{j}\right) \\
y_{j}(t)=-\frac{3}{2} \tilde{b}_{j}\left(t-\phi_{j}\right)+2 \tilde{e}_{j} \sin \left(t-\tau_{j}\right) \\
z_{j}(t)=\tilde{i}_{j} \sin \left(t-\omega_{j}\right)
\end{array}\right.
$$

onde $j=1$ e 2 . Nas equações acima, os doze parâmetros $\tilde{b}_{j}, \tilde{e}_{j}, \tilde{i}_{j}, \tau_{j}, \phi_{j}$ e $\omega_{j}$ são constantes de integração. Para as componentes da velocidade, temos:

$$
\left\{\begin{aligned}
x_{j}^{\prime}(t) & =\tilde{e}_{j} \sin \left(t-\tau_{j}\right) \\
y_{j}^{\prime}(t) & =-\frac{3}{2} \tilde{b}_{j}+2 \tilde{e}_{j} \cos \left(t-\tau_{j}\right) \\
z_{j}^{\prime}(t) & =\tilde{i}_{j} \cos \left(t-\omega_{j}\right)
\end{aligned}\right.
$$

É possível mostrar que, para $\tilde{b}_{j} h, \tilde{e}_{j} h$ e $\tilde{i}_{j} h$ estritamente menores que uma unidade, a solução das equações 4.8 e 4.9 coincide com a obtida para o movimento kepleriano na coordenada de Hill. Essa demonstração pode ser encontrada no apêndice A de Nakazawa et al. (1989a). Assim, as constante de integração possuem relação com os elementos orbitais keplerianos, isto é: $\tilde{b}_{j}=\left(a_{j}+a_{0}\right) / h a_{0}, \tilde{e}_{j}=e_{j} / h$ e $\tilde{i}_{j}=i_{j} / h$, denominados, respectivamente, como o parâmetro de impacto, a excentricidade e a inclinação reduzidas, além disso, temos $\tau_{i}, \phi_{i}$ e $\omega_{i}$ como os ângulos de fase.

Até mesmo no caso mais geral, em que a interação mútua não pode ser negligenciada, é conveniente expressar o movimento da partícula da mesma forma. Neste caso, no entanto, os elementos $\tilde{b}_{j}, \tilde{e}_{j} \ldots$ etc., não são constantes, mas variam com o tempo e são chamados, portanto, de elementos orbitais instantâneos. Portanto, o movimento da partícula pode ser descrito num espaço de fase de 6 dimensões $\left(\boldsymbol{q}_{\boldsymbol{j}}, \boldsymbol{p}_{\boldsymbol{j}}\right)$, ao invés do espaço de fase comum $\left(\boldsymbol{x}_{\boldsymbol{j}}, \boldsymbol{x}_{\boldsymbol{j}}^{\prime}\right)^{1}$, onde:

\footnotetext{
${ }^{1}$ O leitor deve tomar cuidado com a notação. Note que $\left(\boldsymbol{x}_{\boldsymbol{j}}, \boldsymbol{x}_{\boldsymbol{j}}^{\prime}\right)$, em negrito, representa o conjunto das coordenadas de posição e velocidade em todas as direções.
} 


$$
\left\{\begin{array}{l}
\boldsymbol{q}_{j}=\left[\tilde{b}_{j}(t), \tilde{e}_{j}(t), \tilde{i}_{j}(t)\right], \\
\boldsymbol{p}_{\boldsymbol{j}}=\left[\phi_{j}(t), \tau_{j}(t), \omega_{j}(t)\right] .
\end{array}\right.
$$

A matriz jacobiana da transformação de $\left(\boldsymbol{x}_{\boldsymbol{j}}, \boldsymbol{x}_{\boldsymbol{j}}^{\prime}\right)$ para $\left(\boldsymbol{q}_{\boldsymbol{j}}, \boldsymbol{p}_{\boldsymbol{j}}\right)$ é dada por:

$$
J=\left|\frac{\partial\left(\boldsymbol{x}_{\boldsymbol{j}}, \boldsymbol{x}_{\boldsymbol{j}}^{\prime}\right)}{\partial\left(\boldsymbol{q}_{\boldsymbol{j}}, \boldsymbol{p}_{\boldsymbol{j}}\right)}\right|=\frac{3}{4}\left|\tilde{b}_{j}\right| \tilde{e}_{j} \tilde{i}_{j}
$$

É interessante destacar que o movimento dado pelo sistema de equações 4.8 pode ser representado por dois movimentos: o movimento do guinding center $\left(x_{\mathrm{G} j}, y_{\mathrm{G} j}, z_{\mathrm{G} j}\right)$ e o movimento epiciclico $\left(x_{\mathrm{E} j}, y_{\mathrm{E} j}, z_{\mathrm{E} j}\right)$, que são descritos, respectivamente, por:

$$
\left\{\begin{aligned}
x_{\mathrm{G} j} & =\tilde{b}_{j} \\
y_{\mathrm{G} j} & =\frac{3}{2} \tilde{b}_{j}\left(t-\phi_{j}\right), \\
z_{\mathrm{G} j} & =0
\end{aligned}\right.
$$

e

$$
\left\{\begin{array}{l}
x_{\mathrm{E} j}=-\tilde{e}_{j} \cos \left(t-\tau_{j}\right), \\
y_{\mathrm{E} j}=2 \tilde{e}_{j} \sin \left(t-\tau_{j}\right), \\
z_{\mathrm{E} j}=\tilde{i}_{j} \sin \left(t-\omega_{j}\right) .
\end{array}\right.
$$

O movimento do guinding center vem do efeito da rotação diferencial em razão da diferença entre $a_{0}$ e $a_{j}$. Entretanto, o movimento epicíclico descreve uma elipse com eixos $e_{j}$ e $2 e_{j}$ em um período equivalente ao período kepleriano em $a_{0}$. A Figura 4.2 a seguir ilustra alguns exemplos de movimentos keplerianos em coordenadas de Hill.

Até mesmo no caso geral, no qual a interação mutual não é desprezada, é usual expressar o movimento da partícula da mesma forma que realizado acima. Nesse caso, como dito anteriormente, os elementos orbitais não são mais constantes, mas funções do tempo, isto é, são os elementos orbitais instantâneos.

\subsubsection{Separação em movimento relativo e movimento do centro de massa}

As equações de Hill (ver eq. 4.5) não são lineares, o que se deve ao termo de interação mútua, que está em função da distância relativa entre as partículas; então, como demonstra Hill (1878), podemos separar o movimento em duas partes: o movimento do centro de 


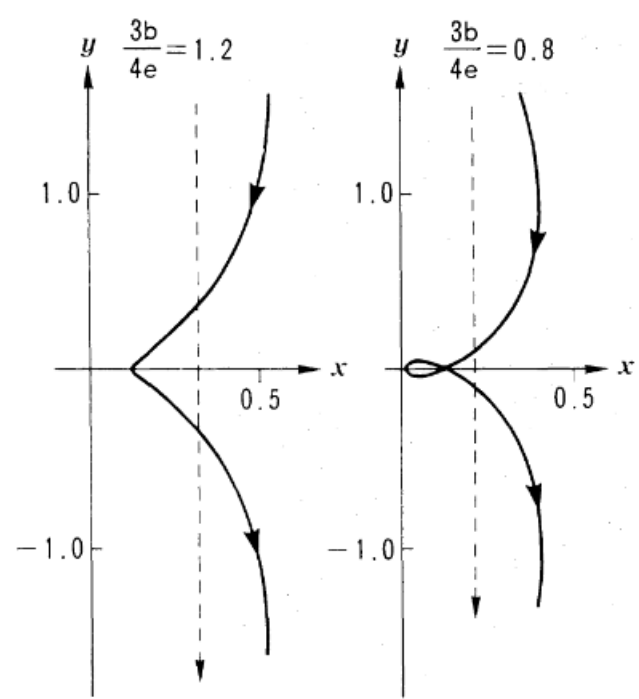

(a)

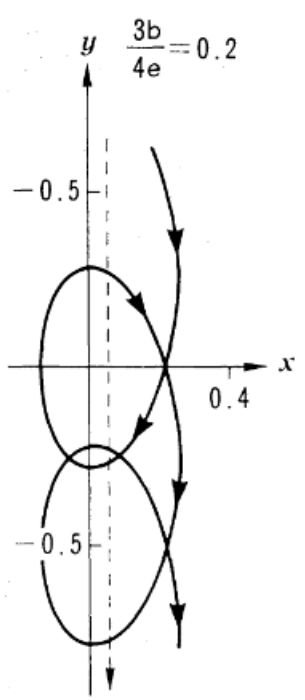

(c)

Figura 4.2: Exemplos de movimentos keplerianos em coordenadas de Hill. Em todos os casos, $\tilde{e}=0.2, \tilde{i}=0$ e $\tau=\phi$. Três casos são mostrados variando-se o parâmetro de impacto b. A linha tracejada indica a trajetória do guiding center. Figura obtida em Nakazawa et al. (1989a).

massa e o movimento relativo. Para isso, vamos introduzir as coordenadas relativas e do centro de massa, respectivamente, como:

$$
\left\{\begin{array}{l}
x=x_{2}-x_{1} \\
y=y_{2}-y_{1} \\
z=z_{2}-z_{1}
\end{array}\right.
$$

$\mathrm{e}$

$$
\left\{\begin{array}{l}
X=\nu_{1} x_{1}+\nu_{2} x_{2} \\
Y=\nu_{1} y_{1}+\nu_{2} y_{2} \\
Z=\nu_{1} z_{1}+\nu_{2} z_{2}
\end{array}\right.
$$

Usando as coordenadas acima, podemos reescrever a equação para o movimento do centro de massa:

$$
\left\{\begin{array}{l}
X^{\prime \prime}-2 Y^{\prime}=3 X, \\
Y^{\prime \prime}+2 X^{\prime}=0, \\
Z^{\prime \prime}=-Z,
\end{array}\right.
$$

e para o movimento relativo: 


$$
\left\{\begin{array}{l}
x^{\prime \prime}-2 y^{\prime}=3 x-\frac{3}{r^{3}} x \\
y^{\prime \prime}+2 x^{\prime}=-\frac{3}{r^{3}} y \\
z^{\prime \prime}=-z-\frac{3}{r^{3}} z
\end{array}\right.
$$

Observe que nenhum dos sistemas de equações anteriores tem dependência implícita com $\nu_{1}$ e $\nu_{2}$. Logo, as soluções são aplicadas para qualquer par de partículas com razão de massa arbitrária, claro que as duas ainda devem ser estritamente menores que a massa central para satisfazer as condições de Hill.

O movimento do centro de massa é puramente kepleriano de modo que pode ser resolvido analiticamente (ver seção 4.2.2). Portanto, a equação para o movimento do baricentro das duas partículas ao longo de uma órbita kepleriana é dada por:

$$
\left\{\begin{array}{l}
X=\tilde{B}-\tilde{E} \cos (t-T) \\
Y=-\frac{3}{2} \tilde{B}(t-\Phi)+2 \tilde{E} \sin (t-T) \\
Z=\tilde{I} \sin (t-W)
\end{array}\right.
$$

onde os seis parâmetros $\tilde{B}, \tilde{E}, \tilde{I}, \Phi, T$ e $W$ são constantes escritas em função dos elementos orbitais, assim como os obtidos na equação 4.8 .

Entretanto, o movimento relativo não é kepleriano devido ao termo de atração mútua e seu comportamento é mais complicado. Mesmo nesse caso, como mencionado anteriormente, a órbita pode ser descrita como indicado nas equações 4.8 e 4.9 com $\tilde{b}_{j}, \tilde{e}_{j} \ldots$ trocados por $\tilde{b}, \tilde{e} \ldots$, os elementos orbitais instantâneos para o movimento relativo, que podem ser relacionados com os elementos orbitais das duas partículas individuais. Usando as equações 4.14 e 4.15 , podemos escrever (ver Fig. 4.3):

$$
\left\{\begin{array}{l}
\tilde{b}=\tilde{b}_{2}-\tilde{b}_{1} \\
\tilde{e}=\tilde{e}_{1}^{2}+\tilde{e}_{2}^{2}-2 \tilde{e}_{1} \tilde{e}_{2} \cos \left(\tau_{2}-\tau_{1}\right) \\
\tilde{i}=\tilde{i}_{1}^{2}+\tilde{i}_{2}^{2}-2 \tilde{i}_{1} \tilde{i}_{2} \cos \left(\omega_{2}-\omega_{1}\right) .
\end{array}\right.
$$

\subsection{Equação de coagulação estatística}

\subsubsection{Função de distribuição dos planetesimais}

Vamos considerar um grande número de planetesimais orbitando uma estrela central de massa $M_{\star}$, e que a massa desses planetesimais é muito menor que a massa da estrela e que 
(a)

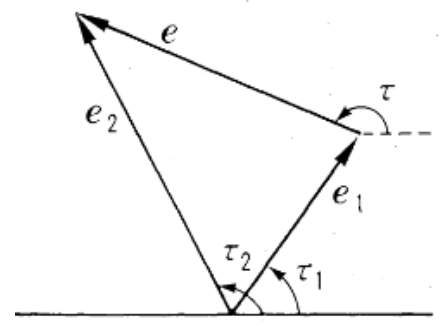

(b)

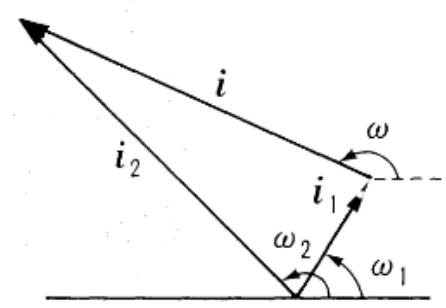

Figura 4.3: Síntese da excentricidade e inclinação do movimento relativo a partir das órbitas individuais. Figura obtida em Nakazawa et al. (1989a).

suas excentricidades e inclinações são estritamente menores que uma unidade. Obtemos, portanto, um disco de planetesimais ao redor da estrela. Dado um número de planetesimais, cada um de massa $m_{2}$, podemos denotar a função densidade de probabilidade das posições e velocidades dos planetesimais por $n_{2}\left(\boldsymbol{x}_{\mathbf{2}}, \boldsymbol{x}_{\mathbf{2}}^{\prime}\right)^{1}$, onde $\left(\boldsymbol{x}_{\mathbf{2}}, \boldsymbol{x}_{\mathbf{2}}^{\prime}\right)$ denota todo o conjunto de posições e velocidades dos planetesimais.

Para descrever a função densidade de probabilidade das posições e velocidades dos planetesimais, podemos fazer três considerações:

1. o guiding centers dos planetesimais são uniformemente distribuídos no plano eclíptico em qualquer instante de tempo;

2. a função de distribuição das excentricidades e inclinações são do tipo gaussiana;

3. os ângulos de fase $\phi_{2}, \tau_{2}$ e $\omega_{2}$ estão distribuídos de forma aleatória.

Como a acreção ocorre numa região estreita ao redor da órbita do protoplaneta, a consideração 1 é correta. A consideração 2 é obtida por meio de simulações N-corpos. De fato, Ida e Makino (1992) mostraram que a distribuição das excentricidades $\left(e_{j}\right)$ e inclinações $\left(i_{j}\right)$ dos planetesimais com massa $m_{j}$ é bem descrita por uma função de distribuição do tipo Rayleigh $f_{\mathrm{R}}\left(e_{j}, i_{j}\right)$ dada por:

$$
f_{\mathrm{R}}\left(e_{j}, i_{j}\right) d e_{j} d i_{j} \equiv \frac{4 e_{j} i_{j}}{\left\langle e_{j}^{2}\right\rangle\left\langle i_{j}^{2}\right\rangle} \exp \left(-\frac{e_{j}^{2}}{\left\langle e_{j}^{2}\right\rangle}-\frac{i_{j}^{2}}{\left\langle i_{j}^{2}\right\rangle}\right) d e_{j} d i_{j},
$$

\footnotetext{
${ }^{1}$ A função de distribuição $F(x)$ descreve a distribuição da probabilidade de uma ou mais variáveis aleatórias de valores reais. Matematicamente, podemos escrever $F(x)=P(X \leqslant x)$, que descreve a probabilidade de a variável $X$ assumir um valor inferior ou igual ao determinado $x$. Para uma variável aleatória contínua, temos $F(x)=\int_{-\infty}^{x} f\left(x_{i}\right) d x$, onde $f\left(x_{i}\right)$ é a função densidade de probabilidade.
} 
onde $\left\langle e_{j}^{2}\right\rangle$ e $\left\langle i_{j}^{2}\right\rangle$ são as medidas da dispersão, respectivamente, de $e_{j}$ e $i_{j}$. Obviamente, o mesmo vale para excentricidade e inclinação reduzidas.

Por fim, a consideração 3 é aceitável já que os planetesimais interagem frequentemente uns com os outros e seus ângulos de fase são randomizados rapidamente.

Pelas considerações 2 e 3 , a função de densidade de probabilidade $n_{2}\left(\boldsymbol{x}_{\mathbf{2}}, \boldsymbol{x}_{\mathbf{2}}^{\prime}\right)$ possui a seguinte forma:

$$
n_{2}\left(\boldsymbol{x}_{\mathbf{2}}, \boldsymbol{x}_{\mathbf{2}}^{\prime}\right) d x_{2} d x_{2}^{\prime}=n_{2}\left(\boldsymbol{q}_{\mathbf{2}}, \boldsymbol{p}_{\mathbf{2}}\right) J_{2} d \boldsymbol{q}_{\mathbf{2}} d \boldsymbol{p}_{\mathbf{2}}=A \exp \left(-\frac{\tilde{e}_{2}^{2}}{\left\langle\tilde{e}_{2}^{2}\right\rangle}-\frac{\tilde{i}_{2}^{2}}{\left\langle\tilde{i}_{2}^{2}\right\rangle}\right) J_{2} d \boldsymbol{q}_{\mathbf{2}} d \boldsymbol{p}_{\mathbf{2}}
$$

onde $d \boldsymbol{q}_{\mathbf{2}} d \boldsymbol{p}_{\mathbf{2}}=d \tilde{b}_{2} d \tilde{e}_{2} d \tilde{i}_{2} d \tau_{2} d \phi_{2} d \omega_{2}$, os valores $\left\langle\tilde{e}_{2}^{2}\right\rangle$ e $\left\langle\tilde{i}_{2}^{2}\right\rangle$ são, respectivamente, as excentricidades e inclinações quadráticas médias reduzidas dos planetesimais, e $J_{2}$ a jacobiana da transformação (ver eq. 4.11). A constante $A$ pode ser obtida da consideração 1 , o número de planetesimais com guiding center $\left(x_{2, g}, y_{2, g}\right)$ entre $x_{2} \leq x_{2, g} \leq x_{2}+\Delta x$ e $y_{2} \leq y_{2, g} \leq y_{2}+\Delta y$ é dado por:

$$
n_{\mathrm{s}} \Delta x \Delta y=\int n_{2}\left(\boldsymbol{q}_{\mathbf{2}}, \boldsymbol{p}_{\mathbf{2}}\right) J_{2} d \boldsymbol{q}_{\mathbf{2}} d \boldsymbol{p}_{\mathbf{2}}
$$

onde $n_{\mathrm{s}}$ é a densidade numérica de planetesimais e é assumida constante no tempo e no espaço. Integrando sobre o espaço de fase apropriado (ver Nakazawa et al. (1989a)), temos:

$$
A=\frac{2 n_{\mathrm{s}}}{\pi^{2}\left\langle\tilde{e}_{2}^{2}\right\rangle\left\langle\tilde{i}_{2}^{2}\right\rangle} .
$$

Assim, a função de distribuição pode ser escrita como:

$$
n_{2}\left(\boldsymbol{q}_{\mathbf{2}}, \boldsymbol{p}_{\mathbf{2}}\right) J_{2} d \boldsymbol{q}_{\mathbf{2}} d \boldsymbol{p}_{\mathbf{2}}=\frac{2 n_{\mathrm{s}}}{\pi^{2}\left\langle\tilde{e}_{2}^{2}\right\rangle\left\langle\tilde{i}_{2}^{2}\right\rangle} \exp \left(-\frac{\tilde{e}_{2}^{2}}{\left\langle\tilde{e}_{2}^{2}\right\rangle}-\frac{\tilde{i}_{2}^{2}}{\left\langle\tilde{i}_{2}^{2}\right\rangle}\right) J_{2} d \boldsymbol{q}_{\mathbf{2}} d \boldsymbol{p}_{\mathbf{2}}
$$

Por conveniência podemos reescrever a equação acima usando a função de distribuição dos planetesimais observada a partir do protoplaneta. Sejam $\boldsymbol{q}$ e $\boldsymbol{p}$ as coordenadadas de fase (elementos orbitais instantâneos) relativos entre o movimento da partícula 1 (protoplaneta com coordenadas de fase $\boldsymbol{q}_{\mathbf{1}}$ e $\boldsymbol{p}_{\mathbf{1}}$ ) e a partícula 2 (planetesimais com coordenadas de fase $q_{2}$ e $\left.p_{2}\right)$, podemos escrever:

$$
\tilde{e}_{2}^{2}=\tilde{e}_{1}^{2}+\tilde{e}^{2}+2 \tilde{e} \tilde{e}_{1} \cos \left(\tau-\tau_{1}\right)
$$




$$
\tilde{i}_{2}^{2}=\tilde{i}_{1}^{2}+\tilde{i}^{2}+2 \tilde{i}_{1} \cos \left(\omega-\omega_{1}\right)
$$

No estudo da acreção planetária, não estamos interessados nos ângulos de fase $\tau_{1}$ e $\omega_{1}$ do protoplaneta. Portanto, é conveniente fazer uma média sobre eles na função de distribuição:

$$
\left\langle n_{2}\right\rangle=\frac{1}{(2 \pi)^{2}} \int n_{2}\left(\boldsymbol{q}_{\mathbf{2}}\left(\boldsymbol{q}, \boldsymbol{p}, \boldsymbol{q}_{\mathbf{1}}, \boldsymbol{p}_{\mathbf{2}}\right), \boldsymbol{p}_{\mathbf{2}}\left(\boldsymbol{q}, \boldsymbol{p}, \boldsymbol{q}_{\mathbf{1}}, \boldsymbol{p}_{\mathbf{2}}\right)\right) d \omega_{1} d \tau_{1},
$$

onde assumimos a distribuição randômica dos ângulos $\omega_{1}$ e $\tau_{1}$. Substituindo as equações 4.25 e 4.26 na equação 4.24 e integrando sobre $\omega_{1}$ e $\tau_{1}$, encontramos:

$$
\begin{array}{r}
\left\langle n_{2}\right\rangle J d \boldsymbol{q} d \boldsymbol{p}=\frac{2 n_{\mathrm{s}}}{\pi^{2}\left\langle\tilde{e}_{2}^{2}\right\rangle\left\langle\tilde{i}_{2}^{2}\right\rangle} \exp \left(-\frac{\tilde{e}_{1}^{2}}{\left\langle\tilde{e}_{2}^{2}\right\rangle}-\frac{\tilde{i}_{1}^{2}}{\left\langle\tilde{i}_{2}^{2}\right\rangle}\right) \exp \left(-\frac{\tilde{e}^{2}}{\left\langle\tilde{e}_{2}^{2}\right\rangle}\right) I_{0}\left(\frac{2 \tilde{e} \tilde{e}_{1}}{\left\langle\tilde{e}_{2}^{2}\right\rangle}\right) \\
\exp \left(-\frac{\tilde{i}^{2}}{\left\langle\tilde{i}_{2}^{2}\right\rangle}\right) I_{0}\left(\frac{2 \tilde{i} \tilde{i}_{1}}{\left\langle\tilde{i}_{2}^{2}\right\rangle}\right) J d \boldsymbol{q} d \boldsymbol{p}
\end{array}
$$

onde $I_{0}(z)$ é uma função de Bessel de segundo tipo modificada de ordem 0, dada por:

$$
I_{0}(z)=\frac{1}{\pi} \int_{0}^{\pi} \exp (-z \cos \xi) d \xi
$$

e $J$ é a transformação jacobiana, dada por:

$$
J=\left|\frac{\partial\left(\boldsymbol{x}_{\boldsymbol{j}}, \dot{\boldsymbol{x}}_{\boldsymbol{j}}\right)}{\partial(\boldsymbol{q}, \boldsymbol{p})}\right|=\frac{3}{4} b \tilde{e} i
$$

Note que, quando $\tilde{e}_{1}=\tilde{i}_{1}=0$, temos $\tilde{e} \rightarrow \tilde{e}_{2}$ e $\tilde{i} \rightarrow i_{2}$ e então a equação se reduz à forma da equação 4.24. Entretanto, quando $\tilde{e}_{2} \ll \tilde{e}_{1} \simeq \tilde{e}$ e $\tilde{i}_{2} \ll \tilde{i}_{1} \simeq \tilde{i}$, a função de distribuição média tem a forma:

$$
\left\langle n_{2}\right\rangle \propto \exp \left(-\frac{\left(\tilde{e}-\tilde{e}_{1}\right)^{2}}{\left\langle\tilde{e}_{2}^{2}\right\rangle}\right) \exp \left(-\frac{\left(\tilde{i}-\tilde{i}_{1}\right)^{2}}{\left\langle\tilde{i}_{2}^{2}\right\rangle}\right),
$$

já que $I_{0}(z)$ comporta-se como $e^{z} /(2 \pi z)^{1 / 2}$ no limite de $z \gg 1$ (ver Fig. 4.4).

\subsubsection{Taxa de colisão total}

Agora, podemos obter a taxa de colisão do conjunto de planetesimais, que obedece à função de distribuição dada pela equação 4.24, sobre o protoplaneta com elementos orbitais 


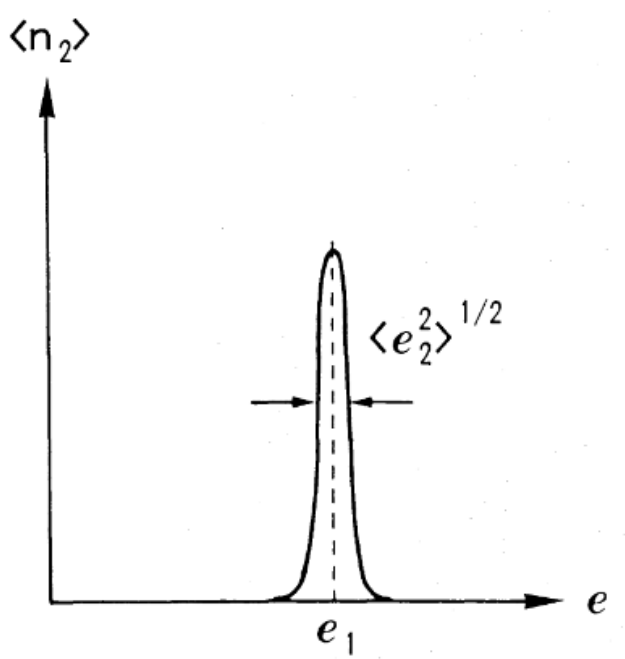

Figura 4.4: Esquema da função densidade de probabilidade $\left\langle n_{2}\right\rangle$ como função de $e$ no caso de $e_{2} \ll e_{1} \simeq e$. Figura obtida em: Nakazawa et al. (1989a)

$\left(\boldsymbol{q}_{\mathbf{1}}\right.$ e $\left.\boldsymbol{p}_{\mathbf{1}}\right)$. Seja $\Delta N_{\mathrm{c}}$ o número de colisões durante o intervalo de tempo $\Delta t$, a taxa de colisão $\Gamma\left(\boldsymbol{q}_{\mathbf{1}}, \boldsymbol{p}_{\mathbf{1}}\right)$ pode ser escrita como:

$$
\Gamma\left(\boldsymbol{q}_{\mathbf{1}}, \boldsymbol{p}_{\mathbf{1}}\right)=\frac{\Delta N_{\mathrm{c}}}{\Delta t}
$$

Usando a equação 4.24, podemos escrever $\Delta N_{\mathrm{c}}$ na forma:

$$
\Delta N_{\mathrm{c}}=\int n_{2}\left(\boldsymbol{q}_{\mathbf{2}}, \boldsymbol{p}_{\mathbf{2}}\right) p_{t}\left(\boldsymbol{q}_{\mathbf{1}}, \boldsymbol{p}_{\mathbf{1}} ; \boldsymbol{q}_{\mathbf{2}}, \boldsymbol{p}_{\mathbf{2}}\right) J_{2} d \boldsymbol{q}_{\mathbf{2}} d \boldsymbol{p}_{\mathbf{2}}
$$

onde $p_{t}\left(\boldsymbol{q}_{\mathbf{1}}, \boldsymbol{p}_{\mathbf{1}} ; \boldsymbol{q}_{\mathbf{2}}, \boldsymbol{p}_{\mathbf{2}}\right)$ é a probabilidade de colisão entre o protoplaneta e o planetesimal com elementos orbitais $\left(\boldsymbol{q}_{\mathbf{2}}, \boldsymbol{p}_{\mathbf{2}}\right)$; se a colisão ocorrer em um intervalo de tempo $t$ e $t+\Delta t$, nós temos $p_{t}\left(\boldsymbol{q}_{\mathbf{1}}, \boldsymbol{p}_{\mathbf{1}} ; \boldsymbol{q}_{\mathbf{2}}, \boldsymbol{p}_{\mathbf{2}}\right)=1$ e, caso contrário, $p_{t}\left(\boldsymbol{q}_{\mathbf{1}}, \boldsymbol{p}_{\mathbf{1}} ; \boldsymbol{q}_{\mathbf{2}}, \boldsymbol{p}_{\mathbf{2}}\right)=0$.

Note que $p_{t}\left(\boldsymbol{q}_{\mathbf{1}}, \boldsymbol{p}_{\mathbf{1}} ; \boldsymbol{q}_{\mathbf{2}}, \boldsymbol{p}_{\mathbf{2}}\right)$ é, aparentemente, somente função dos elementos orbitais do movimento relativo, $(\boldsymbol{q}, \boldsymbol{p})$, isto é, $p_{t}\left(\boldsymbol{q}_{\mathbf{1}}, \boldsymbol{p}_{\mathbf{1}} ; \boldsymbol{q}_{\mathbf{2}}, \boldsymbol{p}_{\mathbf{2}}\right)=p_{t}(\boldsymbol{q}, \boldsymbol{p})$. Portanto, obtemos:

$$
\left\langle\Gamma\left(\boldsymbol{q}_{\mathbf{1}}\right)\right\rangle=\frac{1}{\Delta t} \int\left\langle n_{2}\right\rangle p_{t}(\boldsymbol{q}, \boldsymbol{p}) J d \boldsymbol{q} d \boldsymbol{p},
$$

onde $\left\langle n_{2}\right\rangle$ é a função de distribuição média do campo de partículas observado a partir do protoplaneta e é dado pela equação 4.28. A função $p_{t}(\boldsymbol{q}, \boldsymbol{p})$ pode ser escrita como produto de dois fatores, isto é:

$$
p_{t}(\boldsymbol{q}, \boldsymbol{p})=p_{\mathrm{col}}(\boldsymbol{q}, \tau, \omega) p_{\mathrm{G}}(\phi)
$$


onde

$$
p_{\text {col }}= \begin{cases}1 & \text { para órbitas com colisão }, \\ 0 & \text { caso contrario },\end{cases}
$$

e $p_{\mathrm{G}}(\phi)$ denota a probabilidade do guiding center do movimento relativo cruzar o eixo $x$ durante o intervalo de tempo entre $t$ e $t+\Delta t$. Em outras palavras, é a probabilidade de o guiding center cruzar $y=y_{\mathrm{g}}\left(\left|y_{\mathrm{g}}\right| \gg 1\right)$ em um intervalo de tempo entre $t_{0}$ e $t_{0}+\Delta t$, onde $t_{0} \simeq t-2 y_{\mathrm{g}} / 3 b{ }^{1}$. Assim, temos:

$$
p_{\mathrm{G}}(\phi)= \begin{cases}1 & \text { para } t_{0} \leq \phi \leq t_{0}+\Delta t \\ 0 & \text { caso contrario } .\end{cases}
$$

Substituindo as equações 4.35 e 4.37 na equação 4.34 , encontramos:

$$
\left\langle\Gamma\left(\boldsymbol{q}_{\mathbf{1}}\right)\right\rangle=\int_{0 \leq \tau, \omega \leq 2 \pi} p_{\mathrm{col}}(\boldsymbol{q}, \tau, \omega)\left\langle n_{2}\right\rangle J d \boldsymbol{q} d \tau d \omega .
$$

Como $\left\langle n_{2}\right\rangle J$ não contém os ângulos de fase, $\tau$ e $\omega$, nós podemos integrar sobre esses ângulos. Assim, a equação acima pode ser escrita como:

$$
\left\langle\Gamma\left(\boldsymbol{q}_{\mathbf{1}}\right)\right\rangle=(2 \pi)^{2} \int\left\langle p_{\mathrm{col}}(\boldsymbol{q})\right\rangle\left\langle n_{2}\right\rangle J d \boldsymbol{q}
$$

onde:

$$
\left\langle p_{\mathrm{col}}(\boldsymbol{q})\right\rangle=\frac{1}{(2 \pi)^{2}} \int_{0 \leq \tau, \omega \leq 2 \pi} p_{\mathrm{col}}(\boldsymbol{q}, \tau, \omega) d \tau d \omega .
$$

Algumas vezes, é mais conveniente escrever uma expressão alternativa para a taxa de colisão integrando $\left\langle p_{\text {col }}(\boldsymbol{q})\right\rangle$ sobre o parâmetro de impacto $b$, assim:

$$
\langle P(\tilde{e}, \tilde{i})\rangle=\frac{3}{2} \int|b|\left\langle p_{\mathrm{col}}(\boldsymbol{q})\right\rangle d b,
$$

e a taxa de de colisão pode ser escrita como:

$$
\left\langle\Gamma\left(\boldsymbol{q}_{1}\right)\right\rangle=2 \pi^{2} \int\left\langle n_{2}\right\rangle\langle P(\tilde{e}, \tilde{i})\rangle \tilde{e} \tilde{i} d \tilde{e} d \tilde{i}
$$

\footnotetext{
${ }^{1}$ Note que o sistema de equações 4.17 obtido para o movimento relativo pode ser escrito na forma das equações 4.8 e 4.9 e separados no movimento do guiding center e epiciclico. A velocidade do guiding center é dada por $-3 \mathrm{~b} / 2$.
} 
onde nós usamos $J=3|b| \tilde{e} \tilde{i} / 4$.

Com base no conhecimento sobre $\langle P(\tilde{e}, \tilde{i})\rangle$ dado, por exemplo, com o o uso de soluções númericas de órbitas do movimento relativo, podemos deduzir a taxa de colisão total de uma distribuição arbitrária de planetesimais.

Para obter $\langle P(\tilde{e}, \tilde{i})\rangle$, várias órbitas são analisadas através da variação das variáveis $\tilde{b}$, $\tau$ e $\omega$ para o conjunto de valores de $\tilde{e}$ e $\tilde{i}$, a partir do qual se verifica se ocorre colisão ou não. Para diminuir o tempo computacional, ocorre uma simplificação para o problema de dois corpos dentro de uma região específica (Nakazawa et al., 1989b). A Figura 4.5 mostra um exemplo de órbita obtida com integração numérica da equação de Hill. Dado $y_{\mathrm{t}}$ como a posição do guiding center no turn-off da órbita, temos que, se $y_{\mathrm{t}}-2 \tilde{e}$ for maior que uma certa distância não ocorre colisão, caso contrário, registra-se a colisão. A distância de referência para colisão é obtida através da análise da energia da partícula e varia de acordo com cada órbita (Ida e Nakazawa, 1989a).

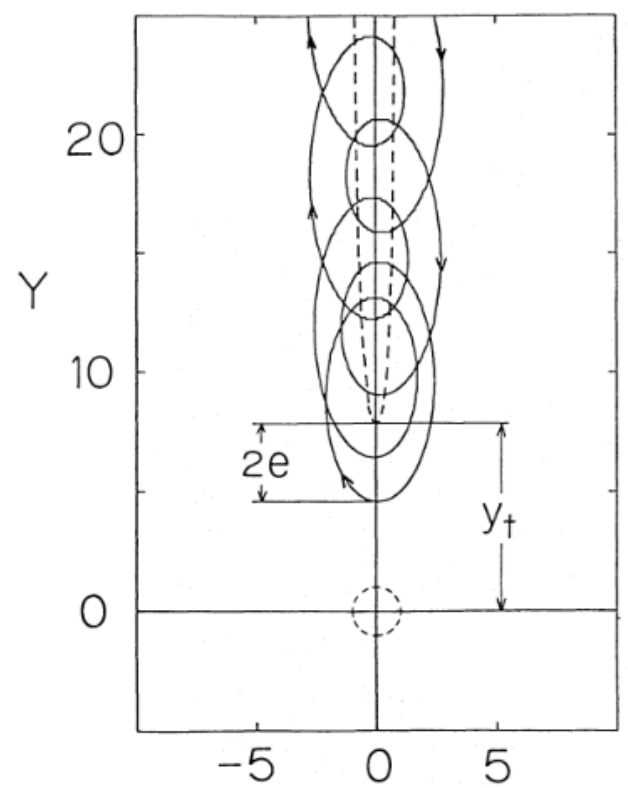

Figura 4.5: Exemplo de órbita para um parâmetro de impacto $b$ pequeno. A linha pontilhada denota a trajetória do guiding center. A esfera de Hill também é mostrada. Figura obtida em: Ida e Nakazawa (1989a)

A partir de um dado valor para $\tilde{e}, \tilde{i}$ e $\tilde{b}$, variam-se os elementos orbitais $\tau$ e $\omega$, e, utilizando a equação 4.40 , obtêm-se a probabilidade de colisão em função de $\tilde{b}$, como mostra a Figura 4.6. Na figura, é possível observar que as órbitas são separadas em: (1st) quando a partícula entra na esfera de aproximação para dois corpos e sai dela sem um 
encontro próximo; (2nd) quando a partícula entra na esfera de aproximação para dois corpos e há um encontro próximo, e (3rd) órbitas com colisões recorrentes. Em seguida, obtêm-se $\langle P(\tilde{e}, \tilde{i})\rangle$ através da integração numérica da equação 4.41 . Os procedimentos numéricos completos e detalhados para obtenção de $\langle P(\tilde{e}, \tilde{i})\rangle$ podem ser vistos em Ida e Nakazawa 1989a).

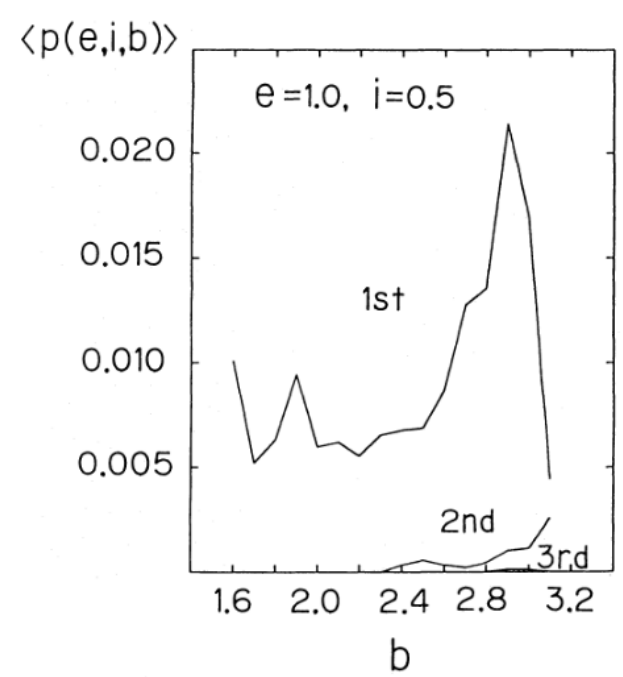

Figura 4.6: Taxa de colisão plotada em função de $b$ para o caso de $(e, i)=(1.0 ; 0.5)$. Figura obtida em: Ida e Nakazawa 1989a)

Obtido a expressão para $\langle P(\tilde{e}, \tilde{i})\rangle$, é possível obter a taxa de colisão entre planetesimais por meio da equação 4.42. Essa expressão tem sido estudada por muitos autores considerando diferentes regimes. De fato, Greenzweig e Lissauer (1990) e Greenzweig e Lissauer (1992) encontraram uma expressão analítica para a probabilidade de colisão no regime de planetesimais em altas velocidades $(\tilde{e}, \tilde{i} \gtrsim 2)$, dada por:

$$
P_{\text {high }}(\langle\tilde{e}\rangle,\langle\tilde{i}\rangle)=\frac{r_{\mathrm{p}}^{2}}{2 \pi}\left(F(\beta)+\frac{6}{r_{\mathrm{p}}} \frac{G(\beta)}{\left\langle\tilde{e}^{2}\right\rangle}\right),
$$

onde $\langle\tilde{e}\rangle$ e $\langle\tilde{i}\rangle$ são a excentricidade e inclinação quadráticas médias reduzidas dos planetesimais,

$$
r_{\mathrm{p}} \equiv \frac{R_{\text {core }}+r_{\mathrm{m}}}{h a}
$$

e $R_{\text {core }}$ é o raio do protoplaneta, $r_{\mathrm{m}}$ são os raios dos planetesimais que estão colidindo, e $\beta \equiv \frac{\langle\tilde{i}\rangle}{\langle\tilde{e}\rangle}$. As funções $F(\beta)$ e $G(\beta)$ são definidas, respectivamente, por: 


$$
F(\beta) \equiv \frac{4 \sqrt{1+\beta^{2}}}{\beta} E(k)
$$

e

$$
G(\beta) \equiv \frac{4}{\beta \sqrt{1+\beta^{2}}} K(k),
$$

onde $K(k)$ e $E(k)$ são integrais elípticas completas de primeiro e segundo tipo, respectivamente, e $k^{2} \equiv 3 /\left(4+4 \beta^{2}\right)$. As integrais são dadas por:

$$
F(\beta) \equiv 8 \int_{0}^{1} d \lambda \frac{\beta^{2} E\left[\sqrt{3\left(1-\lambda^{2} / 2\right)}\right]}{\left[\beta^{2}+\left(1-\beta^{2}\right) \lambda^{2}\right]^{2}}
$$

e

$$
G(\beta) \equiv 8 \int_{0}^{1} d \lambda \frac{K\left[\sqrt{3\left(1-\lambda^{2} / 2\right)}\right]}{\left[\beta^{2}+\left(1-I^{2}\right) \lambda^{2}\right]^{2}} .
$$

Na equação 4.43, o segundo termo expressa o aumento da probabilidade de colisão devido ao foco gravitacional, como discutido no modelo analítico simplificado da seção 2.2 .2 . Este termo é, portanto, responsável pela entrada no regime de crescimento desenfreado, isto é, o regime de runaway (Ohtsuki e Ida, 1990a).

Para baixas velocidades $(\tilde{e}, \tilde{i} \lesssim 2)$, Ida e Nakazawa $(1989 \mathrm{~b})$ encontraram que a probabilidade de colisão torna-se independente de $\tilde{e}$ e $\tilde{i}$, e é dada por:

$$
P_{\text {low }}=11.3 \sqrt{R_{\text {core }}} \text {. }
$$

O regime de baixas velocidades ocorre, por exemplo, quando $(\tilde{e}, \tilde{i})$ aproxima-se de zero.

Além disso, para o regime de médias velocidades $(0.2 \lesssim \tilde{e}, \tilde{i} \lesssim 2)$, Ida e Nakazawa (1989b) mostraram que a probabilidade de colisão depende somente da inclinação quadrática média reduzida $\langle\tilde{i}\rangle$ :

$$
P_{\text {medium }}=\frac{R_{\text {core }}^{2}}{4 \pi\left\langle\tilde{i}^{2}\right\rangle^{1 / 2}}\left(17.3+\frac{232}{R_{\text {core }}}\right)
$$

Em um sistema de planetesimais, sabe-se que $\langle\tilde{i}\rangle$ é da mesma ordem de magnitude de $\langle\tilde{e}\rangle$. Assim, Inaba et al. (2001) encontraram que uma probabilidade de colisão média pode ser aproximada para todos os regimes através da expressão: 


$$
P_{\text {coll }}=\min \left(P_{\text {medium }},\left(P_{\text {high }}^{-2}+P_{\text {low }}^{-2}\right)^{-1 / 2}\right) \text {. }
$$

A Figura 4.7 mostra as probabilidades de colisão calculadas usando a equação 4.51 quando comparadas com os resultados de uma simulação N-corpos realizada por Greenzweig e Lissauer (1992) para o caso em que $\langle\tilde{e}\rangle=\langle\tilde{i}\rangle, 2\langle\tilde{i}\rangle$ e $4\langle\tilde{i}\rangle$. Os resultados analíticos se aproximam dos resultados numéricos com um erro da ordem de 2. Nesta tese, essa será a expressão usada para o cálculo da taxa de acreção de sólidos.

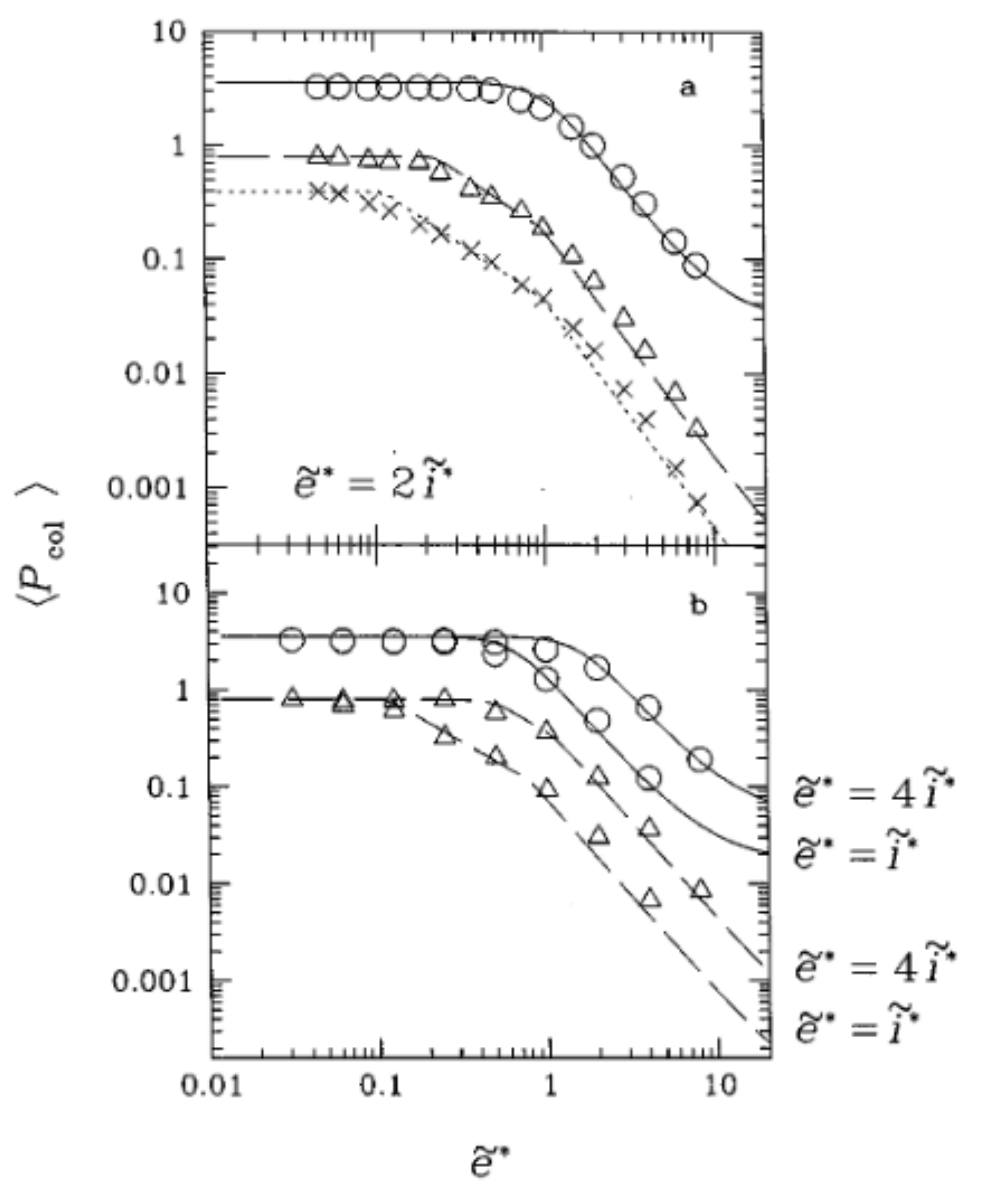

Figura 4.7: Comparação da probabildiade de colisão média analítica (curvas) com a solução numérica (círculo, triângulo e cruzes). A probabilidade de colisão média é mostrada como função de $\tilde{e}^{*}$ para os casos (a) $\tilde{e}^{*}=2 \tilde{i}^{*}$ e (b) $\tilde{e}^{*}=\tilde{i}^{*}, 4 \tilde{i}^{*}$, o asterisco denota que se tratam da excentricidade e inclinação quadráticas médias reduzidas dos planetesimais. A linha sólida, a tracejada e a pontilhada equivalem, respectivamente, a $r_{p}=0.1,0.005$ e 0.0012 . Figura obtida em: Inaba et al. (2001). 


\subsection{Evolução da excentricidade e da inclinação quadrática média dos planetesimais}

Como a probalilidade de colisão entre o protoplaneta e os planetesimais depende da excentricidade e inclinação quadrática média dos planetesimais, isto é, da velocidade de dispersão dos planetesimais, estes valores precisam ser calculados precisamente. Além disso, as excentricidades e inclinações desses planetesimais mudam como resultado da perturbação gravitacional do protoplaneta e decrescem devido ao arrasto do gás, alterando os valores quadráticos médios ao longo do tempo. Portanto, podemos escrever:

$$
\left\{\begin{array}{l}
\frac{d\left\langle e^{2}\right\rangle}{d t}=\left(\frac{d\left\langle e^{2}\right\rangle}{d t}\right)_{\text {grav }}+\left(\frac{d\left\langle e^{2}\right\rangle}{d t}\right)_{\text {gas }}, \\
\frac{d\left\langle i^{2}\right\rangle}{d t}=\left(\frac{d\left\langle i^{2}\right\rangle}{d t}\right)_{\text {grav }}+\left(\frac{d\left\langle i^{2}\right\rangle}{d t}\right)_{\text {gas }},
\end{array}\right.
$$

onde os termos grav e gas expressam a variação da excentricidade e da inclinação quadráticas médias em razão da perturbação gravitacional do protoplaneta e do arrasto do gás.

\subsubsection{Evolução da excentricidade e da inclinação quadrática média dos planetesimais devido à perturbação gravitacional do protoplaneta}

$\mathrm{Na}$ teoria de formação planetária, o termo viscous stirring denota a transferência da energia orbital de uma partícula para a energia cinética de outras partículas. Por exemplo, um corpo massivo pode aumentar significativamente a velocidade de um corpo menos massivo por meio da interação gravitacional entre eles. Quando esta aceleração ocorre, o corpo mais massivo fornece uma parte da sua energia ao corpo menos massivo. Esta situação não deve ser confundida com o termo dynamical friction, na qual a velocidade de um corpo massivo sofre alteração como resultado do excesso de pequenos corpos menos massivos agindo gravitacionalmente sobre ele. Usaremos os termos ação impulsiva para o primeiro caso e fricção dinâmica para o segundo. A evolução da excentricidade e da inclinação quadráticas médias dos planetesimais devido a esses dois efeitos combinados foi calculada por Ohtsuki et al. (2002) usando a combinação de resultados semianalíticos e da integração numérica do problema de três corpos. Para entender um pouco do trabalho realizado por Ohtsuki et al. (2002), considere a evolução da velocidade de dispersão de uma população bimodal de partículas, em que cada população consiste de planetesimais, 
respectivamente, de massas $m_{1}$ e $m_{2}$ 1.

Antes de iniciar a análise, é útil introduzir os vetores excentricidade e inclinação reduzidas do planetesimal $j$, definidos por (Henon e Petit, 1986):

$$
\left\{\begin{array}{l}
\tilde{\boldsymbol{e}}_{j} \equiv\left(\tilde{e}_{j} \cos \tau_{j}, \tilde{e}_{j} \sin \tau_{j}\right) \\
\tilde{\boldsymbol{i}}_{j} \equiv\left(\tilde{i}_{j} \cos \omega_{j}, \tilde{i}_{j} \sin \omega_{j}\right)
\end{array}\right.
$$

Da mesma forma, para o movimento relativo e do centro de massa, temos, respectivamente:

$$
\left\{\begin{array}{l}
\tilde{\boldsymbol{e}} \equiv(\tilde{e} \cos \tau, \tilde{e} \sin \tau)=\tilde{\boldsymbol{e}}_{2}-\tilde{\boldsymbol{e}}_{1} \\
\tilde{\boldsymbol{i}} \equiv(\tilde{i} \cos \omega, \tilde{i} \sin \omega)=\tilde{\boldsymbol{i}}_{2}-\tilde{\boldsymbol{i}}_{1}
\end{array}\right.
$$

e

$$
\left\{\begin{array}{l}
\tilde{\boldsymbol{E}} \equiv(\tilde{E} \cos T, \tilde{E} \sin T)=m_{1} \tilde{\boldsymbol{e}}_{1}+m_{2} \tilde{\boldsymbol{e}}_{2}, \\
\tilde{\boldsymbol{I}} \equiv(\tilde{E} \cos W, \tilde{E} \sin W)=m_{1} \tilde{\boldsymbol{i}}_{1}+m_{2} \tilde{\boldsymbol{i}}_{2}
\end{array}\right.
$$

Como o movimento do centro de massa não é afetado, a mudança da excentricidade reduzida $\tilde{e}_{1}$ de uma partícula de massa $m_{1}$ devido a um encontro com uma partícula de massa $m_{2}$ é escrito como (Ohtsuki e Ida, 1990b):

$$
\Delta \tilde{e}_{1}^{2}=m_{2}^{2} \Delta \tilde{e}^{2}-2 m_{2} \tilde{\boldsymbol{E}} \cdot \Delta \tilde{\boldsymbol{e}}
$$

Então, a mudança da excentricidade quadrática média reduzida da população $1,\left\langle\tilde{e}_{1}\right\rangle$, decorrentes das interações com a população 2 é escrita como:

$$
\frac{d\left\langle\tilde{e}_{1}^{2}\right\rangle}{d t}=N_{s 2} \int f\left(\tilde{e}_{1}, \tilde{i}_{1}\right) f\left(\tilde{e}_{2}, \tilde{i}_{2}\right) \Delta \tilde{e}_{1}^{2} \frac{3}{2} \tilde{b} d \tilde{b} \frac{d \tau_{1} d \omega_{1}}{(2 \pi)^{2}} \frac{d \tau_{2} d \omega_{2}}{(2 \pi)^{2}} d \tilde{e}_{1} d \tilde{i}_{1} d \tilde{e}_{2} d \tilde{i}_{2}
$$

onde $N_{s 2}$ é a densidade superficial numérica das partículas $2, \tilde{b}=\tilde{b}_{2}-\tilde{b}_{1}$ é a diferença no parâmetro de impacto, $f$ é a função de distribuição da excentricidade e inclinação reduzida $\tilde{e}_{j}$ e $\tilde{i}_{j}$ (ver eq. 4.20 com $j=1$ ou 2 , e os ângulos de fases $\tau_{j}$ e $\omega_{j}$ são uniformemente distribuídos entre 0 e $2 \pi$.

\footnotetext{
${ }^{1} \mathrm{O}$ artigo também apresenta o cálculo para casos mais gerais. Ver Ohtsuki et al. (2002).
} 
Utilizando o mesmo procedimento realizado por Ohtsuki e Ida (1990b), com o intuito de obter o segundo termo da equação 4.56, as variáveis $\tilde{\boldsymbol{E}}$ e $\Delta \tilde{\boldsymbol{e}}$ podem ser decompostas em uma componente paralela e normal a $\tilde{\boldsymbol{e}}$, assim:

$$
\begin{gathered}
\tilde{E}_{\|}=\tilde{\boldsymbol{E}} \cdot \tilde{\boldsymbol{e}} / \tilde{e}, \\
\tilde{E}_{\perp}=\left(\tilde{E}^{2}+\tilde{E}_{\|}^{2}\right)^{1 / 2},
\end{gathered}
$$

e

$$
\begin{gathered}
\Delta \tilde{e}_{\|}=\cos \tau \cdot \Delta(\tilde{e} \cos \tau)+\sin \tau \cdot \Delta(\tilde{e} \sin \tau), \\
\Delta \tilde{e}_{\perp}=\sin \tau \cdot \Delta(\tilde{e} \cos \tau)-\cos \tau \cdot \Delta(\tilde{e} \sin \tau) .
\end{gathered}
$$

Ainda seguindo Ohtsuki e Ida (1990b), ao invés de $\tilde{\boldsymbol{E}}$, nós introduzimos uma variável alternativa $\tilde{\boldsymbol{E}}^{*}$, definida por:

$$
\tilde{\boldsymbol{E}}^{*}=\frac{\left\langle\tilde{e}_{2}^{2}\right\rangle \tilde{\boldsymbol{e}}_{1}+\left\langle\tilde{e}_{1}^{2}\right\rangle \tilde{\boldsymbol{e}}_{2}}{\left\langle\tilde{e}_{1}^{2}\right\rangle+\left\langle e_{2}^{2}\right\rangle}
$$

que é relacionada com $\tilde{\boldsymbol{E}}$ e $\tilde{\boldsymbol{e}}$ na forma:

$$
\tilde{\boldsymbol{E}}^{*}=\tilde{\boldsymbol{E}}-\frac{m_{2}\left\langle\tilde{e}_{2}^{2}\right\rangle-m_{1}\left\langle\tilde{e}_{1}^{2}\right\rangle}{\left\langle\tilde{e}_{1}^{2}\right\rangle+\left\langle\tilde{e}_{2}^{2}\right\rangle} \tilde{\boldsymbol{e}} .
$$

Usando o mesmo raciocínio, definimos $\tilde{\boldsymbol{I}}^{*}$ ao invés de $\tilde{\boldsymbol{I}}$.

Assim como na equação 4.55, as componentes de $\tilde{\boldsymbol{E}}^{*}$ e $\tilde{\boldsymbol{I}}^{*}$ podem ser expressas como:

$$
\left\{\begin{array}{l}
\tilde{\boldsymbol{E}}^{*}=\left(\tilde{E}^{*} \cos T^{*}, \tilde{E}^{*} \sin T^{*}\right), \\
\tilde{\boldsymbol{I}}^{*}=\left(\tilde{I}^{*} \cos W^{*}, \tilde{I}^{*} \sin W^{*}\right) .
\end{array}\right.
$$

Portanto, em termos de $\tilde{\boldsymbol{E}}^{*}$ e $\tilde{\boldsymbol{e}}, \tilde{E}_{\|}$e $\tilde{E}_{\perp}$, são escritos como:

$$
\left\{\begin{array}{l}
\tilde{E}_{\|}=\tilde{E}^{*} \cos \left(T^{*}-\tau\right)+\frac{m_{2}\left\langle\tilde{e}_{2}^{2}\right\rangle-m_{1}\left\langle\tilde{e}_{1}^{2}\right\rangle}{\left\langle\tilde{e}_{1}^{2}\right\rangle+\left\langle\tilde{e}_{2}^{2}\right\rangle} \tilde{e} \\
\tilde{E}_{\perp}=\tilde{E}^{*} \sin \left(T^{*}-\tau\right) .
\end{array}\right.
$$

Logo, $\Delta \tilde{e}_{1}^{2}$ (ver eq. 4.56) pode ser escrita na forma: 
$\Delta \tilde{e}_{1}^{2}=m_{2}^{2} \Delta \tilde{e}^{2}-2 m_{2}\left\{\left[\tilde{E}^{*} \cos \left(T^{*}-\tau\right)+\frac{m_{2}\left\langle\tilde{e}_{2}^{2}\right\rangle-m_{1}\left\langle\tilde{e}_{1}^{2}\right\rangle}{\left\langle\tilde{e}_{1}^{2}\right\rangle+\left\langle\tilde{e}_{2}^{2}\right\rangle} \tilde{e}\right] \times \Delta \tilde{e}_{\|}+\tilde{E}^{*} \sin \left(T^{*}-\tau\right) \Delta \tilde{e}_{\perp}\right\}$.

Além disso, para calcular a integral 4.57 , as variáveis são alteradas de $\left(\tilde{e}_{1}, \tilde{i}_{1}, \tau_{1}, \omega_{1}, \tilde{e}_{2}, \tilde{i}_{2}, \tau_{2}, \omega_{2}\right)$ para $\left(\tilde{e}, \tilde{i}, \tau, \omega, \tilde{\boldsymbol{E}}^{*}, \tilde{\boldsymbol{I}}^{*}, \boldsymbol{T}^{*}, \boldsymbol{W}^{*}\right)$. O jacobiano para esta transformação é:

$$
\frac{\partial\left(\tilde{e}_{1}, \tilde{i}_{1}, \tau_{1}, \omega_{1}, \tilde{e}_{2}, \tilde{i}_{2}, \tau_{2}, \omega_{2}\right)}{\partial\left(\tilde{e}, \tilde{i}, \tau, \omega, \tilde{E}^{*}, \tilde{I}^{*}, T^{*}, W^{*}\right)}=\frac{\tilde{e} \tilde{i} \tilde{E}^{*} \tilde{I}^{*}}{\tilde{e}_{1} \tilde{i}_{1} \tilde{e}_{2} \tilde{i}_{2}} .
$$

Assim, a equação 4.57, em conjunto com a equação 4.20, podem ser expressas em termos de $\tilde{\boldsymbol{e}}, \tilde{\boldsymbol{i}}, \tilde{\boldsymbol{E}}^{*}$ e $\tilde{\boldsymbol{I}}^{*}$ como:

$$
\begin{array}{r}
\frac{d\left\langle\tilde{e}_{1}^{2}\right\rangle}{d t}=N_{s 2} \int \frac{16 \tilde{e} \tilde{i} \tilde{E}^{*} \tilde{I}^{*}}{\left\langle\tilde{e}^{2}\right\rangle\left\langle\tilde{i}^{2}\right\rangle\left\langle\tilde{E}^{*^{2}}\right\rangle\left\langle\tilde{I}^{*^{2}}\right\rangle} \\
\times \exp \left(-\frac{\tilde{e}^{2}}{\left\langle\tilde{e}^{2}\right\rangle}-\frac{\tilde{i}^{2}}{\left\langle\tilde{i}^{2}\right\rangle}-\frac{\tilde{E}^{*^{2}}}{\left\langle\tilde{E}^{*^{2}}\right\rangle}-\frac{\tilde{I}^{*^{2}}}{\left\langle\tilde{I}^{*^{2}}\right\rangle}\right) \\
\Delta \tilde{e}_{1}^{2} \frac{3}{2} \tilde{b} d \tilde{b} \frac{d \tau d \omega}{(2 \pi)^{2}} \frac{d \tilde{T}^{*} \tilde{W}^{*}}{(2 \pi)^{2}} d \tilde{e} d \tilde{i} d \tilde{E}^{*} d \tilde{I}^{*},
\end{array}
$$

onde $\Delta \tilde{e}_{1}^{2}$ é dada pela equação 4.66. As variáveis com dispersão que aparecem em 4.68 podem ser expressas em termos de $\left\langle\tilde{e}_{1}^{2}\right\rangle,\left\langle\tilde{i}_{1}^{2}\right\rangle,\left\langle\tilde{e}_{2}^{2}\right\rangle$ e $\left\langle\tilde{i}_{2}^{2}\right\rangle$ como:

$$
\left\{\begin{array}{l}
\left\langle\tilde{e}^{2}\right\rangle=\left\langle\tilde{e}_{1}^{2}\right\rangle+\left\langle\tilde{e}_{2}^{2}\right\rangle \\
\left\langle\tilde{i}^{2}\right\rangle=\left\langle\tilde{i}_{1}^{2}\right\rangle+\left\langle\tilde{i}_{2}^{2}\right\rangle
\end{array}\right.
$$

e

$$
\left\{\begin{array}{l}
\left\langle\tilde{E}^{*^{2}}\right\rangle=\frac{\left\langle\tilde{e}_{1}^{2}\right\rangle\left\langle\tilde{e}_{2}^{2}\right\rangle}{\left\langle\tilde{e}_{1}^{2}\right\rangle+\left\langle\tilde{e}_{2}^{2}\right\rangle}, \\
\left\langle\tilde{I}^{*^{2}}\right\rangle=\frac{\left\langle\tilde{i}_{1}^{2}\right\rangle\left\langle\tilde{i}_{2}^{2}\right\rangle}{\left\langle\tilde{i}_{1}^{2}\right\rangle+\left\langle\tilde{i}_{2}^{2}\right\rangle} .
\end{array}\right.
$$

No lado direito da equação $4.66, \Delta \tilde{e}^{2}, \Delta \tilde{e}_{\|}$e $\Delta \tilde{e}_{\perp}$ são funções de $\tilde{\boldsymbol{e}}$ e $\tilde{\boldsymbol{i}}$ somente. Portanto, as integrais sobre $T^{*}$ e $W^{*}$ na equação 4.68 podem ser calculadas diretamente, e os termos contendo $\tilde{E}^{*} \cos \left(T^{*}-\tau\right)$ ou $\tilde{E}^{*} \sin \left(T^{*}-\tau\right)$ se anulam. Então, as integrais sobre $\tilde{E}^{*}$ e $\tilde{I}^{*}$ podem ser calculadas, assim, obtemos:

$$
\frac{d\left\langle\tilde{e}_{1}^{2}\right\rangle}{d t}=N_{s 2} m_{2}\left[m_{2}\left\langle P_{\mathrm{VS}}\right\rangle+\frac{m_{2}\left\langle\tilde{e}_{2}^{2}\right\rangle-m_{1}\left\langle\tilde{e}_{1}^{2}\right\rangle}{\left\langle\tilde{e}_{1}^{2}\right\rangle+\left\langle\tilde{e}_{2}^{2}\right\rangle}\left\langle P_{\mathrm{DF}}\right\rangle\right]
$$


com

$$
\left\{\begin{array}{l}
\left\langle P_{\mathrm{VS}}\right\rangle=\int P_{\mathrm{VS}}(\tilde{e}, \tilde{i}) f(\tilde{e}, \tilde{i}) d \tilde{e} \tilde{d}, \\
\left\langle P_{\mathrm{DF}}\right\rangle=\int P_{\mathrm{DF}}(\tilde{e}, \tilde{i}) f(\tilde{e}, \tilde{i}) d \tilde{e} \tilde{d},
\end{array}\right.
$$

onde $f$ é a função de distribuição de Rayleigh (ver eq. 4.20), com as variáveis de dispersão dadas pela equações 4.69 e 4.70 , e $P_{\mathrm{VS}}(\tilde{e}, \tilde{i})$ e $P_{\mathrm{DF}}(\tilde{e}, \tilde{i})$, as taxas de interação gravitacional, definidas por:

$$
\left\{\begin{array}{l}
P_{\mathrm{VS}}(\tilde{e}, \tilde{i})=\int \Delta \tilde{e}^{2} \frac{3}{2} \tilde{b} d \tilde{b} \frac{d \tau d \omega}{(2 \pi)^{2}} \\
P_{\mathrm{DF}}(\tilde{e}, \tilde{i})=-2 \tilde{e} \int \Delta \tilde{e}{ }_{\|} \frac{3}{2} \tilde{b} d \tilde{b} \frac{d \tau d \omega}{(2 \pi)^{2}} .
\end{array}\right.
$$

Os termos $P_{\mathrm{VS}}(\tilde{e}, \tilde{i})$ e $P_{\mathrm{DF}}(\tilde{e}, \tilde{i})$ são responsáveis, respectivamente, pelo efeito impulsivo (viscous stirring) e fricção dinâmica (dynamical friction). A mudança de $\left\langle\tilde{i}_{1}^{2}\right\rangle$ pode ser obtida usando o mesmo raciocínio.

Para completar a equação para evolução da excentricidade quadrática média, a interação com partículas do mesmo tamanho precisa ser considerada. Para isso, é importante destacar que o raio de Hill mútuo $h_{12} a_{0}$, definido em termos de $m_{1}$ e $m_{2}$, foi usado como unidade de comprimento na equação 4.71. Desse modo, a equação 4.71 não pode ser usada diretamente nesta escala para interação entre partículas do mesmo tamanho $m_{1}$. Assim, na forma não escalonada, a equação 4.71 é escrita na forma:

$$
\frac{d\left\langle e_{1}^{2}\right\rangle}{d t}=N_{s 2} m_{2} h_{12}^{4} a_{0}^{2} \Omega\left[m_{2}\left\langle P_{\mathrm{VS}}\right\rangle_{12}+\frac{m_{2}\left\langle e_{2}^{2}\right\rangle-m_{1}\left\langle e_{1}^{2}\right\rangle}{\left\langle e_{1}^{2}\right\rangle+\left\langle e_{2}^{2}\right\rangle}\left\langle P_{\mathrm{DF}}\right\rangle_{12}\right]
$$

Na equação acima, o subscrito 12 foi adicionado aos termos $\left\langle P_{\mathrm{VS}}\right\rangle$ e $\left\langle P_{\mathrm{DF}}\right\rangle$ para denotar a interação entre $m_{1}$ e $m_{2}$, estes termos estão em função dos elementos orbitais relativos escalonados com $h_{12}$. Adicionando o termo para interação entre partículas do mesmo tamanho (i.e., mesma massa), obtemos:

$$
\frac{d\left\langle e_{1}^{2}\right\rangle}{d t}=\sum_{j=1,2}\left[N_{s 2} m_{j}^{\prime} h_{1 j}^{4} a_{0}^{2} \Omega\left(m_{j}^{\prime}\left\langle P_{\mathrm{VS}}\right\rangle_{1 j}+\frac{m_{j}^{\prime}\left\langle e_{j}^{2}\right\rangle-m_{1}\left\langle e_{1}^{2}\right\rangle}{\left\langle e_{1}^{2}\right\rangle+\left\langle e_{2}^{2}\right\rangle}\left\langle P_{\mathrm{DF}}\right\rangle_{1 j}\right)\right]
$$

onde $m_{j}^{\prime}=m_{j} /\left(m_{1}+m_{j}\right) \mathrm{e}$

$$
h_{1 j}=\left(\frac{m_{1}+m_{j}}{3 M_{\star}}\right) .
$$


Quando $j=1$, o termo da fricção dinâmica se anula e $\left\langle P_{\mathrm{VS}}\right\rangle_{11}$ denota a interação entre partículas do mesmo tamanho.

Nesta tese, vamos nos limitar ao caso limite das expressões acima. Isto é, o efeito gravitacional de protoplanetas de massa $M$ sobre planetesimais de massa $m$. Neste limite, a evolução da excentricidade e da inclinação quadráticas médias é dada por:

$$
\frac{d\left\langle e^{2}\right\rangle}{d t}=a^{2} \Omega N_{\mathrm{e}}\left(\frac{M+m}{3 M_{\star}}\right)^{4 / 3} \frac{M^{2}}{(M+m)^{2}} P_{\mathrm{VS}}
$$

e

$$
\frac{d\left\langle i^{2}\right\rangle}{d t}=a^{2} \Omega N_{\mathrm{e}}\left(\frac{M+m}{3 M_{\star}}\right)^{4 / 3} \frac{M^{2}}{(M+m)^{2}} Q_{\mathrm{VS}},
$$

onde $N_{\mathrm{e}}=\Sigma_{\mathrm{e}} / M_{\text {core }}$ é a densidade numérica de embriões planetários que possuem uma densidade superficial de $\Sigma_{\mathrm{e}}$. Para $m<<M$, estas expressões podem ser simplificadas consideravelmente. Então, podemos escrever:

$$
\left\{\begin{array}{l}
\frac{d\left\langle e^{2}\right\rangle}{d t}=\frac{a \Omega R_{\mathrm{H}}}{3 M_{\star}} P_{\mathrm{VS}} \\
\frac{d\left\langle i^{2}\right\rangle}{d t}=\frac{a \Omega R_{\mathrm{H}}}{3 M_{\star}} Q_{\mathrm{VS}}
\end{array}\right.
$$

onde $R_{\mathrm{H}}$ é o raio de Hill do embrião.

Considerando uma distribuição de Rayleigh e o regime de baixas e altas velocidades, Ohtsuki et al. (2002) obtiveram as seguintes relações para os termos $P_{\mathrm{VS}}$ e $Q_{\mathrm{Vs}}$ :

$$
\left\{\begin{array}{l}
P_{\mathrm{VS}}=\left[\frac{73\left\langle\tilde{e}^{2}\right\rangle}{10 \Lambda^{2}}\right] \ln \left(1+10 \Lambda^{2} /\left\langle\tilde{e}^{2}\right\rangle\right)+\left[\frac{72 I_{\mathrm{PVS}}(\beta)}{\pi\left\langle\tilde{e}^{2}\right\rangle^{1 / 2}\left\langle\tilde{i}^{2}\right\rangle^{1 / 2}}\right] \ln \left(1+\Lambda^{2}\right) \\
Q_{\mathrm{VS}}=\left[\frac{4\left\langle\tilde{i}^{2}\right\rangle+0.2\left\langle\tilde{e}^{2}\right\rangle^{3 / 2}\left\langle\tilde{i}^{2}\right\rangle^{1 / 2}}{10 \Lambda^{2}\left\langle\tilde{e}^{2}\right\rangle^{1 / 2}}\right] \ln \left(1+10 \Lambda^{2}\left\langle\tilde{e}^{2}\right\rangle^{1 / 2}\right)+\left[\frac{72 I_{\mathrm{QVS}}(\beta)}{\pi\left\langle\tilde{e}^{2}\right\rangle^{1 / 2}\left\langle\tilde{i}^{2}\right\rangle^{1 / 2}}\right] \ln \left(1+\Lambda^{2}\right)
\end{array}\right.
$$

$\operatorname{com} \Lambda=\left\langle\tilde{i}^{2}\right\rangle^{1 / 2}\left(\left\langle\tilde{e}^{2}\right\rangle+\left\langle\tilde{i}^{2}\right\rangle\right) / 12$. As funções $I_{\mathrm{PVS}}(\beta)$ e $I_{\mathrm{QVS}}(\beta)$ são integrais elípticas que podem ser aproximadas por:

$$
\left\{\begin{array}{l}
I_{\mathrm{PVS}}(\beta) \simeq \frac{\beta-0.36251}{0.061547+0.16112 \beta+0.054473 \beta^{2}} \\
I_{\mathrm{QVS}}(\beta) \simeq \frac{0.71946-\beta}{0.21239+0.49764 \beta+0.14369 \beta^{2}}
\end{array}\right.
$$

onde $\beta=\frac{\langle\tilde{i}\rangle}{\langle\tilde{e}\rangle}$. 
Os cálculos mostrados acima são complexos e exigem aproximações numéricas, o intuito é fornecer ao leitor um resumo dos procedimentos. Mais detalhes podem ser obtidos em Ohtsuki et al. (2002).

\subsubsection{Evolução da excentricidade e da inclinação quadrática média devido ao arrasto do gás}

Conforme vimos nas seções 2.2.1 e 2.2.2, o gás desempenha um papel primordial na formação da poeira e na captura dos planetesimais pelo protoplaneta. De fato, o arrasto é responsável por deslocar a poeira para o plano médio do disco e em direção à estrela criando regiões de sobredensidade. No caso dos planetesimais, o arrasto altera sua energia diferenciando aqueles que podem ou não entrar no raio de Hill do protoplaneta.

Nesta seção, vamos investigar um problema tridimensional de um planetesimal sofrendo uma força de arrasto por meio de uma lei de resistência realística, para isso vamos utilizar os mesmos procedimentos descritos em Adachi et al. (1976).

Sabemos que o gás, em movimento circular, possui uma velocidade de rotação levemente menor que a kepleriana em decorrência do gradiente de pressão (ver seção 2.1.3). Além disso, vamos assumir que o planetesimal é uma esfera, e, que a equação para o arrasto do gás dependa do tamanho desse planetesimal, da velocidade relativa e de algumas condições para o gás.

Quando a força de arrasto é pequena, comparada com a força gravitacional solar, é possivel tratá-la como uma pequena perturbação no movimento kepleriano. A equação de movimento do planetesimal no disco de gás sob influência da força gravitacional e da frição do gás é escrita, no sistema heliocêntrico, como:

$$
\frac{d^{2} \vec{R}}{d t^{2}}+\frac{G M_{\star}}{R^{2}} \vec{R}=\vec{f}
$$

onde $G, \vec{R}, M_{\star}$ e $\vec{f}$ são, respectivamente, a constante gravitacional, o vetor posição do planetesimal, a massa da estrela e a força de arrasto por unidade de massa do planetesimal. Seja $(x, y, z)$ o sistema de coordenadas retangular cujo eixo $z$ coincide com o eixo de rotação do disco e que o plano $(x, y)$ coincide com o plano equatorial, e ainda que $(r, \theta, z)$ seja o correspondente sistema de coordenadas cilindricas.

Quando $\vec{f}$ é pequeno, comparado com a força gravitacional, o movimento do planetesimal é o movimento kepleriano e suas coordenadas $x, y, z$ e velocidades $\dot{x}, \dot{y}, \dot{z}$ são expressas 
em termos do tempo $t$ e seis constantes de integração. Para essas constantes de integração, nós tomamos os elementos orbitais: semieixo maior $a$, excentricidade $e$, inclinação $i$, longitude do nodo ascendente $\Omega$, argumento do periélio $\omega$ e tempo de passagem pelo periélio $t_{0}$.

Seja $(\xi, \eta, \varsigma)$ o sistema de coordenadas retangulares orbitais, o eixo $\xi$ passa diretamente pelo periélio e usamos $(R, \psi, \varsigma)$ como o correspondente sistema de coordenadas cilíndricas (ver Fig. 4.8).

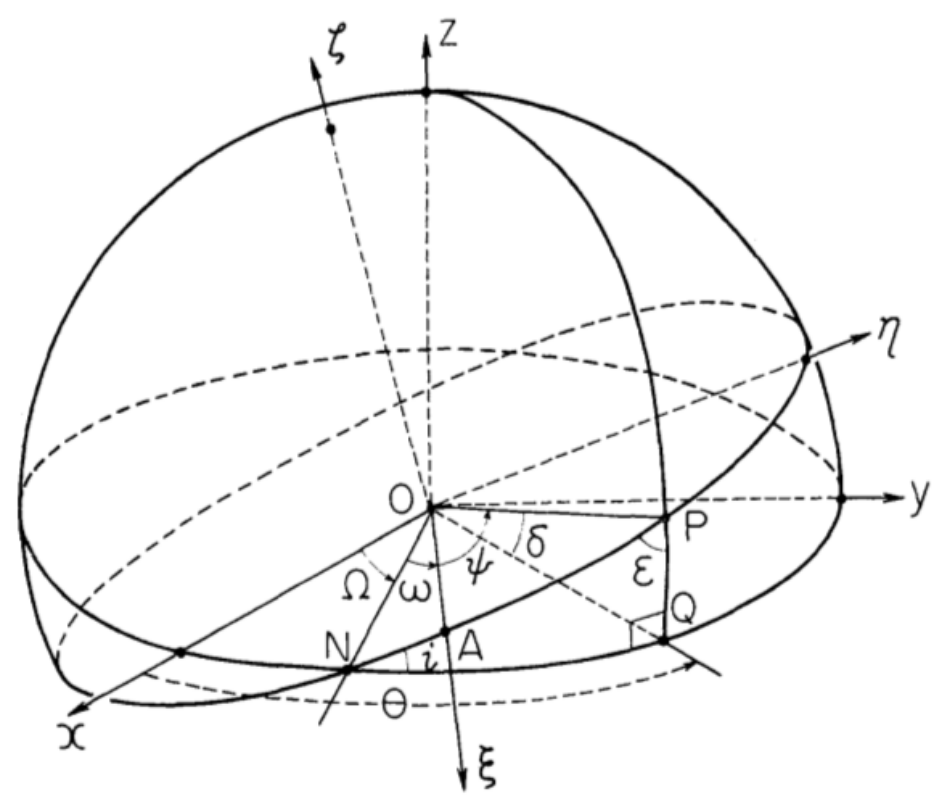

Figura 4.8: Coordenadas heliocêntricas equatoriais $(x, y, z)$ e coordenadas heliocêntricas orbitais $(\xi, \eta, \varsigma)$. Os pontos $N, A$ e $P$ denotam, respectivamente, o nodo ascendente, o periélio e a posição da partícula. A órbita elíptica da partícula está no plano $(\xi, \eta)$. Figura obtida em: Adachi et al. (1976).

Temos, então:

$$
\begin{gathered}
R=a(1-e \cos E)=\frac{a\left(1-e^{2}\right)}{1+e \cos \psi}, \quad \varsigma=0, \\
\dot{R}=\left(\frac{G M_{\star}}{a}\right)^{1 / 2} \frac{e \sin \psi}{\left(1-e^{2}\right)^{1 / 2}}, \quad \dot{\varsigma}=0,
\end{gathered}
$$

e

$$
R \dot{\psi}=\left(\frac{G M_{\star}}{a}\right)^{1 / 2} \frac{1+e \cos \psi}{\left(1-e^{2}\right)^{1 / 2}}
$$


onde $\psi$ e $E$ são a anomalia verdadeira e a anomalia excêntrica. A última definida pela equação de Kepler:

$$
E-e \sin E=n\left(t-t_{0}\right)
$$

onde $n=\left(\frac{G M_{\star}}{a^{3}}\right)^{1 / 2}$ é a velocidade angular do planetesimal.

Quando uma pequena perturbação $\vec{f}$ é incluída, esses elementos orbitais não são mais constantes, mas variam lentamente no tempo $t$. Sejam $f_{r}$ a componente de $\vec{f}$ na direção do vetor radial instantâneo, $f_{\phi}$ a componente perpendicular ao vetor radial no plano orbital e $f_{\xi}$ a componente perpendicular ao plano orbital, as variações dos elementos $a, e$ e $i$ são dadas por (Brouwer e Clemence, 1961):

$$
\begin{gathered}
\frac{d a}{d t}=\frac{2}{n\left(1-e^{2}\right)^{1 / 2}}\left[f_{r} e \sin \psi+f_{\psi} \frac{a\left(1-e^{2}\right)}{R}\right], \\
\frac{d e}{d t}=\frac{\left(1-e^{2}\right)^{1 / 2}}{n a}\left[f_{r} \sin \psi+f_{\psi}(\cos E+\cos \psi)\right], \\
\frac{d i}{d t}=\frac{1}{n a\left(1-e^{2}\right)^{1 / 2}}\left[f_{\varsigma} \frac{R}{a} \cos (\psi+\omega)\right] .
\end{gathered}
$$

Para os elementos de fase $\Omega, \omega$ e $t_{0}$, equações similares podem ser obtidas, mas não precisam ser consideradas para esse problema, pois são randômicos. As equações acima funcionam de forma exata se tomarmos os valores instantâneos dos elementos orbitais. No entanto, no caso de pequenas perturbações, podemos resolver as equações usando um método numérico.

A força de arrasto no planetesimal pode ser expressa de diferentes formas de acordo com o formato do planetesimal, o tamanho, a velocidade relativa e as condições do gás. No caso de um corpo esférico, a força de arrasto está em direção oposta à sua velocidade e sua magnitude $f_{\mathrm{D}}$ pode ser expressa na forma:

$$
f_{\mathrm{D}}=\frac{1}{2} \mathrm{C}_{\mathrm{D}} \pi r_{\mathrm{m}}^{2} \rho_{\mathrm{m}} u^{2}
$$

onde $\rho_{\mathrm{m}}$ é a densidade volumétrica do planetesimal, $r_{\mathrm{m}}$ é o raio do planetesimal, $u$ a velocidade relativa e $C_{D}$ o coeficiente de arrasto. Em geral, $C_{D}$ é uma função de duas ou três quantidades não dimensionais: o número de Mach, o número de Knudsen e o número 
de Reynolds, mais detalhes pode ser visto em Adachi et al. (1976). Para partículas grandes, usaremos a força de arrasto por unidade de massa na forma:

$$
f=A \rho_{\mathrm{m}} u^{2}
$$

com

$$
A=\frac{\mathrm{C}_{\mathrm{D}} \pi r_{\mathrm{m}}^{2}}{2}
$$

com $0.5 \leqslant \mathrm{C}_{\mathrm{D}} \leqslant 1.5$, onde assumimos $A$ constante.

Sejam $\left(v_{R}, v_{\psi}, v_{\varsigma}\right)$ as componentes da velocidade do planetesimal e $\left(V_{R}, V_{\psi}, V_{\varsigma}\right)$ as componentes da velocidade do gás. Então, as componentes das forças são dadas por:

$$
\begin{gathered}
f_{R}=\frac{\left(V_{R}-v_{R}\right) f}{u}, \\
f_{\psi}=\frac{\left(V_{\psi}-v_{\psi}\right) f}{u}, \\
f_{\varsigma}=\frac{\left(V_{\varsigma}-v_{\varsigma}\right) f}{u},
\end{gathered}
$$

onde $u$ é a velocidade relativa:

$$
u=\sqrt{\left(V_{R}-v_{R}\right)^{2}+\left(V_{\psi}-v_{\psi}\right)^{2}+\left(V_{\varsigma}-v_{\varsigma}\right)^{2}} .
$$

As componentes $\left(v_{R}, v_{\psi}, v_{\varsigma}\right)$ são dadas pelas equações 4.84 e 4.85. E as componentes $\left(V_{R}, V_{\psi}, V_{\varsigma}\right)$ são escritas como:

$$
\left\{\begin{array}{l}
V_{R}=0, \\
V_{\psi}=r \omega_{\mathrm{g}}(r) \sin \varepsilon, \\
V_{\varsigma}=-r \omega_{\mathrm{g}}(r) \cos \varepsilon,
\end{array}\right.
$$

onde $\pi / 2-\varepsilon$ é o ângulo entre a direção $\theta$ e a direção $\psi$ (ver Fig. 4.8) e $\omega_{\mathrm{g}}$ é a velocidade angular do gás. A partir do triângulo esférico $N P Q$ da Figura 4.8, encontramos:

$$
\sin \varepsilon=\frac{\cos i}{\cos \partial}
$$




$$
\begin{gathered}
\cos \varepsilon=\sin i \frac{\cos (\psi+\omega)}{\cos \partial}, \\
\cos \partial=\left[1-\sin ^{2} i \sin ^{2}(\psi+\omega)\right]^{1 / 2}=\frac{r}{R}=\frac{r}{a} \frac{1+e \cos \psi}{1-e^{2}} .
\end{gathered}
$$

Usando lei de potências (ver seção 2.1) podemos escrever a densidade volumétrica do gás $\rho$, a temperatura $T$ e a velocidade angular $\omega_{g}$, comq ${ }^{1}$.

$$
\begin{gathered}
\rho=\rho_{0} r^{-\alpha}, \\
T=T_{0} r^{-\beta}, \\
\omega_{g}(r)=\omega_{K}(r)[1-2 \eta(r)]^{1 / 2},
\end{gathered}
$$

onde:

$$
\eta=\frac{\pi}{16}(\alpha+\beta)\left(\frac{c_{\mathrm{s}}}{v_{\mathrm{K}}}\right)^{2} .
$$

$c_{\mathrm{s}}$ é a velocidade do som, $v_{\mathrm{K}}$ a velocidade kepleriana e $\alpha$ e $\beta$ são constantes que dependem do modelo de disco utilizado, por exemplo, $\alpha=3$ e $\beta=1$, se levarmos em conta o modelo da nebulosa solar miníma (Hayashi, 1981).

Assim, podemos escrever as relações 4.87, 4.88 e 4.89 como:

$$
\begin{gathered}
\frac{d a}{d t}=-A \rho u \frac{2 a}{1-e^{2}}\left[1+2 e \cos \psi+e^{2}-(1+e \cos \psi)^{3 / 2} h \cos i\right] \\
\frac{d e}{d t}=-A \rho u\left[2 \cos \psi+2 e-\frac{2 \cos \psi+e+e \cos ^{2} \psi}{(1+e \cos \psi)^{1 / 2}} h \cos i\right], \\
\frac{d i}{d t}=-A \rho u \frac{h}{(1-e \cos \psi)^{1 / 2}} \cos ^{2}(\psi+\omega) \sin i
\end{gathered}
$$

onde $\rho, h, \eta$, e $u$ são dados por:

$$
\rho=\rho(a)\left[\frac{\left(1-e^{2}\right) \cos \partial}{1+e \cos \psi}\right]^{-\alpha},
$$

${ }^{1}$ Usaremos a mesma notação do artigo citado para facilitar o estudo do leitor em conjunto com o artigo. Como trata-se de uma seção particular não haverá confusão com a notação empregada na tese. 


$$
\begin{gathered}
h(r)=\left[\frac{1-2 \eta(r)}{\cos ^{2} \partial}\right]^{1 / 2}, \\
\eta(r)=\eta\left[\frac{\left(1-e^{2}\right) \cos \partial}{1+e \cos \psi}\right]^{1-\beta}, \\
u=\frac{v_{\mathrm{K}}(a)}{\left(1-e^{2}\right)^{1 / 2}}\left[1+2 e \cos \psi+e^{2}-2(1+e \cos \psi)^{3 / 2} h \cos i\right. \\
\left.\left.=v_{\mathrm{K}}(a)\left[\left(1-\frac{3}{4} \cos ^{2} \psi\right) e^{2}+\cos ^{2}(\psi+\omega) i^{2}+\eta^{2}+\eta e \cos \psi\right) h^{2} \cos ^{2} \partial\right]^{1 / 2}+\ldots\right]^{1 / 2},
\end{gathered}
$$

onde usamos $\eta=\eta(a)$ e, na última equação, as ordens mais baixas para $e, i$ e $\eta$.

Quando a força de arrasto é muito menor que a força gravitacional da estrela central, a variação de $a, e$ e $i$ em um período orbital é muito pequena. Então, assumindo que todos os elementos $a, e, i$ e $\omega$ são constantes dentro de um período kepleriano, nós consideramos a taxa de mudança desses elementos como médias sobre um período, isto é:

$$
\left\langle\frac{d a}{d t}\right\rangle=\frac{1}{P_{\text {orbital }}} \int_{0}^{P_{\text {orbital }}} \frac{d a}{d t} d t=\frac{1}{2 \pi} \int_{0}^{2 \pi} \frac{d a}{d t} \frac{\left(1-e^{2}\right)^{3 / 2}}{(1+e \cos \psi)^{2}} d \psi .
$$

Para os propósitos deste trabalho, é suficiente considerar o caso em que $e, i$ e $\eta$ são menores que a unidade. Então, por meio da expansão de potências de $e, i$ e $\eta$ nas equações 4.108 , 4.109, 4.110 e 4.111, podemos fazer uma integração sobre $\psi$ no lado direito da equação 4.112 e obter os termos principais para cada caso limitante, (i) $e>>i, \eta$, (ii) $i>>$ e (iii) $\eta>>e, i$. Assim, adicionando estes termos principais, nós obtemos as fórmulas aproximadas que funcionam para um caso geral:

$$
\begin{gathered}
\frac{\tau_{\text {drag }}}{a}\left\langle\frac{d a}{d t}\right\rangle=-2\left\{\left[\frac{2(2 E+K)}{3 \pi} e+\frac{2}{\pi} i+\eta\right] \eta+\left(\frac{2 E+K}{9 \pi} \alpha+\frac{68 E-11 K}{54 \pi}\right) e^{3}+\frac{1}{2 \pi} i^{3}\right\} \\
\frac{\tau_{\text {drag }}}{e}\left\langle\frac{d e}{d t}\right\rangle=-\left(\frac{2 E}{\pi} e+\frac{2}{\pi} i+\eta\right) \\
\frac{\tau_{\text {drag }}}{i}\left\langle\frac{d i}{d t}\right\rangle=-\frac{1}{2}\left(\frac{2 E}{\pi} e+\frac{8}{3 \pi} i+\eta\right)
\end{gathered}
$$

onde $\tau_{\text {drag }}$ é o tempo de escala característico dado por: 


$$
\tau_{\mathrm{drag}}=\frac{1}{A \rho(a) v_{\mathrm{K}}(a)}=\frac{2 m}{\pi \mathrm{C}_{\mathrm{D}} r_{\mathrm{p}}^{2} \rho(a) v_{\mathrm{K}}(a)},
$$

$m$ é a massa do planetesimal e, $K=K(3 / 4)=2.157$ e $E=E(3 / 4)=1.211$, são a primeira e a segunda integral elíptica completa de argumento 3/4. Os termos de ordem mais alta foram desprezados.

Dessa maneira, verificamos que a variação relativa de $a$ é pequena quando comparada com $e$ e $i$, da ordem de $\eta+e^{2}+i^{2}$. Assim, em geral, um planetesimal em uma órbita elíptica com inclinação gradualmente muda para uma órbita circular sem inclinação. Quanto maiores a excentricidade e a inclinação orbital mais rápido será o decrescimento do semieixo maior do planetesimal. Além disso, se a inclinação e a excentricidade são nulas, o semieixo maior decai proporcionalmente a $\eta$, que é o termo que surge devido ao gradiente da pressão radial.

O método perturbativo usado para deduzir as expressões só é válido quando a variação relativa de $a, e$ e $i$, dentro de um período kepleriano, é muito menor que a unidade. Assim, o critério de validade é aproximadamente dado por:

$$
\frac{P_{\text {orbital }}(e+i+\eta)}{\tau_{\text {drag }}}=2 \pi A a \rho(e+i+\eta)<1 .
$$

A condição acima é satisfeita para planetesimais maiores que $10^{18} \mathrm{~g}$ (Adachi et al., 1976).

Para uma força de arrasto expressa por $F=B \rho^{\lambda} T^{\mu} u$ ( $B, \lambda$ e $\mu$ constantes), o cálculo de $d a / d t, d e / d t$ e $d i / d t$ é mais simples que o caso anterior, desde que o termo $u$ não apareça do lado direito das expressões. Teremos então para os termos de primeira ordem:

$$
\begin{gathered}
\frac{1}{a}\left\langle\frac{d a}{d t}\right\rangle=-2 B \rho^{\lambda}(a) T^{\mu}(a)\left[\eta+\frac{1}{4}\left(\lambda \alpha+\mu \beta+\frac{5}{4}\right) e^{2}+\frac{1}{8} i^{2}\right], \\
\frac{1}{e}\left\langle\frac{d e}{d t}\right\rangle=-B \rho^{\lambda}(a) T^{\mu}(a) \\
2 \frac{1}{i}\left\langle\frac{d e}{d t}\right\rangle=-B \rho^{\lambda}(a) T^{\mu}(a) .
\end{gathered}
$$

Do ponto de vista dos resultados acima, nós podemos simplificar os cálculos de $d a / d t$ nos casos em que $F=A \rho u^{2}$ por meio da aproximação: 


$$
\langle u F\rangle=\langle u\rangle\langle F\rangle=\left\langle u^{2}\right\rangle^{1 / 2}\langle F\rangle
$$

onde $F$ denota os fatores que não dependem de $u$. Assim, simplificando, temos:

$$
\left\langle u^{2}\right\rangle=v_{\mathrm{K}}^{2}(a)\left(\frac{5}{8} e^{2}+\frac{1}{2} i^{2}+\eta^{2}\right) .
$$

A aproximação dada por 4.121 é baseada no fato de que a parte constante de $u^{2}$ é maior que a amplitude da parte oscilatória, tal como $\cos 2 \psi$ e $\cos 2(\psi+\omega)$. Nesta aproximação, finalmente obtemos uma aproximação alternativa para as fórmulas dadas por:

$$
\begin{gathered}
\frac{\tau_{\text {drag }}}{a}\left\langle\frac{d a}{d t}\right\rangle=-2\left(\frac{5}{8} e^{2}+\frac{1}{2} i^{2}+\eta^{2}\right)^{1 / 2}\left[\eta+\left(\frac{\alpha}{4}+\frac{5}{16}\right) e^{2}+\frac{1}{8} i^{2}\right], \\
\frac{\tau_{\text {drag }}}{e}\left\langle\frac{d e}{d t}\right\rangle=-\left(\frac{5}{8} e^{2}+\frac{1}{2} i^{2}+\eta^{2}\right)^{1 / 2}, \\
2 \frac{1}{i}\left\langle\frac{d e}{d t}\right\rangle=-\left(\frac{5}{8} e^{2}+\frac{1}{2} i^{2}+\eta^{2}\right)^{1 / 2},
\end{gathered}
$$

onde $\tau_{\text {drag }}$ é dado por 4.116. A acurácia da equação acima é muito melhor nos casos em que os valores de $e, i$ e $\eta$ são comparáveis um com o outro.

No entanto, um estudo mais completo da equação de arrasto revela que a força de arrasto depende não só da velocidade relativa do corpo com relação ao gás e seu raio, mas também do livre caminho médio $\left(\lambda_{\text {gas }}\right)$ (Whipple, 1972; Weidenschilling, 1977), descrito por:

$$
\lambda_{\text {gas }}=\left(n_{\mathrm{g}} \sigma_{\mathrm{H}_{2}}\right)^{-1}
$$

onde $\sigma_{\mathrm{H}_{2}}$ é a seção de choque da molécula de hidrogênio e $n_{\mathrm{g}}$ é a densidade numérica dessas moléculas. É importante destacar que o valor de $\lambda_{\text {gas }}$ aumenta rapidamente com a distância à estrela central, assim, somente pequenas partículas podem experimentar um arrasto do tipo Epstein em 1 ua, mas, em 30 ua, partículas da ordem de 100 m podem experimentar o mesmo regime.

O valor do livre caminho médio $\lambda_{\text {gas }}$ altera o valor do coeficiente de arrasto na equação 4.90, já que, conforme vimos, este depende do número de Reynolds, definido por: 


$$
\operatorname{Re} \equiv \frac{v_{r} r_{\mathrm{m}}}{\nu_{\text {gas }}}
$$

onde $r_{\mathrm{m}}$ é o raio do planetesimal, $v_{r}$ a velocidade relativa e $\nu_{\text {gas }}$ é a viscosidade cinemática. A viscosidade usada por Rafikov (2004) é a viscosidade molecular, isto é, $\nu_{\text {gas }}=\frac{\lambda_{\text {gas }} c_{\mathrm{s}}}{3}$, este valor é uma aproximação e depende da fonte dessa viscosidade. Aqui seguiremos com o mesmo modelo usado por Rafikov (2004), outras aproximações requerem conhecimento mais profundo do mecanismo de viscosidade.

Para Re $\lesssim 1$, o arrasto do gás está sob o regime de Stokes (Landau e Lifshitz, 1959), onde $C_{D}=6 \pi \mathrm{Re}^{-1}$. Para $\operatorname{Re}>>1$, o coeficiente de arrasto torna-se constante $\left(C_{D} \simeq\right.$ 0.7) (Weidenschilling, 1977). O valor de $\mathrm{C}_{\mathrm{D}}$ possui um comportamento complicado entre $1 \lesssim \operatorname{Re} \gtrsim 10^{2}$, nesse caso, assume-se um comportamento assintótico que liga a continuação da função para $\operatorname{Re}=20$, justamente o caso que deduzimos anteriormente no início desta seção, que chamaremos de regime quadrático. A separação entre os regimes como função de $r_{\mathrm{m}}$ e da velocidade relativa $v_{\mathrm{r}}$ é mostrado na Figura 4.9 a seguir.

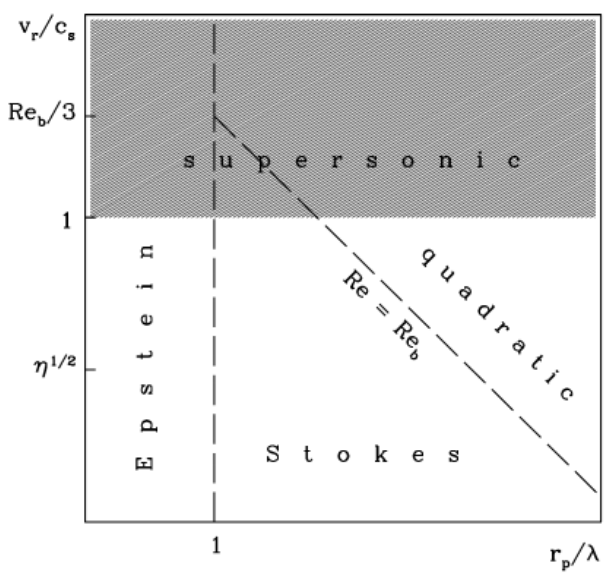

Figura 4.9: Separação da força de arrasto em diferentes regimes em função do tamanho do planetesimal, do livre caminho médio e da velocidade relativa. Figura obtida em: Rafikov (2004)

Usando novas relações para a força de arrasto, Rafikov (2004) obteve, para o regime de Stokes, a relação:

$$
\left\{\begin{array}{l}
\left(\frac{d e^{2}}{d t}\right)_{\text {gas }}=-\frac{3}{2} \frac{\lambda_{\text {gas }} c_{\mathrm{s}} \rho_{\text {gas }} e^{2}}{\rho_{\mathrm{m}} r_{\mathrm{m}}^{2}} \\
\left(\frac{d i^{2}}{d t}\right)_{\text {gas }}=-\frac{3}{4} \frac{\lambda_{\mathrm{gas}} c_{\mathrm{s}} \rho_{\mathrm{gas}} i^{2}}{\rho_{\mathrm{m}} r_{\mathrm{m}}^{2}}
\end{array}\right.
$$


E, para o regime de Epstein, a relação:

$$
\left\{\begin{array}{l}
\left(\frac{d e^{2}}{d t}\right)_{\text {gas }}=-e^{2} \frac{c_{\mathrm{s}} \rho_{\mathrm{gas}}}{\rho_{\mathrm{m}} r_{\mathrm{m}}} \\
\left(\frac{d i^{2}}{d t}\right)_{\mathrm{gas}}=-\frac{i^{2}}{2} \frac{c_{\mathrm{s}} \rho_{\mathrm{gas}}}{\rho_{\mathrm{m}} r_{\mathrm{m}}}
\end{array}\right.
$$

Embora essas equações foram escritas com base na evolução da excentricidade e inclinação de um planetesimal, elas podem ser aplicadas na evolução da excentricidade e inclinação quadráticas médias. A validade desse processo pode ser encontrada em Inaba et al. (2001).

\subsection{Modelo para acreção de sólidos no FARGO3D}

Para que o usuário possa usar, dentro do FARGO3D, o modelo para formação de um ou mais núcleos sólidos, ele deve acionar no arquivo setup. opt a variável COREACCRETION (ver apêndice A.1).

As subseções a seguir descrevem o modelo passo a passo enfatizando as relações com a descrição teórica descrita neste capítulo e com o programa colocado no apêndice.

\subsubsection{Modelagem para o crescimento do núcleo sólido}

Aqui, assumimos que o crescimento de um núcleo sólido, de massa inicial $M_{\text {core }}$ (definida no arquivo planet.cfg), é causado pela acreção de planetesimais. Adotando a aproximação particle-in-box (Chambers, 2006), podemos escrever a taxa de acreção de sólidos, $\dot{M}_{\text {core }}$, como:

$$
\dot{M}_{\text {core }}=\frac{2 \pi \Sigma_{\mathrm{m}} R_{\mathrm{H}}^{2}}{P_{\text {orbital }}} P_{\text {coll }},
$$

onde $\Sigma_{\mathrm{m}}$ é a média azimutal da densidade superficial de sólidos na localição do protoplaneta $R_{\mathrm{H}}$ o raio de Hill do protoplaneta e, $P_{\text {orbital }}$, o período orbital do protoplaneta. A probabilidade de colisão, $P_{\text {coll }}$, é a probabilidade de que os planetesimais sejam acretados pelo protoplaneta. Conforme vimos na seção 4.3.2, a probabilidade de colisão depende

\footnotetext{
${ }^{1}$ É importante destacar que essa média azimutal indica que a média foi realizada considerando todas as células que possuem o mesmo raio da célula que contém o protoplaneta. O uso da média azimutal permite levar em consideração a influência dos valores da zona de alimentação de planetesimais nos cálculos.
} 
da excentricidade e da inclinação quadráticas médias. No nosso modelo, $\langle e\rangle$ e $\langle i\rangle$ são obtidos considerando a média azimutal da excentricidades quadráticas médias e da inclinações quadráticas médias dos planetesimais, e $\langle\tilde{e}\rangle$ e $\langle\tilde{i}\rangle$ seus valores reduzidos, isto é, $\langle\tilde{e}\rangle=\langle e\rangle a_{\mathrm{p}} / R_{\mathrm{H}}$ e $\langle\tilde{i}\rangle=\langle i\rangle a_{\mathrm{p}} / R_{\mathrm{H}}$, onde $a_{\mathrm{p}}$ é a distância do protoplaneta à estrela. Conforme discutido na seção 4.3.2, as taxas de colisão são dadas pelas equações 4.43 , 4.49 e 4.50, que, com um pouco de álgebra, podem ser escritas na forma:

$$
\begin{gathered}
P_{\text {high }}=\frac{\left(R_{\text {core }}+r_{\mathrm{m}}\right)^{2}}{2 \pi R_{\mathrm{H}}}\left(F(\beta)+\frac{6 R_{\mathrm{H}} G(\beta)}{\left(R_{\text {core }}+r_{\mathrm{m}}\right)\left\langle\tilde{e}^{2}\right\rangle}\right), \\
P_{\text {medium }}=\frac{\left(R_{\text {core }}+r_{\mathrm{m}}\right)^{2}}{4 \pi R_{\mathrm{H}}{ }^{2}\langle\tilde{i}\rangle}\left(17.3+\frac{232 R_{\mathrm{H}}}{R_{\text {core }}+r_{\mathrm{m}}}\right), \\
P_{\text {low }}=11.3\left(\frac{R_{\text {core }}+r_{\mathrm{m}}}{R_{\mathrm{H}}}\right)^{1 / 2},
\end{gathered}
$$

onde $R_{\text {core }}$ é o raio geométrico do núcleo, $r_{\mathrm{m}}$ o raio do planetesimal, $\beta=\frac{\langle\tilde{i}\rangle}{\langle\tilde{e}\rangle}$ e as funções $F(\beta)$ e $G(\beta)$ são dadas pelas equações 4.47 e 4.48 , e podem ser aproximadas pelas relações (Inaba et al., 2001):

$$
\begin{gathered}
F(\beta) \simeq \frac{1+0.95925 \beta+0.77251 \beta^{2}}{\beta(0.13142+0.122995 \beta)}, \\
G(\beta) \simeq \frac{1+0.3996 \beta}{\beta\left(0.0369+0.048333 \beta+0.006874 \beta^{2}\right)} .
\end{gathered}
$$

A taxa de colisão $P_{\text {coll }}$, foi aproximada pela relação (ver seção 4.3.2):

$$
P_{\text {coll }}=\min \left(P_{\text {medium }},\left(P_{\text {high }}^{-2}+P_{\text {low }}^{-2}\right)^{-1 / 2}\right)
$$

O raio dos planetesimais, $r_{\mathrm{m}}$, é definido no arquivo setup.par (ver apêndice A.7) pela variável RM e seu valor é mantido constante ao longo da simulação.

É interessante ressaltar que usaremos o raio geométrico do embrião nas equações 4.131 . 4.132 e 4.133 , calculado mediante o uso da densidade volumétrica para o bulbo de planetesimais, $R_{\text {core }}=\left(\frac{3 M_{\text {core }}}{4 \pi \rho_{\text {bulk }}}\right)^{1 / 3}$, onde $\rho_{\text {bulk }}$ é definido no arquivo setup. par pela variável RHOM (ver apêndice A.7). No entanto, quando o embrião captura o gás, torna-se mais difícil definir seu raio, e é comum o uso do termo raio de captura, cujo valor depende da massa do protoplaneta, da velocidade relativa dos planetesimais com relação ao protoplaneta, do 
perfil de densidade do envelope e do tamanho do planetesimal acretado. O raio de captura será implementado no capítulo 5 quando tratarmos da formação completa (sólidos + gás) de um planeta gigante (ver seção 5.7).

A equação 4.130 é resolvida usando o método de euler simples. O método numérico pode ser visualizado nos arquivos computeaccretionsolids.c e computeaccretionsolidsequilibrium.c, que são usados, respectivamente, no cenário sem equilíbrio e com equilíbrio, descritos na seção 4.5.3.

\subsubsection{Densidade superficial inicial de sólidos e a zona de alimentação}

A densidade superficial inicial de sólidos, $\Sigma_{\mathrm{m}}$, é assumida ser proporcional a densidade superficial inicial de gás, $\Sigma_{\text {gas }}$. Portanto:

$$
\Sigma_{\mathrm{m}}=f_{\mathrm{D} / \mathrm{G}} f_{\mathrm{R} / \mathrm{I}} \Sigma_{\text {gas }}
$$

onde $f_{\mathrm{D} / \mathrm{G}}$ é a razão de gás e poeira no disco que, em geral, está em escala com a metalicidade da estrela central, sendo que seu valor varia entre 0.003 e 0.125 (o valor padrão adotado nesta tese será de 0.03$)$, já $f_{\mathrm{R} / \mathrm{I}}$ leva em conta o grau de condensação do material em razão da distância à estrela. Seguindo Mordasini et al. (2009), adotamos o valor de $f_{\mathrm{R} / \mathrm{I}}=1$, além da linha de gelo, e $f_{\mathrm{R} / \mathrm{I}}=1 / 4$, dentro da linha de gelo. Ambos os valores estão definidos no arquivo setup.par pelas variáveis FDG e FRI (ver apêndice A.7) e podem ser alterados de acordo com a conveniência. Nesse arquivo o usuário também pode definir a posição da linha de gelo modificando a variável RICE, cujo valor adotado neste trabalho é de 3 ua. Esse valor foi baseado nos valores estimados de temperatura e pressão para o disco padrão (ver seção 3.10).

A posição da linha de gelo deve levar em consideração a temperatura e a pressão do gás. Em nosso modelo, a linha de gelo não evolui com o tempo e nenhuma condensação ou sublimação do gelo é considerada. Ademais, a linha de gelo também pode depender da altura do disco e da radiação estelar (Min et al., 2011). Devido à complexidade do cálculo da linha de gelo, usaremos uma posição fixą․ Adaptações serão realizadas em trabalhos futuros.

\footnotetext{
${ }^{1}$ Recomendamos ao usuário um estudo inicial das condições físicas do disco de gás utilizado, para que, assim, possa estabeler uma posição coerente para linha de gelo em acordo com seu modelo.
} 
Os planetesimais que podem ser acretados são aqueles que estão na zona de alimentação do protoplaneta. Em nosso modelo, a zona de alimentação é um anel em torno da órbita do protoplaneta e possui uma distância de $(b / 2) R_{\mathrm{H}}$ em cada lado da órbita. Neste trabalho, adotamos $b=10$, no entanto, esse número pode ser modificado pelo usuário no arquivo setup.par, variável B (ver apêndice A.7), de acordo com a conveniência.

A densidade superficial dos planetesimais evolui como resultado da acreção, assim, para cada célula dentro da zona de alimentação, temos uma redução da densidade superficial de sólidos em um intervalo de tempo $d t$ dada por:

$$
\Sigma_{\mathrm{m}}=\Sigma_{\mathrm{m}(0)}-\frac{\dot{M}_{\text {core }} d t}{2 \pi a_{\mathrm{p}} b R_{\mathrm{H}}},
$$

onde $b$ é a largura da zona de alimentação, $R_{\mathrm{H}}$ o raio de Hill, $\Sigma_{\mathrm{m}(0)}$ é a densidade superficial inicial de sólidos na célula, $\dot{M}_{\text {core }}$ é a taxa de acreção de sólidos (ver seção 4.5.1) e $a_{\mathrm{p}}$ é a distância do protoplaneta à estrela.

Em alguns trabalhos, como em Fortier et al. (2013), ocorre a homogenização da zona de alimentação, isto é, a densidade superficial de sólidos dentro da zona de alimentação é a mesma em toda a zona, isso ocorre devido ao espalhamento produzido pelos planetesimais. Além disso, em alguns outros trabalhos, o tamanho da zona de alimentação evolui com a excentricidade e a inclinação quadráticas médias dos planetesimais. Entretanto, esses fenômenos ainda carecem de um estudo mais pormenorizado, assim, neste trabalho, não iremos considerar esses efeitos.

Nesta tese, nós também vamos considerar que a população de planetesimais é representada por corpos esféricos de tamanhos iguais. Não consideraremos os efeitos decorrentes da migração dos planetesimais, da fragmentação e da distribuição dos tamanhos dos planetesimais que também vão ser explorados em trabalhos futuros. Muitos desses efeitos são mais relevantes na evolução de sistemas planetários, que não serão estudados neste trabalho.

A distribuição inicial de sólidos é realizada pelo arquivo condinit.c, que pode ser encontrado no apêndice A.2, e o cálculo da diminuição da densidade superficial de sólidos dentro da zona de acreção (ver eq. 4.138), nos arquivos computeaccretionsolids.c e computeaccretionsolidsequilibrium.c, que são usados, respectivamente, no cenário sem equilíbrio e com equilíbrio, descritos na próxima seção. 


\subsubsection{Modelagem da evolução da excentricidade e da inclinação quadráticas médias}

Para o tratamento da evolução da excentricidade e da inclinação quadráticas médias o usuário pode escolher, no arquivo setup.opt, o tipo de evolução (ver apêndice A.1). Caso o usuário defina a variável EQUILIBRIUM, a excentricidade e a inclinação quadráticas médias dos planetesimais serão estimadas assumindo que o impulso gravitacional no planetesimal pelo protoplaneta é instantaneamente balanceado pelo arrasto do gás (Thommes et al. 2003). Nesse caso, assume-se que a média azimutal da excentricidade quadrática média dos planetesimais é obtida diretamente pela equação:

$$
\langle e\rangle=1.7 \frac{m^{1 / 15} M_{\text {core }}^{1 / 3} \rho_{\text {bulk }}^{2 / 15}}{b^{1 / 5} \mathrm{C}_{\mathrm{D}}^{1 / 5} \rho_{\text {gas }}^{1 / 5} M_{\star}^{1 / 3} a_{\mathrm{p}}^{1 / 5}},
$$

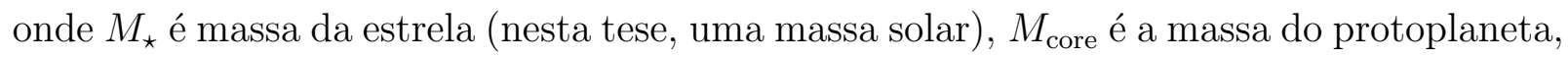
$\mathrm{C}_{\mathrm{D}}$ é o coeficiente de arrasto definido em setup.par pela variável CD e da ordem de uma unidade (ver apêndice A.7), $a_{\mathrm{p}}$ é a distância do protoplaneta à estrela, $\rho_{\text {bulk }}=3.2 \mathrm{~g} / \mathrm{cm}^{3}$ a densidade do bulbo de planetesimais definido em setup. par pela variável RHOM e $m$ é a massa do planetesimal calculada a partir da densidade volumétrica $\rho_{\mathrm{m}}$ do planetesimal que depende da posição desse planetesimal, isto é, para planetesimais dentro da linha de gelo, usamos o valor de $\rho_{\mathrm{m}}=3.2 \mathrm{~g} / \mathrm{cm}^{3}$, e, para planetesimais além da linha de gelo, $\rho_{\mathrm{m}}=1.0$ $\mathrm{g} / \mathrm{cm}^{3}$. Ambos os valores são definidos no arquivo setup.par (ver apêndice A.7) por meio das variáveis RHOICE e RHOROCKY. O valor de $b$ descreve a largura da zona de alimentação (ver seção 4.5.2) e o valor da densidade volumétrica do gás, $\rho_{\text {gas }}$, no caso bidimensional, é obtido por meio de uma estimativa baseada na integração da equação 2.8, obtida para um disco isotérmico (Armitage, 2010), e é dada por:

$$
\rho_{\mathrm{gas}}=\frac{1}{\sqrt{2 \pi}} \frac{\Sigma_{\mathrm{gas}}}{h r}
$$

onde $h$ é a razão de aspecto do disco, $\Sigma_{\text {gas }}$ a densidade superficial do gás e $r$ a distância do centro da célula à estrela.

O cálculo da densidade volumétrica do gás pode ser visualizado no arquivo computerhogas.c, descrito no apêndice B.5.

O valor de equilíbrio para a média azimutal da inclinação quadrática média é considerado a metade do valor da média azimutal da excentricidade quadrática média, esta relação é uma boa aproximação para planetesimais grandes (Ohtsuki et al., 2002), portanto: 


$$
\langle i\rangle=\frac{\langle e\rangle}{2} .
$$

Apesar de a situação de equilíbrio ser menos custosa computacionalmente, não está claro se os planetesimais podem ser assumidos nessa situação, especialmente se considerarmos a dependência com sua massa, já que isso implica diferentes valores para o arrasto do gás. De fato, Chambers (2006) encontrou uma mudança significativa para os valores da excentricidade e da inclinação quadráticas médias no começo da formação do embrião. Todavia, à medida que o protoplaneta cresce, esses valores tendem à situação de equilíbrio. Ainda assim, essa mudança no cálculo da excentricidade e da inclinação quadráticas médias pode ser importante para o caso de protoplanetas migrando, já que eles podem entrar em regiões onde a excitação dos planetesimais não é tão grande (baixos valores de $e$ e $i$ ), ou, até mesmo o contrário, caso os planetesimais já tenham sido excitados por outro protoplaneta em crescimento.

Para o usuário tratar a evolução da excentricidade e da inclinação quadráticas médias fora do equilíbrio, basta ele comentar, ou não colocar, a variável EQUILIBRIUM no arquivo setup.opt. Conforme vimos na seção 4.4 a evolução da excentricidade e da inclinação quadráticas médias depende do arrasto do gás, da interação gravitacional com o protoplaneta e da colisão entre as partículas. Nesta tese, trabalharemos com a evolução devido ao arrasto do gás e à interação gravitacional, portanto:

$$
\left\{\begin{array}{l}
\frac{d e_{i j}{ }^{2}}{d t}=\left(\frac{d e_{i j}{ }^{2}}{d t}\right)_{\text {grav }}+\left(\frac{d e_{i j}{ }^{2}}{d t}\right)_{\text {gas }}, \\
\frac{d i_{i j}^{2}}{d t}=\left(\frac{d i_{i j}^{2}}{d t}\right)_{\text {grav }}+\left(\frac{d i_{i j}^{2}}{d t}\right)_{\text {gas }},
\end{array}\right.
$$

onde o subscrito $i j$ indica que a evolução da excentricidade e da inclinação quadráticas médias será calculada para cada célula da malha computacional. Para evitar um abuso de notação vamos omitir o subscrito nas próximas equações 1 .

\footnotetext{
${ }^{1} \mathrm{O}$ leitor deve tomar cuidado para não confundir a média azimutal da excentricidade quadrática média com a excentricidade quadrática média. Quando o valor se refere à uma célula, estamos falando da excentricidade quadrática média. A média azimutal da excentricidade quadrática simula o valor médio obtido na zona de alimentação do planeta. Como não vamos lidar com valores individuais, usaremos $e$ e $i$ para designar a excentricidade e inclinação quadráticas médias e, $\langle e\rangle$ e $\langle i\rangle$, para as médias azimutais das excentricidades e inclinações quadráticas médias, essa notação é usual na maioria dos artigos de formação planetária.
} 
Do estudo realizado na seção 4.4.2, vimos que a força de arrasto, experimentada por um corpo esférico, depende da velocidade relativa $\left(v_{\text {rel }}\right)$ desse corpo com relação ao gás e, dependendo da relação entre o raio do planetesimal $\left(r_{\mathrm{m}}\right)$ e o livre caminho médio das moléculas $\left(\lambda_{\text {gas }}\right)$, o arrasto sofrido pelo planetesimal pode ser encontrado em três regimes diferentes. Os primeiros dois regimes são obtidos para planetesimais cujos raios são maiores que o livre caminho médio, $r_{\mathrm{m}} \gtrsim \lambda_{\text {gas }}$, podendo estar no regime quadrático ou de Stokes. Para distinguir entre esses regimes, nós adotamos o critério proposto por Rafikov (2004), que utiliza o número de Reynolds molecular $\operatorname{Re}_{\mathrm{mol}}=v_{\mathrm{rel}} / \nu_{\mathrm{mol}}$, onde $\nu_{\mathrm{mol}}=\lambda_{\mathrm{gas}} c_{\mathrm{s}} / 3$ é a viscosidade molecular e $v_{\text {rel }}=v_{\mathrm{K}} \sqrt{5 / 9 e^{2}+1 / 2 i^{2}}$ a velocidade relativa do planetesimal ( $v_{\mathrm{K}}$ é a velocidade kepleriana na célula e $c_{\mathrm{s}}$ a velocidade do som na célula). A viscosidade molecular é obtida no arquivo computenumol.c (ver apêndice B.6) e o número de Reynolds molecular, no arquivo computereymol.c (ver apêndice B.7).

Caso $\operatorname{Re}_{\mathrm{mol}} \gtrsim 20$, assume-se que o arrasto do gás está no regime quadrático, nesse caso, as equações para evolução da excentricidade e da inclinação quadráticas médias, devido ao arrasto do gás, são dadas por:

$$
\left\{\begin{array}{l}
\left(\frac{d e^{2}}{d t}\right)_{\text {gas }}=-\frac{2 e^{2}}{\tau_{\text {drag }}}\left(\frac{9}{4} \eta^{2}+\frac{9}{4 \pi} \xi^{2} e^{2}+\frac{1}{\pi} i^{2}\right)^{1 / 2}, \\
\left(\frac{d i^{2}}{d t}\right)_{\text {gas }}=-\frac{i^{2}}{\tau_{\text {drag }}}\left(\eta^{2}+\frac{\xi^{2}}{\pi} e^{2}+\frac{4}{\pi} i^{2}\right)^{1 / 2},
\end{array}\right.
$$

onde usamos o parâmetro $\xi \simeq 1.211$ (Inaba et al., 2001) e o valor de $\eta$, que depende da distância à estrela e do gradiente de pressão, foi aproximado pela equação Takeuchi e Lin, 2002):

$$
\eta=\left(\frac{H}{r}\right)^{2}\left(p+q+\gamma \frac{z}{H}\right),
$$

onde $H / r$ é a razão de aspecto do disco $(h=H / r=0.05), p=\varphi-\gamma$, onde $\varphi$ é o expoente do perfil de densidade superficial do gás e $\gamma$ é o fator que define a curvatura do disco (ver seção 3.10.1), e $q=2.0 \gamma-3.0$. Nesta tese, usamos um disco bidimensional $\left(\frac{z}{H}=0\right)$ e fator de curvatura nulo $(\gamma=0)$. O valor obtido para $\eta$ foi comparado com o obtido por Guilera et al. (2010) e têm a mesma ordem de grandeza, $10^{-3}$.

Ainda na equação 4.143 , o tempo de escala do arrasto de gás, $\tau_{\text {drag }}$, é dado por:

$$
\tau_{\text {drag }}=\frac{8 \rho_{\mathrm{m}} r_{\mathrm{m}}}{3 \mathrm{C}_{\mathrm{D}} \rho_{\text {gas }} v_{\mathrm{K}}},
$$


onde $v_{\mathrm{K}}$ é a velocidade kepleriana na célula, $\rho_{\mathrm{m}}$ a densidade volumétrica dos planetesimais, $r_{\mathrm{m}}$ o raio dos planetesimais, $\mathrm{C}_{\mathrm{D}}$ o coeficiente de arrasto e $\rho_{\text {gas }}$ a densidade volumétrica do gás. Os valores de $\rho_{\mathrm{m}}$ (gelo ou sólido), $r_{\mathrm{m}}$ e $\mathrm{C}_{\mathrm{D}}$ estão definido no arquivo setup.par (ver apêndice A.7), e $\rho_{\text {gas }}$ é obtido pela equação 4.140 .

O regime de Stokes ocorre para $r_{\mathrm{m}} \gtrsim \lambda_{\text {gas }}$ e $\mathrm{Re}_{\mathrm{mol}}<20$, nesse caso, as equações para excentricidade e inclinação quadráticas médias dos planetesimais são dadas por:

$$
\left\{\begin{array}{l}
\left(\frac{d e^{2}}{d t}\right)_{\mathrm{gas}}=-\frac{3}{2} \frac{\lambda_{\mathrm{gas}} c_{\mathrm{s}} \rho_{\mathrm{gas}} e^{2}}{\rho_{\mathrm{m}} r_{\mathrm{m}}^{2}} \\
\left(\frac{d i^{2}}{d t}\right)_{\mathrm{gas}}=-\frac{3}{4} \frac{\lambda_{\mathrm{gas}} c_{\mathrm{s}} \rho_{\mathrm{gas}} i^{2}}{\rho_{\mathrm{m}} r_{\mathrm{m}}^{2}}
\end{array}\right.
$$

onde $c_{\mathrm{s}}$ é a velocidade do som na célula.

Quando $r_{\mathrm{m}} \lesssim \lambda_{\text {gas }}$, o terceiro regime, regime de Epstein, toma lugar e a evolução da excentricidade e da inclinação quadráticas médias é descrita por:

$$
\left\{\begin{array}{l}
\left(\frac{d e^{2}}{d t}\right)_{\text {gas }}=-e^{2} \frac{c_{\mathrm{s}} \rho_{\mathrm{gas}}}{\rho_{\mathrm{m}} r_{\mathrm{m}}} \\
\left(\frac{d i^{2}}{d t}\right)_{\text {gas }}=-\frac{i^{2}}{2} \frac{c_{\mathrm{s}} \rho_{\mathrm{gas}}}{\rho_{\mathrm{m}} r_{\mathrm{m}}}
\end{array}\right.
$$

É interessante notar que, considerando o tamanho de planetesimais entre $0.1-100 \mathrm{~km}$, o regime atingido na maioria dos caso das simulações desta tese foi o regime quadrático. Em alguns poucos casos, tivemos o regime de Stokes durante o ínicio da simulação, isto é, na fase transiente do disco de gás. Os arquivos responsáveis pela evolução da excentricidade e da inclinação quadráticas médias dos planetesimais devido ao gás são computegasdragecc.c, para as excentricidades (ver apêndice B.8), e, computegasdragecc.c (ver apêndice B.11), para as inclinações.

A excentricidade e a inclinação quadráticas médias também evoluem devido à influência gravitacional do protoplaneta. Conforme vimos na seção 4.4.1, a equação que descreve essa evolução é dada por:

$$
\left\{\begin{array}{l}
\left(\frac{d e^{2}}{d t}\right)_{\text {grav }}=\left(\frac{M_{\mathrm{p}}}{3 b M_{\star} P_{\text {orbital }}}\right) P_{\mathrm{VS}} \\
\left(\frac{d i^{2}}{d t}\right)_{\text {grav }}=\left(\frac{M_{\mathrm{p}}}{3 b M_{\star} P_{\text {orbital }}}\right) Q_{\mathrm{VS}}
\end{array}\right.
$$

onde $M_{\mathrm{p}}$ é massa do planeta, $b$ é a largura da zona de alimentação (ver seção 4.5.2), $M_{\star}$ a massa da estrela $\left(M_{\star}=1 \mathrm{M}_{\odot}\right), P_{\text {orbital }}$ o período orbital do protoplaneta e, os valores de 
$P_{\mathrm{VS}}$ ou $Q_{\mathrm{VS}}$, são dados por:

$$
\left\{\begin{array}{l}
P_{\mathrm{VS}}=\left[\frac{73 \tilde{e}^{2}}{10 \Lambda^{2}}\right] \ln \left(1+10 \Lambda^{2} / \tilde{e}^{2}\right)+\left[\frac{72 I_{\mathrm{PVS}}(\beta)}{\pi \tilde{e} \tilde{i}}\right] \ln \left(1+\Lambda^{2}\right), \\
Q_{\mathrm{VS}}=\left[\frac{4 \tilde{i}^{2}+0.2 \tilde{i} \tilde{e}^{3}}{10 \Lambda^{2} \tilde{e}}\right] \ln \left(1+10 \Lambda^{2} \tilde{e}\right)+\left[\frac{72 I_{\mathrm{QVS}}(\beta)}{\pi \tilde{e} \tilde{i}}\right] \ln \left(1+\Lambda^{2}\right),
\end{array}\right.
$$

$\operatorname{com} \Lambda=\tilde{i}\left(\tilde{e}^{2}+\tilde{i}^{2}\right) / 12$, sendo $\tilde{e}$ e $\tilde{i}$, respectivamente, a excentricidade e inclinação quadráticas médias reduzidas dos planetesimais. Conforme vimos na seção 4.4.1, as funções $I_{\mathrm{PVS}}(\beta)$ e $I_{\mathrm{QVS}}(\beta)$ podem ser aproximadas, para $0<\beta \leq 1$, por:

$$
\left\{\begin{array}{l}
I_{\mathrm{PVS}}(\beta) \simeq \frac{\beta-0.36251}{0.061547+0.16112 \beta+0.054473 \beta^{2}} \\
I_{\mathrm{QVS}}(\beta) \simeq \frac{0.71946-\beta}{0.21239+0.49764 \beta+0.14369 \beta^{2}}
\end{array}\right.
$$

onde $\beta=\tilde{i} / \tilde{e}$.

A excitação que o protoplaneta produz nos planetesimais enfraquece com a distância entre o protoplaneta e o planetesimal. Seguindo a aproximação de Guilera et al. (2010), usamos:

$$
\left\{\begin{array}{l}
\left(\frac{d e^{2}}{d t}\right)_{\text {grav }}^{\text {eff }}=f(\Delta)\left(\frac{d e^{2}}{d t}\right)_{\text {grav }}, \\
\left(\frac{d i^{2}}{d t}\right)_{\text {grav }}^{\text {grf }}=f(\Delta)\left(\frac{d i^{2}}{d t}\right)_{\text {grav }},
\end{array}\right.
$$

onde $f(\Delta)$ assegura que a perturbação do protoplaneta seja confinada na sua vizinhança, sendo dada por:

$$
f(\Delta)=\left[1+\left(\frac{\Delta}{n R_{\mathrm{H}}}\right)\right],
$$

onde $\Delta=\left|a_{\mathrm{p}}-a_{\mathrm{m}}\right|, a_{\mathrm{p}}$ é o semieixo maior do protoplaneta e $a_{\mathrm{m}}$ é o semieixo maior dos planetesimais. Nesta tese, adotamos $\Delta$ como a distância radial entre a célula que contém o protoplaneta e a célula utilizada para calcular a evolução.

É importante destacar que, embora a forma da função $f(\Delta)$ seja arbitrária, sua escala foi modelada usando simulação N-corpos. Aqui, usamos $n=5$, de forma a limitar esse efeito gravitacional do planeta em sua zona de alimentação.

Neste trabalho, desconsideramos a perturbação gravitacional entre os planetesimais, esse efeito não muda significativamente os resultados. Mais detalhes podem ser obtidos em Fortier et al. (2013). 
Os arquivos responsáveis pelo cálculo do efeito gravitacional do protoplaneta na evolução da excentricidade e da inclinação quadráticas médias dos planetesimais são computegravecc.c, para as excentricidades, e computegravinc.c, para as inclinações.

O método numérico usado para resolução do sistema de equações diferenciais 4.142 é o método de Euler semi-implícitg ${ }^{1}$, que também foi usado por Alibert et al. (2005) para resolução do mesmo sistema de equações. Esse método consiste em, inicialmente, usar o método de Euler na primeira equação diferencial utilizando valores iniciais para as variáveis, isto é, $e_{0}$ e $i_{0}$. Em seguida, realiza-se o update para apenas uma das variáveis, no caso $e$ (ver arquivo updateecc.c, transcrito no apêndice B.10), para, por fim, resolver a segunda equação diferencial usando os valores iniciais $e_{1}$ e $i_{0}$, obtendo o update $i_{1}$ (ver arquivo updateinc.c, transcrito no apêndice B.13). O método completo pode ser melhor visualizado no arquivo algogas.c, transcrito no apêndice B.4.

A solução das equações 4.142 exigem uma condição inicial para a excentricidade e a inclinação quadráticas médias dos planetesimais. Nós consideremos duas possibilidades definidas em condinit.c (ver apêndice A.2), seguindo o mesmo procedimento de Fortier et al. (2013). A primeira possibilidade considera um disco inicialmente frio, no qual as excentricidades e inclinações quadráticas médias iniciais são obtidas para uma situação de equilíbrio entre o efeito gravitacional entre os planetesimais e o arrasto do gás. Esses valores podem ser derivados equacionando e igualando a escala de tempo do efeito gravitacional e o arrasto, que resulta em:

$$
\left\{\begin{array}{l}
e=2.31 \frac{m^{4 / 15} \sum_{\text {gas }}^{1 / 5} a_{\mathrm{m}}^{1 / 5} \rho_{\text {bulk }}^{2 / 15}}{\mathrm{C}_{\mathrm{D}}^{1 / 5} \rho_{\text {gas }}^{1 / 5} M_{\star}^{2 / 5}}, \\
i=\frac{1}{2} e,
\end{array}\right.
$$

onde $m$ é a massa do planetesimal, $\Sigma_{\text {gas }}$ a densidade superficial do gás, $a_{\mathrm{m}}$ é a distância do planetesimal (centro da célula) à estrela, $\rho_{\text {bulk }}$ a densidade do bulbo de planetesimais, $\mathrm{C}_{\mathrm{D}}$ o coeficiente de arrasto, $\rho_{\text {gas }}$ a densidade volumétrica do gás e $M_{\star}$ a massa da estrela.

Isso significa que estamos assumindo que o embrião instantaneamente aparece em um disco de planetesimais não perturbado. A segunda possibilidade é definir os valores iniciais para excentricidade e para inclinação quadráticas médias utilizando as equações 4.139 e

\footnotetext{
${ }^{1}$ Nós testamos também o método de Runge Kutta de $5^{\circ}$ para comparação. Não foram encontradas mudanças significativas. Optamos por mantér o método semi-implícito devido ao menor custo computacional.
} 
4.140. Nesse caso, o disco pode ser considerado mais quente, isto é, os planetesimais já iniciam num estado mais excitado.

\subsubsection{Teste do modelo}

Para testar o modelo, vamos reproduzir os resultados obtidos em Fortier et al. (2013), que utilizam um modelo similar para a acreção de sólidos ${ }^{1}$. Para isso, vamos colocar um protoplaneta de massa inicial $0.01 \mathrm{M}_{\otimes}$ em 6 ua e usaremos algumas condições locais que independem do modelo de gás implementado no FARGO3D. Essa escolha se deve ao fato de o modelo de disco de gás implementado por Fortier et al. (2013) ser muito diferente do modelo hidrodinâmico, portanto, não temos acesso aos resultados ao longo de todo o disco de gás, mas apenas às condições locais que foram especificadas no artigo. Assim, esse teste consiste, basicamente, em testar o modelo de acreção de sólidos, implementado no FARGO3D, de forma quase que independente do modelo para o disco de gás. Exceção ocorre para a velocidade do som, cujo valor usado vem diretamente da simulação padrão (ver seção 3.10).

Utilizando os dados fornecidos por Fortier et al. (2013), usamos a densidade volumétrica do gás, na região em que se encontra o protoplaneta, como $\rho_{\text {gas }}=2.4 \times 10^{-9} \mathrm{~g} / \mathrm{cm}^{3}$ e a densidade superficial de gás como $\Sigma_{\text {gas }}=1700 \mathrm{~kg} / \mathrm{m}^{2}$. Esses valores são usados diretamente nos cálculos numéricos e são independentes dos valores obtidos na célula onde se encontra o protoplaneta. Da mesma forma, utilizamos a densidade superficial de sólidos como $\Sigma_{\mathrm{m}}=10 \mathrm{~g} / \mathrm{cm}^{2}$ para todas as células. Ao protoplaneta será permitido crescer, fixo na região, até que atinja a massa da Terra.

Os valores da excentricidade e da inclinação usados nas equações do modelo de Fortier et al. (2013) são obtidos pela média quadrática na zona de alimentação homogeneizada. Isso equivale, em nosso modelo, ao que denominamos de média azimutal. Para evitar um abuso de linguagem e notação usaremos nessa seção apenas os termos excentricidade $(e)$ e inclinação $(i)$ para designar essas grandezas.

Outros parâmetros que dependem do disco de gás foram gentilmente cedidos por Guilera et al. (2010). Assim, o valor de $\eta$ e a escala de tempo para o arrasto, $\tau_{\text {drag }}$, de cada planetesimal vieram de modelos similares aos usados por Fortier et al. (2013). Esses

\footnotetext{
${ }^{1}$ Devido ao alto custo computacional das simulação com planetesimais de raio $100 \mathrm{~km}$ iremos realizar apenas uma simulação para este caso.
} 
valores, que devem ser fixados para que o modelo apresente comportamento similar ao do artigo, estão reproduzidos na Tabela 4.1 a seguir.

\begin{tabular}{c|c} 
Variável & Valor \\
\hline$\eta$ & $3.04 \times 10^{-3}$ \\
$\tau_{\text {drag }}\left(r_{\mathrm{m}}=0.1 \mathrm{~km}\right)$ & $6.35 \times 10^{8} \mathrm{~s}$ \\
$\tau_{\text {drag }}\left(r_{\mathrm{m}}=1 \mathrm{~km}\right)$ & $6.35 \times 10^{9} \mathrm{~s}$ \\
$\tau_{\text {drag }}\left(r_{\mathrm{m}}=10 \mathrm{~km}\right)$ & $6.35 \times 10^{10} \mathrm{~s}$ \\
$\tau_{\text {drag }}\left(r_{\mathrm{m}}=100 \mathrm{~km}\right)$ & $6.35 \times 10^{11} \mathrm{~s}$
\end{tabular}

Tabela 4.1 - Valores de algumas variáveis para teste do modelo de acreção de sólidos.

O valor para a velocidade do som, que influencia no tipo de regime para o arrasto do gás, é o único valor que foi lido diretamente do código hidrodinâmico. Isso se deve ao fato de não ser possível obter uma expressão analítica para seu valor com base no modelo de disco de gás usado por Fortier et al. (2013). Essa caracteristica influencia nas primeiras rodadas do teste, já que o regime de Stokes se encontra presente durante as primeiras iterações do código.

A Figura 4.10 a seguir mostra os resultados do crescimento da massa do núcleo sólido em função do tempo obtidos por Fortier et al. (2013) (figura da esquerda) e o resultado obtido na nossa simulação (figura da direita).

Encontramos uma excelente concordância para a situação dentro do equilíbrio e uma concordância bem próxima para a situação fora do equilíbrio. Isso se deve ao fato da situação fora do equilíbrio, durante os primeiros passos da simulação, cair no regime de Stokes para o arrasto do gás. Esse regime depende da velocidade do som, parâmetro que é obtido a partir do modelo do disco de gás. No entanto, o modelo de disco de gás usado por Fortier et al. (2013) resolve equações de transferência radioativa e energia, enquanto o modelo de disco de gás do FARGO3D é um modelo hidrodinâmico isotérmico, isto é, com velocidade do som constante no local do protoplaneta. Assim, temos uma mudança rápida e brusca na excentricidade no ínicio da simulação que denota a diferença entre os dois modelos, gerando um desvio na condição inicial para a entrada no próximo regime (regime quadrático). No entanto, salvo essa característica, o acordo entre os resultados, em termos de comportamento global, foi excelente.

A diferença na mudança da excentricidade entre os dois modelos pode ser melhor anali- 

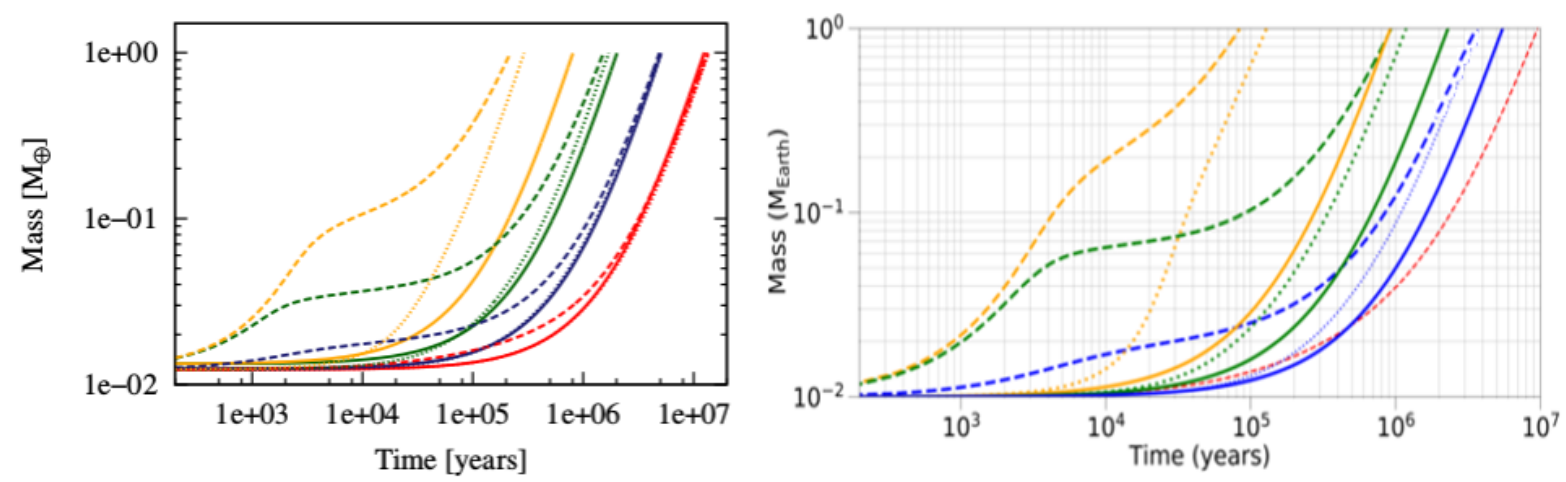

Figura 4.10: Comparação dos gráficos da massa em função do tempo para a formação de um planeta da massa da Terra. A figura da esquerda foi obtida em Fortier et al. (2013) e a figura da direita é a reprodução dos resultados. Cada cor representa um tamanho para os planetesimais (vermelho - $100 \mathrm{~km}$; azul - $10 \mathrm{~km}$; verde - $1 \mathrm{~km}$ e laranja - $0.1 \mathrm{~km}$ ). As linhas tracejadas e pontilhadas representam a situação fora do equilíbrio para duas condições iniciais diferentes (pontilhada - eq. 4.139 e eq. 4.140 tracejada - eq. 4.153). As linhas cheias representam a situação de equilíbrio (eq. 4.139 e eq. 4.141). Devido ao alto custo computacional para os planetesimais com $100 \mathrm{~km}$ de raio, nós realizamos apenas uma simulação para este caso (linha vermelha tracejada).

sada comparando os gráficos para excentricidade em função do tempo da Figura 4.11, para o modelo de Fortier et al. (2013), com o da Figura 4.12, obtido com o modelo implementado no FARGO3D.

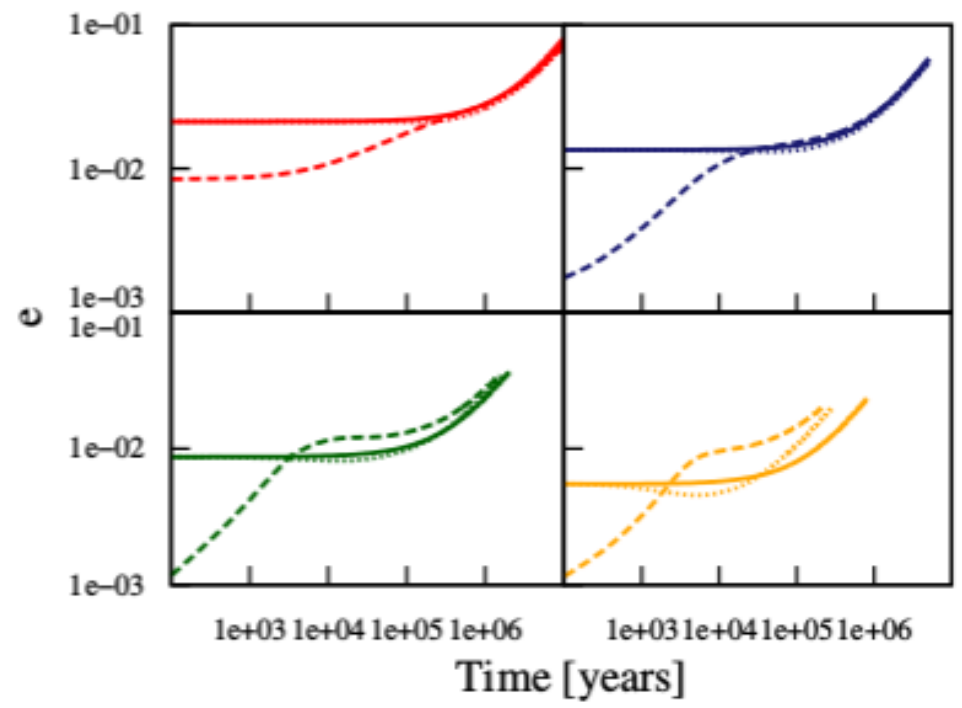

Figura 4.11: Gráficos da excentricidade em função do tempo para a formação de um planeta da massa da Terra obtidos por Fortier et al. (2013). O código de cores e estilo é o mesmo da Figura 4.10 .

Observe que, para a situação de equilíbrio, não foram encontradas diferenças significati- 

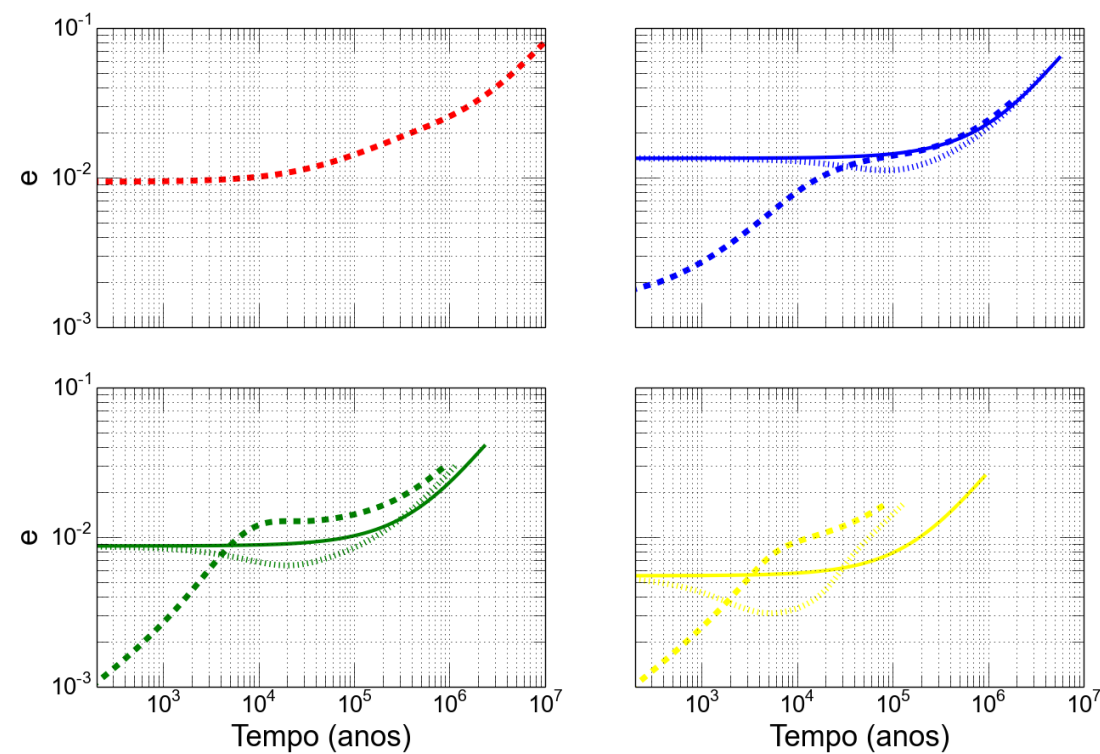

Figura 4.12: Gráficos da excentricidade em função do tempo para a formação de um planeta da massa da Terra obtido com o modelo implementado no FARGO3D. O código de cores e estilo é o mesmo da Figura 4.10. Devido ao alto custo computacional para os planetesimais com $100 \mathrm{~km}$ de raio, nós realizamos apenas uma simulação para este caso (linha vermelha tracejada).

vas. No entanto, para a situação fora do equilíbrio, notamos que, apesar do comportamento similar, ocorre uma mudança mais brusca da excentricidade no início da simulação para o modelo de gás usado em Fortier et al. (2013). Essa diferença de comportamento é consequência da mudança da condição inicial, que ocorre durante a fase transiente, devido à diferença no valor da velocidade do som entre os modelos.

De fato, analisando a Figura 4.13 a seguir, que compara os gráficos para a evolução da excentricidade em função da massa, podemos observar que, embora o comportamento seja similar, no modelo de Fortier et al. (2013) ocorre uma taxa de variação maior para a excentricidade no começo da simulação. Entretanto, para a simulação teste, essa taxa de variação foi menor. Para a situação de equilíbrio, não foram encontradas diferenças significativas, já que, para esse caso, a evolução da excentricidade é independente dos parâmetros fornecidos pelo FARGO3D.

A Figura 4.14 a seguir, compara os gráficos para a evolução da taxa de acreção em função da massa. Vemos, novamente, uma boa concordância entre os gráficos. No entanto, para a situação fora do equilíbrio, isto é, condição inicial para um disco frio (linhas tra- 

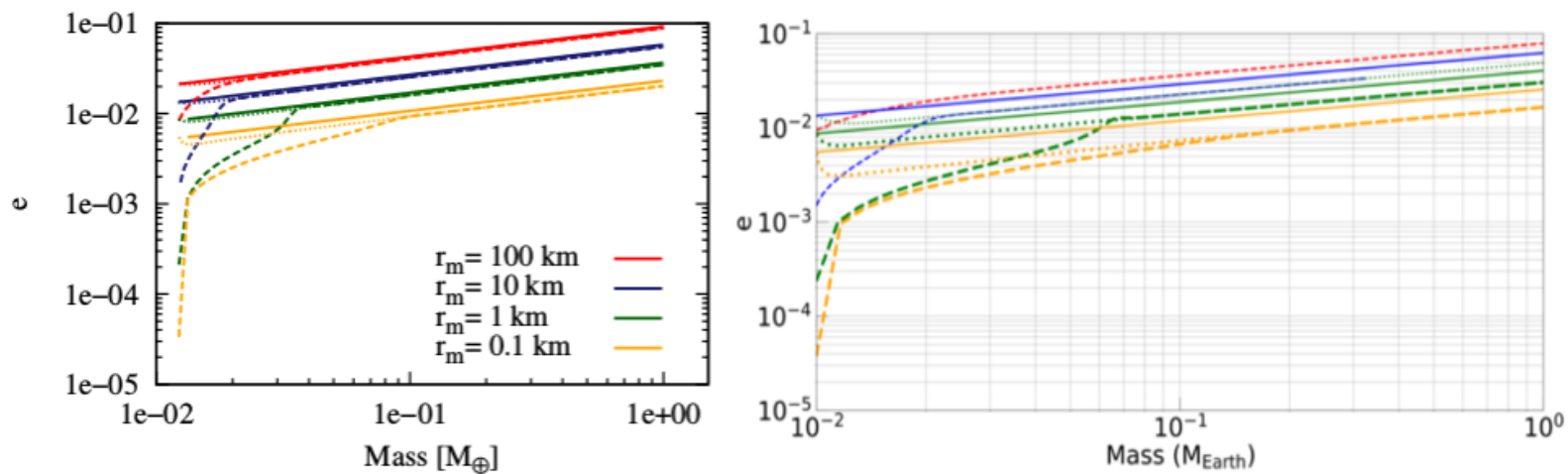

Figura 4.13: Comparação dos gráficos da excentricidade em função da massa para a formação de um planeta da massa da Terra. A figura da esquerda foi obtida em Fortier et al. (2013) e a figura da direita com o modelo implementado no FARGO3D. O código de cores e estilo é o mesmo da Figura 4.10. Devido ao alto custo computacional para os planetesimais com 100 km de raio, nós realizamos apenas uma simulação para este caso (linha vermelha tracejada).
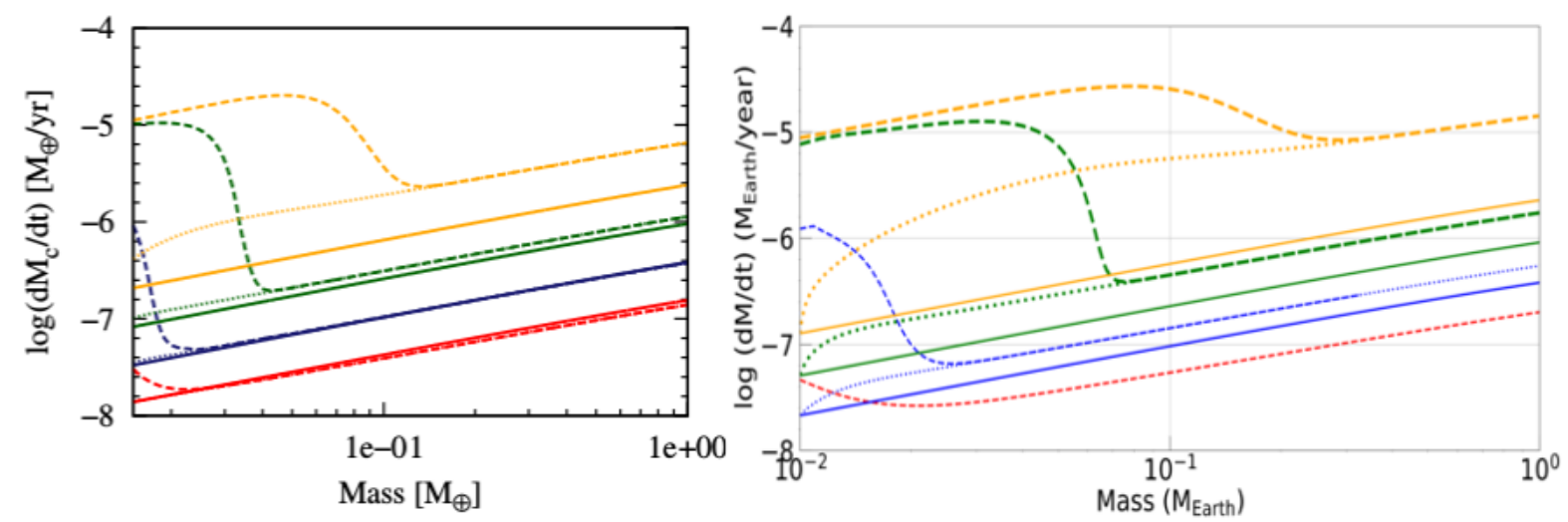

Figura 4.14: Comparação dos gráficos da taxa de acreção de sólidos em função da massa para a formação de um planeta da massa da Terra. A figura da esquerda foi obtida em Fortier et al. (2013) e a figura da direita com o modelo implementado no FARGO3D. O código de cores e estilo é o mesmo da Figura 4.10. Devido ao alto custo computacional para os planetesimais com $100 \mathrm{~km}$ de raio, nós realizamos apenas uma simulação para este caso (linha vermelha tracejada).

cejadas), ocorre uma queda mais brusca na excentricidade dos planetesimais menores (1 km e $0.1 \mathrm{~km}$ ) para o modelo de Fortier et al. (2013), mais uma vez, devido à diferença nos valores da excentricidade e inclinação obtidos no regime transiente. De fato, como obtemos um valor menor para a excentricidade após o transiente, notamos que seu valor deve demorar mais a subir até o ponto em que se obtém a queda na taxa de acreção. Isso resulta numa queda bem menos acentuada para a taxa de acreção. O mesmo ocorre na situação fora do equilíbrio para a condição inicial de um disco frio. Para a situação de 
equilíbrio, não foram encontradas diferenças significativas.

Mesmo não conseguindo reproduzir os dados com alta precisão, principalmente, para os casos fora do equilíbrio, podemos afirmar que o modelo está corretamente implementado, já que o comportamento global é muito próximo do esperado. Levando em conta o fato de o modelo para o disco de gás ser completamente diferente, a concordância entre os resultados é excelente.

\subsection{Formação de um planeta de $1 \mathrm{M}_{\otimes}$}

Seguindo o mesmo procedimento adotado por Fortier et al. $(2013)$, vamos realizar algumas simulações analisando, para nossa simulação padrão (ver seção 3.10), a formação de um planeta de massa $1 \mathrm{M}_{\otimes}$. A massa inicial do protoplaneta é de $0.01 \mathrm{M}_{\otimes}$. Nossa simulação é interrompida após $1.8 \times 10^{6}$ anos, tempo suficiente para estudarmos o crescimento do planeta.

O intuito é analisar como o tamanho dos planetesimais afeta a taxa de acreção de sólidos e as diferenças entre a situação de equilíbrio e fora do equilíbrio para a evolução das excentricidades e inclinações quadráticas médias dos planetesimais. Assim, o protoplaneta será mantido fixo em 6 ua e vamos negligenciar a acreção de gás pelo planeta, fator que será incorporado no capítulo 5 .

A linha de gelo será mantida em 3.0 ua (arquivo setup.par). Da mesma forma que no modelo teste, as linhas cheias nos gráficos representam a situação de equilíbrio na qual a evolução da excentricidade e a inclinação dos planetesimaił $\uparrow^{1}$ são descritas pelas equações 4.139 e 4.140 . Seguindo o mesmo procedimento realizado por Fortier et al. (2013), na situação fora do equilíbrio, resolvemos a equação 4.142 para dois valores iniciais para as excentricidades e inclinações quadráticas médias dos planetesimais. A linha tracejada descreve a situação na qual as excentricidades e inclinações quadráticas médias iniciais dos planetesimais são dadas pela equação 4.153. Já a linha pontilhada descreve a situação no qual as excentricidades e inclinações quadráticas médias iniciais dos planetesimais são dadas pelas equações 4.139 e 4.140. Fisicamente, a segunda condição inicial descreve um disco quente, no qual as excentricidades e inclinações já foram excitadas pelo embrião.

\footnotetext{
${ }^{1}$ Usaremos novamente os termos excentricidade e inclinação para designar, respectivamente, a média azimutal das excentricidades quadráticas médias e a média azimutal das inclinações quadráticas médias.
} 
A Figura 4.15 a seguir mostra os resultados obtidos. Percebe-se que o tempo de formação planetária, independente do caso, é maior quanto maior o tamanho dos planetesimais (ver Fig. 4.15, superior à esquerda), esse resultado também foi obtido por Fortier et al. (2013) (ver seção 4.5.4). Essa diferença se deve ao fato de os planetesimais maiores serem menos afetados pelo arrasto do gás, mantendo por mais tempo seu alto valor para a excentricidade e a inclinação, e, consequentemente, um menor valor para a taxa de acreção de sólidos. Essa característica também pode ser observada no gráfico da taxa de acreção de sólidos em função da massa (ver Fig. 4.15, inferior à direita), que mostra que a diferença entre as taxas de acreção, para planetesimais entre $0.1 \mathrm{~km}$ e $10 \mathrm{~km}$, foi de até 1000 ordens de magnitude para a situação fora do equilíbrio e 10 ordens de magnitude para a situação em equilíbrio.

No entanto, de forma geral, obtemos tempos menores para a formação planetária em relação ao modelo de Fortier et al. (2013). De fato, a formação de um planeta terreste, para planetesimais de $0.1 \mathrm{~km}$, foi da ordem de $3 \times 10^{4}$ anos, enquanto Fortier et al. (2013) encontraram um tempo da ordem de $\sim 10^{5}$ anos. Isso se deve ao fato de o nosso modelo possuir uma disponibilidade maior de material para ser acretado. Isto é, nosso modelo possui uma densidade superficial de sólidos maior em relação ao modelo de Fortier et al. (2013).

Outra característica muito similar à encontrada por Fortier et al. (2013) foi a diferença entre a situação de equilíbrio e fora do equilíbrio para planetesimais pequenos. Percebe-se, por exemplo, uma diferença de aproximadamente $\simeq 1.8 \times 10^{5}$ anos para planetesimais de $0.1 \mathrm{~km}$ e de $\simeq 2.2 \times 10^{5}$ anos para planetesimais de $1 \mathrm{~km}$.

A Figura 4.16 a seguir mostra a evolução da razão da inclinação pela excentricidade obtida em cada caso. Percebe-se que quanto menores forem os planetesimais mais longe estarão da situação de equilíbrio $(i / e=0.5)$. Conclui-se, então, que a situação de equilíbrio funciona bem para planetesimais grandes, no entanto, o tempo de formação planetária nesse caso é muito alto e a formação de planetas gigantes fica comprometida.

Note também que, no caso de pequenos planetesimais, a excentricidade é muito mais afetada que a inclinação (ver Fig. 4.15, superior direita), isso explica a taxa de acreção mais alta obtida nesse caso (ver Fig. 4.15 inferior direita). Quando a inclinação começa a subir, obtemos uma redução na taxa de acreção de sólidos e uma situação mais próxima do equilíbrio é obtida. 

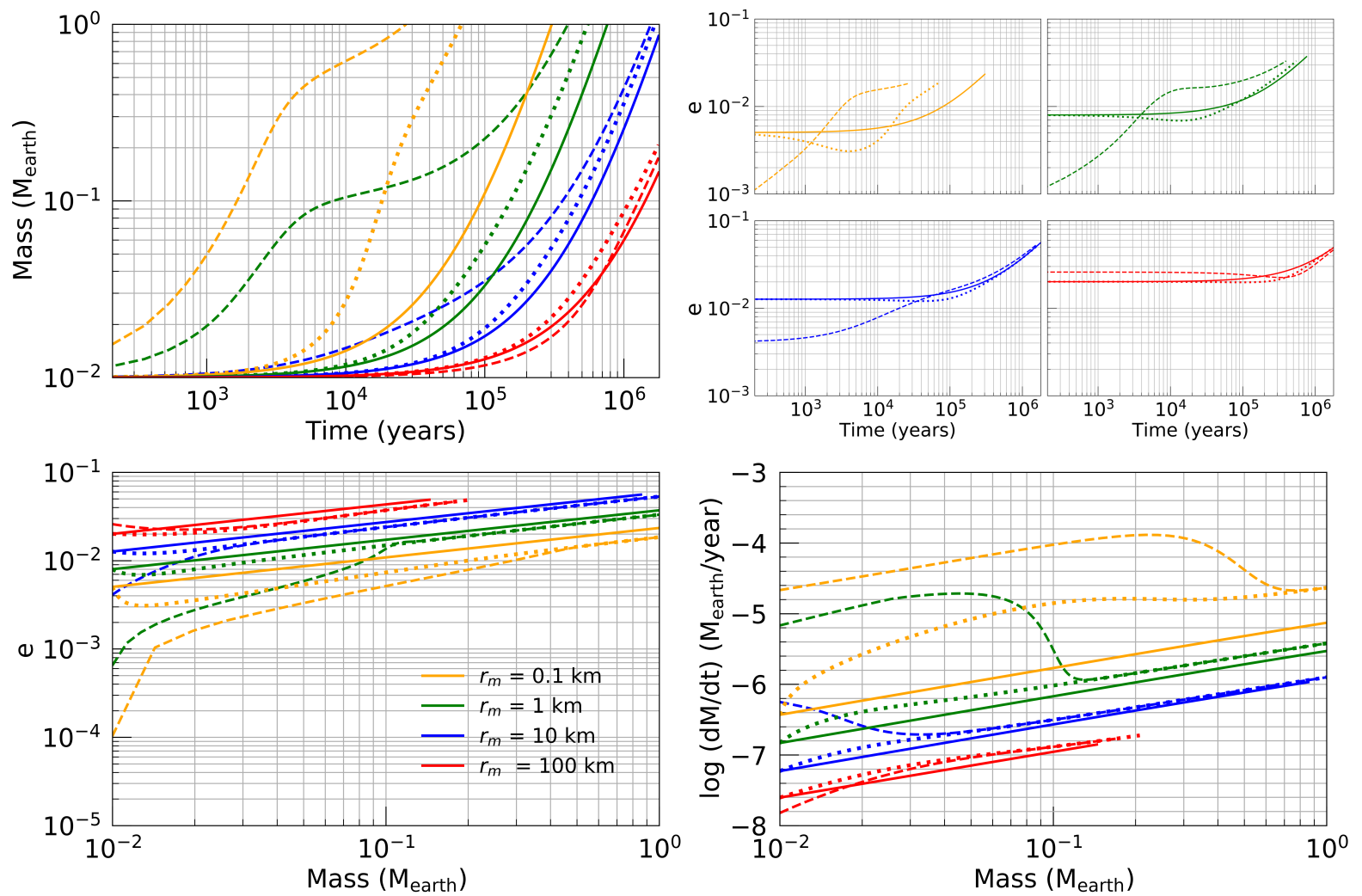

Figura 4.15: Gráfico da massa do planeta em função do tempo (figura superior esquerda), da excentricidade em função do tempo (figura superior direita), da excentricidade em função da massa (figura inferior esquerda) e da taxa de acreção de sólidos em função da massa (figura inferior direita). Cada cor representa um tamanho para os planetesimais (vermelho - $100 \mathrm{~km}$; azul - $10 \mathrm{~km}$; verde - $1 \mathrm{~km}$ e laranja - $0.1 \mathrm{~km}$ ). As linhas tracejadas e pontilhadas representam a situação fora do equilíbrio para duas condições iniciais diferentes (pontilhada - eq. $4.139 \mathrm{e}$ eq. 4.140 tracejada - eq. 4.153). As linhas cheias representam a situação de equilíbrio (eq. 4.139 e eq. 4.141). O corte brusco obtido para as curvas com os planetesimais de $100 \mathrm{~km}$ ocorre porque a simulação é interrompida após $1.8 \times 10^{6}$ anos.

De forma geral, nosso modelo gerou resultados que estão de acordo com os obtidos na literatura (Guilera et al., 2010; Fortier et al., 2013). Vale ressaltar, que nosso modelo pode ser entendido como um primeiro passo na direção de uma modelagem mais complexa. De fato, os modelos mencionados trabalham com um disco unidimensional. Aqui, no entanto, estamos trabalhando com um disco bidimensional, facilmente expandido para um caso tridimensional. Portanto, trabalhos futuros podem ser realizados para uma modelagem mais complexa da zona de alimentação que podem acarretar na mudança da taxa de acreção de sólidos. 


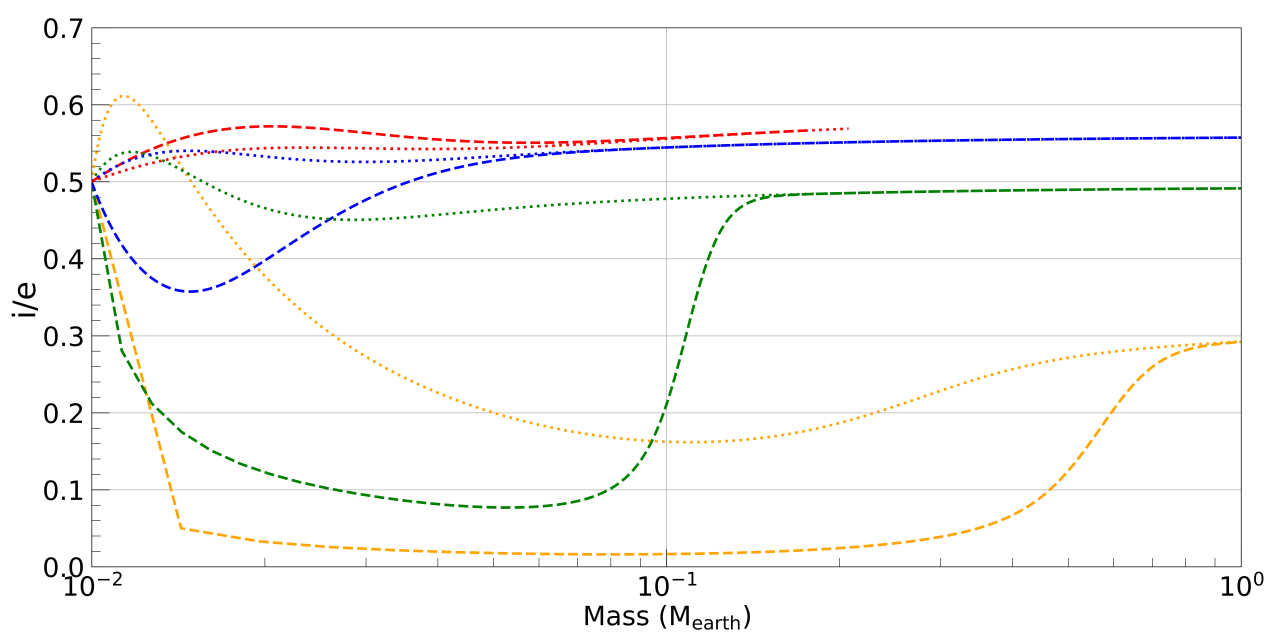

Figura 4.16: Gráfico da razão e/i em função da massa para a formação de um planeta da ordem da massa da Terra. Cada cor representa um tamanho para os planetesimais (vermelho - $100 \mathrm{~km}$; azul - $10 \mathrm{~km}$; verde - $1 \mathrm{~km}$ e laranja - $0.1 \mathrm{~km}$ ). As linhas tracejadas e pontilhadas representam a situação fora do equilíbrio para duas condições iniciais diferentes (pontilhada - eq. 4.139 e eq. 4.140 tracejada - eq. 4.153). As linhas cheias representam a situação de equilíbrio. O corte brusco obtido para as curvas com os planetesimais de $100 \mathrm{~km}$ ocorre porque a simulação é interrompida após $1.8 \times 10^{6}$ anos.

\subsection{Conclusão}

Este capítulo descreveu o modelo para acreção de sólidos que foi implementado no simulador hidrodinâmico FARGO3D. Inicialmente, fizemos uma descrição teórica do modelo descrevendo as principais equações envolvidas. Em seguida, realizamos testes para comparar resultados com os que já existem na literatura. Por fim, simulamos o crescimento de um protoplaneta de massa $0.01 \mathrm{M}_{\otimes}$ até $1 \mathrm{M}_{\otimes}$, fixo em 6 ua, e sem migração. O intuito foi focar nos primeiros estágios da formação planetária, analisar a importância do tamanho dos planetesimais na taxa de acreção planetária e as diferenças entre a situação de equilíbrio e fora do equíbrio para evolução das excentricidades e das inclinações quadráticas médias dos planetesimais.

A acreção de planetesimais, em geral, pode ser investigada por meio de duas técnicas: a utilização de uma simulação de N-corpos ou através de um método estatístico. No entanto, uma simulação N-corpos requer um custo computacional muito alto para descrever o processo de crescimento de um protoplaneta, já que o número de corpos necessários, nos primeiros estágios de crescimento, precisa ser maior que $10^{18}$ planetesimais.

O método estatístico torna-se, portanto, uma ferramenta importante no estudo da 
acreção de um grande número de planetesimais, pois ele não utiliza as quantidades físicas individuais de cada planetesimal, optando pelo uso de quantidades médias. Como resultado, o tempo computacional é muito mais curto do que o obtido numa simulação N-corpos. Entretanto, o método estatístico apresenta algumas desvantagens. Devido ao fato de as quantidades obtidas serem valores médios e a acreção de sólidos um fenômeno não linear, se a média não é realizada corretamente, a solução pode ser fortemente afetada e gerar resultados incorretos. Além disso, após a entrada num regime de crescimento desenfreado (runaway growth), o número de planetesimais pode ser muito baixo para descrever um cenário estatístico confiável.

Para introduzir o modelo teórico, inicialmente, descrevemos as equações de Hill. De fato, a formulação matemática do processo de acreção é obtida tendo como base o problema de três corpos: uma estrela, um núcleo sólido (protoplaneta) e um planetesimal, todos sob ação gravitacional mútua. No entanto, a massa do planetesimal e do núcleo sólido são estritamente menores que a da estrela hospedeira, além disso, podemos considerar que o protoplaneta e o planetesimal orbitam o centro de massa do sistema (estrela, protoplaneta e planetesimal) numa órbita aproximadamente circular. Essas considerações possibilitam o estudo do movimento do planetesimal em torno da vizinhança do protoplaneta por meio das equações de Hill.

A análise do problema por meio das equações de Hill oferece algumas vantagens, como a possibilidade de decompor o estudo desse movimento em dois movimentos: o do centro de massa, que pode ser obtido analiticamente, e o movimento relativo. Além disso, as soluções desses dois movimentos, sob certas restrições, são obtidas de forma independente da massa dos planetesimais. Essas características tornam o cenário de Hill muito útil para estudo do espalhamento gravitacional e das colisões dos planetesimais com o núcleo sólido.

Assim, as seções 4.2.1, 4.2.2 e 4.2.3, tratam, inicialmente, de mostrar o sistema de coordenadas de Hill e o sistema de equações de Hill. Em seguida, a relação das equações obtidas com o movimento kepleriano, isto é, a forma da equação de Hill em função de parâmetros orbitais e, por fim, a separação das equações de Hilll em um movimento relativo e do centro de massa.

Em seguida, introduzimos o modelo estatístico utilizando três considerações importantes:

1. Os guiding centers dos planetesimais são uniformemente distribuídos no plano eclíptico 
em qualquer instante de tempo.

2. A função de distribuição das excentricidades e inclinações dos planetesimais são do tipo Gaussiana.

3. Os ângulos de fase dos planetesimais estão distribuídos de forma aleatória.

A partir dessas considerações é possível, junto com as equações de Hill, obter a função densidade de probabilidade de colisão desses planetesimais com o protoplaneta (ver seção 4.3.1.

De posse da função densidade de probalilidade, mostramos, através de exemplos, como os principais artigos ligados ao tema obtêm, usando simulações numéricas, obtém a taxa de colisão desses planetesimais com o protoplaneta (ver seção 4.3.2. É importante destacar que a taxa de colisão depende das velocidades dos planetesimais, assim, dadas uma determinada excentricidade e inclinação, as taxas de colisão serão diferentes. Expressões analíticas são obtidas para cada regime (baixa, média e alta velocidade).

Em seguida, nós analisamos na seção 4.4.1 como o potencial gravitacional do protoplaneta pode afetar a evolução da excentricidade e da inclinação quadráticas médias dos planetesimais. Para isso, nós seguimos o artigo de Ohtsuki et al. (2002). Essa seção teve como o intuito fornecer conceitos introdutórios para entendimento de como se aplica esse mecanismo no modelo estatístico.

Da mesma forma, seguindo o trabalho de Adachi et al. (1976) e Kokubo e Ida (1998) nós mostramos na seção 4.4.2, como o arrasto do gás pode influenciar a evolução da excentricidade e da inclinação dos planetesimais. Vimos que a forma da força de arrasto pode variar dentro de determinados regimes para o gás. Isto é, o número de Reynolds molecular e o tamanho dos planetesimais diferenciam o arrasto em três regimes: o regime quadrático, de Stokes e de Epstein. Na maior parte das simulações desta tese, o regime quadrático teve maior predominância.

Na seção 4.5, nós finalmente descrevemos o modelo para acreção de sólidos que foi incorporado no FARGO3D. Assim, tendo como base todo o referencial teórico das seções anteriores, implementamos um modelo para a densidade superficial de sólidos e sua evolução, para a evolução da excentricidade e da inclinação quadráticas médias dos planetesimais e, por fim, para a taxa de acreção do protoplaneta. 
É importante destacar que o usuário poderá escolher entre trabalhar no regime fora do equilíbrio, no qual terá que definir condições iniciais para a excentricidade e a inclinação dos planetesimais, ou para a situação em equilíbrio, que já possui as condições iniciais pré-fixadas. Para isso, basta manipular o arquivo setup.opt.

Para testar o modelo, implementamos um setup o mais próximo possível do usado por Fortier et al. (2013), de modo a tentar reproduzir seus resultados. O acordo foi muito bom, dado que não tínhamos acesso a todos os dados numéricos de forma global. Pequenas divergências foram encontradas quando há uma dependência da velocidade do som, já que os modelos para o disco de gás são diferentes. No entanto, o aspecto comportamental global foi muito similar, mostrando que o modelo foi implementado de forma correta.

Por fim, geramos nossos resultados tendo como base um modelo padrão para o disco de gás (ver seção 3.10). Assim como na simulação teste, iniciamos a simulação com um protoplaneta de massa $0.01 \mathrm{M}_{\otimes}$ e o deixamos crescer, sempre no mesmo raio orbital (6 ua), até atingir $1 \mathrm{M}_{\otimes}$. A partir desses resultados, foi possível visualizar a dependência da formação do protoplaneta com o tamanho do raio dos planetesimais. De fato, nós obtemos que, quanto maior o raio do planetesimal mais difícil seu crescimento. Isto ocorre porque o arrasto do gás não é forte o suficiente para diminuir a excentricidade e inclinação quadráticas médias dos planetesimais maiores.

Além disso, notamos que a situação de equilíbrio é muito próxima da situação fora do equilíbrio para planetesimais grandes, e que há uma divergência grande no caso de planetesimais pequenos. No caso fora do equilíbrio para planetesimais pequenos o crescimento foi mais rápido que no caso em eqúlibrio. Isso ocorre devido a mudança rápida da excentricidade que não é acompanhada por uma mudança rápida na inclinação. É possível ver na Figura 4.16 que a razão entre essas duas grandezas não foi próxima da situação em equilíbrio para o caso dos planetesimais menores. Também é possível ver na mesma figura, que a situação de equilíbrio é mais próxima da situação fora do equilíbrio quanto maior o tamanho dos planetesimais.

Com o modelo de acreção de sólidos implementado será possível a análise da formação e migração de um núcleo sólido utilizando o simulador hidrodinâmico FARGO3D. Essa análise será realizada no próximo capítulo em conjunto com a inserção de um modelo para a acreção de gás. 
Capítulo 5

\section{Modelo para acreção de gás}

Neste capítulo, iremos implementar, dentro do código FARGO3D, um modelo para acreção de gás e analisar as consequências desse modelo no processo de migração planetária de tipo II, que possui como característica a abertura de um gap no disco de gás. Conforme vimos na seção 3.10 para a simulação padrão, essa análise será realizada para o cenário de um disco de acreção em equilíbrid]. Veremos na seção 5.1 que o tempo necessário para o disco da simulação padrão atingir uma situação próxima do equilíbrio, quando imerso um planeta de $1 \mathrm{M}_{\mathrm{J}}$, é de aproximadamente 5000 órbitas (no sistema CGS ou MKS corresponde a órbita de Júpiter). Este valor foi obtido analisando o tempo necessário para que o fluxo radial de gás se aproxime da taxa de acreção teórica do disco, no caso, uma taxa de acreção constante.

Atingida a situação próxima do equilíbrio, na qual o gap já está completamente formado, iremos estudar, considerando uma massa planetária fixa em $r=1$ (5.2 ua) efeito de abertura desse gap com a massa planetária $\left(M_{\mathrm{p}}=0.2 \mathrm{M}_{\mathrm{J}}, 0.5 \mathrm{M}_{\mathrm{J}}\right.$ ou $\left.1.0 \mathrm{M}_{\mathrm{J}}\right)$, com a viscosidade do disco $(\alpha=0.001,0.003$ ou 0.01$)$ e com a taxa de acreção do disco $\left(\dot{M}=10^{-7}, 10^{-8}\right.$ ou $10^{-9} \mathrm{M}_{\odot} /$ ano $)$. Vamos também analisar o torque total no planeta depois da completa formação do gap e sua relação com a viscosidade e a taxa de acreção

\footnotetext{
${ }^{1}$ Seguindo o trabalho de Dürmann e Kley (2015) usaremos a notação equilíbrio para descrever um disco de gás cujo os parâmetros já se encontram estabilizados. O leitor deve entender essa nomenclatura como a de um disco quase-estacionário e não no sentido de equilíbrio físico propriamente dito. Optamos pela nomenclatura do artigo para evitar uma confusão de nomenclatura.

2 As unidades do FARGO3D podem ser escolhidas em sua forma adimensional, assim, quando a unidade for omitida o leitor deve estar ciente que estamos nos referindo a unidade adimensional do código. Entre parênteses colocamos o equivalente em unidades astrônomicas quando é escolhido o sistema CGS ou MKS.
} Em caso de dúvidas, consultar a seção 3.5 
do disco.

Em seguida, iremos permitir que o planeta migre e analisar a evolução do gap e o fluxo de massa dentro do gap durante a migração planetária. Para que a análise seja feita de maneira rigorosa e cuidadosa, os planetas só poderão migrar após o tempo necessário para que o disco padrão atinja o equilíbrio. Esta análise será realizada, inicialmente, com o código padrão do FARGO3D, em que não há acreção de gás. Isso nos fornecerá uma base de comparação com o modelo com acreção de gás que foi implementado. Chamaremos a versão original do FARGO3D de versão sem acreção de gás.

Utilizando como base o modelo de Kley (1999), iremos adaptar no FARGO3D um modelo mais consistente para a acreção de gás, denominado versão com acreção de gás. Essas adaptações foram realizadas seguindo o trabalho de Russell (2011). No modelo de Kley (1999), define-se, de forma arbitrária, uma frequência para a retirada de massa de gás dentro de uma região de captura definida pelo raio de Hill do planeta. No entanto, o novo modelo utiliza o critério de raio de Bondi que leva em conta características físicas do disco de gás que alteram o tamanho da região de acreção. Além disso, mudaremos a frequência da retirada de massa que passa a ter como período fundamental o período orbital do gás em torno do planeta, conceito que fornece um limite para a taxa de acreção que está relacionado com o limite teórico imposto pela taxa de acreção de Bondi (ver seção 2.5.).

Entretanto, a situação descrita acima já considera os planetas em regime de runaway, fato que só ocorre para planetas massivos, isto é, quando a massa do envelope é próxima da massa do núcleo planetário. Assim, para englobar uma faixa maior de massas planetárias, utilizamos o trabalho de Ikoma et al. (2000) e Ida e Lin (2004a) e, adaptamos no modelo a acreção de gás para planetas que ainda não alcançaram o regime de runaway.

Analisaremos também a influência desse modelo de acreção de gás na evolução do gap e no fluxo de massa dentro do gap durante a migração planetária. Logo, iremos reproduzir os resultados anteriores permitindo que o planeta migre acretando gás durante esse processo. No entanto, a massa retirada da zona de acreção não será acrescentada ao planeta. Assim, comparando os resultados, vamos analisar como o esvaziamento da zona de acreção influencia na evolução do gap sem o aumento da inércia do planeta.

Após o estudo da evolução do gap descrito no parágrafo anterior, vamos estudar a formação de um planeta de massa $1 \mathrm{M}_{\mathrm{J}}$ fixo em $r=1$, e comparar nossos resultados com 
os obtidos na literatura.

Por fim, terminaremos analisando um cenário de formação planetária completo (acreção de gás e sólidos), que inclui a migração planetária de tipo I e de tipo II com o intuito de comparar as escalas de tempo de formação e migração planetária dentro do novo modelo com formação planetária.

\subsection{Disco standard em equílibrio}

Antes de iniciar a análise da acreção de gás e da migração de planetas gigantes, iremos analisar nosso disco padrão (ver seção 3.10) com um planeta fixo em $r=1$ (5.2 ua). Para isso, vamos esperar que nosso modelo de disco de gás alcance a situação de equilíbrio, isto é, que a taxa de acreção do disco seja aproximadamente constante ao longo do raio do disco, já que esse é o cenário teórico esperado. Apesar de esse disco ser fisicamente muito simples, a taxa de acreção constante será importante para comparar a evolução do gap, causado pelo planeta, com a evolução viscosa do disco de gás, quando os planetas migrarem. Isso possibilitará comparar os resultados numéricos com o cenário teórico da migração planetária de tipo II descrito na seção 2.3.2. Além disso, permitirá analisar a dependência do formato e da profundidade do gap com a massa total do disco, já que esse parâmetro está intrinsecamente ligado à taxa de acreção do disco (ver equação 3.119).

A Figura 5.1 mostra a evolução do perfi 11 da taxa de acreção do disco de gás, $\dot{M}(r)$, em diferentes períodos de tempo. A taxa de acreção local foi obtida mediante a integração do fluxo de massa na direção azimutal para cada raio. Para isso, nós simplesmente criamos um vetor no código que guarda os valores do fluxo de massa na direção radial (coordenadas cilíndricas), calculado em transport.c na rotina VanLeerY_b(dt, Density, DensStar), e plotamos os resultados num arquivo de saída na formatação usual do FARGO3D. Em seguida, usando uma rotina escrita em python, somamos o fluxo de todas as células na direção azimutal para cada raio do disco.

Para nosso modelo padrão, a taxa de acreção é de $10^{-7} \mathrm{M}_{\odot} /$ ano, portanto, era esperado que, após determinado tempo, se encontrasse uma reta horizontal no gráfico, como pode ser visualizado na seção 3.10 .4 (ver Fig. 3.7). No entanto, isso não ocorre porque a taxa

\footnotetext{
${ }^{1}$ Para evitar abuso de linguagem, sempre que nos referirmos ao perfil de uma grandeza estamos considerando a variação da grandeza ao longo do raio do disco. Essa nomenclatura será usada ao longo de todo o capítulo.
} 


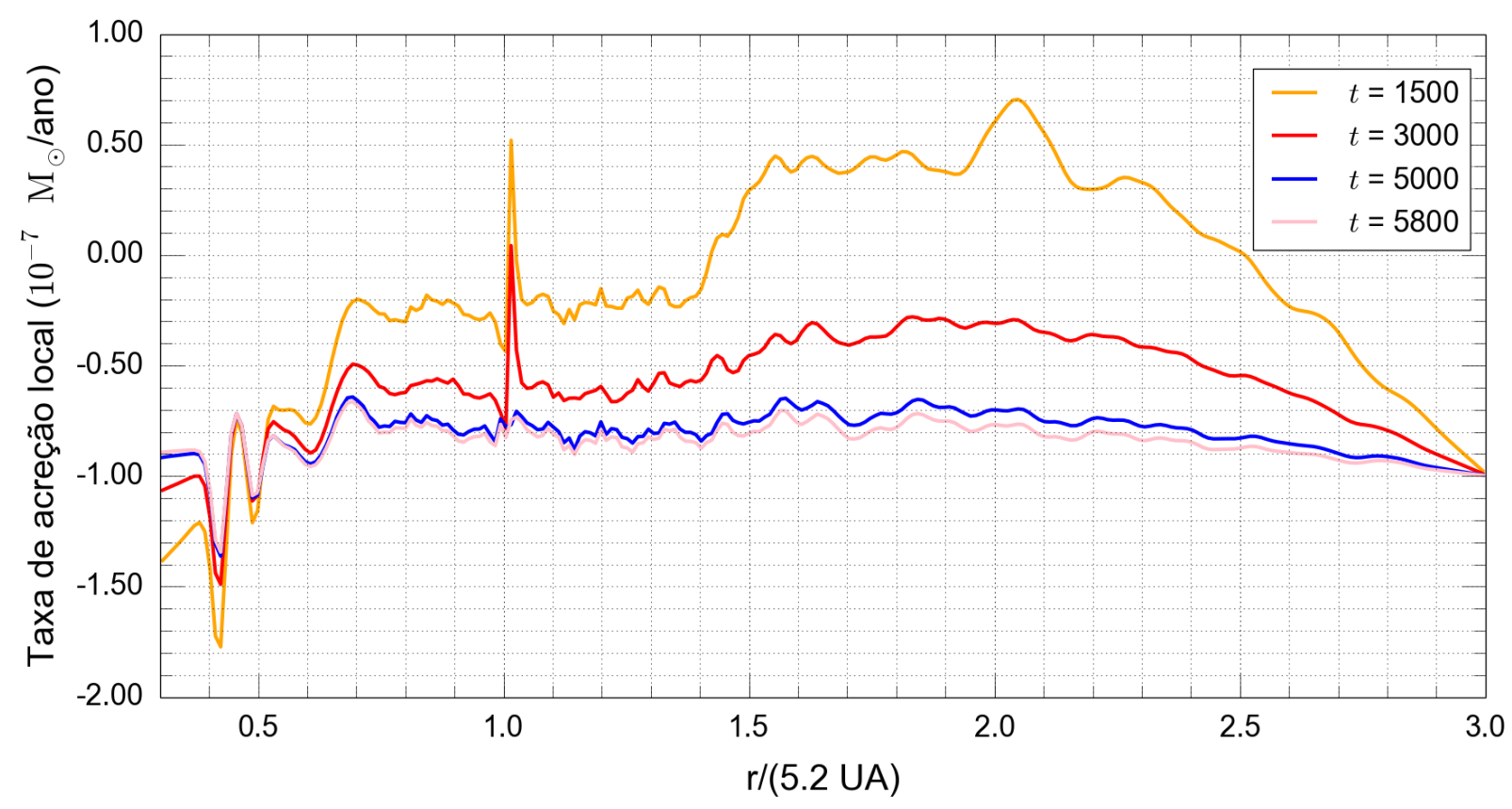

Figura 5.1: Perfil da taxa de acreção ao longo do tempo para o disco padrão $(\alpha, \dot{M})=$ $\left(0.003,10^{-7}\right)$ com um planeta de $1 \mathrm{M}_{\mathrm{J}}$ em $r=1$.

de acreção local é muito sensível a qualquer tipo de perturbação. A velocidade radial na situação de equilíbrio é da ordem de $v_{\mathrm{r}} / c_{\mathrm{s}} \approx 10^{-4}$ para nosso modelo padrão. Assim, pequenas variações na pressão permitem uma grande variação na velocidade radial em comparação com seu valor de equilíbrio. Todavia, embora o perfil não seja plano, não há mudanças significativas entre 5000 e 5800 órbitas. Portanto, usaremos como tempo característico para o disco atingir o equilíbrio o valor de 5000 órbitas. A Figura 5.2, com o perfil da média azimutal da densidade superficial, mostra que o gap, após 5000 órbitas, já está complementamente desenvolvido.

É importante destacar que na situação de equilíbrio o gás precisa cruzar o gap, assim, os discos interno e externo estão, portanto, conectados e não há acumulo significativo de gás na borda externa ou interna do gap, isso pode ser visto pela comparação do perfil do gap em 5000 órbitas e 5800 órbitas, que mostra dois perfis muito similares.

Note que, na região externa do disco $(r>1.7)$, a densidade superficial do gás aumenta em relação ao perfil inicial. Isso ocorre porque o planeta, ao transferir momento angular para o disco de gás, empurra o gás para as regiões externas e internas do disco. Na borda externa, as condições de contorno impedem o fluxo de gás de sair para fora da malha computacional, criando, portanto, um aumento no perfil da média azimutal da densidade 


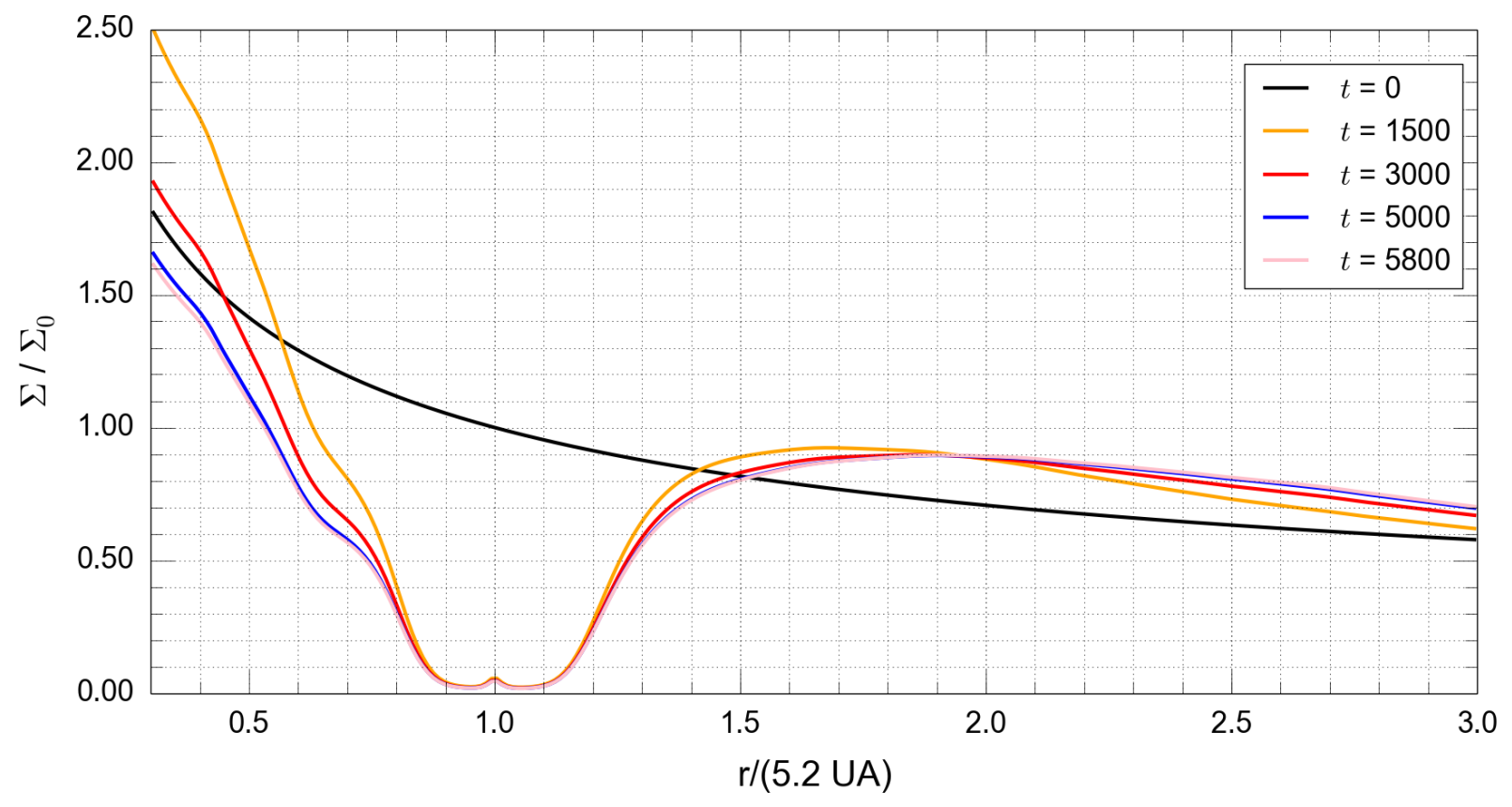

Figura 5.2: Perfil da média azimutal da densidade superficial de gás para o disco padrão $(\alpha, q, \dot{M})=\left(0.003,0.001,10^{-7}\right)$ com um planeta de $1 \mathrm{M}_{\mathrm{J}}$ fixo em $r=1$. O parâmetro $q$ é a razão entre a massa do planeta e a massa do Sol $\left(q=\frac{M_{\mathrm{p}}}{\mathrm{M}_{\odot}}\right)$.

superficial do gás nessa região, isso também implica o salto obtido em $r=3.0$. Esse salto na densidade superficial do gás não interfere nos nossos resultados, já que o gap está afastado da borda externa. Na borda interna, pelo mesmo motivo, obtemos, inicialmente, um aumento no perfil de densidade superficial do gás, em seguida, devido às condições de borda, a massa sai do domínio computacional ocorrendo uma diminuição no perfil da densidade superficial de gás nessa região.

\subsection{Análise do formato do gap para planetas fixos - cenário sem acreção de gás}

Antes de analisar a migração planetária, iremos estudar as condições do disco de gás logo após a situação de equílibrio, variando alguns parâmetros físicos. Isto é, iremos comparar o tamanho e a profundidade do gap produzido pelo planeta em função da massa planetária $\left(0.2 \mathrm{M}_{\mathrm{J}}, 0.5 \mathrm{M}_{\mathrm{J}}\right.$ e $\left.1.0 \mathrm{M}_{\mathrm{J}}\right)$, da viscosidade $(\alpha=0.001,0.003$ e 0.010$)$ e da taxa de acreção do disco de gás $\left(10^{-7}, 10^{-8}\right.$ e $10^{-9} \mathrm{M}_{\odot} /$ ano $)$.

Conforme descrito na seção anterior, a análise vai ocorrer assim que forem atingidas as 5000 órbitas, tempo suficiente para uma estabilização do gap e para o disco de gás alcançar 
uma situação próxima do equilíbrio.

O gráfico a seguir (Fig. 5.3) mostra a média azimutal da densidade superficial do gás obtida para diferentes valores de $\alpha$ e diferentes massas planetárias para um disco de gás com taxa de acreção de $10^{-7} \mathrm{M}_{\odot} /$ ano, utilizando a versão padrão do FARGO3D (versão sem acreção de gás).
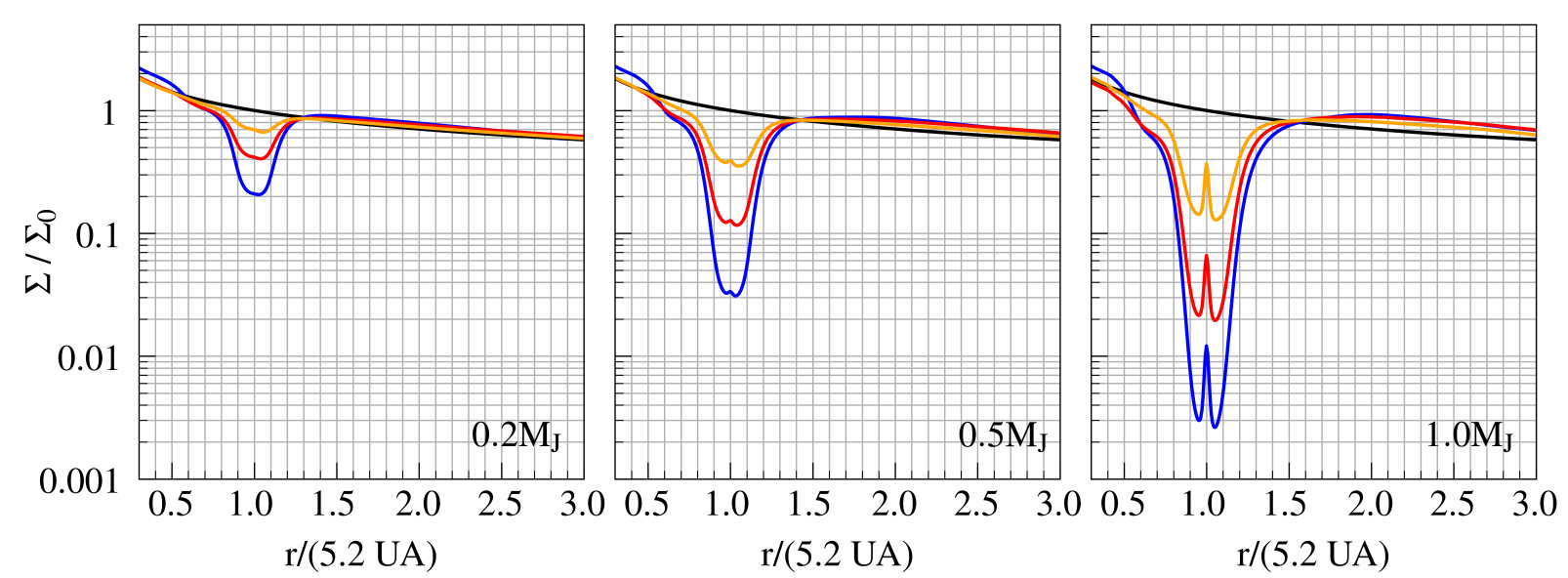

Figura 5.3: Gráfico do perfil da média azimutal da densidade superficial do gás para várias massas planetárias (da esquerda para a direita $0.2 \mathrm{M}_{\mathrm{J}}, 0.5 \mathrm{M}_{\mathrm{J}}$ e $1.0 \mathrm{M}_{\mathrm{J}}$ ) e para diferentes valores de viscosidade (azul: $\alpha=0.001$, vermelho: $\alpha=0.003$ e laranja: $\alpha=0.010$ ) após atingida a situação de equilíbrio. A linha preta indica o perfil inicial para densidade superficial do gás no começo da simulação. Os gráficos correspondem à versão sem acreção de gás e a um disco de gás cuja taxa de acreção é de $10^{-7} \mathrm{M}_{\odot} /$ ano.

Como esperado, os gaps são mais profundos quanto maior a massa planetária e menor a viscosidade. Assim, planetas maiores numa região de menor viscosidade produzem um gap mais profundo e planetas menores numa região de maior viscosidade produzem um gap menos profundo.

Na versão original do FARGO3D, não há acreção de gás, nota-se, portanto, uma região de sobredensidade na posição do planeta. Isso ocorre em razão da concentração de gás ao redor do planeta, tratado como um ponto na malha hidrodinâmica.

As Figuras 5.4 e 5.5 mostram a mesma análise para diferentes taxas de acreção para o disco de gás. Não detectamos nenhuma diferença significativa entre as diferentes taxas de acreção. Isso mostra que a profundidade e o formato do gap obtidos com o planeta fixo são independentes da massa total do disco. Isso ocorre porque no disco isotérmico, apesar de a distribuição de massa possuir um fator de escala que depende linearmente da taxa de acreção, a forma da distribuição é sempre igual a $r^{-1 / 2}$ (ver equação 3.119). 
Para entender melhor a influência da produção do gap na interação gravitacional entre o disco e o planeta, podemos analisar o torque total gerado pelo disco de gás sobre o planeta após atingir as 5000 órbitas. Na realidade, utilizamos a média do torque total nas últimas 5 órbitas, apenas para descaracterizar as pequenas oscilações no valor do torque total. Na Figura 5.6, mostramos o valor do torque em função da massa do planeta $M_{\mathrm{P}}$ para diferentes valores de viscosidade. A normalização do torque é dada por (Paardekooper et al., 2010):

$$
\Gamma_{0}=-\Sigma_{\mathrm{P}} \Omega_{\mathrm{K}}^{2} a_{\mathrm{P}}^{4}\left(\frac{q}{h}\right)^{2},
$$

onde $\Sigma_{\mathrm{P}}$ é a densidade do disco não perturbado na localização do planeta e $a_{\mathrm{p}}$ é o semieixo maior do planeta. Essa expressão fornece o torque que existiria numa possível migração de tipo I dadas as mesmas condições locais do disco de gáș
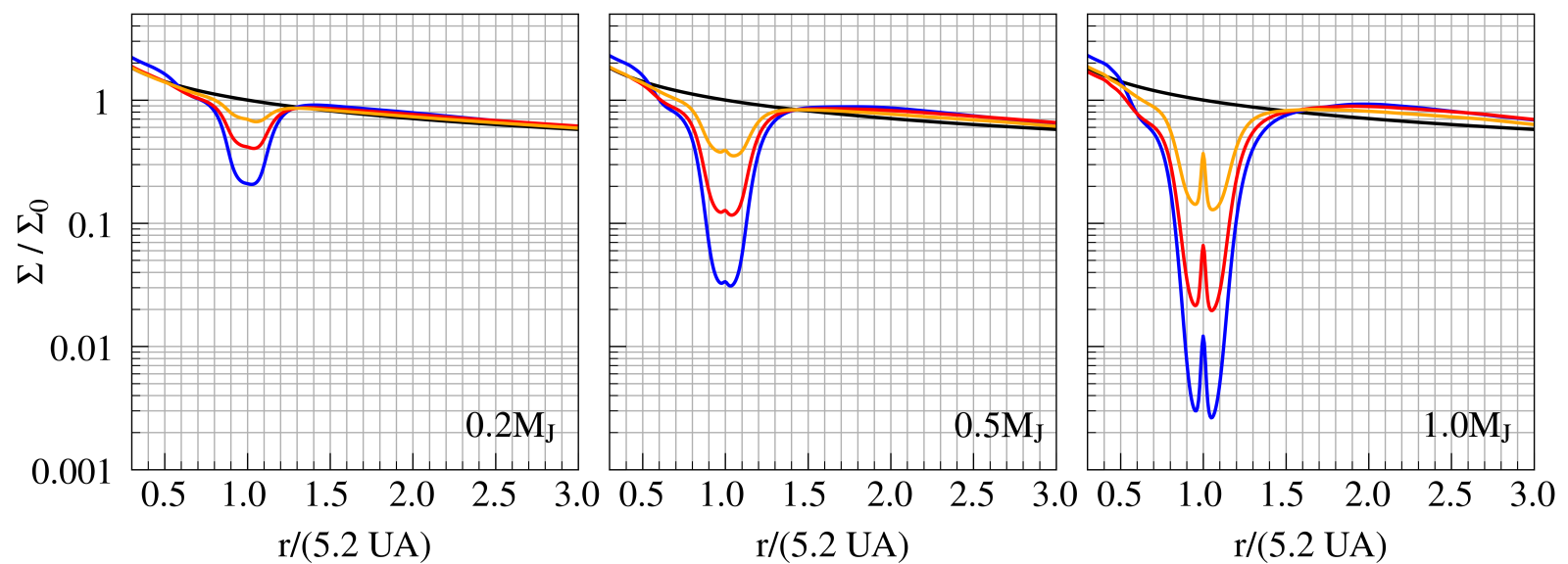

Figura 5.4: Idem à Figura 5.3 para uma taxa de acreção de $10^{-8} \mathrm{M}_{\odot} /$ ano.

Observe que a grandeza $f_{\text {still }}=\frac{\Gamma}{\Gamma_{0}}$ da Figura 5.6 é um fator de redução do torque que mostra quanto ele foi reduzido em relação a uma migração de tipo I. Note que o fator de redução $f_{\text {still }}$ é mais intenso para planetas maiores e que, para massas planetárias grandes, quanto menor a viscosidade maior é a redução do torque. Isto ocorre porque a profundidade do gap nesses casos é maior, portanto, há menor disponibilidade de material próximo do planeta e, assim, menor é o torque do disco de gás no planeta próximo dessa região.

\footnotetext{
${ }^{1}$ Existem outras expressões mais complexas para normalização (Tanaka et al., 2002). No entanto, essa expressão aproximada é suficiente para a análise realizada.
} 

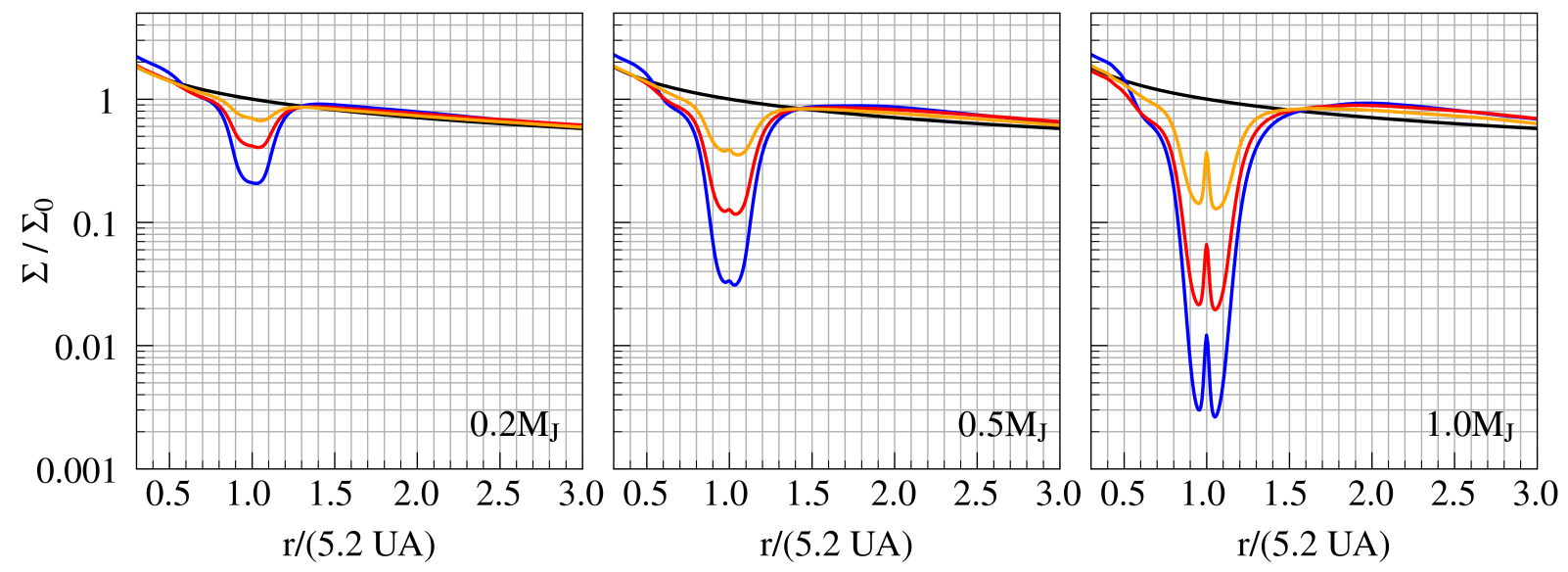

Figura 5.5: Idem à Figura 5.3 para uma taxa de acreção de $10^{-9} \mathrm{M}_{\odot} /$ ano.

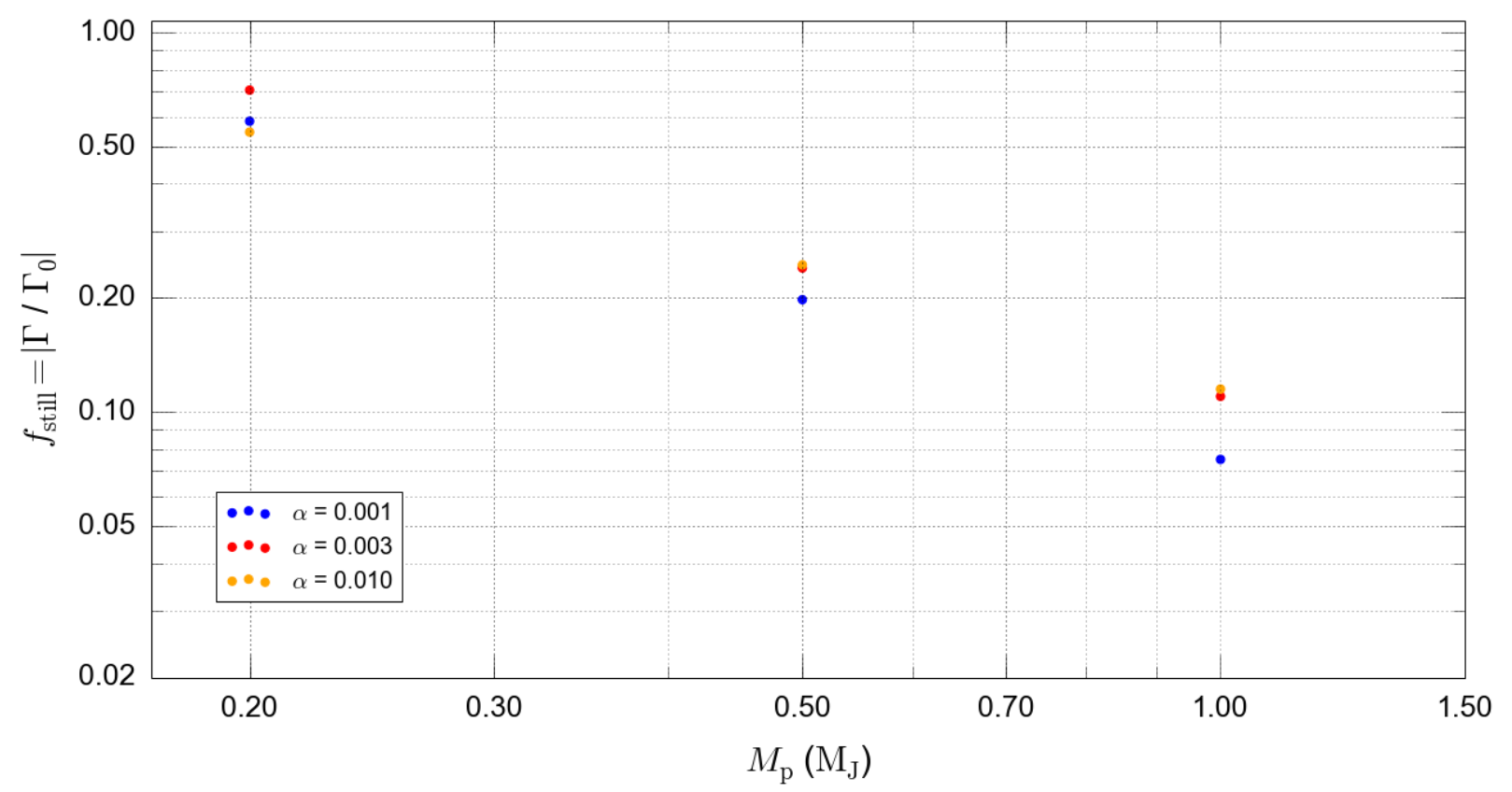

Figura 5.6: Torque normalizado agindo no planeta numa órbita fixa depois de 5000 órbitas em função da massa do planeta e da viscosidade do disco (azul: $\alpha=0.001$, vermelho: $\alpha=$ 0.003 e laranja: $\alpha=0.010$ ). O disco usado possui uma taxa de acreção de $10^{-7} \mathrm{M}_{\odot} /$ ano.

No entanto, para massas menores, o gap não foi suficiente para reduzir de forma significativa a massa de gás próxima do planeta, resultando em uma situação mais complicada na qual os torques devido à ressonância de Lindblad ainda possuem contribuição significativa em regiões próximas do planeta (ver seção 2.3.1). Veremos na próxima seção que, em alguns casos, o torque no planeta foi forte o suficiente para tirar o planeta do gap e, portanto, o planeta sofre uma migração diferente do cenário esperado de uma migração 
de tipo II. Como estamos particularmente interessados no estudo da migração de tipo II, sofrida por planetas gigantes, esses casos fogem do escopo desta tese.

Não foram encontradas diferenças significativas na Figura 5.6 para as outras taxas de acreção do disco de gás, isso demontra que, para o planeta fixo e o gap bem estabelecido, a estrutura do torque no planeta não depende da taxa de acreção do disco, ou, consequentemente, da massa total do disco, que aqui estão correlacionadas. De fato, isso já era esperado pois não foram obtidas mudanças no formato do gap para diferentes taxas de acreção, isto é, embora o disco seja mais massivo, a distribuição de densidade após a situação de equilíbrio é igual.

\subsection{Migração de planetas massivos - cenário sem acreção de gás}

Após o disco alcançar a situação próxima do equilíbrio (5000 órbitas), os planetas podem migrar. A Figura 5.7 a seguir mostra a evolução do semieixo maior do planeta com o tempo, para diferentes parâmetros de massa planetária e viscosidade, em um disco de gás cuja taxa de acreção é de $10^{-7} \mathrm{M}_{\odot} /$ ano. Essa figura corresponde ao modelo padrão do FARGO3D no qual o planeta não acreta de gás. Os planetas podem migrar por 1200 órbitas após o equilíbrio ou até chegarem à distância de $0.5(\simeq 2.6$ ua), onde os efeitos de borda se tornam significativos, situação que foge do escopo desta tese.

Usaremos os termos regime de baixa viscosidade quando $\alpha=0.001$, regime de média viscosidade quando $\alpha=0.003$ e regime de alta viscosidade quando $\alpha=0.010$. É importante ressaltar que o estudo realizado nesta tese considera uma faixa de valores para o parâmetro de Shakura-Sunyaev entre 0.001 e 0.010, que está dentro dos valores observacionais estipulados (Hartmann et al., 1998; Mukhopadhyay, 2008). Portanto, o leitor deve tomar cuidado para não utilizar as conclusões obtidas em extrapolações para além dessa faixa de valores.

Observe que, no regime de baixa viscosidade $(\alpha=0.001)$ e média viscosidade $(\alpha=$ 0.003), a mudança do semieixo maior foi muito brusca para os planetas de massa $0.2 \mathrm{M}_{\mathrm{J}}$ e $0.5 \mathrm{M}_{\mathrm{J}}$. Nitidamente, esses planetas não sofreram um processo de migração de tipo II. Isto é, não conseguiram manter o gap inicial durante seu processo migratório. Considerando o planeta de massa $0.2 \mathrm{M}_{\mathrm{J}}$, isso pode ser constatado pela Figura 5.8 , que mostra o formato do gap estático ao longo da migração planetária no regime de baixa e média viscosidade. Ob- 

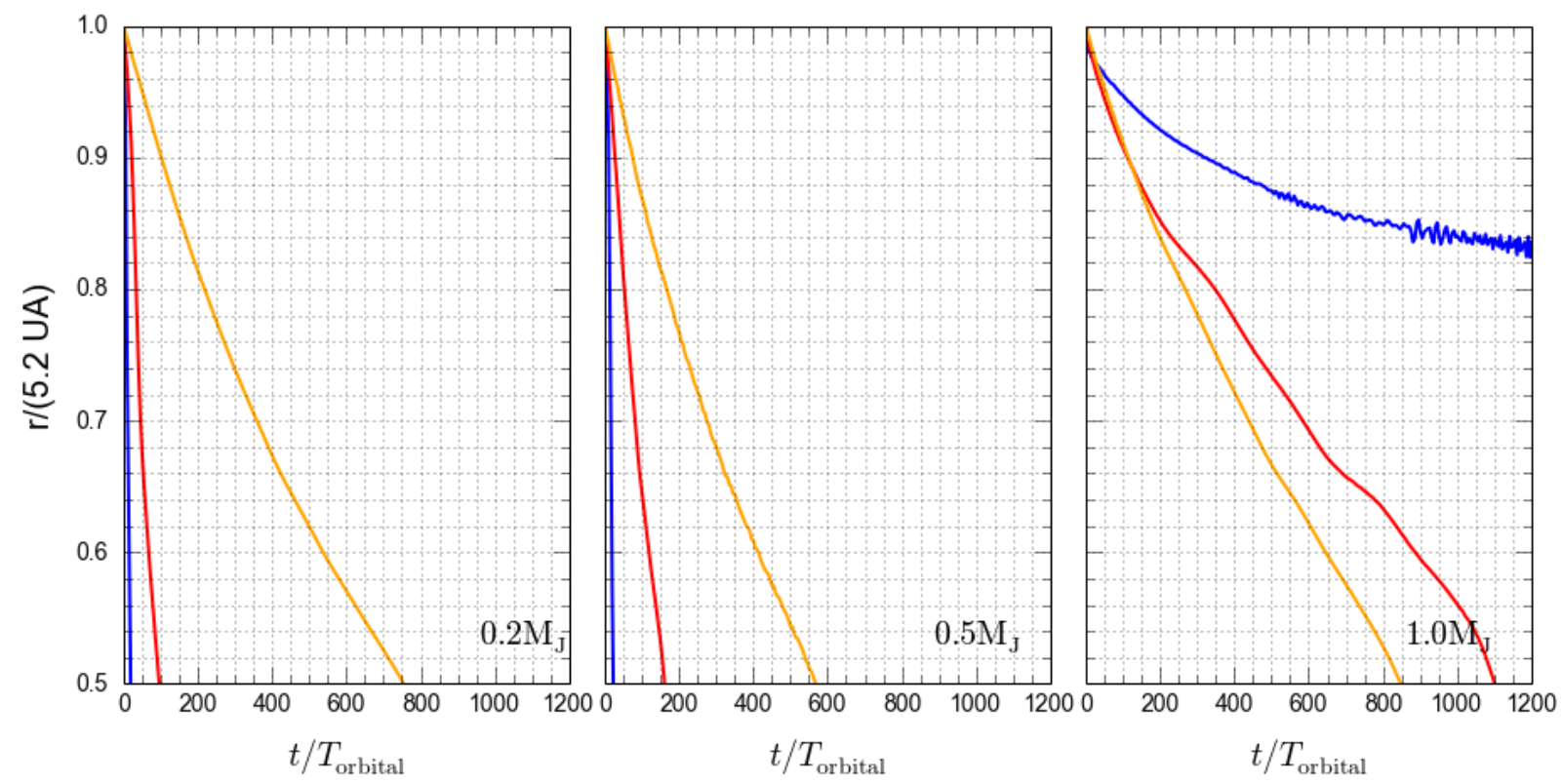

Figura 5.7: Gráfico da evolução do semieixo maior dos planetas em função do tempo para várias massas planetárias (da esquerda para a direita $0.2 \mathrm{M}_{\mathrm{J}}, 0.5 \mathrm{M}_{\mathrm{J}}$ e $1.0 \mathrm{M}_{\mathrm{J}}$ ) e para diferentes valores de viscosidade (azul: $\alpha=0.001$, vermelho: $\alpha=0.003$ e laranja: $\alpha=0.010$ ). Os gráficos correspondem à versão sem acreção de gás e a um disco de gás cuja taxa de acreção é de $10^{-7}$ $\mathrm{M}_{\odot} /$ ano.

serve a diferença para o caso de alta viscosidade, no qual o gap foi mantido dinamicamente pelo planeta ao longo do processo migratório.
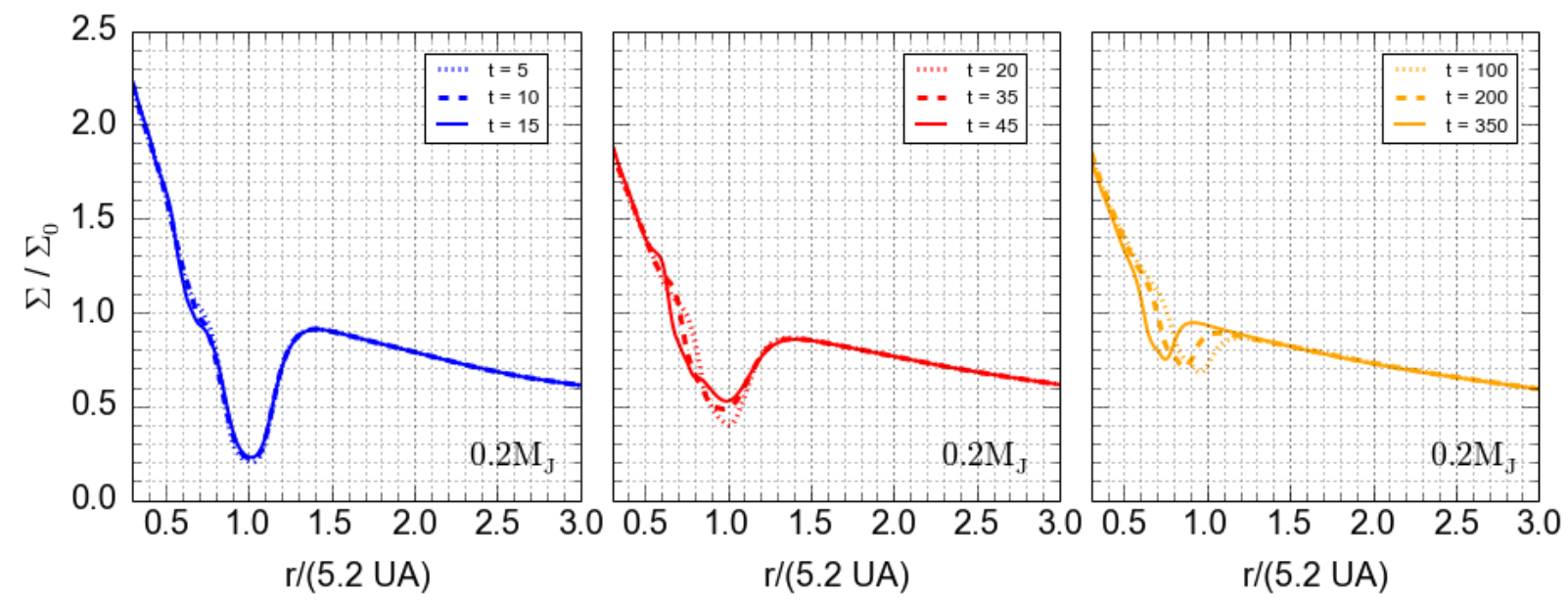

Figura 5.8: Evolução do perfil da média azimutal da densidade superficial do gás ao longo do tempo para o planeta de massa $0.2 \mathrm{M}_{\mathrm{J}}$ para diferentes viscosidades. Da esquerda para a direita, temos $\alpha=0.001, \alpha=0.003$ e $\alpha=0.015$. A taxa de acreção do disco de gás é de $10^{-7} \mathrm{M}_{\odot} /$ ano e o planeta não acreta gás.

A análise anterior pode ser melhor elucidada observando a Figura 5.9, que mostra 
o perfil local da média azimutal da densidade superficial do gás, para isso, escalonamos o raio do disco em função da escala de altura do disco e da posição planetáriạ. Essa figura pode ser interpretada como o formato do gap próximo do planeta ao longo do processo migratório. As posições do planeta estão relacionadas com os tempos da Figura 5.8. Observe que, no caso de baixa e média viscosidade, o gap planetário foi deixado para trás e manteve, aproximadamente, seu formato no caso de alta viscosidade, com uma leve modificação da profundidade do gap.
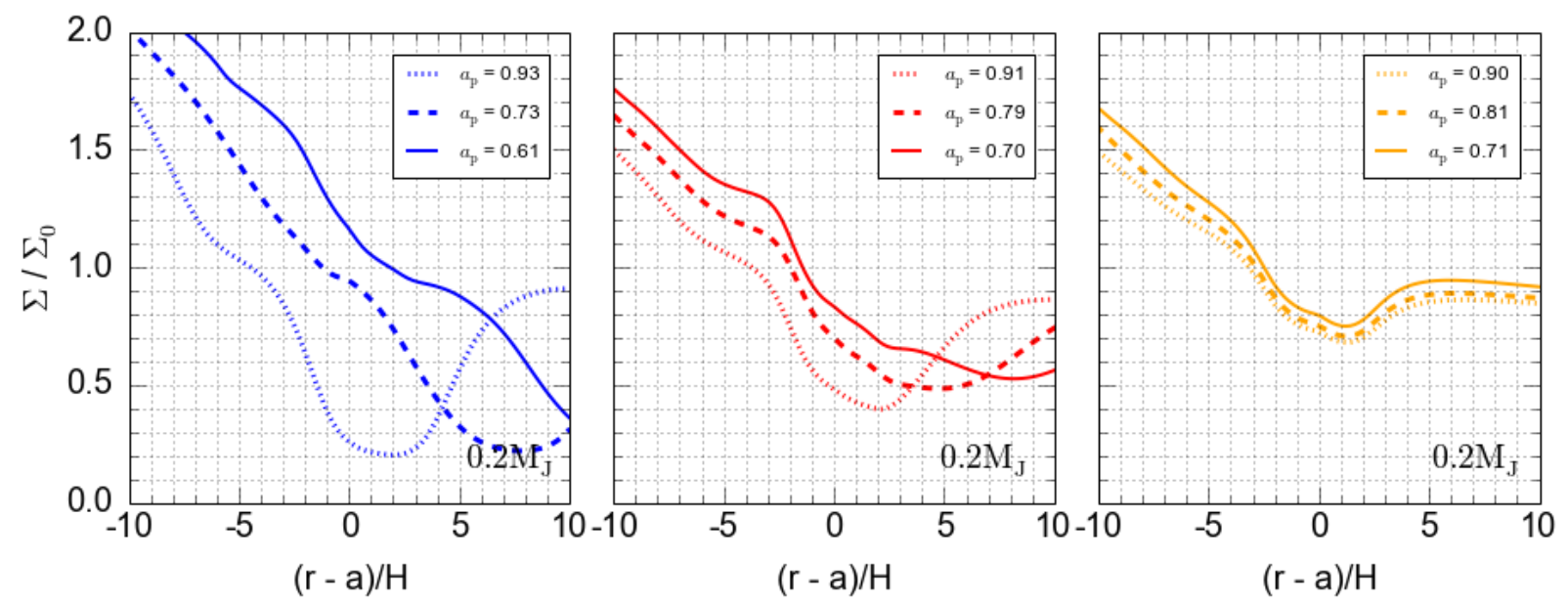

Figura 5.9: Evolução do perfil local da média azimutal da densidade superficial do gás em diferentes posições do planeta de massa $0.2 \mathrm{M}_{\mathrm{J}}$ para diferentes viscosidades. Da esquerda para a direita, temos $\alpha=0.001, \alpha=0.003$ e $\alpha=0.015$. A taxa de acreção do disco de gás é de $10^{-7} \mathrm{M}_{\odot} /$ ano e o planeta não acreta gás.

Constatamos, portanto, que o planeta de massa $0.2 \mathrm{M}_{\mathrm{J}}$, nos regimes de baixa e média viscosidade, escapou do gap e seguiu seu processo evolutivo num cenário diferente do esperado para a migração de tipo II, isto é, a condição inicial imposta não foi suficiente para aprisionar o planeta dentro do gap.

É interessante notar que, considerando o tempo de abertura do gap devido ao efeito gravitacional do planeta e o tempo de fechamento do gap devido à viscosidade do gás, é possível obter uma medida teórica da massa crítica necessária para abrir o gap Armitage, 2010). Assim, o valor da massa crítica $\left.\right|^{1}$ pode ser obtido pela expressão:

\footnotetext{
${ }^{1}$ Em todas as situações que estivermos analisando uma grandeza de forma local (região próxima do planeta) iremos usar a escala $\left(r-a_{\mathrm{p}}\right) / H$.

${ }^{1}$ Usamos uma ideia bastante simplificada para o cálculo da massa crítica, apenas para possuir um valor de referência. Um estudo mais pormenorizado pode ser encontrado em Crida et al. (2006).
} 


$$
\frac{M_{\mathrm{p}}}{M_{\star}}=\left(\frac{27 \pi}{8}\right)^{1 / 2}\left(\frac{H}{r}\right)^{5 / 2} \alpha^{1 / 2},
$$

onde $H / r=0.05$ é a razão de aspecto do disco (ver seção 2.1.2) e $\alpha$ o valor da parametrização de Shakura-Sunyaev (ver seção 2.1.1).

Considerando nosso modelo para o disco de gás, obteríamos $M_{\mathrm{p}} \simeq 0.05 \mathrm{M}_{\mathrm{J}}$ para o regime de baixa viscosidade, $M_{\mathrm{p}} \simeq 0.10 \mathrm{M}_{\mathrm{J}}$ para o regime de média viscosidade e $M_{\mathrm{p}} \simeq 0.21 \mathrm{M}_{\mathrm{J}}$ para o regime de alta viscosidade. No entanto, os resultados numéricos mostraram que, para uma massa planetária de $0.2 \mathrm{M}_{\mathrm{J}}$, apenas no regime de alta viscosidade foi possível a manutenção do gap planetário. Isso ocorre porque o cenário teórico usado para este cálculo desconsidera o torque coorbital e a concentração diferencial da massa de gás em regiões próximas do gap. Apesar de as simulações numéricas possuírem um fator de atenuação na região dentro de $0.8 R_{\mathrm{H}}$ (ver eq · 3.115), ainda há uma grande contribuição do torque gravitacional do gás no planeta ${ }^{1}$ em regiões próximas, fato que não está previsto nas considerações teóricas da massa crítica. A Figura 5.10 a seguir mostra a contribuição no valor do torque ao longo do raio do disco obtida numa região próxima do planeta (local), para isso usamos a mesma escala da abscissa da Figura 5.9. O valor do torque para cada raio foi obtido através de uma soma azimutal do torque de cada célula e normalizado em termos do valor máximo obtido ao longo do raio do disco.

De fato, podemos observar uma grande contribuição do torque dentro da região atenuada. Portanto, nesses casos, a redução da densidade superficial do gás não foi suficiente para reduzir o torque na região próxima do planeta. Assim, o planeta sofre um processo de migração mais complexo com uma contribuição significativa do torque devido as ressonâncias de Lindblad.

É interessante notar que, em todos os casos, o perfil da proporção do torque não depende da posição do planeta e que esse perfil atinge rapidamente o equilíbrio. Além disso, a maior contribuição do torque se encontra numa região próxima de $5 H$ do planeta em todos os casos.

A Figura 5.11 mostra o fluxo de gás na região próxima do planeta de massa $0.2 \mathrm{M}_{\mathrm{J}}$ durante seu processo migratório. A figura utiliza a mesma escala da abscissa das figuras anteriores e possibilitará estudar o comportamento do fluxo de gás dentro do gap durante

\footnotetext{
${ }^{1}$ Daqui por diante usaremos ao longo de toda a tese apenas a palavra torque, já que está claro que se trata do torque gravitacional do gás no planeta.
} 

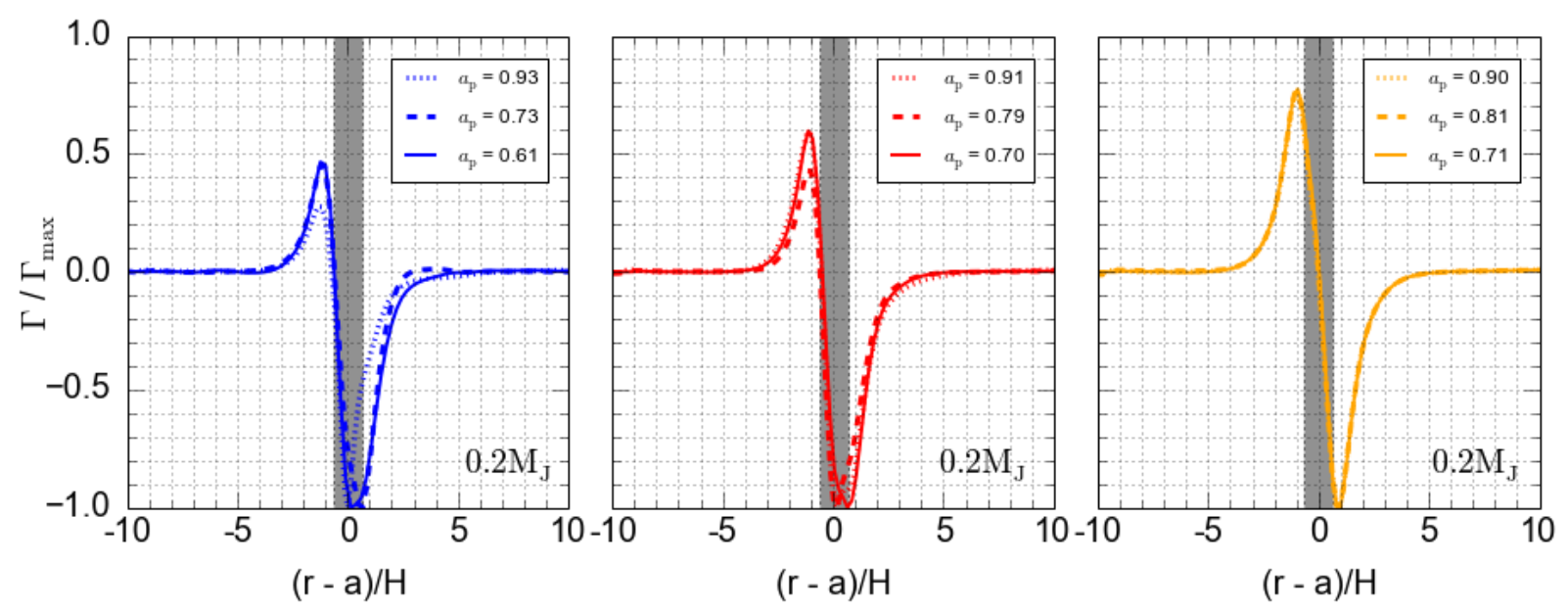

Figura 5.10: Evolução do perfil local do torque em diferentes posições do planeta de massa $0.2 \mathrm{M}_{\mathrm{J}}$ para diferentes viscosidades. Da esquerda para a direita, temos $\alpha=0.001, \alpha=0.003$ e $\alpha=0.015$. A região cinza indica a região na qual o torque sofre uma atenuação, isto é, a região dentro de $0.8 \mathrm{R}_{\mathrm{H}}$. A taxa de acreção do disco de gás é de $10^{-7} \mathrm{M}_{\odot} /$ ano e o planeta não acreta gás. O valor do torque para cada raio foi obtido através de uma soma azimutal do torque de cada célula e normalizado em termos do valor máximo obtido ao longo do raio do disco.

a migração planetária.
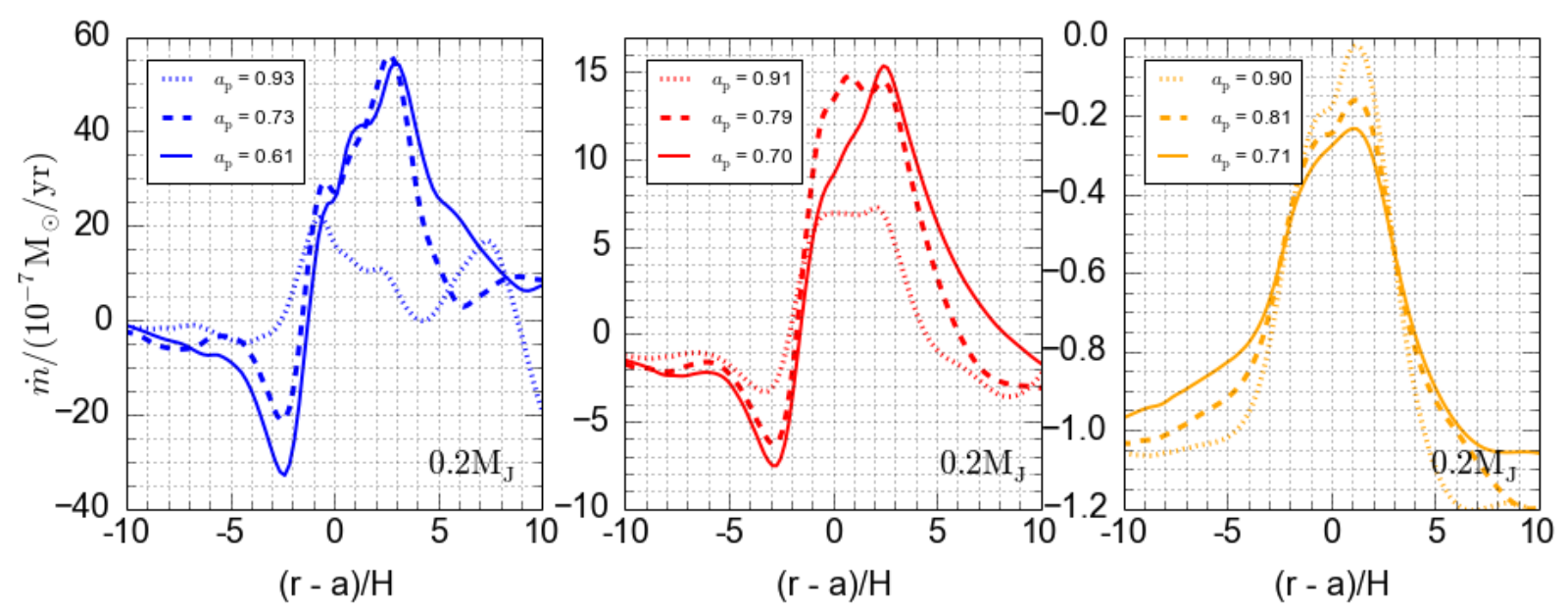

Figura 5.11: Evolução do perfil local do fluxo de gás em diferentes posições do planeta de massa $0.2 \mathrm{M}_{\mathrm{J}}$ para diferentes viscosidades. Da esquerda para a direita, temos $\alpha=0.001, \alpha$ $=0.003$ e $\alpha=0.015$. A taxa de acreção do disco de gás é de $10^{-7} \mathrm{M}_{\odot} /$ ano e o planeta não acreta gás.

Podemos observar que, no caso de média e baixa viscosidade, há um grande fluxo positivo (contrário ao movimento do planeta). Este fluxo positivo surge devido ao rápido movimento do planeta, isto é, à medida que o planeta se move transfere parte da massa do 
disco interno para o disco externo. O caso que nos interessa aqui é o de alta viscosidade, no qual o gap se manteve. Nesse caso, é possível observar que o fluxo de material é sempre negativo na região próxima do gap planetário. Isso ocorre porque o planeta se move numa taxa menor que a velocidade viscosa do gás. Isto é, a evolução do gap criado pelo planeta não é acoplado à evolução do disco, assim, conforme o planeta se desloca, o gap precisa ser mantido dinamicamente pela pertubação local; como o planeta se desloca numa taxa menor que a velocidade viscosa do gás, parte da massa precisa ser retirada do disco externo e enviada para o disco interno para manter a formação do gap. O gap move-se 0.3 ua em, aproximadamente, 500 órbitas, o tempo de escala para o gás cobrir esta distância é dado, aproximadamente, por (Dürmann e Kley, 2015):

$$
\tau_{\text {visc. }}=\frac{\Delta r^{2}}{\nu} \approx 2000 \text { órbitas }
$$

Isso demonstra, como esperado, que o planeta migra numa taxa menor que a velocidade viscosa do gás.

Podemos fazer a mesma análise considerando o planeta de massa $0.5 \mathrm{M}_{\mathrm{J}}$. Os perfis global e local da média azimutal da densidade superficial do gás são dados, respectivamente, pelas Figuras 5.12 e 5.13 .
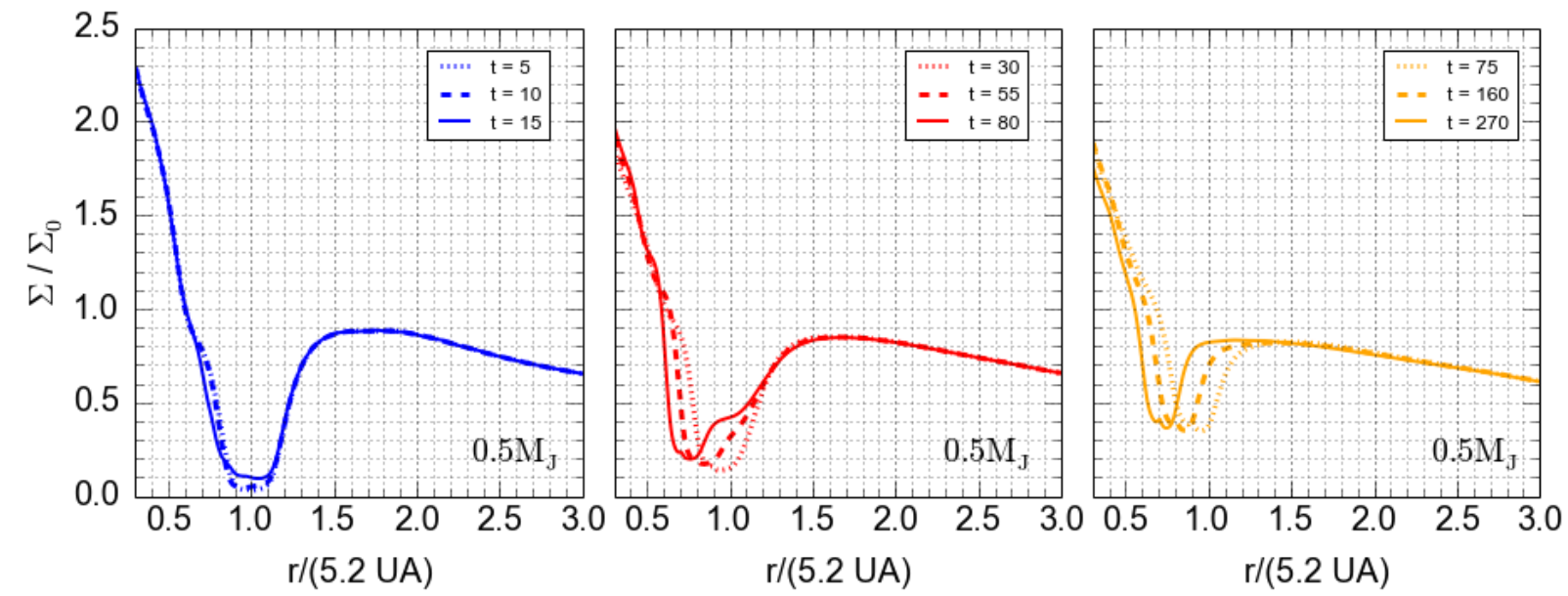

Figura 5.12: Evolução do perfil da média azimutal da densidade superficial do gás ao longo do tempo para o planeta de massa $0.5 \mathrm{M}_{\mathrm{J}}$ para diferentes viscosidades. Da esquerda para a direita, temos $\alpha=0.001, \alpha=0.003$ e $\alpha=0.015$. A taxa de acreção do disco de gás é de $10^{-7} \mathrm{M}_{\odot} /$ ano e o planeta não acreta gás.

Mais uma vez vemos que, no regime de baixa viscosidade, o planeta não foi capaz de manter o gap dinamicamente. No entanto, observe que, para essa massa planetária, já foi 

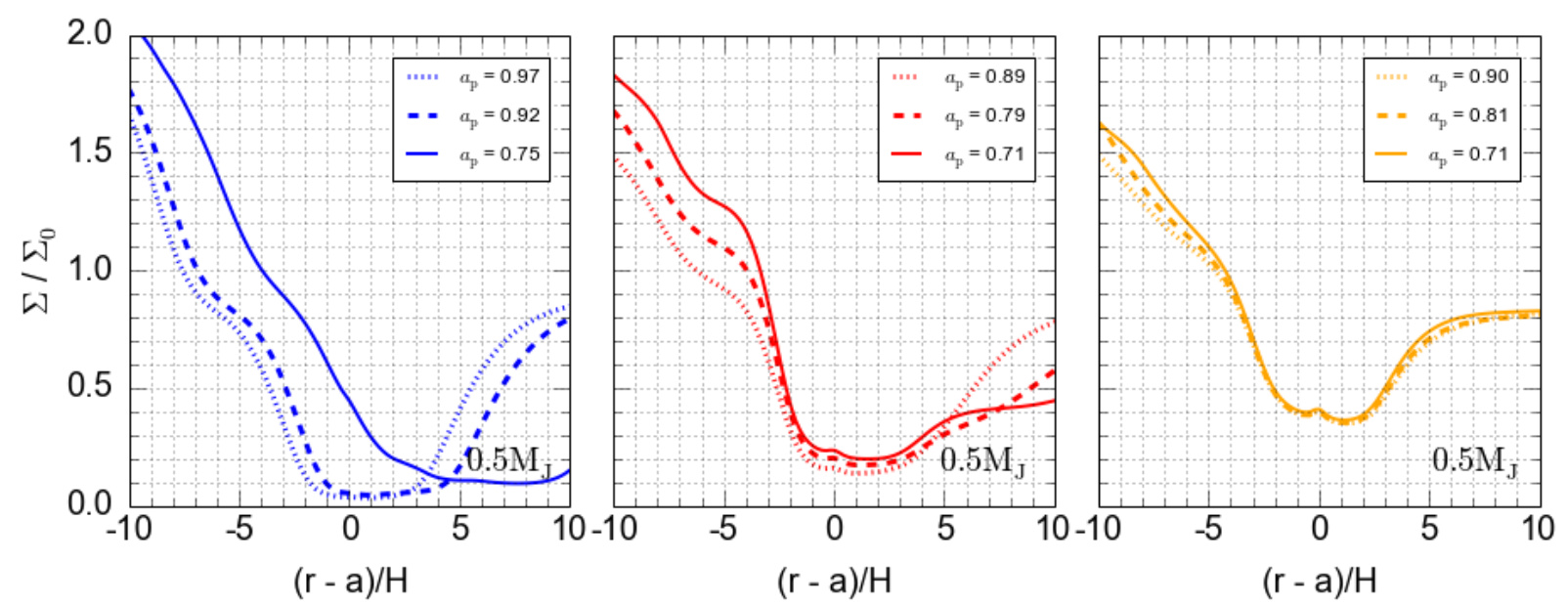

Figura 5.13: Evolução do perfil local da média azimutal da densidade superficial do gás em diferentes posições do planeta de massa $0.5 \mathrm{M}_{\mathrm{J}}$ para diferentes viscosidades. Da esquerda para a direita, temos $\alpha=0.001, \alpha=0.003$ e $\alpha=0.015$. A taxa de acreção do disco de gás é de $10^{-7} \mathrm{M}_{\odot} /$ ano e o planeta não acreta gás.

possível a manutenção do gap no regime de média viscosidade. Observe também que, no regime de média viscosidade, a alta taxa de migração deforma o gap, fazendo com que parte da matéria se acumule na borda interna e esvazie a borda externa, isto é, as bordas iniciais do gap não conseguem acompanhar a migração rápida do planeta sofrendo uma deformação. Essa rápida migração também pode ser caracterizada observando a Figura 5.14 que mostra o perfil local do torque em diferentes posições do planeta. É possível notar que há uma grande contribuição do torque dentro da região atenuada, isto é, próximo da região coorbital. Isso ocorre porque o planeta não conseguiu retirar momento angular suficiente do disco interno para impedir a massa de penetrar no gap, como mostra a Figura 5.15.

De fato, analisando o fluxo de massa na Figura 5.15, podemos observar que há um grande fluxo de massa contrário ao movimento do planeta para os casos de baixa e média viscosidade. No caso de média viscosidade o planeta consegue manter o gap dinamicamente, assim, como o planeta se move numa taxa de migração maior que a velocidade viscosa do gás ele precisa enviar uma grande quantidade de massa do disco interno para o disco externo para manter a formação do gap. O mesmo ocorre no regime de alta viscosidade, no entanto, o fluxo positivo de massa é bem menor, já que sua taxa de migração é menor.

Continuando nossa análise, podemos fazer os mesmos gráficos para o caso do planeta de massa $1.0 \mathrm{M}_{\mathrm{J}}$. O perfil do gap e do gap escalonado são dados, respectivamente, pelas 

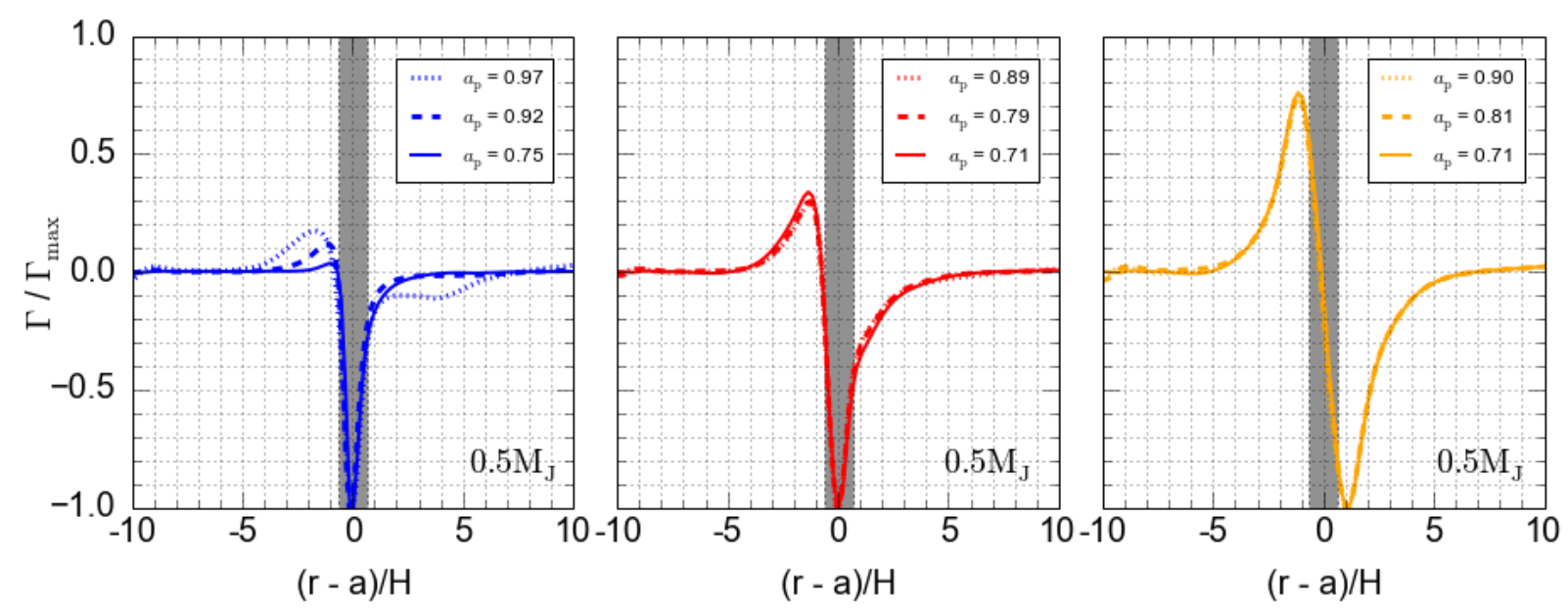

Figura 5.14: Evolução do perfil local do torque em diferentes posições do planeta de massa $0.5 \mathrm{M}_{\mathrm{J}}$ para diferentes viscosidades. Da esquerda para a direita, temos $\alpha=0.001, \alpha=0.003$ e $\alpha=0.015$. A região cinza indica a região na qual o torque sofre uma atenuação, isto é, a região dentro de $0.8 \mathrm{R}_{\mathrm{H}}$. A taxa de acreção do disco de gás é de $10^{-7} \mathrm{M}_{\odot} /$ ano e o planeta não acreta gás. O valor do torque para cada raio foi obtido através de uma soma azimutal do torque de cada célula e normalizado em termos do valor máximo obtido ao longo do raio do disco.
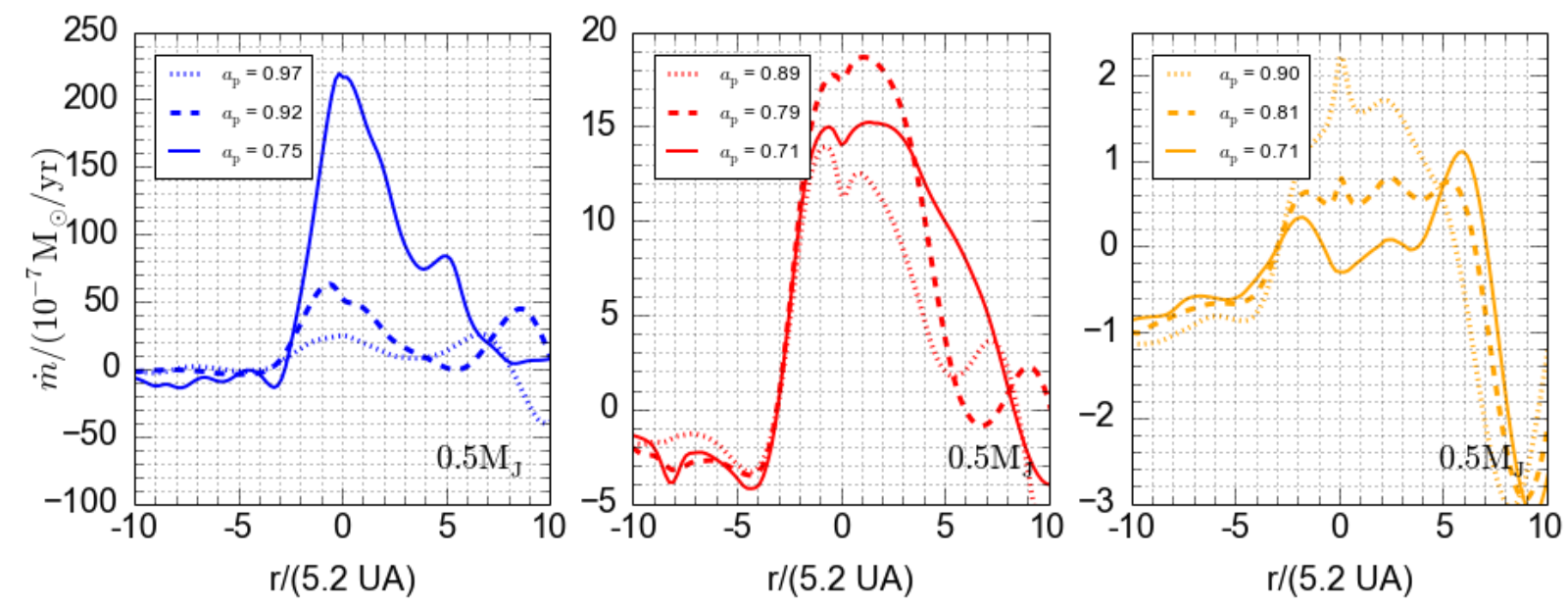

Figura 5.15: Evolução do perfil local do fluxo de gás em diferentes posições do planeta de massa $0.5 \mathrm{M}_{\mathrm{J}}$ para diferentes viscosidades. Da esquerda para a direita, temos $\alpha=0.001, \alpha$ $=0.003$ e $\alpha=0.015$. A taxa de acreção do disco de gás é de $10^{-7} \mathrm{M}_{\odot} /$ ano e o planeta não acreta gás.

Figuras 5.16 5.17. Para essa massa planetária, observamos que o gap foi bem estabelecido e segue o movimento do planeta em todos os regimes de viscosidade. É interessante notar que, no regime de alta viscosidade, a presença de uma região de sobredensidade em torno do planeta é evidente. Essa sobredensidade é presente durante todo o processo migratório. 

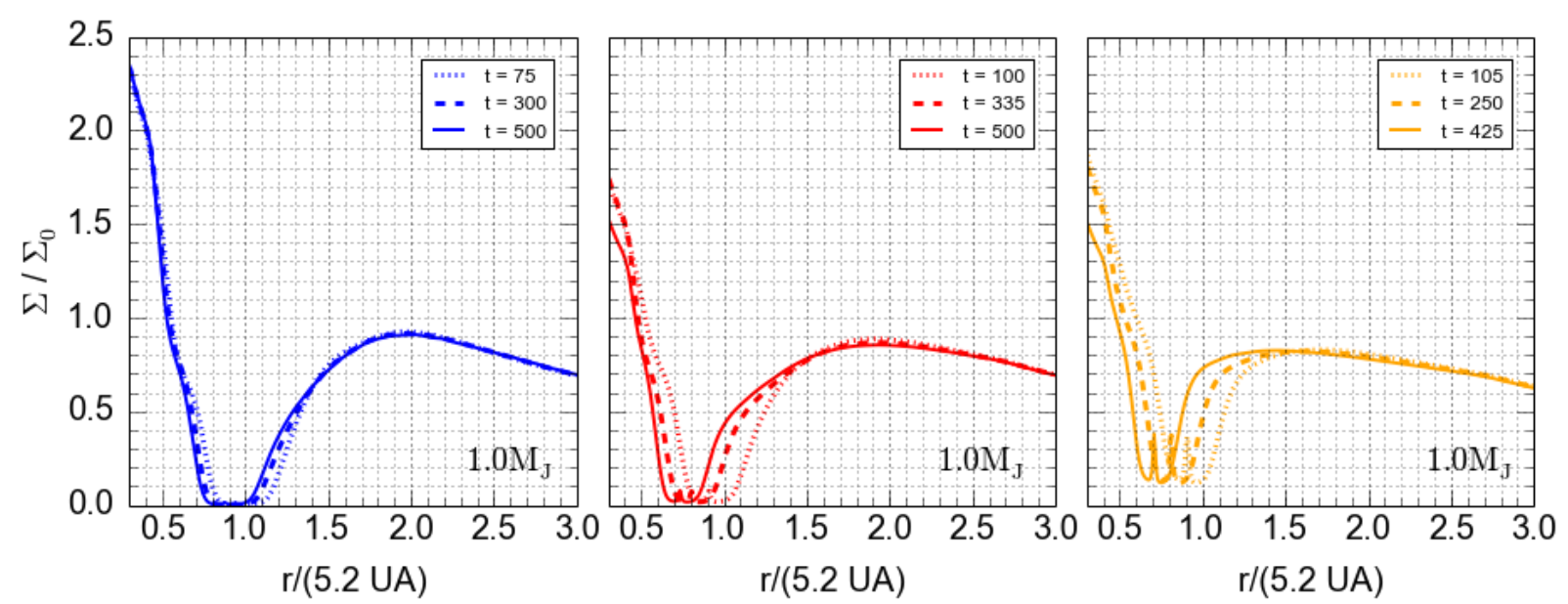

Figura 5.16: Evolução do perfil da média azimutal da densidade superficial do gás ao longo do tempo para o planeta de massa $1.0 \mathrm{M}_{\mathrm{J}}$ para diferentes viscosidades. Da esquerda para a direita, temos $\alpha=0.001, \alpha=0.003$ e $\alpha=0.015$. A taxa de acreção do disco de gás é de $10^{-7} \mathrm{M}_{\odot} /$ ano e o planeta não acreta gás.
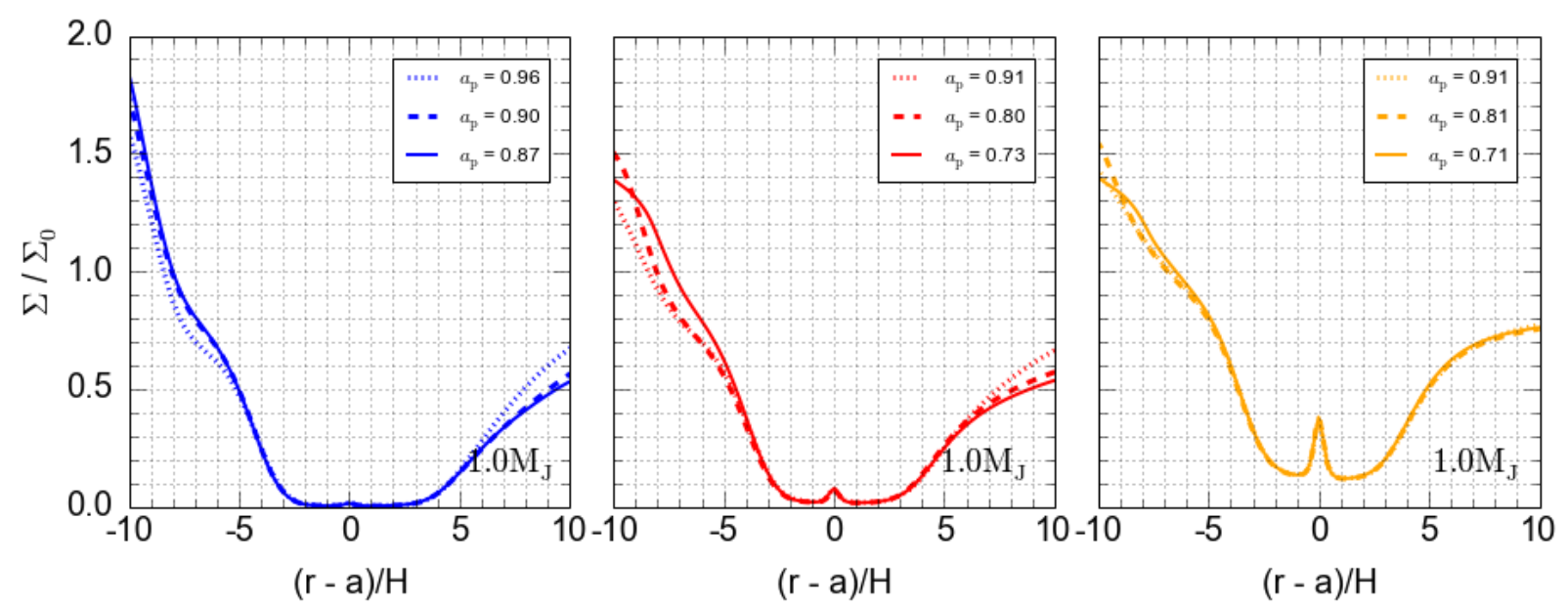

Figura 5.17: Evolução do perfil local da média azimutal da densidade superficial do gás em diferentes posições do planeta de massa $1.0 \mathrm{M}_{\mathrm{J}}$ para diferentes viscosidades. Da esquerda para a direita, temos $\alpha=0.001, \alpha=0.003$ e $\alpha=0.015$. A taxa de acreção do disco de gás é de $10^{-7} \mathrm{M}_{\odot} /$ ano e o planeta não acreta gás.

A Figura 5.18 e a Figura 5.19, mostram o perfil local do torque e do fluxo de gás em diferentes posições do planeta.

Para essa massa planetária, notamos a presença de um pico no torque dentro da região atenuada e, comparando com as massas anteriores, o deslocamento dos picos mais largos para regiões mais afastadas. O esvaziamento da densidade superficial do gás, ocasionado pelo gap, faz com que os dois picos mais largos sejam deslocados para regiões mais afastadas. Além disso, comparando a Figura 5.18 para o torque planetário com a Figura 5.17 para 

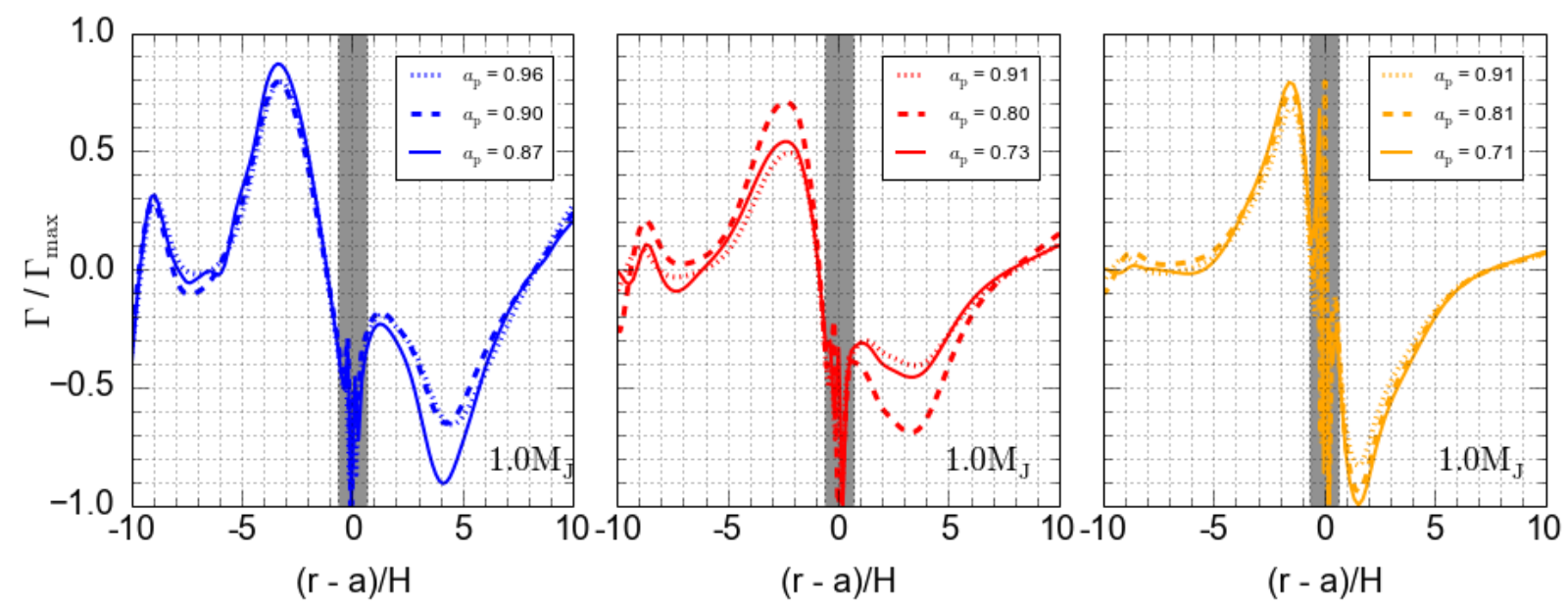

Figura 5.18: Evolução do perfil local do torque em diferentes posições do planeta de massa $1.0 \mathrm{M}_{\mathrm{J}}$ para diferentes viscosidades. Da esquerda para a direita, temos $\alpha=0.001, \alpha=0.003$ e $\alpha=0.015$. A região cinza indica a região na qual o torque sofre uma atenuação, isto é, a região dentro de $0.8 \mathrm{R}_{\mathrm{H}}$. A taxa de acreção do disco de gás é de $10^{-7} \mathrm{M}_{\odot} /$ ano e o planeta não acreta gás. O valor do torque para cada raio foi obtido através de uma soma azimutal do torque de cada célula e normalizado em termos do valor máximo obtido ao longo do raio do disco.
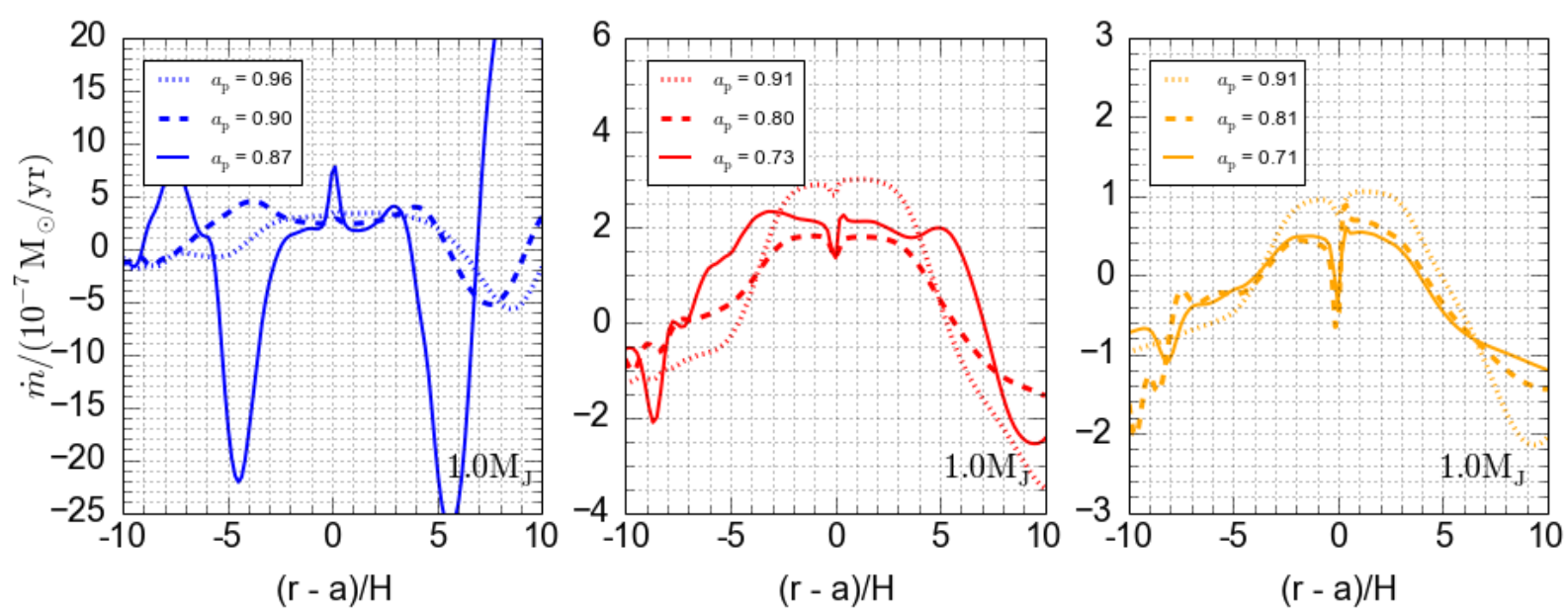

Figura 5.19: Evolução do perfil local do fluxo de gás em diferentes posições do planeta de massa $1.0 \mathrm{M}_{\mathrm{J}}$ para diferentes viscosidades. Da esquerda para a direita, temos $\alpha=0.001, \alpha$ $=0.003$ e $\alpha=0.015$. A taxa de acreção do disco de gás é de $10^{-7} \mathrm{M}_{\odot} /$ ano e o planeta não acreta gás.

o perfil local da densidade superficial do gás, observamos que parece haver uma relação entre o efeito do pico do torque dentro da região atenuada com a região de sobredensidade próxima ao planeta. Como o disco de menor viscosidade apresenta uma maior massa, esse efeito pode ter ocasionado as pequenas oscilações geradas no planeta observadas na Figura 
5.7. No entanto, essas oscilações também podem estar relacionadas com a presença de vórtices, em consequência de um gap muito estreito. Esse fenômeno foge do escopo desta tese e poderá ser estudado em trabalhos futuros. Além disso, o fato de não existir uma solução de equilíbrio exata também pode conduzir a um fluxo de gás muito particular em torno do planeta que poderia levar a essas oscilações. De fato, a Figura 5.19 revela uma mudança brusca no fluxo de massa na região próxima do planeta para o caso de baixa viscosidade.

Em todos os casos, observamos um fluxo positivo de massa próximo do planeta indicando que o planeta se move numa taxa de migração maior que a velocidade viscosa do gás.

As Figuras 5.20 e 5.21 a seguir mostram a mudança no semieixo do planeta ao longo do tempo para uma taxa de acreção do disco, respectivamente, de $10^{-8} \mathrm{M}_{\odot} /$ ano e $10^{-9}$ $\mathrm{M}_{\odot} /$ ano.
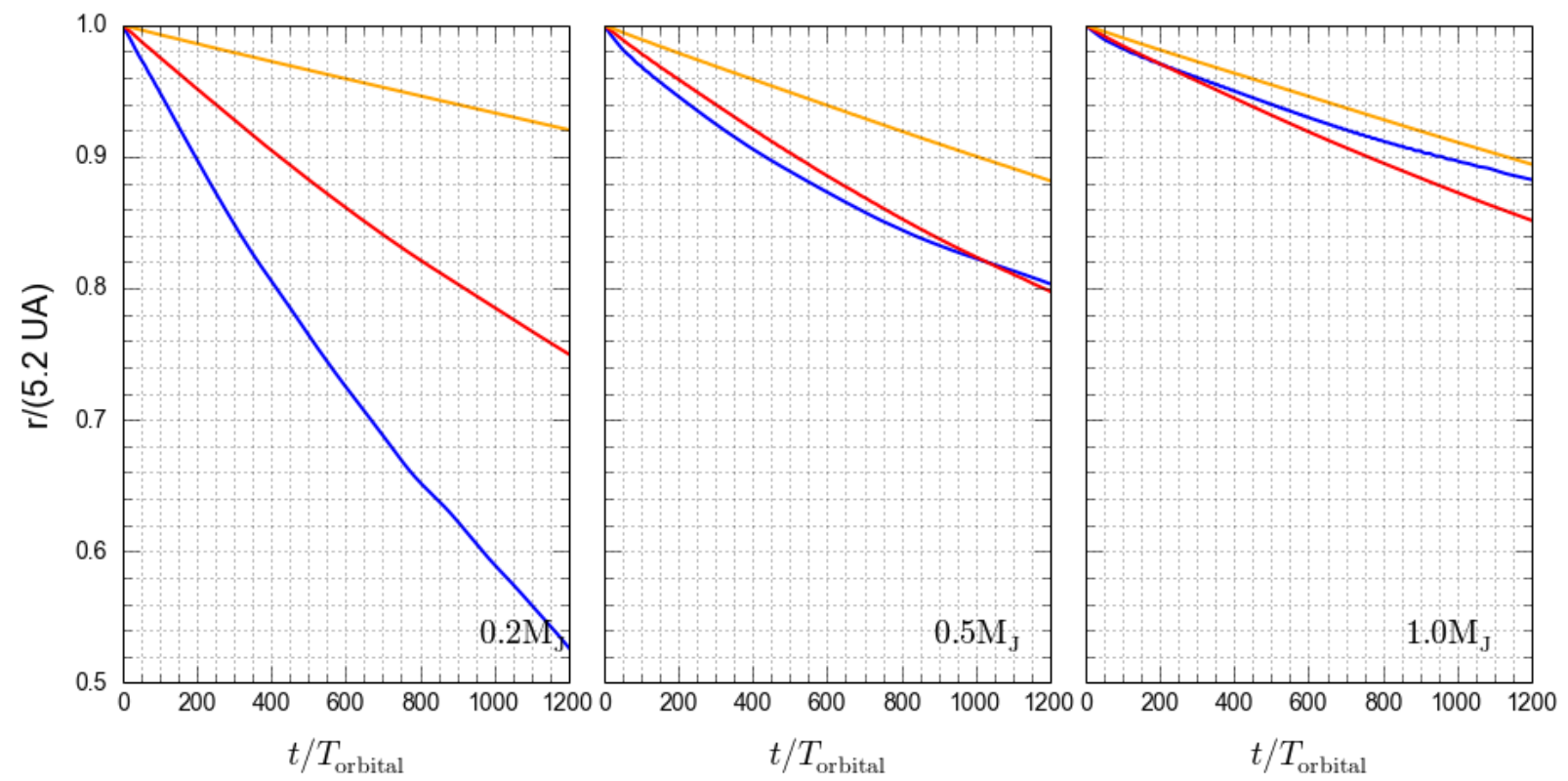

Figura 5.20: Gráfico da evolução do semieixo maior dos planetas em função do tempo para várias massas planetárias (da esquerda para a direita, $0.2 \mathrm{M}_{\mathrm{J}}, 0.5 \mathrm{M}_{\mathrm{J}}$ e $1.0 \mathrm{M}_{\mathrm{J}}$ ) e para diferentes valores de viscosidade (azul: $\alpha=0.001$, vermelho: $\alpha=0.003$ e laranja: $\alpha=0.010$ ). Os gráficos correspondem ao modelo sem acreção de gás e a um disco de gás cuja taxa de acreção é de $10^{-8} \mathrm{M}_{\odot} /$ ano.

Podemos observar, nas duas figuras, que o cenário de migração apresentado é característico de uma migração de tipo II, portanto, o gap foi mantido dinamicamente pelo planeta independentemente do regime de viscosidade e da massa planetária. Isso pode 

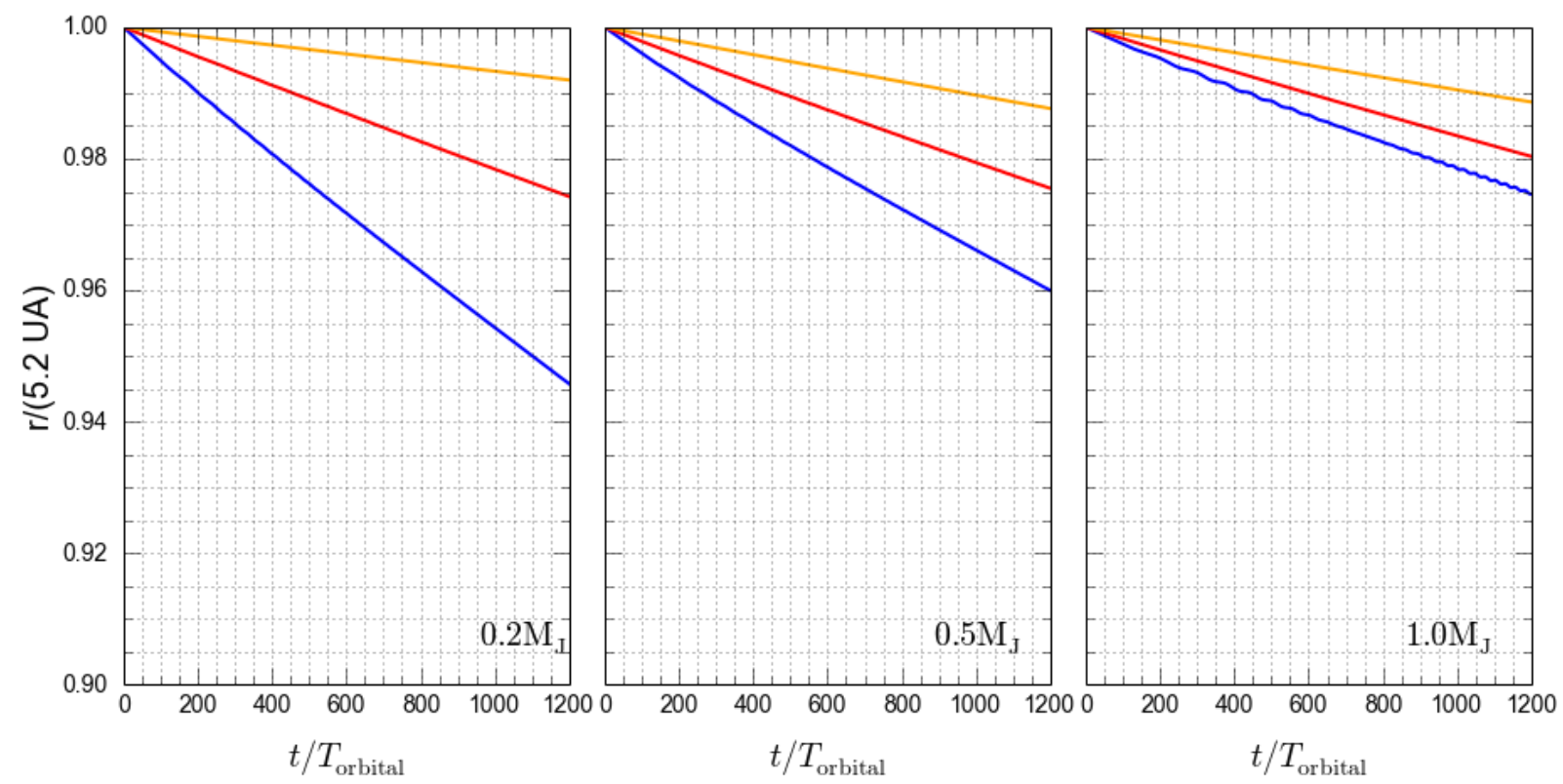

Figura 5.21: Gráfico da evolução do semieixo maior dos planetas em função do tempo para várias massas planetárias (da esquerda para a direita, $0.2 \mathrm{M}_{\mathrm{J}}, 0.5 \mathrm{M}_{\mathrm{J}}$ e $1.0 \mathrm{M}_{\mathrm{J}}$ ) e para diferentes valores de viscosidade (azul: $\alpha=0.001$, vermelho: $\alpha=0.003$ e laranja: $\alpha=0.010$ ). Os gráficos correspondem ao modelo sem acreção de gás e a um disco de gás cuja taxa de acreção é de $10^{-9} \mathrm{M}_{\odot} /$ ano.

ser visualizado, por exemplo, nas Figuras 5.22 e 5.23, que mostram, respectivamente, a evolução do perfil do gap e do gap reescalado para o caso do planeta de massa $0.2 \mathrm{M}_{\mathrm{J}}$ para o disco de gás cuja taxa de acreção é de $10^{-8} \mathrm{M}_{\odot} /$ ano.
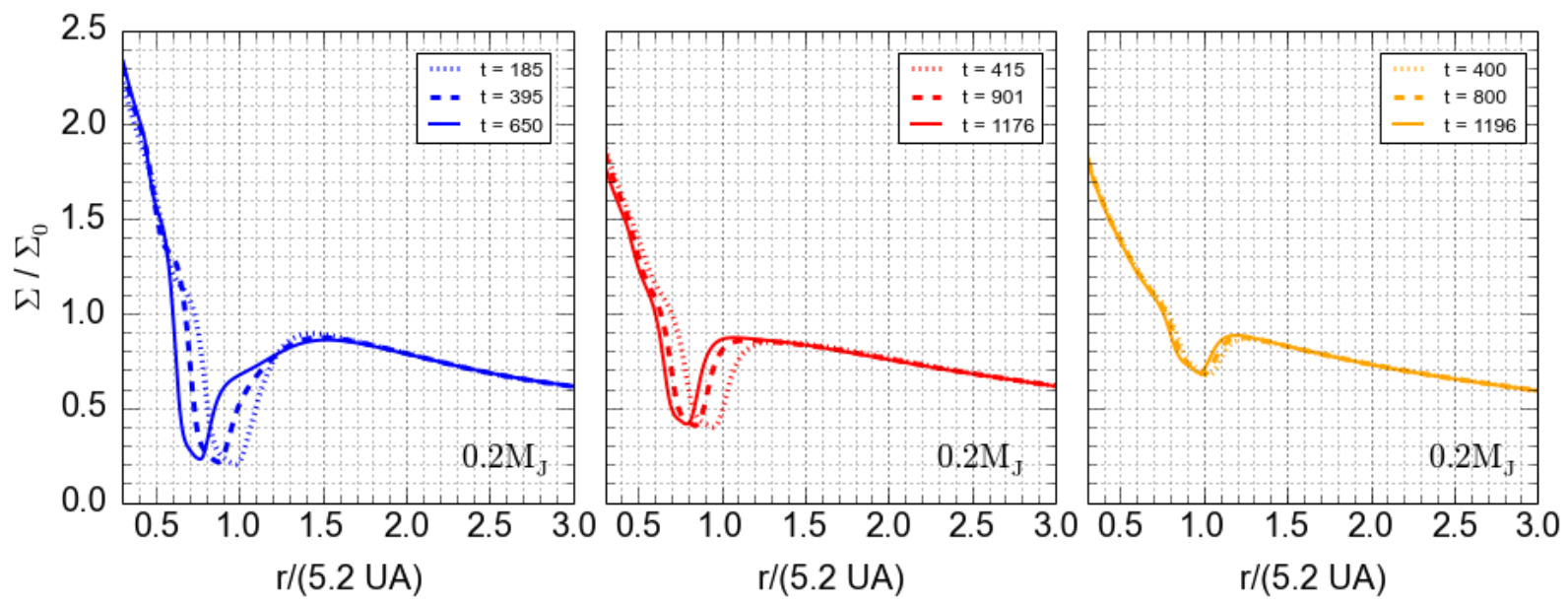

Figura 5.22: Evolução do perfil da média azimutal da densidade superficial do gás ao longo do tempo para o planeta de massa $0.2 \mathrm{M}_{\mathrm{J}}$ para diferentes viscosidades. Da esquerda para a direita, temos $\alpha=0.001, \alpha=0.003$ e $\alpha=0.015$. A taxa de acreção do disco de gás é de $10^{-8} \mathrm{M}_{\odot} /$ ano e o planeta não acreta gás. 

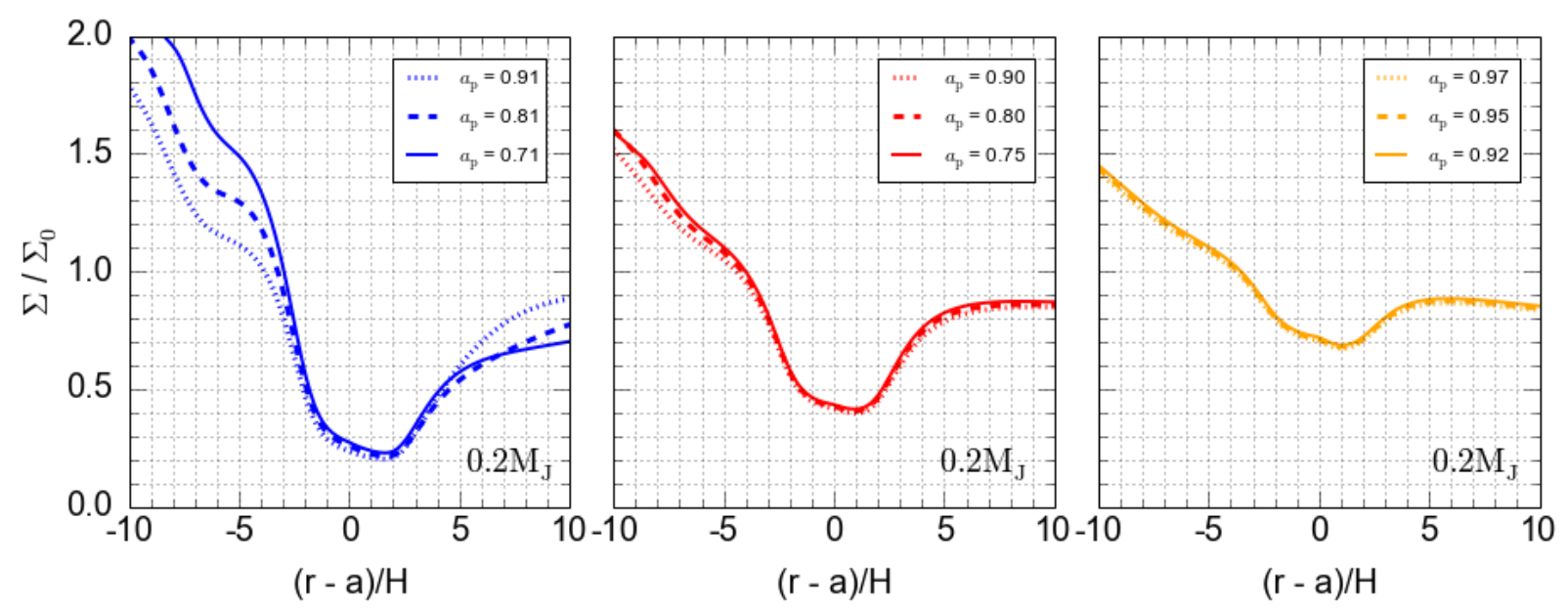

Figura 5.23: Evolução do perfil local da média azimutal da densidade superficial do gás em diferentes posições do planeta de massa $0.2 \mathrm{M}_{\mathrm{J}}$ para diferentes viscosidades. Da esquerda para a direita, temos $\alpha=0.001, \alpha=0.003$ e $\alpha=0.015$. A taxa de acreção do disco de gás é de $10^{-8} \mathrm{M}_{\odot} /$ ano e o planeta não acreta gás.

Para essa massa planetária, no regime de baixa viscosidade e taxa de acreção de $10^{-8}$ $\mathrm{M}_{\odot} /$ ano, observamos um acúmulo de massa na borda interna do gap maior que nos outros casos e um decréscimo de massa na borda externa do gap. No entanto, nos outros casos, que envolvem diferentes massas planetárias, taxas de acreções e viscosidades, não foram encontradas alterações significativas no formato do gap ao longo do processo de migração. Assim, para esses casos, vamos nos preocupar em analisar apenas o torque e o fluxo de massa próximo do planeta.

Note também que, comparando a escala do eixo y das Figuras 5.7, 5.20 e 5.21, quanto menor a taxa de acreção do disco, menor é a variação do semieixo do planeta devido o processo de migração. Isso ocorre porque no disco de menor taxa de acreção (menos massivo), há uma quantidade menor de massa de gás responsável pelo torque. Outra característica interessante é que quanto menor a massa do disco, mais definida fica a diferença entre os regimes de viscosidade. Isto é, note que, para o disco de gás cuja taxa de acreção é de $10^{-9} \mathrm{M}_{\odot} /$ ano, a taxa de migração média do planeta é menor quanto maior a viscosidade, independentemente do tamanho do planeta. Entretanto, para o disco cuja taxa de acreção é $10^{-8} \mathrm{M}_{\odot} /$ ano, essa característica nem sempre foi obtida. De fato, para o planeta de massa $0.5 \mathrm{M}_{\mathrm{J}}$, as taxas de migração média no regime de baixa e média viscosidade são bem próximas. Esse fator está associado com a massa disponível dentro do gap, que pode alterar o torque diferencial. 
As Figuras 5.24 e 5.25 a seguir mostram a proporção do torque e o fluxo de massa próximo do planeta de $0.2 \mathrm{M}_{\mathrm{J}}$ num disco de gás cuja taxa de acreção é de $10^{-8} \mathrm{M}_{\odot} /$ ano.
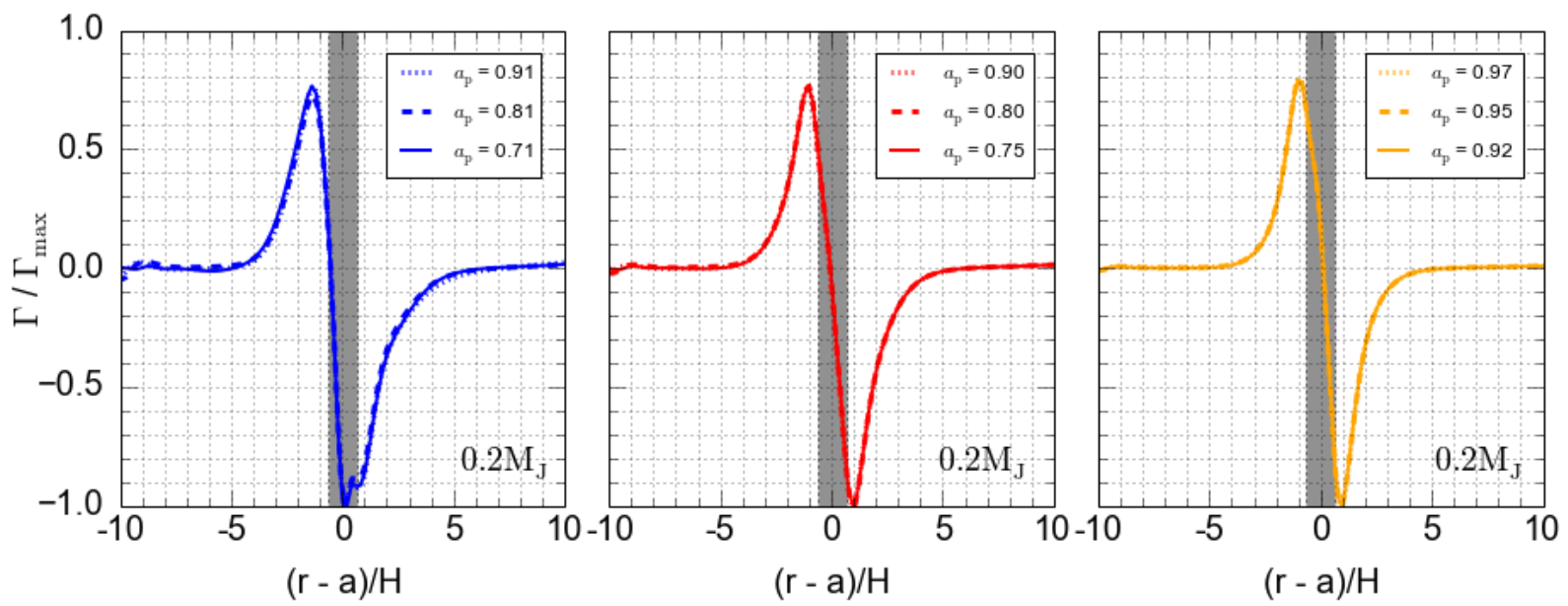

Figura 5.24: Evolução do perfil local do torque em diferentes posições do planeta de massa $0.2 \mathrm{M}_{\mathrm{J}}$ para diferentes viscosidades. Da esquerda para a direita, temos $\alpha=0.001, \alpha=0.003$ e $\alpha=0.015$. A região cinza indica a região na qual o torque sofre uma atenuação, isto é, a região dentro de $0.8 \mathrm{R}_{\mathrm{H}}$. A taxa de acreção do disco de gás é de $10^{-8} \mathrm{M}_{\odot} /$ ano e o planeta não acreta gás. O valor do torque para cada raio foi obtido através de uma soma azimutal do torque de cada célula e normalizado em termos do valor máximo obtido ao longo do raio do disco.
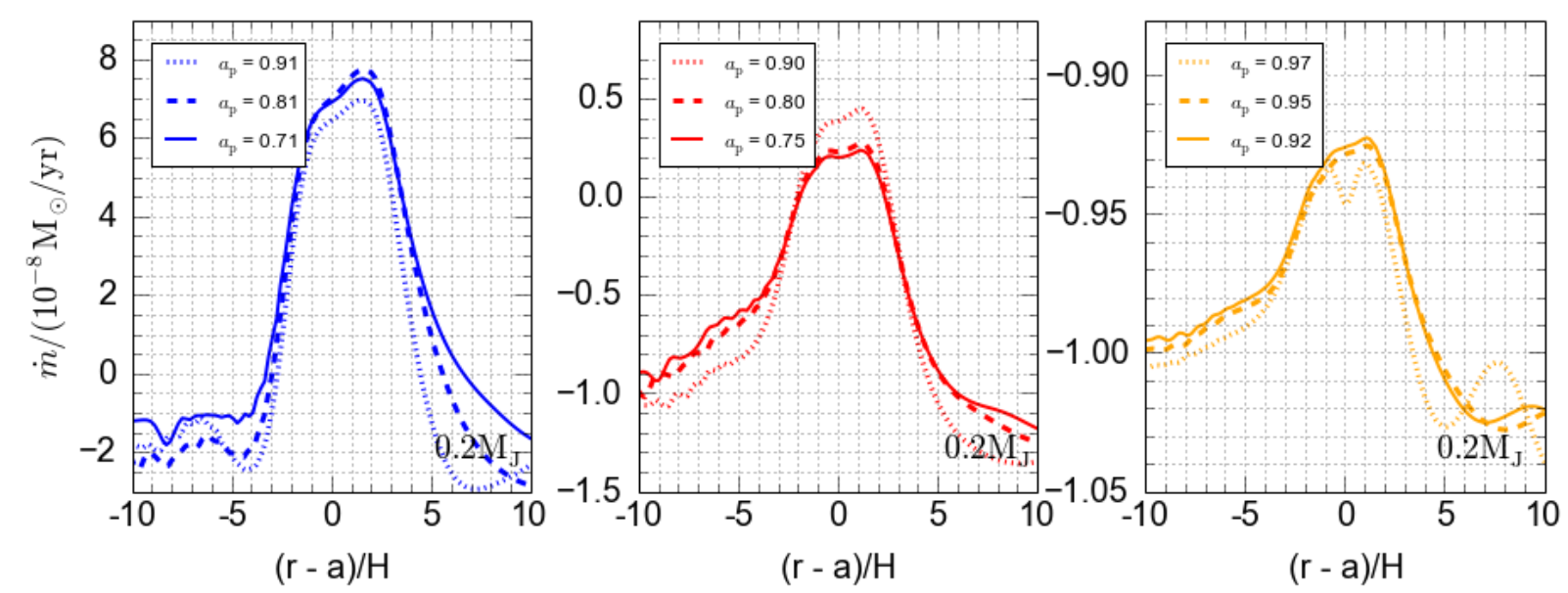

Figura 5.25: Evolução do perfil local do fluxo de gás em diferentes posições do planeta de massa $0.2 \mathrm{M}_{\mathrm{J}}$ para diferentes viscosidades. Da esquerda para a direita, temos $\alpha=0.001, \alpha$ $=0.003$ e $\alpha=0.015$. A taxa de acreção do disco de gás é de $10^{-8} \mathrm{M}_{\odot} /$ ano e o planeta não acreta gás.

Note que a massa do disco se torna importante para caracterizar se o planeta consegue ou não manter seu gap dinamicamente. Isso ocorre devido à concentração de massa próximo 
do gap que gera um torque diferencial menor, como observado ao comparar as Figuras 5.24 e 5.10. De fato, podemos notar, comparando as figuras, que o torque positivo devido ao disco interno possui uma proporção maior no caso do disco de menor massa, também notamos um pequeno deslocamento do torque negativo para fora da região atenuada. Essa mesma característica foi encontrada, para a mesma massa planetária, num disco de gás com taxa de acreção de $10^{-9} \mathrm{M}_{\odot} /$ ano em todos os regimes de viscosidade.

Com relação à Figura 5.25, obtemos, no caso de baixa viscosidade e média viscosidade, um fluxo positivo próximo do gap e, no caso de alta viscosidade, um fluxo totalmente negativo; logo, o planeta se move numa taxa de migração maior que a velocidade viscosa do gás no caso de baixa e média viscosidade, e numa taxa de migração menor que a velocidade viscosa do gás no caso de alta viscosidade. Para uma taxa de acreção de $10^{-9}$ $\mathrm{M}_{\odot} /$ ano, foi possível obter um fluxo totalmente negativo também para o regime de média viscosidade, como mostra a Figura 5.26 .

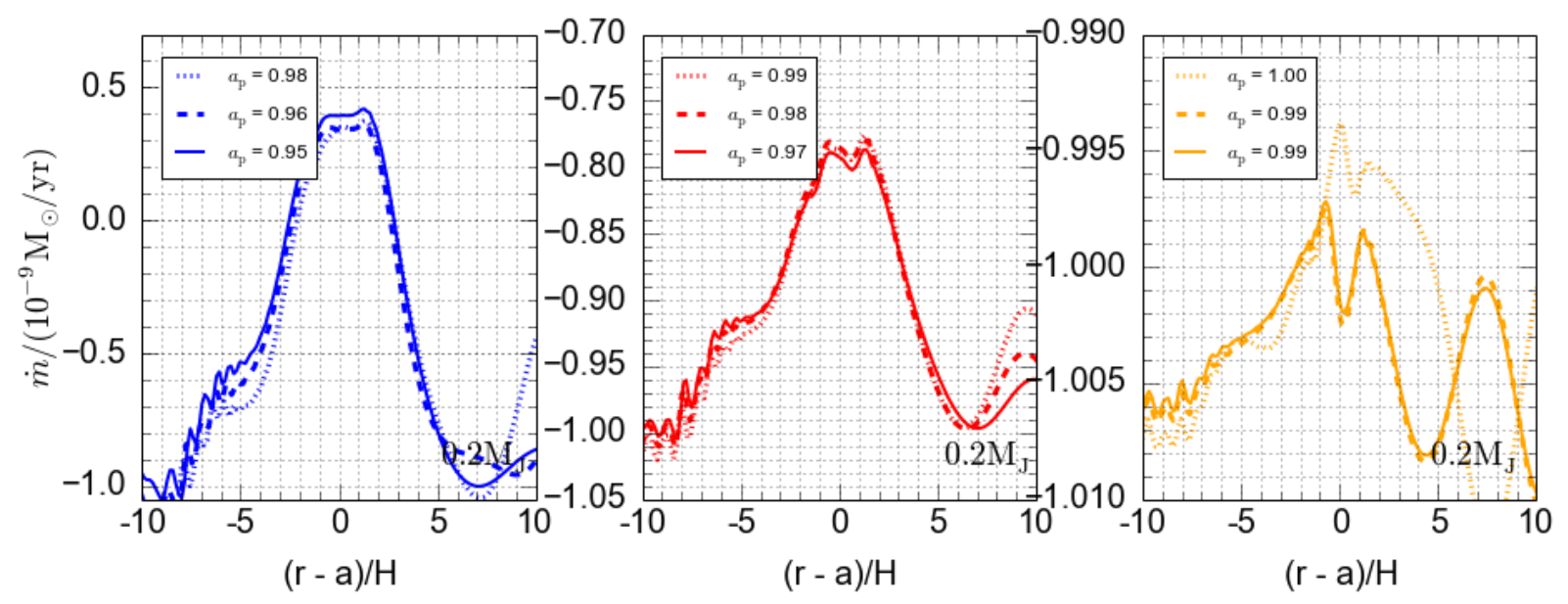

Figura 5.26: Evolução do perfil local do fluxo de gás em diferentes posições do planeta de massa $0.2 \mathrm{M}_{\mathrm{J}}$ para diferentes viscosidades. Da esquerda para a direita, temos $\alpha=0.001, \alpha$ $=0.003$ e $\alpha=0.015$. A taxa de acreção do disco de gás é de $10^{-9} \mathrm{M}_{\odot} /$ ano e o planeta não acreta gás.

Isso permite concluir que, quanto menor for a massa do disco de gás e maior for a viscosidade, menor será a taxa de migração de tipo II sofrida por uma planeta de massa $0.2 \mathrm{M}_{\mathrm{J}}$.

Para o planeta de massa $0.5 \mathrm{M}_{\mathrm{J}}$, num disco com taxa de acreção de $10^{-8} \mathrm{M}_{\odot} /$ ano, obtemos as Figuras 5.27 e 5.28 para, respectivamente, a proporção do torque e o fluxo de gás próximo do planeta. 

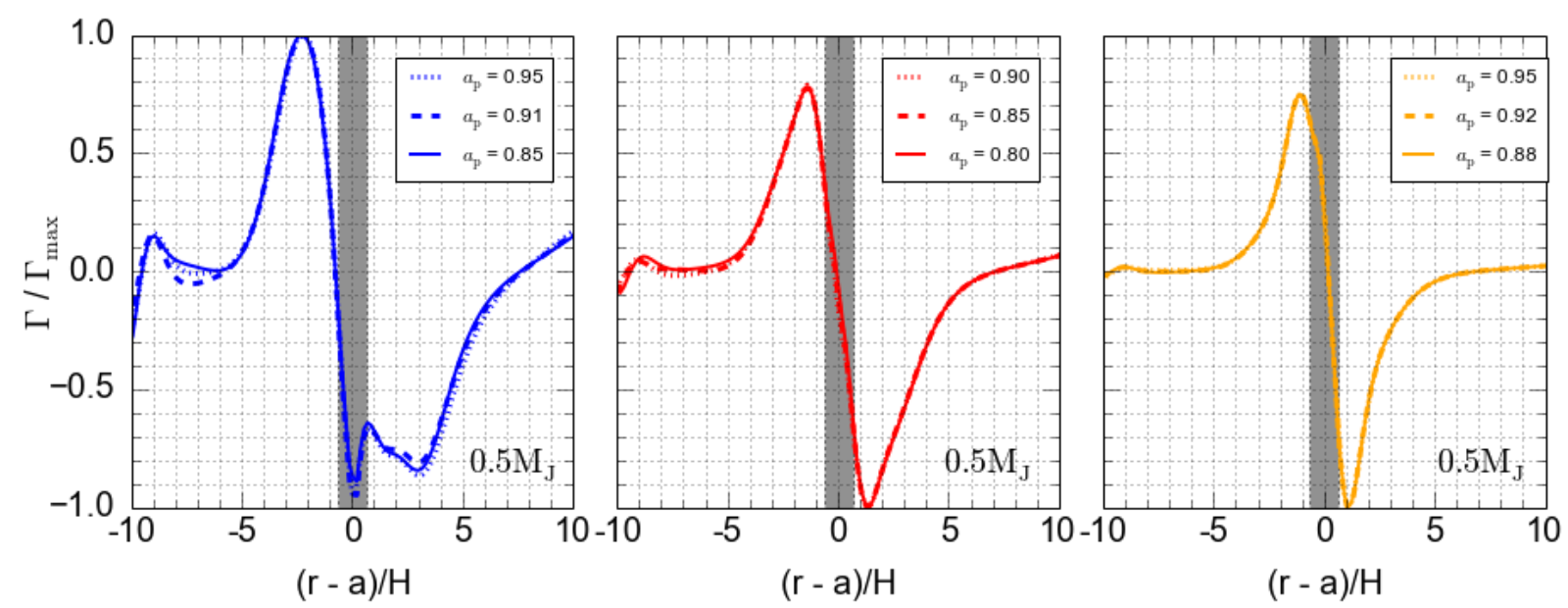

Figura 5.27: Evolução do perfil local do torque em diferentes posições do planeta de massa $0.5 \mathrm{M}_{\mathrm{J}}$ para diferentes viscosidades. Da esquerda para a direita, temos $\alpha=0.001, \alpha=0.003$ e $\alpha=0.015$. A região cinza indica a região na qual o torque sofre uma atenuação, isto é, a região dentro de $0.8 \mathrm{R}_{\mathrm{H}}$. A taxa de acreção do disco de gás é de $10^{-8} \mathrm{M}_{\odot} /$ ano e o planeta não acreta gás. O valor do torque para cada raio foi obtido através de uma soma azimutal do torque de cada célula e normalizado em termos do valor máximo obtido ao longo do raio do disco.
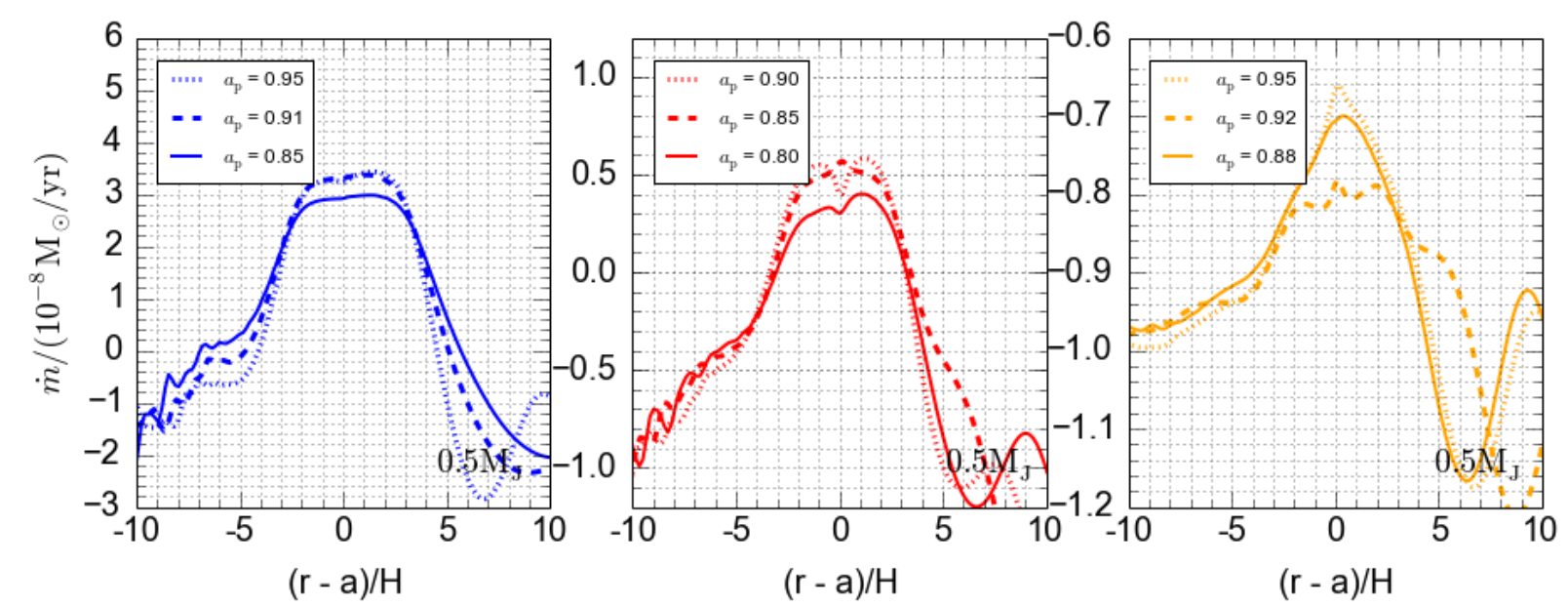

Figura 5.28: Evolução do perfil local do fluxo de gás em diferentes posições do planeta de massa $0.5 \mathrm{M}_{\mathrm{J}}$ para diferentes viscosidades. Da esquerda para a direita, temos $\alpha=0.001, \alpha$ $=0.003$ e $\alpha=0.015$. A taxa de acreção do disco de gás é de $10^{-8} \mathrm{M}_{\odot} /$ ano e o planeta não acreta gás.

Da mesma forma que ocorreu com o planeta de massa $0.2 \mathrm{M}_{\mathrm{J}}$, notamos a presença de um torque positivo maior devido ao disco interno. Esse fato é mais nítido quando se compara as Figuras 5.14 e 5.27. Isso está de acordo com o fato de estarmos num cenário de migração de tipo II, diferente do caso do disco com taxa de acreção de $10^{-7} \mathrm{M}_{\odot} /$ ano, no 
qual o planeta sofre um processo migratório mais brusco. O mesmo ocorreu para o disco de gás com taxa de acreção $10^{-9} \mathrm{M}_{\odot} /$ ano.

Ainda considerando o planeta de massa $0.5 \mathrm{M}_{\mathrm{J}}$ num disco com taxa de acreção de $10^{-8}$ $\mathrm{M}_{\odot} /$ ano, obtemos para o fluxo de gás (ver Fig. 5.28) algo muito similar ao obtido para a massa de $0.2 \mathrm{M}_{\mathrm{J}}$ com a mesma taxa de acreção para o disco. Para o caso de baixa e média viscosidade, obtivemos um fluxo positivo próximo do gap, e, no caso de alta viscosidade, um fluxo totalmente negativo; logo, o planeta se move numa taxa maior que a velocidade viscosa do gás no caso de baixa e média viscosidade e numa taxa de migração menor que a velocidade viscosa do gás no caso de alta viscosidade. No caso da taxa de acreção de $10^{-9} \mathrm{M}_{\odot} /$ ano, similarmente à massa de $0.2 \mathrm{M}_{\mathrm{J}}$ com a mesma taxa de acreção, foi possível obter também um fluxo totalmente negativo no regime de média viscosidade, como mostra a Figura 5.29.
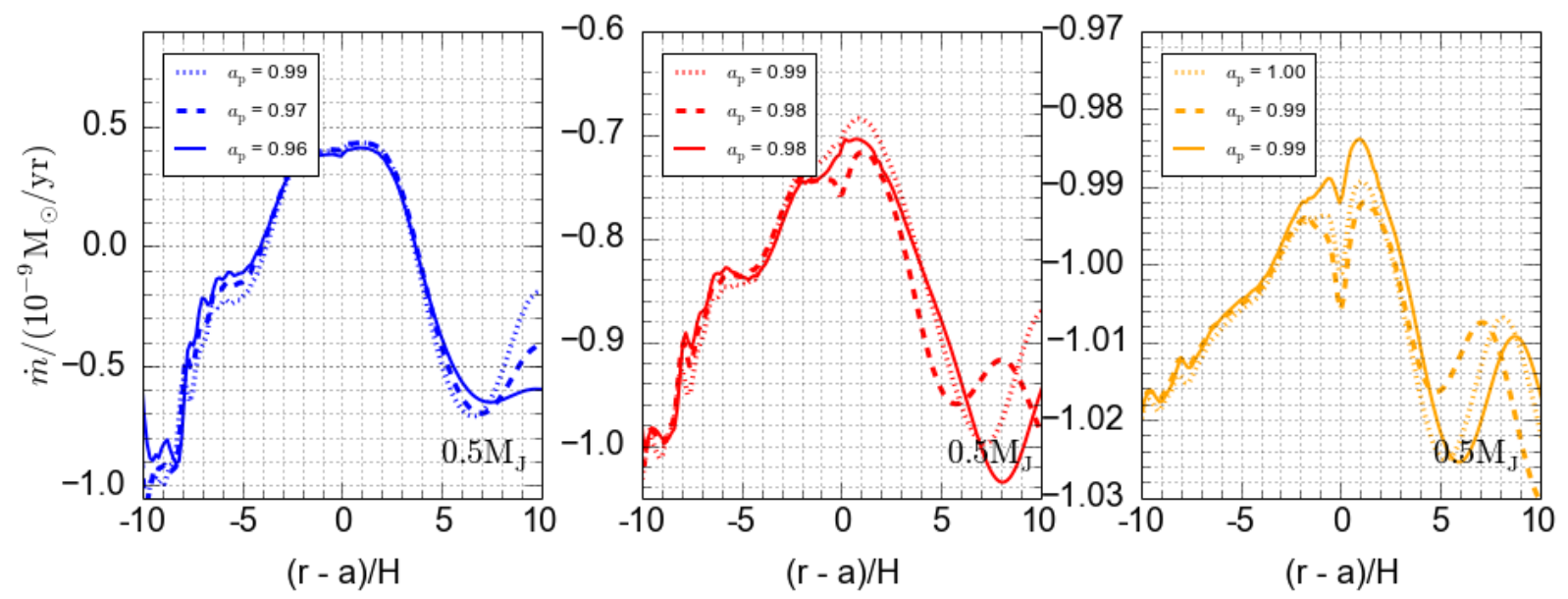

Figura 5.29: Evolução do perfil local do fluxo de gás em diferentes posições do planeta de massa $0.5 \mathrm{M}_{\mathrm{J}}$ para diferentes viscosidades. Da esquerda para a direita, temos $\alpha=0.001, \alpha$ $=0.003$ e $\alpha=0.015$. A taxa de acreção do disco de gás é de $10^{-9} \mathrm{M}_{\odot} /$ ano e o planeta não acreta gás.

Para o planeta de massa $1.0 \mathrm{M}_{\mathrm{J}}$, num disco com taxa de acreção de $10^{-8} \mathrm{M}_{\odot} /$ ano, obtemos as Figuras 5.30 e 5.31 para, respectivamente, a proporção do torque e o fluxo de gás próximo do planeta.

Para essa massa planetária, comparando as Figuras 5.18 e 5.30 , podemos notar uma mudança significativa do torque devido ao disco externo no regime de média viscosidade. De fato, houve uma redução do torque na região atenuada e uma proporção do torque maior devido ao disco externo nesse novo cenário. Notamos o mesmo efeito para o disco 

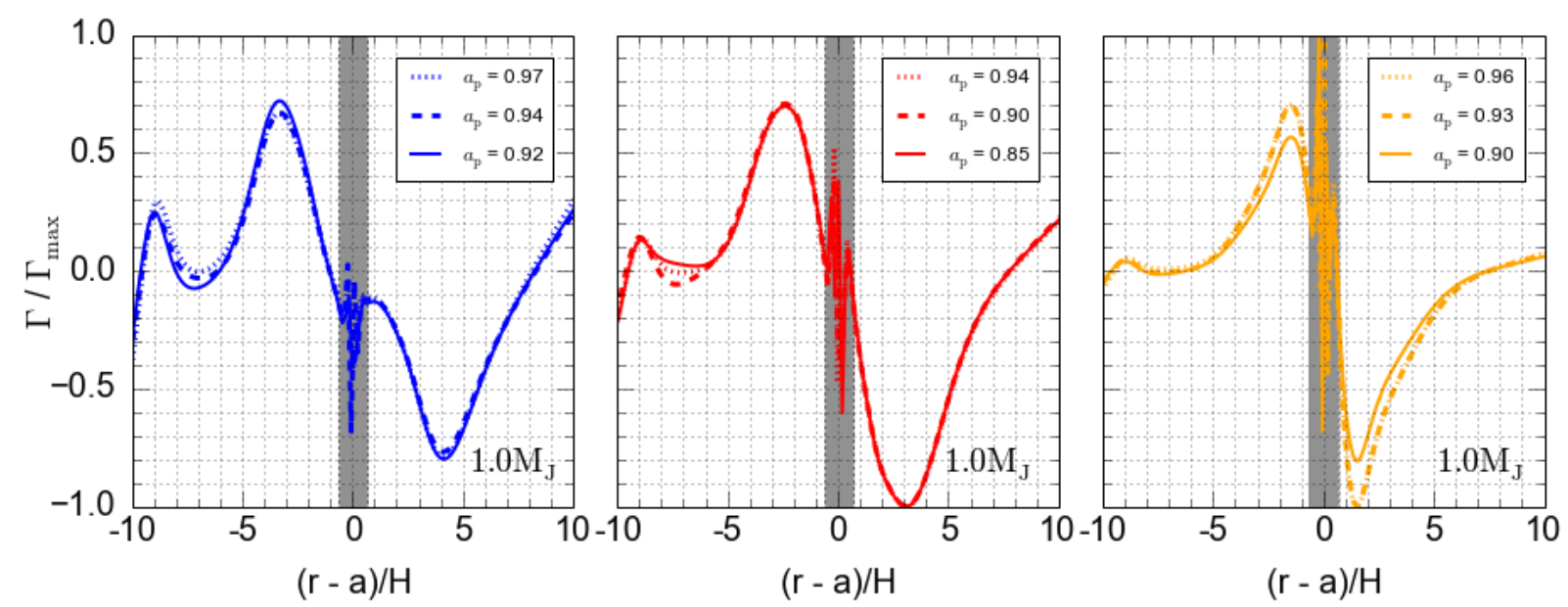

Figura 5.30: Evolução do perfil local do torque em diferentes posições do planeta de massa $1.0 \mathrm{M}_{\mathrm{J}}$ para diferentes viscosidades. Da esquerda para a direita, temos $\alpha=0.001, \alpha=0.003$ e $\alpha=0.015$. A região cinza indica a região na qual o torque sofre uma atenuação, isto é, a região dentro de $0.8 \mathrm{R}_{\mathrm{H}}$. A taxa de acreção do disco de gás é de $10^{-8} \mathrm{M}_{\odot} /$ ano e o planeta não acreta gás. O valor do torque para cada raio foi obtido através de uma soma azimutal do torque de cada célula e normalizado em termos do valor máximo obtido ao longo do raio do disco.
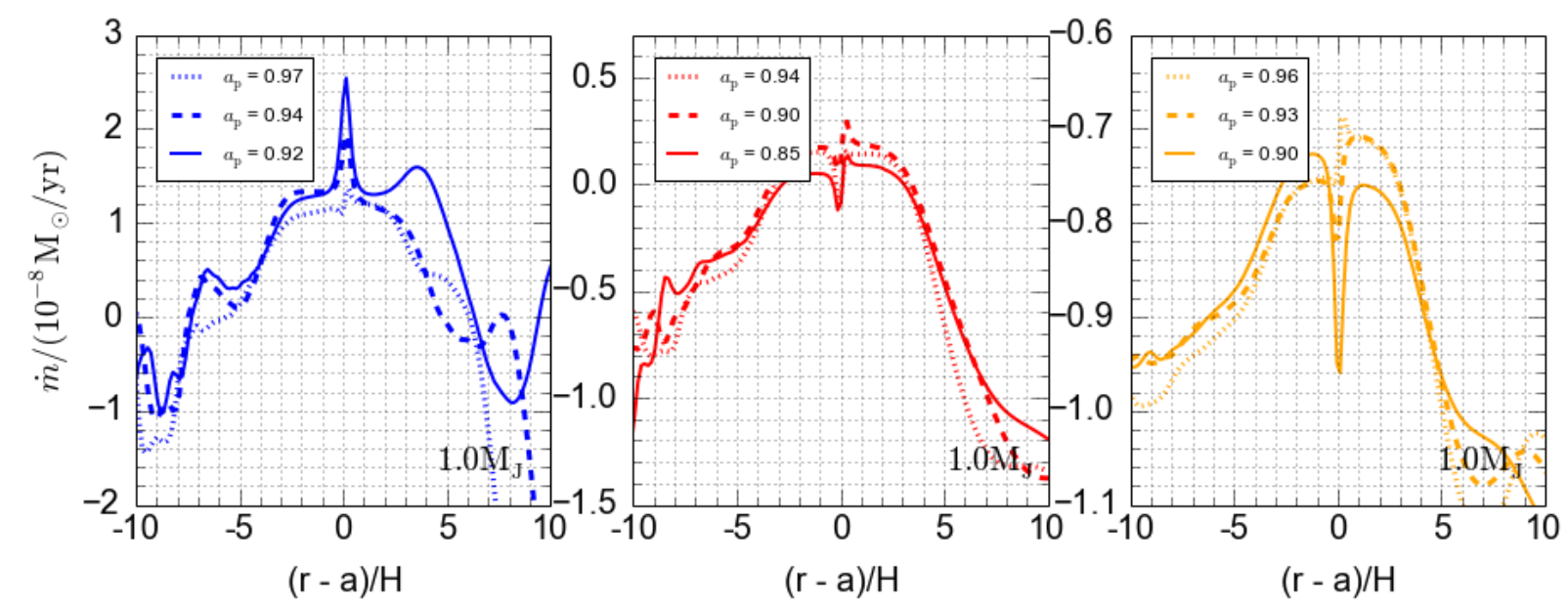

Figura 5.31: Evolução do perfil local do fluxo de gás em diferentes posições do planeta de massa $1.0 \mathrm{M}_{\mathrm{J}}$ para diferentes viscosidades. Da esquerda para a direita, temos $\alpha=0.001, \alpha$ $=0.003$ e $\alpha=0.015$. A taxa de acreção do disco de gás é de $10^{-8} \mathrm{M}_{\odot} /$ ano e o planeta não acreta gás.

com a taxa de acreção de $10^{-9} \mathrm{M}_{\odot} /$ ano.

Com relação ao fluxo de gás (ver Fig. 5.31), observamos para essa massa planetária algo muito similar ao obtido com as massas anteriores num disco com a mesma taxa de acreção. No caso de baixa viscosidade e média viscosidade, um fluxo positivo próximo do 

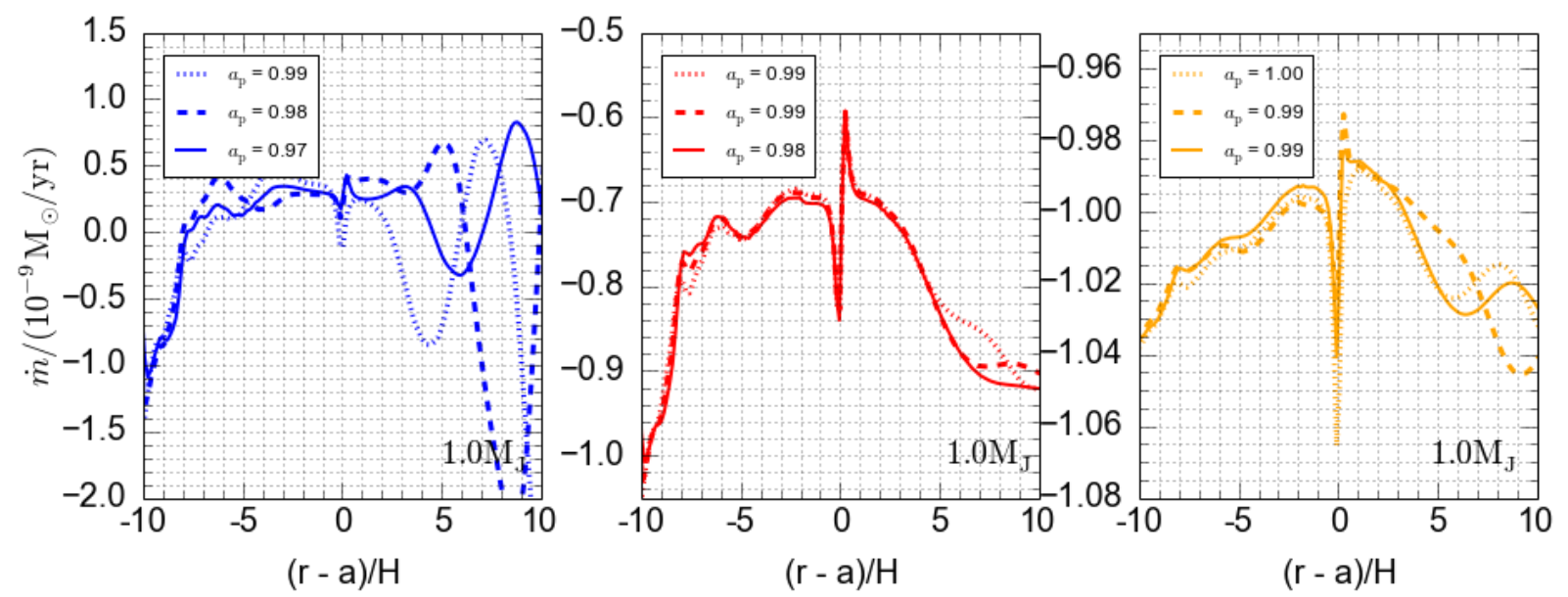

Figura 5.32: Evolução do perfil local do fluxo de gás em diferentes posições do planeta de massa $1.0 \mathrm{M}_{\mathrm{J}}$ para diferentes viscosidades. Da esquerda para a direita, temos $\alpha=0.001, \alpha$ $=0.003$ e $\alpha=0.015$. A taxa de acreção do disco de gás é de $10^{-9} \mathrm{M}_{\odot} /$ ano e o planeta não acreta gás.

gap e, no caso de alta viscosidade, obtivemos um fluxo totalmente negativo. Para uma taxa de acreção de $10^{-9} \mathrm{M}_{\odot} /$ ano, foi possível obter também um fluxo totalmente negativo no regime de média viscosidade, como mostra a Figura 5.32 .

A descrição de todos os cenários anteriores permite concluir que, quanto menor a massa do disco de gás e quanto maior a viscosidadệ, mais próxima da migração de tipo II teórica estará a migração do planeta, isto é, o planeta se move próximo da velocidade viscosa do gás. Notamos também que isso está relacionado à presença de massa nas regiões próximas do planeta, que será menor quanto menor for a massa do disco de gás. Agora que entendemos o processo sem acreção de gás, podemos partir para a implementação de um modelo de acreção de gás e verificar como este modelo pode interferir no processo migratório, já que a acreção do gás será responsável por diminuir a massa de gás nas regiões próximas do planeta.

\footnotetext{
${ }^{1}$ Vale ressaltar que estamos considerando a faixa de 0.001 até 0.01 para o parâmetro de ShakuraSunyaev.
} 


\subsection{Novo modelo para acreção de gás}

\subsubsection{Modelo de acreção de gás do FARGO}

No modelo de acreção de gás do FARGO, antecessor do FARGO3D, o gás é removido das células de uma região específica em torno do planeta em frações de uma frequência característica definida por $\frac{k_{a}}{T_{\text {orbital }}}$, onde $T_{\text {orbital }}$ é o período orbital do planeta em $r=1(5.2$ ua). O parâmetro $k_{a}$ é definido no arquivo planet.cfg, através da variável Accretion, e é um fator de proporção para aumento ou diminuição da taxa de acreção. Assim, uma taxa de acreção usando Accretion $=1.0$ refere-se a uma taxa padrão, e uma taxa de acreção com Accretion $=2.3$ refere-se a uma taxa 2.3 vezes maior que a taxa padrão . Os planetas dentro do disco são tratados essencialmente como um sorvedouro de gás. A acreção do gás transfere massa e momento angular para o planeta.

O tamanho da zona de acreção é definida em termos do raio de Hill (ver seção 2.4), dado pela equação 2.64. Essa zona de acreção é dividida em três subzonas com diferentes taxas de acreção. Os parâmetros $c_{1}=0.75$ e $c_{2}=0.45$ descrevem a fração do raio de Hill que é usada para o cálculo do tamanho das zonas de acreção (ver Fig. 5.33).
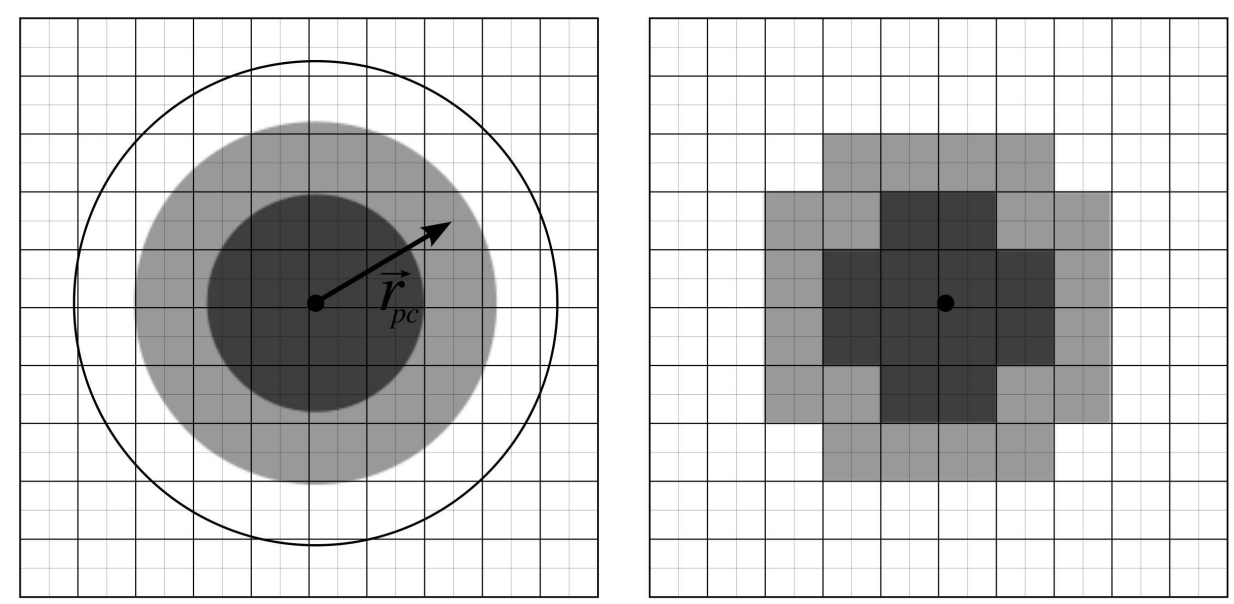

Figura 5.33: Representação das zonas de acreção no FARGO. O ponto preto representa o planeta, a região mais clara e a escura representam, respectivamente, a área definida pelo raio $c_{1} R_{\mathrm{H}}$ e $c_{2} R_{\mathrm{H}}$. A circunferência mais externa delimita a região correspondente ao raio de Hill.

A área definida pelo raio $c_{1} R_{\mathrm{H}}$ define a maior zona da qual o gás é acretado, nessa região, a frequência para retirada da massa é limitada por $\frac{1}{3}$ da frequência característica $\left(f_{1}=\frac{1}{3} \frac{k_{a}}{T_{\text {orbital }}}\right)$. 
A menor zona de alimentação é defina pelo raio $c_{2} R_{\mathrm{H}}$, nessa região, a frequência para retirada da massa é limitada por $\frac{2}{3}$ da frequência característica $\left(f_{2}=\frac{2}{3} \frac{k_{a}}{T_{\text {orbital }}}\right)$. Nenhum gás é acretado entre $c_{1} R_{\mathrm{H}}$ e $R_{\mathrm{H}}$.

A determinação de qual célula deve cair dentro da zona acretada é obtida de forma discreta, como mostra a Figura 5.33. A distância do planeta até a célula é usada para determinar qual célula pertence a cada zona. A distância é obtida considerando a posição do planeta e o centro de cada célula.

Levando em conta a posição da célula em relação ao planeta, a massa é retirada de cada célula para cada passo da simulação. A massa removida de cada célula é dada por:

$$
\partial m_{i, j}=f_{m} d t \Sigma_{i, j} A_{i, j}
$$

onde $f_{m}$ é um dos dois parâmetros mencionados acima $\left(f_{1}\right.$ ou $\left.f_{2}\right)$ e depende da distância da célula ao planeta, $d t$ é o passo de tempo intrínsico a simulação hidrodinâmica, $\Sigma_{i, j}$ é a densidade superficial de gás na célula e $A_{i, j}$ é a área da célula.

A massa total $(\Delta m)$ é obtida pela soma da massa retirada de cada célula dentro das zonas de acreção, logo:

$$
\Delta m=\sum_{i, j} \partial m_{i, j}
$$

Essa massa é adicionada ao planeta, assim:

$$
M_{n+1}=M_{n}+\Delta m
$$

onde $M_{n}$ e $M_{n+1}$ é a massa do planeta, respectivamente, antes e depois do passo de tempo.

Para determinar o momento linear transferido das células acretadas para o planeta, calcula-se a velocidade radial, $\widehat{v}_{r_{i, j}}$, e azimutal, $\widehat{v}_{\theta_{i, j}}$, no centro das células ${ }^{1}$, assim:

$$
\begin{gathered}
\widehat{v}_{\theta_{i, j}}=\frac{1}{2}\left(v_{\theta_{i, j-1 / 2}}+v_{\theta_{i, j+1 / 2}}\right)+\widehat{R}_{i} \Omega_{\mathrm{f}}, \\
\widehat{v}_{r_{i, j}}=\frac{1}{2}\left(v_{r_{i-1 / 2, j}}+v_{r_{i+1 / 2, j}}\right),
\end{gathered}
$$

onde $\widehat{R}_{i}$ é a posição central da $i$-ésima célula e $\Omega_{\mathrm{f}}$ é a velocidade angular do referencial.

\footnotetext{
${ }^{1}$ Vale relembrar que os valores das velocidades são dados no centro das arestas de cada célula, em caso de dúvida recomendamos a leitura da seção 3.2
} 
Em coordenadas cartesianas $2^{2} \widehat{v}_{x_{i, j}}$ e $\widehat{v}_{y_{i, j}}$, usa-se:

$$
\begin{gathered}
\widehat{v}_{x_{i, j}}=\frac{\widehat{v}_{r_{i, j}} x_{i, j}-\widehat{v}_{\theta_{i, j}} y_{i, j}}{\widehat{R}_{i}}, \\
\widehat{v}_{y_{i, j}}=\frac{\widehat{v}_{r_{i, j}} y_{i, j}+\widehat{v}_{\theta_{i, j}} x_{i, j}}{\widehat{R}_{i}} .
\end{gathered}
$$

Assim, o momento linear na direção $x$ e $y$ (coordenadas cartesianas), retirado de cada célula é dado, respectivamente, por:

$$
\begin{aligned}
\Delta p_{x} & =\sum_{i, j} \partial m_{i, j} v_{x_{i, j}}, \\
\Delta p_{y} & =\sum_{i, j} \partial m_{i, j} v_{y_{i, j}} .
\end{aligned}
$$

Esse momento linear é transferido ao planeta, logo:

$$
\begin{aligned}
& p_{x_{n+1}}=p_{x_{n}}+\Delta p_{x_{n}}, \\
& p_{y_{n+1}}=p_{y_{n}}+\Delta p_{y_{n}},
\end{aligned}
$$

onde $p_{x_{n+1}}$ e $p_{x_{n}}$ representam o momento linear do planeta na direção cartesiana $x$, respectivamente, antes e depois do passo de tempo, e $p_{y_{n+1}}$ e $p_{y_{n}}$ representam o momento linear do planeta na direção cartesiana $y$, antes e depois do passo de tempo.

Esse algoritmo não estava implementado no FARGO3D, então, com base no algoritmo do código antecessor, reescrevemos o código e o adaptamos à nova versão. Para testar a implementação, reproduzimos um dos resultados obtidos por Kley (1999) que mostra o crescimento de um gap causado pela pertubação gravitacional de um planeta de $1 \mathrm{M}_{\mathrm{J}}$ fixo em $r=1$, com acreção de gás. A Figura 5.34 mostra a comparação entre os resultados. Os detalhes da simulação podem ser encontrados em Kley (1999) (ver Tabela 1 do artigo citado).

\footnotetext{
${ }^{2}$ As posições e velocidades do(s) planeta(s) no FARGO e no FARGO3D, estão sempre em coordenadas cartesianas, independente do sistema de coordenadas escolhido, por isso, a necessidade dessa transformação.
} 

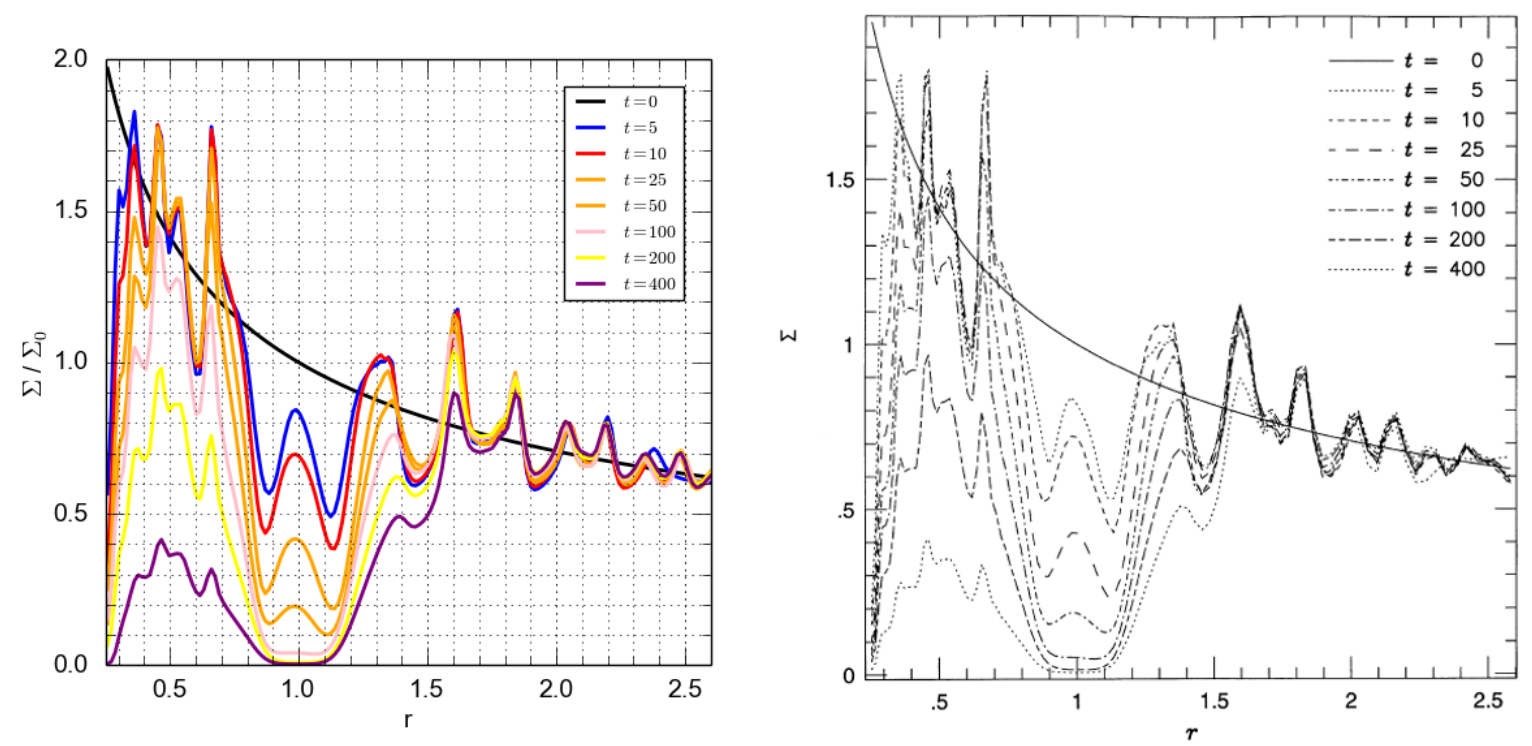

Figura 5.34: Comparação de resultados entre o modelo de Kley (1999), figura reproduzida a direita, e a reprodução da implementação no FARGO3D, figura à esquerda.

Em nosso modelo, não acrescentamos o momento do gás no planeta, isso será realizado em trabalhos futuros. Todavia, isso não altera de forma significativa o processo de migração, como pode ser visto em Dürmann e Kley (2017).

\subsubsection{Adaptação do tamanho da região de acreção de gás}

O cenário de acreção anterior utiliza como critério o raio de Hill para determinar a região na qual as células do gás poderão ser acretadas. Isto se deve ao fato de o gás dentro dessa região ser considerado gravitacionalmente ligado ao planeta. No entanto, a velocidade relativa do planeta em relação ao gás e a velocidade térmica do gás podem influir significamente no cálculo do raio dessa região. Para levar em conta o efeito térmico, adicionamos o raio de Bondi como fator limitante para determinar qual célula poderá ser acretada.

O raio de Bondi, conforme descrito na seção 2.5, determina a região do gás que pode ser acretada por um corpo massivo se movendo numa nuvem de gás. Trata-se da região na qual a velocidade resultante (térmica + relativa) do gás, ao redor do corpo massivo, é menor que a velocidade de escape do gás.

Para determinar o raio de Bondi de uma célula numa dada posição $(i, j)$, utilizamos a equação 2.69, escrita na forma: 


$$
R_{B_{i j}}=\frac{2 G M}{c_{\mathrm{s}_{i j}}^{2}+\Delta v_{i j}^{2}},
$$

onde $c_{\mathrm{s}_{i j}}$ é a velocidade do som da célula e $\Delta v_{i j}$ a velocidade relativa entre a célula e o planeta, dada por:

$$
\Delta v_{i j}^{2}=\sqrt{\left(v_{p_{x}}-v_{x_{i j}}\right)^{2}+\left(v_{p_{y}}-v_{y_{i j}}\right)^{2}}
$$

onde, $v_{p_{x}}$ e $v_{p_{y}}$, são as componentes da velocidade do planeta em coordenadas cartesianas e, $v_{x_{i j}}$ e $v_{y_{i j}}$, as componentes da velocidade do gás no centro da célula $(i, j)$, também em coordenadas cartesianas (ver eq. 5.9 e 5.10.

Desse modo, o efeito gravitacional obtido da análise do raio de Hill e o efeito térmico obtido da análise do raio de Bondi são condições necessárias para definir a região onde o gás será acretado pelo planeta, isso permite escrever:

$$
R_{a_{i j}}=\min \left(R_{B_{i j}}, R_{\mathrm{H}}\right)
$$

onde o raio $R_{a_{i j}}$ determina a distância mínima na qual a célula deveria estar para ser considerada dentro da região de acreção do planeta. Para cada célula em torno do planeta, se a distância da célula até o planeta, $r_{i j}$, for menor que $R_{a_{i j}}$, então o gás será removido da célula durante a acreção.

\subsubsection{Ajuste da escala de tempo do processo de acreção de gás}

Outra característica que deve ser adaptada no código anterior é o ajuste da escala de tempo usada no processo de acreção. De fato, conforme vimos na seção 5.4.1, a densidade da célula na zona de acreção é reduzida por um fator $1-f_{\mathrm{m}} d t$ a cada passo de tempo $d t$, tempo intrínseco à resolução da malha hidrodinâmica. Portanto, o fator $f_{\mathrm{m}}$ descreve a frequência característica com que a massa é retirada da zona de acreção, logo, possui unidade de $T^{-1}$. O tempo característico $T$ do FARGO3D é o período orbital de um planeta numa órbita de raio $r=1$. Assim, por exemplo, $f_{\mathrm{m}}=0.5$ significa que $50 \%$ da massa dentro da zona de acreção é acretada pelo planeta quando passada 1 unidade de período orbital 1 .

\footnotetext{
${ }^{1}$ Nos sistemas MKS ou CGS, o período orbital do FARGO3D é o período de translação de Júpiter, portanto, no mesmo exemplo, seriam retirados $50 \%$ da massa de gás dentro da zona de acreção a cada período de translação de Júpiter.
} 
Esse cenário pode se tornar não realístico dado que a frequência característica será sempre a mesma, independente das características físicas do disco de gás e do planeta. Assim, seguindo Russell (2011), usaremos uma escala de tempo mais apropriada para a acreção de gás que leva em conta o período orbital do gás em torno do planeta, ao invés do tempo de translação do planeta ao redor da sua estrela. Devido aos efeitos viscosos e à transferência de momento angular, o gás dentro da região de acreção é comprimido em direção ao planeta. Assim, a tendência é que o gás nas órbitas internas em torno do planeta seja acretado mais rapidamente que o gás das órbitas mais externas. Portanto, iremos definir um tempo característico $T_{r_{i j}}$ para cada órbita dentro do raio de acreção, dado por:

$$
T_{r_{i j}}=2 \pi \sqrt{\frac{r_{i j}^{3}}{G M_{\mathrm{p}}}},
$$

onde $r_{i j}$ é a distância do centro da célula (na zona de acreção) ao planeta, $G$ a constante gravitacional e $M_{\mathrm{p}}$ a massa do planeta.

Isso resulta em uma taxa de acreção dinâmica que varia de acordo com o raio de acreção e a massa planetária. Isso configura uma modelagem para o regime de runaway, já que, no mesmo período de tempo, as células mais próximas do planeta sofrem um decréscimo maior de massa do que as células mais externas, criando uma região de baixa pressão que posteriormente é ocupada por uma nova camada de gás (ver seção 2.2.3). No entanto, a taxa de acreção no regime de runaway não pode ser maior que a taxa de acreção de Bondi (ver seção 2.5).

Uma estimativa teórica para a taxa de acreção de gás $\dot{M}$ pode ser obtida para o modelo descrito nesta seção. Considere uma região esférica de volume $V$, delimitada pelo raio de Bondi, $R_{\mathrm{B}}$, e preenchida de gás de densidade constante e igual a $\rho$. Dada uma escala de tempo para acreção, $\tau$, aproximada pelo período orbital da camada mais externa do raio de Bondi, $\tau=2 \pi \sqrt{\frac{R_{\mathrm{B}}^{3}}{G M_{\mathrm{p}}}}$, a taxa de acreção estimada será:

$$
\dot{M} \approx \frac{\rho V}{\tau} \approx \frac{\rho \frac{4}{3} \pi R_{\mathrm{B}}^{3}}{2 \pi \sqrt{\frac{R_{\mathrm{B}}^{3}}{G M_{\mathrm{p}}}}} \approx \frac{\sqrt{2}}{3 \pi} \frac{4 \pi G M_{\mathrm{p}} \rho}{\left(\Delta v^{2}+c_{\mathrm{s}}\right)^{3 / 2}} .
$$

A taxa de acreção de gás obtida acima é apenas $\frac{\sqrt{2}}{3 \pi}$ da taxa de acreção de Bondi $\left(\dot{M}_{\mathrm{B}}\right)$, isto é: 


$$
\dot{M} \approx \frac{\sqrt{2}}{3 \pi} \dot{M}_{\mathrm{B}}
$$

A estimativa teórica se revelou menor do que o obtido com o modelo de Bondi. No entanto, a taxa de acreção no regime de runaway, $\dot{M}_{\text {run }}$, é obtida através da soma da massa retirada de cada célula $\partial m_{i j}$, assim:

$$
\dot{M}_{\text {run }}=\sum_{i j} \frac{\partial m_{i j}}{d t} .
$$

Logo, a taxa de acreção total no modelo tende a ser um pouco maior que a estimativa teórica, dado que as células mais próximas do planeta perdem massa numa frequência maior. Assim, o valor numérico obtido para a taxa de acreção de gás quando nosso modelo alcança o regime de runaway é próximo do valor teórico imposto para a taxa de acreção de Bondi.

\subsubsection{Efeitos da altura do disco}

Outra característica que devemos levar em conta é que, mesmo no caso de um disco bidimensional, há uma altura implícita definida pelo aspecto de altura e seu achatamento. Algumas propriedades das células, como densidade superficial do gás e velocidades, precisam ser consideradas como médias verticais sobre essa altura. O código FARGO utiliza o parâmetro ThicknessSmoothing para, por exemplo, suavisar o potencial gravitacional do planeta e calcular as forças gravitacionais envolvidas no processo de migração. Aqui, seguindo Russell (2011), vamos usar um raciocínio similar para modificar o cenário de acreção de gás por meio de uma mudança na escala de tempo na equação 5.18 .

Assim, a distância $r_{i j}$ é ainda usada para determinar que células estão dentro da região de acreção. No entanto, o tempo característico no qual a célula $[i, j]$ é acretada leva em conta a distância suavizada, $\tilde{r}_{i j}=\sqrt{r_{i j}^{2}+(\varepsilon H)^{2}}$, assim:

$$
\tilde{T}_{\tilde{r}_{i j}}=2 \pi \sqrt{\frac{\tilde{r}_{i j}^{3}}{G M_{p}}},
$$

onde $H$ é a altura do disco e $\varepsilon$ o parâmetro ThicknessSmoothing definido em setup.par (ver seção 3.6).

O uso de uma distância suavizada permite considerar um período orbital suavizado para levar em conta a influência do efeito da altura do disco. Para uma simulação 3D 
esse fator não é necessário. No entanto, uma investigação mais apurada deve ser realizada nesse caso. Uma descrição interessante para o potencial no caso 3D pode ser encontrada em Kley et al. (2009).

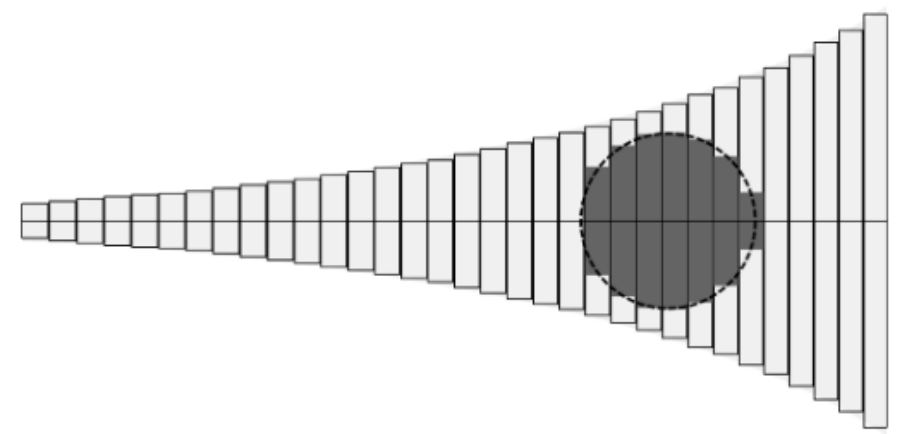

Figura 5.35: Representação geométrica do volume de gás acretado. A linha sólida representa o plano médio do disco e cada coluna representa o efeito da altura do disco. A região escura representa a região acretada. O formato do disco foi exagerado para facilita a visualização. Figura obtida em: Russell (2011).

Como as propriedades de cada célula variam entre $\pm H_{i j}$, precisamos encontrar valores médios que levem em conta a altura do disco. Para isso, vamos considerar apenas o volume dentro da região de acreção (ver Fig 5.35). Suponha que para cada célula $[i, j]$ tivéssemos uma coluna de gás, de tal forma que a massa disponível para acreção em cada coluna $[i, j]$ seria:

$$
m_{i j}=\rho_{\operatorname{gas}_{i j}} A_{i j}\left(2 H_{a i j}\right)
$$

onde $\rho_{\text {gas }_{i j}}$ é uma densidade volumétrica média, $A_{i j}$ a área superficial da célula e $H_{a i j}$ é a altura daquela célula dentro da região de acreção, isto é:

$$
H_{a i j}=\sqrt{R_{a i j}^{2}-r_{i j}^{2}},
$$

onde $R_{a i j}$ é o raio de acreção (ver eq. 5.17).

Para estimar $\rho_{\operatorname{gas}_{i j}}$, nós podemos considerar a média sobre a altura total, logo:

$$
\rho_{\operatorname{gas}_{i j}}=\frac{\Sigma_{\operatorname{gas}_{i j}}}{2 H_{i j}} .
$$

Portanto, a equação 5.23 pode ser escrita na forma: 


$$
m_{i j}=\left(\frac{\Sigma_{\operatorname{gas}_{i j}}}{2 H_{i j}}\right) A_{i j}\left(2 H_{a i j}\right)=h_{i j} \Sigma_{\operatorname{gas}_{i j}} A_{i j}
$$

onde $h_{i j}=\frac{H_{a i j}}{H_{i j}}$, se $H_{a i j} \leq H_{i j}$, e, $h=1$, se $H_{a i j}>H_{i j}$. Desta maneira, caso o raio de acreção exceda a altura do disco, a massa disponível não se torna maior que a disponível. Para o caso 3D, vamos tomar $h=0$, já que, nesse caso, o efeito da altura não é necessário.

O modelo acima ainda não é o ideal para reproduzir os dados de uma simulação 3D. Isso porque em regiões afastadas da estrela, no qual a altura da zona de acreção é menor que a altura do disco, poderá ocorrer uma subestimativa da quantidade de gás disponível. Considere, por exemplo, que o valor $h_{i j}$ seja igual a 0.5 , isto é, a altura da zona de acreção é metade da altura do disco. O valor indica que estamos considerando que metade da massa de gás contida na célula está na região de acreção. No entanto, sabemos que para um disco verticalmente isotérmico ocorre um decaimento exponencial do gás em relação a altura (ver seção 2.1.2), assim sendo, poderemos ter uma subestimativa da massa de gás disponível para acreção. Em nossas simulações esse efeito não será tão significativo, pois a taxa de acreção para planetas menores será modelada utilizando a taxa de acreção de Kelvin-Helmholtz, assim, quando o planeta alcança o regime de runaway já possui uma altura para a zona de acreção próxima do valor da altura do disco, já que estará em regiões próxima da estrela. Ajustes no modelo para englobar a acreção gás em regiões mais afastadas serão realizados em trabalhos futuros.

\subsubsection{Acreção de gás fora do regime de runaway}

O cenário de acreção visto até aqui descreve apenas o regime de runamay, no qual a taxa de acreção depende essencialmente da queda do gás dentro da região de acreção de gás. Portanto, ele não é capaz de descrever de forma consistente a fase anterior a esse regime, no qual a estrutura térmica e física do envelope planetário se tornam importante.

A condição necessária para qualquer gás se acumular próximo do núcleo sólido é que sua velocidade de escape não exceda a velocidade do som do disco de gás, que está associada com sua energia térmica. Em geral, isso permite que núcleos sólidos pequenos possam atrair uma parcela do gás para próximo da sua superfície. No entanto, esse disco de gás se acumula dentro de um envelope em equilíbrio quase estático ao redor do núcleo sólido. Dentro desse envelope, a atração gravitacional é balanceada pelo gradiente de pressão 
mantida pela energia do bombardemento dos planetesimais. O envelope, nesse caso, é levemente ligado ao disco e seus parâmetros físicos mudam de forma suave.

No entanto, quando o núcleo atinge uma massa crítica, $M_{\text {crit }}^{\text {core }}$ o estado de equilíbrio quase estático não é mais mantido e a fase de acreção de gás é iniciada. Um conjunto de soluções numéricas, baseadas na estrutura física do envelope em equilíbrio quase estático (Ikoma et al., 2000), fornece um valor estimado para a massa crítica do núcleo dada por:

$$
M_{\text {crit }}^{\text {core }} \simeq 10\left(\frac{\dot{M}_{\text {core }}}{10^{-6} \mathrm{M}_{\otimes} \mathrm{yr}^{-1}}\right)^{c}\left(\frac{\kappa}{1 \mathrm{~cm}^{2} \mathrm{~g}^{-1}}\right)^{c} \mathrm{M}_{\otimes},
$$

onde $c$ varia entre 0.2 e 0.3 e $\dot{M}_{\text {core }}$ é a taxa de acreção dos planetesimais.

Seguindo Ida e Lin (2004b), nós adotamos o valor de $c=0.25$ para a lei de potência em $\dot{M}_{\text {core }}$ e, considerando uma abundância de partículas de poeira similar ao do meio interestelar, usamos $\kappa \sim 1 \mathrm{~cm}^{2} \mathrm{~g}^{-1}$. Esse valor para opacidade é discutível, dado que a fração de elementos durante essa fase de formação planetária não é muito bem conhecida.

É interessante destacar que a massa crítica do núcleo depende da taxa de acreção de planetesimais e da opacidade do disco de gás. Assim, acreções rápidas (de planetesimais) e altas opacidades resultam num aquecimento do envelope que inibe o ínicio da acreção de gás, e taxas de acreção menores e baixa opacidades podem fazer com que núcleos pequenos deem início à acreção do gás.

O fato é que, com o fim da taxa de acreção de planetesimais, o gás perde esse fator de aquecimento, o envelope contrai, e o gás é acretado em direção ao planeta. Na nossa implementação, a massa crítica do núcleo irá manter o mesmo valor após o início da acreção de gás. No entanto, essa aproximação não é fisicamente correta, já que envelope pode mudar sua opacidade com a poluição do envelope devido a acreção de planetesimais (Hubickyj et al., 2005; Venturini et al., 2016). Esse fator deve ser melhor explorado em trabalhos futuros num estudo mais pormenorizado

Iniciada a acreção de gás, o envelope do protoplaneta contrai no tempo de escala de Kelvin-Helmholtz, obtida por Ikoma et al. (2000) e dada por:

$$
\tau_{\mathrm{KH}} \simeq 10^{b}\left(\frac{M_{\mathrm{p}}}{\mathrm{M}_{\otimes}}\right)^{-c}\left(\frac{\kappa}{1 \mathrm{~cm}^{2} \mathrm{~g}^{-1}}\right) \text { anos },
$$

seguindo Ida e Lin (2004b), adotamos os valores $b \simeq 8$ e $c \simeq 2.5$. Esses valores dependem da opacidade, que neste trabalho será tomada como $\kappa \sim 1 \mathrm{~cm}^{2} \mathrm{~g}^{-1}$. 
Obtido esse parâmetro, o programa calcula a taxa de acreção de Kelvin-Helmholtz, dada por:

$$
\dot{M}_{\mathrm{KH}}=\frac{M_{\mathrm{p}}}{\tau_{\mathrm{KH}}} .
$$

Em seguida, compara o valor obtido com o valor da taxa no regime de runamay, logo:

$$
\dot{M}_{\text {gas }}=\min \left(\dot{M}_{\text {run }}, \dot{M}_{\mathrm{KH}}\right)
$$

onde a taxa de acreção, $\dot{M}_{\text {run }}$, no regime de runamay, é dada pela equação 5.21 .

Essa limitação da taxa de acreção mínima determina que fração de gás é retirada das células na zona de acreção, ou seja:

$$
\partial m_{i j}=\mu \Sigma_{\operatorname{gas}_{i j}} A_{i j}
$$

onde $\Sigma_{\operatorname{gas}_{i j}}$ é a densidade superficial de gás, $A_{i j}$ é a área da célula e $\mu=\frac{\dot{M}_{\mathrm{KH}}}{\dot{M}_{\mathrm{run}}}$. Isso implica que, se $\dot{M}_{\mathrm{KH}}<\dot{M}_{\text {run }}$, então $\mu<1$, e a taxa de acreção é limitada pelo regime de Kelvin-Helmholtz. Caso contrário, $\mu=1$, e a acreção de gás encontra-se no regime de runamay.

O modelo completo para acreção de gás está descrito no apêndice B.16.

\subsection{Análise do formato do gap para planetas fixos - versão com acreção de gás}

Vimos na seção 5.3, que o tempo necessário para que o disco atinja a situação próxima do equilíbrio é de, aproximadamente, 5000 órbitas. No entanto, a acreção de gás terá uma influência significativa nesse processo de equilíbrio. Assim, a acreção de gás será acionada 300 anos antes de atingir 5000 órbitas, para que o disco de gás possa adaptar ao cenário sem uma perturbação muito grande. Em seguida, atingidas as 5000 órbitas, os planetas podem migrar.

A Figura 5.36 a seguir mostra o perfil da média azimutal da densidade superficial de gás obtida para diferentes valores de $\alpha$ e diferentes massas planetárias para um disco com taxa de acreção de $10^{-7} \mathrm{M}_{\odot} /$ ano utilizando a versão com e sem acreção de gás após 5000 órbitas. 

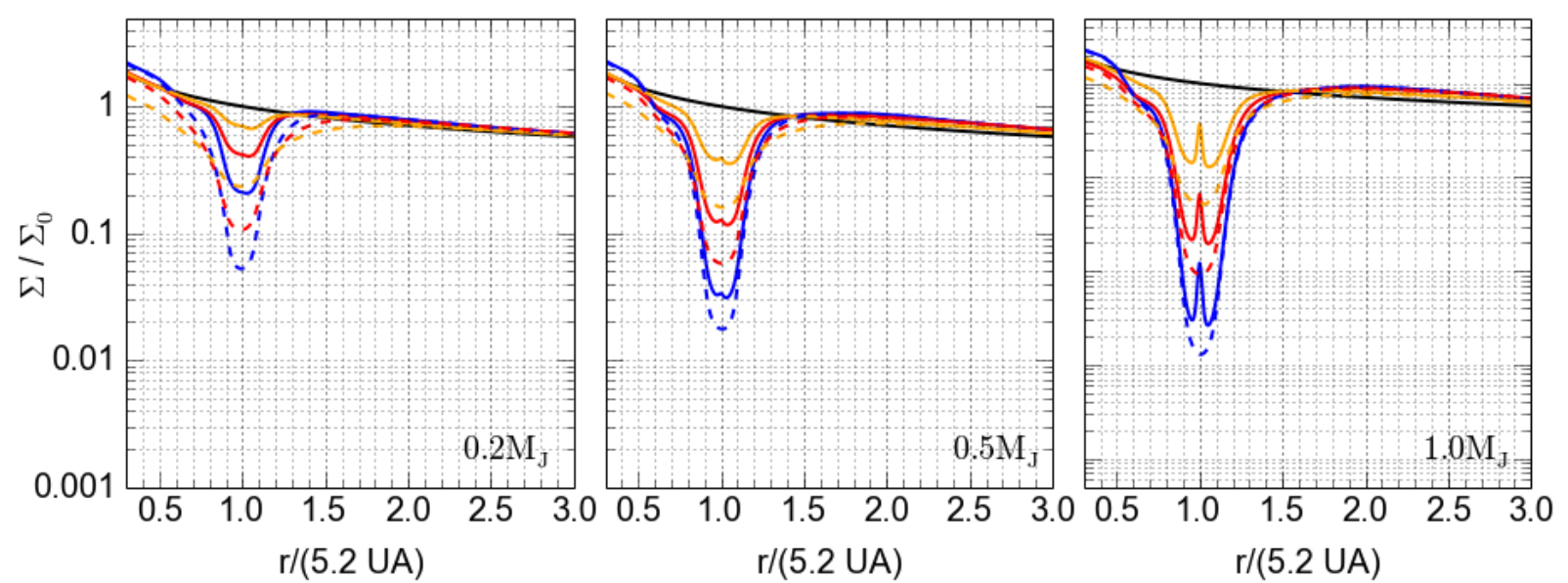

Figura 5.36: Gráfico do perfil da média azimutal da densidade superficial para várias massas planetárias (da esquerda para a direita, $0.2 \mathrm{M}_{\mathrm{J}}, 0.5 \mathrm{M}_{\mathrm{J}}$ e $1.0 \mathrm{M}_{\mathrm{J}}$ ) e para diferentes valores de viscosidade (azul: $\alpha=0.001$, vermelho: $\alpha=0.003$ e laranja: $\alpha=0.010$ ) após o disco atingir o equilíbrio. A linha preta indica o perfil inicial para densidade superficial no começo da simulação. Os gráficos correspondem a um disco de gás cuja taxa de acreção é de $10^{-7}$ $\mathrm{M}_{\odot} /$ ano. As linhas tracejadas correspondem ao modelo com acreção de gás e as linhas cheias ao modelo sem acreção de gás.

Da mesma forma que na versão sem acreção de gás (ver Fig. 5.3), os gaps são mais profundos quanto maior a massa planetária e menor a viscosidade. Assim, planetas maiores, numa região de menor viscosidade, produzem um gap mais profundo, e planetas menores, numa região de maior viscosidade, produzem um gap menos profundo.

No entanto, para o caso com acreção de gás, não encontramos a região de sobredensidade na posição do planeta. Isso ocorre em razão da acreção de gás que não permitiu essa concentração de gás ao redor do planeta.

Observe que temos uma diferença bastante significativa na profundidade dos gaps entre os modelos com e sem acreção para os planetas de menor massa. De fato, a acreção do gás possibilita que o gap formado no mesmo período de tempo seja, obviamente, maior. Vale ressaltar que em todos os casos o planeta já alcançou o regime de runaway, portanto, a massa retirada da região é uma fração que depende do período orbital do gás em torno do planeta (ver seção 5.4.3).

As Figuras 5.37 e 5.38 mostram a mesma análise para diferentes taxas de acreção para o disco de gás. Não detectamos nenhuma diferença significativa entre as diferentes taxas de acreção. 

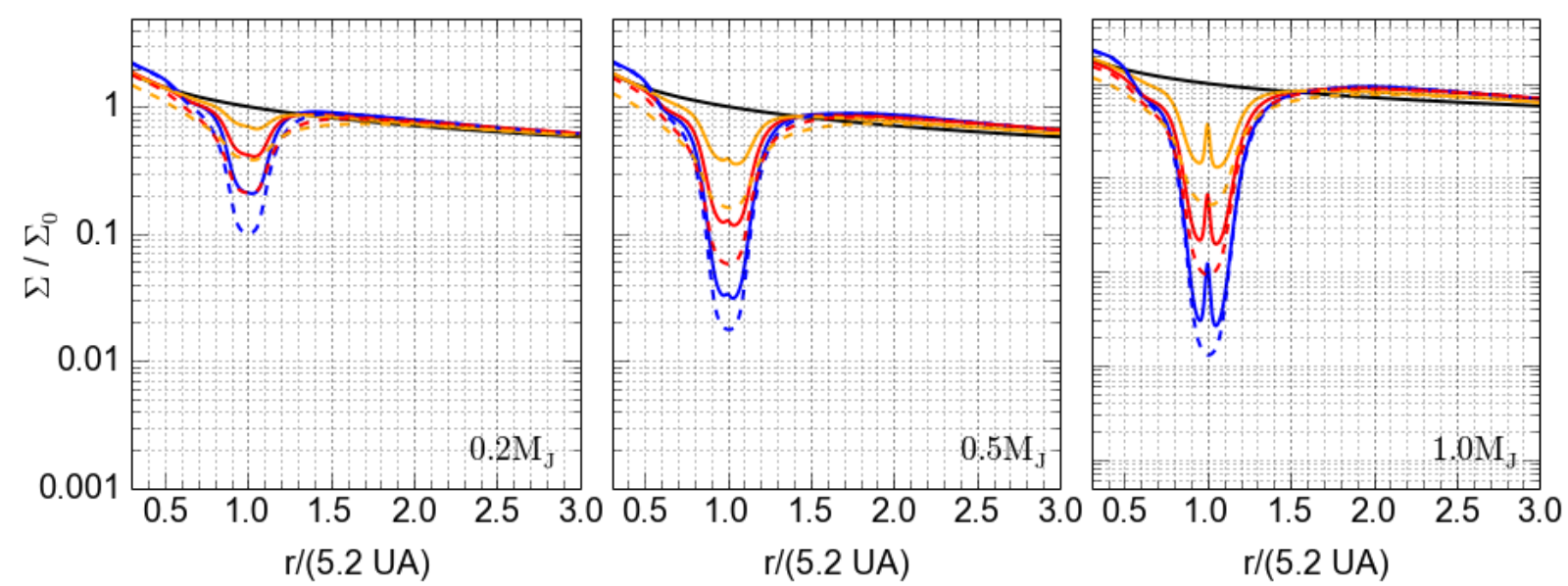

Figura 5.37: Idem à Figura 5.36 para uma taxa de acreção de $10^{-8} \mathrm{M}_{\odot} /$ ano.
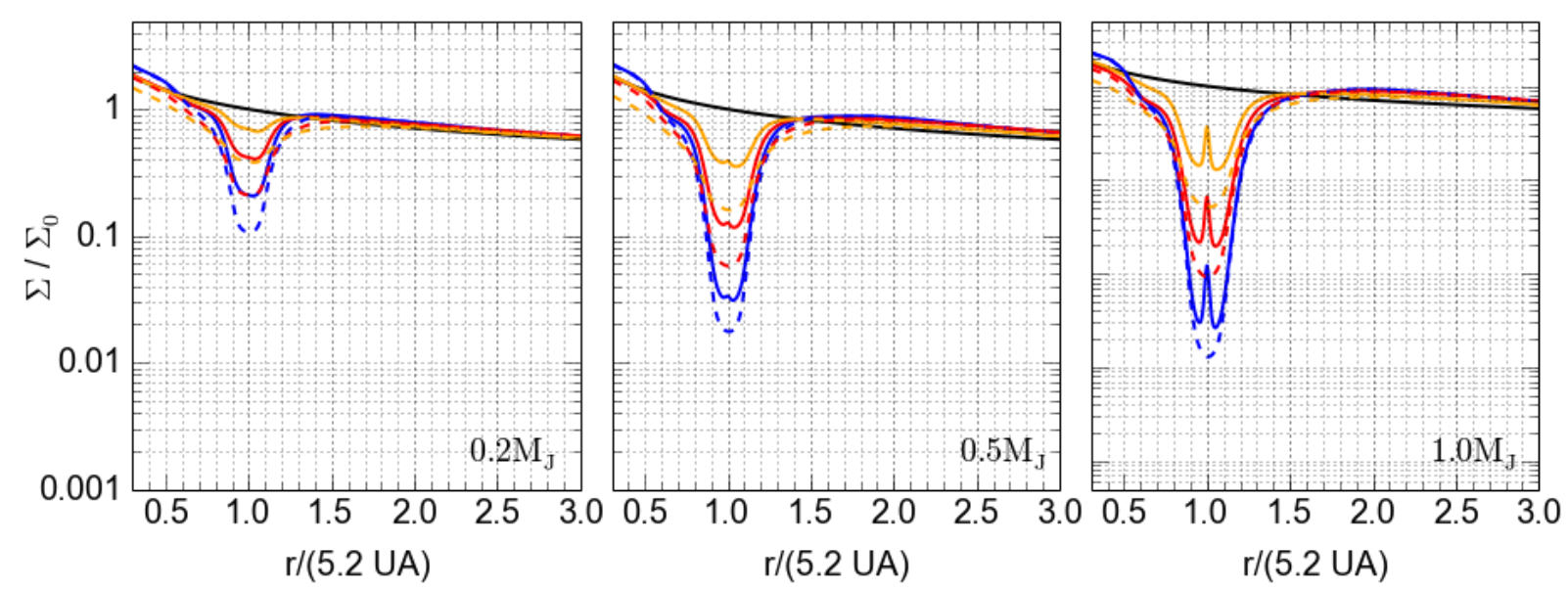

Figura 5.38: Idem à Figura 5.36 para uma taxa de acreção de $10^{-9} \mathrm{M}_{\odot} /$ ano.

\subsection{Migração de planetas massivos - cenário com acreção de gás}

Conforme mencionamos na seção anterior, a acreção de gás será acionada 300 anos antes de 5000 órbitas, assim, o disco pode adaptar a presença do cenário sem uma perturbação muito grande. Em seguida, atingido esse tempo os planetas podem migrar.

A Figura 5.39 a seguir mostra a evolução do semieixo maior do planeta com o tempo para um disco de gás cuja taxa de acreção é de $10^{-7} \mathrm{M}_{\odot} /$ ano, com diferentes parâmetros de massa planetária e viscosidade. Diferente da Figura 5.7, os planetas agora podem acretar a massa do disco de gás. No entanto, essa massa retirada da região de acreção não é adicionada ao planeta. Isso se deve ao fato de querermos investigar a influência do cenário de acreção de gás sem aumento da inércia planetária. Os planetas são assumidos já no 
regime de runaway para acreção de gás e podem migrar por 1200 órbitas após o disco atingir o equilíbrio, ou até chegarem à distância de 0.5 ( 22.6 ua), onde os efeitos de borda se tornam significativos, situação que foge do escopo desta tese.

Da mesma forma que na seção 5.3 , usaremos os termos regime de baixa viscosidade para $\alpha=0.001$, regime de média viscosidade para $\alpha=0.003$ e regime de alta viscosidade para $\alpha=0.010$. É importante ressaltar que o estudo realizado nesta tese considera uma faixa de valores para o parâmetro de Shakura-Sunyaev entre 0.001 e 0.010, que está dentro dos valores observacionais estipulados (Hartmann et al., 1998; Mukhopadhyay, 2008). Portanto, o leitor deve tomar cuidado para não utilizar as conclusões obtidas em extrapolações para além dessa faixa de valores.
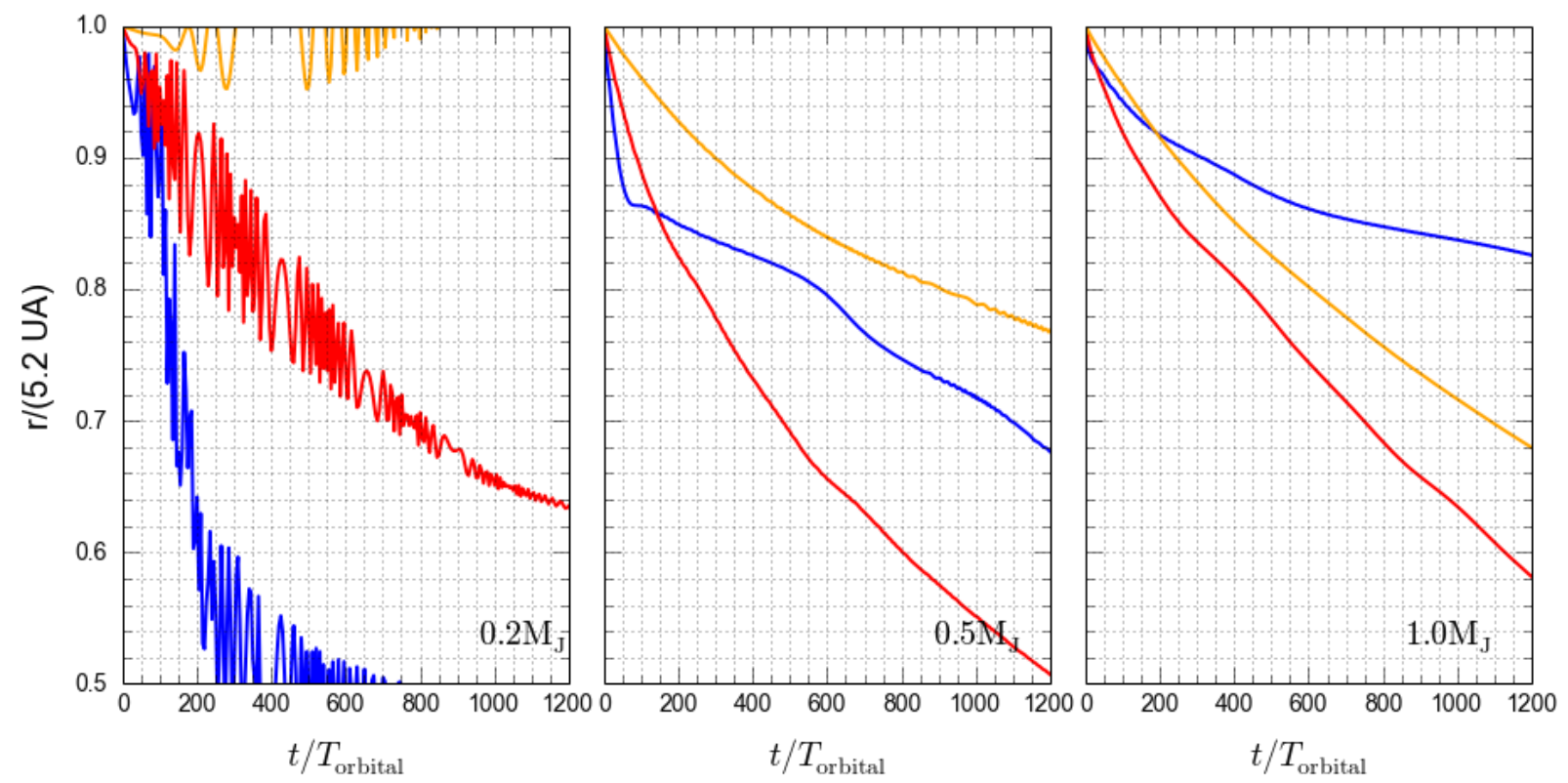

Figura 5.39: Evolução do semieixo maior dos planetas para várias massas planetárias (da esquerda para a direita, $0.2 \mathrm{M}_{\mathrm{J}}, 0.5 \mathrm{M}_{\mathrm{J}}$ e $1.0 \mathrm{M}_{\mathrm{J}}$ ) e para diferentes valores de viscosidade (azul: $\alpha=0.001$, vermelho: $\alpha=0.003$ e laranja: $\alpha=0.010)$. Os gráficos correspondem à versão com acreção de gás e a um disco de gás cuja taxa de acreção é de $10^{-7} \mathrm{M}_{\odot} /$ ano.

Observe que houve uma oscilação muito grande do semieixo maior para o planeta de massa $0.2 \mathrm{M}_{\mathrm{J}}$ em todos os regimes de viscosidade. Nitidamente, esse planeta não sofreu um processo de migração de tipo II. Isto é, a condição inicial imposta para formação do gap não foi capaz de manter o planeta dentro dele durante seu processo migratório e fez com que o planeta oscilasse muito dentro e fora do gap. Portanto, esses resultados podem ser descartados, já que não são fisicamente possíveis. Essa grande oscilação ocorreu porque a 
massa planetária não foi suficientemente grande para impedir a massa de entrar no gap, devido à acreção houve um fluxo de massa intenso dentro do gap gerando oscilações no torque, também é possível que ocorra a presença de vórtices nas bordas que poderiam aumentar esse efeito. No entanto, esses efeitos não fazem parte do assunto de estudo nesta tese.

Comparando os resultados obtidos na Figura 5.39, com acreção de gás, com o da Figura 5.7, sem acreção de gás, podemos observar que, para o planeta de massa $0.5 \mathrm{M}_{\mathrm{J}}$, a mudança entre os cenários foi bastante significativa. No caso com acreção de gás, o planeta pode manter dinamicamente o gap, em todos os regimes de viscosidade, levando a um tempo de migração muito mais elevado. No regime de baixa viscosidade, verificamos um início brusco, mas, passado um intervalo de tempo, o planeta entrou num cenário migratório muito mais lento do que o obtido no cenário sem acreção de gás. Já o planeta de massa $1 \mathrm{M}_{\mathrm{J}}$, no caso de baixa viscosidade, apresentou uma variação de semieixo maior muito próxima entre os dois cenários, com e sem acreção de gás. Notamos também, para essa massa planetária, o desaparecimento das pequenas oscilações, mostrando que, de fato, elas estavam associadas com a presença da massa nas regiões próximas do planeta. Isto é, a acreção do gás possibilitou a retirada dessa massa e, por sua vez, o desaparecimento dessas oscilações.

É interessante notar que, em todos os outros casos, descartando o planeta de massa $0.2 \mathrm{M}_{\mathrm{J}}$ pelos motivos já explicados, a variação do semieixo maior total foi menor. Isso mostra que, para essa massa de disco de gás (ou taxa de acreção), a acreção de gás foi responsável pela diminuição da taxa na migração de tipo II. Embora a mudança não seja tão brusca dentro da escala de tempo para formação planetária.

Outra característica peculiar para o planeta de massa $1 \mathrm{M}_{\mathrm{J}}$ é que a taxa média de migração no regime de média viscosidade foi maior que no regime de alta viscosidade, ao contrário do que ocorreu no cenário sem acreção de gás (ver Fig. 5.7). Esse fato será investigado com mais cuidado mais adiante.

Excluindo, portanto, o caso da massa planetária de $0.2 \mathrm{M}_{\mathrm{J}}$, vamos iniciar nossa análise com o planeta de massa $0.5 \mathrm{M}_{\mathrm{J}}$. Os perfis global e local da média azimutal da densidade superficial, respectivamente, pelas Figuras 5.40 e 5.41 .

Observe que, para essa massa planetária, foi possível a manutenção do gap em todos os regimes de viscosidade. De fato, a Figura 5.40 mostra que o planeta manteve dinami- 

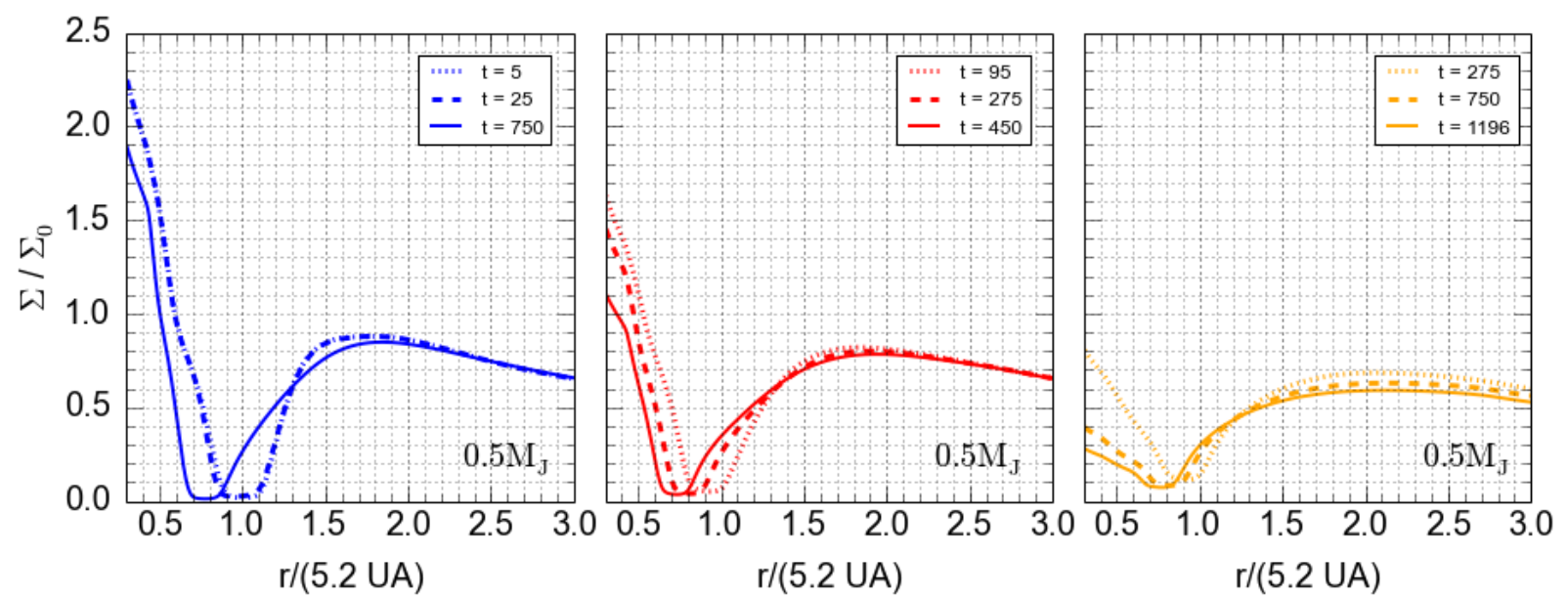

Figura 5.40: Evolução do perfil da média azimutal da densidade superficial do gás ao longo do tempo para o planeta de massa $0.5 \mathrm{M}_{\mathrm{J}}$ para diferentes viscosidades. Da esquerda para a direita, temos $\alpha=0.001, \alpha=0.003$ e $\alpha=0.015$. A taxa de acreção do disco de gás é de $10^{-7} \mathrm{M}_{\odot} /$ ano e o planeta acreta gás.
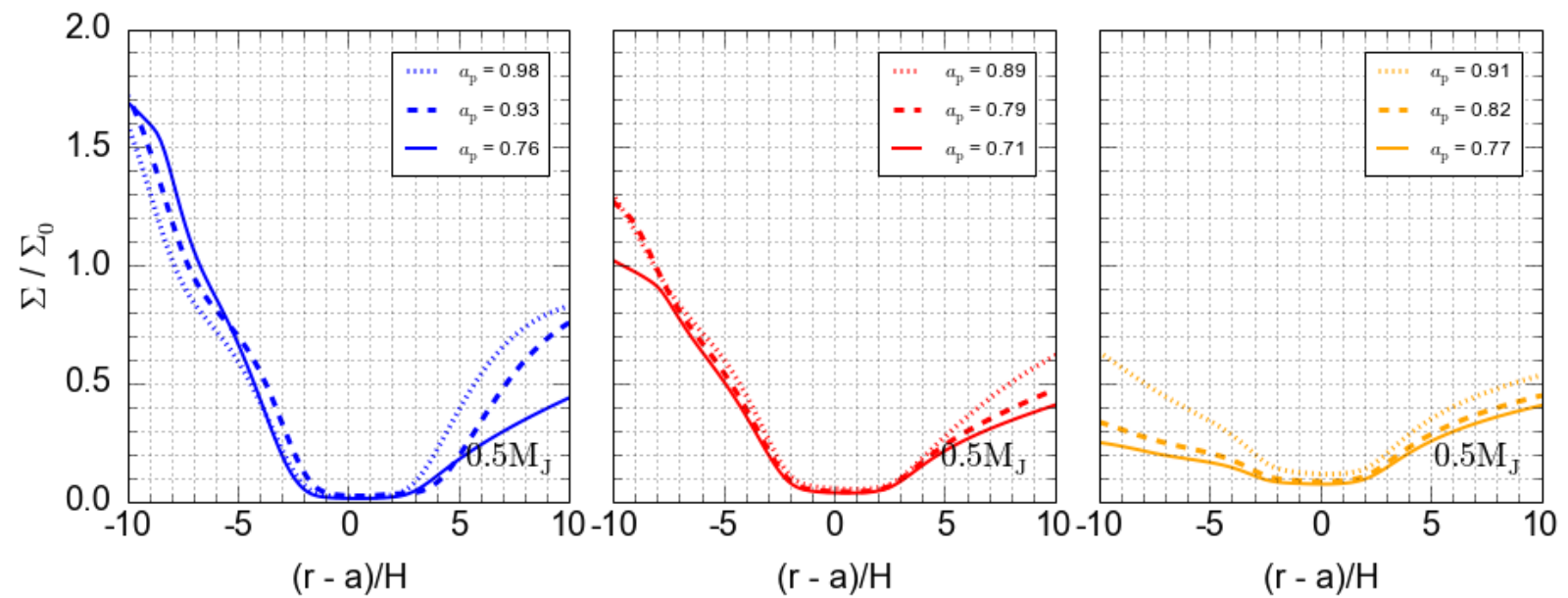

Figura 5.41: Evolução do perfil local da média azimutal da densidade superficial do gás em diferentes posições do planeta de massa $0.5 \mathrm{M}_{\mathrm{J}}$ para diferentes viscosidades. Da esquerda para a direita, temos $\alpha=0.001, \alpha=0.003$ e $\alpha=0.015$. A taxa de acreção do disco de gás é de $10^{-7} \mathrm{M}_{\odot} /$ ano e o planeta acreta gás.

camente o gap no regime de baixa viscosidade, diferentemente do cenário sem acreção de gás (ver Fig. 5.12). Observe também que, comparando os cenários com e sem acreção de gás no regime de média viscosidade, o gap sofre um aumento de sua profundidade no caso com acreção de gás. Isso mostra que o processo de acreção da massa ajudou o planeta a manter o formato do gap e auxiliou na manutençao do estado migratório.

A maior diferença entre o cenário com e sem acreção ocorre no regime de alta viscosidade. Devido ao fato de a massa do disco ser menor nesse caso, boa parte da massa foi 
acretada ou perdida na borda interna do disco de gás. Isso causou um desnível significativo na região à esquerda do gap. Esse resultado deve ser visto com mais cuidado. Isso porque nós desabilitamos o amortecimento da densidade superficial do gás na função STOCKHOLM, o que possibilitou a eliminação de um pico não físico na condição de borda que viola a condição de equilíbrio para o disco de gás, que é a situação que nos interessa. Caso essa função fosse religada, o fluxo de massa na borda interna do disco de gás seria menos intenso e o gás se preservaria por mais tempo. Enquanto o planeta se encontra longe da borda, esses efeitos não interferirão nos resultados. No entanto, uma forma diferente de condição de borda deve ser aplicada dependendo do estudo realizado. Aqui, vamos priorizar a situação de equilíbrio para o disco de gás.
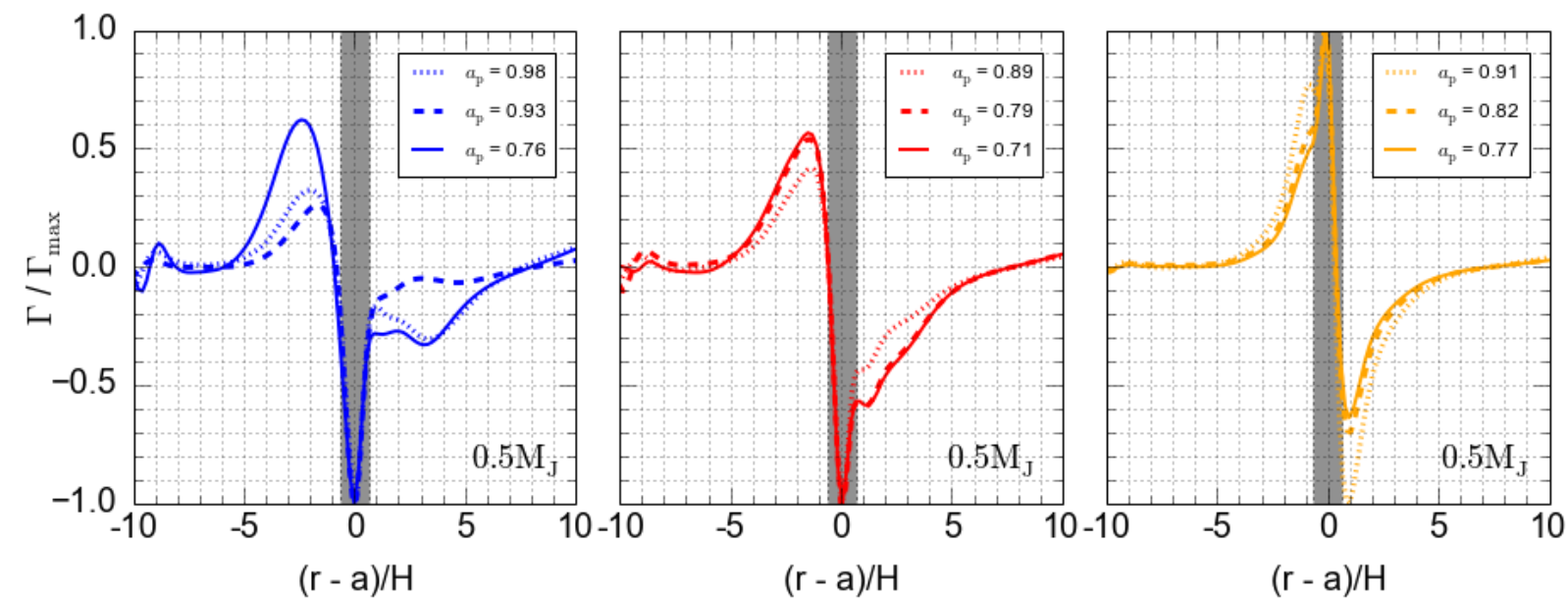

Figura 5.42: Evolução do perfil local do torque em diferentes posições do planeta de massa $0.5 \mathrm{M}_{\mathrm{J}}$ para diferentes viscosidades. Da esquerda para a direita, temos $\alpha=0.001, \alpha=0.003$ e $\alpha=0.015$. A região cinza indica a região na qual o torque sofre uma atenuação, isto é, a região dentro de $0.8 \mathrm{R}_{\mathrm{H}}$. A taxa de acreção do disco de gás é de $10^{-7} \mathrm{M}_{\odot} /$ ano e o planeta acreta gás. O valor do torque para cada raio foi obtido através de uma soma azimutal do torque de cada célula e normalizado em termos do valor máximo obtido ao longo do raio do disco.

É interessante notar que, no regime de baixa viscosidade, ocorreu uma migração brusca no início da simulação. Isso mostra que o planeta ficou instável no início do processo migratório e a condição inicial quase não foi suficiente para manter o gap. Isso pode ser observado na Figura 5.41, que mostra a deformação sofrida pelo gap na borda externa, isto ocorre devido à rápida migração inicial sofrida pelo planeta.

Essa rápida migração também pode ser caracterizada observando a Figura 5.42 , que mostra a contribuição do torque ao longo do raio do disco numa região próxima do planeta. 
É possível notar que há uma grande contribuição do torque dentro da região atenuada, isto é, próximo da região coorbital. Isso ocorre porque o planeta não conseguiu retirar momento angular suficiente do disco interno para impedir a massa de penetrar no gap, isso pode ser observado na Figura 5.43, que mostra um fluxo positivo intenso na região à esquerda do gap.

De fato, analisando o fluxo de massa na Figura 5.43 para o regime de baixa viscosidade, podemos observar que há um enorme fluxo de massa contrário ao movimento do planeta. Esse fluxo faz com que o gás se acumule próximo da região coorbital do planeta gerando um alto torque diferencial negativo. À medida que o planeta migra, parte da massa consegue se acumular na borda interna e diminuir o torque diferencial. Note que a situação já é mais estável para o caso de média e alta viscosidade. No entanto, ocorre uma diferença bastante interessante entre os dois casos. Observando a Figura 5.42, é possível notar que o torque positivo é maior que o negativo no regime de alta viscosidade. Poderia-se esperar que o planeta migrasse no sentido oposto, para fora do disco, mas isso não ocorre porque o torque positivo ocorre na região atenuada, isto é, dentro do raio de Hill do planeta. Assim, o torque diferencial total ainda é negativo. No entanto, obviamente, isso resultou numa taxa de migração muito menor para o regime de alta viscosidade.
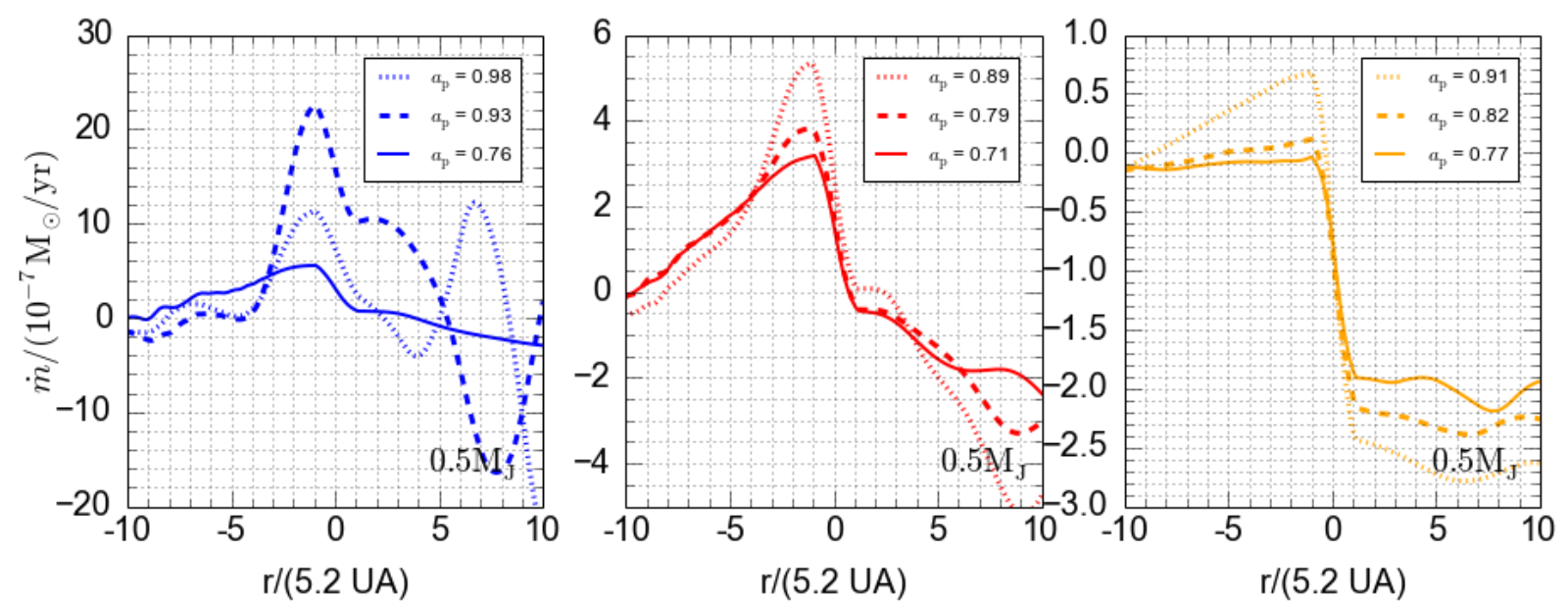

Figura 5.43: Evolução do perfil local do fluxo de gás em diferentes posições do planeta de massa $0.5 \mathrm{M}_{\mathrm{J}}$ para diferentes viscosidades. Da esquerda para a direita, temos $\alpha=0.001, \alpha=$ 0.003 e $\alpha=0.015$. A taxa de acreção do disco de gás é de $10^{-7} \mathrm{M}_{\odot} /$ ano e o planeta acreta gás.

Ainda comparando as Figuras 5.14 e 5.42, observamos, para o regime de baixa viscosidade, uma proporção maior do torque, devido ao disco interno, do que no caso sem acreção 
de gás. Essa figura mostra, portanto, a mudança na estrutura do torque devido ao disco, resultante da manutenção do gap planetário auxiliado pela acreção de gás. O mesmo fato é visto no regime de média viscosidade.

Nota-se também uma diminuição no fluxo de massa próximo do gap em relação ao caso sem acreção de gás (ver Fig. 5.15) em todos os regimes.

Comparando as Figuras 5.15 e 5.43 , podemos notar, nos regimes de média e alta viscosidade, que ocorre um estreitamento da região onde há um fluxo positivo. Essa quase descontinuidade gerada no gráfico ocorre pelo fato de a massa desaparecer do disco, criando uma região onde há massa entrando dos dois lados e desaparecendo dentro da região de acreção. Essa condição não é fisicamente correta e modelos mais completos em alta resolução seriam necessários. No entanto, mesmo esse cenário abrupto pode ser útil para estudo da migração numa escala global, já que um modelo mais sofisticado demandaria maior tempo computacional.

Podemos também analisar o caso do planeta de massa $1.0 \mathrm{M}_{\mathrm{J}}$ no disco de mesma massa. O perfil global e local da média azimutal da densidade superficial do gás são dados, respectivamente, pelas Figuras 5.44 e 5.45 .
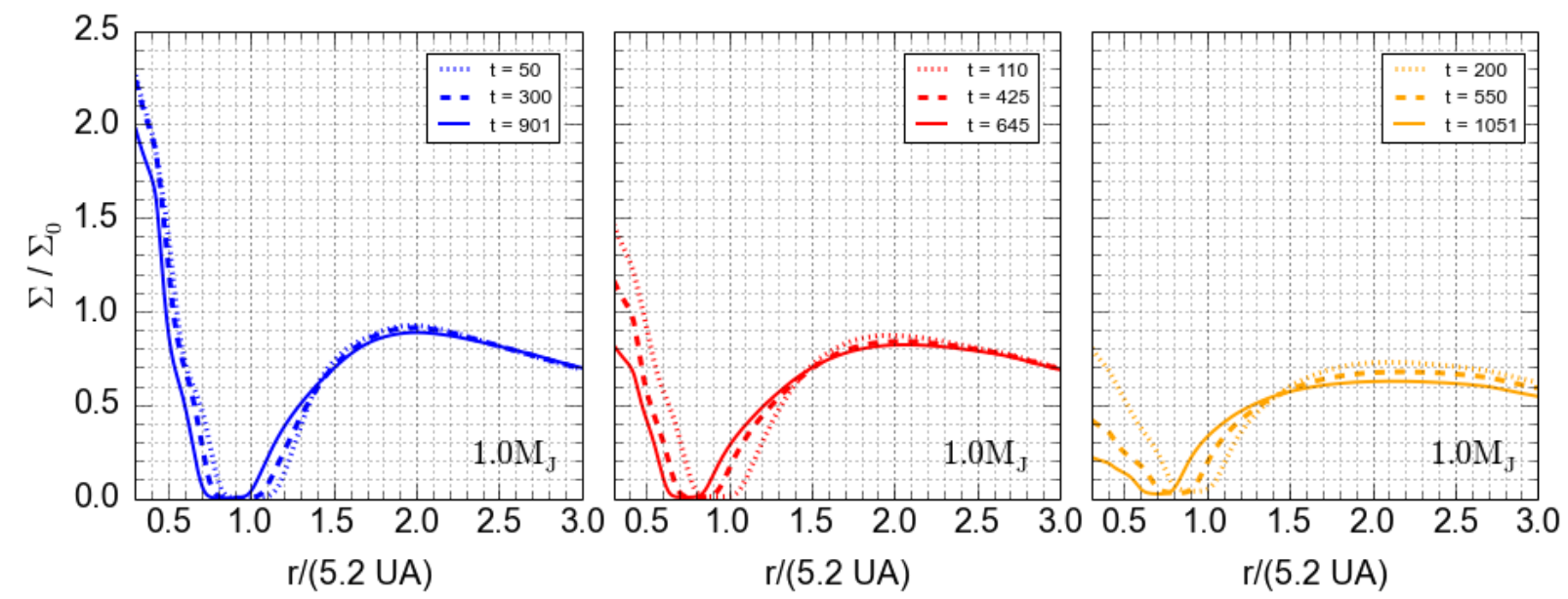

Figura 5.44: Evolução do perfil da média azimutal da densidade superficial do gás ao longo do tempo ao longo do tempo para o planeta de massa $1.0 \mathrm{M}_{\mathrm{J}}$ para diferentes viscosidades. Da esquerda para a direita, temos $\alpha=0.001, \alpha=0.003$ e $\alpha=0.015$. A taxa de acreção do disco de gás é de $10^{-7} \mathrm{M}_{\odot} /$ ano e o planeta acreta gás.

Nesse caso, observamos que o gap também foi bem estabelecido e segue o movimento do planeta em todos os regimes de viscosidade. Notamos, mais uma vez, uma deformação do gap em relação ao modelo sem acreção de gás, principalmente, no regime de alta vis- 

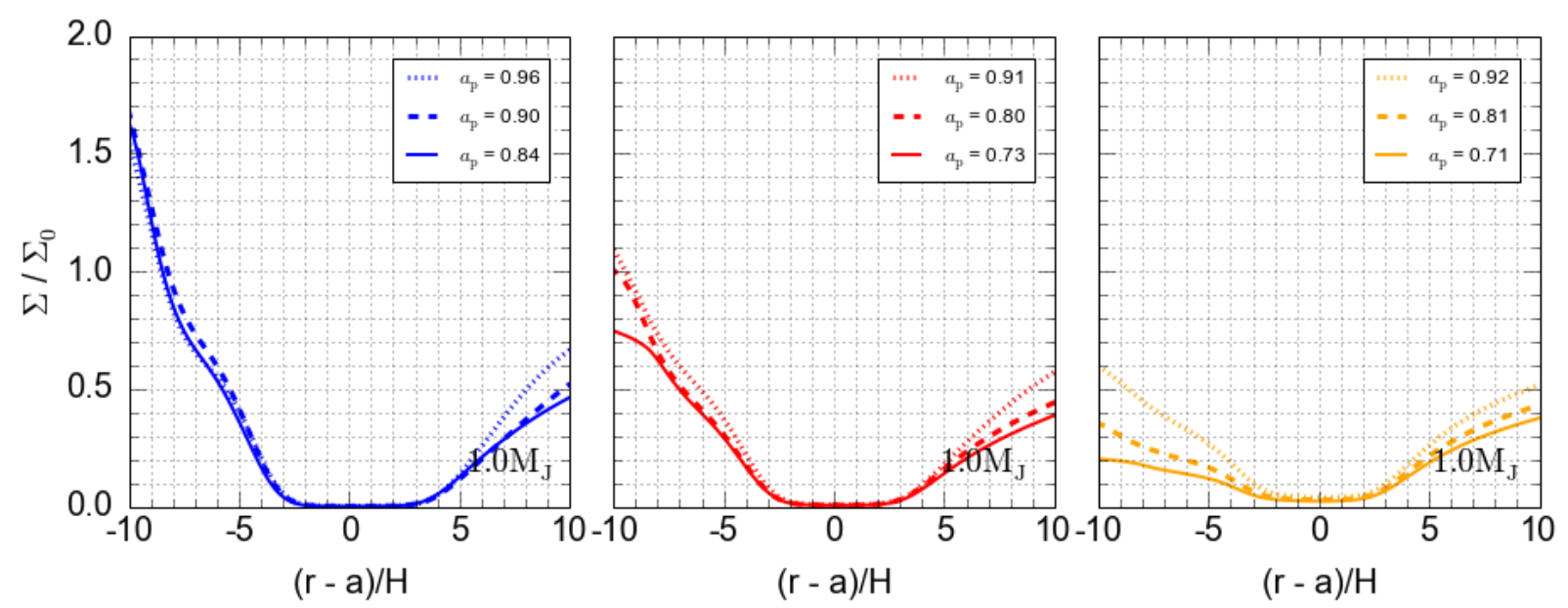

Figura 5.45: Evolução do perfil local da média azimutal da densidade superficial do gás em diferentes posições do planeta de massa $1.0 \mathrm{M}_{\mathrm{J}}$ para diferentes viscosidades. Da esquerda para a direita, temos $\alpha=0.001, \alpha=0.003$ e $\alpha=0.015$. A taxa de acreção do disco de gás é de $10^{-7} \mathrm{M}_{\odot} /$ ano e o planeta acreta gás.

cosidade. De fato, comparando as Figuras 5.17 e 5.45, nota-se o achatamento muito mais pronunciado do gap no caso com acreção de gás em todos os regimes. Observamos também a eliminação da concentração de massa em torno do planeta, que ocorre no caso sem acreção de gás, esse fator é fácil de visualizar comparando-se o caso com e sem acreção de gás no regime de alta viscosidade.

A Figura 5.46 e a Figura 5.47 mostram o perfil local do torque e do fluxo de gás em diferentes posições do planeta. É interessante notar que, no regime de baixa e média viscosidade há um pequeno desnível no fluxo de gás na região próxima da acreção de gás (ver Fig 5.19 e 5.47). Nota-se ainda a presença de uma mudança acentuada na região de acreção. No entanto, para o caso de alta viscosidade, o desnível do fluxo de gás é muito mais significativo. Isso ocorre em razão da pouca massa restante do gás próxima do planeta. Isto é, veremos mais adiante que, quanto menor a massa do disco de gás, maior será esse desnível do fluxo de massa.

Ao contrário do caso sem acreção de gás, notamos a ausência de oscilações no torque na região dentro do raio de Hill do planeta. Além disso, no caso de baixa viscosidade, é possivel notar um torque relativamente menor no lado interno e externo ao gap em relação ao caso sem acreção de gás. O oposto ocorre para o regime de média viscosidade, que apresenta um valor relativativamente maior para o torque na região externa e interna do gap. Para o caso de alta viscosidade, nota-se o desaparecimento da oscilação do torque 

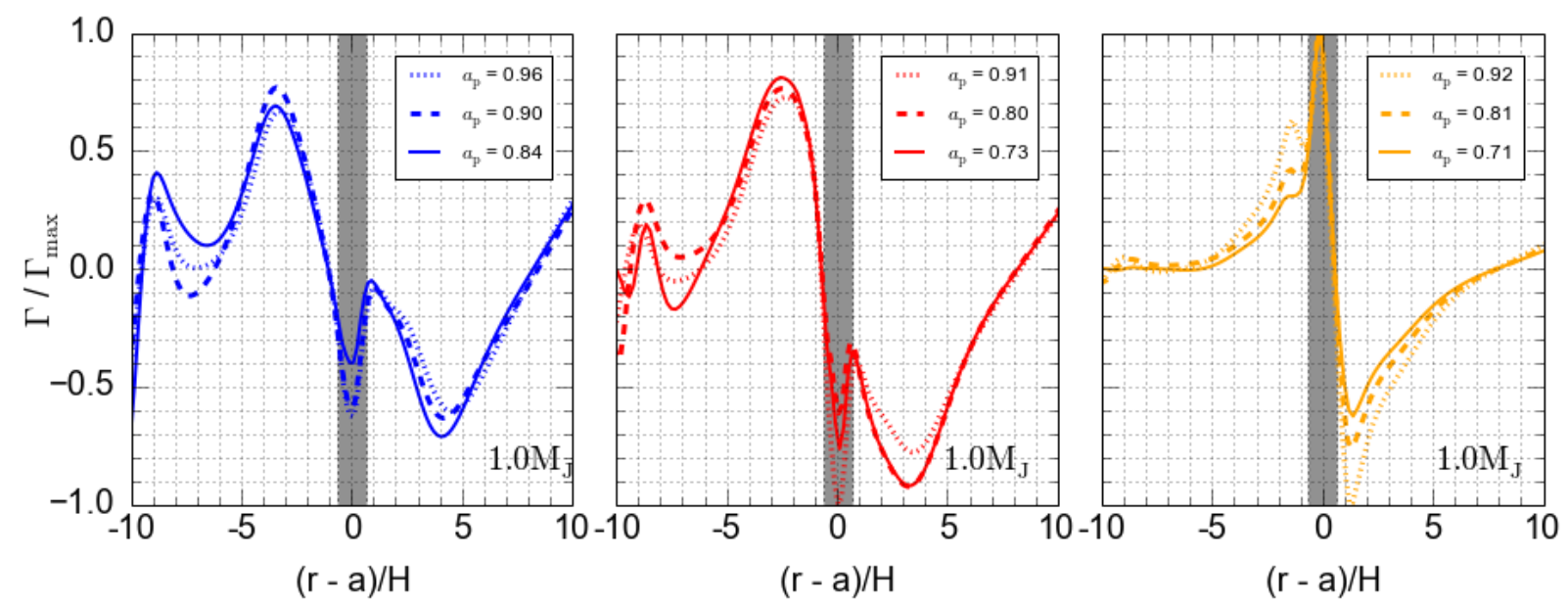

Figura 5.46: Evolução do perfil local do torque em diferentes posições do planeta de massa $1.0 \mathrm{M}_{\mathrm{J}}$ para diferentes viscosidades. Da esquerda para a direita, temos $\alpha=0.001, \alpha=0.003$ e $\alpha=0.015$. A região cinza indica a região na qual o torque sofre uma atenuação, isto é, a região dentro de $0.8 \mathrm{R}_{\mathrm{H}}$. A taxa de acreção do disco de gás é de $10^{-7} \mathrm{M}_{\odot} /$ ano e o planeta acreta gás. O valor do torque para cada raio foi obtido através de uma soma azimutal do torque de cada célula e normalizado em termos do valor máximo obtido ao longo do raio do disco.
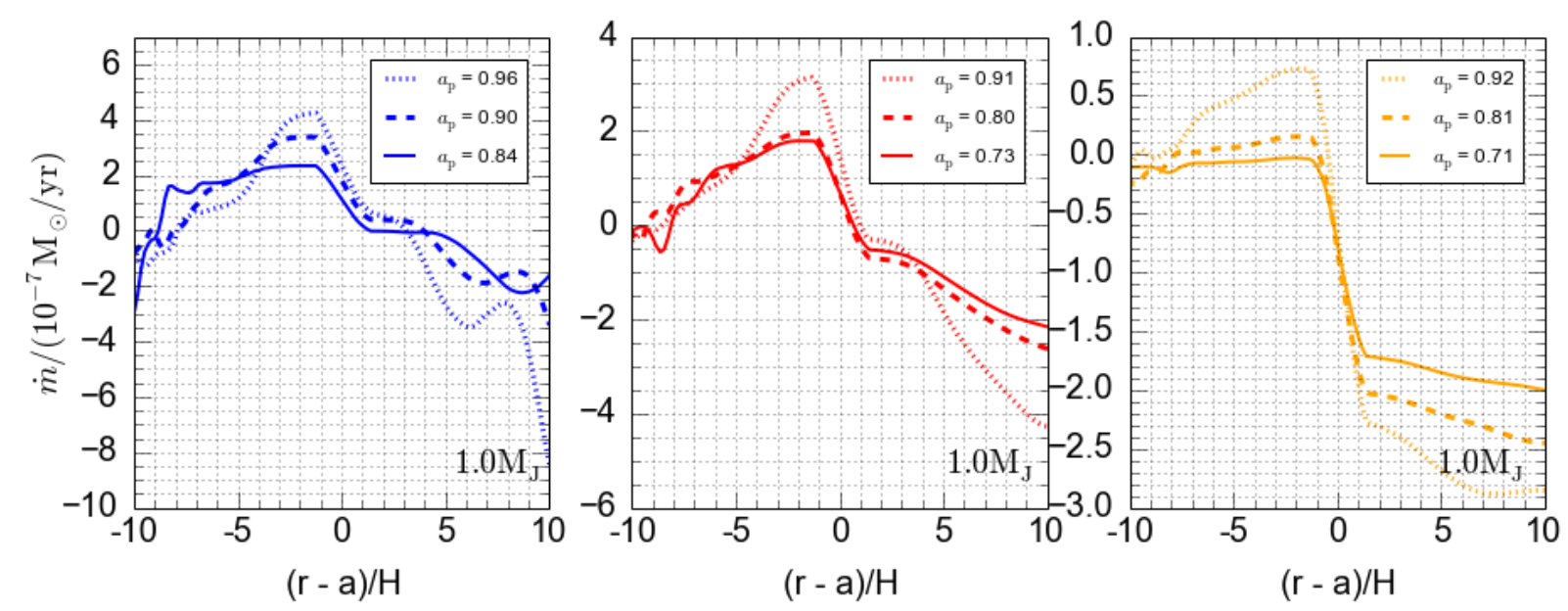

Figura 5.47: Evolução do perfil local do fluxo de gás em diferentes posições do planeta de massa $1.0 \mathrm{M}_{\mathrm{J}}$ para diferentes viscosidades. Da esquerda para a direita, temos $\alpha=0.001, \alpha=$ 0.003 e $\alpha=0.015$. A taxa de acreção do disco de gás é de $10^{-7} \mathrm{M}_{\odot} /$ ano e o planeta acreta gás.

na região de atenuação, além de um aumento significativo do torque nessa região. Além disso, percebe-se que, quanto menor a massa do disco, maior será o fator de desnível no fluxo de massa e, consequentemente, teremos um torque positivo relativamente maior e mais próximo da região atenuada. Isso fará com que a migração planetária, nesses casos, 
seja cada vez mais lenta.

Note (ver Fig. 5.47), para os casos de baixa e média viscosidade, que há fluxo de massa positivo no lado interno do gap, e, um fluxo negativo no lado externo. Note também que, para o caso de alta viscosidade, o fluxo que, começa positivo no lado esquerdo do gap, tende a ficar completamente negativo. Isso explica porque o gap planetário, no regime de alta viscosidade, sofre um decréscimo de massa no lado esquerdo em relação aos outros casos, já que a condição da borda interna do disco só permite a saída da massa de gás, isso impede a concentração de massa no disco interno.

As Figuras 5.48 e 5.49 a seguir mostram a variação do semieixo maior dos planetas para uma taxa de acreção do disco, respectivamente, de $10^{-8} \mathrm{M}_{\odot} /$ ano e $10^{-9} \mathrm{M}_{\odot} /$ ano.
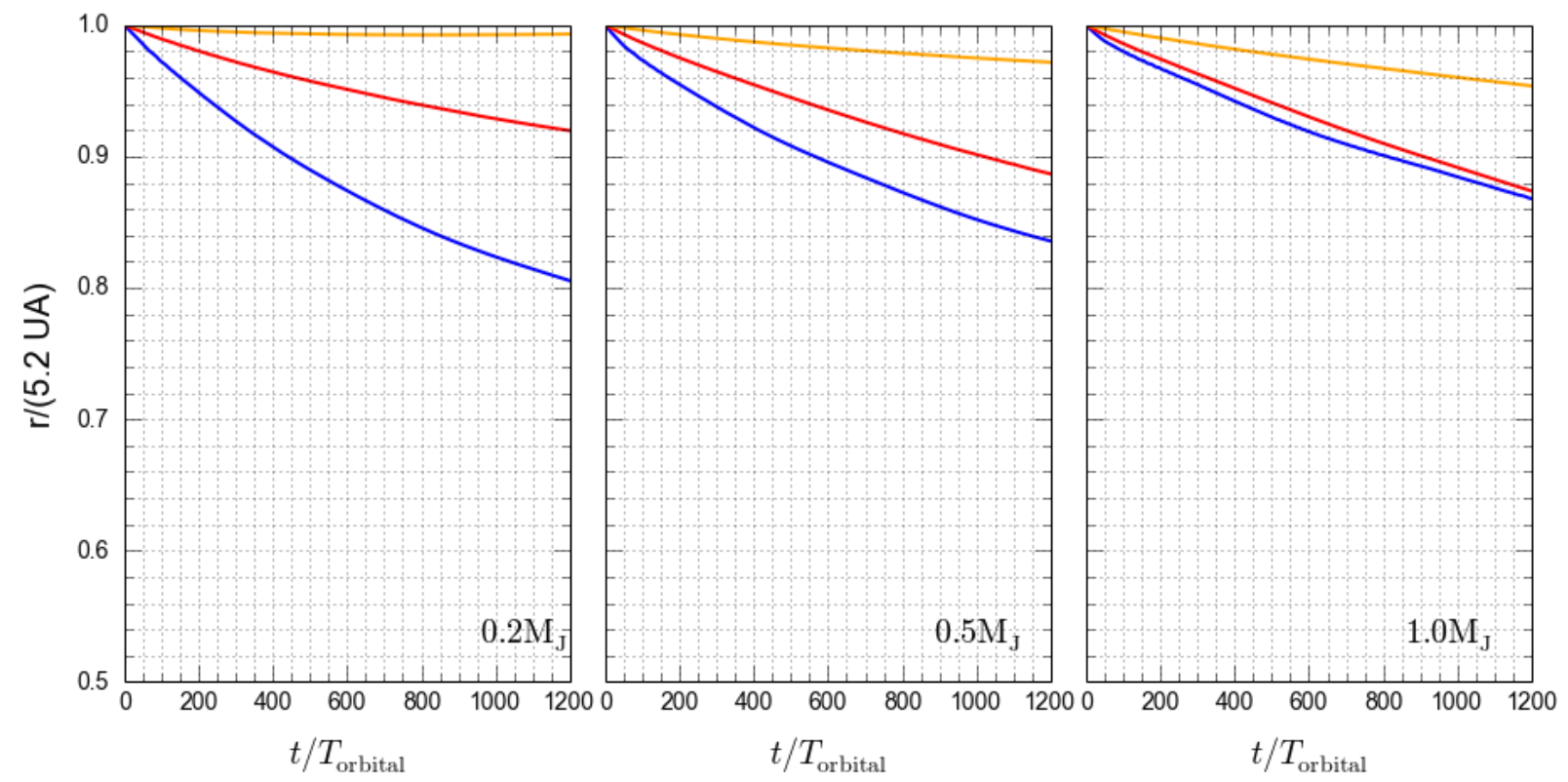

Figura 5.48: Gráfico da evolução do semieixo maior dos planetas em função do tempo para várias massas planetárias (da esquerda para a direita, $0.2 \mathrm{M}_{\mathrm{J}}, 0.5 \mathrm{M}_{\mathrm{J}}$ e $1.0 \mathrm{M}_{\mathrm{J}}$ ) e para diferentes valores de viscosidade (azul: $\alpha=0.001$, vermelho: $\alpha=0.003$ e amarelo: $\alpha=0.010$ ). Os gráficos correspondem ao modelo com acreção de gás e a um disco de gás cuja taxa de acreção é de $10^{-8} \mathrm{M}_{\odot} /$ ano.

Comparando a escala do eixo y das Figuras 5.39, 5.48 e 5.49, notamos que, assim como no caso sem acreção de gás, quanto menor a taxa de acreção do disco, menor é a variação do semieixo maior do planeta. Isso se deve ao fato de, no disco menos massivo, obtermos um torque menor por causa da menor quantidade de massa de gás disponível.

A comparação da Figura 5.20 com a 5.48 revela que, de forma geral, a taxa de migração média foi menor no caso com acreção de gás do que no caso sem acreção de gás. Essa 

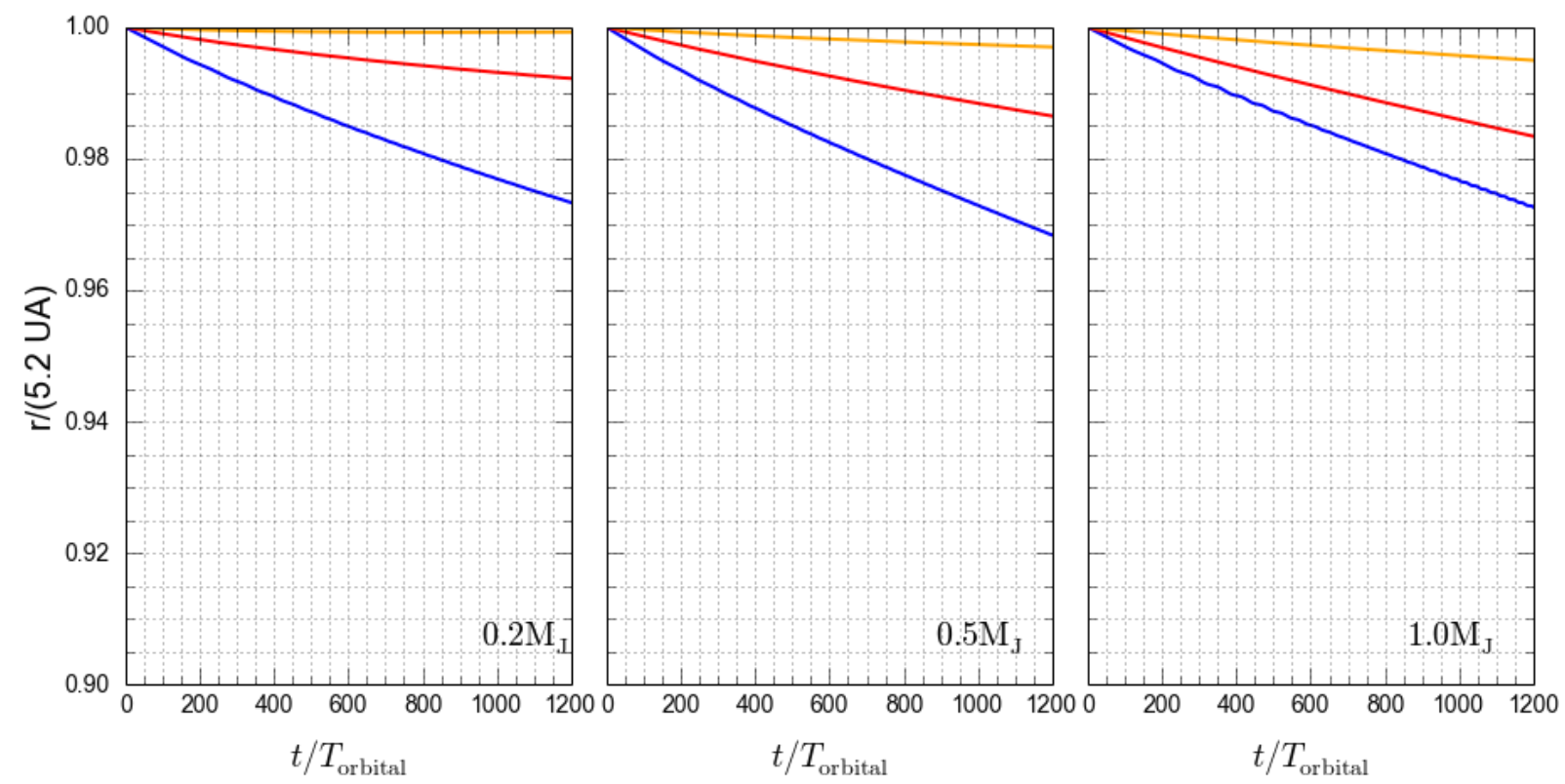

Figura 5.49: Gráfico da evolução do semieixo maior dos planetas em função do tempo para várias massas planetárias (da esquerda para a direita, $0.2 \mathrm{M}_{\mathrm{J}}, 0.5 \mathrm{M}_{\mathrm{J}}$ e $1.0 \mathrm{M}_{\mathrm{J}}$ ) e para diferentes valores de viscosidade (azul: $\alpha=0.001$, vermelho: $\alpha=0.003$ e amarelo: $\alpha=0.010$ ). Os gráficos correspondem ao modelo com acreção de gás e a um disco de gás cuja taxa de acreção é de $10^{-9} \mathrm{M}_{\odot} /$ ano.

diferença se torna menos significativa com o aumento da massa planetária e com o aumento da taxa de acreção (Figs 5.21 e 5.49). Isso está relacionado com o menor valor do torque que ocorre em razão da menor massa do disco de gás e também com a diminuição da densidade do gás próximo da região planetária devida à acreção de gás. De fato, quanto menor a massa de gás, menor serão os efeitos gerados pelo torque, assim, planetas grandes em discos de baixa massa terão, obviamente, um efeito menor no seu processo migratório devido à acreção de gás.

Analisando o gap, em todos os regimes, para as próximas duas taxas de acreção do disco de gás, notamos uma relação similar ao já explicitado para a taxa de acreção do disco $10^{-7}$ $\mathrm{M}_{\odot} /$ ano. Isto é, o gap planetário é mantido dinamicamente em todos os casos e há uma mudança na massa do disco interno, que é mais significativa no caso de alta viscosidade. Observe, por exemplo, as Figuras 5.50 e 5.51, que mostram o gap normalizado para o caso do planeta de massa $1 \mathrm{M}_{\mathrm{J}}$, respectivamente, para o disco com taxa de acreção $10^{-8}$ $\mathrm{M}_{\odot} /$ ano e $10^{-9} \mathrm{M}_{\odot} /$ ano. Além disso, comparando os casos com e sem acreção de gás, notamos novamente um achatamento mais pronunciando do gap para o caso com acreção de gás, independente da taxa de acreção do disco de gás. 

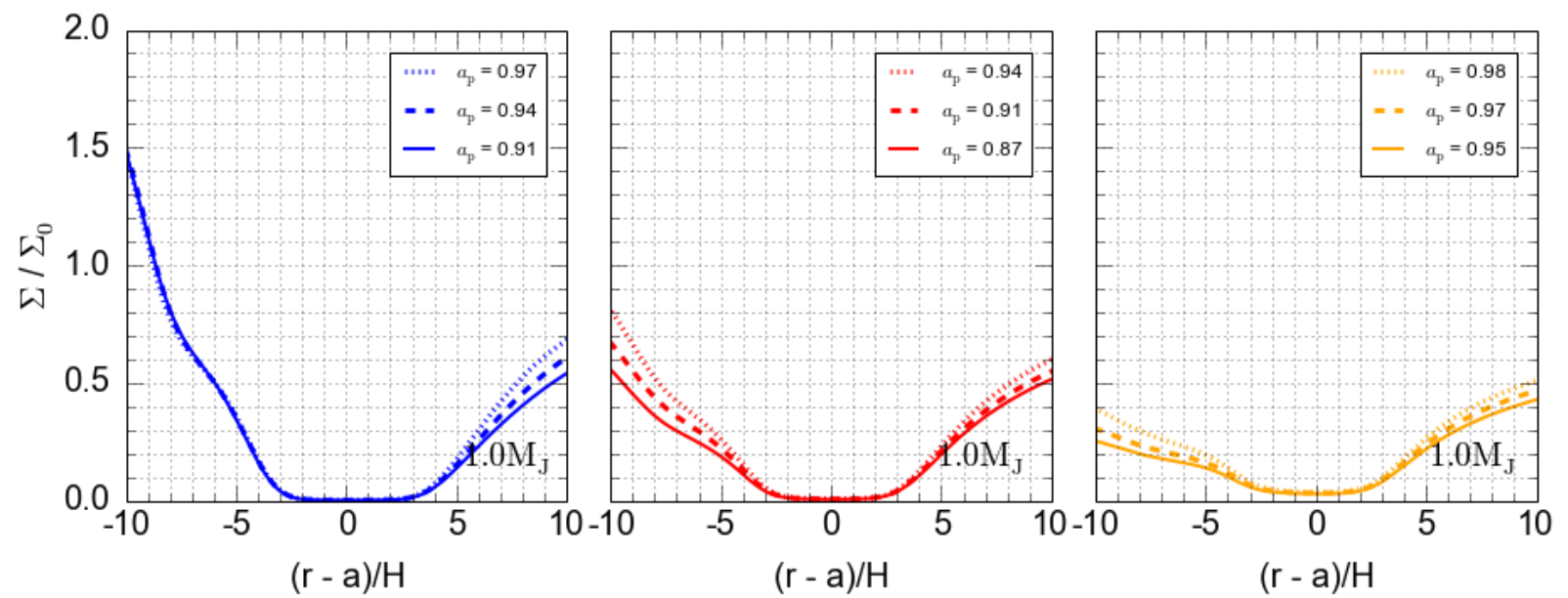

Figura 5.50: Evolução do perfil local da média azimutal da densidade superficial do gás em diferentes posições do planeta de massa $1.0 \mathrm{M}_{\mathrm{J}}$ para diferentes viscosidades. Da esquerda para a direita, temos $\alpha=0.001, \alpha=0.003$ e $\alpha=0.015$. A taxa de acreção do disco de gás é de $10^{-8} \mathrm{M}_{\odot} /$ ano e o planeta acreta gás.
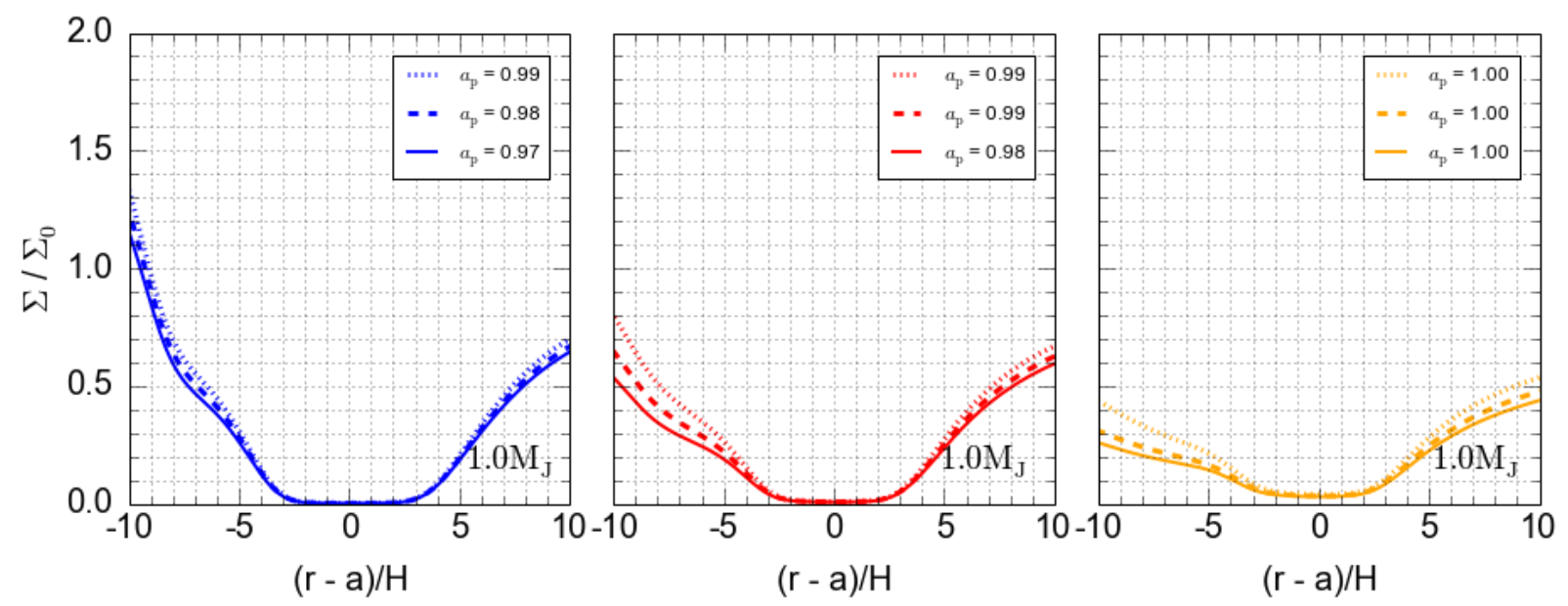

Figura 5.51: Evolução do perfil local da média azimutal da densidade superficial do gás em diferentes posições do planeta de massa $1.0 \mathrm{M}_{\mathrm{J}}$ para diferentes viscosidades. Da esquerda para a direita, temos $\alpha=0.001, \alpha=0.003$ e $\alpha=0.015$. A taxa de acreção do disco de gás é de $10^{-9} \mathrm{M}_{\odot} /$ ano e o planeta acreta gás.

As Figuras 5.52 e 5.53 mostram o torque em regiões próximas do planeta para o caso do planeta de massa $1 \mathrm{M}_{\mathrm{J}}$, respectivamente, para o disco com taxa de acreção $10^{-8} \mathrm{M}_{\odot} /$ ano e $10^{-9} \mathrm{M}_{\odot}$ /ano. No caso do torque planetário, comparando as Figuras $5.46,5.52$ e 5.53 para diferentes taxas de acreção, foi possível observar, em todos os regimes de viscosidade, a mesma característica já enunciada para o caso do disco de acreção de $10^{-7} \mathrm{M}_{\odot} /$ ano. Isto é, observamos um aumento na proporção do torque positivo do disco interno que se 
aproxima da zona de atenuação com o aumento da viscosidade.
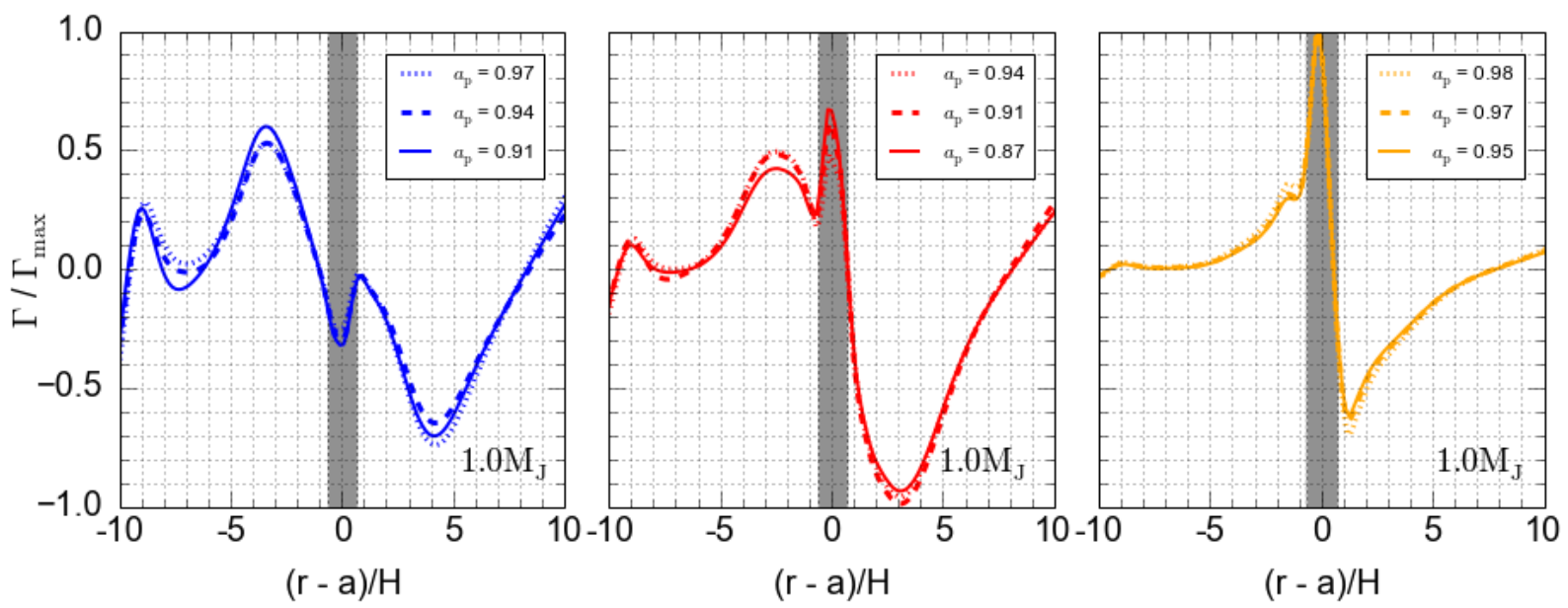

Figura 5.52: Evolução do perfil local do torque em diferentes posições do planeta de massa $1.0 \mathrm{M}_{\mathrm{J}}$ para diferentes viscosidades. Da esquerda para a direita, temos $\alpha=0.001, \alpha=0.003$ e $\alpha=0.015$. A região cinza indica a região na qual o torque sofre uma atenuação, isto é, a região dentro de $0.8 \mathrm{R}_{\mathrm{H}}$. A taxa de acreção do disco de gás é de $10^{-8} \mathrm{M}_{\odot} /$ ano e o planeta acreta gás. O valor do torque para cada raio foi obtido através de uma soma azimutal do torque de cada célula e normalizado em termos do valor máximo obtido ao longo do raio do disco.
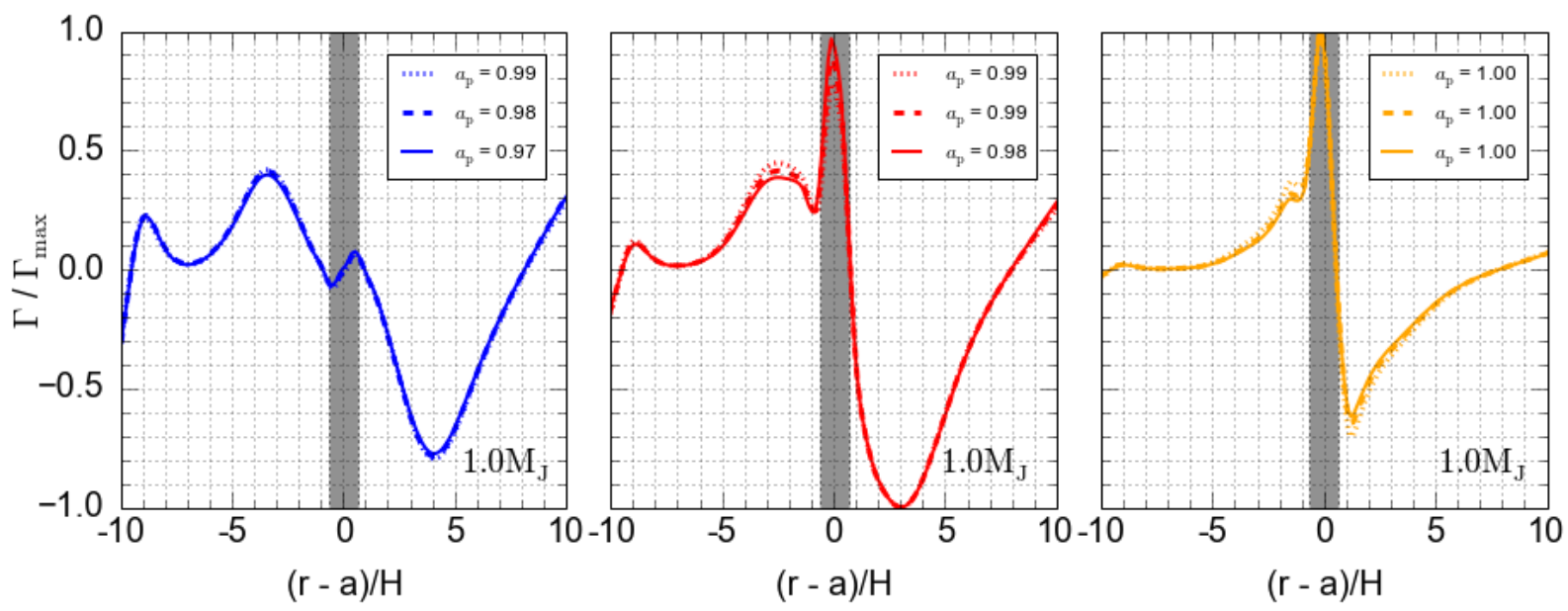

Figura 5.53: Evolução do perfil local do torque em diferentes posições do planeta de massa $1.0 \mathrm{M}_{\mathrm{J}}$ para diferentes viscosidades. Da esquerda para a direita, temos $\alpha=0.001, \alpha=0.003$ e $\alpha=0.015$. A região cinza indica a região na qual o torque sofre uma atenuação, isto é, a região dentro de $0.8 \mathrm{R}_{\mathrm{H}}$. A taxa de acreção do disco de gás é de $10^{-9} \mathrm{M}_{\odot} /$ ano e o planeta acreta gás. O valor do torque para cada raio foi obtido através de uma soma azimutal do torque de cada célula e normalizado em termos do valor máximo obtido ao longo do raio do disco.

No caso do fluxo de gás, observamos que o desnível do fluxo de gás aumentou com a 
diminuição da massa do disco (ou diminuição da taxa de acreção do disco) e com o aumento da viscosidade. As Figuras 5.54 e 5.55 mostram o gráfico do fluxo de gás em uma região próxima do planeta de massa $1 \mathrm{M}_{\mathrm{J}}$, respectivamente, para o disco com taxa de acreção $10^{-8}$ $\mathrm{M}_{\odot} /$ ano e $10^{-9} \mathrm{M}_{\odot} /$ ano.
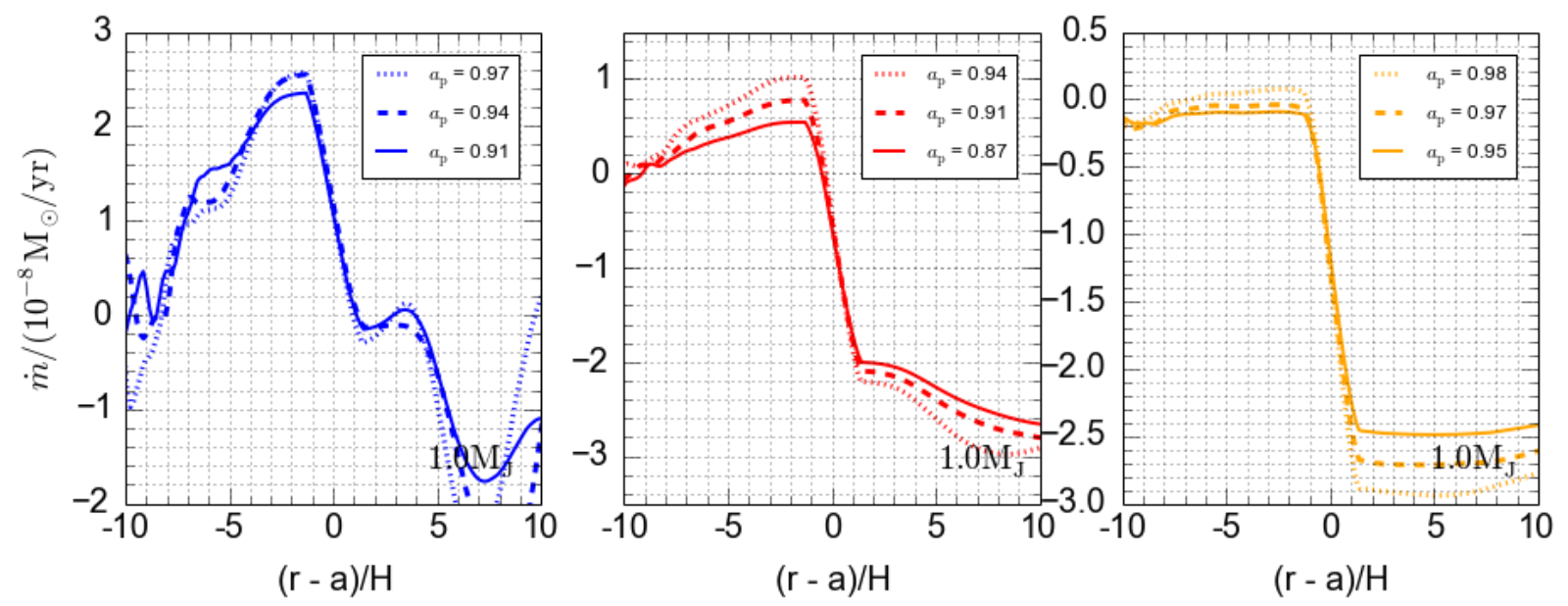

Figura 5.54: Evolução do perfil local do fluxo de gás em diferentes posições do planeta de massa $1.0 \mathrm{M}_{\mathrm{J}}$ para diferentes viscosidades. Da esquerda para a direita, temos $\alpha=0.001, \alpha=$ 0.003 e $\alpha=0.015$. A taxa de acreção do disco de gás é de $10^{-8} \mathrm{M}_{\odot} /$ ano e o planeta acreta gás.
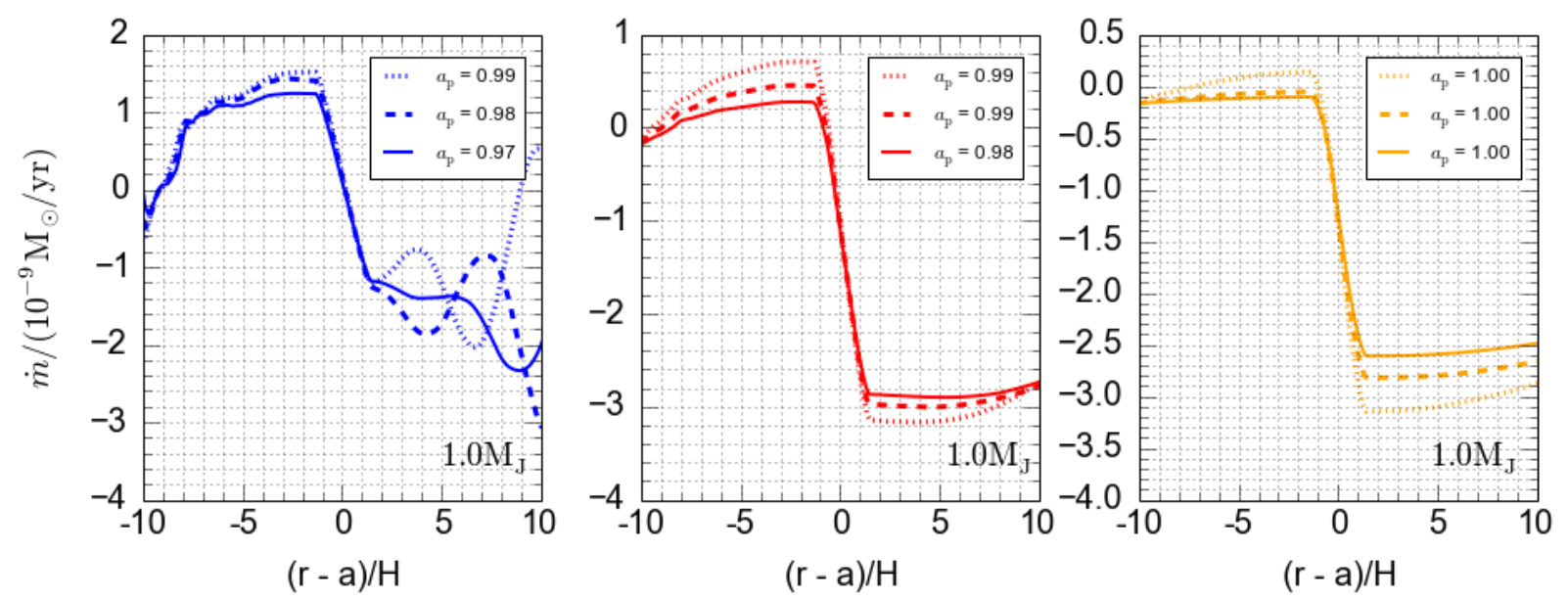

Figura 5.55: Evolução do perfil local do fluxo de gás em diferentes posições do planeta de massa $1.0 \mathrm{M}_{\mathrm{J}}$ para diferentes viscosidades. Da esquerda para a direita, temos $\alpha=0.001, \alpha=$ 0.003 e $\alpha=0.015$. A taxa de acreção do disco de gás é de $10^{-9} \mathrm{M}_{\odot} /$ ano e o planeta acreta gás.

De forma geral, podemos afirmar que o modelo de acreção de gás influencia de forma a diminuir a taxa de migração média do planeta. Esse efeito é mais significativo quanto 
maior a viscosidadẹ menor a massa do disco de gás (ou taxa de acreção do disco) e menor a massa planetária. De fato, em disco menos viscosos a massa de gás tende a ocupar a região do gap de forma muito rápida, não permitindo que a acreção de gás seja rápida o suficiente para limpar a região, assim, obtemos um efeito maior da acreção de gás em disco mais viscosos, onde a região do gap permanece com baixos valores de densidade superficial do gás. Além disso, quanto maior a massa planetária, maior é a barreira gravitacional imposta pelo planeta que impede o fluxo de massa para dentro do gap, assim, teremos menos massa de gás dentro do gap para planetas de massas maiores e, portanto, o efeito da acreção de gás será menos significativo já que a mudança na densidade superficial de gás na região do gap devido a acreção será menor. Obviamente, isso também vale para a massa global do disco, disco mais massivos sofrem uma mudança mais acentuada na densidade superficial do gás dentro da região do gap devido à acreção de gás pelo planeta.

Vale ressaltar, que em discos de baixa massa, observamos que o desnível do fluxo de gás aumenta de forma significativa e um modelo melhor para a acreção de gás necessita ser implementado.

\subsection{Formação de um planeta de $1 \mathrm{M}_{\mathrm{J}}$}

Nesta seção, nós iremos analisar a formação de um planeta da massa de Júpiter, seguindo o mesmo procedimento realizado na seção 4.6, com a mesma distribuição de sólidos e as mesmas condições para o disco de gás. No entanto, devido ao alto custo computacional, usaremos um planeta de massa inicial $0.1 \mathrm{M}_{\otimes}$, fixo em 6 ua, que acretará sólidos até atingir a massa crítica (ver eq. 5.27), a partir do qual se inicia a acreção de gás com o novo modelo descrito na seção 5.4 .

A simulação é interrompida quando o planeta atinge $1 \mathrm{M}_{\mathrm{J}}$ ou o tempo da simulação alcança $1.3 \times 10^{6}$ anos, estimado como o tempo de vida restante do disco, considerando que já iniciamos com um planeta de massa $0.1 \mathrm{M}_{\otimes}$. Neste trabalho, não vamos incorporar uma função para fotoevaporação do disco de gás, que poderia mudar a quantidade de gás disponível ao longo do tempo. A construção de uma função para simular esse efeito será realizada em trabalhos futuros. Outra característica importante que vai ser incorporada

\footnotetext{
${ }^{1}$ Vale ressaltar que estamos considerando a faixa de 0.001 até 0.01 para o parâmetro de ShakuraSunyaev.
} 
na próxima seção é o raio de captura. De fato, a presença de um envelope planetário de gás acelera a acreção de planetesimais, fazendo com que a taxa de acreção de sólidos aumente, principalmente, para planetesimais pequenos. Assim, nessa seção estamos mais preocupados com a transição entre o modelo de acreção de sólidos e de acreção de gás e, em analisar as mudanças que ocorrem nos parâmetros de formação planetária durante essa transição.

A Figura 5.56 a seguir é análoga à Figura 4.15 para a formação de um planeta terrestre. No entanto, vamos permitir que o planeta cresça até $1 \mathrm{M}_{\mathrm{J}}$ e consideramos a acreção de gás. Da mesma forma que fizemos na seção 4.6 usaremos dois modelos para a evolução das excentricidades e inclinações quadráticas médias dos planetesimais: a situação fora do equilíbrio (linha tracejada e pontilhada do gráfico) e a situação em equilíbrio (linha cheia do gráfico). Para a situação fora do equilíbrio usamos duas condições iniciais para a excentricidade e inclinação quadráticas médias dos planetesimais: a linha tracejada descreve a situação na qual as excentricidades e inclinações quadráticas médias iniciais dos planetesimais são dadas pela equação 4.153. Já a linha pontilhada descreve a situação no qual as excentricidades e inclinações quadráticas médias iniciais dos planetesimais são dadas pelas equações 4.139 e 4.140. Fisicamente, a segunda condição inicial descreve um disco quente, no qual as excentricidades e inclinações já foram excitadas pelo embrião. Usaremos os termos excentricidade e inclinação para designar, respectivamente, a média azimutal das excentricidades quadráticas médias e a média azimutal das inclinações quadráticas médias na zona de alimentação. A linha de gelo será mantida em 3.0 ua (arquivo setup.par). Maiores detalhes sobre o modelo de acreção de sólidos podem ser vistos nas seções 4.5 e as condições iniciais são as mesmas das já descritas na seção 4.6 .

Note que o crescimento do planeta (ver Fig. 5.56 - superior esquerda), para planetesimais de tamanhos $r_{\mathrm{m}}=10 \mathrm{~km}$ e $100 \mathrm{~km}$, foi muito mais lento. A massa final atingida, após $1.3 \times 10^{6}$ anos, foi de $0.3 \mathrm{M}_{\otimes}$ para planetesimais de raio $r_{\mathrm{m}}=100 \mathrm{~km}$, e de $1 \mathrm{M}_{\otimes}$ para planetesimais de raio $r_{\mathrm{m}}=10 \mathrm{~km}$. Isto é, para esses tamanhos de planetesimais e, considerando o tempo de vida restante do disco, não seria possível obter a formação de um planeta da ordem da massa de Júpiter fixo nessa posição. Isso ocorre principalmente devido ao modelo de acreção de sólidos demorar a atingir o regime de runaway para esses tamanhos de planetesimais. Assim, conforme constatamos na seção 4.6, a acreção de sólidos depende fortemente do tamanho dos planetesimais e possui um impacto importante na massa final 

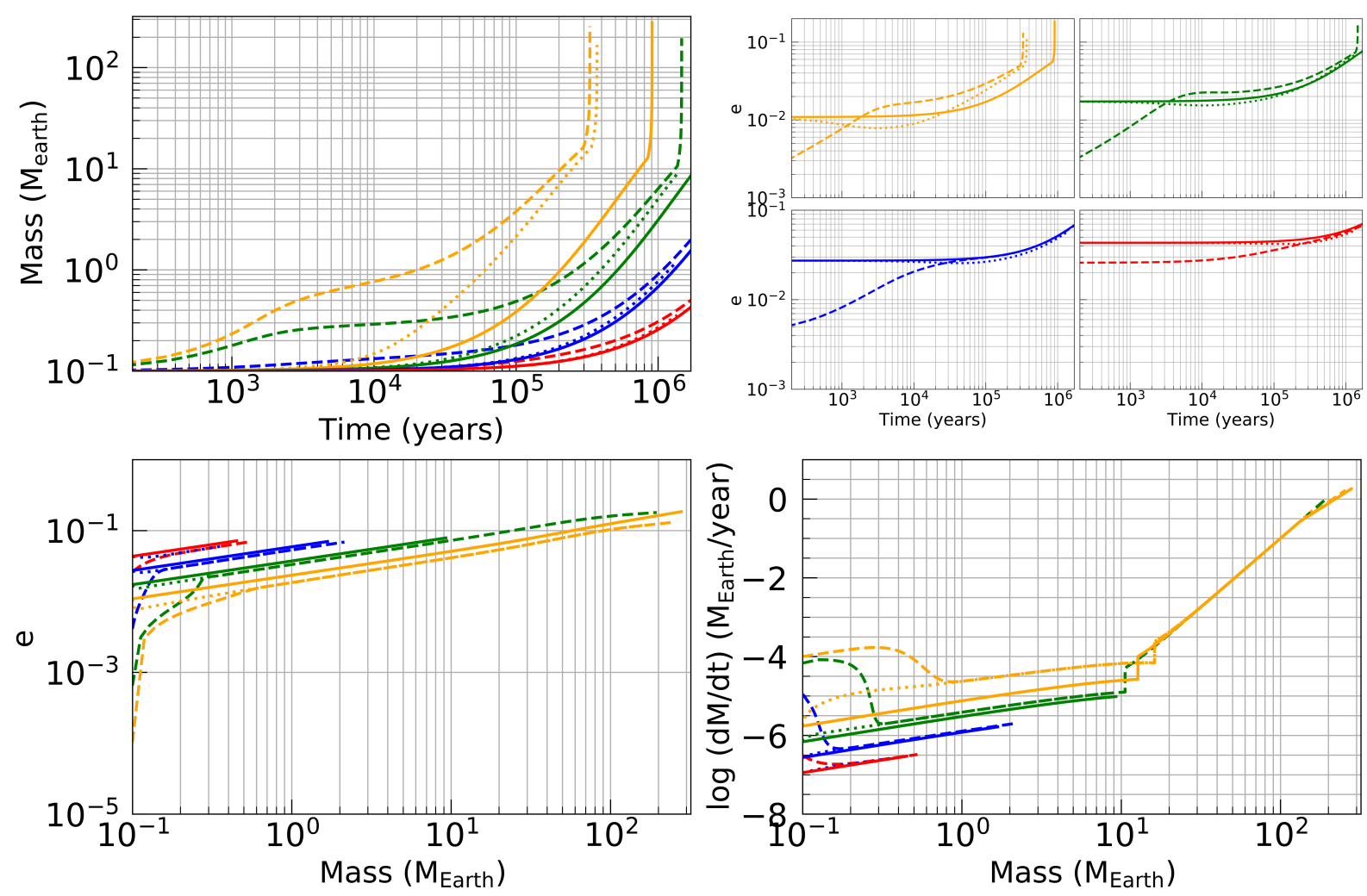

Figura 5.56: Gráfico da massa do planeta em função do tempo (figura superior esquerda), da excentricidade em função do tempo (figura superior direita), da excentricidade em função da massa (figura inferior esquerda) e da taxa de acreção de gás em função da massa (figura inferior direita). Cada cor representa um tamanho para os planetesimais (vermelho - $100 \mathrm{~km}$; azul - $10 \mathrm{~km}$; verde - $1 \mathrm{~km}$ e laranja - $0.1 \mathrm{~km}$ ). As linhas tracejadas e pontilhadas representam a situação fora do equilíbrio para duas condições iniciais diferentes (pontilhada - eq. 4.139 e eq. 4.140 tracejada - eq. 4.153. As linhas cheias representam a situação de equilíbrio 4.139 e 4.141). A simulação é interrompida quando o planeta atinge $1 \mathrm{M}_{\mathrm{J}}$ ou o tempo da simulação alcança $1.3 \times 10^{6}$ anos, estimado como o tempo de vida do disco.

do planeta. De fato, para planetesimais pequenos, $r_{\mathrm{m}}=0.1 \mathrm{~km}$ e $1 \mathrm{~km}$, a situação foi bem diferente, já que a massa crítica para o núcleo foi atingida num tempo hábil. Uma vez atingida esse massa, a rápida acreção de gás possibilitou a formação de um planeta gigante da ordem da massa de Júpiter. Logo, podemos concluir que o arrasto do gás, para planetesimais pequenos, é uma característica importante para facilitar o crescimento de um núcleo sólido até sua massa crítica, e que, a partir desse ponto, a acreção de gás é rápida o suficiente para formação de planetas gigantes.

Portanto, a dificuldade do núcleo sólido em atingir a massa crítica é um fator primordial para a formação de planetas gigantes, pois, atingida essa massa a acreção de gás é rápida o suficiente para formação de um planeta gigante. De fato, a mudança na taxa de aumento 
da massa é bastante brusca após a entrada no regime de acreção de gás (ver Fig. 5.56 - inferior direita). Vale ressaltar que a massa crítica depende da opacidade e da taxa de acreção de sólidos (ver eq. 5.27). Assim, a mudança desses fatores em razão de outros mecanismos não explorados aqui, como contaminação do envelope planetário ou aumento da acreção devido ao arrasto do planetesimal com o envelope de gás, poderia alterar a massa necessária para iniciar a captura de gás.

Os gráficos para evolução da excentricidade em função do tempo (ver Fig. 5.56 superior direita) e para evolução da excentridadade em função da massa (ver Fig. 5.56 inferior esquerda) mostraram um comportamento que estão de acordo com os resultados obtidos por Fortier et al. (2013), mesmo se tratando de modelos diferentes para a acreção de gás e com condições iniciais diferentes, observamos o mesmo comportamento assintótico para evolução da excentricidade dos planetesimais ao longo do tempo quando a massa do planeta cresce muito rápido (ver Fig. 5.56- superior direita) e também o comportamento linear da excentricidade em função da massa (ver Fig. 5.56 - inferior esquerda). Vale ressaltar algumas diferenças e similaridades. A primeira delas é que em nosso modelo há uma transição mais brusca entre o modelo de acreção de sólidos e o modelo de acreção de gás, que depende do fato do núcleo atingir a massa crítica. O modelo de Fortier et al.(2013) possui uma transição mais suave, pois resolve as equações físicas do envelope planetário que seguem a evolução contínua do crescimento do núcleo. No entanto, notamos que essa simplificação não interfere significativamente no resultado final da massa planetária, já que a transição para o regime de runaway na acreção de gás é muito rápida. Esse fato também foi analisado em Ronco et al. (2017) que utiliza uma transição para acreção de gás similar ao que usamos em neste trabalho. Além disso, Fortier et al. (2013) utiliza um disco adiabático e um cálculo para o raio de captura de planetesimais que varia de acordo com a massa do envelope. O cálculo do raio de captura será realizado na próxima seção e a formação de um planeta em um disco adiabático será analisado em trabalhos futuros. Entretanto, mesmo utilizando um modelo simplificado para a transição entre o modelo de acreção de sólidos e gás, o comportamento do nosso modelo está de acordo com os resultados obtidos na literatura.

Outra característica interessante é que a formação do gap planetário não foi um fator limitante para acreção de gás, pois uma grande massa de gás é transferida do disco externo para o disco interno, e, parte dessa massa, é acretada pelo planeta. 
Assim como foi constatado para a formação de uma massa da Terra, a diferença entre o método de equilíbrio e o fora do equilíbrio foi maior para planetesimais pequenos do que para planetesimais grandes. De fato, para planetesimais pequenos, o método fora do equilíbrio possibilitou a formação de $1 \mathrm{M}_{\mathrm{J}}$ de forma mais rápida do que o cenário em equilíbrio. Para os outros tamanhos de planetesimais, essa diferença não foi significativa. Portanto, a situação de equilíbrio é uma aproximação adequada somente para planetesimais de tamanhos maiores.

Os resultados mostrados na Figura 5.56 mostram que a distribuição dos tamanhos dos planetesimais no disco de gás exerce forte influência na massa final do planeta, a ponto de determinar se o planeta será capaz de se tornar um planeta gigante ou não.

\subsection{Formação planetária com migração}

Nesta seção, iremos completar nossa análise incluindo a migração dos protoplanetas. Vale ressaltar que acrescentamos no modelo o raio de captura para acreção de sólidos, que possui influência significativa na taxa de acreção. De fato, o raio de captura leva em consideração o envelope planetário que age de forma a reduzir a velocidade dos planetesimais e, consequentemente, aumenta o raio de ação no qual os planetesimais podem ser acretados. Nesta tese, seguiremos o modelo de Ormel e Kobayashi (2012) no qual se utiliza um envelope radiativo de baixa opacidade e aproximações para a estrutura do envelope planetário. Assim, o raio de captura, $R_{\text {cap }}$, é dado por:

$$
R_{\text {cap }} \approx R_{\mathrm{B}}\left\{\begin{array}{l}
{\left[1+\frac{2 W_{\mathrm{neb}}\left(\sigma_{a}-1\right)+\log \sigma_{a}}{\gamma}\right]^{-1}, \quad\left(1 \leqslant \sigma_{a} \leqslant \sigma_{1}\right),} \\
{\left[\frac{1}{x_{1}}+\frac{4\left(W_{\mathrm{neb}}\right)^{1 / 3}}{\gamma}\left(\sigma_{a}^{1 / 3}-\sigma_{1}^{1 / 3}\right)\right]^{-1}, \quad\left(\sigma_{a}>\sigma_{1}\right),}
\end{array}\right.
$$

onde $R_{\mathrm{B}}=G M_{\mathrm{p}} / \gamma c_{\mathrm{s}}^{2}(\operatorname{com} \gamma=1.4)$ é o raio de Bondi do planeta e $\sigma_{a}=\rho_{a} / \rho_{\text {gas }}$ é a razão da densidade requerida para captura da partícula e a densidade volumétrica do gás. De acordo com Ormel e Kobayashi (2012), podemos escrever:

$$
\sigma_{a}=\frac{\left(6+e^{2}\right) r_{\mathrm{p}} \rho_{\mathrm{m}}}{9 R_{\mathrm{H}}}
$$

onde usamos e como a média azimutal das excentricidades quadráticas médias dos planetesimais na zona de alimentação, $r_{\mathrm{p}}$ o raio do planetesimal, $\rho_{\mathrm{m}}$ a densidade volumétrica do 
planetesimal e $R_{\mathrm{H}}$ o raio de Hill do planeta.

A grandeza $\sigma_{1}=1 /\left(5 W_{\text {neb }}\right)$ é uma grandeza adimensional que define uma transição entre regimes de pressão para o gás (ver Ormel e Kobayashi (2012)) e $x_{1}=R_{1} / R_{\mathrm{B}}=$ $1+2 W_{\text {neb }}\left(\sigma_{1}-1\right)+\log \sigma_{1}$ é um parâmetro de normalização do raio do envelope. O parâmetro que define a estrutura da atmosfera do envelope é $W_{\text {neb }}$, definido por:

$$
W_{\text {neb }}=\frac{3 \kappa_{\mathrm{B}} L_{c}}{64 \pi \sigma_{\mathrm{sb}}} \frac{P_{\text {gas }}}{G M_{\text {core }} T_{\text {gas }}^{4}},
$$

onde $\kappa_{\mathrm{B}}$ é a opacidade do envelope, $\sigma_{\mathrm{sb}}$ a constante de Stefan-Boltzman, $P_{\text {gas }}$ a pressão do gás, $T_{\text {gas }}$ a temperatura do gás, $M_{\text {core }}$ a massa do núcleo e $L_{c}$ a luminosidade devido a acreção de planetesimais, dada por:

$$
L_{c}=\left(\frac{G M_{\text {core }}}{R_{\text {core }}}\right) \dot{M}_{\text {core }}
$$

onde $\dot{M}_{\text {core }}$ é a taxa de acreção de sólidos.

A Figura 5.57 a seguir mostra a evolução da massa em função do tempo (figura de cima) e a evolução do semieixo maior em função do tempo (figura de baixo). Da mesma forma que na seção 5.7 a massa inicial do protoplaneta será de $0.1 \mathrm{M}_{\otimes}$ e sua posição inicial é 6 ua. No entanto, o protoplaneta será permitido migrar num disco de gás com planetesimais pequenos cujo raio é $r_{\mathrm{p}}=0.1 \mathrm{~km}$. Essa condição é justificada pelos modelos de formação de planetesimais que indicam a maior presença no disco protoplanetário de planetesimais pequenos (Simon et al., 2016). A evolução dos planetesimais seguem as mesmas considerações da seção 5.7 uma situação fora do equilíbrio para duas condições iniciais diferentes e uma situação em equilíbrio. Para evitar os efeitos de borda do disco e os efeitos de maré com a estrela hospedeira, o planeta só poderá migrar até 0.2 ua ou até atingir a massa de $5 \mathrm{M}_{\mathrm{J}}$. Atingida essa massa, os planetas já estarão no regime de migração de tipo II e não mudam significativamente seu semieixo maior com o tempo.

Observardo a figura vemos claramente que a situação é diferente do cenário sem migração. Em todos os casos, os planetas migraram e sua posição final é diferente da posição inicial. Considerando a situação em equilíbrio (linha cheia), obtemos, para planetesimais com $r_{\mathrm{m}}=0.1 \mathrm{~km}$, um planeta de massa $5 \mathrm{M}_{\mathrm{J}}$ em 0.73 ua, num tempo de $6.95 \times 10^{4}$ anos. Já para a situação fora do equilíbrio e um disco quente (linha tracejada), o planeta alcançou uma massa de $5 \mathrm{M}_{\mathrm{J}}$ em 1.1 ua, num tempo de $1.2 \times 10^{4}$ anos. Na segunda condição inicial 

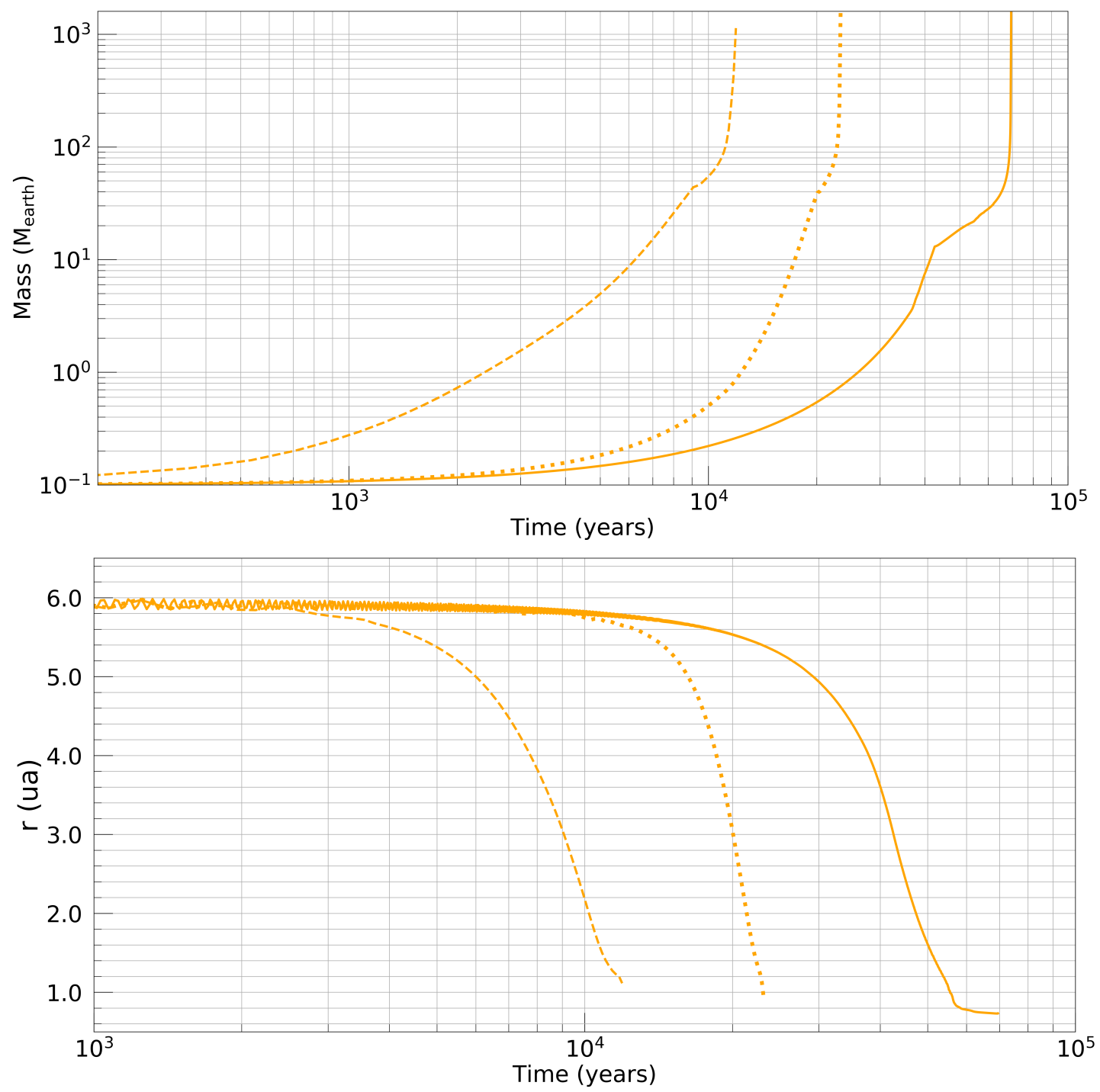

Figura 5.57: Gráfico da massa do planeta em função do tempo (figura de cima) e da posição do planeta em função do tempo (figura de baixo) para formação planetária com migração. Os planetesimais possuem um raio fixo de $0.1 \mathrm{~km}$. As linhas tracejadas e pontilhadas representam a situação fora do equilíbrio para duas condições iniciais diferentes para as excentricidades quadráticas médias dos planetesimais (pontilhada - eq. 4.139 e eq. 4.140 tracejada - eq. 4.153. As linhas cheias representam a situação de equilíbrio $4.139 \mathrm{e} 4.141$.

para a situação fora do equilíbrio, disco frio (linha pontilhada), a massa de $5 \mathrm{M}_{\mathrm{J}}$ foi obtida em 0.9 ua, num tempo próximo de $2.3 \times 10^{4}$ anos. Portanto, em todos os casos foi possível a formação de planetas gigantes em regiões muito próximas da estrela, sem que o planete caisse no envelope estelar.

A Figura 5.58 a seguir mostra a massa em função do semieixo maior para todos os casos descritos anteriormente. Observamos que, em todos os casos, as curvas obtidas são muito similares em termos de comportamento. Diferentemente do resultado obtido por Fortier 
et al. (2013), não obtivemos uma migração reversa e o planeta seguiu em direção à estrela em todas as situações. É importante destacar que estamos utilizando um disco isotérmico. Para um disco adiabático, a migração de tipo I poderia alcançar um regime saturado no qual a contribuição do torque de corrotação seria alterado e, consequentemente, a taxa de migração (Dittkrist et al., 2014).

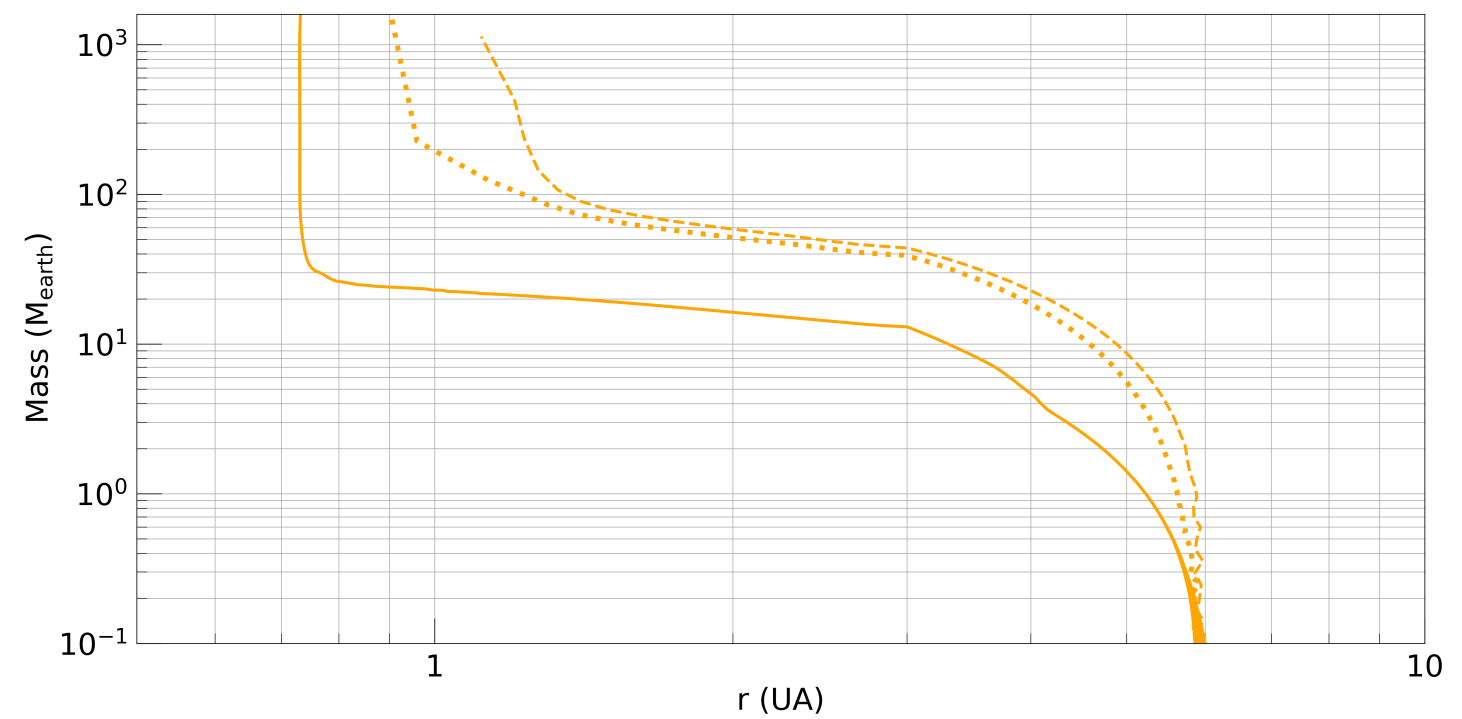

Figura 5.58: Gráfico da massa do planeta em função da posição do planeta para formação planetária com migração. Os planetesimais possuem um raio fixo de $0.1 \mathrm{~km}$. As linhas tracejadas e pontilhadas representam a situação fora do equilíbrio para duas condições iniciais diferentes (pontilhada - eq. 4.139 e eq. 4.140 tracejada - eq. 4.153). As linhas cheias representam a situação de equilíbrio 4.139 e 4.141 .

É interessante observar que quando o planeta atravessa a linha de gelo em 3 ua, ocorre uma queda substancial do seu crescimento. Isso ocorre devido o fator de condensação que diminui a quantidade de material disponível para a acreção de sólidos. Entretanto, o núcleo sólido, próximo do seu valor crítico, continua a crescer e migrar até dar início à acreção de gás. Após o início da acreção de gás, a entrada no regime de runaway para a acreção ocorre rapidamente e o planeta adquiri massa de forma exponencial e entra na migração de tipo II. Podemos observar que no modelo em equilíbrio (linha cheia) a massa crítica para o núcleo sólido foi próxima de $20 \mathrm{M}_{\otimes}$, enquanto no modelo fora do equilíbrio obtemos uma massa crítica em torno de $40 \mathrm{M}_{\otimes}$ nos dois casos analisados (linha tracejada e pontilhada). Esses valores estão de acordo com os valores obtidos na literatura entre 10 e $50 \mathrm{M}_{\otimes}$ (Ikoma et al., 2000). No entanto, seria interessante analisar a influência de um modelo para a opacidade do envelope que poderia alterar significativamente o valor crítico 
obtido e o início da captura do gás. Esses efeitos podem ser explorados em trabalhos futuros.

Podemos analisar a relação entre o crescimento do planeta e sua migração de forma mais apurada pela análise da Figura 5.59, que compara o tempo de escala de crescimento do planeta $\left(\tau_{\text {growth }}=M / \dot{M}_{\text {core }}\right)$ com o tempo de escala de migração $\left(\tau_{\text {mig }}=a / \dot{a}\right)$ para a situação fora do equilíbrio (linha tracejada da Figura 5.57).

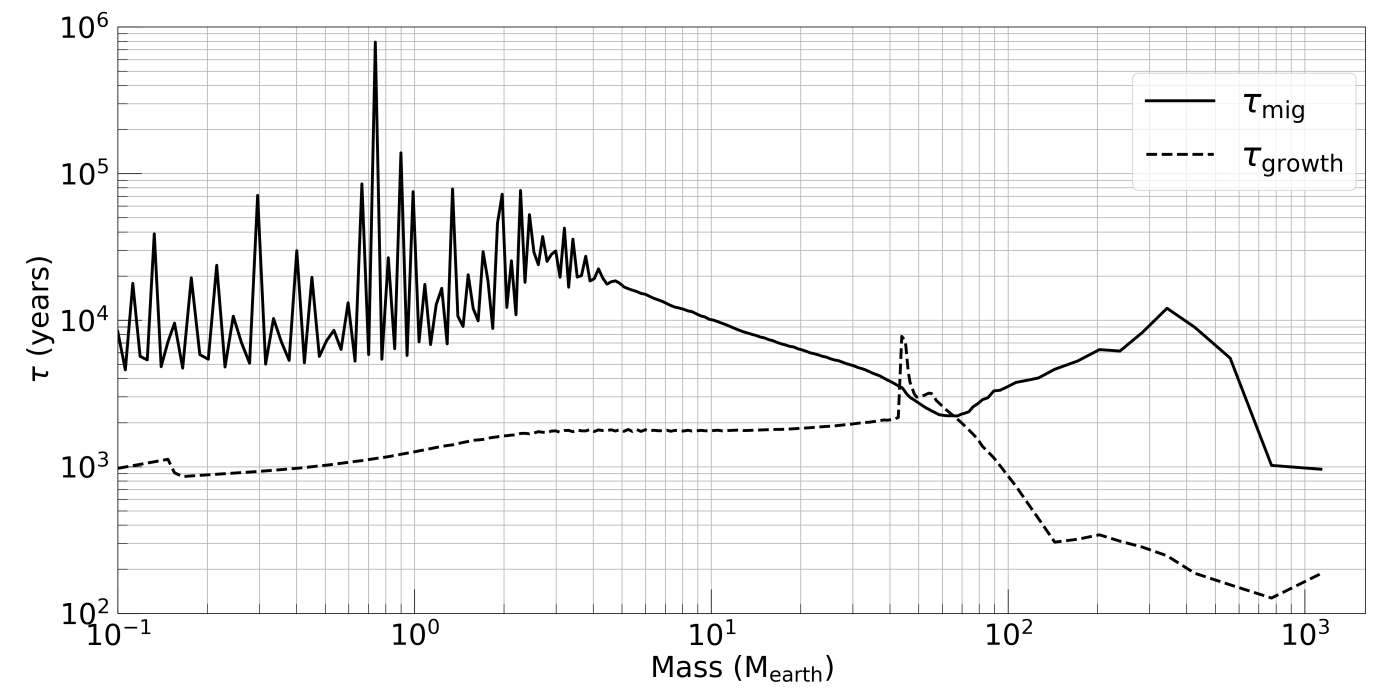

Figura 5.59: Gráfico do tempo de escala de crescimento do planeta $\left(\tau_{\text {growth }}=M / \dot{M}_{\text {core }}\right.$, linha pontilhada) em função do tempo de escala de migração $\left(\tau_{\text {mig }}=a / \dot{a}\right.$, linha cheia $)$ para a situação fora do equilíbrio (linha tracejada da Figura 5.57).

Analisando a figura podemos observar que a escala de tempo da migração é maior que a escala de tempo do crescimento até que o planeta alcance uma massa próxima de $30 \mathrm{M}_{\otimes}$ a partir do qual as duas escalas começam a se tornar muito próximas. Isso se deve ao fato da taxa de migração depender da massa do planeta e devido o planeta atravessar a linha de gelo, a partir do qual diminui sua a taxa de crescimento. No entanto, quando o núcleo do planeta alcança sua massa crítica e inicia a acreção de gás a escala de crescimento se torna menor que a escala de migração. Isto é, o planeta ganha massa rapidamente e entra na migração de tipo II. Essa característica também foi observada nos outros casos analisados.

Outra característica importante a destacar é que o tamanho dos planetesimais é um fator considerável na evolução do semieixo e da massa do planeta. Isto porque o tamanho dos planetesimais possui um forte impacto na taxa de acreção de sólidos e, portanto, na relação entre os tempos de escala de formação e migração planetária que estão fortemente acoplados. Isto mostra que a distribuição de sólidos do disco é um fator importante para 
análise da formação dos diversos tipos de sistemas planetários. Nesta tese, usamos sempre a mesma distribuição.

A situação pode ser resumida da seguinte forma: quando o crescimento do planeta é dominado pela acreção de sólidos no regime oligárquico, o crescimento do planeta é proporcional a $M^{1 / 3}$ (ver seção 2.2.2). No entanto, para planetas que alcançam uma massa suficiente para acretar gás, o crescimento do planeta é muito mais rápido. Mas a migração de tipo I possui uma dependência com $M^{-1}$, enquanto a migração de tipo II é quase independente da massa planetária. Consequentemente, se o planeta migra devido a uma migração de tipo I, e seu crescimento é dominado pelo regime oligárquico, é muito provável que caia na estrela. Assim, somente se o planeta conseguir se tornar suficientemente massivo para acretar gás e adentrar na migração de tipo II, que será possível obter planetas massivos em regiões próximas da estrela. É importante destacar que a presença da linha de gelo é importante, pois, devido ao fator de condensação, ocorre a diminuição da quantidade de material disponível para a acreção de sólidos. Assim, para que o planeta não caia no envelope estelar, a massa do núcleo deve estar próximo da sua massa crítica quando atravessar a linha de gelo. Desse modo, o núcleo terá tempo hábil para alcançar sua massa crítica e iniciar a acreção de gás permitindo um crescimento rápido da massa e a entrada na migração tipo II.

\subsection{Conclusão}

Neste capítulo, inicialmente estudamos o tempo necessário para o disco de gás padrão (ver seção 3.10 alcançar uma situação próxima do equilíbrio, quando um planeta de $1 \mathrm{M}_{\mathrm{J}}$ está imerso. Isto é, o cenário teórico esperado é de uma taxa de acreção constante ao longo do raio do disco. No entanto, isso não ocorre porque a taxa de acreção local é muito sensível a qualquer tipo de perturbação. Assim, pequenas variações na pressão permitem uma grande variação na velocidade radial em comparação com seu valor de equilíbrio. Por meio da Figura 5.1, obtemos um tempo aproximado de 5000 órbitas. Após esse tempo, não ocorrem muitas mudanças no perfil do fluxo radial e o gap já se encontra completamente formado (ver Fig. 5.2). Mais detalhes podem ser encontrados na seção 5.1.

Em seguida, na seção 5.2 , analisamos o formato do gap obtido com a massa planetária $\left(M_{\mathrm{p}}=0.2 \mathrm{M}_{\mathrm{J}}, 0.5 \mathrm{M}_{\mathrm{J}}\right.$ ou $\left.1.0 \mathrm{M}_{\mathrm{J}}\right)$, com a viscosidade do disco $(\alpha=0.001,0.003$ ou 0.01$) \mathrm{e}$ 
com a taxa de acreção do disco $\left(\dot{M}=10^{-7}, 10^{-8}\right.$ ou $10^{-9} \mathrm{M}_{\odot} /$ ano $)$. Como esperado, os gaps são mais profundos quanto maior a massa planetária e menor a viscosidade. Assim, planetas maiores numa região de menor viscosidade produzem um gap mais profundo e planetas menores numa região de maior viscosidade produzem um gap menos profundo.

Após o disco alcançar o equilíbrio, o planeta pôde migrar (ver seção 5.3). As Figuras 5.7. 5.20 e 5.21 mostram a evolução do semieixo maior do planeta em função do tempo para diferentes taxas de acreção, respectivamente, $10^{-7}, 10^{-8}$ e $10^{-9} \mathrm{M}_{\odot} /$ ano.

Realizamos uma análise individual analisando o formato do gap, a proporção do torque ao longo do disco e o fluxo de massa através do gap para cada simulação. A análise do fluxo através do gap permitiu analisar se a velocidade de migração do planeta era menor, ou maior, que a velocidade viscosa do gás. A comparação entre as figuras nos permitiu concluir que, quanto menor a massa do disco e maior a viscosidade, mais próxima a migração do planeta será do cenário de migração de tipo II teórico, no qual o planeta se move próximo da taxa de acreção do disco. Notamos também que isso está relacionado à presença de massa nas regiões próximas do planeta, que são maiores quanto maior a massa do disco de gás.

Em seguida, na seção 5.4, descrevemos o novo modelo para acreção de gás. Esse modelo foi construído com base no trabalho de Kley (1999). No entanto, algumas características foram adaptadas. A primeira delas foi usar o raio de Bondi conjuntamente com o raio de Hill para definir a região de acreção a partir da qual a massa é retirada do disco. Também modelamos um efeito para compensar a altura do disco já que a simulação utilizada é 2D. Ajustamos também a escala de tempo da acreção, utilizando o tempo orbital do gás em torno do planeta para determinar a taxa com que o gás é acretado. Por fim, utilizando a escala de tempo de Kelvin-Helmholtz pudemos incorporar a acreção de gás para planetas de menor massa. Essas adaptações foram realizadas seguindo o trabalho de Russell (2011).

Com o modelo de acreção de gás contruído, refizemos as simulações anteriores, na quais não havia acreção de gás e comparamos os resultados. Inicialmente, analisamos o perfil do gap após 5000 órbitas, tempo necessário ao equilíbrio. A acreção de gás é ligada 300 órbitas antes para que o disco possa se estabilizar devido à presença do novo cenário. Da mesma forma que na versão sem acreção de gás, os gaps são mais profundos quanto maior a massa planetária e menor a viscosidade (ver Fig. 5.39). Entretanto, para o caso com acreção de gás, não encontramos a região de sobredensidade na posição do planeta. Isso 
ocorre em razão da acreção de gás que não permitiu essa concentração de gás ao redor do planeta, tratado como um ponto massivo na malha hidrodinâmica. Assim como no modelo sem acreção de gás, não foram encontradas diferenças no formato do gap para as diferentes taxas de acreção.

Observamos também uma diferença significativa na profundidade dos gaps entre os modelos com e sem acreção, principalmente, para os planetas de menor massa. De fato, a acreção do gás possibilita que o gap formado no mesmo período de tempo seja, obviamente, maior. Para os planetas de menor massa, o aumento do gap é maior porque há mais massa dentro do gap para ser acretada que no caso dos planetas maiores, já que estes esvaziaram a região devido ao efeito gravitacional.

Em seguida, colocamos o planeta migrando com o processo de acreção de gás acionado. Analisando os vários casos, constatamos que o modelo de acreção de gás influencia de forma a diminuir a taxa de migração média do planeta. Esse efeito será tão mais significativo quanto maior a massa do disco. Em discos de baixa massa, observamos que o desnível do fluxo aumenta de forma significativa e um modelo melhor necessita ser implementado. Também podemos notar que o efeito da acreção será mais significativo quanto maior a viscosidade do disco. De fato, em um disco pouco viscoso, a massa tende a se acumular mais rapidamente nas regiões em torno do planeta, e a acreção pode não dar conta de limpar a região, de forma a mudar significativamente o torque diferencial. Massas planetárias menores sofrem mais significativamente com o processo de acreção de gás, isso porque, quanto menor a massa do planeta, menor o efeito gravitacional que impede a massa de entrar no gap, portanto, o processo de acreção tende a limpar a região próxima do planeta favorecendo o aparecimento do gap planetário. Por fim, notamos também um aumento do torque positivo próximo da região atenuada, que aumenta com a diminuição da massa do disco e com a viscosidade, o que faz com que o planeta de alta massa consiga diminuir ainda mais seu processo migratório.

Na seção 5.7, usando o novo modelo para a acreção de gás, analisamos a formação de um planeta da massa de Júpiter, seguindo o mesmo procedimento realizado na seção 4.6 . No entanto, devido ao alto custo computacional, optamos por um planeta de massa inicial $0.1 \mathrm{M}_{\otimes}$, fixo em 6 ua, que acreta sólidos até atingir a massa crítica (ver eq. 5.27), a partir do qual inicia a acreção de gás.

Assim como foi constatado para a formação de uma massa da Terra, a diferença entre 
o método de equilíbrio e o fora do equilíbrio foi maior para planetesimais pequenos, de raio $0.1 \mathrm{~km}$ a $1 \mathrm{~km}$, do que para planetesimais grandes, de raio $10 \mathrm{~km}$ e $100 \mathrm{~km}$. De fato, para planetesimais pequenos, o método fora do equilíbrio possibilitou a formação de $1 \mathrm{M}_{\mathrm{J}}$ de forma mais rápida do que o cenário em equilíbrio. Para os outros tamanhos de planetesimais, essa diferença não foi significativa. Portanto, a situação de equilíbrio é uma aproximação adequada para planetesimais de tamanhos maiores.

Outra característica interessante é que a formação do gap planetário não foi um fator limitante para acreção de gás. De fato, uma grande massa de gás é transferida do disco externo para o disco interno, e, parte dessa massa, é acretada pelo planeta.

Os resultados indicados na Figura 5.56 mostram que a distribuição dos tamanhos dos planetesimais no disco exerce forte influência na massa final do planeta, a ponto de determinar se o planeta será capaz de se tornar um planeta gigante ou não.

Por fim, permitimos que os planetas migrassem e acompanhamos a formação planetária ao longo do processo migratório (ver seção 5.8). Nossos resultados mostram que, quando o crescimento do protoplaneta é dominado pela acreção de sólidos no regime oligárquico, o tempo de escala de crescimento é menor que a escala de tempo da migração planetária. No entanto, a migração planetária de tipo I possui uma dependência com a massa planetária, assim, a medida que o planeta ganha massa as duas escalas tendem a se aproximar até que o planeta migra rapidamente numa escala mais rápida que a escala de crescimento. No entanto, para planetas que alcançam uma massa suficiente para acretar gás, o tempo de escala de crescimento se torna muito mais curto e o planeta entra na migração de tipo II, prevenindo a queda do planeta no envelope estelar. Consequentemente, se o planeta migra em decorrência de uma migração de tipo I, e seu crescimento é dominado pelo regime oligárquico, é muito provável que caia na estrela. Logo, somente se o planeta consegue se tornar suficientemente massivo para acretar gás e adentrar na migração de tipo II, será possível obter planetas massivos em regiões próximas da estrela. Assim, é importante que o planeta alcance uma massa próxima da massa crítica quando adentrar na linha de gelo, onde a disponibilidade de material é menor, para que tenha tempo hábil de superar sua massa crítica e iniciar a acreção de gás. É importante destacar que a presença da linha de gelo é importante, pois, devido ao fator de condensação, ocorre a diminuição da quantidade de material disponível para a acreção de sólidos. Assim, para que o planeta não caia no envelope estelar, a massa do núcleo deve estar próximo da sua massa crítica 
quando atravessar a linha de gelo. Desse modo, o núcleo terá tempo hábil para alcançar sua massa crítica e iniciar a acreção de gás permitindo um crescimento rápido da massa e a entrada na migração tipo II. 


\section{Capítulo 6}

\section{Conclusões}

O principal intuito desta tese foi construir um cenário para a formação planetária dentro do simulador hidrodinâmico FARGO3D e com isso, fazer uma análise mais robusta do processo de formação com migração planetária.

Esse objetivo foi alcançado de forma satisfatória. Iniciamos o estudo com a modelagem da acreção de sólidos e testamos nosso modelo reproduzindo os resultados obtidos por Fortier et al. (2013). Mesmo sem ter acesso a todos os valores locais do modelo de disco usado por Fortier et al. (2013), especialmente valores sobre a velocidade do som, a concordância entre os resultados foi excelente. Esse teste pode ser encontrado na seção 4.5.4, e a descrição do modelo de acreção de sólidos, na seção 4.5.

Em seguida, utilizando um modelo padrão para um disco isotérmico de gás, descrito na seção 3.10, nós implementamos a formação de um planeta terrestre de massa inicial $0.01 \mathrm{M}_{\otimes}$ fixo na posição 6 ua. Os resultados obtidos mostram uma forte dependência com o tamanho dos planetesimais, pois os planetas crescem mais rápido quando imersos em regiões de planetesimais menores. Isto se deve ao fato de o arrasto de gás diminuir mais rapidamente suas excentricidades e inclinações, possibilitando a entrada mais rápida num regime de alta acreção de sólidos. Planetesimais maiores sofrem um efeito menor do arrasto de gás, e permanecem com excentridades e inclinações maiores por mais tempo.

É importante destacar que o modelo para a formação planetária implementado nesta tese é bastante complexo, assim, algumas outras características ainda precisam ser revisadas e estudadas de forma mais apurada.

A primeira delas é a região de acreção dos planetesimais, isto é, a zona de alimentação. Aqui nós utilizamos uma zona de alimentação que depende do raio de Hill do planeta multiplicado por um fator constante definido pelo usuário $(b=10)$. No entanto, a zona 
de alimentação vai depender das excentricidades e inclinações dos planetesimais. Essa característica deverá ser revista em trabalhos futuros. Além disso, a densidade superficial média de sólidos, a excentricidade e a inclinação, usados para o cálculo da taxa de acreção, foram obtidas pela média azimutal das excentricidade e inclinações quadráticas médias, isto é, utilizando o anel de células que contém o planeta. Essa técnica foi empregada para evitar o uso de resoluções computacionais muito altas, usando, portanto, condições locais do planeta. No entanto, uma integração na zona de alimentação, num cenário 2D e 3D, seria mais condizente com o cenário físico esperado.

A segunda característica que deve ser ajustada no modelo em trabalhos futuros, é uma distribuição diferenciada de planetesimais. Isto é, aqui trabalhamos com planetesimais de tamanhos fixos. No entanto, uma distribuição diferencial de tamanhos seria importante para descrever com mais precisão um cenário físico mais confiável.

Esses dois processos já estão sendo trabalhados em conjunto com Guilera et al. (2010) na Universidad de La Plata. De fato, a visita técnica realizada com auxílio da FAPESP teve como intuito estudar uma forma de trabalhar essas questões dentro do código. Também estamos trabalhando num modelo para migração dos planetesimais.

Nesta tese, também incorporamos um modelo para a acreção de gás. Este modelo teve como base o modelo de Kley (1999). Entretanto, esse modelo trabalhava num regime de runaway e numa taxa de acreção definida de forma ad hoc. Assim, nós modificamos o código para incluir efeitos de altura do disco, uma taxa de acreção limitada fisicamente pela taxa de acreção de Bondi e o efeito do crescimento inicial do envelope utilizando a escala de tempo para acreção de gás de Kelvin-Helmhotz. Isso permitiu o estudo do crescimento de um planeta para uma faixa maior de massas iniciais. Mais detalhes sobre o modelo de acreção de gás podem ser vistos na seção 5.4 .

É interessante notar que o modelo completo para acreção de gás exigiria a resolução de diversas equações para descrição do envelope. Obviamente, esse cenário exigiria maior tempo computacional. Mas, a alternativa usada nesta tese, conforme vimos na seção 5.7 , se mostrou muito próxima dos modelos que utilizam métodos mais refinados.

Outro ponto que também deve ser explorado é a evolução da linha de gelo, uma vez que o fator de condensação de material se mostrou importante no processo de formação planetária quando permitimos a migração do planeta. Como vimos na seção 5.8, o crescimento planetário precisa ser rápido o suficientemente para fazer o planeta entrar na migração de 
tipo II. É importante destacar que a presença da linha de gelo é importante, pois, devido ao fator de condensação, ocorre a diminuição da quantidade de material disponível para a acreção de sólidos. Assim, para que o planeta não caia no envelope estelar, a massa do núcleo deve estar próximo da sua massa crítica quando atravessar a linha de gelo. Desse modo, o núcleo terá tempo hábil para alcançar sua massa crítica e iniciar a acreção de gás permitindo um crescimento rápido da massa e a entrada na migração tipo II.

Todavia, apesar dessas limitações, o modelo construído nesta tese é sólido o suficiente para ser usado para estudo de diversas outras características importantes da formação e migração planetária. Uma delas é usar as taxas de acreção planetária (de sólidos e gás) para aquecer a região local do planeta. Este aquecimento poderia reduzir a taxa de migração de tipo I, e até mesmo reverter essa migração, como indicam Benítez-Llambay et al. (2015). Além disso, o aquecimento local poderia ser usado para obter um feedback radiativo, que pode ser explorado para obter características observacionais como indicam Montesinos et al. (2015).

Ademais, o trabalho conjunto com a Universidad de La Plata possibilitará o estudo da evolução de sistemas planetários de uma forma física extremamente confiável. Inclusive, um sistema particularmente interessante, HD 200964, que apresenta dificuldades de estudo na sua formação, em razão de uma configuração ressonante (Tadeu dos Santos et al., 2015), poderá ser analisado com bastante acuidade dentro do modelo.

O uso do modelo em um cenário 3D também pode ser explorado. Para isso, estamos trabalhando numa malha computacional específica para redução do tempo de computação.

Outro ponto de destaque é a participação brasileira na missão do satélite PLATO (PLAnetary Transits and Oscillations of stars) em 2025. O objetivo dessa missão é encontrar um grande número de planetas extrasolares, com ênfase nas propriedades de planetas terrestres em zonas habitáveis ao redor de estrelas similares ao Sol. O satélite PLATO tem sido desenvolvido para investigar atividades sísmicas nas estrelas, permitindo uma excelente caracterização da estrela que hospeda o planeta, isso inclui sua idade. Isso permitirá uma análise mais consisa dos tempos de vida do disco e de evolução do sistema planetário. O modelo construído nessa tese poderá ser aperfeiçoado e explorado com base na leitura desses novos dados obtidos. 


\section{Referências Bibliográficas}

Adachi I., Hayashi C., Nakazawa K., The gas drag effect on the elliptical motion of a solid body in the primordial solar nebula., Progress of Theoretical Physics, 1976, vol. 56, p. 1756

Alibert Y., Carron F., Fortier A., Pfyffer S., Benz W., Mordasini C., Swoboda D., Theoretical models of planetary system formation: mass vs. semi-major axis, A\&A, 2013, vol. 558, p. A109

Alibert Y., Mordasini C., Benz W., Winisdoerffer C., Models of giant planet formation with migration and disc evolution, A\&A, 2005, vol. 434, p. 343

Andrews S. M., Williams J. P., Circumstellar Dust Disks in Taurus-Auriga: The Submillimeter Perspective, ApJ, 2005, vol. 631, p. 1134

Armitage P. J., Astrophysics of Planet Formation, 2010, 294

Artymowicz P., Disk-Satellite Interaction via Density Waves and the Eccentricity Evolution of Bodies Embedded in Disks, ApJ, 1993, vol. 419, p. 166

Bai X.-N., Stone J. M., Wind-driven Accretion in Protoplanetary Disks. I. Suppression of the Magnetorotational Instability and Launching of the Magnetocentrifugal Wind, ApJ, 2013, vol. 769 , p. 76

Balbus S. A., Hawley J. F., On the Nature of Angular Momentum Transport in Nonradiative Accretion Flows, ApJ, 2002, vol. 573, p. 749 
Baruteau C., Crida A., Paardekooper S.-J., Masset F., Guilet J., Bitsch B., Nelson R., Kley W., Papaloizou J., Planet-Disk Interactions and Early Evolution of Planetary Systems, Protostars and Planets VI, 2014, pp 667-689

Baruteau C., Papaloizou J. C. B., Disk-Planets Interactions and the Diversity of Period Ratios in Kepler's Multi-planetary Systems, ApJ, 2013, vol. 778, p. 7

Bell K. R., Cassen P. M., Klahr H. H., Henning T., The Structure and Appearance of Protostellar Accretion Disks: Limits on Disk Flaring, ApJ, 1997, vol. 486, p. 372

Benítez-Llambay P., Masset F., Beaugé C., The mass-period distribution of close-in exoplanets, A\&A, 2011, vol. 528, p. A2

Benítez-Llambay P., Masset F., Koenigsberger G., Szulágyi J., Planet heating prevents inward migration of planetary cores, Nature, 2015, vol. 520, p. 63

Benítez-Llambay P., Masset F. S., FARGO3D: A New GPU-oriented MHD Code, ApJS, 2016, vol. 223, p. 11

Benvenuto O. G., Brunini A., Methods for computing giant planet formation and evolution, MNRAS, 2005, vol. 356, p. 1383

Bitsch B., Kley W., Orbital evolution of eccentric planets in radiative discs, A\&A, 2010, vol. 523, p. A30

Blum J., Dust Evolution in Protoplanetary Discs and the Formation of Planetesimals. What Have We Learned from Laboratory Experiments?, Space Sci. Rev., 2018, vol. 214, p. 52

Bondi H., On spherically symmetrical accretion, MNRAS, 1952, vol. 112, p. 195

Boss A. P., Giant planet formation by gravitational instability., Science, 1997, vol. 276, p. 1836

Brauer F., Dullemond C. P., Henning T., Coagulation, fragmentation and radial motion of solid particles in protoplanetary disks, A\&A, 2008, vol. 480, p. 859

Brouwer D., Clemence G. M., Methods of celestial mechanics, 1961 
Bryden G., Lin D. N. C., The effects of gap formation and orbital migration on planetary systems.. In Bulletin of the American Astronomical Society , vol. 31 of BAAS, 1999, p. 1130

Cash J. R., Karp A. H., A variable order Runge-Kutta method for initial value problems with rapidly varying right-hand sides, ACM Transactions on Mathematical Software (TOMS), 1990, vol. 16, p. 201

Chambers J., A semi-analytic model for oligarchic growth, Icarus, 2006, vol. 180, p. 496

Colella P., Woodward P. R., The Piecewise Parabolic Method (PPM) for Gas-Dynamical Simulations, Journal of Computational Physics, 1984, vol. 54, p. 174

Crida A., Baruteau C., Kley W., Masset F., The dynamical role of the circumplanetary disc in planetary migration, A\&A, 2009, vol. 502, p. 679

Crida A., Morbidelli A., Masset F., On the width and shape of gaps in protoplanetary disks, Icarus, 2006, vol. 181, p. 587

Cuzzi J. N., Hogan R. C., Shariff K., Toward Planetesimals: Dense Chondrule Clumps in the Protoplanetary Nebula, ApJ, 2008, vol. 687, p. 1432

Dauphas N., Pourmand A., Very Rapid Accretion of Mars and Implications for its Magmatic Evolution. In Lunar and Planetary Science Conference, vol. 42 of Lunar and Planetary Inst. Technical Report, 2011, p. 1040

de Val-Borro M., Edgar R. G., Artymowicz P., A comparative study of disc-planet interaction, MNRAS, 2006, vol. 370, p. 529

DePaula L. A., Estudo da formação e migração de um núcleo sólido planetário, São Paulo: Universidade de São Paulo, 2014, Dissertação de Mestrado

Dittkrist K.-M., Mordasini C., Klahr H., Alibert Y., Henning T., Impacts of planet migration models on planetary populations. Effects of saturation, cooling and stellar irradiation, A\&A, 2014, vol. 567, p. A121

Drążkowska J., Alibert Y., Moore B., Close-in planetesimal formation by pile-up of drifting pebbles, A\&A, 2016, vol. 594, p. A105 
Dullemond C. P., Hollenbach D., Kamp I., D'Alessio P., Models of the Structure and Evolution of Protoplanetary Disks, Protostars and Planets V, 2007, pp 555-572

Duncan M. J., Levison H. F., Lee M. H., A Multiple Time Step Symplectic Algorithm for Integrating Close Encounters, AJ, 1998, vol. 116, p. 2067

Durisen R. H., Boss A. P., Mayer L., Nelson A. F., Quinn T., Rice W. K. M., Gravitational Instabilities in Gaseous Protoplanetary Disks and Implications for Giant Planet Formation, Protostars and Planets V, 2007, pp 607-622

Dürmann C., Kley W., Migration of massive planets in accreting disks, A\&A, 2015, vol. 574, p. A52

Dürmann C., Kley W., The accretion of migrating giant planets, A\&A, 2017, vol. 598, p. A 80

Edgar R., A review of Bondi-Hoyle-Lyttleton accretion, New A Rev., 2004, vol. 48, p. 843

Fortier A., Alibert Y., Carron F., Benz W., Dittkrist K.-M., Planet formation models: the interplay with the planetesimal disc, A\&A, 2013, vol. 549, p. A44

Fortuna A. O., Técnicas computacionais para dinâmica dos fluidos. 2 Edição. São Paulo: Editora da Universidade de São Paulo, 2012

Frank J., King A., Raine D. J., Accretion Power in Astrophysics: Third Edition, 2002, 398

Goldreich P., Tremaine S., Disk-satellite interactions, ApJ, 1980, vol. 241, p. 425

Goldreich P., Ward W. R., The Formation of Planetesimals, ApJ, 1973, vol. 183, p. 1051

Goodman A. A., Benson P. J., Fuller G. A., Myers P. C., Dense cores in dark clouds. VIII - Velocity gradients, ApJ, 1993, vol. 406, p. 528

Greenzweig Y., Lissauer J. J., Accretion rates of protoplanets, Icarus, 1990, vol. 87, p. 40

Greenzweig Y., Lissauer J. J., Accretion rates of protoplanets. II - Gaussian distributions of planetesimal velocities, Icarus, 1992, vol. 100, p. 440

Guilera O. M., Giant planet formation via pebble accretion, Boletin de la Asociacion Argentina de Astronomia La Plata Argentina, 2016, vol. 58, p. 316 
Guilera O. M., Brunini A., Benvenuto O. G., Consequences of the simultaneous formation of giant planets by the core accretion mechanism, A\&A, 2010, vol. 521, p. A50

Guilera O. M., Sándor Z., Giant planet formation at the pressure maxima of protoplanetary disks, A\&A, 2017, vol. 604, p. A10

Han E., Wang S. X., Wright J. T., Feng Y. K., Zhao M., Fakhouri O., Brown J. I., Hancock C., Exoplanet Orbit Database. II. Updates to Exoplanets.org, PASP, 2014, vol. 126, p. 827

Harlow F. H., Welch J. E., Numerical Calculation of Time-Dependent Viscous Incompressible Flow of Fluid with Free Surface, Physics of Fluids, 1965, vol. 8, p. 2182

Hartmann L., Calvet N., Gullbring E., D'Alessio P., Accretion and the Evolution of T Tauri Disks, ApJ, 1998, vol. 495, p. 385

Hayashi C., Structure of the Solar Nebula, Growth and Decay of Magnetic Fields and Effects of Magnetic and Turbulent Viscosities on the Nebula, Progress of Theoretical Physics Supplement, 1981, vol. 70, p. 35

Henon M., Petit J.-M., Series expansion for encounter-type solutions of Hill's problem, Celestial Mechanics, 1986, vol. 38, p. 67

Hill G. W., Mr. Hill's paper on the motion of the Moon's perigee, MNRAS, 1878, vol. 38, p. 192

Hubickyj O., Bodenheimer P., Lissauer J. J., Accretion of the gaseous envelope of Jupiter around a 510 Earth-mass core, Icarus, 2005, vol. 179, p. 415

Ida S., Lin D. N. C., Toward a Deterministic Model of Planetary Formation. I. A Desert in the Mass and Semimajor Axis Distributions of Extrasolar Planets, ApJ, 2004a, vol. 604, p. 388

Ida S., Lin D. N. C., Toward a Deterministic Model of Planetary Formation. II. The Formation and Retention of Gas Giant Planets around Stars with a Range of Metallicities, ApJ, 2004b, vol. 616, p. 567

Ida S., Lin D. N. C., Toward a Deterministic Model of Planetary Formation. IV. Effects of Type I Migration, ApJ, 2008, vol. 673, p. 487 
Ida S., Makino J., N-body simulation of gravitational interaction between planetesimals and a protoplanet. I - Velocity distribution of planetesimals, Icarus, 1992, vol. 96, p. 107

Ida S., Nakazawa K., Collisional probability of planetesimals revolving in the solar gravitational field. III, A\&A, 1989a, vol. 224, p. 303

Ida S., Nakazawa K., Collisional probability of planetesimals revolving in the solar gravitational field. III, A\&A, 1989b, vol. 224, p. 303

Ikoma M., Nakazawa K., Emori H., Formation of Giant Planets: Dependences on Core Accretion Rate and Grain Opacity, ApJ, 2000, vol. 537, p. 1013

Inaba S., Tanaka H., Nakazawa K., Wetherill G. W., Kokubo E., High-Accuracy Statistical Simulation of Planetary Accretion: II. Comparison with N-Body Simulation, Icarus, 2001, vol. 149 , p. 235

Johansen A., Klahr H., Henning T., Gravoturbulent Formation of Planetesimals, ApJ, 2006, vol. 636, p. 1121

Johansen A., Lambrechts M., Forming Planets via Pebble Accretion, Annual Review of Earth and Planetary Sciences, 2017, vol. 45, p. 359

Kippenhahn R., Weigert A., Stellar Structure and Evolution, 1990, 192

Kley W., Mass flow and accretion through gaps in accretion discs, MNRAS, 1999, vol. 303, p. 696

Kley W., Bitsch B., Klahr H., Planet migration in three-dimensional radiative discs, A\&A, 2009, vol. 506, p. 971

Kley W., Lee M. H., Murray N., Peale S. J., Modeling the resonant planetary system GJ 876, A\&A, 2005, vol. 437, p. 727

Kley W., Nelson R. P., Planet-Disk Interaction and Orbital Evolution, ARA\&A, 2012, vol. 50 , p. 211

Kokubo E., Ida S., Oligarchic Growth of Protoplanets, Icarus, 1998, vol. 131, p. 171

Korycansky D. G., Pollack J. B., Numerical calculations of the linear response of a gaseous disk to a protoplanet, Icarus, 1993, vol. 102, p. 150 
Lambrechts M., Johansen A., Forming the cores of giant planets from the radial pebble flux in protoplanetary discs, A\&A, 2014, vol. 572, p. A107

Lambrechts M., Lega E., Reduced gas accretion on super-Earths and ice giants, A\&A, 2017, vol. 606, p. A146

Landau L. D., Lifshitz E. M., Fluid mechanics, 1959

Laughlin G., Chambers J. E., Short-Term Dynamical Interactions among Extrasolar Planets, ApJ, 2001, vol. 551, p. L109

Lega E., Lambrechts M., Low-mass gas envelopes around accreting cores embedded in radiative 3D discs. In AAS/Division for Planetary Sciences Meeting Abstracts \#48, vol. 48 of AAS/Division for Planetary Sciences Meeting Abstracts, 2016, p. 105.06

Lesur G., Kunz M. W., Fromang S., Thanatology in protoplanetary discs. The combined influence of Ohmic, Hall, and ambipolar diffusion on dead zones, A\&A, 2014, vol. 566, p. A56

Levison H. F., Thommes E., Duncan M. J., Modeling the Formation of Giant Planet Cores. I. Evaluating Key Processes, AJ, 2010, vol. 139, p. 1297

Li M., Xiao L., Lifetimes and Accretion Rates of Protoplanetary Disks, ApJ, 2016, vol. 820, p. 36

Lissauer J. J., Planet formation, ARA\&A, 1993, vol. 31, p. 129

Lynden-Bell D., Pringle J. E., The evolution of viscous discs and the origin of the nebular variables., MNRAS, 1974, vol. 168, p. 603

Lyra W., Turner N. J., McNally C. P., Rossby wave instability does not require sharp resistivity gradients, A\&A, 2015, vol. 574, p. A10

Masset F., FARGO: A fast eulerian transport algorithm for differentially rotating disks, A\&AS, 2000, vol. 141, p. 165

Masset F., Snellgrove M., Reversing type II migration: resonance trapping of a lighter giant protoplanet, MNRAS, 2001, vol. 320, p. L55 
Matsuo T., Shibai H., Ootsubo T., Tamura M., Planetary Formation Scenarios Revisited: Core-Accretion versus Disk Instability, ApJ, 2007, vol. 662, p. 1282

Meyer-Vernet N., Sicardy B., On the physics of resonant disk-satellite interaction, Icarus, 1987, vol. 69 , p. 157

Mignone A., Zanni C., Tzeferacos P., van Straalen B., Colella P., Bodo G., The PLUTO Code for Adaptive Mesh Computations in Astrophysical Fluid Dynamics, ApJS, 2012, vol. 198 , p. 7

Miguel Y., Guilera O. M., Brunini A., The diversity of planetary system architectures: contrasting theory with observations, MNRAS, 2011, vol. 417, p. 314

Min M., Dullemond C. P., Kama M., Dominik C., The thermal structure and the location of the snow line in the protosolar nebula: Axisymmetric models with full 3-D radiative transfer, Icarus, 2011, vol. 212, p. 416

Mizuno H., Formation of the Giant Planets, Progress of Theoretical Physics, 1980, vol. 64, p. 544

Montesinos M., Cuadra J., Perez S., Baruteau C., Casassus S., Protoplanetary Disks Including Radiative Feedback from Accreting Planets, ApJ, 2015, vol. 806, p. 253

Morbidelli A., Nesvorny D., Dynamics of pebbles in the vicinity of a growing planetary embryo: hydro-dynamical simulations, A\&A, 2012, vol. 546, p. A18

Mordasini C., Alibert Y., Benz W., Extrasolar planet population synthesis. I. Method, formation tracks, and mass-distance distribution, A\&A, 2009, vol. 501, p. 1139

Mordasini C., Klahr H., Alibert Y., Benz W., Dittkrist K.-M., Theory of planet formation, ArXiv e-prints, 2010

Mukhopadhyay B., Estimate of the Shakura-Sunyaev Viscosity Parameter in the Keplerian Accretion Disk from Hydrodynamic Turbulence, International Journal of Modern Physics D, 2008, vol. 17, p. 467

Müller T. W. A., Kley W., Meru F., Treating gravity in thin-disk simulations, A\&A, 2012, vol. 541, p. A123 
Murray C. D., Dermott S. F., Solar system dynamics, 1999

Nakazawa K., Ida S., Nakagawa Y., Collisional probability of planetesimals revolving in the solar gravitational field. I - Basic formulation, A\&A, 1989a, vol. 220, p. 293

Nakazawa K., Ida S., Nakagawa Y., Collisional probability of planetesimals revolving in the solar gravitational field. II - The validity of the two-body approximation, A\&A, 1989b, vol. 221 , p. 342

Nelson R. P., On the orbital evolution of low mass protoplanets in turbulent, magnetised disks, A\&A, 2005, vol. 443, p. 1067

Nelson R. P., Papaloizou J. C. B., Masset F., Kley W., The migration and growth of protoplanets in protostellar discs, MNRAS, 2000, vol. 318, p. 18

Ohtsuki K., Ida S., Runaway planetary growth with collision rate in the solar gravitational field, Icarus, 1990a, vol. 85, p. 499

Ohtsuki K., Ida S., Runaway planetary growth with collision rate in the solar gravitational field, Icarus, 1990b, vol. 85, p. 499

Ohtsuki K., Stewart G. R., Ida S., Evolution of Planetesimal Velocities Based on ThreeBody Orbital Integrations and Growth of Protoplanets, Icarus, 2002, vol. 155, p. 436

Ormel C. W., Dullemond C. P., Spaans M., Accretion among preplanetary bodies: The many faces of runaway growth, Icarus, 2010, vol. 210, p. 507

Ormel C. W., Kobayashi H., Understanding How Planets Become Massive. I. Description and Validation of a New Toy Model, ApJ, 2012, vol. 747, p. 115

Paardekooper S.-J., Baruteau C., Crida A., Kley W., A torque formula for non-isothermal type I planetary migration - I. Unsaturated horseshoe drag, MNRAS, 2010, vol. 401, p. 1950

Paardekooper S.-J., Baruteau C., Kley W., A torque formula for non-isothermal Type I planetary migration - II. Effects of diffusion, MNRAS, 2011, vol. 410, p. 293

Papaloizou J. C. B., Disc-Planet Interactions: Migration and Resonances in Extrasolar Planetary Systems, Celestial Mechanics and Dynamical Astronomy, 2003, vol. 87, p. 53 
Papaloizou J. C. B., Nelson R. P., Kley W., Masset F. S., Artymowicz P., Disk-Planet Interactions During Planet Formation, Protostars and Planets V, 2007, pp 655-668

Papaloizou J. C. B., Terquem C., Critical Protoplanetary Core Masses in Protoplanetary Disks and the Formation of Short-Period Giant Planets, ApJ, 1999a, vol. 521, p. 823

Papaloizou J. C. B., Terquem C., Critical Protoplanetary Core Masses in Protoplanetary Disks and the Formation of Short-Period Giant Planets, ApJ, 1999b, vol. 521, p. 823

Penna R. F., Sądowski A., Kulkarni A. K., Narayan R., The Shakura-Sunyaev viscosity prescription with variable $\alpha$ (r), MNRAS, 2013, vol. 428, p. 2255

Pierens A., Raymond S. N., Two phase, inward-then-outward migration of Jupiter and Saturn in the gaseous solar nebula, A\&A, 2011, vol. 533, p. A131

Pollack J. B., Hubickyj O., Bodenheimer P., Lissauer J. J., Podolak M., Greenzweig Y., Formation of the Giant Planets by Concurrent Accretion of Solids and Gas, Icarus, 1996, vol. 124, p. 62

Pringle J. E., Accretion discs in astrophysics, ARA\&A, 1981, vol. 19, p. 137

Rafikov R. R., Fast Accretion of Small Planetesimals by Protoplanetary Cores, AJ, 2004, vol. 128 , p. 1348

Rein H., Tamayo D., Second-order variational equations for N-body simulations, MNRAS, 2016, vol. 459 , p. 2275

Robertson B. E., Kravtsov A. V., Gnedin N. Y., Abel T., Rudd D. H., Computational Eulerian hydrodynamics and Galilean invariance, MNRAS, 2010, vol. 401, p. 2463

Romanova M. M., Lovelace R. V. E., The Magnetospheric Gap and the Accumulation of Giant Planets Close to a Star, ApJ, 2006, vol. 645, p. L73

Ronco M. P., Guilera O. M., de Elía G. C., Formation of solar system analogues - I. Looking for initial conditions through a population synthesis analysis, MNRAS, 2017, vol. 471, p. 2753 
Russell J. L., Development of a self-consistent gas accretion model for simulating gas giant formation in protoplanetary disks, Canada: Univerty of Guelph, 2011, Tese de Doutorado

Ryu D., Ostriker J. P., Kang H., Cen R., A cosmological hydrodynamic code based on the total variation diminishing scheme, ApJ, 1993, vol. 414, p. 1

Shakura N. I., Sunyaev R. A., Black holes in binary systems. Observational appearance., A\&A, 1973, vol. 24, p. 337

Shima E., Matsuda T., Takeda H., Sawada K., Hydrodynamic calculations of axisymmetric accretion flow, MNRAS, 1985, vol. 217, p. 367

Simon J. B., Armitage P. J., Li R., Youdin A. N., The Mass and Size Distribution of Planetesimals Formed by the Streaming Instability. I. The Role of Self-gravity, ApJ, 2016, vol. 822 , p. 55

Stone J. M., Norman M. L., ZEUS-2D: A radiation magnetohydrodynamics code for astrophysical flows in two space dimensions. I - The hydrodynamic algorithms and tests., ApJS, 1992, vol. 80, p. 753

Tadeu dos Santos M., Correa-Otto J. A., Michtchenko T. A., Ferraz-Mello S., Formation and evolution of the two 4/3 resonant giants planets in HD 200964, A\&A, 2015, vol. 573, p. A94

Takeuchi T., Lin D. N. C., Radial Flow of Dust Particles in Accretion Disks, ApJ, 2002, vol. 581, p. 1344

Tanaka H., Takeuchi T., Ward W. R., Three-Dimensional Interaction between a Planet and an Isothermal Gaseous Disk. I. Corotation and Lindblad Torques and Planet Migration, ApJ, 2002, vol. 565, p. 1257

Tanigawa T., Watanabe S.-i., Gas Accretion Flows onto Giant Protoplanets: HighResolution Two-dimensional Simulations, ApJ, 2002, vol. 580, p. 506

Thommes E. W., Duncan M. J., Levison H. F., Oligarchic growth of giant planets, Icarus, 2003, vol. 161, p. 431 
Touboul M., Kleine T., Bourdon B., Palme H., Wieler R., Late formation and prolonged differentiation of the Moon inferred from W isotopes in lunar metals, Nature, 2007, vol. 450 , p. 1206

Trac H., Pen U.-L., A moving frame algorithm for high Mach number hydrodynamics, New A, 2004, vol. 9, p. 443

Trilling D. E., Lunine J. I., Benz W., Orbital migration and the frequency of giant planet formation, A\&A, 2002, vol. 394, p. 241

Turner N. J., Fromang S., Gammie C., Klahr H., Lesur G., Wardle M., Bai X.-N., Transport and Accretion in Planet-Forming Disks, Protostars and Planets VI, 2014, pp 411-432

Udry S., Santos N. C., Statistical Properties of Exoplanets, ARA\&A, 2007, vol. 45, p. 397

van Leer B., Towards the ultimate conservative difference scheme. III - Upstream-centered finite-difference schemes for ideal compressible flow. IV - A new approach to numerical convection, Journal of Computational Physics, 1977, vol. 23, p. 263

Venturini J., Alibert Y., Benz W., Planet formation with envelope enrichment: new insights on planetary diversity, A\&A, 2016, vol. 596, p. A90

Venturini J., Alibert Y., Benz W., Ikoma M., Critical core mass for enriched envelopes: the role of $\mathrm{H}_{2} \mathrm{O}$ condensation, A\&A, 2015, vol. 576, p. A114

Von Neumann J., Richtmyer R. D., A Method for the Numerical Calculation of Hydrodynamic Shocks, Journal of Applied Physics, 1950, vol. 21, p. 232

Ward W. R., Density waves in the solar nebula - Differential Lindblad torque, Icarus, 1986, vol. 67, p. 164

Ward W. R., Protoplanet Migration by Nebula Tides, Icarus, 1997, vol. 126, p. 261

Weidenschilling S. J., Aerodynamics of solid bodies in the solar nebula, MNRAS, 1977, vol. 180, p. 57

Wetherill G. W., The Formation and Habitability of Extra-Solar Planets, Icarus, 1996, vol. 119 , p. 219 
Whipple F. L., On certain aerodynamic processes for asteroids and comets. In From Plasma to Planet, 1972, p. 211

Williams J. P., Cieza L. A., Protoplanetary Disks and Their Evolution, ARA\&A, 2011, vol. 49 , p. 67 
Apêndice 

Apêndice A

SETUP da simulação padrão, inclusão de novas variáveis/funções e modificações no código padrão

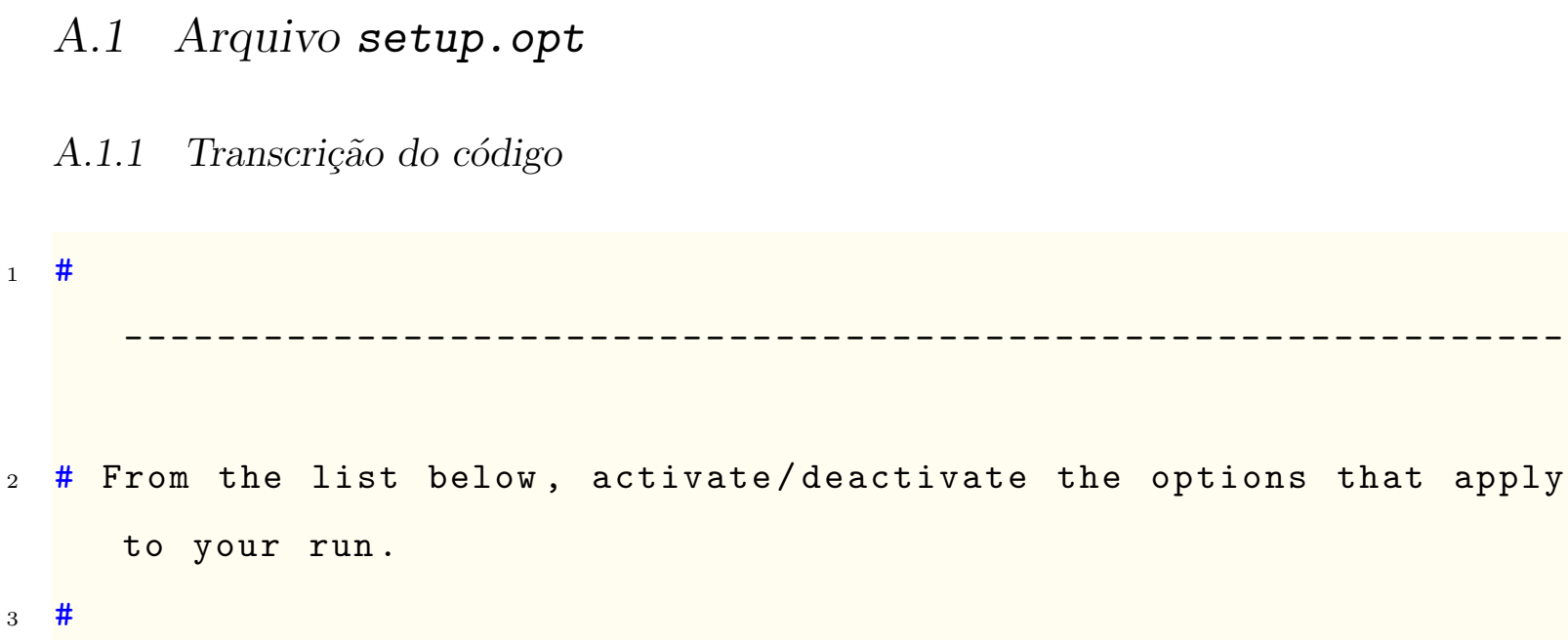

A.1 Arquivo setup.opt

A.1.1 Transcrição do código

$1 \quad \#$

2 \# From the list below, activate/deactivate the options that apply to your run.

$3 \#$

\#Problem

5 \#MONITOR_SCALAR = MASS | MOM_X | TORQ

6 \#MONITOR_Y_RAW = TORQ

8 FARGO_OPT $+=-$ DSTOCKHOLM

10 \#Dimension(s) of Simulation. Here 2D ( $r$,Phi) like the former FARGO code

11 FARGO_OPT $+=-$ DX \#X $-\rightarrow$ PHI

12 FARGO_OPT $+=-$ DY $\# \mathrm{Y}-->\mathrm{R}$ 
\#Equation of State
FARGO_OPT $+=$-DISOTHERMAL STATE

\#Coordinate System.

FARGO_OPT $+=\quad$-DCYLINDRICAL

FARGO SETUP, ALWAYS IS

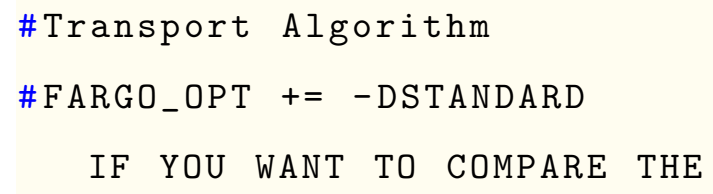

(3)

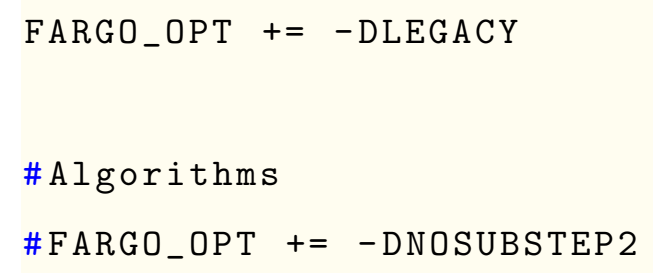




\section{A.1.2 Comentários gerais}

A linha 5 habilita a saída dos arquivos com o valor da massa total do disco de gás, momento angular total do disco e torque total no planeta a cada intervalo de tempo DT * Ninterm. Já a linha 6 habilita a saída do arquivo com o valor do torque específico em função do raio a cada intervalo de tempo DT. Nesse exemplo, essas linhas estão comentadas, mas podem ser alteradas de acordo com a conveniência (ver seção 3.9).

Outros dois arquivos são gerados por causa do módulo LEGACY (linha 25), são eles: dims.dat e used_rad.dat, que podem ser usados em alguns programas específicos para manipular os arquivos de saída. Nesta tese, esses arquivos não foram usados.

Os módulos X e Y (linha 11 e 12) indicam que a simulação é bidimensional (2D), e o módulo CYLINDRICAL (linha 18) indica que o sistema de coordenadas usado é o cilíndrico (ver seção 3.2).

Conforme discutido na seção 3.1.4, trabalhamos com um disco isotérmico, portanto, usamos o módulo ISOTHERMAL (linha 15). Além disso, usamos um disco regido pela parametrização de Shakura-Sunyaev, descrita na seção 2.1.1, e que é acionado utilizando o módulo ALPHAVISCOSITY (linha 34).

Para prevenir os efeitos de flutuações geradas pela reflexão das ondas nas bordas, usamos o módulo STOCKHOLM (linha 8), que foi levemente modificado, conforme descrito no final da seção 3.10 .3

Para o cálculo do torque planetário, desconsideramos a região próxima do planeta, em torno do raio de Hill, usando o módulo HILLCUT (linha 36). Essa função também foi 
levemente modificada, conforme descrito na seção 3.10 .1 .

O usuário pode manter os dois módulos, descritos nos dois parâgrafos anteriores, da forma como estão programados originalmente, já que eles não produzirão uma diferença significativa nos resultados, desde que o planeta se mantenha longe das bordas.

O módulo POTENTIAL (linha 31) ativa o cálculo do potencial da estrela e dos planetas.

Novos módulos foram inseridos para lidar com a formação planetária. O módulo COREACCRETION (linha 39) habilita o modelo de acreção de planetesimais; se o módulo EQUILIBRIUM (linha 40) estiver ativo, a evolução das médias azimutais das excentricidades e inclinações quadráticas médias será obtida a partir da situação de equilíbrio, caso contrário, essa evolução é obtida considerando o arrasto do gás e a influência gravitacional do protoplaneta (ver seção 4.5.3). Vale ressaltar que, caso a situação escolhida seja fora do equilíbrio, o usuário deverá especificar as condições iniciais para as excentricidades e inclinações quadráticas médias no arquivo A.2.

Caso o usuário coloque um planeta gigante, com núcleo já formado, e habilite a acreção de sólidos, o programa utilizará um tamanho de núcleo padrão de $10 \mathrm{M}_{\otimes}$. Mais detalhes serão vistos no apêndice B.2, para situação fora do equilíbrio, e no apêndice B.3 para situação em equilíbrio.

Além disso, o usuário pode habilitar o módulo GASACCRETION (linha 41), que permite a acreção de gás usando o modelo descrito na seção 5.4. O modelo de acreção de gás é independente do modelo de acreção de sólidos, assim, o usuário pode habilitar a acreção de gás sem necessidade de um núcleo sólido, isto é, de acionar a acreção de sólidos. A única diferença é que o programa irá desconsiderar o cálculo da massa crítica para iniciar a acreção de gás, isto é, a acreção de gás terá início imediato.

Por fim, os módulos BLOCK_X=16, BLOCK_Y=16 e BLOCK_Z=1 (linha 45 a 47) são blocos para linguagem CUDA. Nesta tese, nós usamos, no terminal, o comando make blocks setup=nome_setup, para gerar o arquivo setup.blocks. Isso possibilita que o script c2cuda. py leia o tamanho dos blocos que são melhores para cada kernel. Mais detalhes podem ser obtidos no endereço http://fargo.in2p3.fr/manuals/html/cuda_perf.html\#performance

\section{A.2 Arquivo condinit.c}

\section{A.2.1 Transcrição do código}




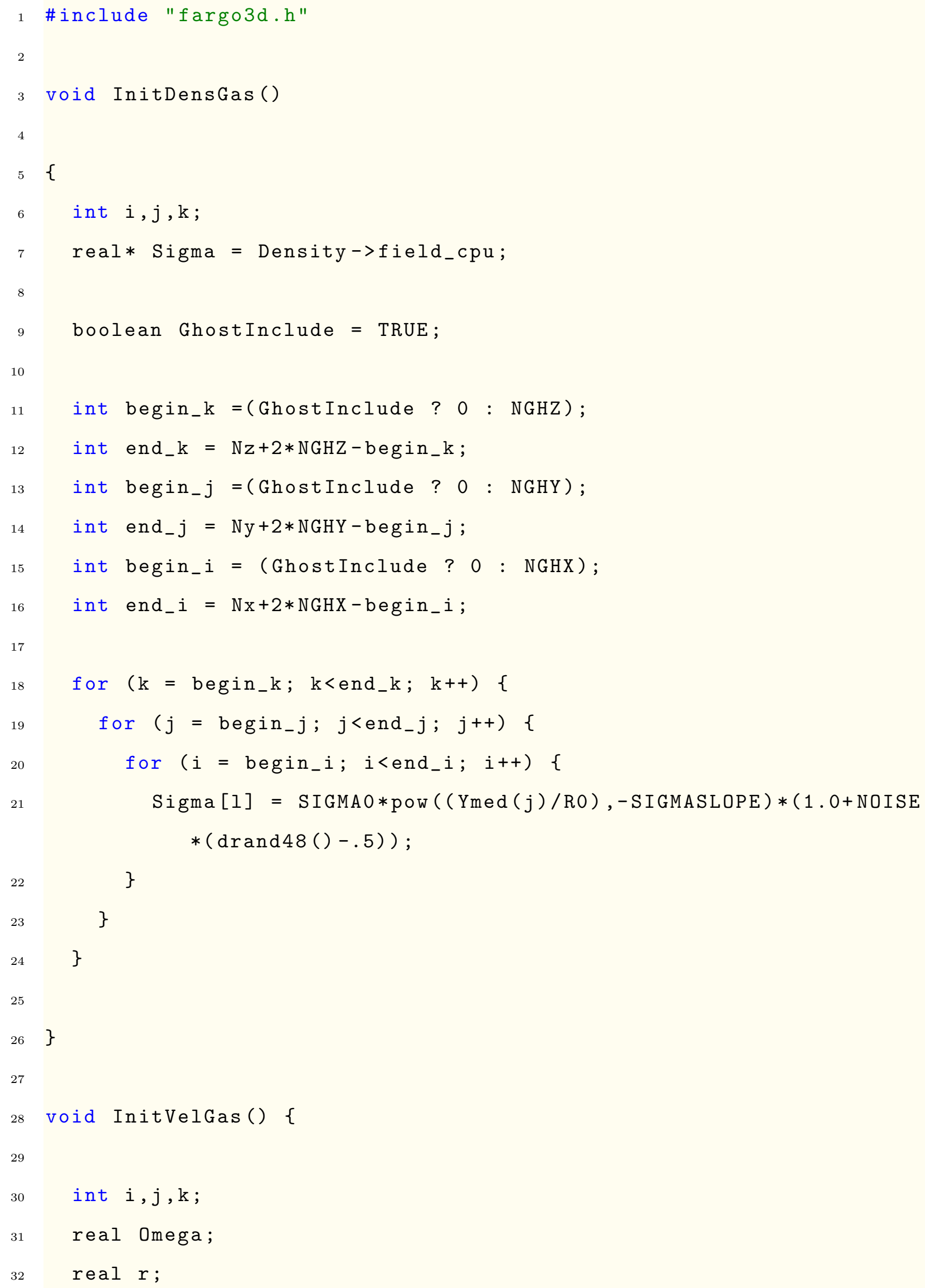




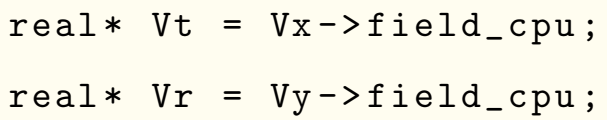


65

67

68 int i, j, k;

$69 \quad$ real $r$;

$70 \quad$ real vk;

71 real cs;

72

void InitSoundSpeedGas ( ) \{

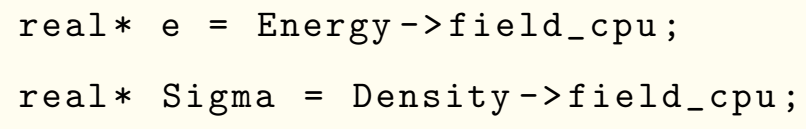


/*Pressure $\mathrm{P}=($ gamma - 1) e */

\#ifdef ADIABATIC

$$
\mathrm{e}[1]=\operatorname{cs} * \operatorname{cs} * \operatorname{Sigma}[1] /(\operatorname{GAMMA}-1.0) \text {; }
$$

\#endif

\}

\}

\}

\section{\}}

void InitSolDens()

\{

int $i, j, k$;

real* Sigma $=$ Density->field_cpu;

real* Sigmasol = Sigmam->field_cpu;

boolean GhostInclude = TRUE;

real rcell;

real Sigmagas;

int begin_k =(GhostInclude ? 0 : NGHZ);

int end_k $=\mathrm{Nz}+2 * \mathrm{NGHZ-begin \_ k}$;

int begin ${ }_{-}=$(GhostInclude ? 0 : NGHY);

int end $d_{-}=N y+2 * N G H Y-b_{\text {begin }} j$;

int begin $i=$ (GhostInclude ? 0 : NGHX);

int end_i $=\mathrm{Nx}+2 * \mathrm{NGHX}-$ begin_i;

for $(k=$ begin_k; $k<$ end_k; $k++)\{$

for $\left(j=b_{\text {begin }} j ; j<\operatorname{end} d_{-} ; j++\right)\{$

for $\left(i=b_{\text {begin }} i ; i<e n d_{-} i ; i++\right)\{$ 


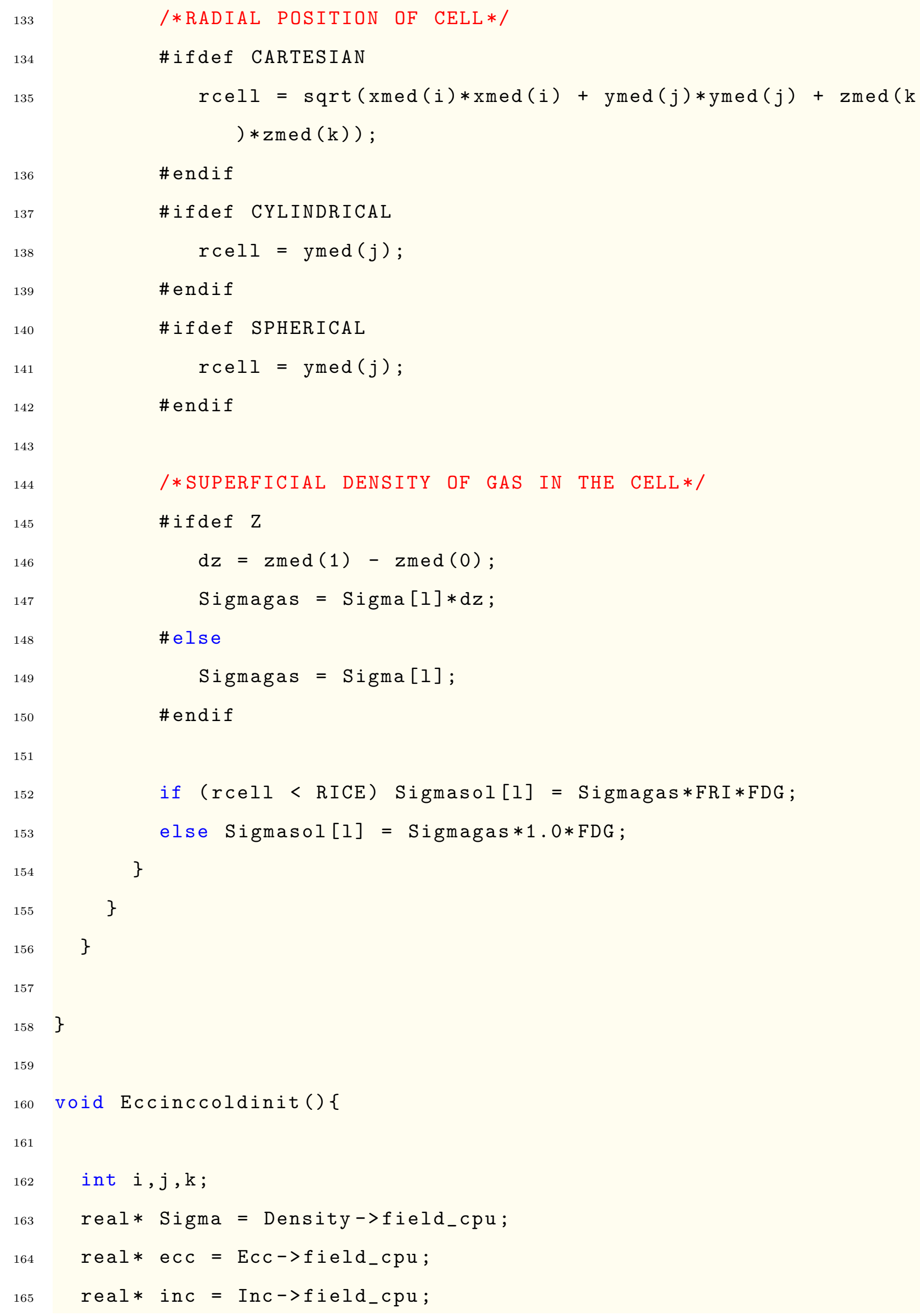

/*RADIAL POSITION OF CELL*/

\#ifdef CARTESIAN

$\operatorname{rcell}=\operatorname{sqrt}(\operatorname{xmed}(i) * x \operatorname{xmed}(i)+\operatorname{ymed}(j) * \operatorname{ymed}(j)+\operatorname{zmed}(k$ )$* \operatorname{zmed}(\mathrm{k}))$;

\# endif

\#ifdef CYLINDRICAL

$\operatorname{rcell}=\operatorname{ymed}(j) ;$

\# endif

\#ifdef SPHERICAL

$\operatorname{rcell}=\operatorname{ymed}(j)$;

\# endif

/*SUPERFICIAL DENSITY OF GAS IN THE CELL*/

\#ifdef $Z$

$\mathrm{dz}=\operatorname{zmed}(1)-\operatorname{zmed}(0) ;$

Sigmagas $=\operatorname{Sigma}[1] * d z ;$

\# else

Sigmagas = Sigma [1];

\#endif

if $($ rcell < RICE) Sigmasol $[1]=$ Sigmagas*FRI*FDG;

else Sigmasol[1] = Sigmagas*1.0*FDG;

\}

\}

\}

void Eccinccoldinit() \{
real $*$ inc $=$ Inc->field $-c p u$; 
real $*$ eccquad $=$ Eccquad $->$ field_cpu;

real $*$ incquad $=$ Incquad $->f_{i e l d} c$ cpu;

boolean GhostInclude = TRUE;

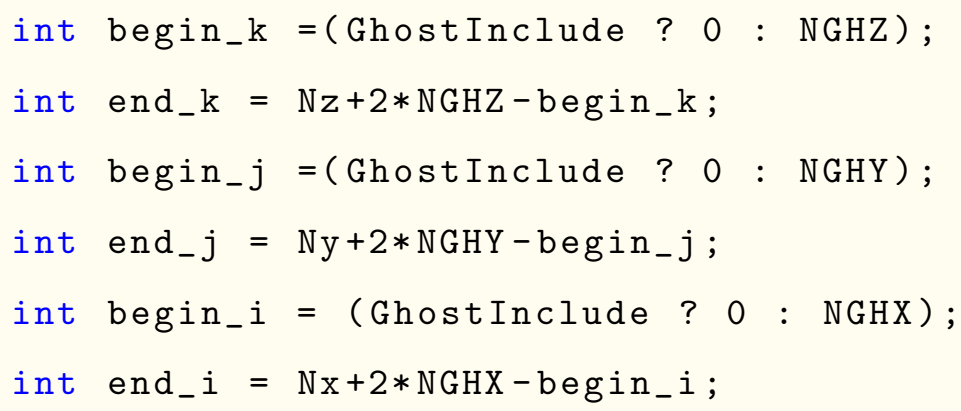




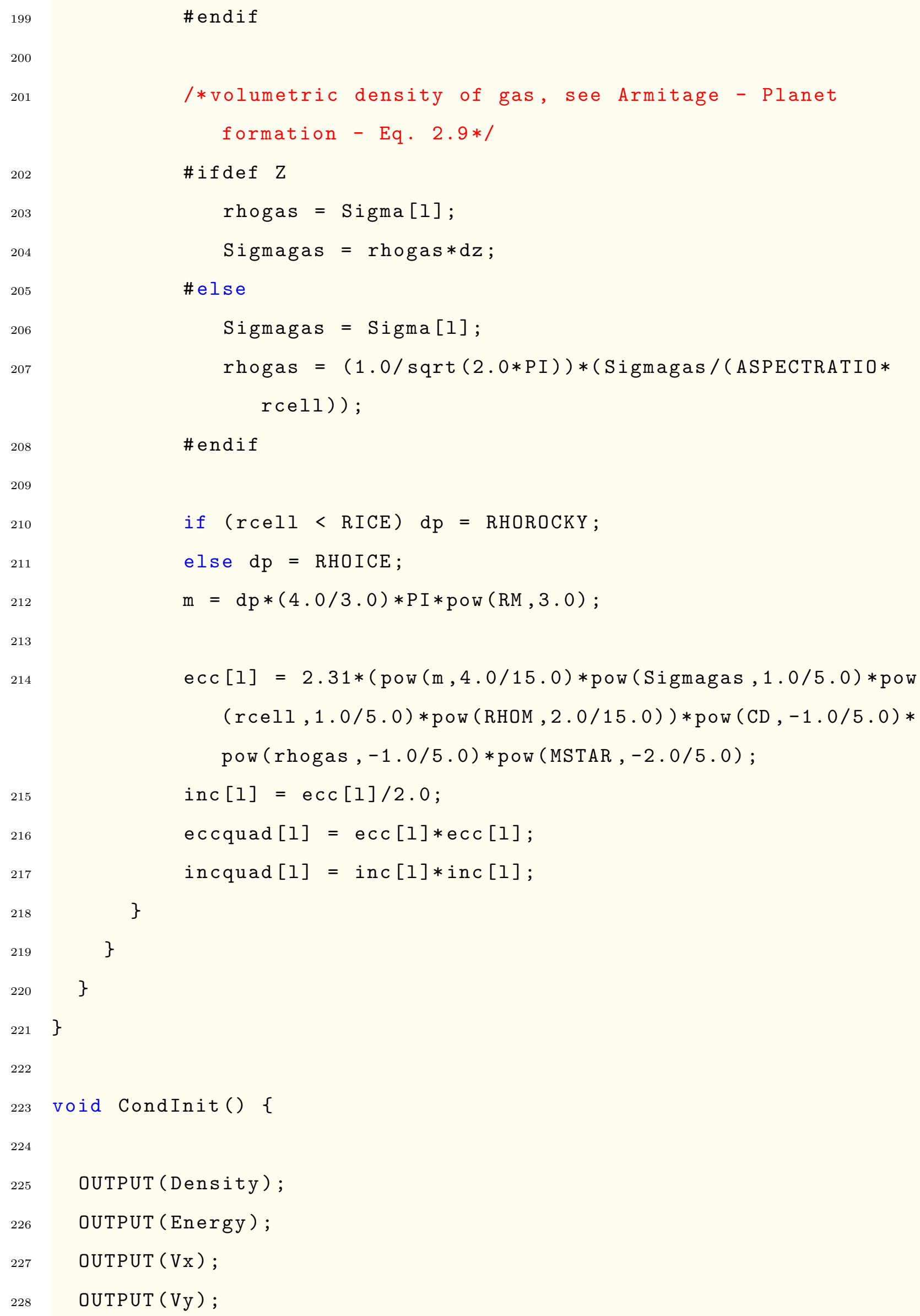

209

213

224

225

226

227

228

\# endif 


\section{A.2.2 Comentários gerais}

Esse arquivo foi construído de forma a ser o mais geral possível. Isso possibilita seu uso em outras simulações sem necessidade de muitas alterações. O intuito desse arquivo é calcular a distribuição inicial da densidade superficial do gás (simulação 2D), da velocidade radial do gás, da velocidade tangencial do gás, da energia ou velocidade do som ao longo do 
domínio computacional, e também os valores para excentricidades e inclinações quadráticas médias dos planetesimais em cada célula. As variáveis e índices aqui utilizados são descritos nas seções 3.2, 3.3 e 3.6 .

A função InitDensGas() gera os valores iniciais para a densidade superficial do gás (simulação 2D) e corresponde à aplicação da equação 3.120 (linha 21). A função NOISE (linha 21, 56 e 60), conhecida como ruído de Perlin Noise, faz com que a sequência aleatória $[-0.5 ; 0.5]$ gerada por $(\operatorname{drand48}()-.5)$ fique suave. Essa parte da função possibilita gerar uma certa aleatoriedade na distribuição de forma a simular flutuações, tornando o cenário mais realista.

A distribuição da velocidade tangencial e radial do gás é realizada pela função InitVelGas(), observe que a velocidade tangencial é calculada a partir da equação 2.15 (linha 51 a 56), em sua forma generalizada (ver seção 2.1.3). Nesta tese, essa função é reduzida para função 3.121 dado que o parâmetro FlaringIndex, responsável pela curvatura do disco, é tomado como nulo. A distribuição da velocidade radial (linha 59 a 60) também é escrita numa forma generalizada (ver seção 2.1.4) que, para o caso FlaringIndex = 0 , leva à equação 3.118 .

O cálculo da distribuição de energia ou da velocidade do som é obtido na função InitSoundSpeedGas () (linha 90 a 104). No caso isotérmico, temos simplesmente o cálculo da velocidade do som por meio da equação 3.122, numa forma generalizada, que leva em conta a curvatura do disco. No caso adiabático, essa velocidade do som, calculada independentemente de ser isotérmico ou adiabático, é usada para obtenção da energia por meio da equação 3.47, na qual se estima a pressão inicial como a do caso isotérmico, dada pela equação 3.42 .

Esse arquivo, salvo condições muito específicas, pode ser usado em um grande número de simulações sem necessidade de qualquer modificação.

A função InitSolDens() é responsável pelo cálculo da densidade superficial inicial de sólidos guardada na variável de campo Sigmam. No caso de uma simulação 3D, a entrada da variável de campo Density é a densidade volumétrica do gás, assim, é necessário obter a densidade superficial do gás (linha 146 e 147). No caso da simulação 2D, isso não é necessário (linha 149).

A densidade superficial inicial de planetesimais é assumida proporcional à densidade superficial inicial de gás (linhas 152 e 153). Portanto: 


$$
\Sigma_{\mathrm{m}}=f_{\mathrm{D} / \mathrm{G}} f_{\mathrm{R} / \mathrm{I}} \Sigma_{\text {gas }}
$$

onde $f_{\mathrm{D} / \mathrm{G}}$ é a razão de gás e poeira no disco e $f_{\mathrm{R} / \mathrm{I}}$ o grau de condensação devido a evaporação do material mais próximo da estrela, da mesma forma que Mordasini et al. (2009), adotamos seu valor como sendo de $f_{\mathrm{R} / \mathrm{I}}=1$, além da linha de gelo, e, $f_{\mathrm{R} / \mathrm{I}}=1 / 4$, dentro da linha de gelo. Ambas as constantes estão definidas no arquivo setup.par (ver apêndice A.7 e podem ser alteradas de acordo com a conveniência. Além disso, o usuário pode definir a posição da linha de gelo no mesmo arquivo modificando a variável RICE, adotada aqui com o valor de 3 ua, com base nos valores estimados de temperatura e pressão para o disco padrão (ver seção 3.10.4).

Por fim, a função Eccinccoldinit() estima um valor inicial para a excentricidade e a inclinação quadráticas médias dos planetesimais em cada célula. Essa função é necessária para o caso da situação fora do equilíbrio, que resolve um sistema de equações diferenciais (ver eq. 4.142), que exige uma condição inicial para a excentricidade e a inclinação quadráticas médias dos planetesimais. No exemplo acima, consideramos um disco inicialmente frio no qual as excentricidades e inclinações quadráticas médias iniciais são dadas para uma situação de equilíbrio entre o efeito gravitacional entre os planetesimais e o arrasto do gás, esses valores podem ser derivados equacionando o tempo de escala entre o efeito gravitacional e o arrasto, que resulta em:

$$
\left\{\begin{array}{l}
e=2.31 \frac{m^{4 / 15} \Sigma_{\text {gas }}^{1 / 5} a_{\mathrm{m}}^{1 / 5} \rho_{\mathrm{m}}^{2 / 15}}{\mathrm{C}_{\mathrm{D}}^{1 / 5} \rho_{\mathrm{gas}}^{1 / 5} M_{\star}^{2 / 5}}, \\
i=\frac{1}{2} e .
\end{array}\right.
$$

Isso significa que estamos assumindo que o embrião instantaneamente aparece em um disco de planetesimais não perturbado. Outro opção é definir os valores iniciais para excentricidade e inclinação quadráticas médias como os valores obtidos nas equações 4.139 e 4.140.

O cálculo das excentricidades e inclinações quadráticas médias é obtido nas linhas 214 e 215. É importante destacar que o cálculo da evolução das excentricidades e inclinações é obtido usando os valores quadráticos para essas grandezas, assim, o usuário deve sempre guardar o quadrado desses valores nas variáveis de campo eccquad e incquad (linha 216 e 217) para que o programa funcione corretamente. 


\section{A.3 Arquivos para as condições de borda}

\section{A.3.1 Arquivo boundaries.txt}

\section{A.3.1.1 Transcrição do código}

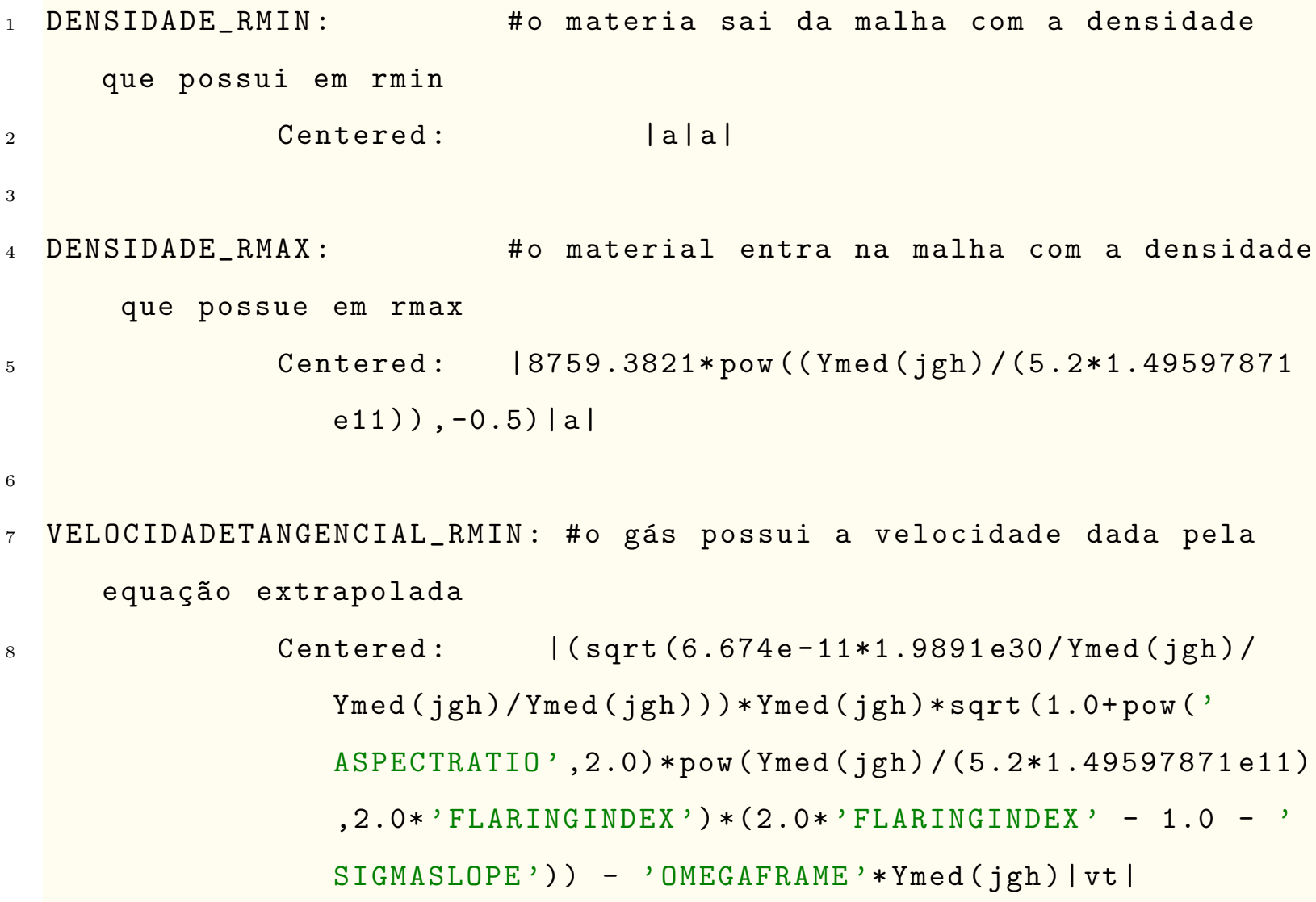

7 VELOCIDADETANGENCIAL_RMIN: \#o gás possui a velocidade dada pela equação extrapolada equação extrapolada

$$
\text { I (sqrt (6.674e-11*1.9891e30/Ymed (jgh)/ }
$$

$\operatorname{Ymed}(j g h) / \operatorname{Ymed}(j g h))) * \operatorname{Ymed}(j g h) * \operatorname{sqrt}(1.0+$ pow (' ASPECTRATIO', 2.0)*pow(Ymed (jgh)/(5.2*1.49597871 e11) , 2.0*'FLARINGINDEX') *(2.0*'FLARINGINDEX' - 1.0 - ' SIGMASLOPE') ) - 'OMEGAFRAME'*Ymed (jgh) |vt |

VELOCIDADERADIAL_RMIN : \#o gás sai da malha com a velocidade imposta pela equação

$$
\begin{aligned}
& \text { Staggered: |-3.0*'ALPHA'*Ymed (jgh)*(sqrt (6.674e } \\
& -11 * 1.9891 \text { e30/Ymed (jgh)/Ymed (jgh)/Ymed (jgh)))*pow(' }
\end{aligned}
$$




\section{A.3.2 Arquivo setup. bound}

\section{A.3.2.1 Transcrição do código}

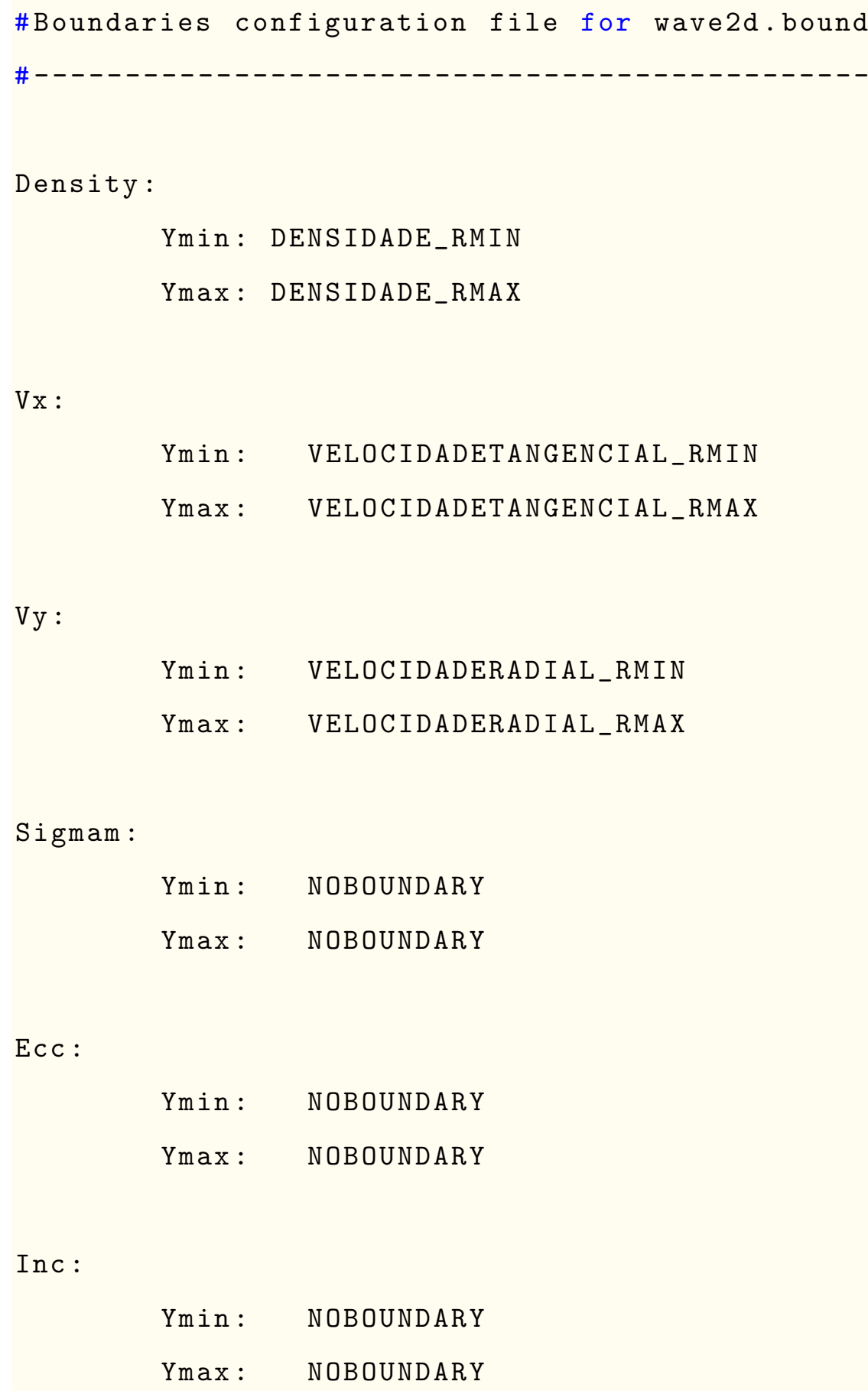

\section{A.3.2.2 Comentários gerais}

Esse arquivo apenas aplica nas respectivas bordas as condições descritas em boundaries . txt

Para o modelo de formação planetária, três novas variáveis primitivas foram criadas: a densidade superficial de sólidos (Sigmam), a excentricidade quadrática média dos plane- 
tesimais (Ecc) e a inclinação quadrática média dos planetesimais (Inc). Para essas novas variáveis, usamos a condição NOBOUNDARY, que apenas copia para as células fantasmas os valores da borda. Nesta tese, as equações para evolução dessas novas grandezas são locais e não dependem das células vizinhas.

\section{A.3.3 Arquivo centering.txt}

\section{A.3.3.1 Transcrição do código}

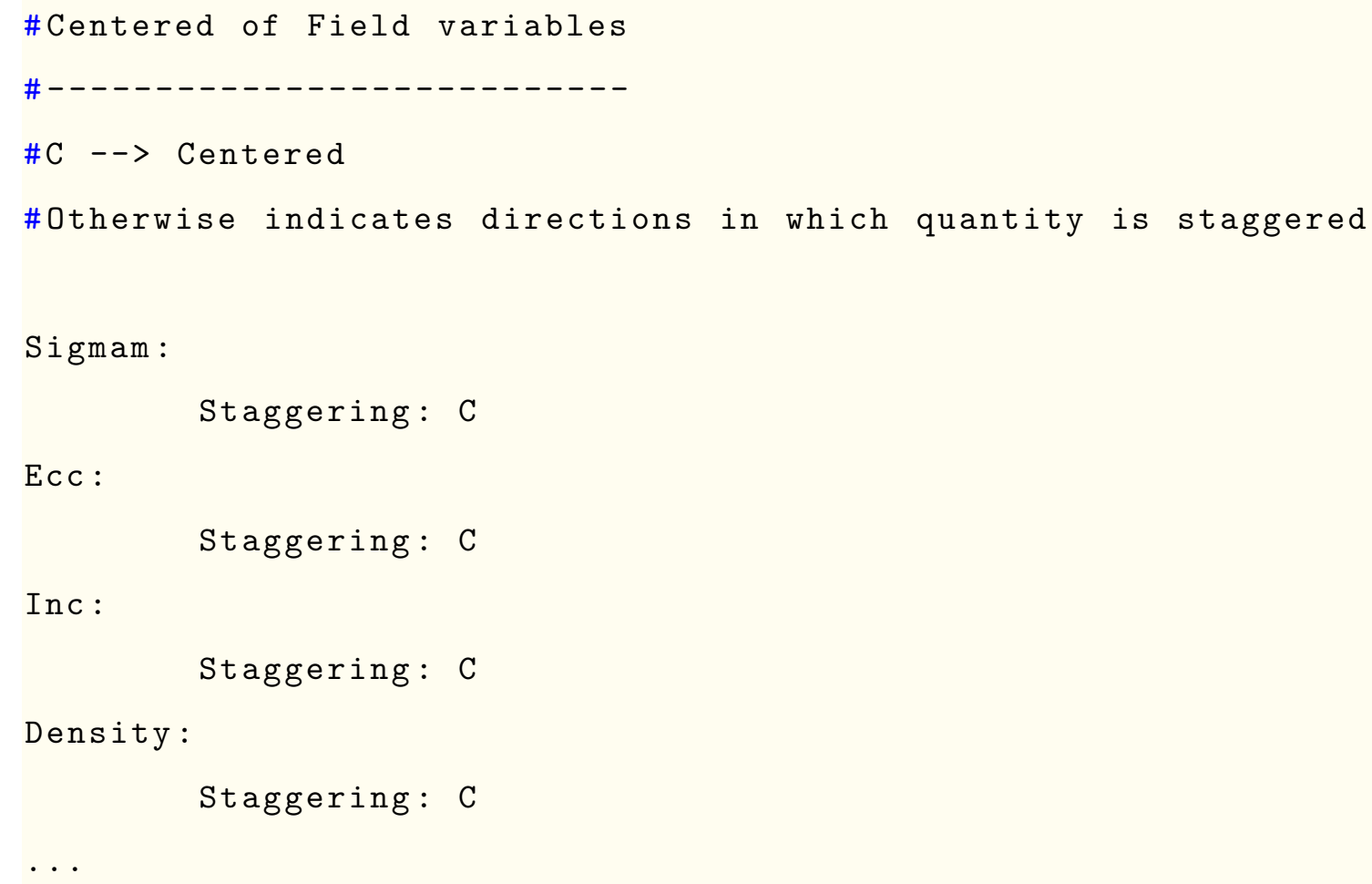

\section{A.3.3.2 Comentários gerais}

Esse arquivo descreve o posicionamento da grandeza calculada na célula (ver seção 3.3).

Para o modelo de formação planetária, três novas variáveis primitivas foram criadas: a densidade superficial de sólidos (Sigmam), a excentricidade quadrática média dos planetesimais (Ecc) e a inclinação quadrática média dos planetesimais (Inc). Como essas variáveis são primitivas, torna-se necessário colocar, no arquivo centering.txt, o posicionamento da grandeza na célula. Assim, as condições de borda serão aplicadas de forma correta. Todas as novas grandezas são centradas na célula Staggering: C . Em caso de dúvida, recomendamos a leitura da seção 3.3 junto com o manual do FARGO3D. 


\section{A.4 Declaração das novas variáveis e funções}

\section{A.4.1 Arquivo global.h}

A.4.1.1 Transcrição das modificações no código

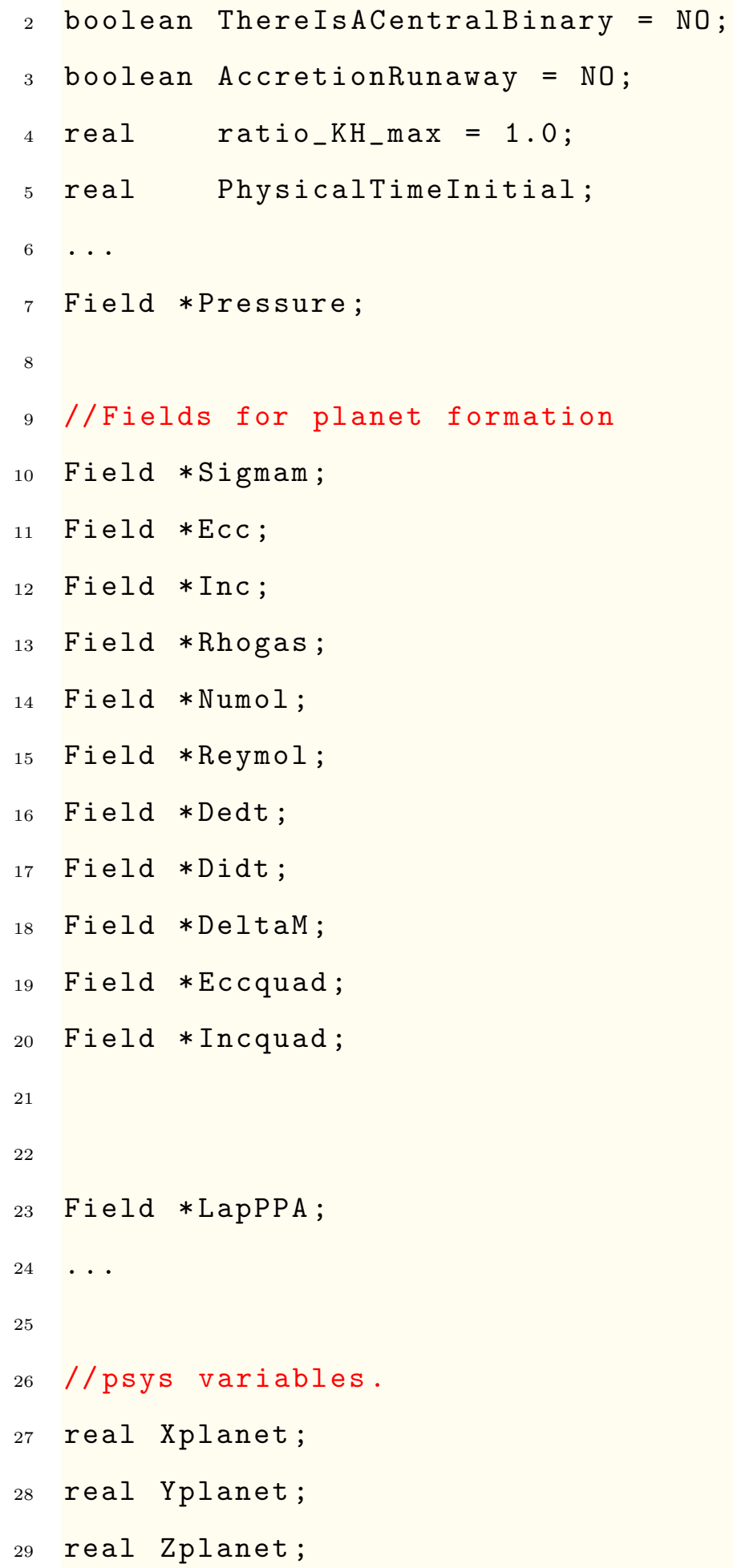




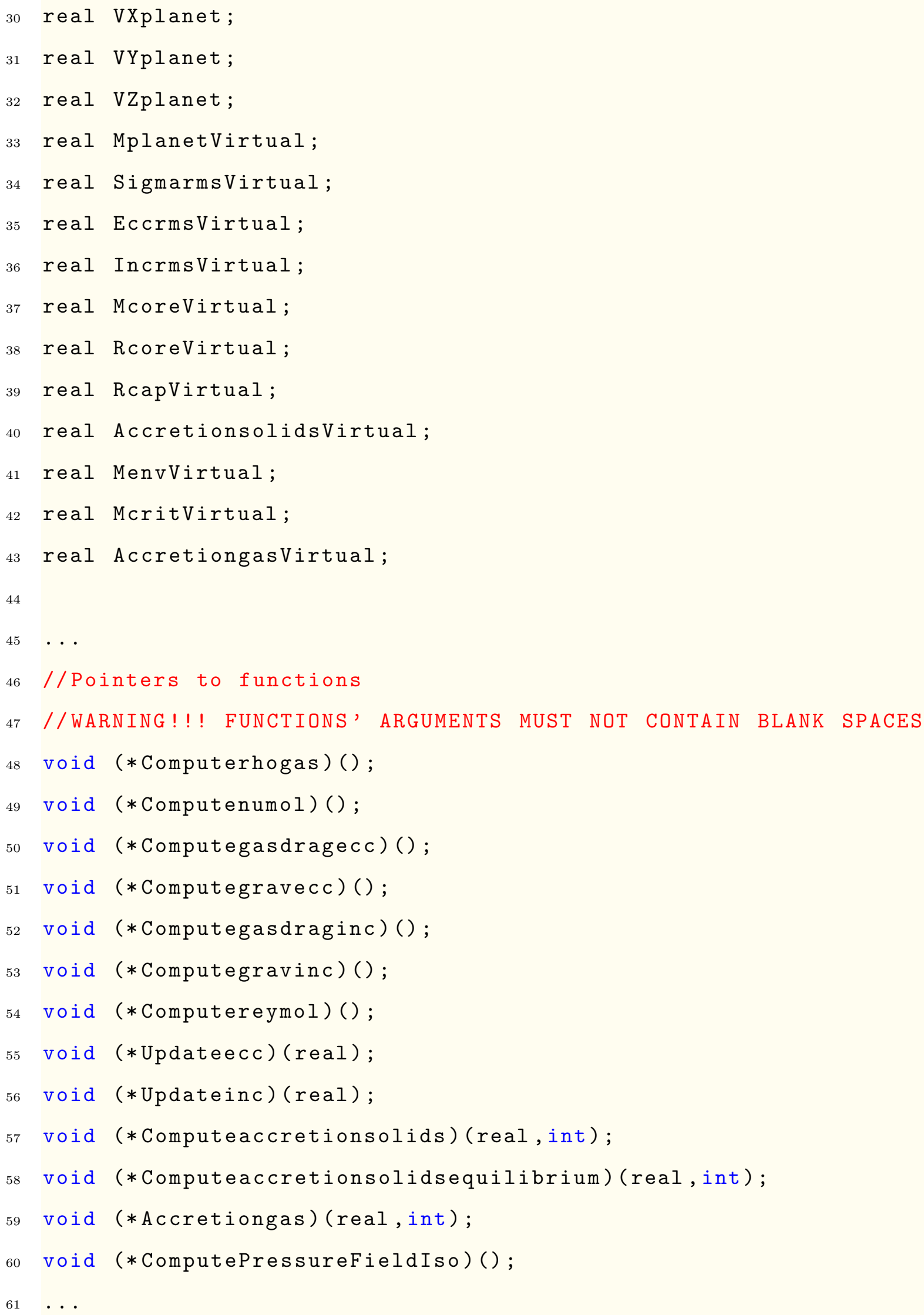




\section{A.4.1.2 Comentários gerais}

Neste arquivo, acrescentamos variáveis globais, variáveis na struct, variáveis de campo e as novas funções que serão usadas no modelo de formação planetária. Quanto as variáveis globais, temos:

- AccretionRunaway (linha 3) - essa variável é usada no modelo de acreção de gás. Quando o regime de runamay é atingido, ela recebe o valor 1, caso contrário, 0;

- ratio_KH_max (linha 4) - essa variável é usada no modelo de acreção de gás. Antes de atingir o regime de runamay, a acreção de gás é menor do que o máximo, assim, essa variável mede a fração de gás que será capturada dentro da região de acreção de gás em relação ao máximo permitido.

Para as variáveis de campo, temos:

- Sigmam (linha 10) - guarda os valores da densidade superficial de sólidos ao longo da malha;

- Ecc (linha 11) - guarda os valores da excentricidade quadrática média dos planetesimais ao longo da malha;

- Inc (linha 12) - guarda os valores da inclinação quadrática média dos planetesimais ao longo da malha;

- Rhogas (linha 13) - guarda os valores da densidade volumétrica do gás ao longo da malha;

- Numol (linha 14) - guarda os valores da viscosidade molecular ao longo da malha;

- Reymol (linha 15) - guarda os valores do número de Reynolds molecular ao longo da malha;

- Dedt (linha 16) - guarda os valores da taxa de variação da excentricidade quadrática média ao longo da malha;

- Didt (linha 17) - guarda os valores da taxa de variação da inclinação quadrática média ao longo da malha; 
- DeltaM (linha 18) - guarda os valores da massa retirada pelo planeta durante a acreção de gás ao longo da malha;

- Eccquad (linha 19) - guarda os valores da excentricidade quadrática média ao quadrado dos planetesimais ao longo da malha;

- Incquad (linha 20) - guarda os valores da inclinação quadrática média ao quadrado dos planetesimais ao longo da malha.

Para as variáveis de struct, temos:

- SigmarmsVirtual (linha 34) - guarda o valor da média azimutal da densidade superficial de sólidos na localização do planeta;

- EccrmsVirtual (linha 35) - guarda o valor da média azimutal da excentricidade quadrática média na localização do planeta;

- IncrmsVirtual (linha 36) - guarda o valor da média azimutal da inclinação quadrática média na localização do planeta;

- McoreVirtual (linha 37) - guarda o valor da massa do núcleo sólido;

- RcoreVirtual (linha 38) - guarda o valor do raio geométrico do núcleo sólido;

- RcapVirtual (linha 39) - guarda o valor do raio de captura de planetesimais;

- AccretionsolidsVirtual (linha 39) - guarda o valor da taxa de acreção de sólidos;

- MenvVirtual (linha 40) - guarda o valor da massa do envelope de gás acretado pelo planeta;

- McritVirtual (linha 41) - guarda o valor da massa crítica do núcleo a partir do qual começa a acreção de gás;

- AccretiongasVirtual (linha 42) - guarda o valor da taxa de acreção de gás;

Para as novas funções, temos:

- Computerhogas (linha 48) - calcula a densidade volumétrica de gás ao longo da malha; 
- Computenumol (linha 49) - calcula a viscosidade molecular ao longo da malha;

- Computegasdragecc (linha 50) - calcula a taxa para evolução da excentricidade quadrática média devido ao arrasto do gás ao longo da malha;

- Computegravecc (linha 51) - calcula a taxa para evolução da excentricidade quadrática média devido ao efeito gravitacional do planeta ao longo da malha;

- Computegasdraginc (linha 52) - calcula a taxa para evolução da inclinação quadrática média devido ao arrasto do gás ao longo da malha;

- Computegravinc (linha 53) - calcula a taxa para evolução da inclinação quadrática média devido ao efeito gravitacional do planeta ao longo da malha;

- Computereymol (linha 54) - calcula o número de Reynolds molecular ao longo da malha;

- Updateecc (linha 55) - calcula o novo valor para excentricidade quadrática média ao longo da malha;

- Updateinc (linha 56) - calcula o novo valor para inclinação quadrática média ao longo da malha;

- Computeaccretionsolids (linha 57) - calcula a taxa de acreção de sólidos, a massa crítica e a nova massa do núcleo sólido para a situação fora do equilíbrio;

- Computeaccretionsolidsequilibrium (linha 58) - calcula a taxa de acreção de sólidos, a massa crítica e a nova massa do núcleo sólido para a situação no equilíbrio;

- Accretiongas (linha 59) - calcula a taxa de acreção de gás, a massa do envelope e a nova massa do planeta.

\section{A.4.2 Arquivo LowTasks.c}

\section{A.4.2.1 Transcrição das modificações no código}




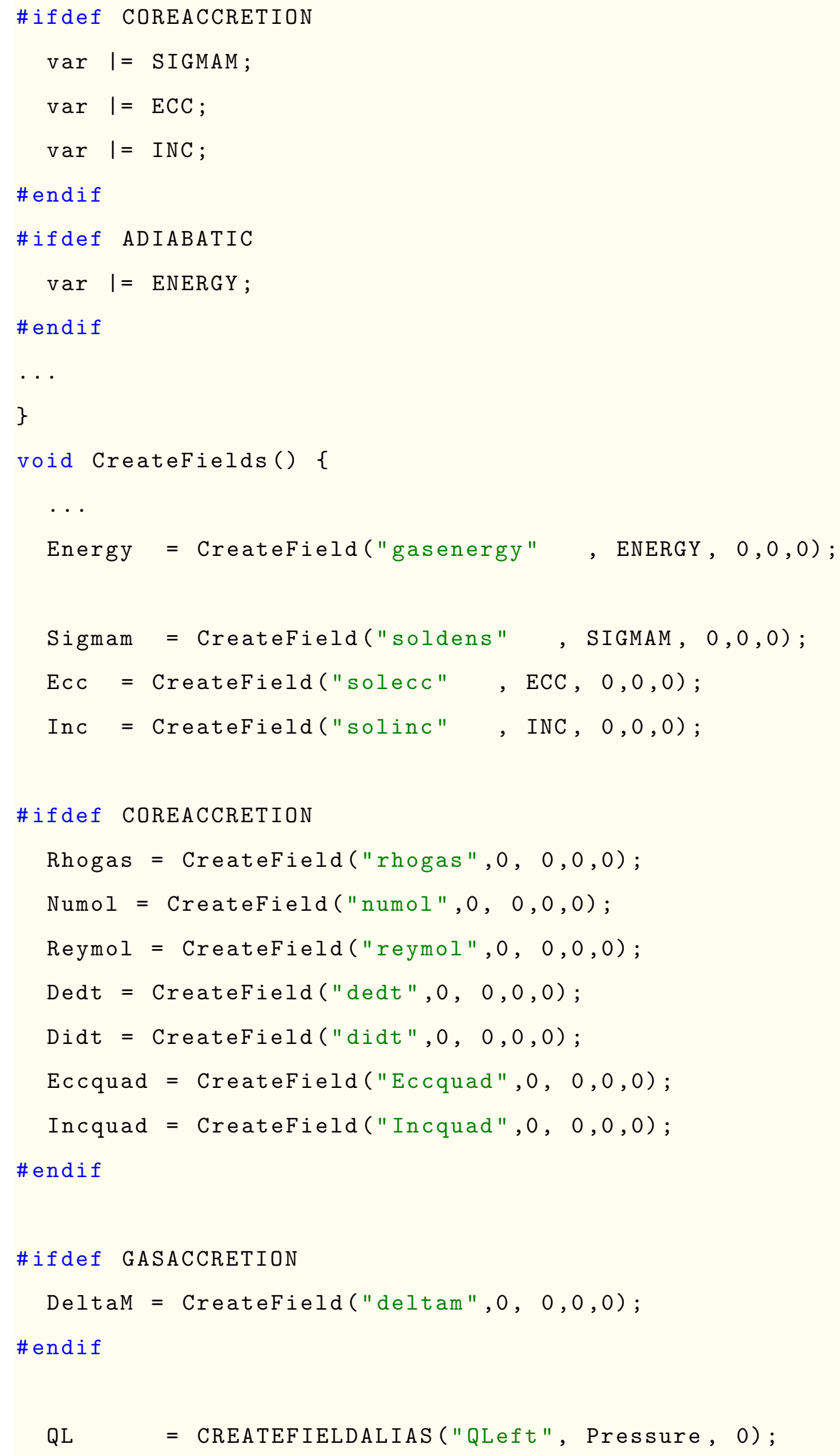




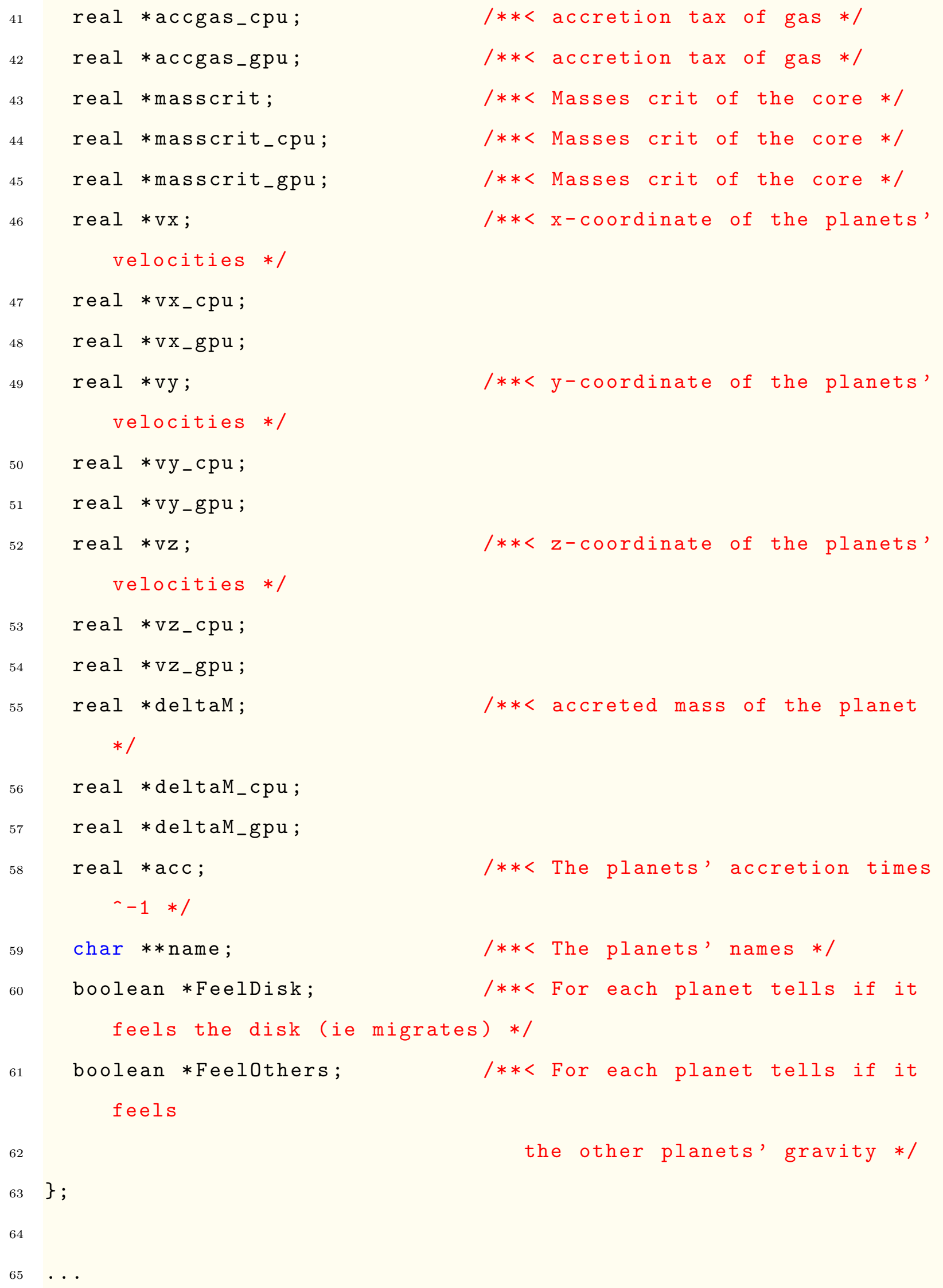




\section{A.4.3.2 Comentários gerais}

Esse arquivo é responsável pelo cadastro das structs usadas nos programas. Portanto, adicionamos as novas variáveis de structs definidas em global.h (ver apêndice A.4.1) na structs planetary_system. O modelo segue o mesmo padrão para as variáveis já cadastradas no código.

\section{A.4.4 Arquivo psys.c}

A.4.4.1 Transcrição das modificações no código

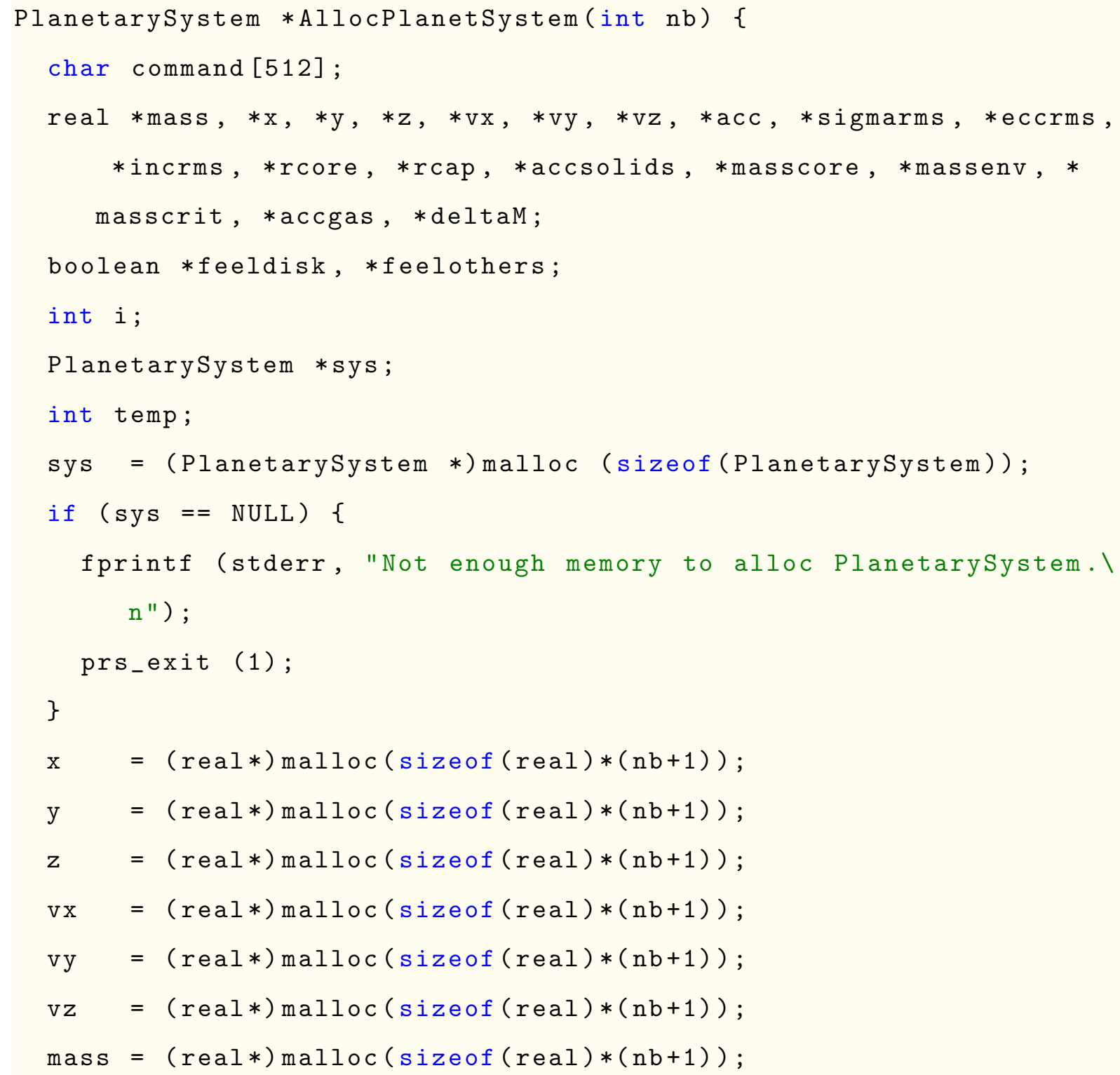




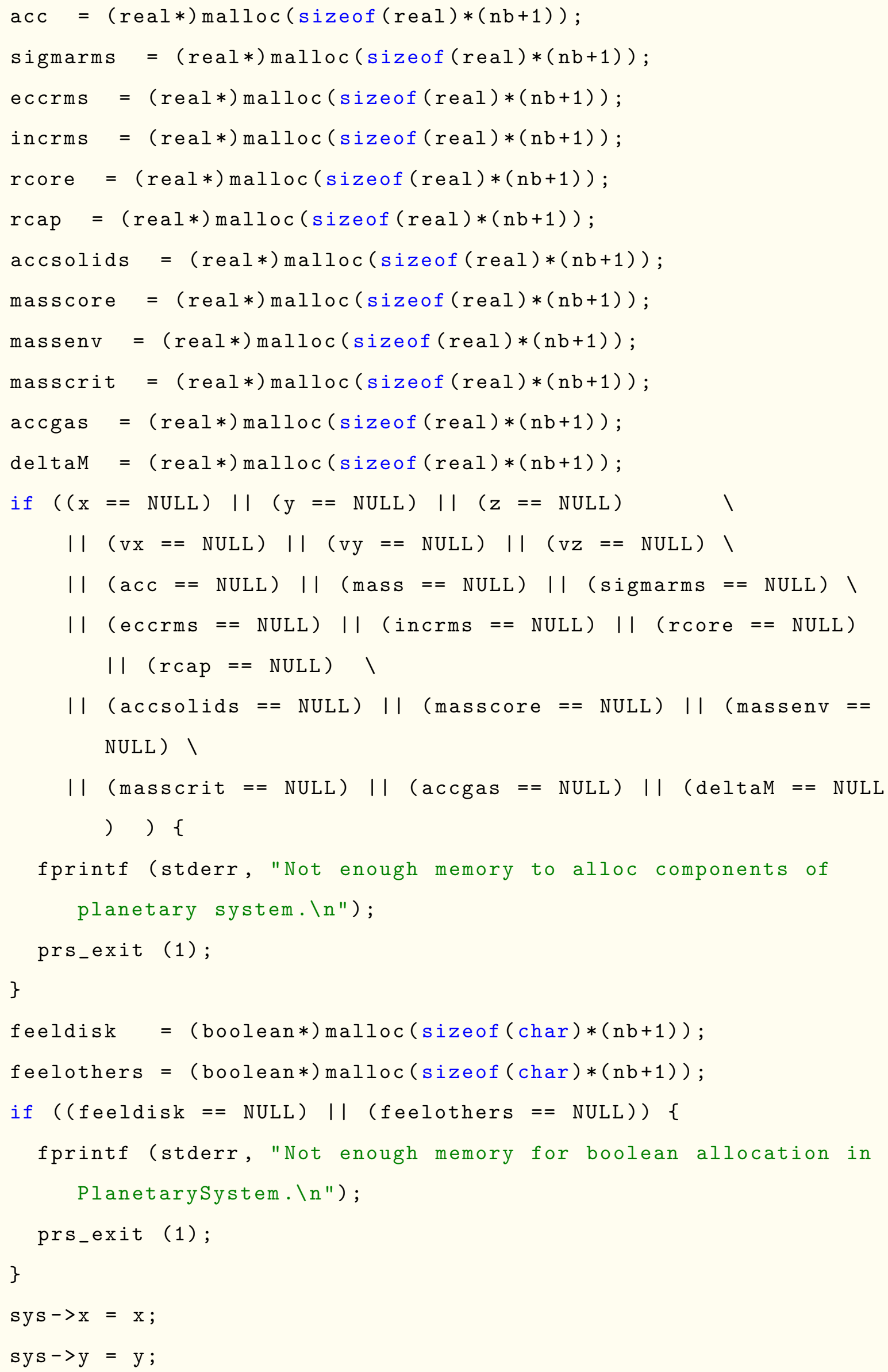




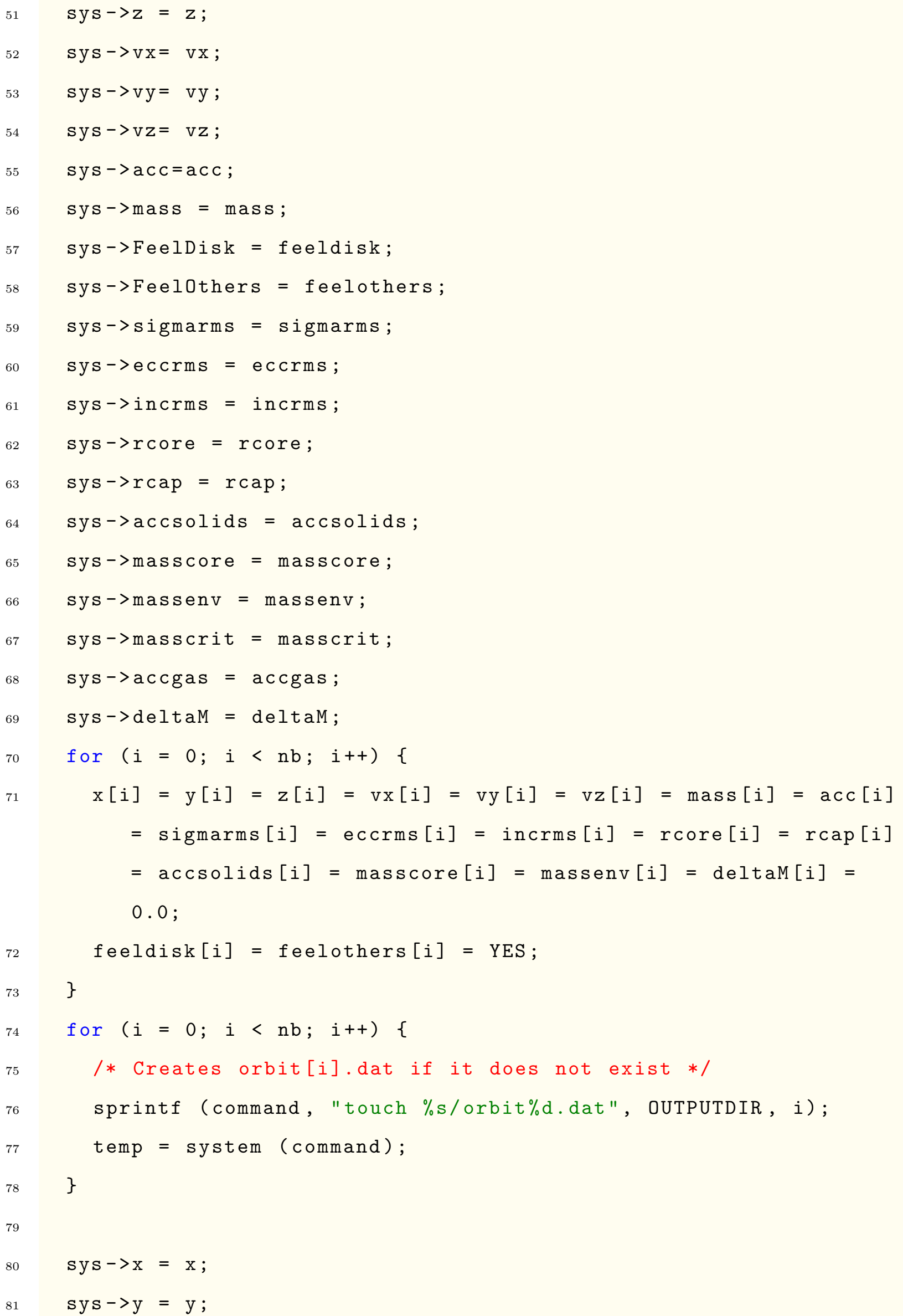




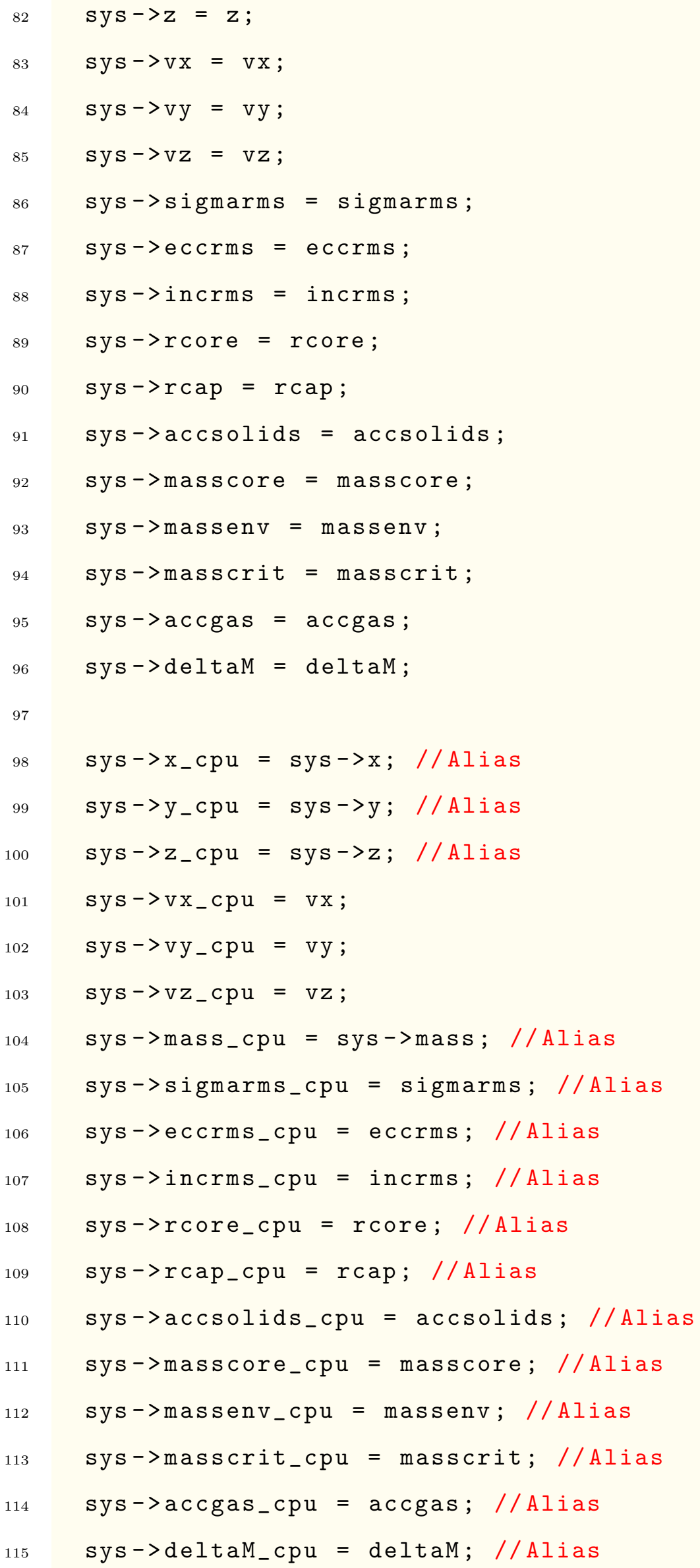


sys $->a c c=a c c$;

sys->mass = mass;

sys->FeelDisk = feeldisk;

sys->Feelothers = feelothers;

\section{\#ifdef GPU}

int status;

status $=$ DevMalloc $\left(\&\left(\operatorname{sys}->x_{-} g p u\right),(\operatorname{sizeof}(\operatorname{real}) *(n b+1))\right) ;$

status $=$ DevMalloc $\left(\&\left(\operatorname{sys}->y_{-} g p u\right),(\operatorname{sizeof}(r e a l) *(n b+1))\right)$;

status $=$ DevMalloc $\left(\&\left(\operatorname{sys}->z_{-} g p u\right),(\operatorname{sizeof}(r e a l) *(n b+1))\right)$;

status $=$ DevMalloc $\left(\&\left(\operatorname{sys}->v x_{-} g p u\right),(\operatorname{sizeof}(\right.$ real $\left.) *(n b+1))\right)$;

status $=$ DevMalloc $\left(\&\left(\operatorname{sys}->v_{-} g p u\right),(\operatorname{sizeof}(\right.$ real $\left.) *(n b+1))\right) ;$

status $=\operatorname{DevMalloc}\left(\&\left(\operatorname{sys}->v z_{-} g p u\right),(\operatorname{sizeof}(\right.$ real $\left.) *(n b+1))\right)$;

status $=\operatorname{DevMalloc}\left(\&\left(\operatorname{sys}_{-}>\right.\right.$mass_gpu $\left.),(\operatorname{sizeof}(\operatorname{real}) *(n b+1))\right)$;

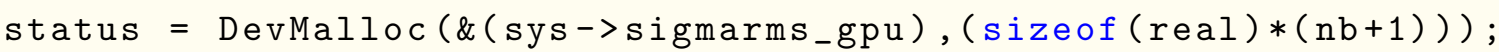

status $=\operatorname{DevMalloc}\left(\&\left(\operatorname{sys}_{-}>\operatorname{eccrms}\right.\right.$ gpu $\left.),(\operatorname{sizeof}(\mathrm{real}) *(\mathrm{nb}+1))\right)$;

status $=$ DevMalloc (\&(sys->incrms_gpu), (sizeof $($ real $) *(n b+1)))$;

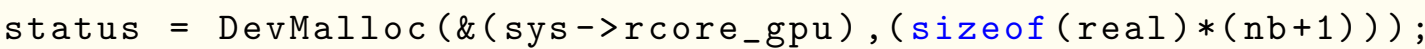

status $=$ DevMalloc $\left(\&\left(\operatorname{sys}_{-}>r c a p_{-} g p u\right),(\operatorname{sizeof}(\operatorname{real}) *(n b+1))\right)$;

status $=$ DevMalloc (\&(sys->accsolids_gpu), (sizeof (real)*(nb+1)));

status $=$ DevMalloc (\&(sys->masscore_gpu $),($ sizeof $($ real $) *(n b+1)))$;

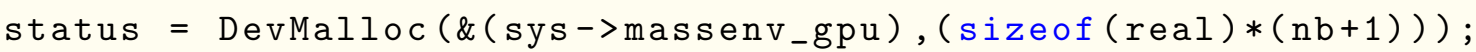

status $=$ DevMalloc (\&(sys->masscrit_gpu $),($ sizeof $($ real $) *(n b+1))) ;$

status $=$ DevMalloc $\left(\&\left(\right.\right.$ sys $\left.\left.->a c c g a s_{-} g p u\right),(\operatorname{sizeof}(r e a l) *(n b+1))\right)$;

status $=$ DevMalloc $(\&($ sys $->$ deltaM_gpu $),($ sizeof $(r e a l) *(n b+1)))$;

$/ /$ status $=$ DevMemcpyH2D(sys $->x_{-} g p u, \quad$ sys $->x_{-} c p u$, sizeof (real)*(nb $+1)$ );

$/ /$ status $=$ DevMemcpyH2D (sys->y_gpu, sys->y_cpu, sizeof(real)*(nb $+1)$ ) ;

$/ /$ status $=$ DevMemcpyH2D (sys->z_gpu, sys->z_cpu, sizeof(real)*(nb $+1)$ );

$/ /$ status $=$ DevMemcpyH2D (sys->vx_gpu, sys->vx_cpu, sizeof(real)*( $\mathrm{nb}+1))$; 


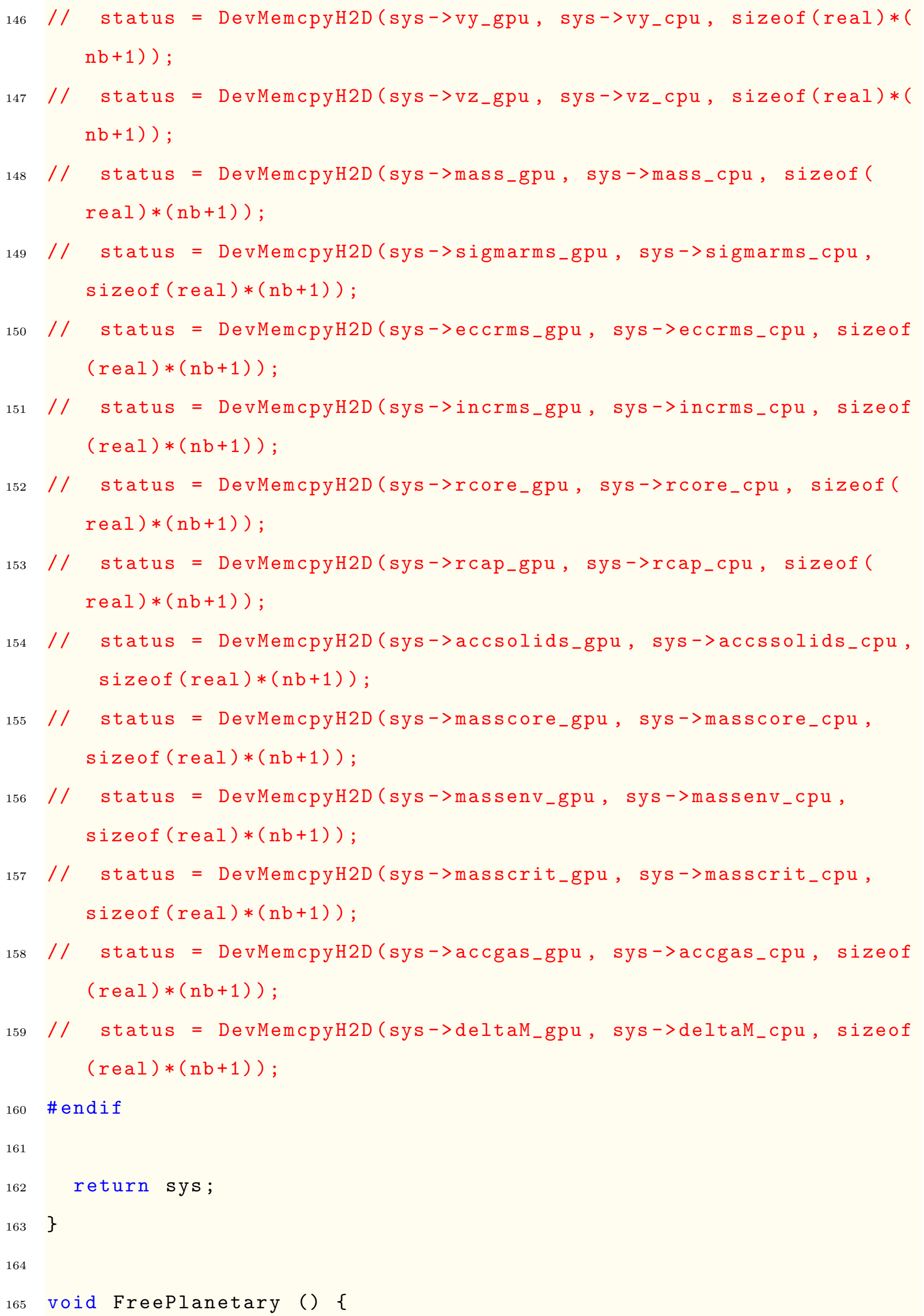




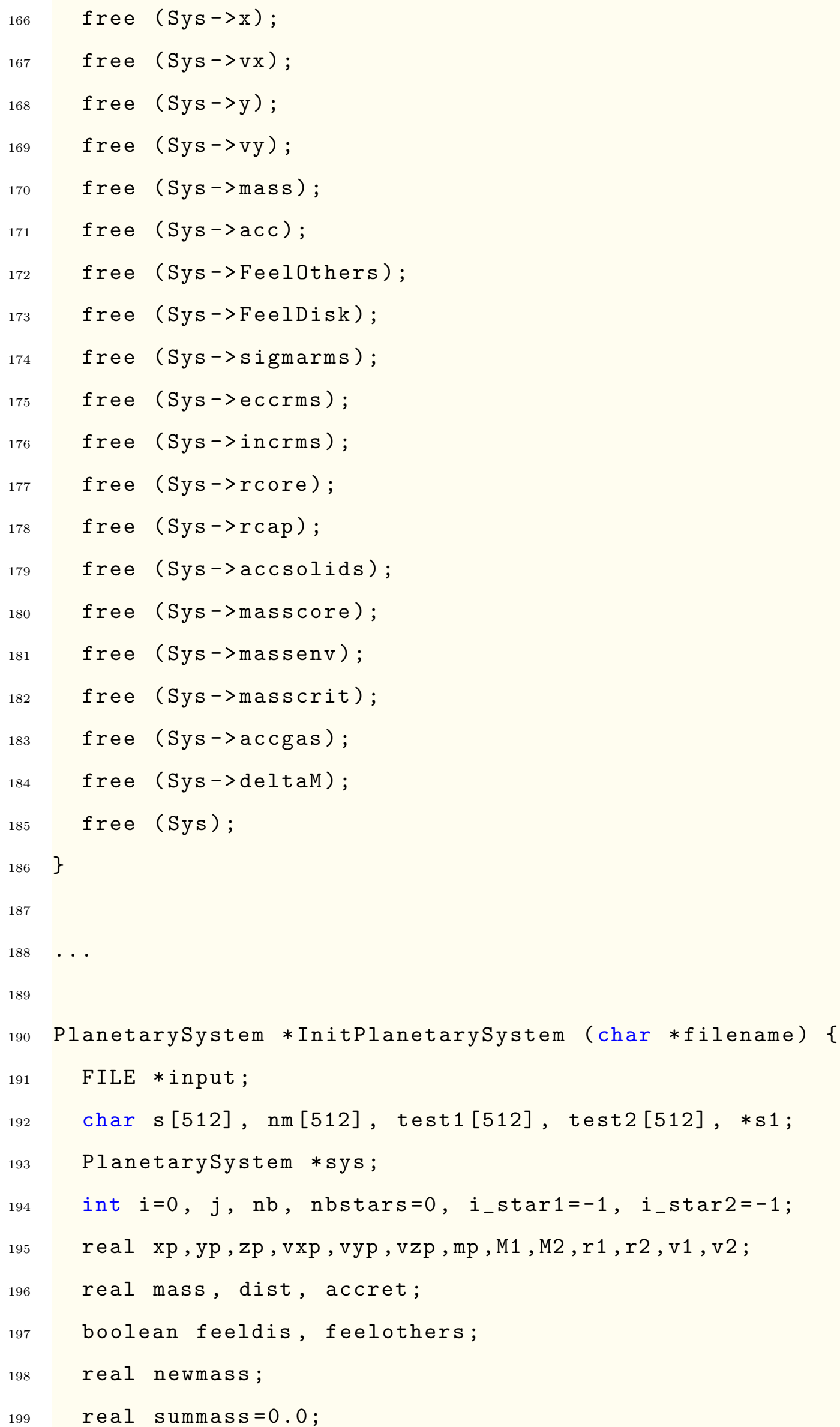




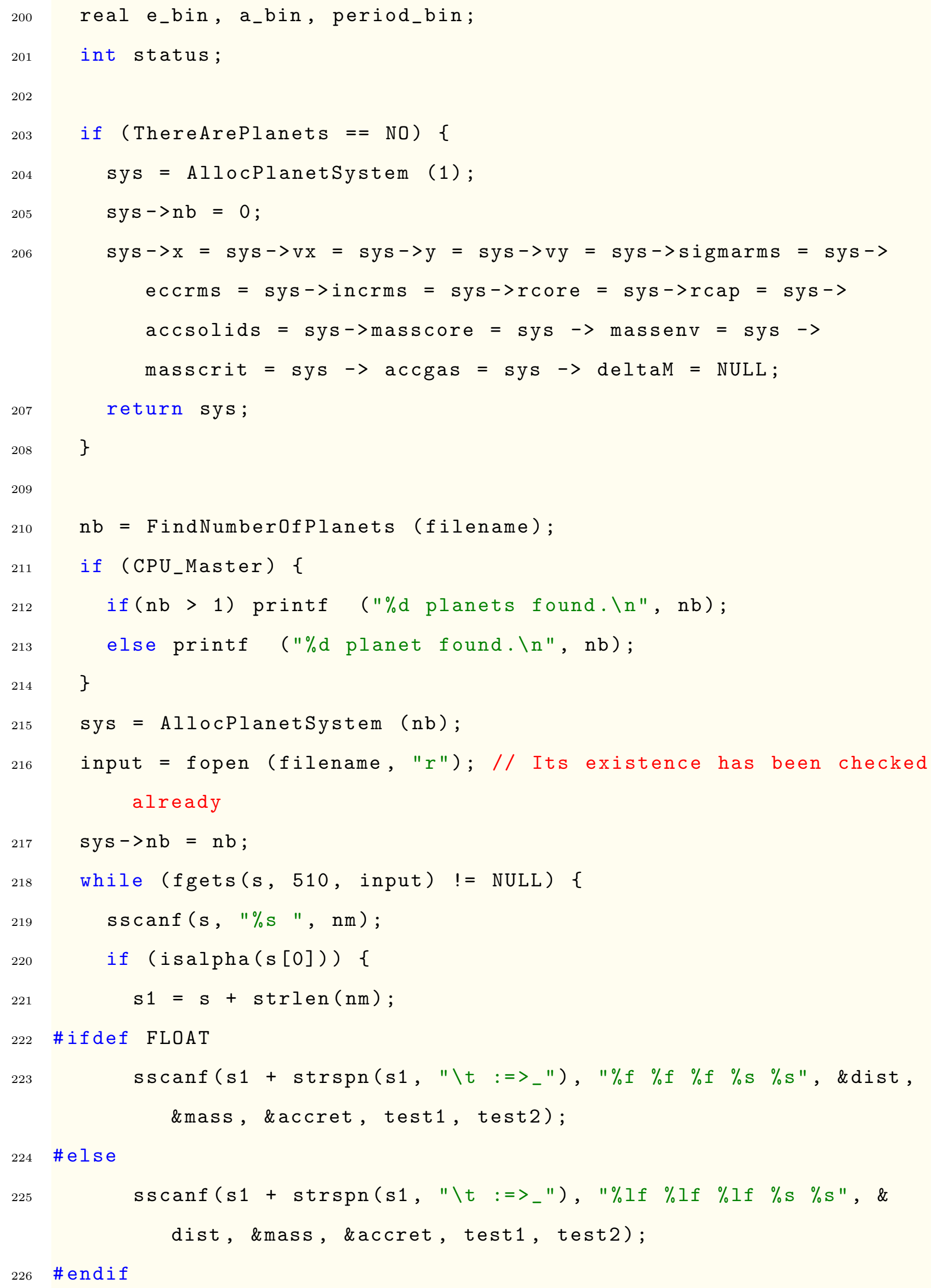

real e_bin, a_bin, period_bin;

int status;

if (ThereArePlanets $==$ NO) \{

sys = AllocPlanetSystem (1);

sys $->n b=0$;

sys $->\mathrm{x}=$ sys $->\mathrm{vx}=$ sys $->\mathrm{y}=$ sys $->\mathrm{vy}=$ sys->sigmarms $=$ sys $->$

eccrms $=$ sys $->$ incrms $=$ sys $->$ rcore $=$ sys $->$ rcap $=$ sys $->$

accsolids $=$ sys $->\operatorname{masscore}=$ sys $\rightarrow$ massenv $=$ sys $\rightarrow$

masscrit $=$ sys $\rightarrow$ accgas $=$ sys $\rightarrow$ deltaM $=$ NULL;

return sys;

\}

$\mathrm{nb}=$ FindNumberOfPlanets (filename);

if (CPU_Master) \{

if $(\mathrm{nb}>1)$ printf ( $\% \mathrm{~d}$ planets found.\n", $\mathrm{nb})$;

else printf ("\%d planet found. \n", nb);

\}

sys $=$ AllocPlanetSystem ( $n b)$;

input = fopen (filename, "r"); // Its existence has been checked already

sys $->n b=n b$;

while (fgets (s, 510, input) != NULL) \{

$\operatorname{sscanf}(\mathrm{s}, " \% \mathrm{~s} ", \mathrm{~nm})$;

if (isalpha(s[0])) \{

$\mathrm{s} 1=\mathrm{s}+\operatorname{strlen}(\mathrm{nm})$;

\#ifdef FLOAT

$\operatorname{sscanf}\left(\mathrm{s} 1+\operatorname{strspn}\left(\mathrm{s} 1, " \backslash t:=>{ }_{-}\right), " \% f \% f \% f \% s \% s "\right.$, \&dist, \&mass, \&accret, test1, test2);

\# else

$\operatorname{sscanf}\left(s 1+\operatorname{strspn}(s 1, " \backslash t:=>\right.$ " $), " \%$ lf $\%$ lf $\%$ lf $\% \mathrm{~s}_{\mathrm{s}} \mathrm{s} "$, \& dist, \&mass, \&accret, test1, test2);

\#endif 
if $(($ SEMIMAJORAXIS $>0.0)$ \& $(i==0)) / /$ SemiMajorAxis can be

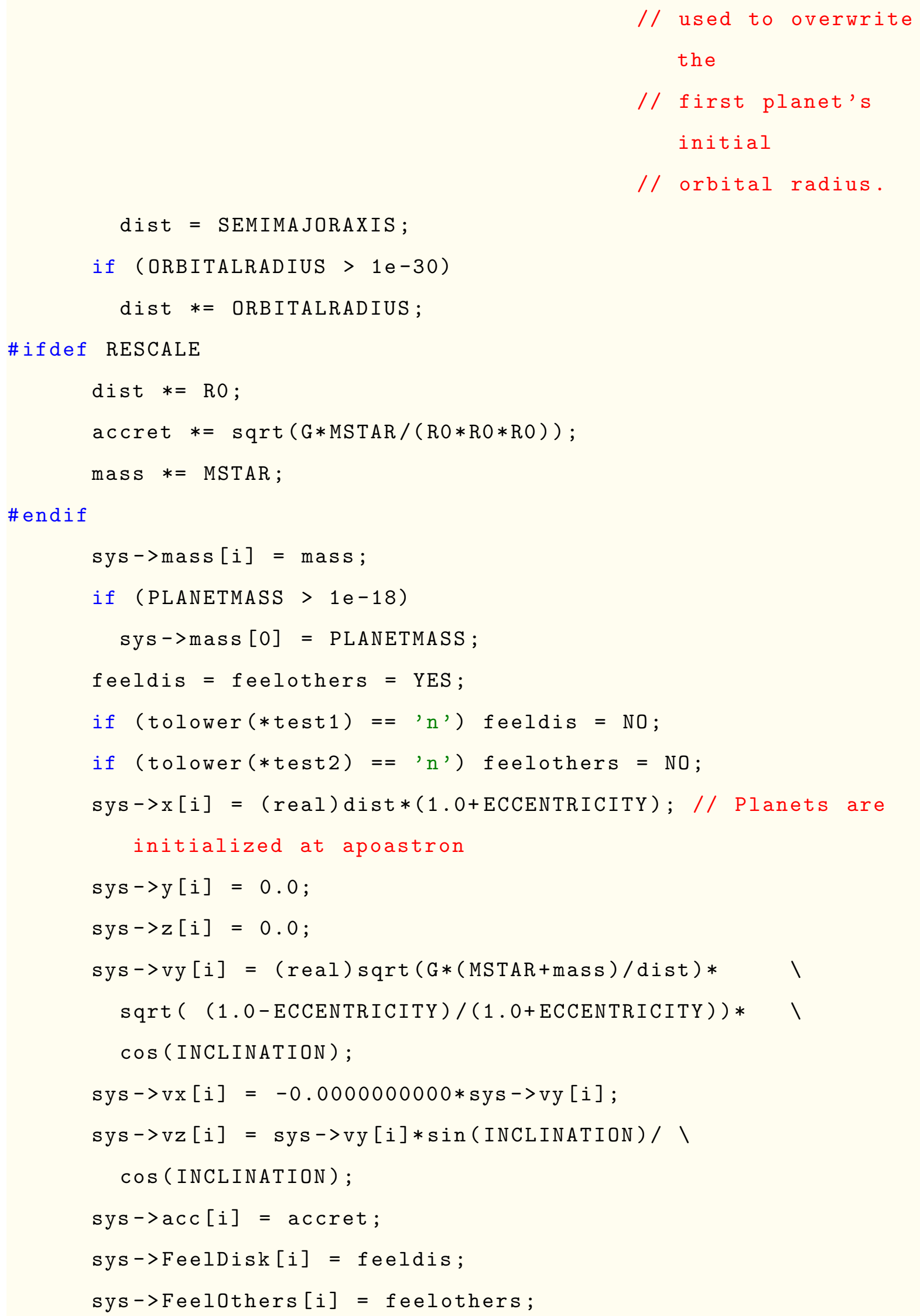




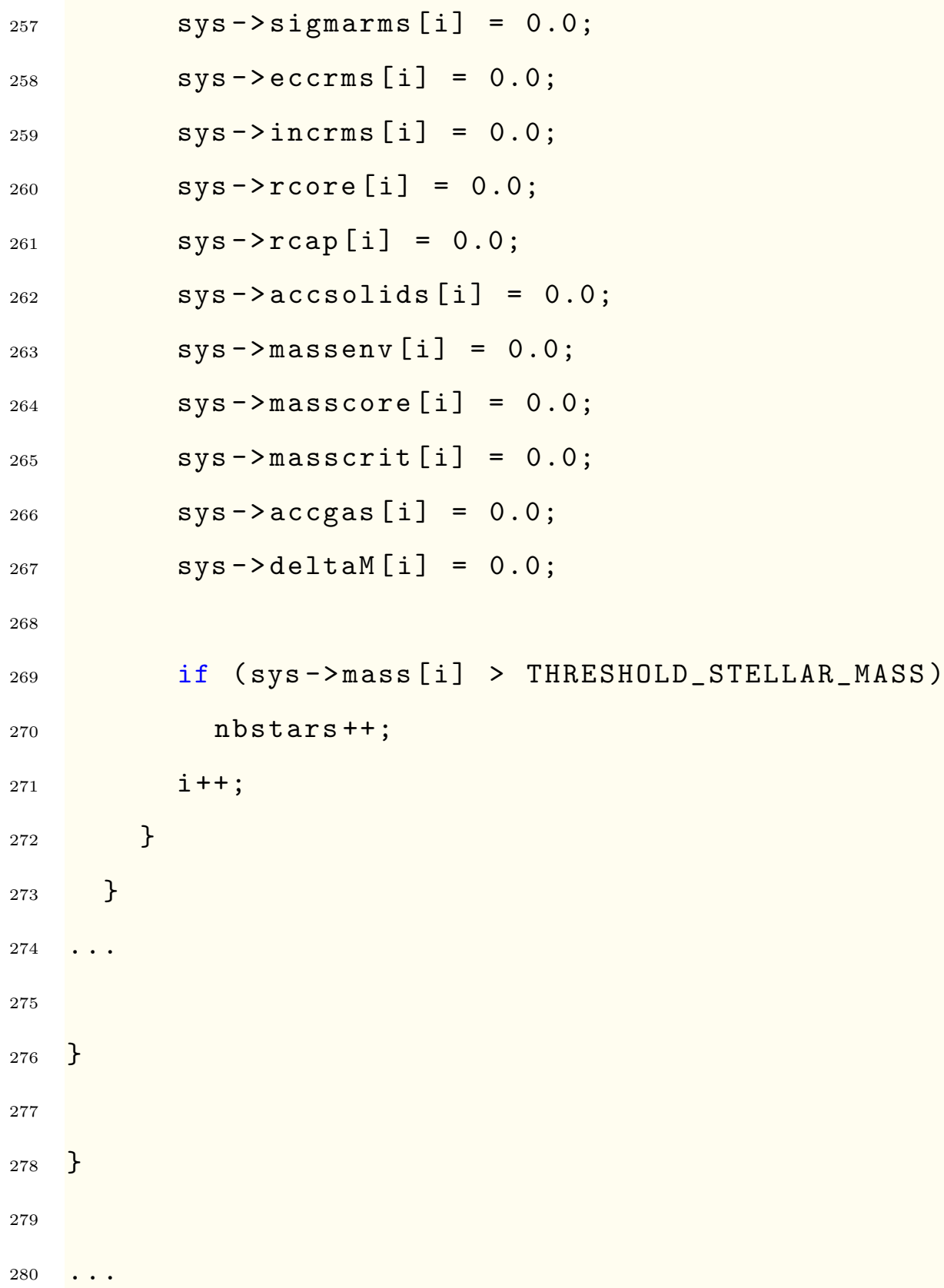

\section{A.4.4.2 Comentários gerais}

Esse arquivo é responsável pela inicialização das variáveis usadas na structs planetary_system e também pela descrição da alocação dessas variáveis na GPU ou CPU. Portanto, nós inicializamos e alocamos as novas variáveis de structs definidas em global.h (ver apêndice A.4.1). O modelo segue o mesmo padrão para as variáveis já cadastradas no código. 


\section{A.4.5 Arquivo prototypes.h}

\section{A.4.5.1 Transcrição das modificações no código}

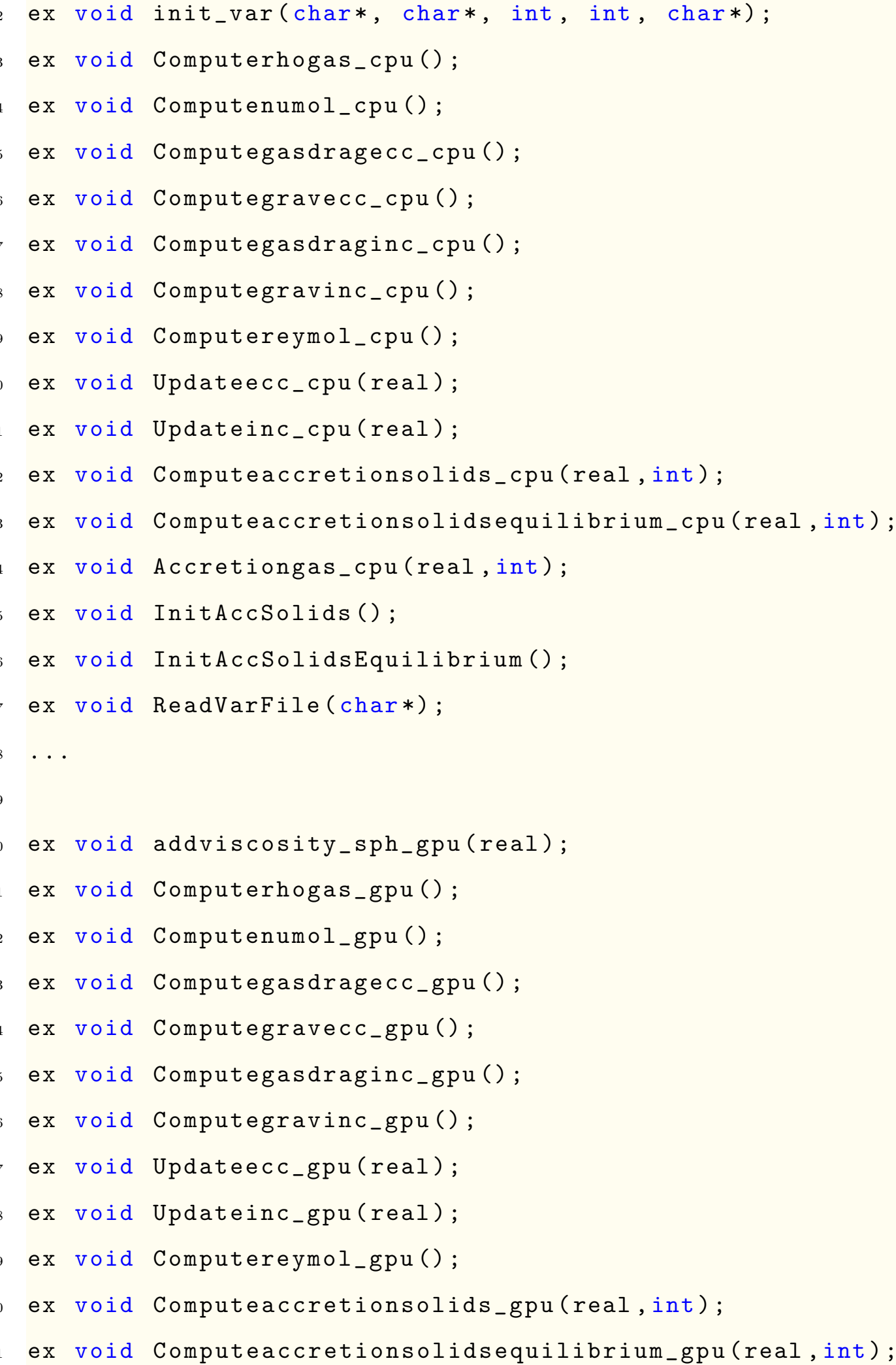




\section{A.4.5.2 Comentários gerais}

Nesse arquivo, seguindo o procedimento do manual (seção Developing a complex setup), inicializamos as funções cadastradas em global.h (ver apêndice A.4.1), que serão rodadas na CPU ou na GPU de acordo com a conveniência.

Note que apenas as funções InitAccSolids e InitAccSolidsEquilibrium não possuem uma correspondente na GPU. Isso ocorre porque essas funções são executadas apenas uma vez durante o início do programa, portanto, não estão dentro do loop hidrodinâmico. Logo, não há necessidade de uma implementação GPU para elas.

\section{A.4.6 Arquivo comm.c}

\section{A.4.6.1 Transcrição das modificações no código}

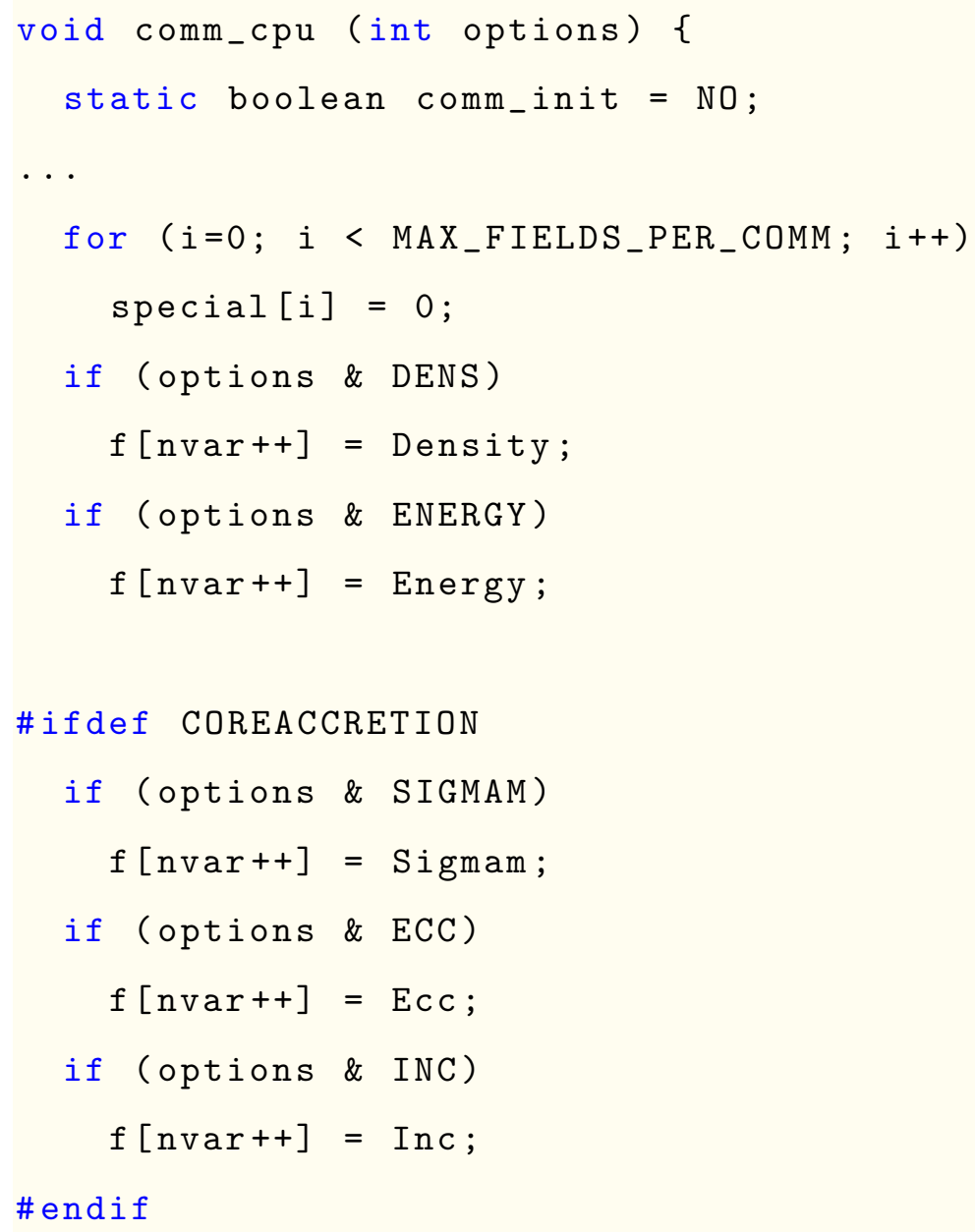




\section{A.4.6.2 Comentários gerais}

Acrescenta as novas variáveis primitivas para realização da comunicação GPU - > CPU.

\section{A.4.7 Arquivo comm_device.c}

\section{A.4.7.1 Transcrição das modificações no código}

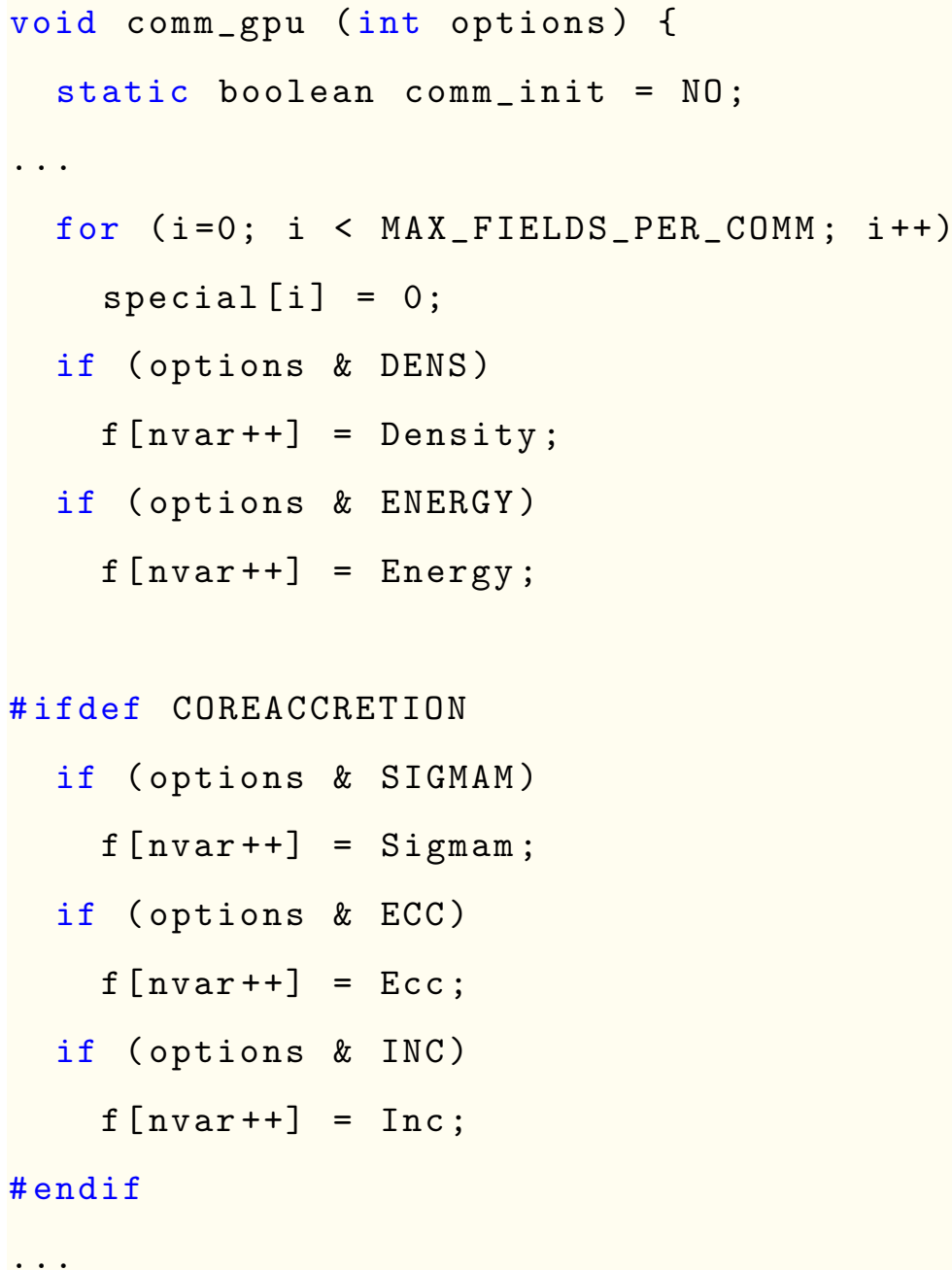

\section{A.4.7.2 Comentários gerais}

Acrescenta as novas variáveis primitivas para realização da comunicação GPU - > CPU. 


\section{A.4.8 Arquivo setup.objects}

\section{A.4.8.1 Transcrição do código}

1 MAINOBJ $+=$ computerhogas.o

2 GPUOBJ $+=$ computerhogas_gpu.o

3

4 MAINOBJ $+=$ computenumol.o

5 GPUOBJ $+=$ computenumol_gpu.o

6

7 MAINOBJ $+=$ computereymol.o

8 GPUOBJ $+=$ computereymol_gpu.o

10 MAINOBJ $+=$ computegasdragecc.o

11 GPUOBJ $+=$ computegasdragecc_gpu.o

12

MAINOBJ $+=$ computegravecc.o

GPUOBJ $+=$ computegravecc_gpu.o

15

MAINOBJ $+=$ computegravinc.o

GPUOBJ $+=$ computegravinc_gpu.o

MAINOBJ $+=$ updateecc.o

GPUOBJ $+=$ updateecc_gpu.o

MAINOBJ $+=$ updateinc.o

GPUOBJ $+=$ updateinc_gpu.o

MAINOBJ $+=$ computeaccretionsolids.o

GPUOBJ $+=$ computeaccretionsolids_gpu.o

MAINOBJ $+=$ computeaccretionsolidsequilibrium.o 
if $($ strcmp (name, "computenumol") == 0$)\{$ if ( strval [0] == ' $g$ ') \{

Computenumol = Computenumol_gpu;

printf("Computenumol hook runs on the GPU \n"); \}

\}

if $($ strcmp (name, "computereymol") $==0)\{$

if ( $\operatorname{strval}[0]=={ }^{\prime} g$ ') \{

Computereymol = Computereymol_gpu;

printf("Computereymol hook runs on the GPU \n"); \}

\}

if $($ strcmp (name, "computegasdragecc") $==0)\{$ if (strval $[0]==$ ' $g$ ') \{

Computegasdragecc $=$ Computegasdragecc_gpu;

printf ("Computegasdragecc hook runs on the GPU \n"); \}

\}

if $($ strcmp (name, "computegravecc") $==0)\{$ if (strval [0] == ' $g$ ') \{

Computegravecc = Computegravecc_gpu;

printf("Computegravecc hook runs on the GPU $\backslash n$ "); \}

\}

if ( $\operatorname{strcmp}$ (name, "computegasdraginc") $==0)\{$

if ( strval [0] == ' $g$ ') \{

Computegasdraginc $=$ Computegasdraginc_gpu;

printf ("Computegasdraginc hook runs on the GPU $\backslash n "$ ); 
\}

if $($ strcmp (name, "updateecc") $==0)\{$

if ( strval [0] $\left.=={ }^{\prime} g{ }^{\prime}\right)\{$

Updateecc = Updateecc_gpu;

printf("Updateecc hook runs on the GPU \n");

\}

\}

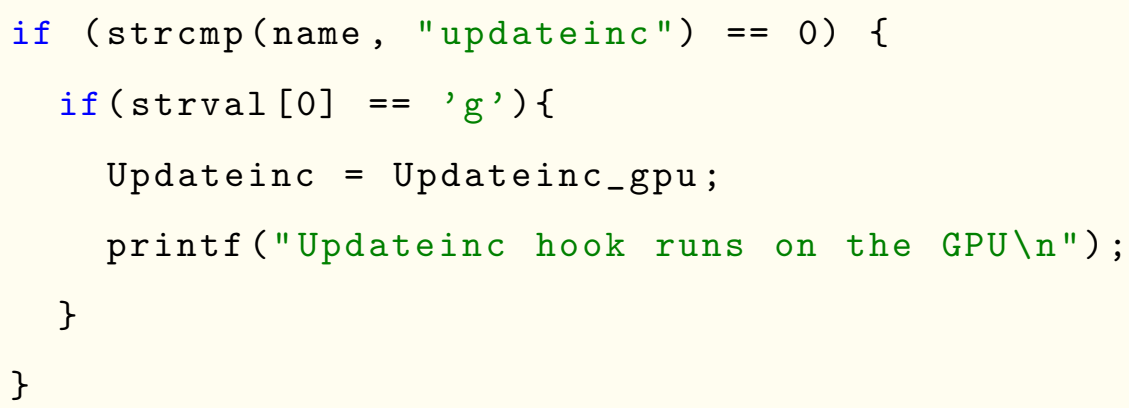




\section{A.4.9.2 Comentários gerais}

A incorporação de um kernel exige a manipulação do arquivo func_arch.cfg e charge_arch.c para acrescentar os apontadores para a função. Para isso, seguindo o procedimento descrito no manual (seção Developing a complex setup), nós acrescentamos os apontadores para todas as novas funções descritas em global.h (ver apêndice A.4.1). Todas as novas funções que serão lidas na GPU têm uma referência nesse arquivo.

\section{A.4.10 Arquivo func_arch.cfg}

\section{A.4.10.1 Transcrição das modificações no código}

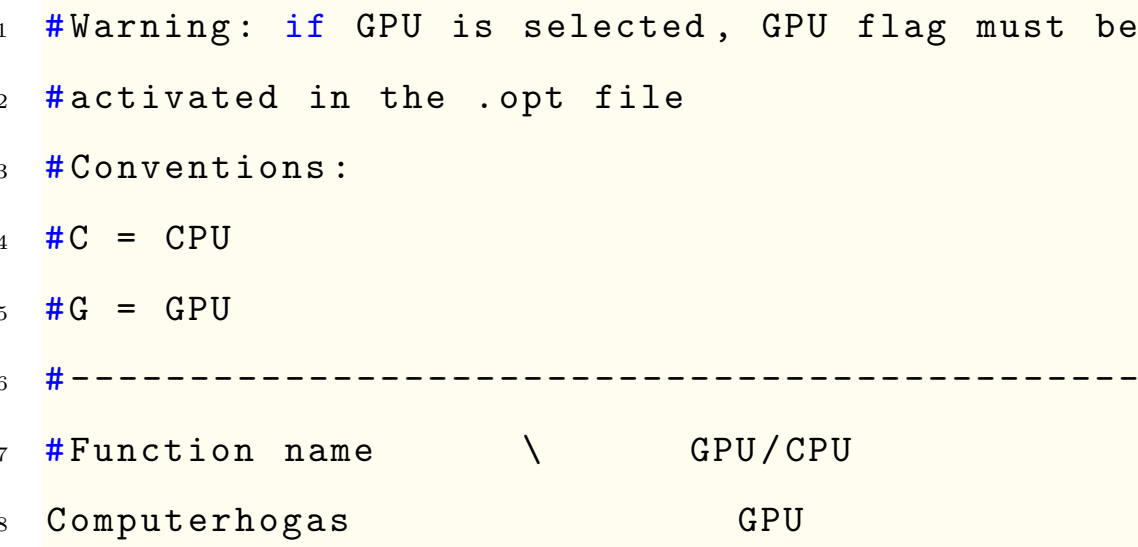




\section{A.4.10.2 Comentários gerais}

A incorporação de um kernel exige a manipulação do arquivo func_arch.cfg e charge_arch.c para acrescentar os apontadores para a função. Para isso, seguindo o procedimento descrito no manual (seção Developing a complex setup), nós acrescentamos os apontadores para todas as novas funções descritas em global.h (ver apêndice A.4.1). Todas as novas funções que serão lidas na GPU têm uma referência nesse arquivo.

\section{A.5 Arquivo output.c}

A.5.0.1 Transcrição das modificações no código

7 if (Sys $==$ NULL) return;
GPU

GPU

GPU

GPU

GPU

GPU

GPU

GPU

GPU

GPU

GPU

GPU 


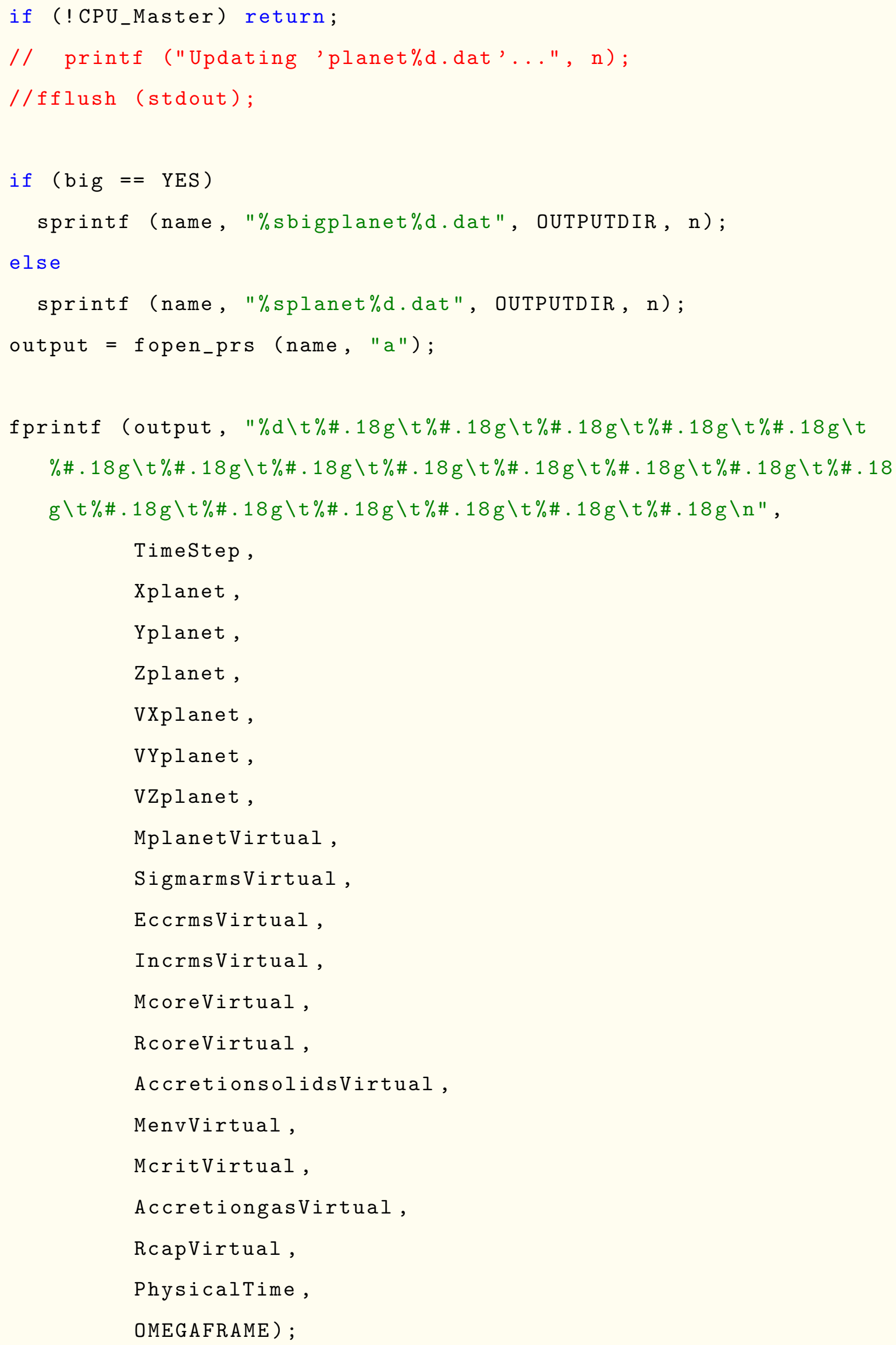




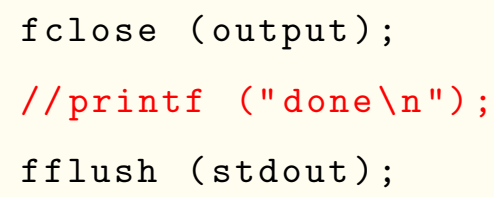




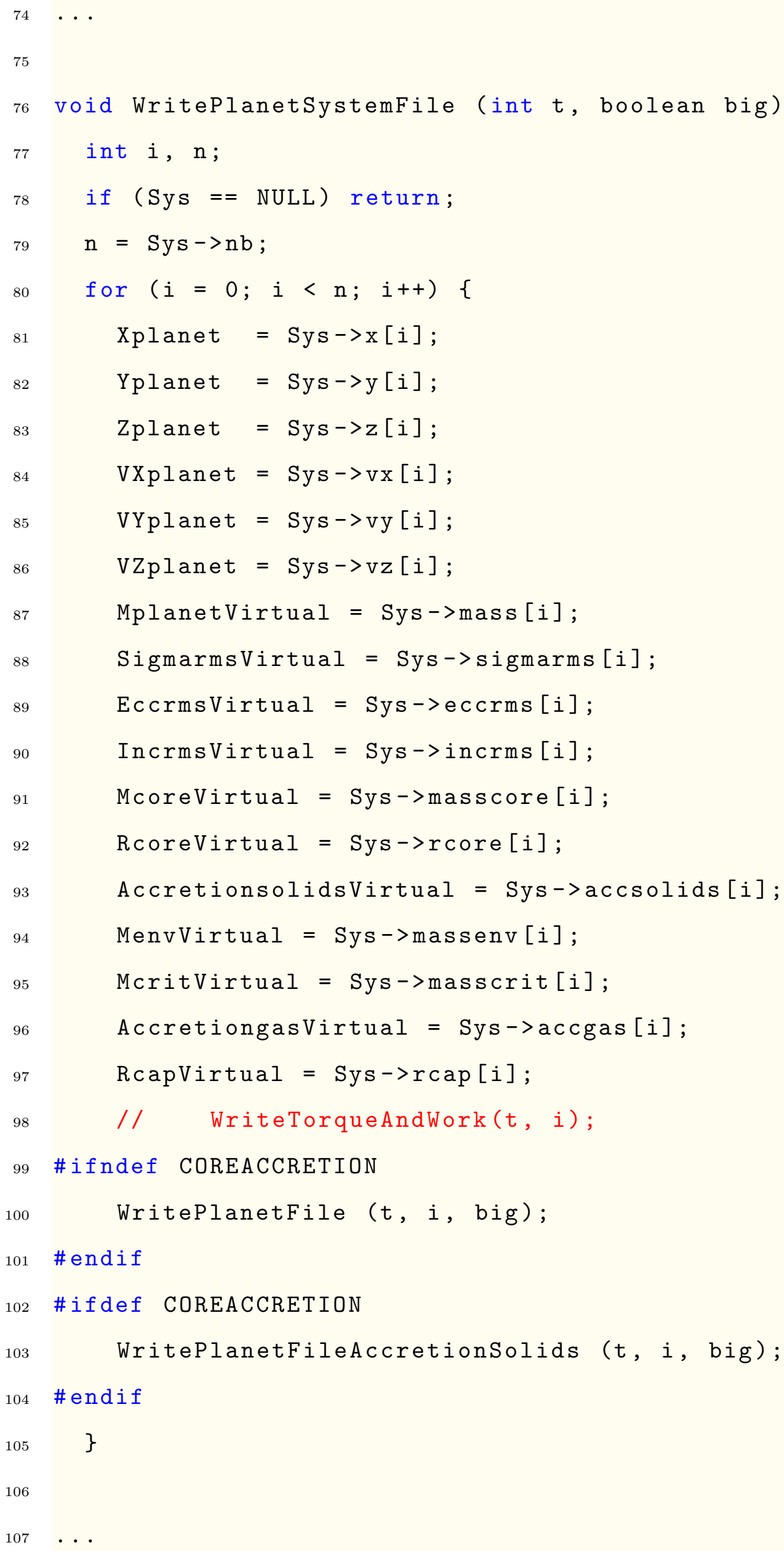


void WriteOutputsAndDisplay (int type) \{

110

111 


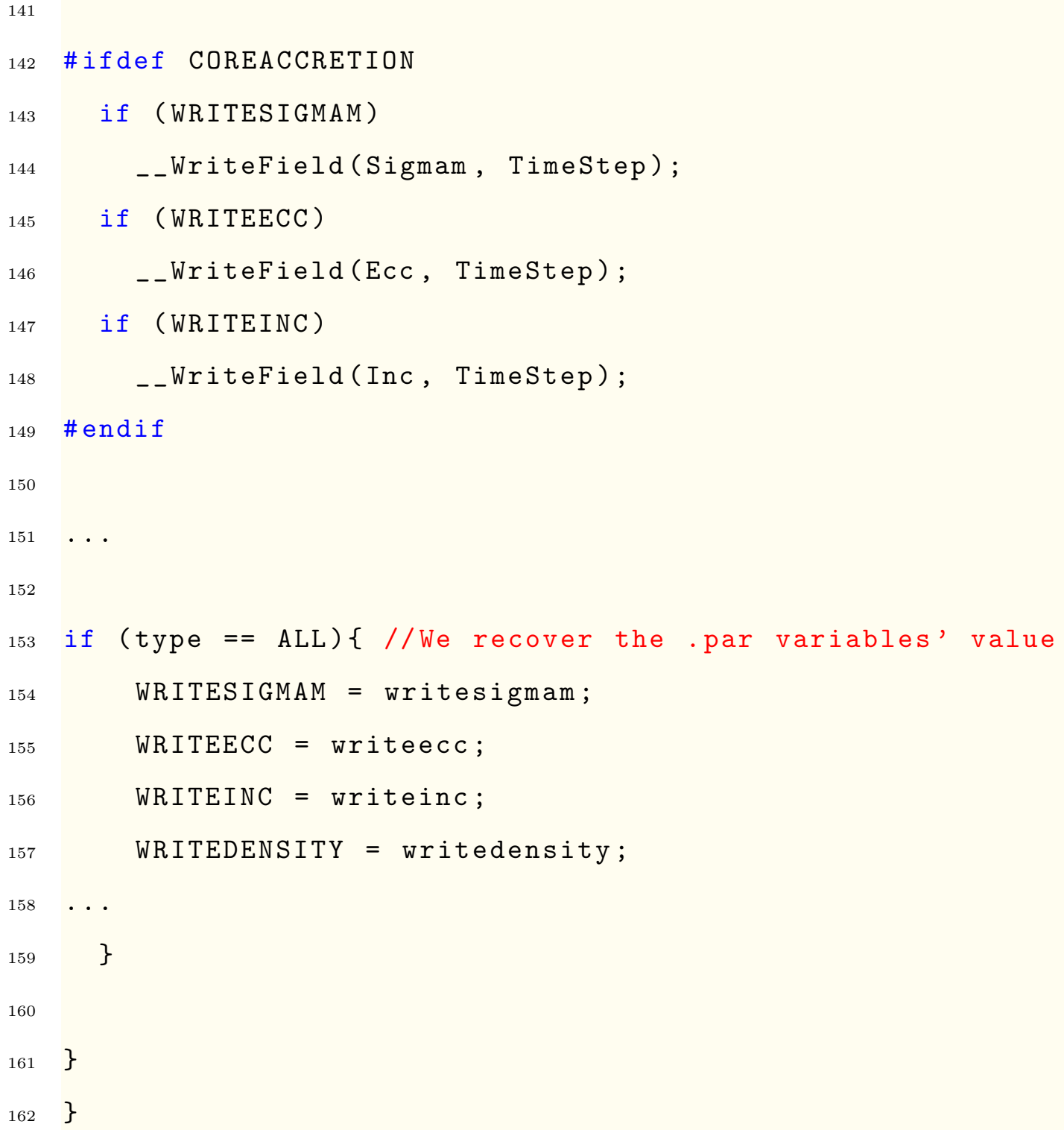

$162\}$

\section{A.5.0.2 Comentários gerais}

Nós modificamos os arquivo output. c criando uma nova função (linhas 3 a 44), para que, caso o usuário escolha a opção para formação de um núcleo sólido (linha 102 a 104) no arquivo setup.opt (ver apêndice A.1), sejam impressos os valores das novas variáveis da struct planetary_system (ver apêndice A.4.3 no arquivo de saída planetX.dat.

As outras modificações seguem a mesma estrutura usada para as variáveis já cadastradas no arquivo, como guardar os valores da struct nas variáveis (linhas 80 a 97) ou reiniciar as variáveis (linhas 53 a 71$)$.

É importante destacar que o usuário pode optar por imprimir os arquivos com as novas variáveis primitivas de campo manipulando as linhas 124 a 130 . 


\section{A.6 Modificação do arquivo foundam.h}

A.6.1 Transcrição das modificações no código

/* \file fondam.h

2

3 This file contains all the information needed to work in a given

4 system of units. Contains fundamental constants used thorough the 5 code.

$6 * /$

7

$8 / * R_{-} M U$ : ideal gas constant divided by mean molecular weight (R/八 $\mathrm{mu}) * /$

9

\#define MEARTH_S

\section{//Scale free}

PI $\quad 3.141592653589793$

NA $6.022 \mathrm{e} 23$ //Avogadro constant

$$
\text { \#define G_SF } 1.0
$$




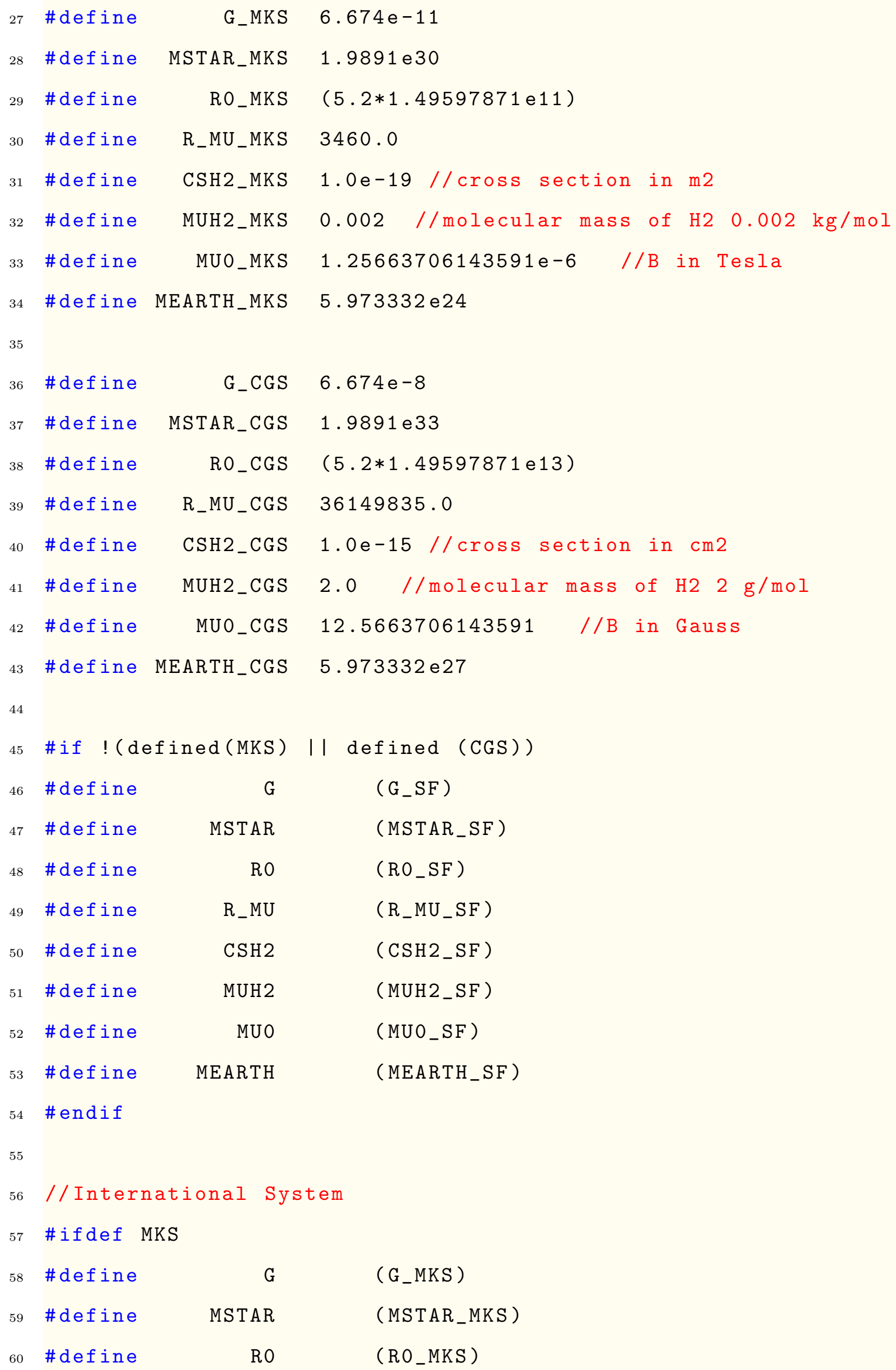




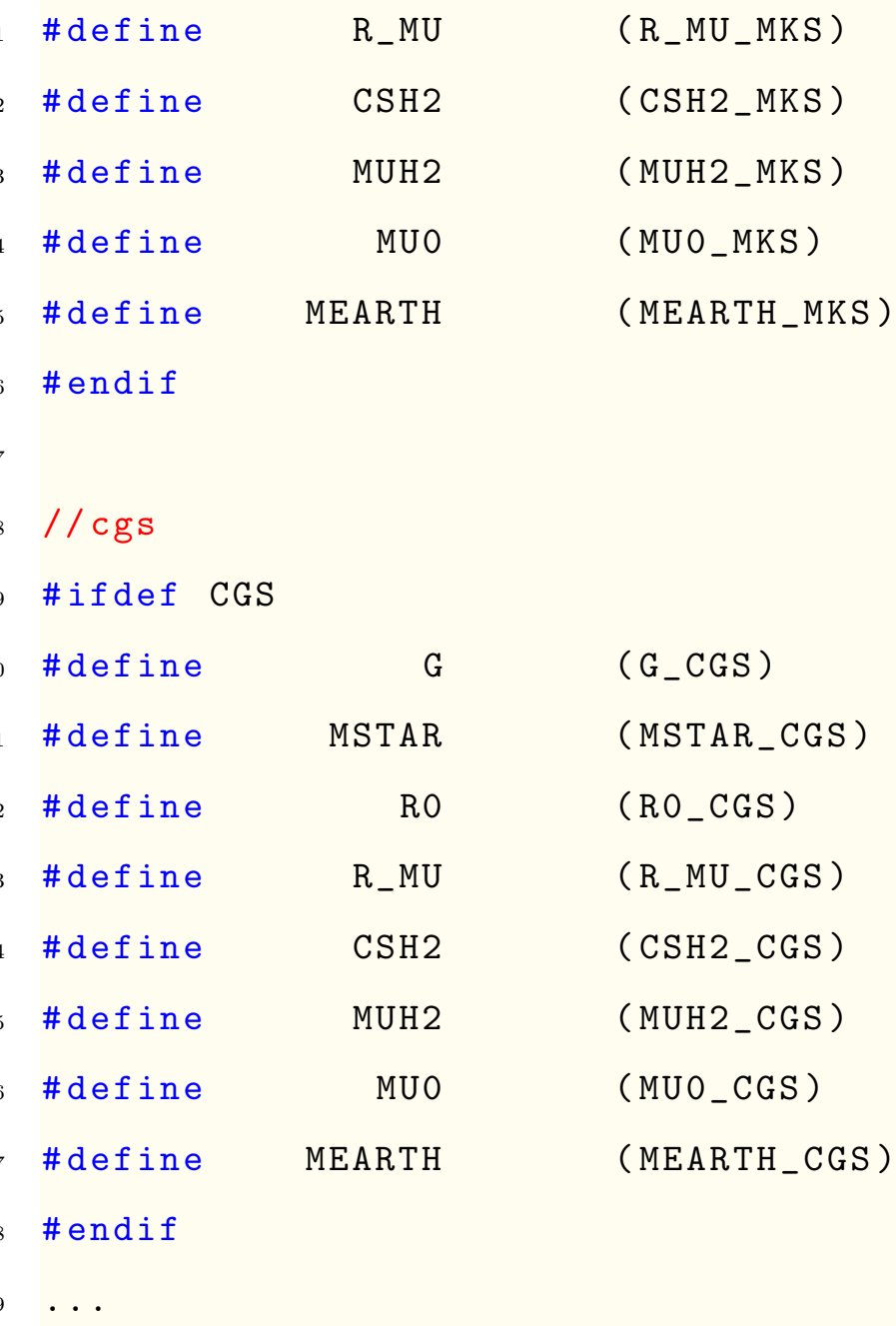

\section{A.6.2 Comentários gerais}

A transcrição acima mostra as mudanças que foram incorporadas ao arquivo foundam .h. Na linha 14, nós definimos o número pi (PI), usado frequentemente em várias operações, e, na linha 15, o número de Avogrado (NA), que também é adimensional.

Três novas variáveis foram definidas para uso no modelo de formação planetária, são elas:

- Seção de choque da molécula de hidrogênio (CSH2) - trata-se de uma estimativa da área frontal de uma molécula de $\mathrm{H}_{2}$. Aqui usamos o valor de $1.0 \times 10^{-15} \mathrm{~cm}^{2}$ (linha 40), e seus respectivos valores em outros sistemas de unidades (linha 22 e 31).

- Massa molecular do $\mathrm{H}_{2}$ (MUH2) - usamos o valor de $2 \mathrm{~g} / \mathrm{mol}$ (linha 41). Os valores para outros sistemas de unidades podem ser encontrados nas linhas 23 e 32 .

- Massa da Terra (MEARTH) - trata-se do valor da massa da Terra em vários sistemas 
de unidades (linha 25, 34 e 43).

As outras linhas acrescentadas no código são usadas para trocar o valor da unidade da variável de acordo com o sistema de unidades definido pelo usuário.

\section{A.7 Arquivo setup.par}

\section{A.7.1 Transcrição do código}

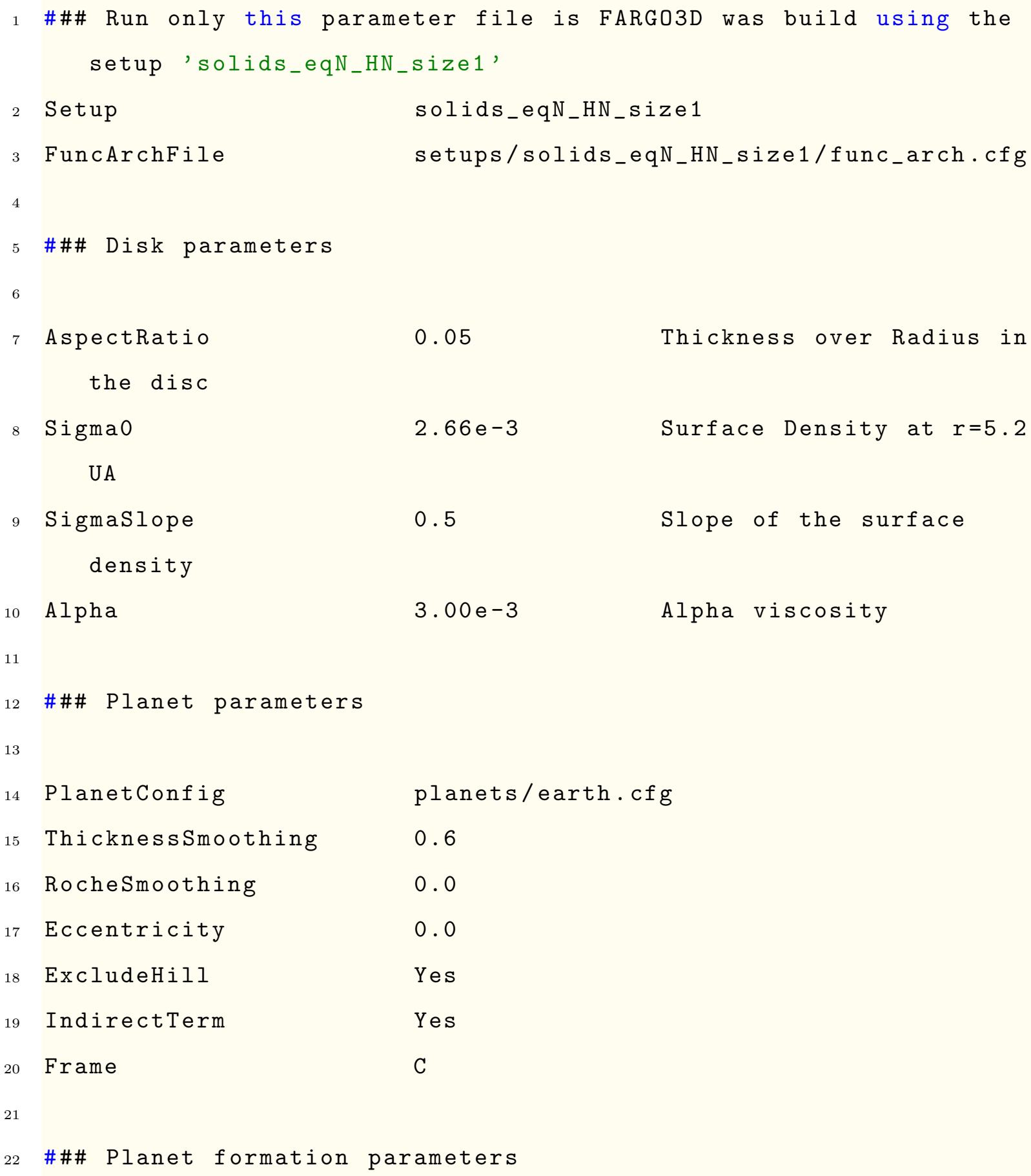


23 rice

UA )
0.03

0.25

2.37 e 8

7.57 e 8

1. $28549 e-10$

aprox $0.1 \mathrm{~km}$ )

1.0

7.57 e 8

10.0

b

\#\#\# Mesh parameters

$\mathrm{Nx}$

Ny

Xmin

$\mathrm{Xmax}$

Ymin

$(=1.56$ UA $)$

$40 \quad Y \max$

$(=15.6 \mathrm{UA})$

42

$44 \quad$ Ntot

( $5.3 \quad 10^{-7}$ anos)

45 Ninterm

300

(178 anos)

$46 \quad \mathrm{DT}$

orbit

$47 \quad$ OutputDir
Position of line ice $(=3$

fraction of dust/gas

degree of condensation

mean density of ice

mean dentity of rocky

radius of planetesimals (

coefficient drag

planetesimals bulk density

width of the feeding zone
583

251

$-3.14159265358979323844$

3. 14159265358979323844

0.3 Inner boundary radius em metros

3.0

Outer boundary radius em metros
Azimuthal number of zones

Radial number of zones 


\section{A.7.2 Comentários gerais}

Esse arquivo começa com o nome do setup e com o caminho do arquivo func_arch.cfg (linha 2 e 3), no qual estão listadas todas as funções que serão habilitadas para uso na GPU ou CPU (ver apêndice A.4.10).

Os valores dos parâmetros acima em unidades adimensionais do código. Caso deseje, o leitor pode alterar as unidades de acordo com sua conveniência. Aqui preferimos deixar as unidades adimensionais e usar o comando make RESCALE=1 e make UNITS=MKS(ver seção 3.5).

A maioria dos parâmetros estão descritos na seção 3.6, portanto, abaixo vamos descrever apenas os novos parâmetros que foram declarados devido ao modelo de formação planetária. São eles:

- rice (real - linha 23): especifica a posição da linha de gelo, a partir da qual ocorre a diferenciação do material. Recomendamos, inicialmente, a simulação do disco sem planetas para determinação de alguma região de temperatura e/ou pressão de interesse, para enfim, fixar esse valor.

- fdg (real - linha 24): atribui um valor para a razão entre o gás e a poeira. Esse fator é usado no começo da simulação para calcular a densidade superficial de sólidos, com base na densidade superficial de gás. Quanto maior essa razão, mais rápido será o crescimento do núcleo sólido do planeta.

- fri (real - linha 25): ainda com relação à quantidade de poeira, esse valor será aplicado como fator de condensação. Assim, entre a linha de gelo e a estrela, teremos uma quantidade menor de sólidos. A densidade superficial de sólidos sofre, portanto, uma diminuição nessa região por causa da multiplicação desse fator.

- rhoice (real - linha 26): densidade volumétrica dos planetesimais que estão depois da linha de gelo.

- rhorocky (real - linha 27): densidade volumétrica dos planetesimais que estão antes da linha de gelo.

- rm (real - linha 28): valor dos raios dos planetesimais. Todos os planetesimais possuem o mesmo tamanho. 
- cd (real - linha 29): atribui um valor para o coeficiente de arrasto.

- rhom (real - linha 30): valor da densidade volumétrica do bulbo de planetesimais.

- b (real - linha 31): largura total da zona de alimentação do planeta, na qual ele captura os planetesimais.

Os valores dos tempos usados nessa simulação devem ser vistos com cuidado, usamos DT como 1/20 órbitas e uma grande quantidade de outputs (a cada 300 órbitas) num tempo total muito grande. Para isso, desabilitamos vários outputs e só plotamos os valores referentes aos dados planetários. Isso pode ser feito no arquivo output.c (ver apêndice A.5). O leitor deve manipular esses valores de acordo com seus propósitos.

Os parâmetros não descritos aqui podem ser encontrados no manual do FARGO3D.

\section{A.8 Arquivo setup.units}

\section{A.8.1 Transcrição do código}

$$
*=\mathrm{R} 0
$$$$
*=\mathrm{RO}
$$$$
*=\operatorname{MSTAR} /(\mathrm{RO} * \mathrm{RO} * \mathrm{RO})
$$$$
*=\operatorname{MSTAR} /(\mathrm{RO} * \mathrm{R} 0 * \mathrm{R} 0)
$$$$
*=\operatorname{MSTAR} /(\mathrm{RO} * \mathrm{R} 0 * \mathrm{R} 0)
$$

\section{A.8.2 Comentários gerais}

Esse arquivo contém as regras de transformação de unidades para os parâmetros novos definidos em setup.par (ver apêndice A.7). O programa irá substituir os valores de MSTAR e R0 de acordo com o sistema de unidades escolhido (ver apêndice A.6). Mais detalhes podem ser encontrados na seção 3.5 .

\section{A.9 Arquivo Fluxdensityy_cpu.c}

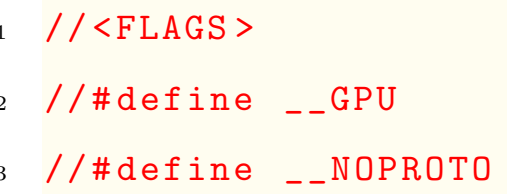




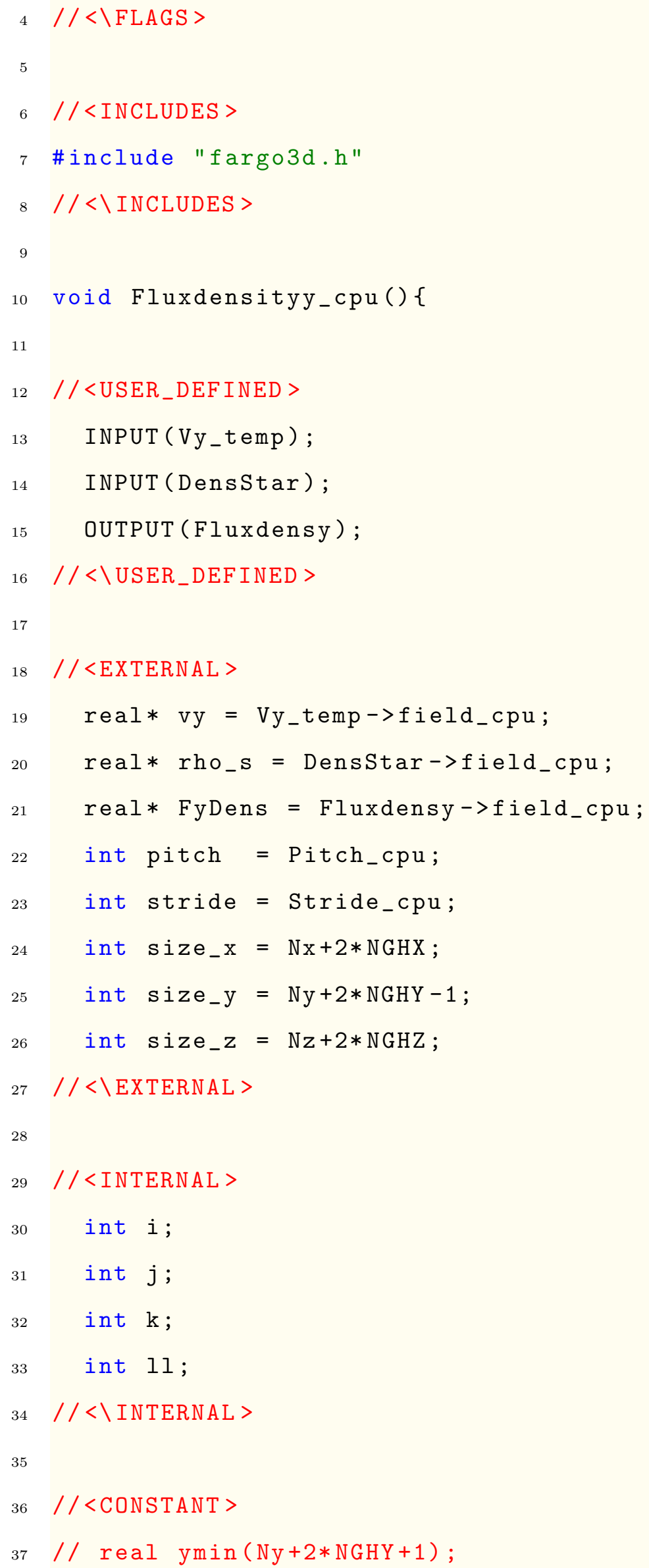




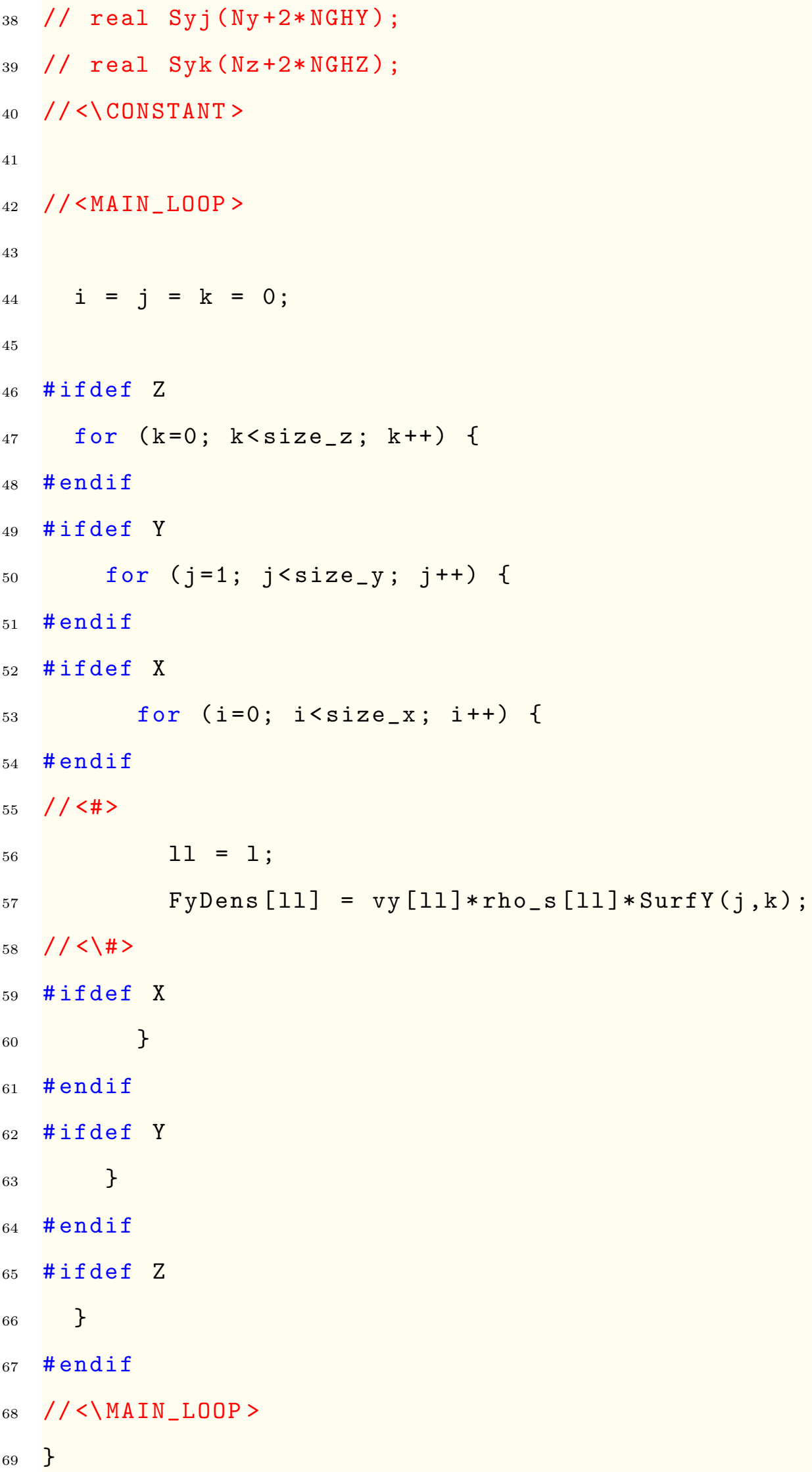




\section{A.9.1 Comentários gerais}

Esse arquivo foi construído apenas para cálculo do fluxo através da célula na direção radial. Ele não faz parte do programa de formação planetária. Assim, não o detalharemos. No entanto, caso o leitor deseje reproduzir alguns resultados desta tese essa transcrição pode ser útil. 


\section{Apêndice B}

Estrutura do programa de formação planetária dentro do FARGO3D

\section{B.1 Arquivo main.c}

B.1.1 Transcrição das modificações no código

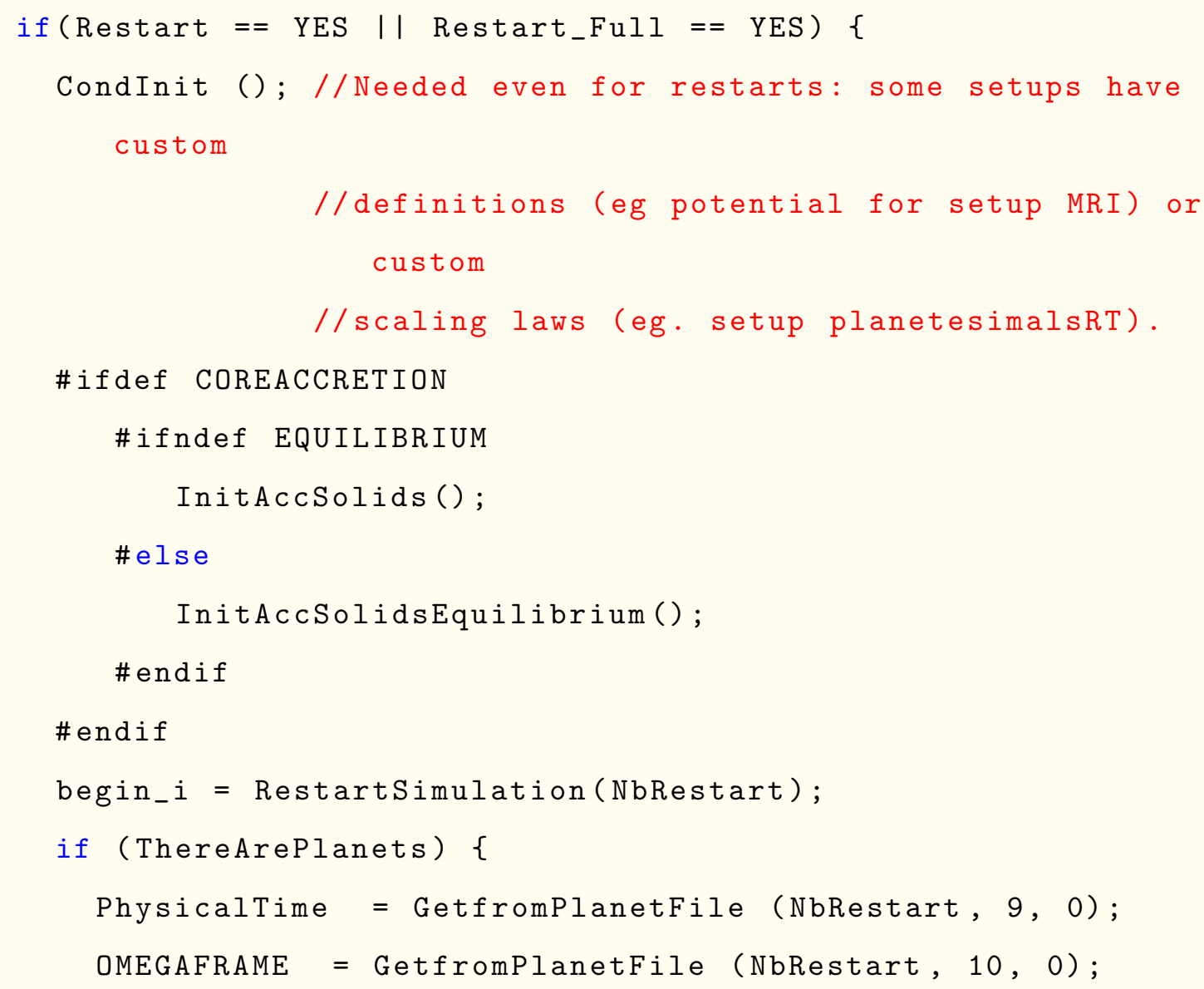




\section{B.1.2 Comentários gerais}

As modificações inseridas na função main. c foram realizadas com o intuito de inicializar alguns parâmetros necessários ao modelo de formação planetária.

A inicialização do modelo de formação planetária é realizada após a leitura do arquivo de condições iniciais (ver apêndice A.2. Em seguida, o programa verifica o modelo que o usuário irá adotar. Os modelos possuem condições iniciais específicas para inicialização dos parâmetros planetários responsáveis pela formação planetária.

Há duas condições possíveis: a primeira se refere à situação fora de equilíbrio para o cálculo da excentricidade e da inclinação quadráticas médias dos planetesimais ao longo da malha do disco, e é realizada pela função InitAccSolids (ver apêndice B.2), enquanto a segunda se refere à situação em equilíbrio e é obtida pela função InitAccSolidsEquilibrium (ver apêndice B.3). A escolha é definida pelo usuário no arquivo setup.opt por meio da ativação da variável de macrocomando EQUILIBRIUM (ver apêndice A.1). 


\section{B.2 Arquivo initAccsolids.c}

\section{B.2.1 Transcrição do código}

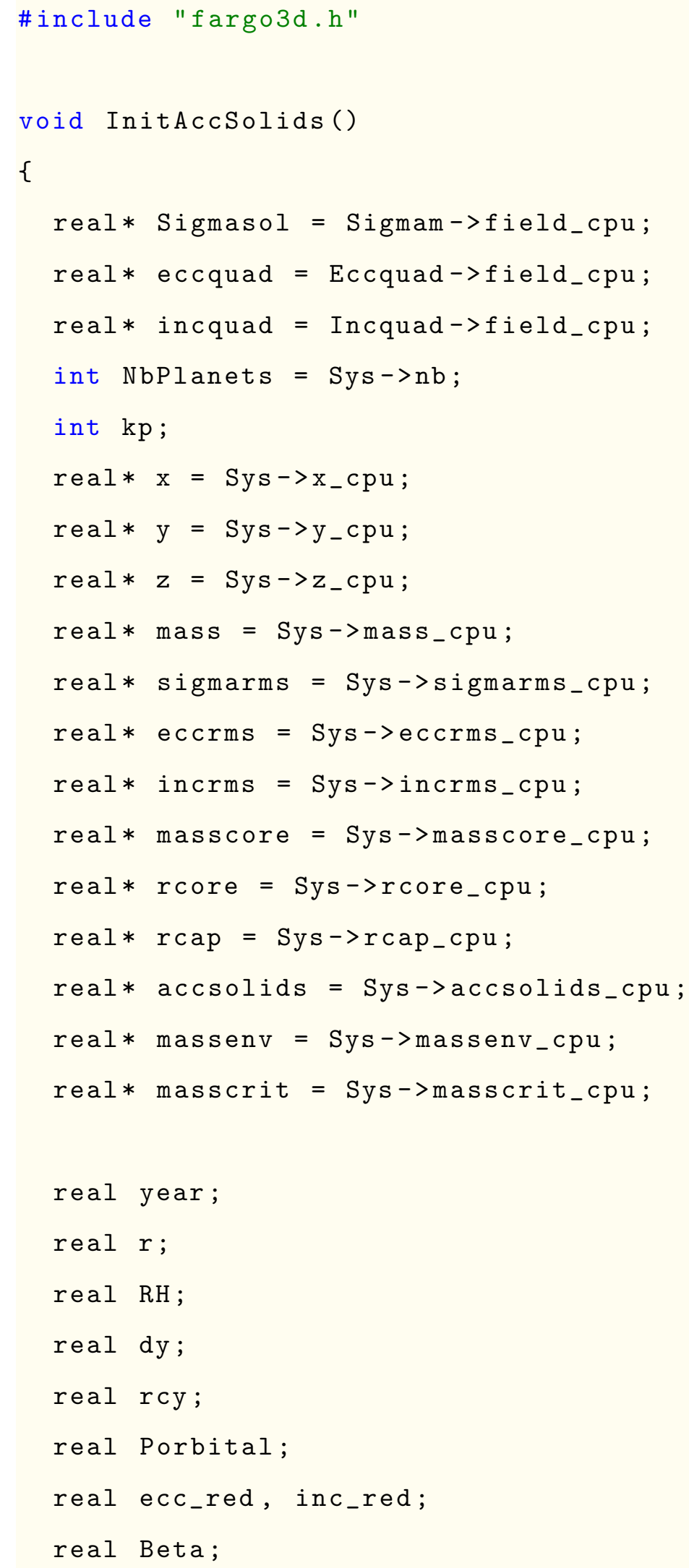




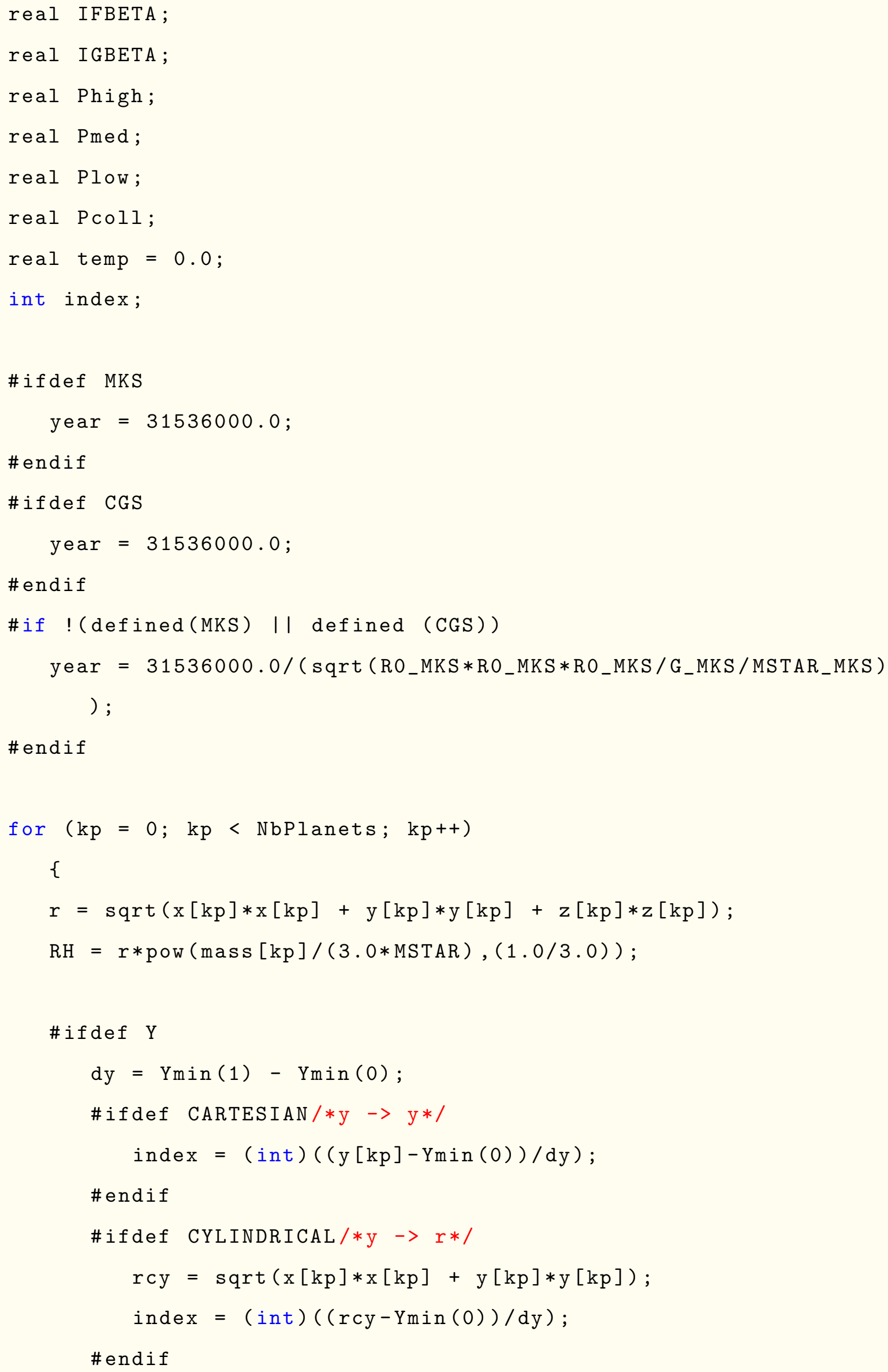




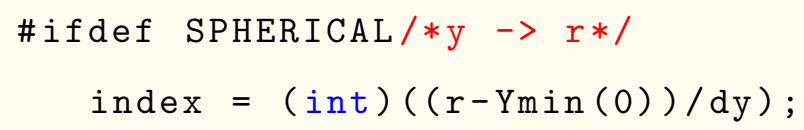


MPI_Allreduce (\&eccrms [kp], \&temp,1,MPI_DOUBLE, MPI_SUM, MPI_COMM_WORLD );

eccrms $[\mathrm{kp}]=$ temp;

MPI_Allreduce (\&incrms [kp], \&temp, 1, MPI_DOUBLE, MPI_SUM, MPI_COMM_WORLD );

incrms $[\mathrm{kp}]=$ temp;

\#endif

if (mass $[\mathrm{kp}]>10.0 * \mathrm{MEARTH})$

\{

masscore $[\mathrm{kp}]=10.0 * \mathrm{MEARTH}$;

masscrit $[\mathrm{kp}]=10.0 * \mathrm{MEARTH}$;

$\operatorname{massenv}[\mathrm{kp}]=\operatorname{mass}[\mathrm{kp}]-\operatorname{masscore}[\mathrm{kp}]$;

rcore $[\mathrm{kp}]=$ pow $(3.0 * \operatorname{masscore}[\mathrm{kp}] /(4.0 * \mathrm{PI} * \mathrm{RHOM}), 1.0 / 3.0)$;

$\operatorname{rcap}[\mathrm{kp}]=\operatorname{rcore}[\mathrm{kp}]$;

accsolids $[\mathrm{kp}]=0.0$;

\}

else

\{

$\operatorname{masscore}[\mathrm{kp}]=\operatorname{mass}[\mathrm{kp}]$

$\operatorname{massenv}[\mathrm{kp}]=0.0$;

rcore $[\mathrm{kp}]=$ pow $(3.0 * \operatorname{masscore}[\mathrm{kp}] /(4.0 * \mathrm{PI} * \mathrm{RHOM}), 1.0 / 3.0) ;$

$\operatorname{rcap}[\mathrm{kp}]=\operatorname{rcore}[\mathrm{kp}]$;

$/ *$ PERIOD ORBITAL $* /$

Porbital $=(2.0 * P I) * \operatorname{pow}((r * r * r) /(G *(\operatorname{MSTAR}+\operatorname{mass}[k p])), 0.5)$;

/*ECCENTRICITY AND INCLINATION REDUCED (see Fortier et. al . , 2012)*/

ecc_red $=r * e c c r m s[k p] / R H ;$

inc_red $=r *$ incrms $[\mathrm{kp}] / \mathrm{RH}$;

/*VALOR OF BETA (see Fortier et. al., 2012)*/ 


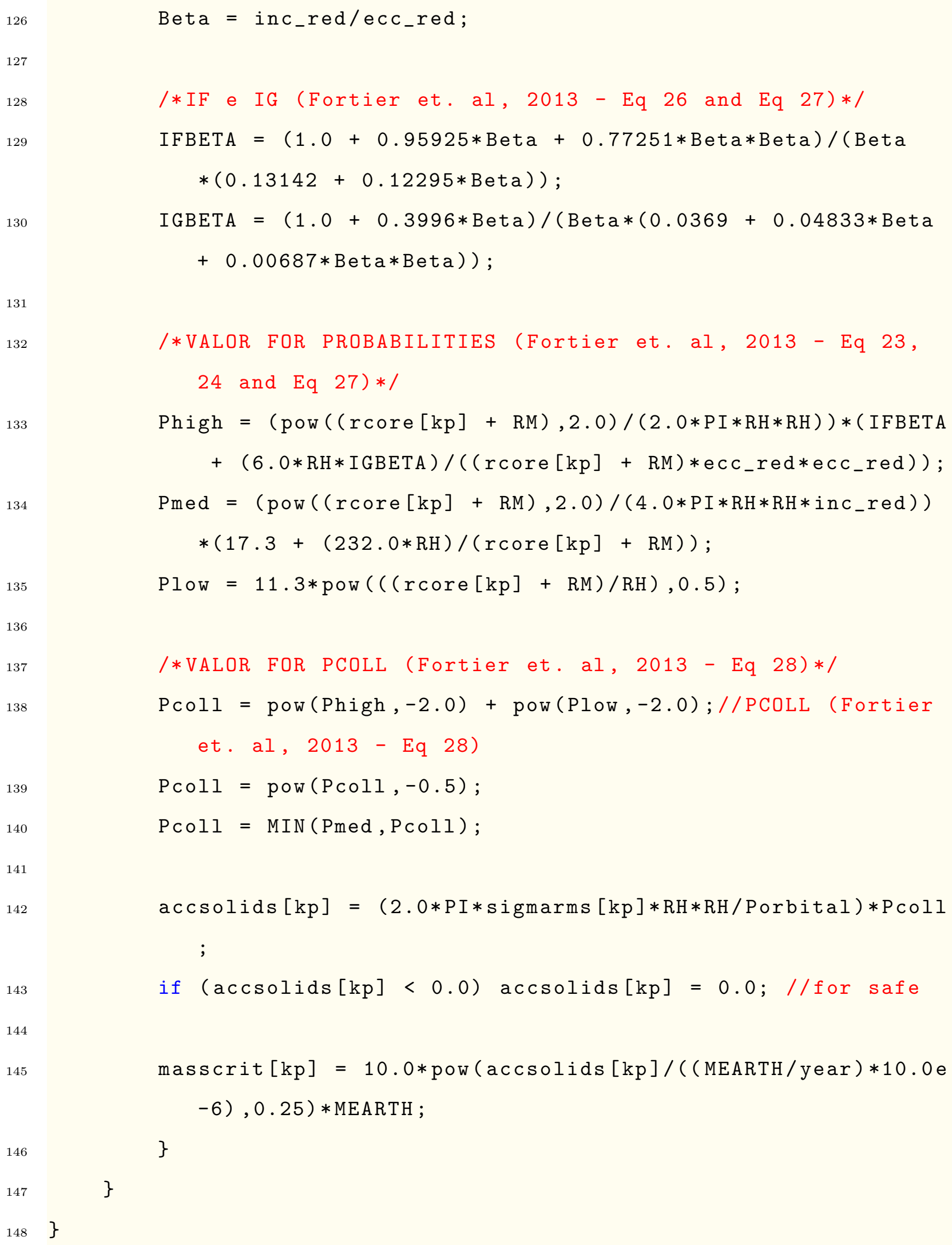




\section{B.2.2 Comentários gerais}

As linhas 53 a 68 são responsáveis pelo cálculo do raio de Hill do planeta e pela localização da posição da célula, que contêm o planeta, na direção y em vários sistemas de coordenadas (ver seção 3.2). Pelo fato de a implementação MPI quebrar a malha em várias submalhas, as linhas 70 a 74 são responsáveis por padronizar um valor nulo para a localização do planeta nas submalhas que não contêm o planeta. Assim, para a submalha que contém o planeta (linha 76), calcula-se a média azimutal da densidade superficial (linha 78), a média azimutal da excentricidade quadrática média (linha 79 e 81) e a média azimutal da inclinação quadrática média (linha 80 e 82). As outras submalhas (quando houver) recebem valores nulos. As linhas 91 a 100 são responsáveis por atribuir os valores obtidos na submalha que contém o planeta para todas as submalhas.

Em seguida, o programa realiza um teste para saber se a massa planetária inicial atribuída pelo usuário é maior que $10 \mathrm{M}_{\otimes}$ (linha 102), caso seja, a massa crítica e a massa do núcleo recebem o valor de $10 \mathrm{M}_{\otimes}$ (linha 104 e 105). Esse é um valor ad hoc adotado como um valor padrão para a massa de um núcleo sólido. A massa do envelope planetário será, portanto, a diferença entre a massa inicial e a massa de $10 \mathrm{M}_{\otimes}$ (linha 106). Perceba que, nesse caso, a taxa de acreção de sólidos recebe o valor nulo (linha 109), pois considera-se um núcleo já completamente formado, cujo raio geométrico é definido na linha 107.

No caso de massas menores que $10 \mathrm{M}_{\otimes}$, calcula-se a taxa de acreção de sólidos por meio da equação 4.130, no qual o período orbital é obtido na linha 119, e a probalidade de acreção nas linhas 120 a 140 (ver equações 4.131, 4.132 e 4.133). Nesse caso, a massa crítica é obtida na linha 145 utilizando a equação 5.27 .

Mais detalhes sobre o modelo podem ser lidos na seção 4.5 e 5.4.5.

A maior parte dos dados obtidos são guardados nas variáveis de struct do planeta (ver apêndice A.4.3.

\section{B.3 Arquivo initAccSolidsEquilibrium.c}

\section{B.3.1 Transcrição do código}

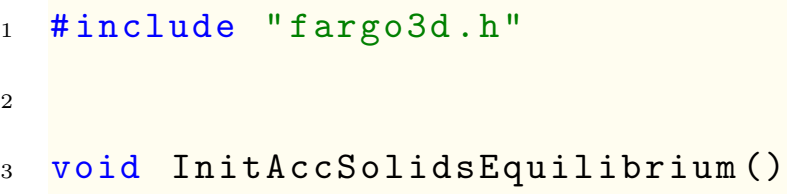




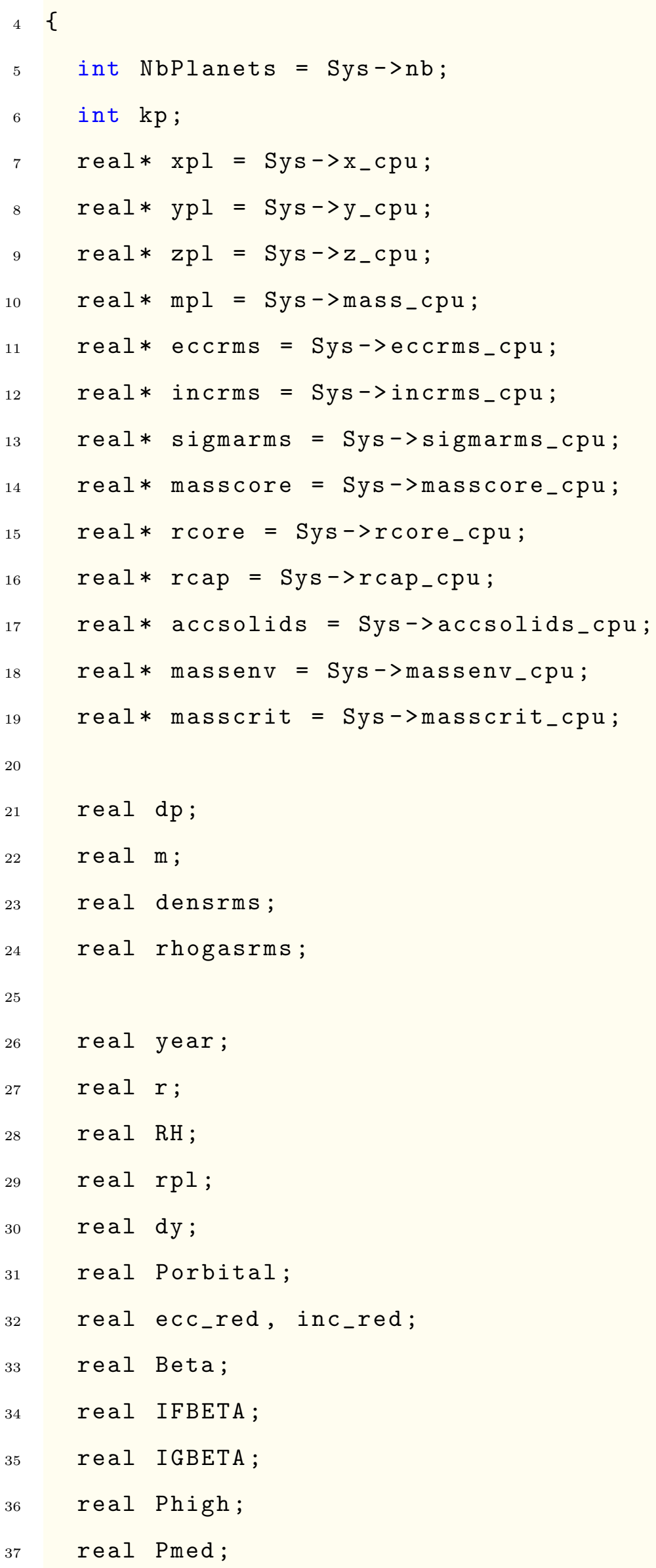




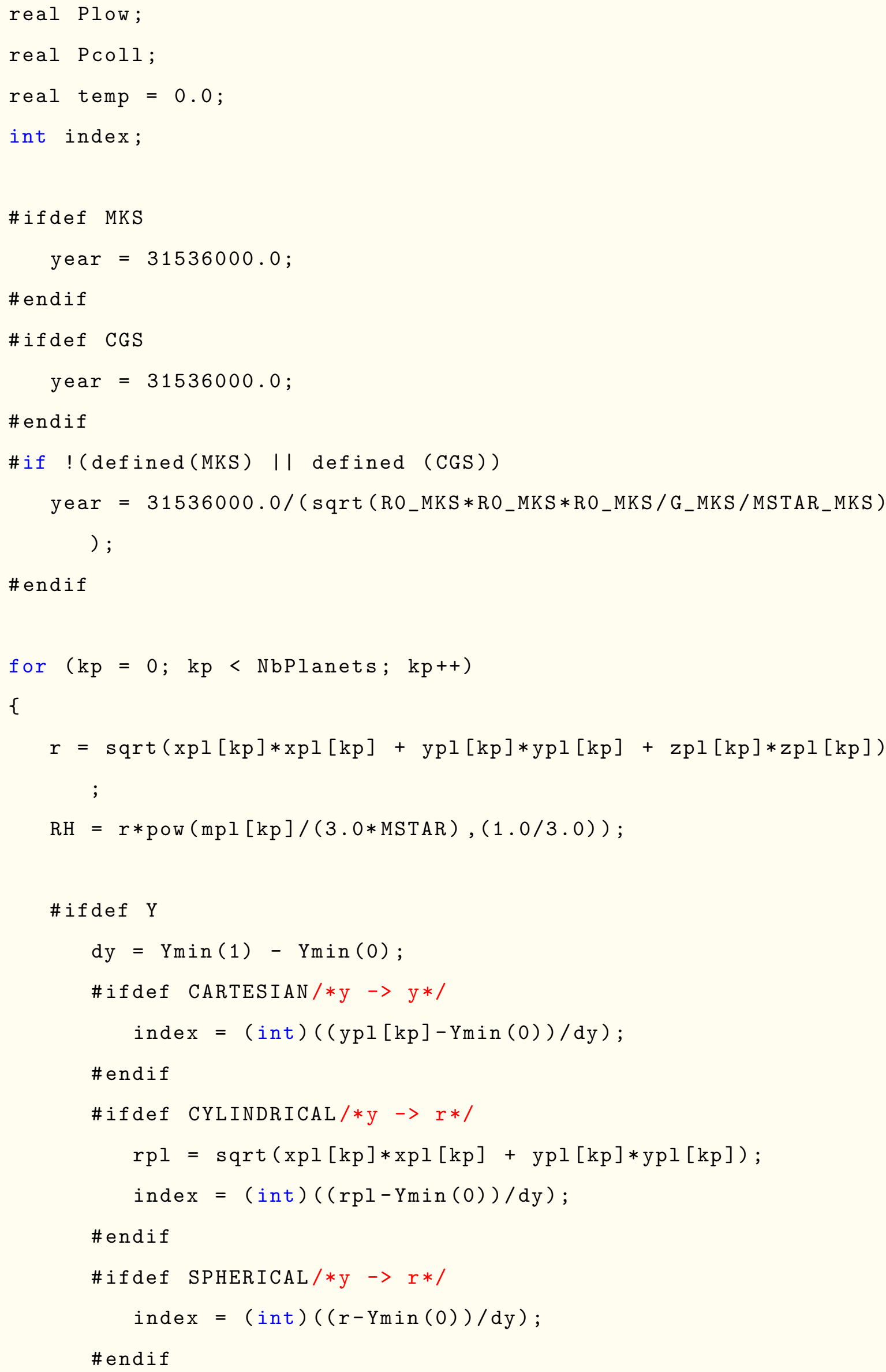


\# endif

\#ifndef __GPU

//for MPI situation - subgrids

if $($ index $<0)$ index $=0$;

if (index $>N y$ ) index $=0$;

\#endif

if (index $!=0$ )

\{

sigmarms $[k p] \quad=$ reduction_full_SUM(Sigmam, index, index $+1,0,1) / N X$;

densrms = reduction_full_SUM(Density, index, index+1,0,1)/ $\mathrm{NX}$;

\}

else

\{

sigmarms $[\mathrm{kp}]=0.0$;

densrms $=0$;

\}

\#ifndef _ _ GPU

MPI_Allreduce (\&sigmarms[kp], \&temp,1, MPI_DOUBLE, MPI_SUM, MPI_COMM_WORLD );

sigmarms $[\mathrm{kp}]=$ temp;

MPI_Allreduce (\&densrms, \& temp, 1, MPI_DOUBLE, MPI_SUM, MPI_COMM_WORLD);

densrms $=$ temp;

\#endif

/*VOLUmetric DENSITY OF GAS In CELL CONTAINING THE PLANET -ARMitage - PLANET FORMATION - EQ. $2.9 * /$

\#ifdef $Z$ 
rhogasrms = densrms;

\# else

rhogasrms $=(1.0 / \operatorname{sqrt}(2.0 * P I)) *($ densrms $/(\operatorname{ASPECTRATIO} * r)) ;$ \#endif

/*WE Calculate ThE Mass OF THE Planetesimal $* *$ /

if $(r<$ RICE) dp = RHOROCKY; //after line ice

else dp = RHOICE; //before line ice

$\mathrm{m}=\mathrm{dp} *(4.0 / 3.0) * \mathrm{PI} * \mathrm{pow}(\mathrm{RM}, 3.0)$;

/*WE Calculate the ECCEntricity and inclination of the

PLANETESIMAl (see Fortier e.t al. 2012 - Eq. 56 and 57*/ eccrms $[\mathrm{kp}]=1.7 *(\operatorname{pow}(\mathrm{m}, 1.0 / 15.0) * \operatorname{pow}(\operatorname{mpl}[\mathrm{kp}], 1.0 / 3.0) *$ pow (

RHOM , 2.0/15.0) )*pow $(B,-1.0 / 5.0) *$ pow $(C D,-1.0 / 5.0) *$ pow (

rhogasrms , -1.0/5.0)*pow(MSTAR, -1.0/3.0)*pow $(r,-1.0 / 5.0)$; incrms $[\mathrm{kp}]=\operatorname{eccrms}[\mathrm{kp}] / 2.0$;

if (mpl[kp] $>10.0 *$ MEARTH)

\{

rcore $[\mathrm{kp}]=\operatorname{pow}(3.0 * \operatorname{masscore}[\mathrm{kp}] /(4.0 * \mathrm{PI} * \mathrm{RHOM}), 1.0 / 3.0)$;

masscore $[\mathrm{kp}]=10.0 * \operatorname{MEARTH}$;

masscrit $[\mathrm{kp}]=10.0 * \mathrm{MEARTH}$;

$\operatorname{massenv}[\mathrm{kp}]=\operatorname{mpl}[\mathrm{kp}]-\operatorname{masscore}[\mathrm{kp}]$;

accsolids $[\mathrm{kp}]=0.0$;

$\operatorname{rcap}[\mathrm{kp}]=\operatorname{rcore}[\mathrm{kp}]$;

\}

else

\{

$\operatorname{masscore}[\mathrm{kp}]=\operatorname{mpl}[\mathrm{kp}]$;

$\operatorname{massenv}[\mathrm{kp}]=0.0$;

rcore $[\mathrm{kp}]=$ pow $(3.0 * \operatorname{masscore}[\mathrm{kp}] /(4.0 * \mathrm{PI} * \mathrm{RHOM}), 1.0 / 3.0)$;

$\operatorname{rcap}[\mathrm{kp}]=\operatorname{rcore}[\mathrm{kp}]$; 


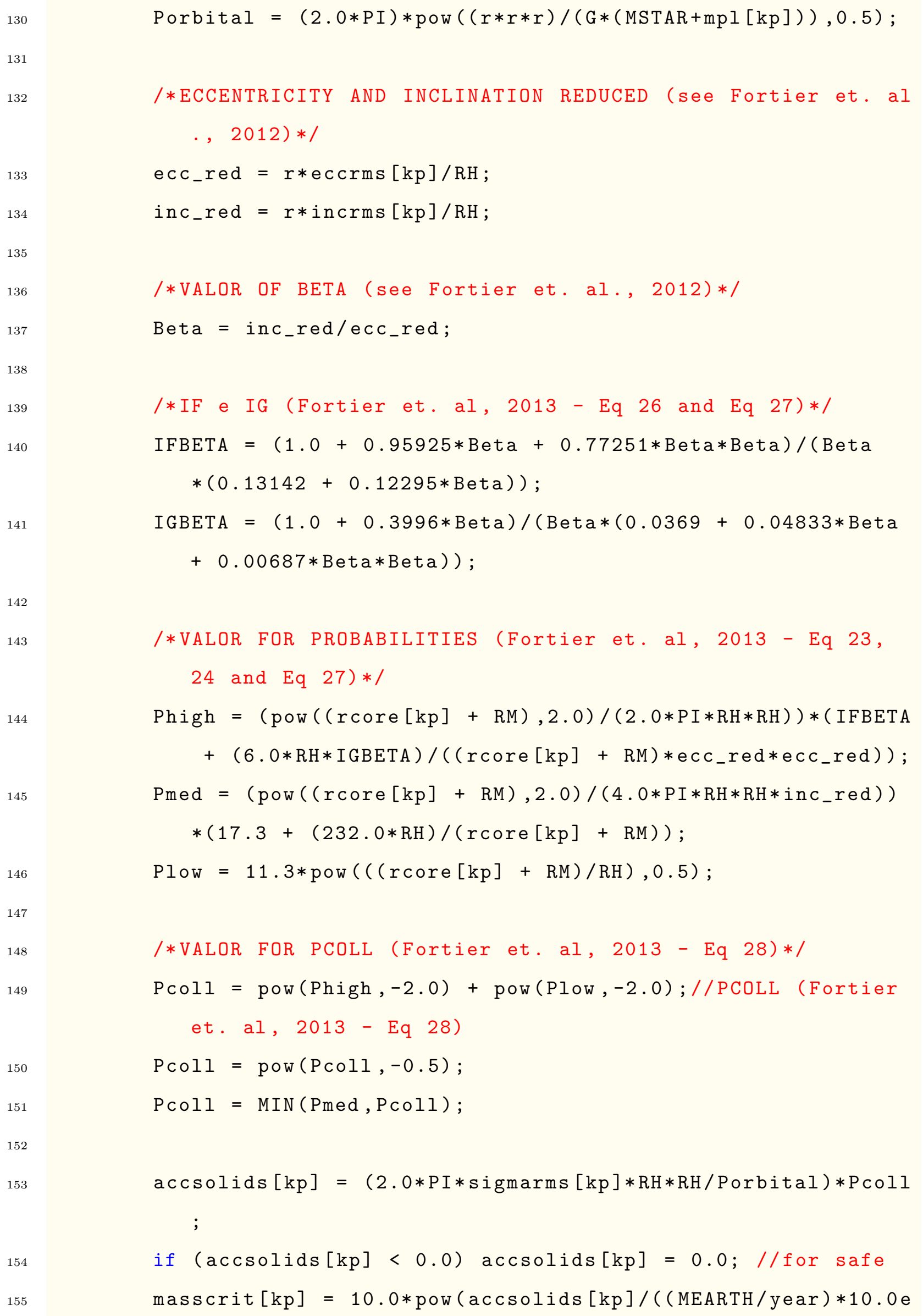


-6), 0.25$) * \mathrm{MEARTH}$;

\section{B.3.2 Comentários gerais}

Essa função é similar à função descrita no apêndice B.2.

A diferença reside no cálculo das médias azimutais das excentricidades e inclinações quadráticas médias. Na situação de equilíbrio, não são utilizados os valores de outras células. Assim, os valores da média azimutal da excentricidade e da inclinação quadráticas médias na situação de equilíbrio são obtidos por meio das expressões analíticas definidas nas linhas 110 e 111 (ver eq. 4.139 e 4.141).

Como a expressão depende da massa dos planetesimais, foram acrescentadas as linhas 105 a 107 para obtenção dessa massa. Lembrando que os planetesimais mudam sua densidade volumétrica de acordo com sua posição em relação à linha de gelo.

O restante do código segue o mesmo procedimento já descrito no apêndice B.2.

\section{B.4 Arquivo AlgoGas.c}

\section{B.4.1 Transcrição das modificações no código}

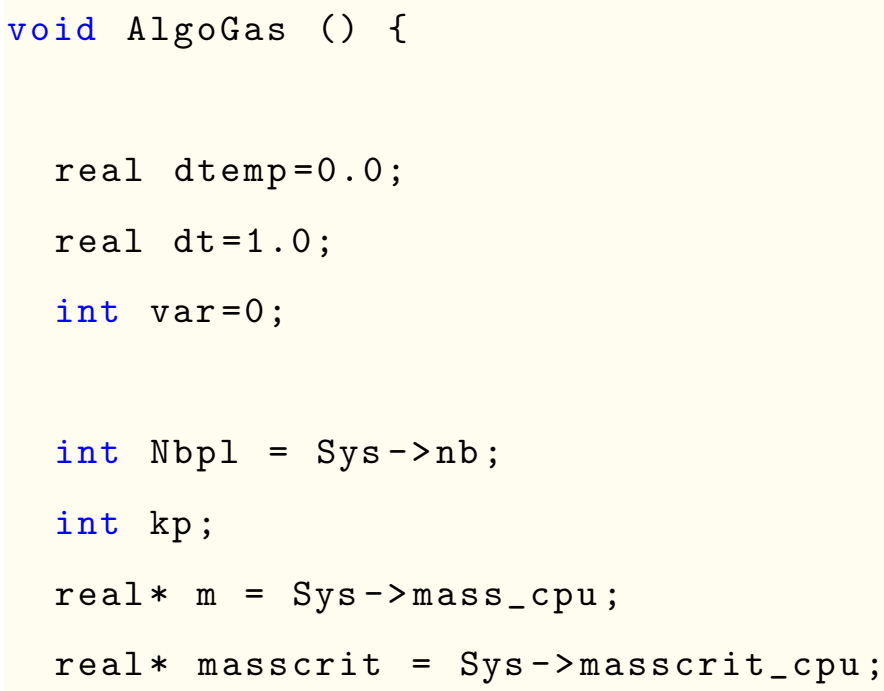




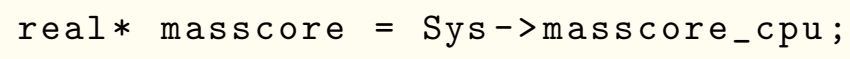




\section{B.4.2 Comentários gerais}

As modificações realizadas na função AlgoGas são responsáveis por chamar as funções do modelo de formação planetária. As chamadas das funções irão depender das variáveis definidas pelo usuário no arquivo SETUP .opt (ver apêndice A.1). 
No caso do modelo fora do equilíbrio, executam-se as linhas 27 a 33. Para o modelo de equilíbrio, essas linhas não são necessárias, e executa-se a linha 35.

Observe que é possível rodar o modelo de acreção de sólidos sem necessidade da acreção de gás (linhas 46 a 51). No entanto, caso o usuário opte pela acreção de sólidos e acreção de gás, o modelo checará se o núcleo alcançou a massa crítica, a partir da qual tem início a acreção de gás. Por isso, foi necessário acrescentar essas variáveis no código (linhas 13 e 14).

Caso o usuário opte apenas pela acreção de gás, as linhas anteriores são puladas e executam-se as linhas 52 a 56 .

A massa do núcleo, da massa crítica e a massa total podem sofrer mudanças durante a passagem em alguma função. Essas mudanças ocorrem sempre na CPU, assim, os valores podem ser enviados para a GPU em alguns momentos (linhas 38 a 42).

Também vale destacar que usamos o método de Euler semi-implícito para resolução do sistema de equações para evolução da excentricidade e inclinação quadrática média em cada célula, assim, primeiro ocorre um update na excentricidade quadrática média de cada célula e, em seguida, esse valor é usado para cálculo do update na inclinação quadrática média de cada célula.

\section{B.5 Arquivo Computerhogas.c}

\section{B.5.1 Transcrição do código}

$1 / /\langle$ FLAGS $>$

2 //\#define _- GPU

3 //\#define _-_NOPROTO

$4 \quad / /<\backslash$ FLAGS $>$

5

$6 / /$ INCLUDES >

7 \#include "fargo $3 d . h "$

$8 / /<\backslash$ INCLUDES >

9

10 void Computerhogas_cpu() \{ 
$/ /<$ USER_DEFINED $>$

INPUT (Density);

OUTPUT (Rhogas);

$/ /<\backslash U S E R \_D E F I N E D>$

$/ /<$ EXTERNAL $>$

real* rhogas = Rhogas->field_cpu;

real $*$ dens $=$ Density $->$ field_cpu;

int pitch = Pitch_cpu;

int stride = Stride spu;

int $\mathrm{size}_{-} \mathrm{x}=\mathrm{NX}+2 * \mathrm{NGHX}$;

int $\mathrm{size}_{-} \mathrm{y}=\mathrm{Ny}+2 * \mathrm{NGHY}$;

int size $_{-} \mathrm{z}=\mathrm{Nz}+2 * \mathrm{NGHZ}$;

$/ /\langle\backslash$ EXTERNAL $>$

$/ /<$ INTERNAL >

int $i$;

int $j$;

int $\mathrm{k}$;

$/ /\langle\backslash$ INTERNAL $>$

$/ /<$ CONSTANT $>$

$/ /$ real $x \min (\mathrm{NX}+2 * \mathrm{NGHX}+1)$;

// real ymin $(\mathrm{Ny}+2 * \mathrm{NGHY}+1)$;

// real zmin $(\mathrm{Nz}+2 * N G H Z+1)$;

// real ASPECTRATIO(1);

$/ /<\backslash$ CONSTANT $>$

$/ /<$ MAIN_LOOP $>$

$i=j=k=0$;

\#ifdef $Z$

for $\left(k=0 ; k<\right.$ size $\left._{-} z k++\right)\{$

\# endif 


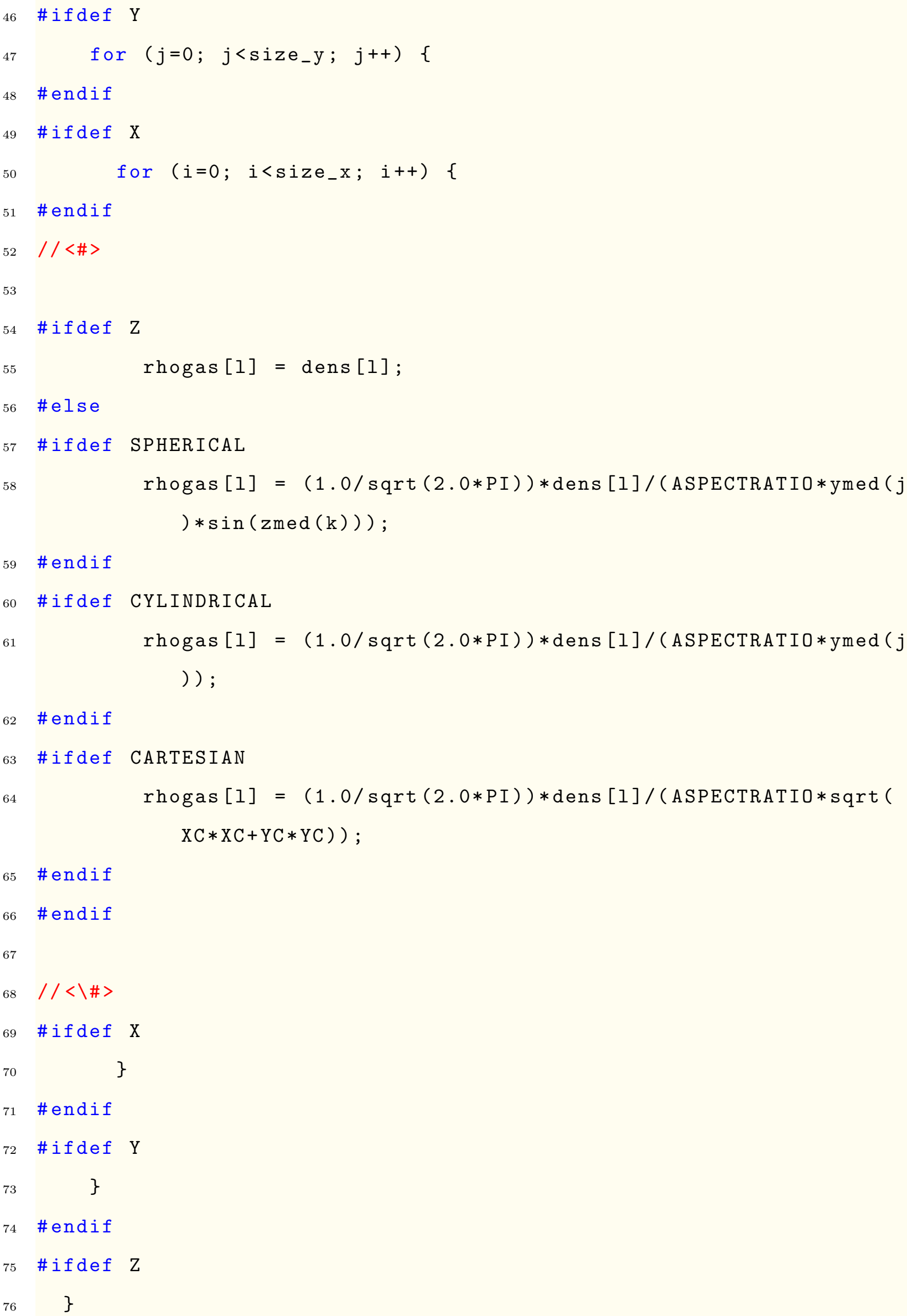


\#endif

$79 \quad\}$

\section{B.5.2 Comentários gerais}

Essa função guarda os valores da densidade volumétrica do gás na variável de campo Rhogas. No caso de uma simulação 3D, esse valor é o próprio valor do campo Density definido pelo usuário e manipulado pelo programa na rotina hidrodinâmica (linha 54 a 56).

No entanto, no caso de uma simulação $2 \mathrm{D}$ ou 1D, precisamos estimar a densidade volumétrica do gás, já que o programa só utiliza a densidade superficial do gás. Nesse caso, vamos utilizar uma estimativa baseada na integração da equação 2.8, obtida para um disco isotérmico (Armitage, 2010), da qual obtemos:

$$
\rho_{\text {gas }}=\frac{1}{\sqrt{2 \pi}} \frac{\Sigma_{\text {gas }}}{h r} .
$$

As linhas 57 a 65 são justamente a declaração da equação acima calculando o valor de $r$ para cada sistema de coordenadas, onde $h$ é a variável ASPECTRATIO definida em setup.par (ver apêndice A.7), e $r$, a distância do centro da célula à origem do sistema de coordenadas.

\section{B.6 Arquivo computenumol.c}

\section{B.6.1 Transcrição do código}

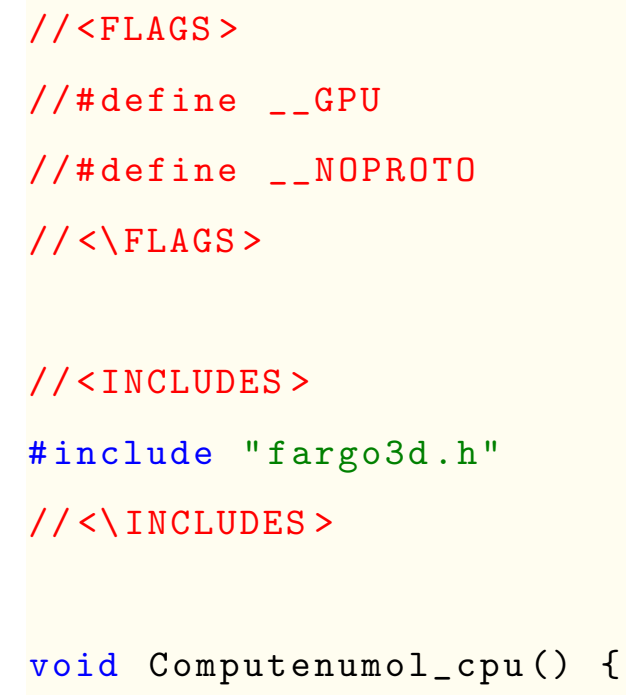




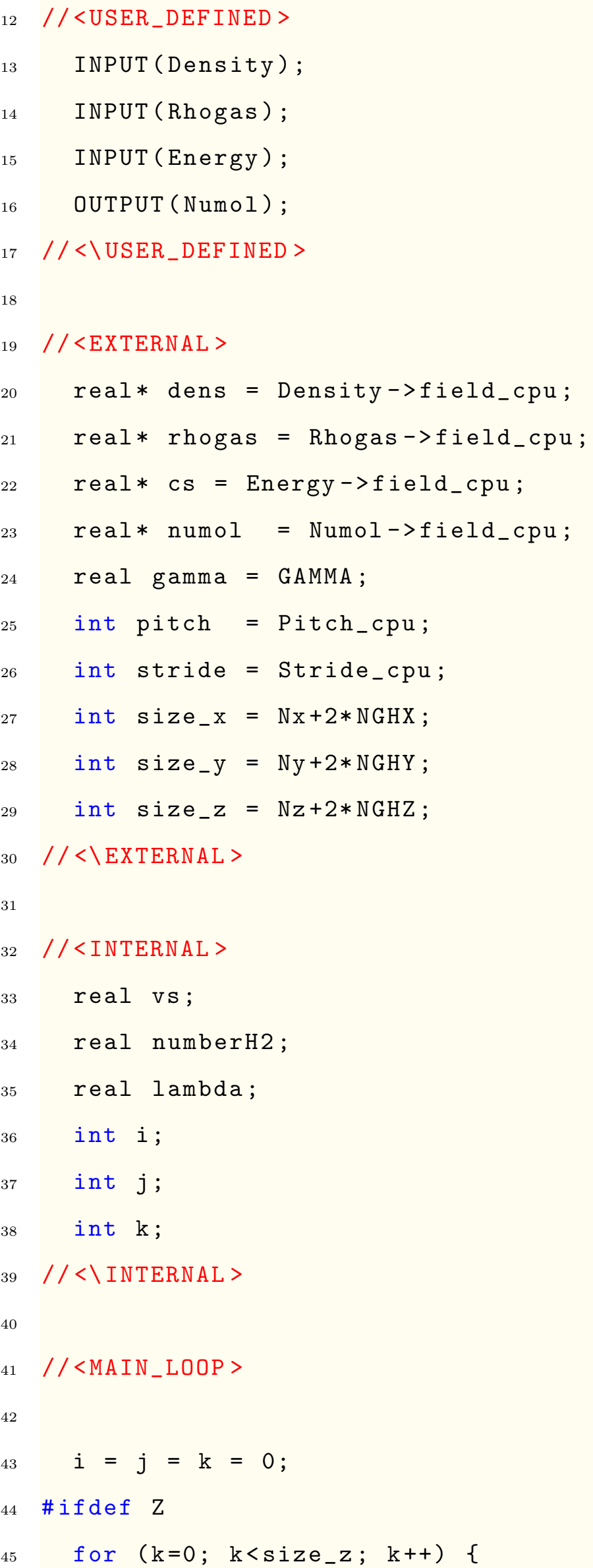




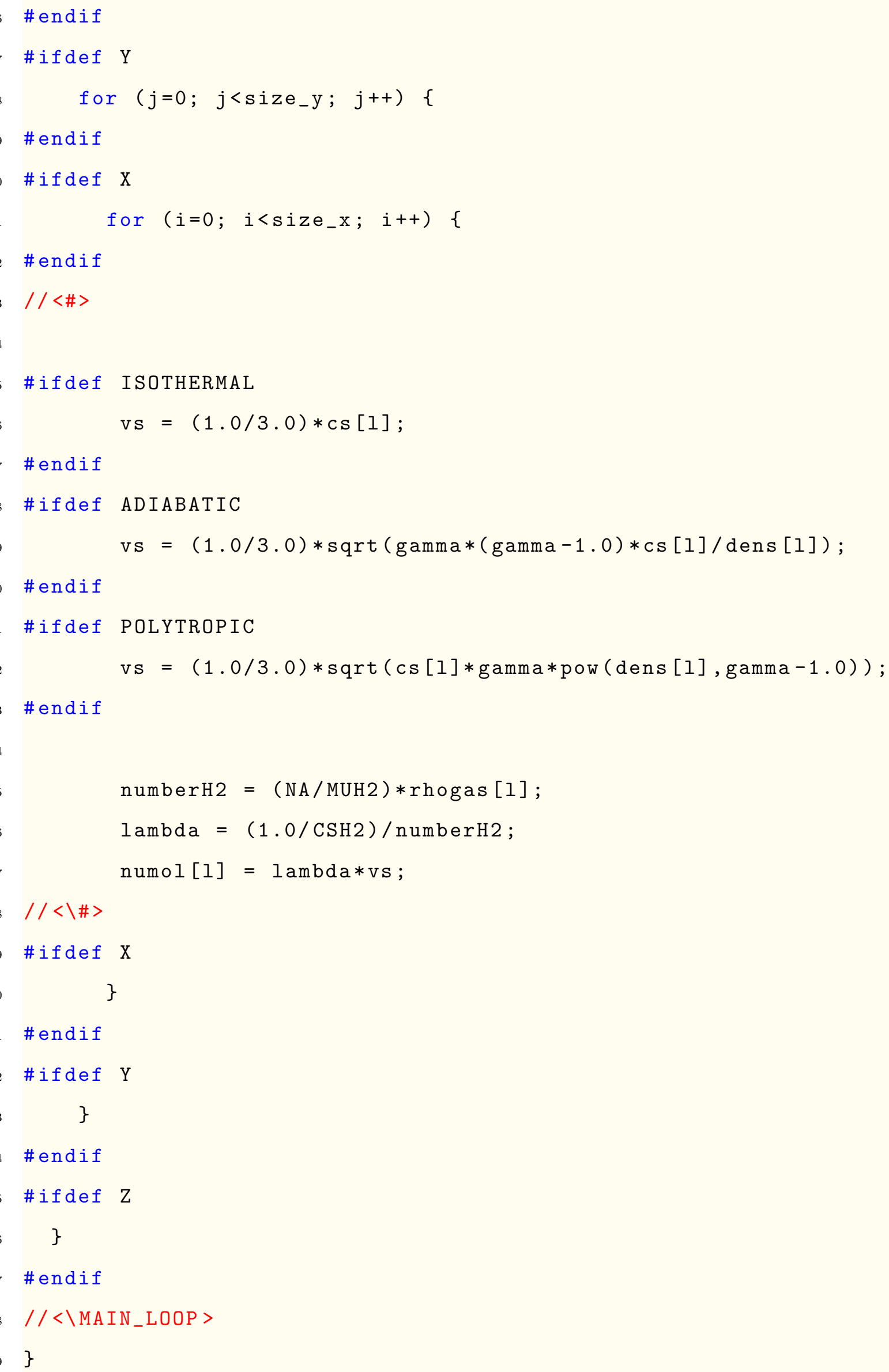




\section{B.6.2 Comentários gerais}

Essa função é responsável pelo cálculo da viscosidade molecular do gás em cada célula do disco e por guardar esses valores na variável de campo Numol (linha 67). A viscosidade molecular do gás é calculada usando a expressão:

$$
\nu_{\text {gas }}=\frac{\lambda_{\text {gas }} c_{\mathrm{s}}}{3}
$$

Assim, as linhas 55 a 63 calculam 1/3 da velocidade do som, dependendo da equação de estado para o gás escolhido no arquivo setup.opt (ver seção 3.1.4). A ordem das operações é alterada para levar em conta a aritmética de ponto flutuante que é diferente na GPU e na CPU.

Para obtermos o livre caminho médio $\lambda_{\text {gas }}$, usamos a equação:

$$
\lambda_{\text {gas }}=\left(n_{\mathrm{g}} \sigma_{\mathrm{H}_{2}}\right)^{-1},
$$

onde $\sigma_{\mathrm{H}_{2}}$ é a seção de choque da molécula de hidrogênio, definida em foundam.c (ver apêndice A.6), e $n_{\mathrm{g}}$ é a densidade numérica dessas moléculas, que é obtida na linha 65 usando a massa molecular da molécula de hidrogênio, também definida em foundam.c, e a densidade volumétrica do gás obtida pela função Computerhogas (ver apêndice B.5).

\section{B.7 Arquivo computereymol.c}

\section{B.7.1 Transcrição do código}

$1 / /<$ FLAGS $>$

2 //\#define _- GPU

3 //\#define __NOPROTO

${ }_{4} \quad / /\langle\backslash$ FLAGS $>$

5

$6 \quad / /<$ INCLUDES $>$

7 \#include "fargo3d.h"

$8 \quad / /<\backslash$ INCLUDES $>$

9 
$/ /<$ USER_DEFINED >

INPUT (ECC);

INPUT ( Inc);

INPUT (Numol);

OUTPUT (Reymol);

$/ /<\backslash U S E R \_D E F I N E D>$

\section{$/ /\langle$ EXTERNAL $>$}

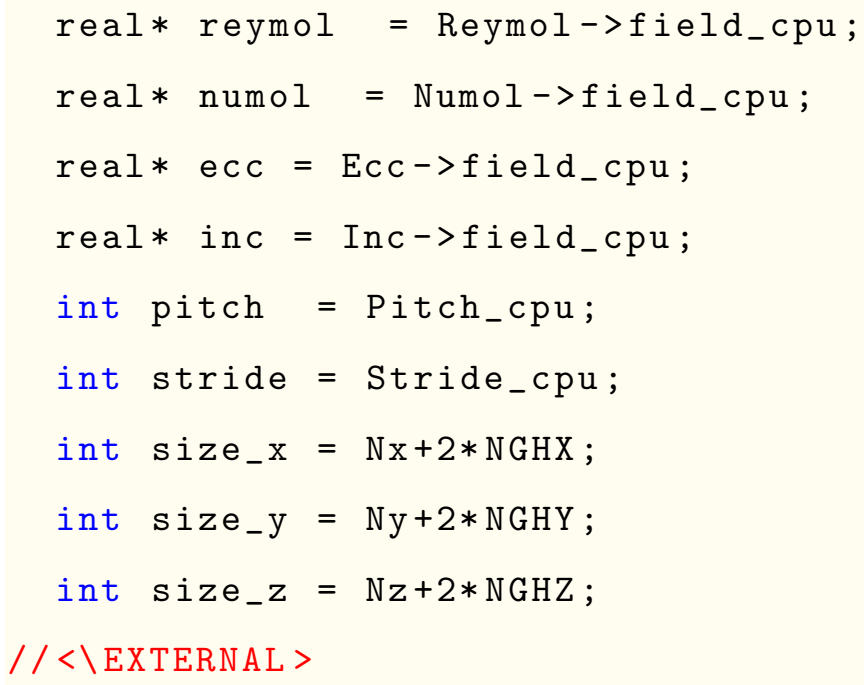




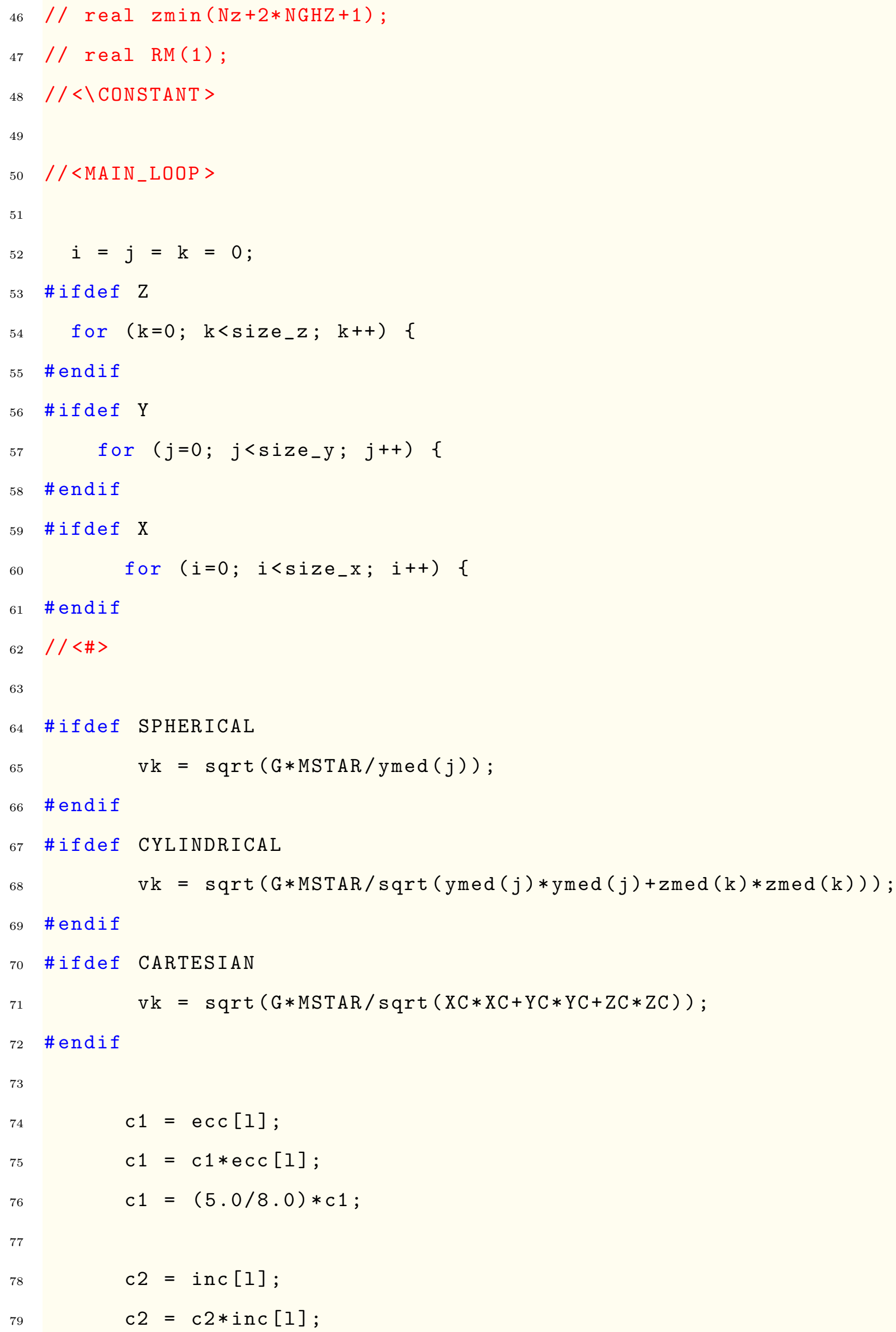




\section{B.7.2 Comentários gerais}

Essa função é responsável pelo cálculo do número de Reynolds molecular e por guardar o valor obtido em cada célula na varíavel de campo Reymol (linha 85).

O número de Reynolds molecular é calculado por meio da equação:

$$
\operatorname{Re} \equiv \frac{v_{r} r_{\mathrm{m}}}{\nu_{\text {gas }}}
$$

onde $r_{\mathrm{m}}$ é o tamanho do planetesimal, definido em setup.par (ver apêndice A.7), $\nu_{\text {gas }}$ é a viscosidade molecular, obtida pela rotina computenumol.c (vêr apêndice B.6),e $v_{r}$, é a velocidade relativa dos planetesimais em relação à velocidade orbital no mesmo raio, definida por (linha 74 a 84):

$$
v_{r} \equiv v_{\mathrm{K}} \sqrt{\frac{5}{8} e^{2}+\frac{1}{2} i^{2}},
$$

onde $v_{\mathrm{K}}$ é a velocidade kepleriana, obtida nas linhas 64 a 72 , e $e$ e $i$ a excentricidade e a inclinação quadráticas médias dos planetesimais. 
A ordem das operações foi colocada nessa forma para evitar diferenças na aritmética de ponto flutuante que ocorre entre a GPU e a CPU.

\section{B.8 Arquivo computegasdragecc.c}

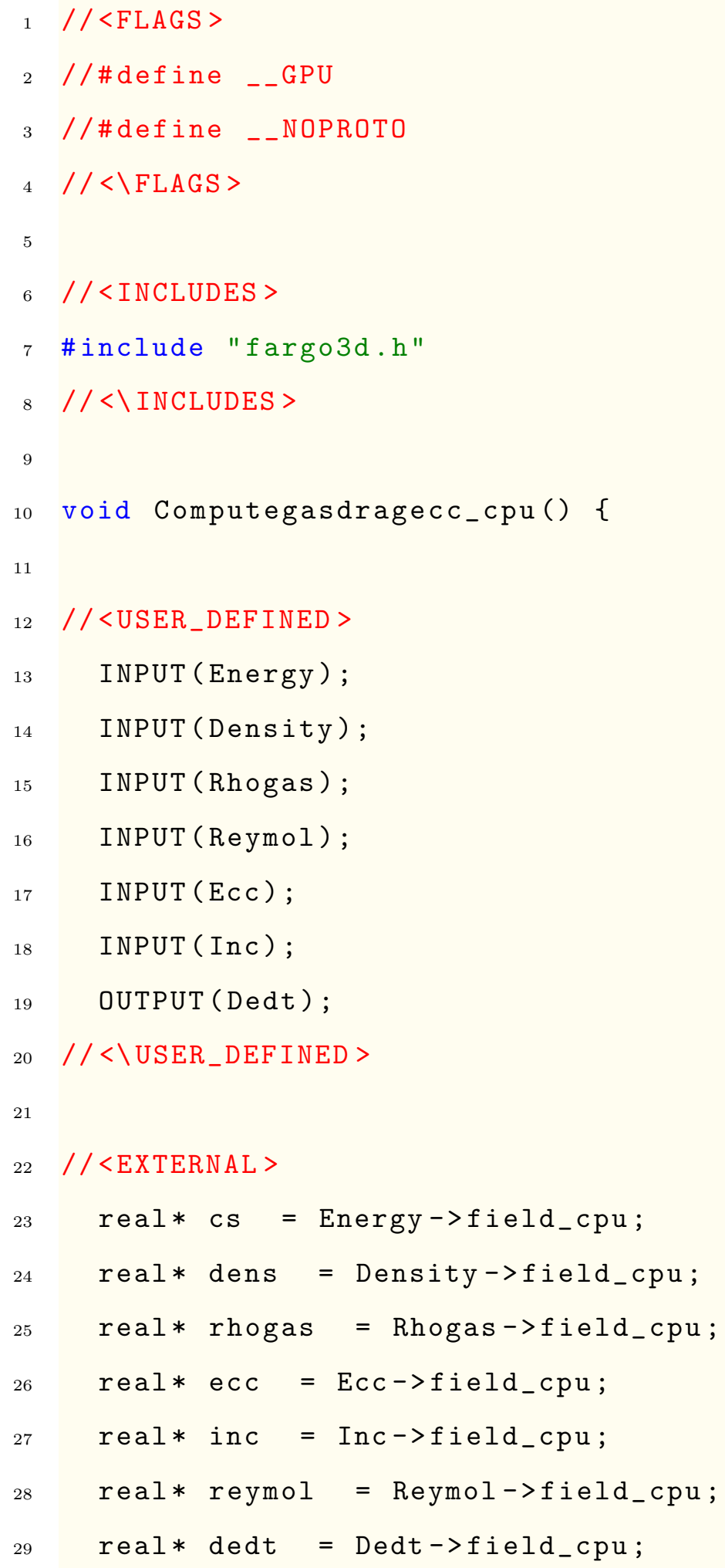


30

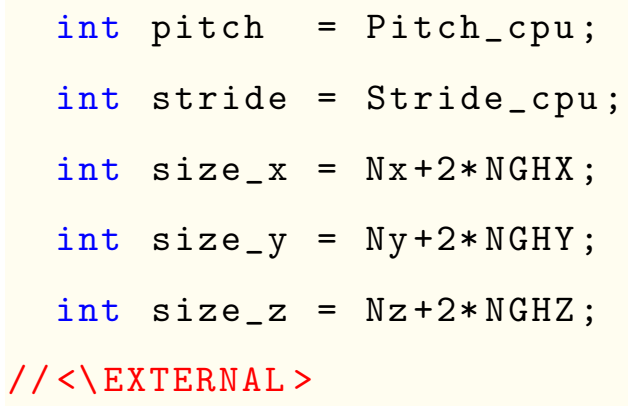




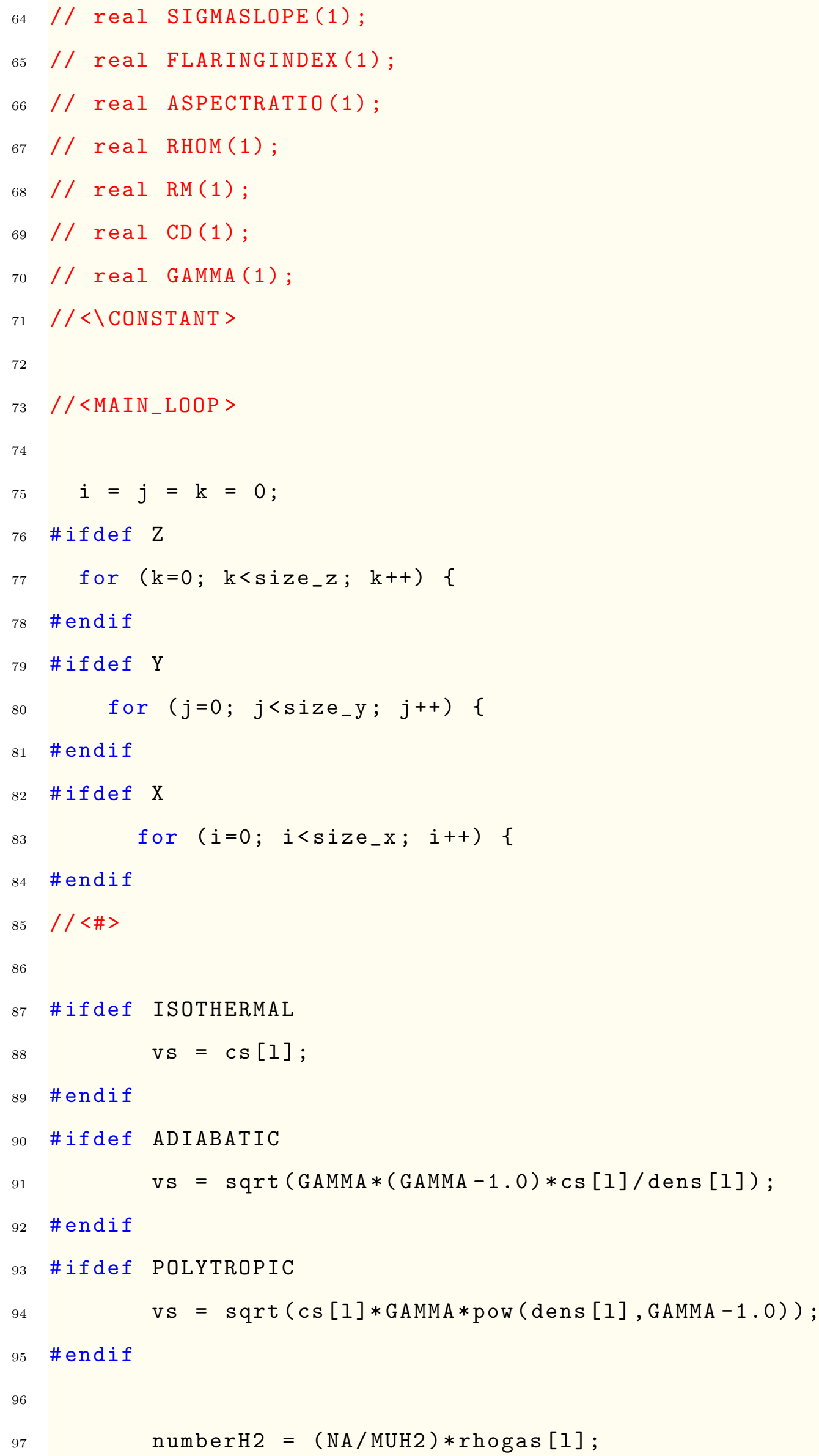


$l \mathrm{ambda}=(1.0 / \mathrm{CSH} 2) /$ numberH2 ;

/*WE CALCULATE nfactor (see Takeuchi 2002 - Eq.17)*/

\#ifdef $z$

$\mathrm{p}=$ SIGMASLOPE;

\# else

$p=($ SIGMASLOPE - FLARINGINDEX);

\#endif

$q=2.0 *$ FLARINGINDEX -3.0 ;

\section{\#ifdef SPHERICAL}

$\operatorname{vk}=\operatorname{sqrt}(G * \operatorname{MSTAR} / \operatorname{ymed}(j)) ;$

dist $=\operatorname{ymed}(j) * \sin (\operatorname{zmed}(k))$;

hg $=($ ASPECTRATIO $*$ dist $) *$ pow $(($ dist/RO $)$, FLARINGINDEX $)$;

nfactor $=-$ pow $($ hg/dist, 2.0$) *(\mathrm{p}+\mathrm{q}+\operatorname{FLARINGINDEX} *(\operatorname{ymed}(j) *$ $\cos (\operatorname{zmed}(k)) *(\operatorname{ymed}(j) * \cos (\operatorname{zmed}(k)) / h g)$;

\section{\# endif}

\section{\#ifdef CYLINDRICAL}

$\mathrm{vk}=\operatorname{sqrt}(G * \operatorname{MSTAR} / \operatorname{sqrt}(\operatorname{ymed}(j) * \operatorname{ymed}(j)+\operatorname{zmed}(k) * \operatorname{zmed}(k))) ;$

dist $=\operatorname{ymed}(j)$;

hg $=($ ASPECTRATIO $*$ dist $) *$ pow $(($ dist/RO $)$, FLARINGINDEX $) ;$

nfactor $=-$ pow $(\mathrm{hg} /$ dist, 2.0$) *(\mathrm{p}+\mathrm{q}+$ FLARINGINDEX $*$ zmed $(\mathrm{k}) *$ zmed $(\mathrm{k}) / \mathrm{hg})$;

\# endif

\#ifdef CARTESIAN

$\mathrm{vk}=\operatorname{sqrt}(\mathrm{G} * \mathrm{MSTAR} / \operatorname{sqrt}(\mathrm{XC} * \mathrm{XC}+\mathrm{YC} * \mathrm{YC}+\mathrm{ZC} * \mathrm{ZC})) ;$

dist $=\operatorname{sqrt}(X C * X C+Y C * Y C)$;

hg $=($ ASPECTRATIO $*$ dist $) *$ pow $(($ dist/RO $)$, FLARINGINDEX $)$;

nfactor $=-$ pow $(\mathrm{hg} /$ dist, 2.0$) *(\mathrm{p}+\mathrm{q}+$ FLARINGINDEX $*$ zmed $(\mathrm{k}) *$ zmed $(\mathrm{k}) / \mathrm{hg})$;

\# endif

if $(($ reymol $[1]>=20.0)$ \&\& (RM $>=1$ ambda $))$ 


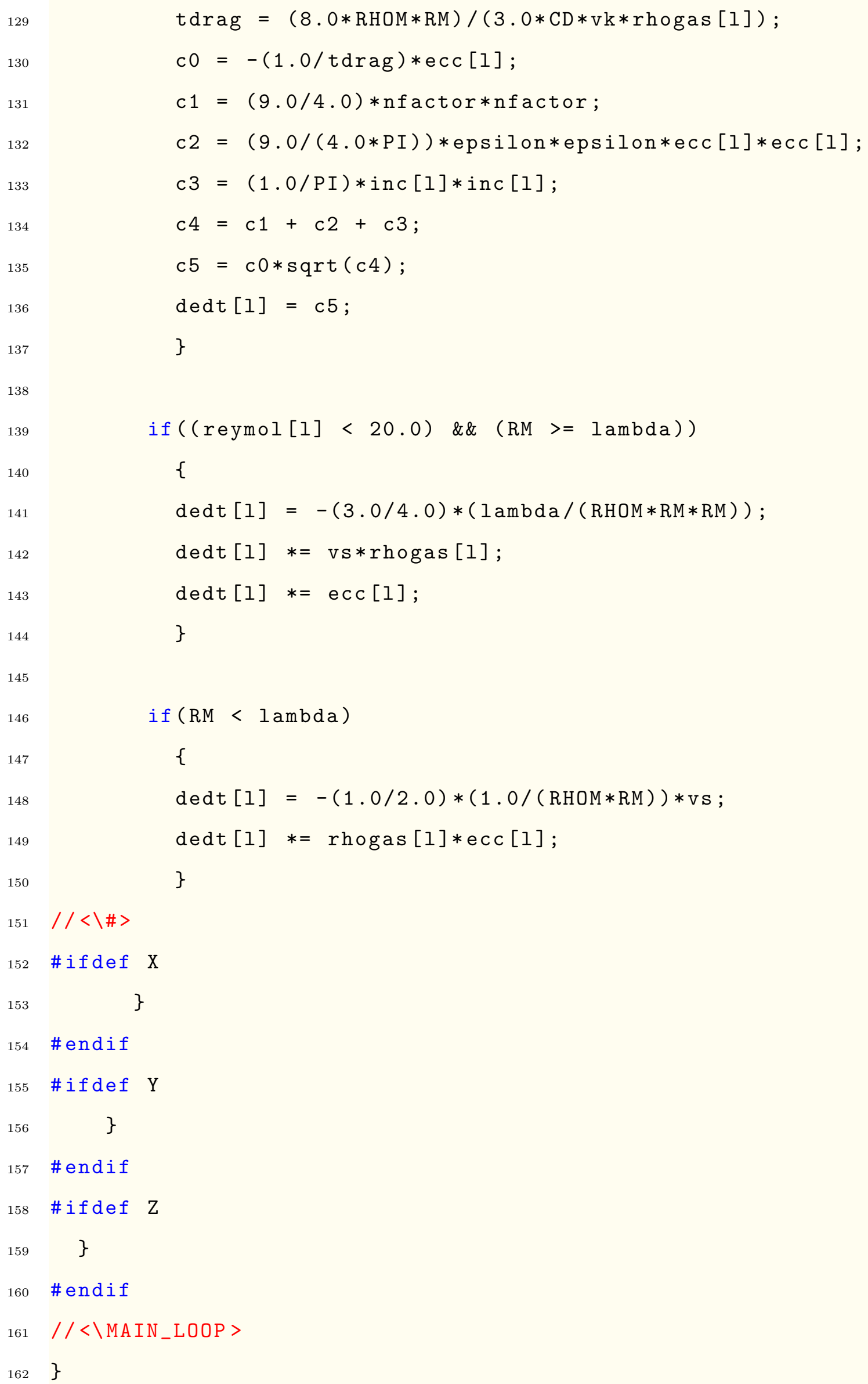




\section{B.8.1 Comentários gerais}

Essa função é responsável por obter a taxa de mudança da excentricidade quadrática média devido à força de arrasto experimentada por um corpo esférico. Esta força depende da velocidade relativa do corpo com relação ao gás, e, dependendo da razão entre o raio do planetesimal e o livre caminho médio da moléculas, pode ser encontrada em três regimes diferentes. Os primeiros dois regimes são obtidos para planetesimais cujos raios são maiores que o livre caminho médio, $r_{\mathrm{m}} \gtrsim \lambda_{\text {gas }}$, podendo estar no regime quadrático ou de Stokes. Para distinguir esses regimes, nós adotamos o critério proposto por Rafikov (2004), que utiliza o número de Reynolds molecular, $\mathrm{Re}_{\mathrm{mol}}$, obtido no arquivo computereymol.c (ver apêndice B.7).

Caso $\operatorname{Re}_{\mathrm{mol}} \gtrsim 20$ (linha 127 ), assume-se que o arrasto do gás está no regime quadrático, nesse caso, a equação para evolução da excentricidade quadrática média, devido ao arrasto do gás, é dada por (linhas 129 a 136):

$$
\left(\frac{d e^{2}}{d t}\right)_{\text {gas }}=-\frac{2 e^{2}}{\tau_{\text {drag }}}\left(\frac{9}{4} \eta^{2}+\frac{9}{4 \pi} \xi^{2} e^{2}+\frac{1}{\pi} i^{2}\right)^{1 / 2} .
$$

Nesta tese, usamos o valor de $\xi \simeq 1.211$ e o valor de $\eta$, que depende da distância à estrela, é aproximado pela equação (Takeuchi e Lin, 2002) (linha 101 a 125):

$$
\eta=\left(\frac{h}{r}\right)^{2}\left(p+q+\gamma \frac{z}{h}\right),
$$

onde $p=\varphi$, se o disco for bidimensional, ou $p=\varphi-\gamma$, se o disco for tridimensional, além disso, $q=2.0 \gamma-3.0$ e $\gamma$ é o fator que define a curvatura do disco. Nesta tese, usamos um disco bidimensional e fator de curvatura nulo. Em caso de dúvida sobre o significado físico desses parâmetros, recomendamos a leitura da seção 3.10 .1 .

O tempo de escala do arrasto de gás, $\tau_{\text {drag }}$, é dado por (linha 129):

$$
\tau_{\text {drag }}=\frac{8 \rho_{\mathrm{m}} r_{\mathrm{m}}}{3 \mathrm{C}_{\mathrm{D}} \rho_{\text {gas }} v_{\mathrm{K}}},
$$

onde $v_{\mathrm{K}}$ é a velocidade kepleriana na célula.

O regime de Stokes ocorre para $r_{\mathrm{m}} \gtrsim \lambda_{\text {gas }}$ e $\operatorname{Re}_{\text {mol }}<20$ (linha 139), neste caso, a equação para evolução da taxa da excentricidade quadrática média dos planetesimais, é dada por (linha 141 e 143): 


$$
\left(\frac{d e^{2}}{d t}\right)_{\text {gas }}=-\frac{3}{2} \frac{\lambda_{\text {gas }} c_{\mathrm{s}} \rho_{\text {gas }} e^{2}}{\rho_{\mathrm{m}} r_{\mathrm{m}}^{2}},
$$

onde $c_{\mathrm{S}}$ é a velocidade do som na célula.

Quando $r_{\mathrm{m}} \lesssim \lambda_{\text {gas }}$ (linha 146), o terceiro regime, regime de Epstein, toma lugar e a evolução da taxa da excentricidade quadrática média é descrita por (linha 148 e 149):

$$
\left(\frac{d e^{2}}{d t}\right)_{\text {gas }}=-e^{2} \frac{c_{\mathrm{s}} \rho_{\mathrm{gas}}}{\rho_{\mathrm{m}} r_{\mathrm{m}}},
$$

\section{B.9 Arquivo computegravecc.c}

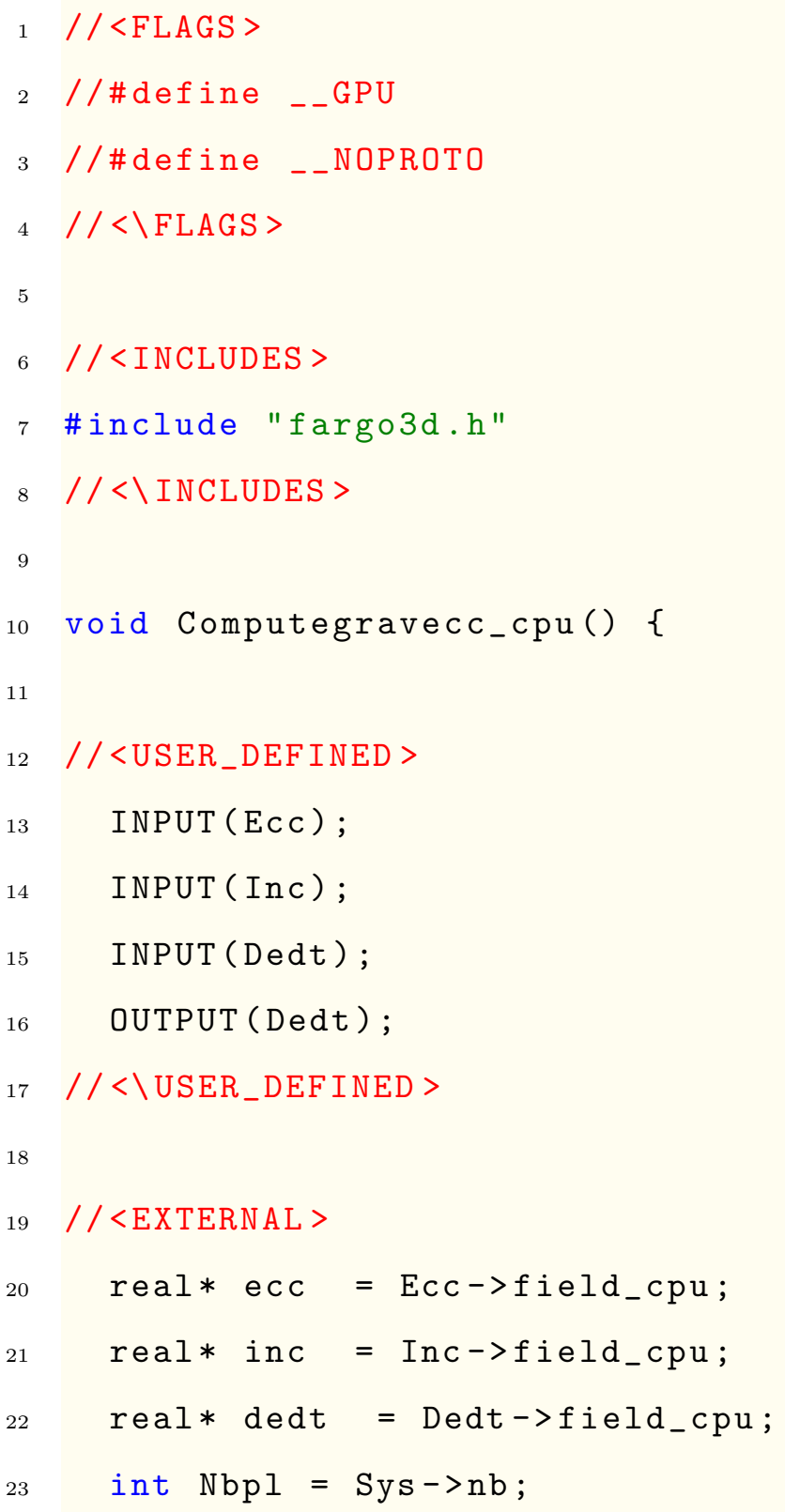




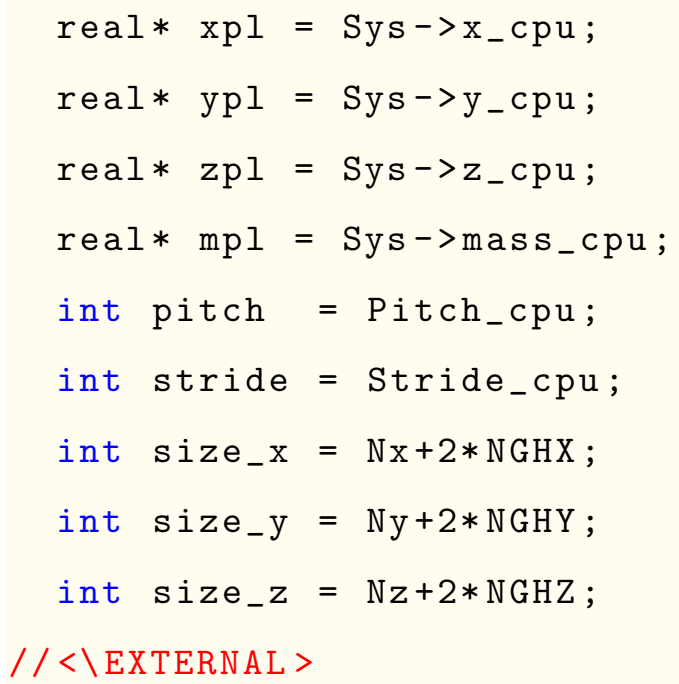




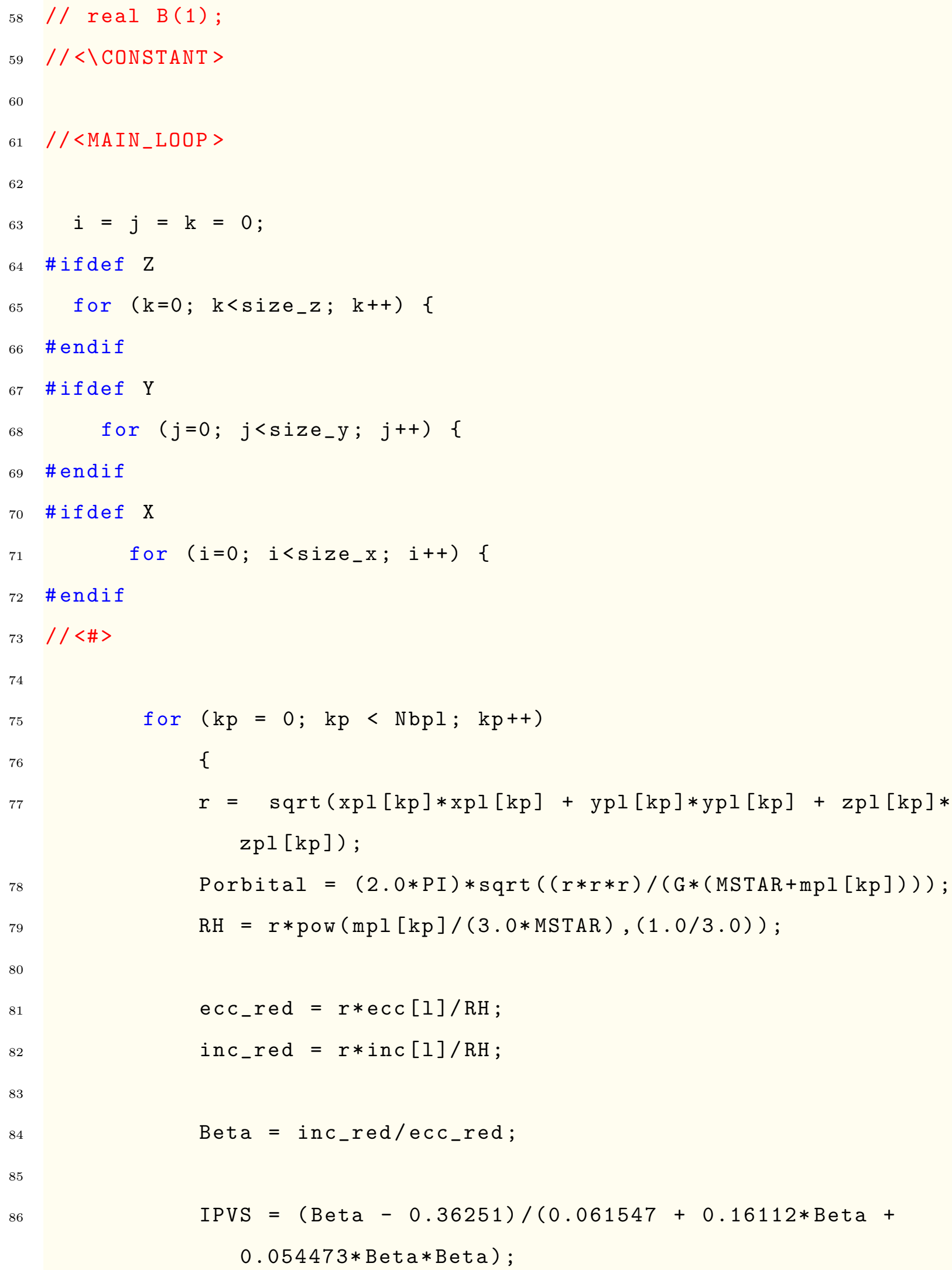

87 
$\operatorname{PVS}=\left(\left(73.0 * e c c_{\_} r e d * e c c_{-} r e d\right) /(10.0 *\right.$ Lambda*Lambda $\left.)\right) * l o g$

$(1.0+10.0 *$ Lambda*Lambda/(ecc_red*ecc_red) $)$; $\mathrm{PVS}=\mathrm{PVS}+(72.0 * \mathrm{IPVS} /(\mathrm{PI} *$ ecc_red*inc_red $)) * \log (1.0+$

Lambda*Lambda);

\#ifdef SPHERICAL

delta $=\operatorname{ymed}(j) * \sin (\operatorname{zmed}(k))-r ;$

\# endif

\#ifdef CYLINDRICAL

delta $=\operatorname{ymed}(j)-r ;$

\# endif

\#ifdef CARTESIAN

delta $=\operatorname{sqrt}(X C * X C+Y C * Y C)-r ;$

\# endif

if $($ delta $<0)$ delta $=(-1.0) *$ delta;

$f_{\text {_delta }}=$ pow $(\operatorname{delta} /(5.0 * \mathrm{RH}), 5.0)$;

$f_{-}$delta $=$pow $\left(1.0+f_{-}\right.$delta, -1.0$)$;

$\mathrm{c0}=(1.0 / 2.0) * f_{-} \operatorname{delta} *(\operatorname{mpl}[\mathrm{kp}] /(3.0 * B * \operatorname{MSTAR} *$ Porbital $))$ $* \mathrm{PVS}$;

$\operatorname{dedt}[1]+=\operatorname{co} /$ ecc $[1]$;

\}

$/ /<\backslash \#>$

\#ifdef $X$

\}

\#endif

\#ifdef $Y$

\}

\#endif

\#ifdef Z 


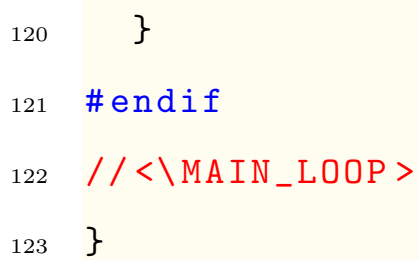

\section{B.9.1 Comentários gerais}

Essa função determina a taxa da evolução da excentricidade quadrática média devido à influência gravitacional do protoplaneta. A equação que descreve essa evolução é dada por (linha 108 e 110):

$$
\left(\frac{d e^{2}}{d t}\right)_{\text {grav }}=\left(\frac{M_{\mathrm{p}}}{3 b M_{\star} P_{\text {orbital }}}\right) P_{\mathrm{VS}},
$$

o valor de $P_{\mathrm{VS}}$ é dado por (linha 90 e 91 ):

$$
P_{\mathrm{VS}}=\left[\frac{73 \tilde{e}^{2}}{10 \Lambda^{2}}\right] \ln \left(1+10 \Lambda^{2} / \tilde{e}^{2}\right)+\left[\frac{72 I_{\mathrm{PVS}}(\beta)}{\pi \tilde{e} \tilde{i}}\right] \ln \left(1+\Lambda^{2}\right)
$$

$\operatorname{com} \Lambda=\tilde{i}\left(\tilde{e}^{2}+\tilde{i}^{2}\right) / 12$ (linha 88). Conforme vimos na seção 4.4.1, a função $I_{\mathrm{PVS}}(\beta)$ pode ser aproximada para $0<\beta \leq 1$ por (linha 86):

$$
I_{\mathrm{PVS}}(\beta) \simeq \frac{\beta-0.36251}{0.061547+0.16112 \beta+0.054473 \beta^{2}} .
$$

A excitação que o protoplaneta produz nos planetesimais enfraquece com a distância entre o protoplaneta e o planetesimal. Seguindo a aproximação de Guilera et al. (2010), usamos:

$$
\left(\frac{d e^{2}}{d t}\right)_{\text {grav }}^{\text {eff }}=f(\Delta)\left(\frac{d e_{i j}{ }^{2}}{d t}\right)_{\text {grav }},
$$

onde $f(\Delta)$ assegura que a perturbação do protoplaneta seja confinada na sua vizinhança, e dada por (linha 93 a 106):

$$
f(\Delta)=\left[1+\left(\frac{\Delta}{n R_{\mathrm{H}}}\right)\right]
$$

onde $\Delta=\left|a_{\mathrm{p}}-a_{\mathrm{m}}\right|, a_{\mathrm{p}}$ é o semieixo maior do protoplaneta e $a_{\mathrm{m}}$ é o semieixo dos planetesimais. Nesta tese, adotamos $\Delta$ como a distância radial entre a célula que contém o protoplaneta e a célula onde se calcula a evolução. 


\section{B.10 Arquivo updateecc.c}

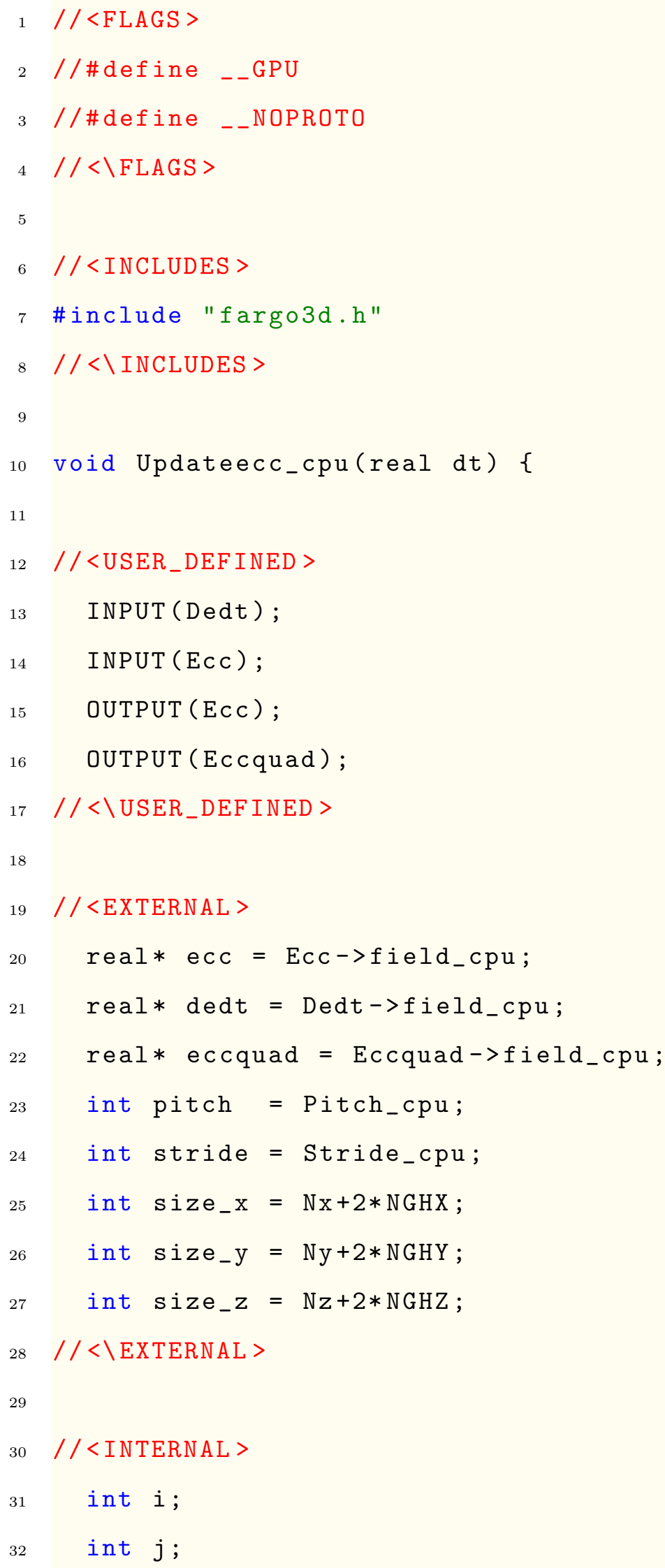

/ / < INTERNAL >

31 int i;

32 int $j$; 


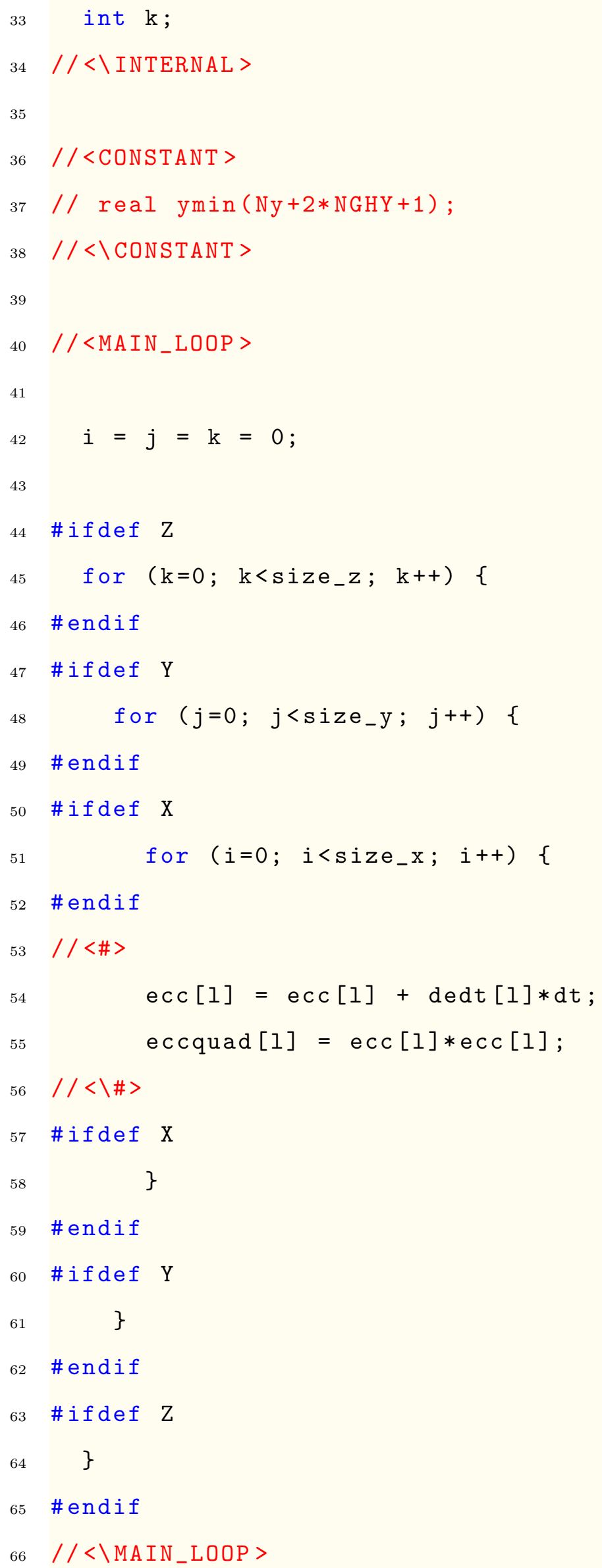


$/ /<L_{A S T}$ BLOCK $>$

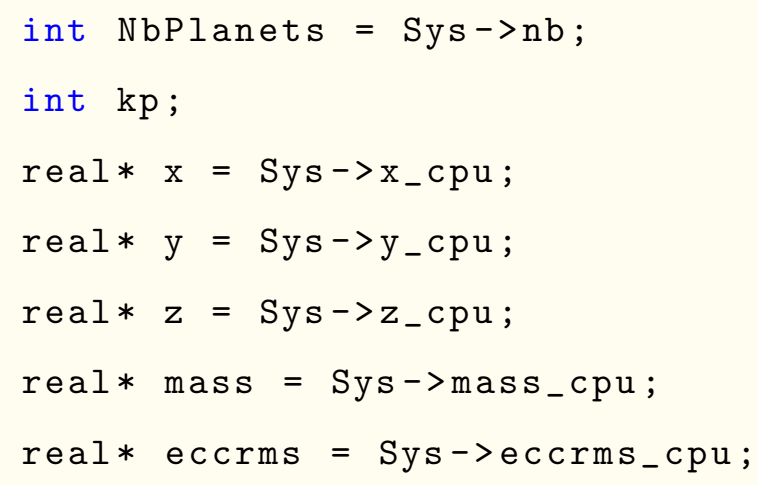




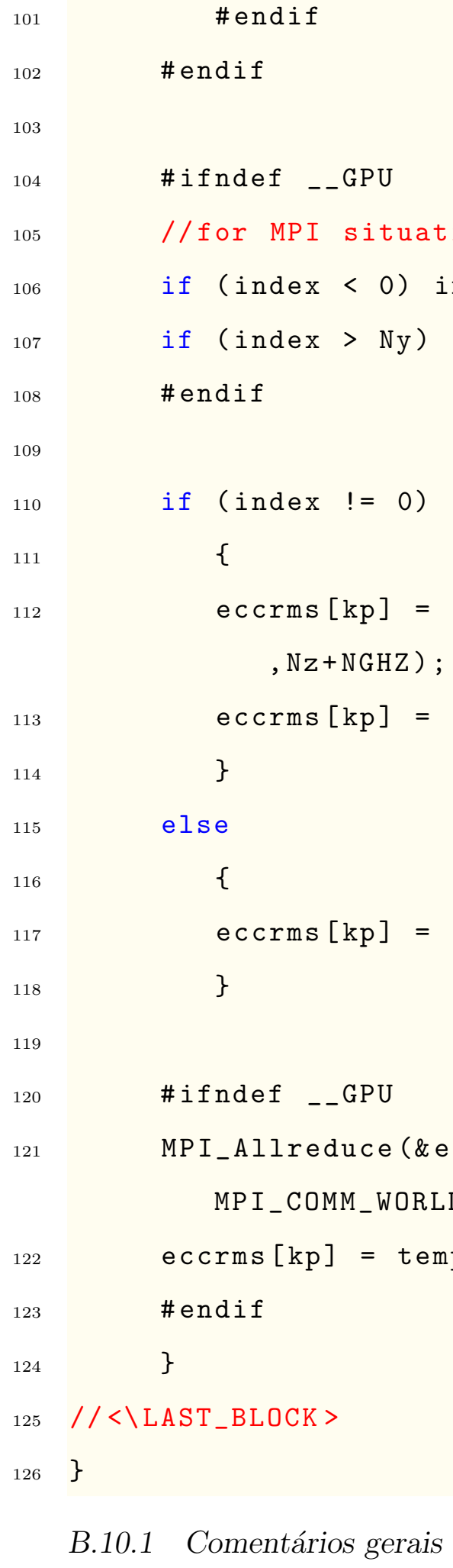

\section{B.10.1 Comentários gerais}

Essa função é responsável pelo update nos valores da excentricidade quadrática média das células (linhas 54 e 55).

Por fim, dentro do bloco MAIN_LOOP (linhas 87 a 124), calcula-se o valor da média azimutal da excentricidade quadrática média para o planeta. Mais detalhes podem ser 
obtidos no apêndice B.2, que utiliza procedimentos similares.

\section{B.11 Arquivo computegasdraginc.c}

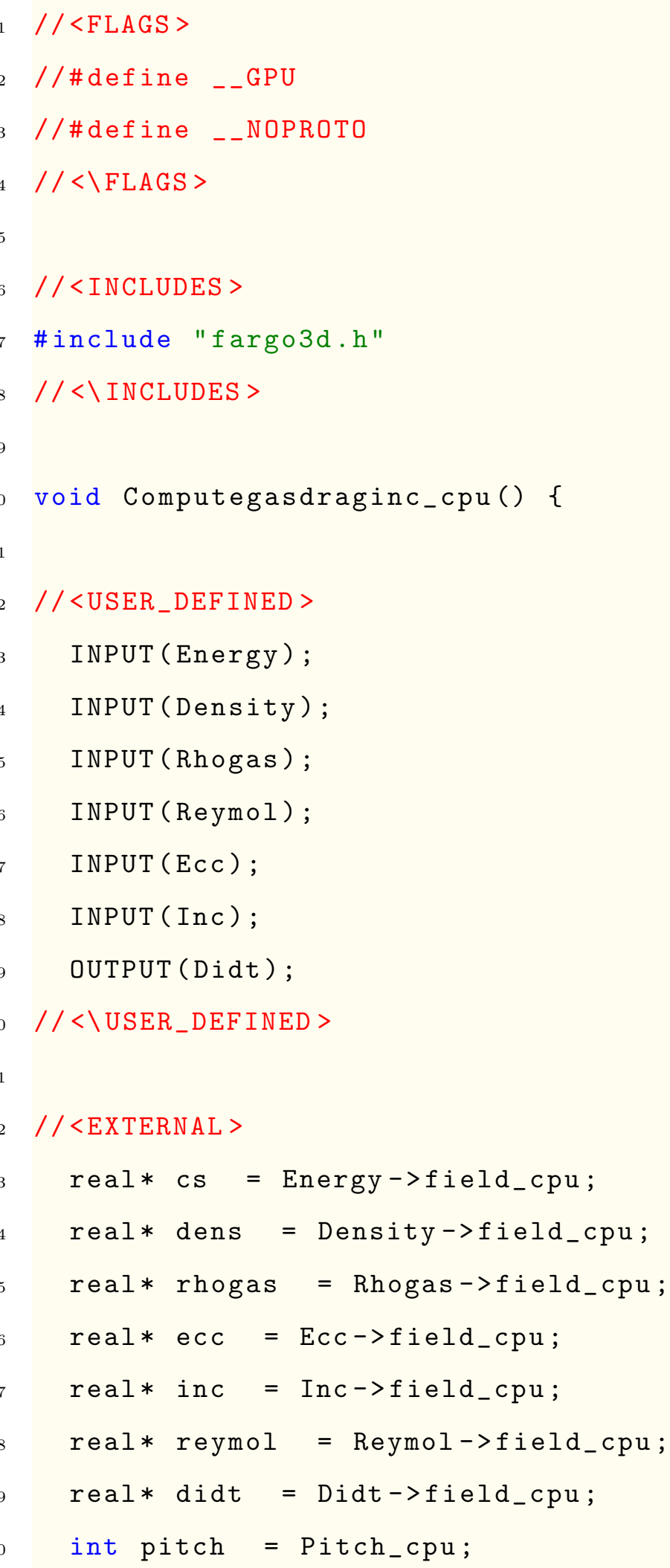




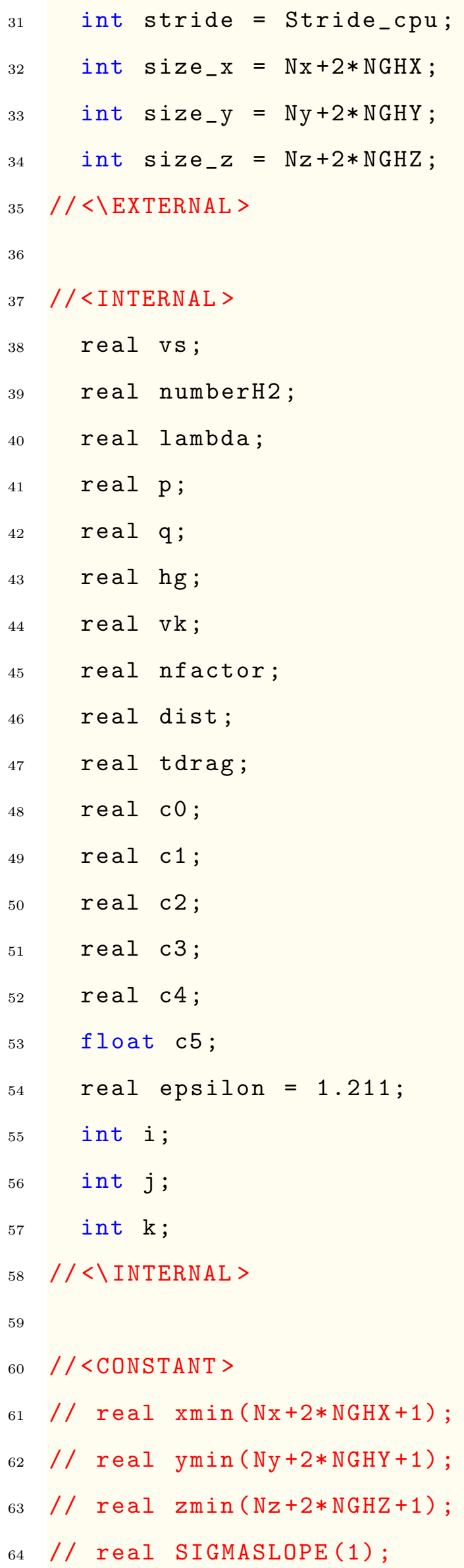




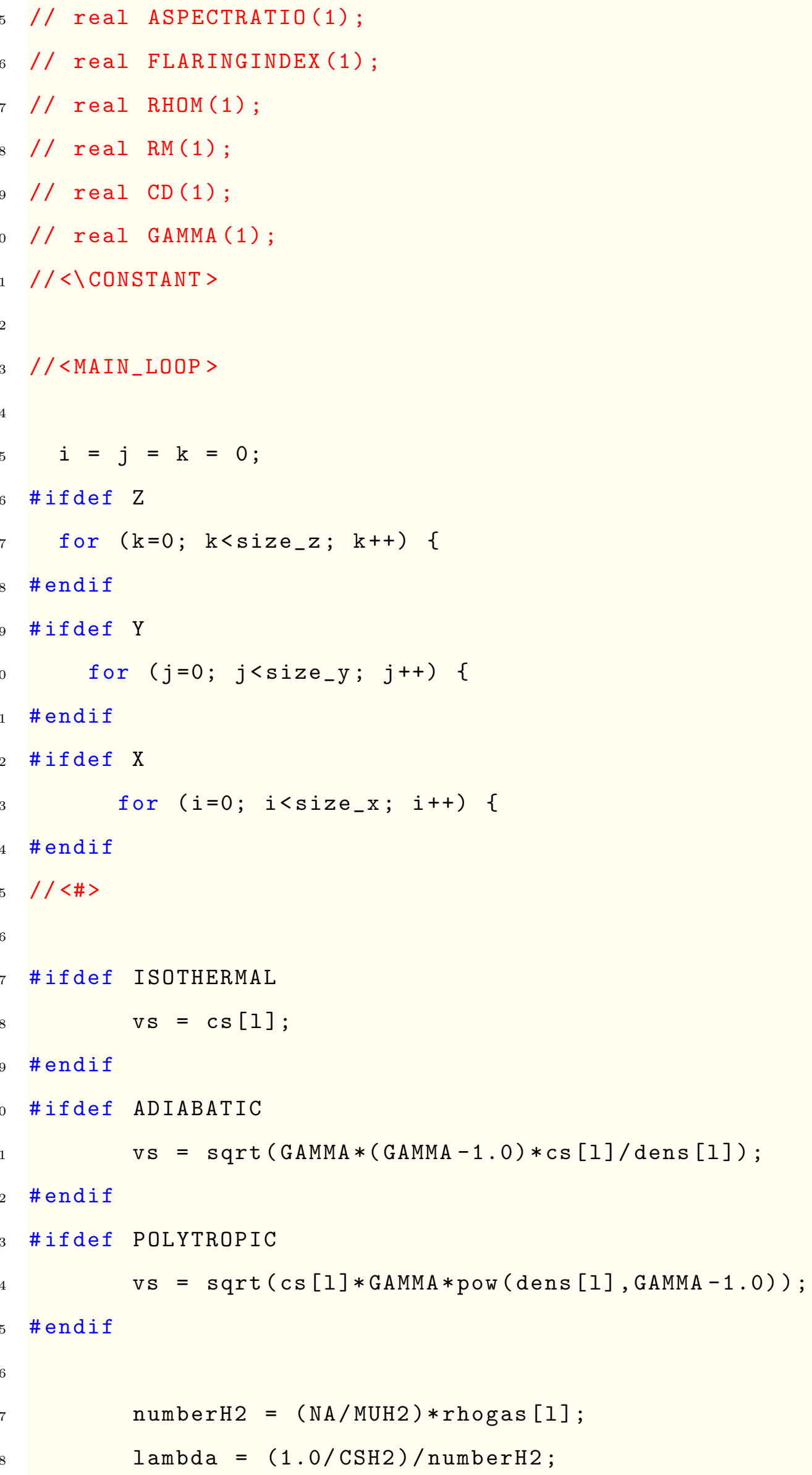
$1 \mathrm{ambda}=(1.0 / \mathrm{CSH} 2) /$ numberH2; 


\section{/*WE CALCULATE nfactor (see Takeuchi 2002 - Eq.17)*/}

\#ifdef $z$

$\mathrm{p}=$ SIGMASLOPE;

$\#$ else

$p=$ (SIGMASLOPE - FLARINGINDEX);

\# endif

$q=2.0 *$ FLARINGINDEX $-3.0 ;$

\section{\#ifdef SPHERICAL}

$\mathrm{vk}=\operatorname{sqrt}(G * \operatorname{MSTAR} / \operatorname{ymed}(j)) ;$

dist $=\operatorname{ymed}(j) * \sin (\operatorname{zmed}(k) ;$

$h g=($ ASPECTRATIO $*$ dist $) *$ pow $(($ dist/RO), FLARINGINDEX $)$;

nfactor $=-$ pow $(h g /$ dist, 2.0$) *(p+q+$ FLARINGINDEX $*(\operatorname{ymed}(j) *$ $\cos (\operatorname{zmed}(k)) *(\operatorname{ymed}(j) * \cos (\operatorname{zmed}(k)) / h g)$;

\#endif

\#ifdef CYLINDRICAL

$\mathrm{vk}=\operatorname{sqrt}(G * \operatorname{MSTAR} / \operatorname{ymed}(j)) ;$

dist $=\operatorname{ymed}(j)$;

hg $=($ ASPECTRATIO $*$ dist $) *$ pow $(($ dist/RO $)$, FLARINGINDEX $) ;$

nfactor $=-$ pow $($ hg/dist, 2.0$) *(\mathrm{p}+\mathrm{q}+$ FLARINGINDEX $*$ zmed $(\mathrm{k}) *$ zmed $(\mathrm{k}) / \mathrm{hg})$;

\#endif

\#ifdef CARTESIAN

$\mathrm{vk}=\operatorname{sqrt}(\mathrm{G} * \mathrm{MSTAR} / \operatorname{sqrt}(\mathrm{XC} * \mathrm{XC}+\mathrm{YC} * \mathrm{YC}+\mathrm{ZC} * \mathrm{ZC})) ;$

dist $=\operatorname{sqrt}(X C * X C+Y C * Y C)$;

hg $=($ ASPECTRATIO $*$ dist $) *$ pow $(($ dist/RO), FLARINGINDEX $)$;

nfactor $=-$ pow $($ hg/dist, 2.0$) *(\mathrm{p}+\mathrm{q}+$ FLARINGINDEX $*$ zmed $(\mathrm{k}) *$ $\operatorname{zmed}(\mathrm{k}) / \mathrm{hg})$;

\#endif

if $(($ reymol $[1]>=20.0)$ \&\& (RM $>=\operatorname{lambda}))$

\{

$\operatorname{tdrag}=(8.0 * \mathrm{RHOM} * \mathrm{RM}) /(3.0 * \mathrm{CD} * \mathrm{vk} * \mathrm{rhogas}[1]) ;$ 


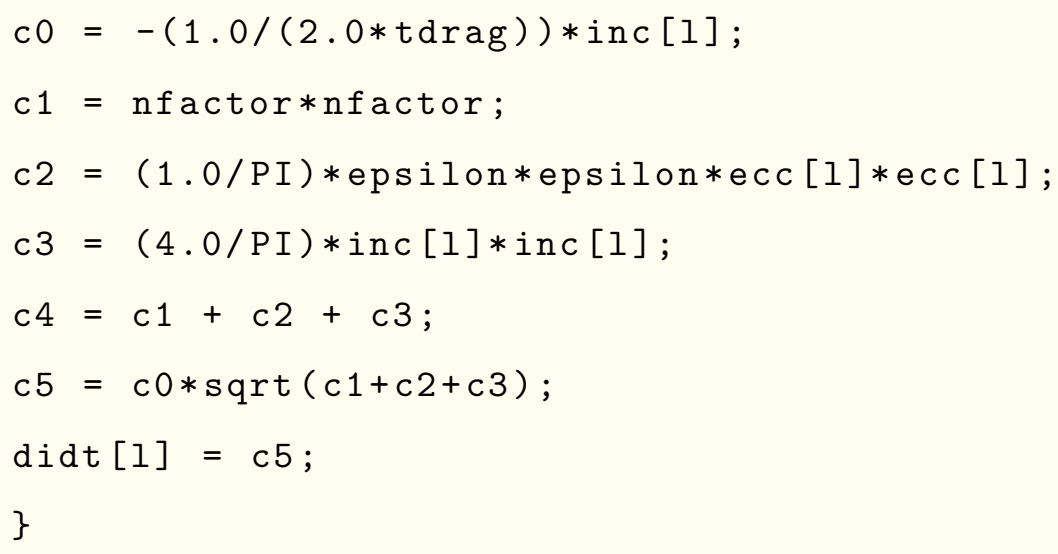




\section{B.11.1 Comentários gerais}

Essa função é responsável por obter a taxa de mudança da inclinação quadrática média devido à da força de arrasto experimentada por um corpo esférico. Esta força depende da velocidade relativa do corpo com relação ao gás e da razão entre o raio do planetesimal e o livre caminho médio da moléculas. Essa força de arrasto pode ser encontrada em três regimes diferentes. Os primeiros dois regimes são obtidos para planetesimais cujos raios são maiores que o livre caminho médio, $r_{\mathrm{m}} \gtrsim \lambda_{\text {gas }}$, podendo estar no regime quadrático ou de Stokes. Para distinguir entre esses regimes, nós adotamos o critério proposto por Rafikov (2004), que utiliza o número de Reynolds molecular $\operatorname{Re}_{\mathrm{mol}}$, obtido no arquivo computereymol.c (ver apêndice B.7).

Caso $\operatorname{Re}_{\mathrm{mol}} \gtrsim 20$ (linha 127), assume-se que o arrasto do gás está no regime quadrático, nesse caso, a equação para evolução da inclinação quadrática média devido ao arrasto do gás é dada por (linhas 129 a 136):

$$
\left(\frac{d i^{2}}{d t}\right)_{\text {gas }}=-\frac{i^{2}}{\tau_{\text {drag }}}\left(\eta^{2}+\frac{\xi^{2}}{\pi} e^{2}+\frac{4}{\pi} i^{2}\right)^{1 / 2} .
$$

Nesta tese, usamos o valor de $\xi \simeq 1.211$ e o valor de $\eta$, que depende da distância à estrela, e é aproximado pela equação (Takeuchi e Lin, 2002) (linha 100 a 125):

$$
\eta=\left(\frac{h}{r}\right)^{2}\left(p+q+\gamma \frac{z}{h}\right)
$$

onde $p=\varphi$, se o disco for bidimensional, ou $p=\varphi-\gamma$, se o disco for tridimensional, além disso, $q=2.0 \gamma-3.0$ e $\gamma$ é o fator que define a curvatura do disco. Nesta tese, usamos um disco bidimensional e fator de curvatura nulo. Em caso de dúvida sobre o significado físico desses parâmetros recomendamos a leitura da seção 3.10.1.

O tempo de escala do arrasto de gás, $\tau_{\text {drag }}$, é dado por (linha 129):

$$
\tau_{\text {drag }}=\frac{8 \rho_{\mathrm{m}} r_{\mathrm{m}}}{3 \mathrm{C}_{\mathrm{D}} \rho_{\text {gas }} v_{\mathrm{K}}},
$$

onde $v_{\mathrm{K}}$ é a velocidade kepleriana na célula.

O regime de Stokes ocorre para $r_{\mathrm{m}} \gtrsim \lambda_{\text {gas }}$ e $\operatorname{Re}_{\mathrm{mol}}<20$ (linha 139), neste caso, a equação para evolução da taxa da inclinação quadrática média dos planetesimais é dada por (linha 141 e 143): 


$$
\left(\frac{d i^{2}}{d t}\right)_{\text {gas }}=-\frac{3}{4} \frac{\lambda_{\text {gas }} c_{\mathrm{s}} \rho_{\text {gas }} i^{2}}{\rho_{\mathrm{m}} r_{\mathrm{m}}^{2}},
$$

onde $c_{\mathrm{s}}$ é a velocidade do som na célula.

Quando $r_{\mathrm{m}} \lesssim \lambda_{\text {gas }}$ (linha 146), o terceiro regime, regime de Epstein, toma lugar e a evolução da taxa da inclinação quadrática média é descrita por (linha 148 e 150):

$$
\left(\frac{d i^{2}}{d t}\right)_{\mathrm{gas}}=-\frac{i^{2}}{2} \frac{c_{\mathrm{s}} \rho_{\mathrm{gas}}}{\rho_{\mathrm{m}} r_{\mathrm{m}}}
$$

\section{B.12 Arquivo computegravinc.c}

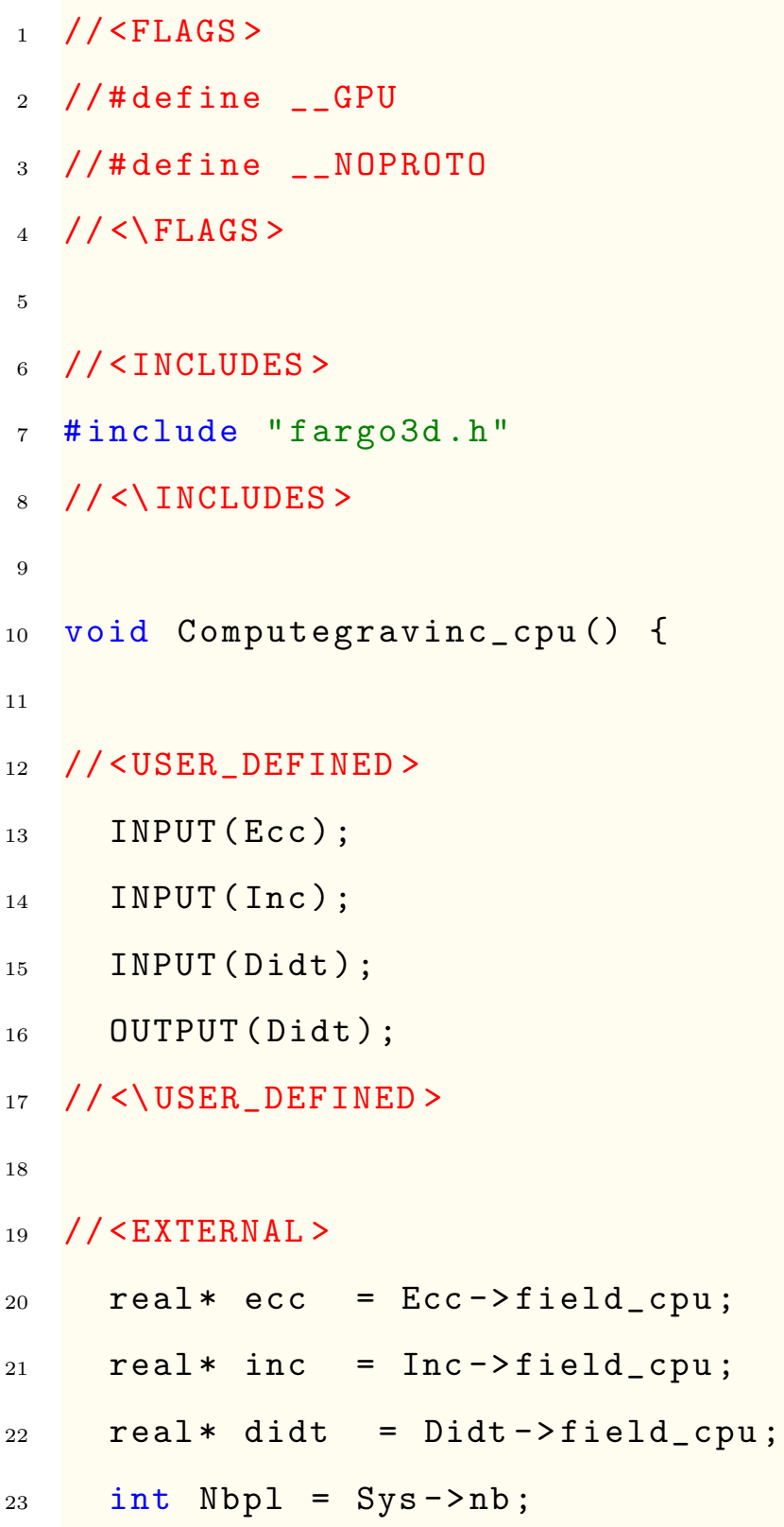




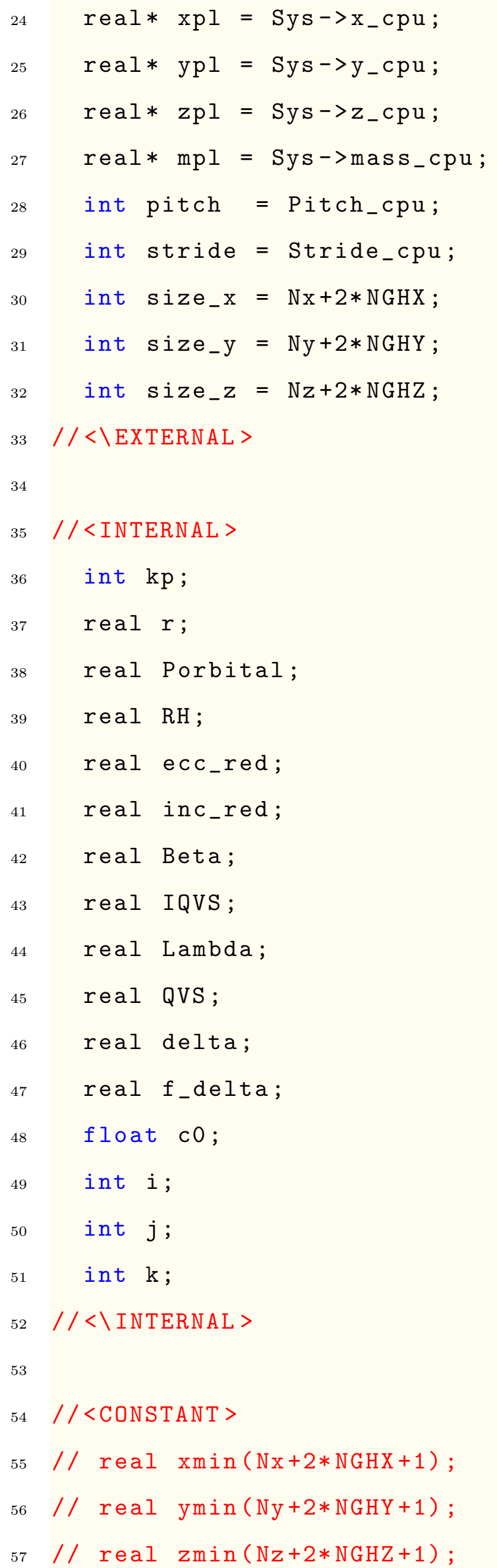




\section{// real B(1);}

$/ /\langle\backslash$ CONSTANT $>$

$/ /<$ MAIN_LOOP >

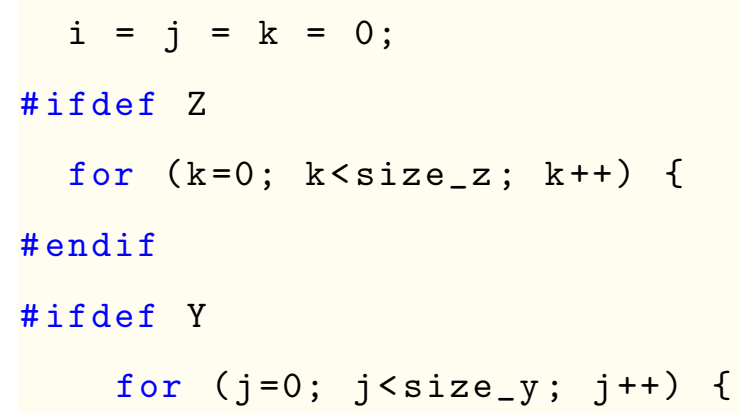


89

103

105

108

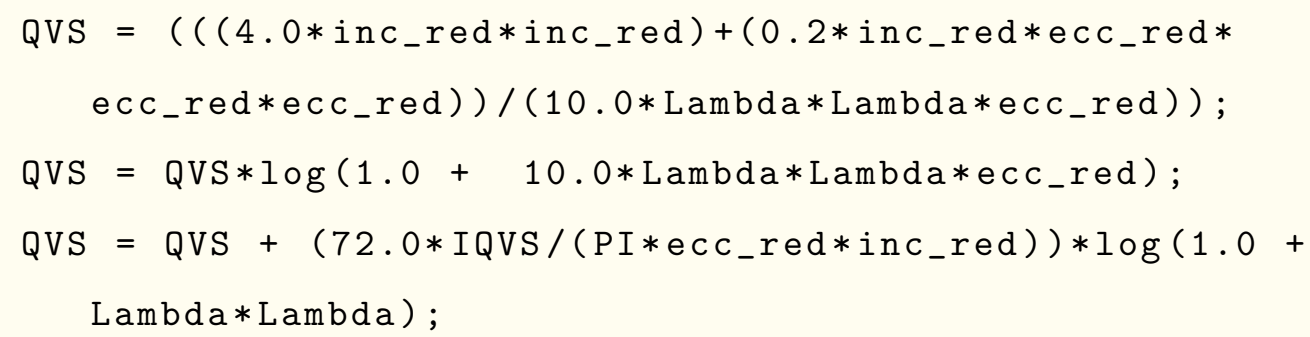




\section{B.12.1 Comentários gerais}

Essa função determina a taxa da evolução da excentricidade quadrática média devido à influência gravitacional do protoplaneta. A equação que descreve essa evolução é dada por (linha 109 e 111):

$$
\left(\frac{d i^{2}}{d t}\right)_{\text {grav }}=\left(\frac{M_{\mathrm{p}}}{3 b M_{\star} P_{\text {orbital }}}\right) Q_{\mathrm{VS}}
$$

o valor de $Q_{\mathrm{VS}}$ é dado por (linha 90 a 92):

$$
Q_{\mathrm{VS}}=\left[\frac{4 \tilde{i}^{2}+0.2 \tilde{i} \tilde{e}^{3}}{10 \Lambda^{2} \tilde{e}}\right] \ln \left(1+10 \Lambda^{2} \tilde{e}\right)+\left[\frac{72 I_{\mathrm{QVS}}(\beta)}{\pi \tilde{e} \tilde{i}}\right] \ln \left(1+\Lambda^{2}\right),
$$

$\operatorname{com} \Lambda=\tilde{i}\left(\tilde{e}^{2}+\tilde{i}^{2}\right) / 12$ (linha 88). Conforme vimos na seção 4.4.1, a função $I_{\mathrm{QVS}}(\beta)$ pode ser aproximada para $0<\beta \leq 1$ por (linha 86 ):

$$
I_{\mathrm{QVS}}(\beta) \simeq \frac{0.71946-\beta}{0.21239+0.49764 \beta+0.14369 \beta^{2}} .
$$

A excitação que o protoplaneta produz nos planetesimais enfraquece com a distância entre o protoplaneta e o planetesimal. Seguindo a aproximação de Guilera et al. (2010), usamos:

$$
\left(\frac{d e^{2}}{d t}\right)_{\mathrm{grav}}^{\mathrm{eff}}=f(\Delta)\left(\frac{d e^{2}}{d t}\right)_{\mathrm{grav}},
$$

onde $f(\Delta)$ assegura que a perturbação do protoplaneta seja confinada na sua vizinhança, e dada por (linha 94 a 107):

$$
f(\Delta)=\left[1+\left(\frac{\Delta}{n R_{\mathrm{H}}}\right)\right]
$$


onde $\Delta=\left|a_{\mathrm{p}}-a_{\mathrm{m}}\right|, a_{\mathrm{p}}$ é o semieixo maior do protoplaneta e $a_{\mathrm{m}}$ é o semieixo dos planetesimais. Nesta tese, adotamos $\Delta$ como a distância radial entre a célula que contêm o protoplaneta e a célula onde se calcula a evolução.

\section{B.13 Arquivo updateinc.c}

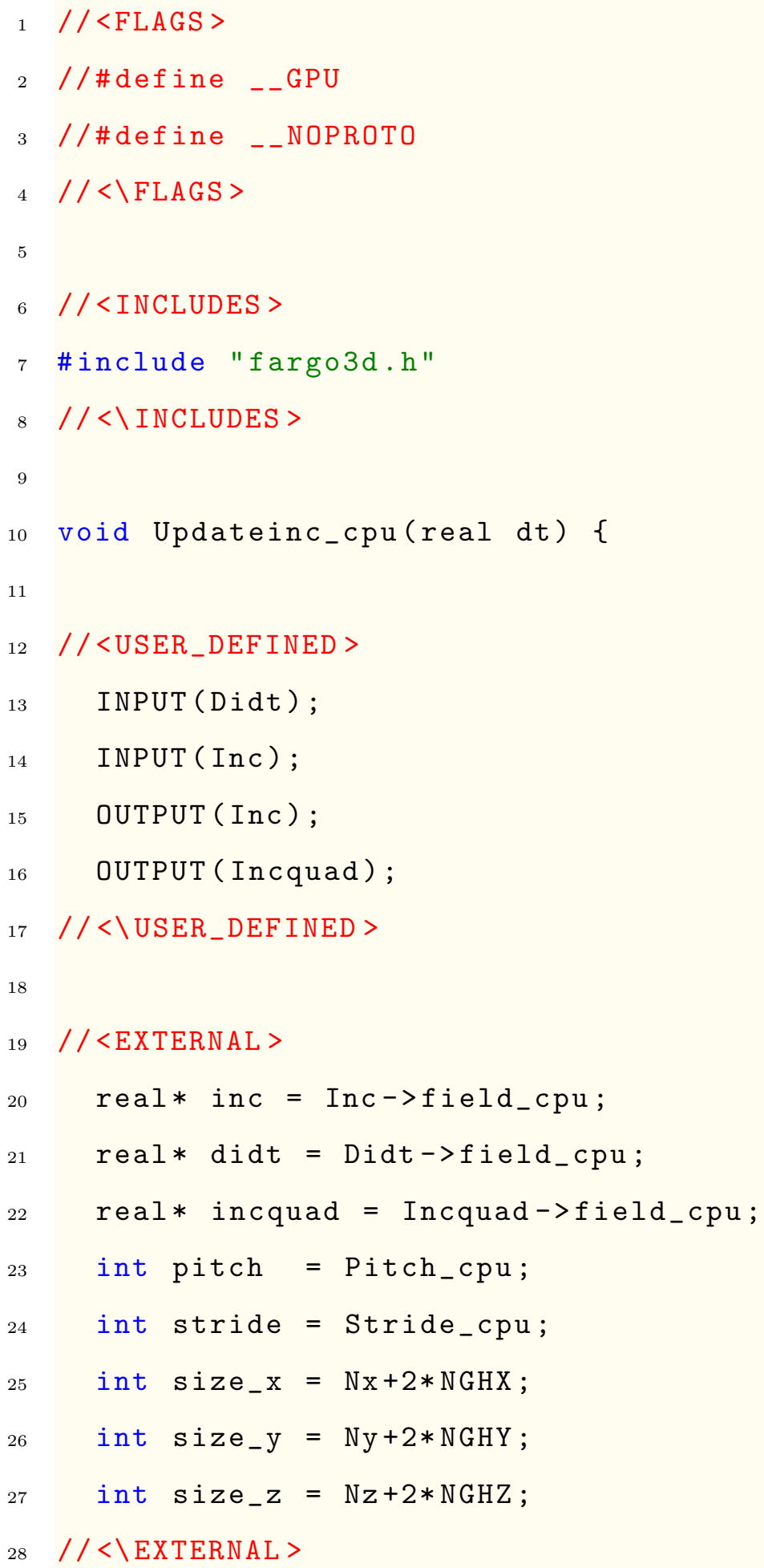


$/ /\langle$ INTERNAL $>$

31 


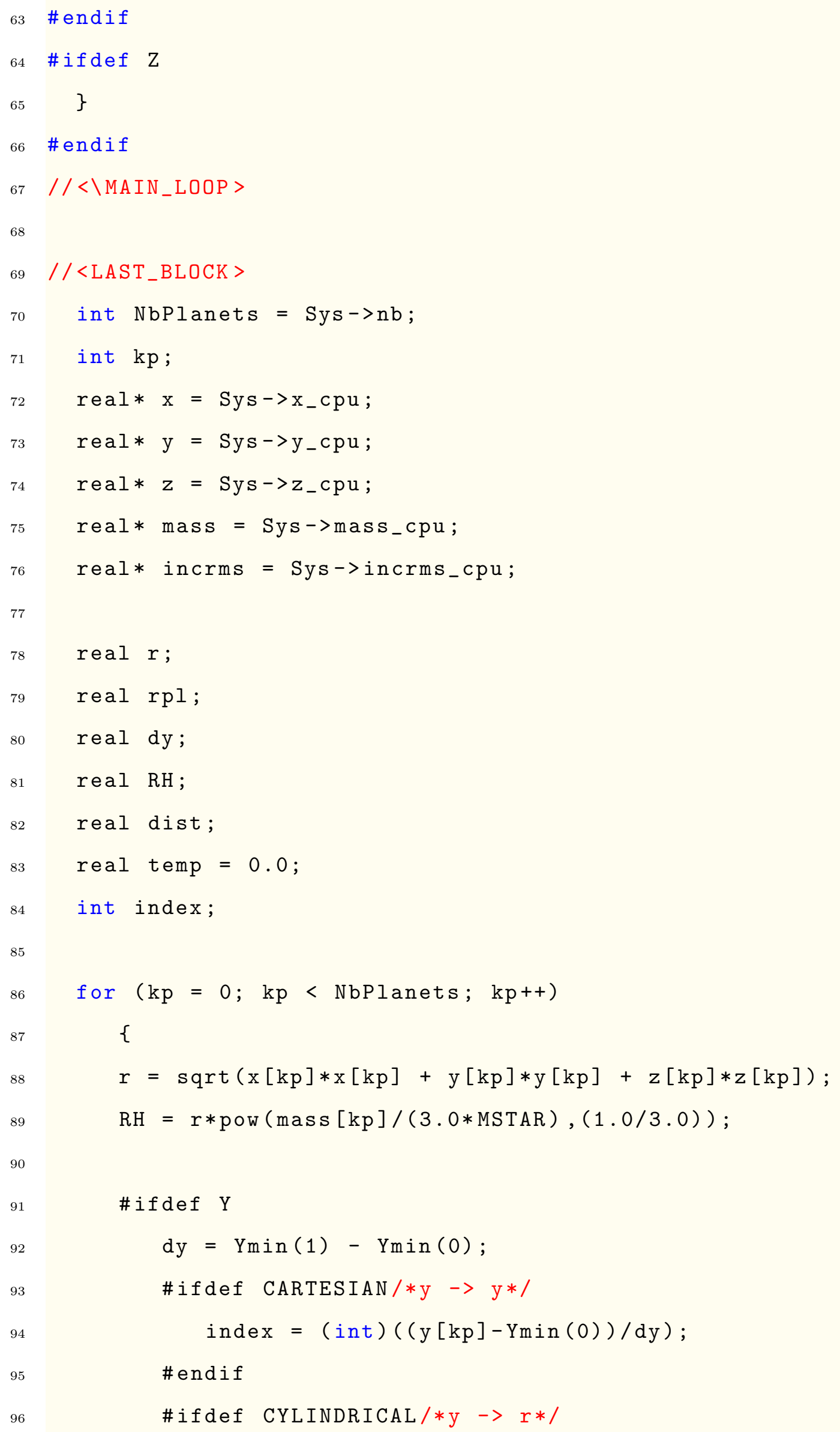




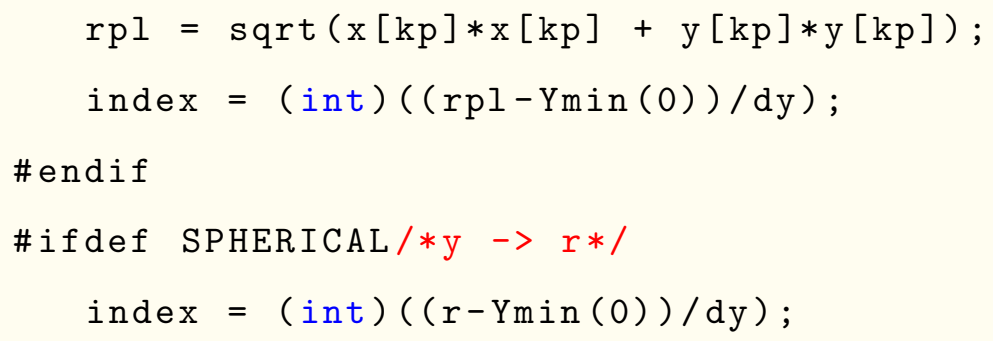




\section{B.13.1 Comentários gerais}

Essa função é responsável pelo update nos valores da inclinação quadrática média das células (linhas 55 e 56).

Por fim, dentro do bloco MAIN_LOOP (linhas 86 a 125), calcula-se o valor da média azimutal da inclinação quadrática média para o planeta. Mais detalhes podem ser obtidos no apêndice B.2, que utiliza procedimentos similares.

\section{B.14 Arquivo computeaccretionsolids.c}

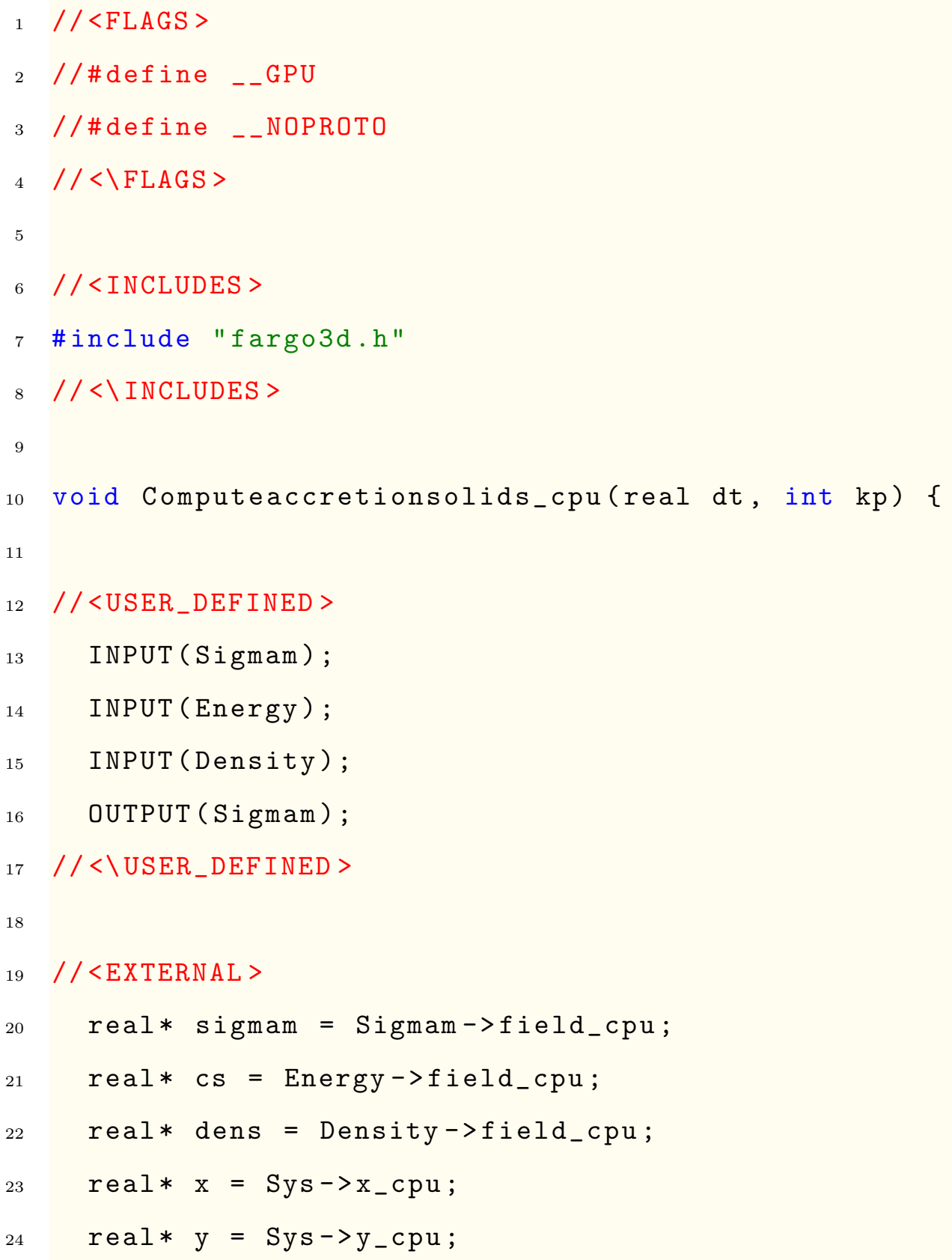




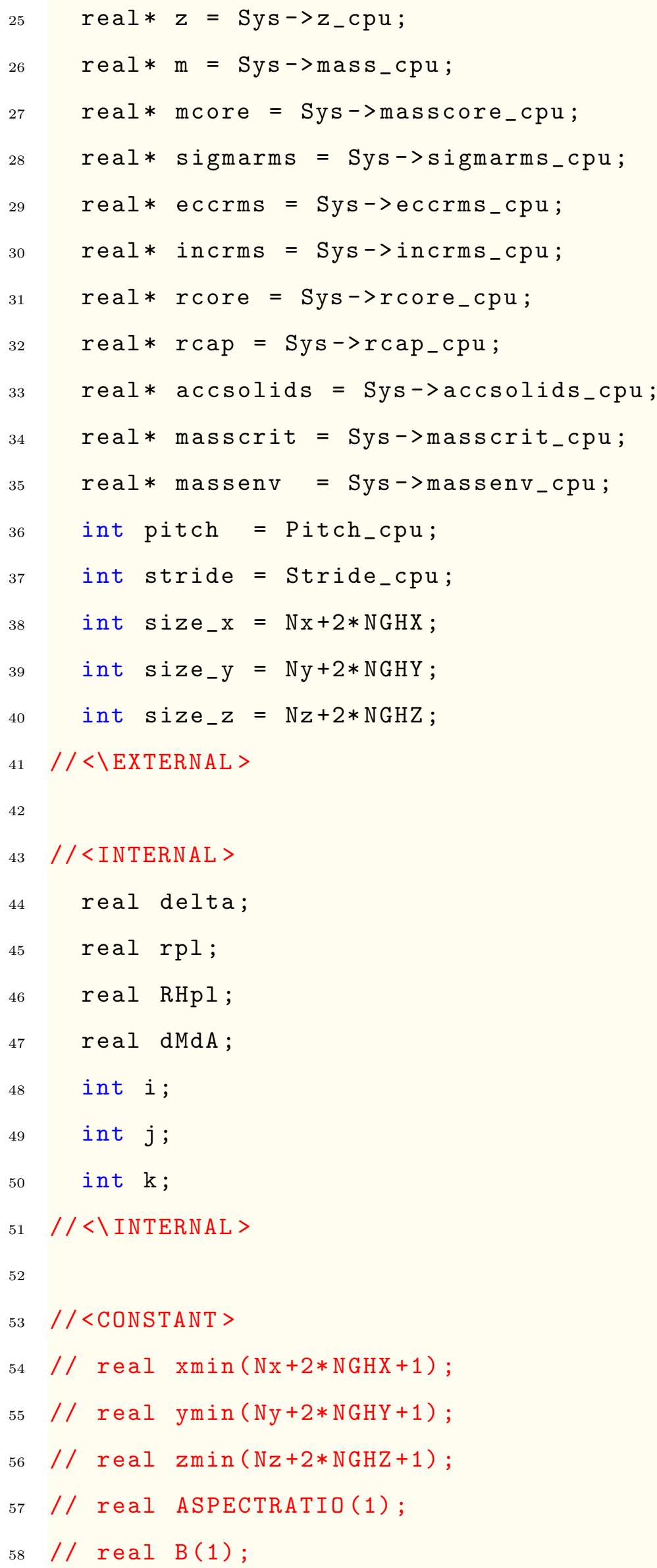




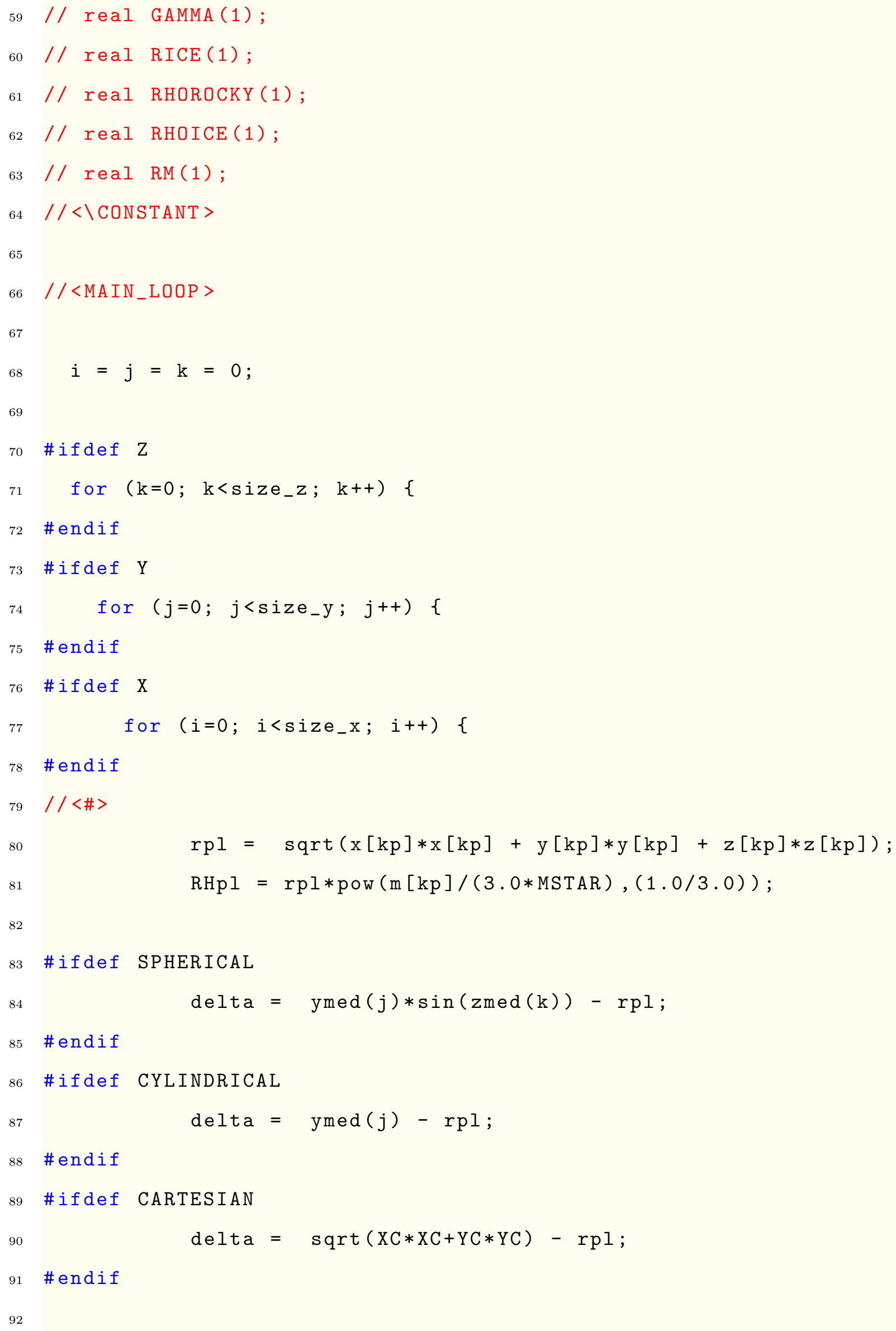


if $($ delta $<0)$ delta $=(-1.0) *$ delta;

if $($ delta $<(B / 2.0) *$ RHpl $)$

\{

$\mathrm{dMdA}=\operatorname{accsolids}[\mathrm{kp}] * \mathrm{dt} /(2.0 * \mathrm{PI} * \mathrm{rpl} * \mathrm{~B} * \mathrm{RHpl}) ;$ $\operatorname{sigmam}[1]=\operatorname{sigmam}[1]-\operatorname{dMdA}$; if $(\operatorname{sigmam}[1]<0.0)$ sigmam $[1]=0.0$;

\}

$/ /\langle\backslash \#\rangle$

\#ifdef $X$

\# endif

\#ifdef $Y$

\}

\# endif

\#ifdef $Z$

\}

\# endif

$/ /<\backslash$ MAIN_LOOP >

\section{$/ /\left\langle\mathrm{LAST}_{-}\right.$BLOCK $\rangle$}

\#ifdef __ GPU

real $* \mathrm{x}=$ Sys $->\mathrm{x}_{-} \mathrm{cpu}$;

real $*$ y $=$ Sys $->y_{-} c p u$;

real*z $=$ Sys $->z_{-} c p u$;

real $* \mathrm{~m}=$ Sys $_{-}>\mathrm{mass}_{-} \mathrm{cpu}$;

real* mcore $=$ Sys $->$ masscore_cpu;

real* sigmarms = Sys->sigmarms_cpu;

real $*$ eccrms $=$ Sys->eccrms_cpu;

real $*$ incrms $=$ Sys->incrms_cpu;

real* rcore $=$ Sys $>$ rcore_cpu;

real $*$ rcap $=$ Sys $->r c a p \_c p u$;

real $*$ accsolids = Sys $->a c c s_{0} i d s_{-} c p u$; 


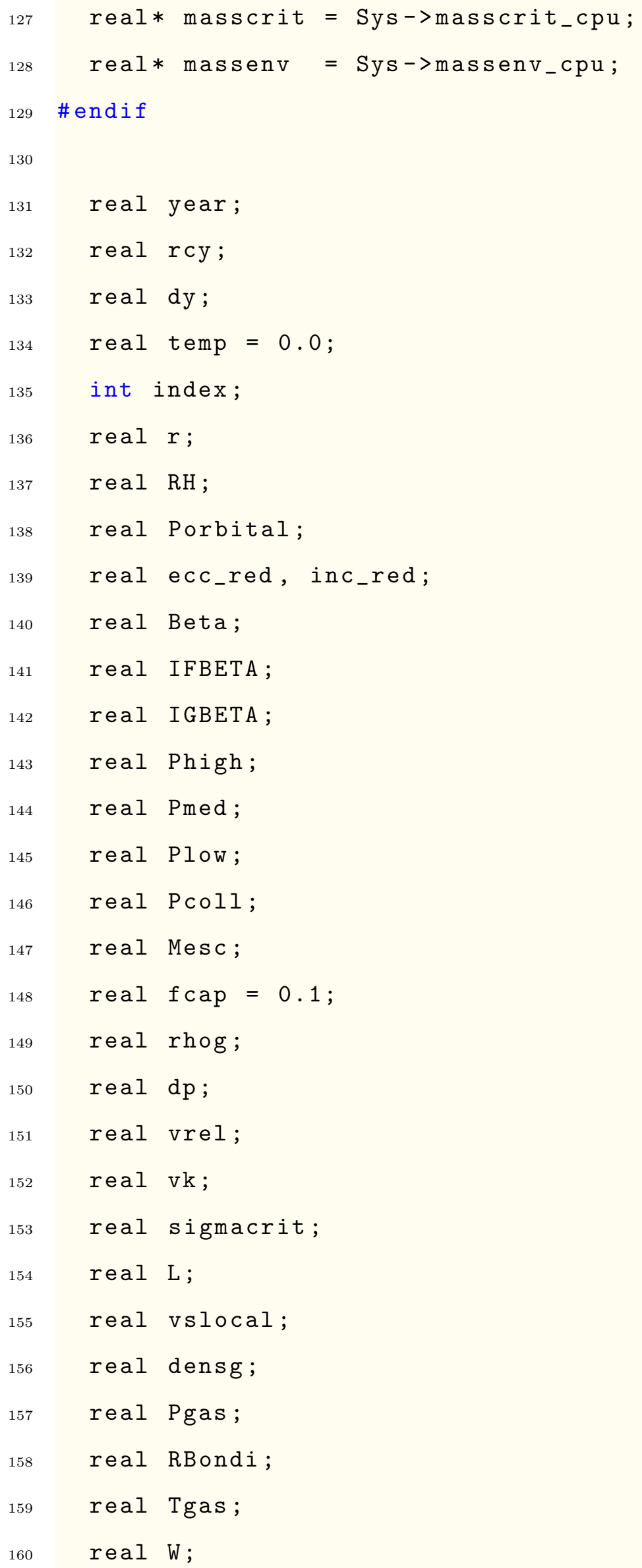


real sigmat;

real gamma;

real c1;

real c2;

\#ifdef MKS

year $=31536000.0$;

\# endif

\#ifdef CGS

year $=31536000.0$;

\# endif

\#if !(defined(MKS) || defined (CGS)) year $=31536000.0 /\left(\operatorname{sqrt}\left(R_{0} 0_{\text {MKS }} * R_{0} 0_{\text {MKS }} *\right.\right.$ RO_MKS $/ G_{-}$MKS $/$MSTAR_MKS $)$ ) ;

\# endif

$\mathrm{r}=\operatorname{sqrt}(\mathrm{x}[\mathrm{kp}] * \mathrm{x}[\mathrm{kp}]+\mathrm{y}[\mathrm{kp}] * \mathrm{y}[\mathrm{kp}]+\mathrm{z}[\mathrm{kp}] * \mathrm{z}[\mathrm{kp}])$;

$R H=r *$ pow $(m[k p] /(3.0 * \operatorname{MSTAR}),(1.0 / 3.0)) ;$

\#ifdef $Y$

$\mathrm{dy}=\operatorname{Ymin}(1)-\operatorname{Ymin}(0)$;

\#ifdef CARTESIAN/*y $\rightarrow y * /$

index $=($ int $)((y[k p]-Y m i n(0)) / d y)$;

\# endif

\#ifdef CYLINDRICAL/*y $\rightarrow r * /$

$\mathrm{rcy}=\operatorname{sqrt}(\mathrm{x}[\mathrm{kp}] * \mathrm{x}[\mathrm{kp}]+\mathrm{y}[\mathrm{kp}] * \mathrm{y}[\mathrm{kp}]) ;$

index $=($ int $)(($ rcy - Ymin $(0)) / d y)$;

\# endif

\#ifdef SPHERICAL/*y $\rightarrow r * /$ index $=($ int $)((r-\operatorname{Ymin}(0)) / d y)$;

\#endif

\# endif

\#ifndef __ GPU 


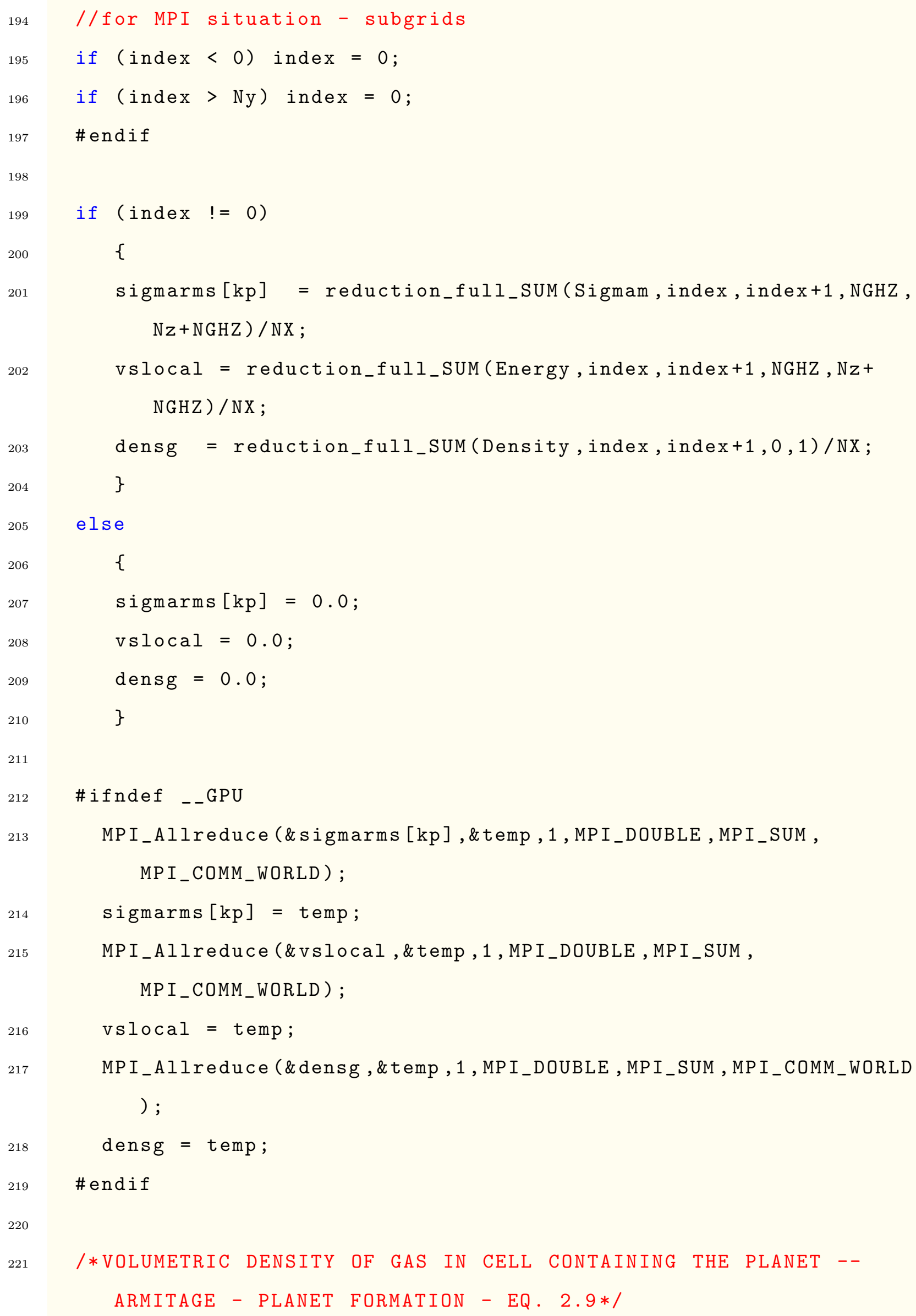




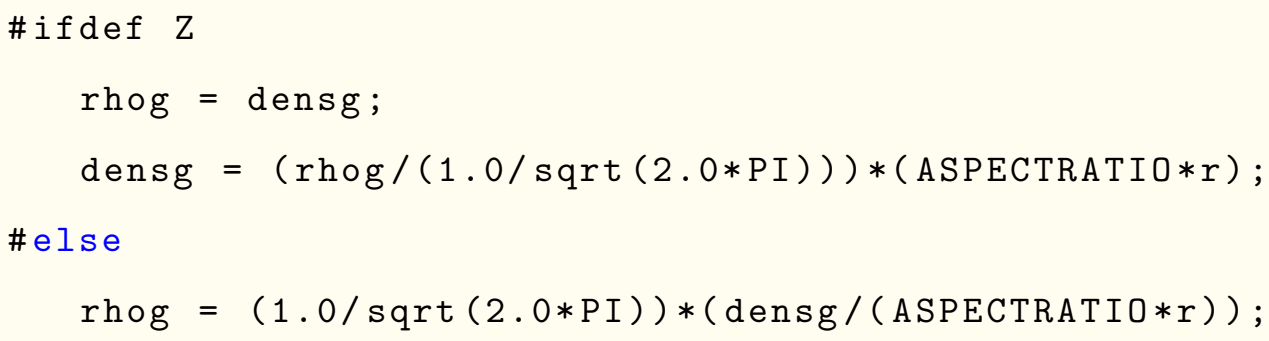




$$
/(9.0 * \mathrm{RH}) / \mathrm{rhog} \text {; }
$$

$\mathrm{L}=(\mathrm{G} * \mathrm{mcore}[\mathrm{kp}] / \mathrm{rcore}[\mathrm{kp}]) * \operatorname{accsolids}[\mathrm{kp}] ;$

RBondi $=(G * m[\mathrm{kp}] /($ gamma*vslocal*vslocal $))$;

Tgas $=\left(\right.$ vslocal*vslocal) $/ R_{-} M U$;

$\mathrm{W}=(3.0 * \mathrm{KE} * \mathrm{~L} * \mathrm{Pgas}) /(64.0 * \mathrm{PI} * \mathrm{STEFANK} * \mathrm{G} *$ mcore $[\mathrm{kp}] *$ pow $(\mathrm{Tgas}, 4.0))$; sigmat $=(1.0 /(5.0 * W))$;

if ( sigmacrit $<$ sigmat) \{ $\mathrm{c} 1=1.0+(2.0 * \mathrm{~W} *($ sigmacrit -1.0$)+\log ($ sigmacrit $)) /($ gamma $)$

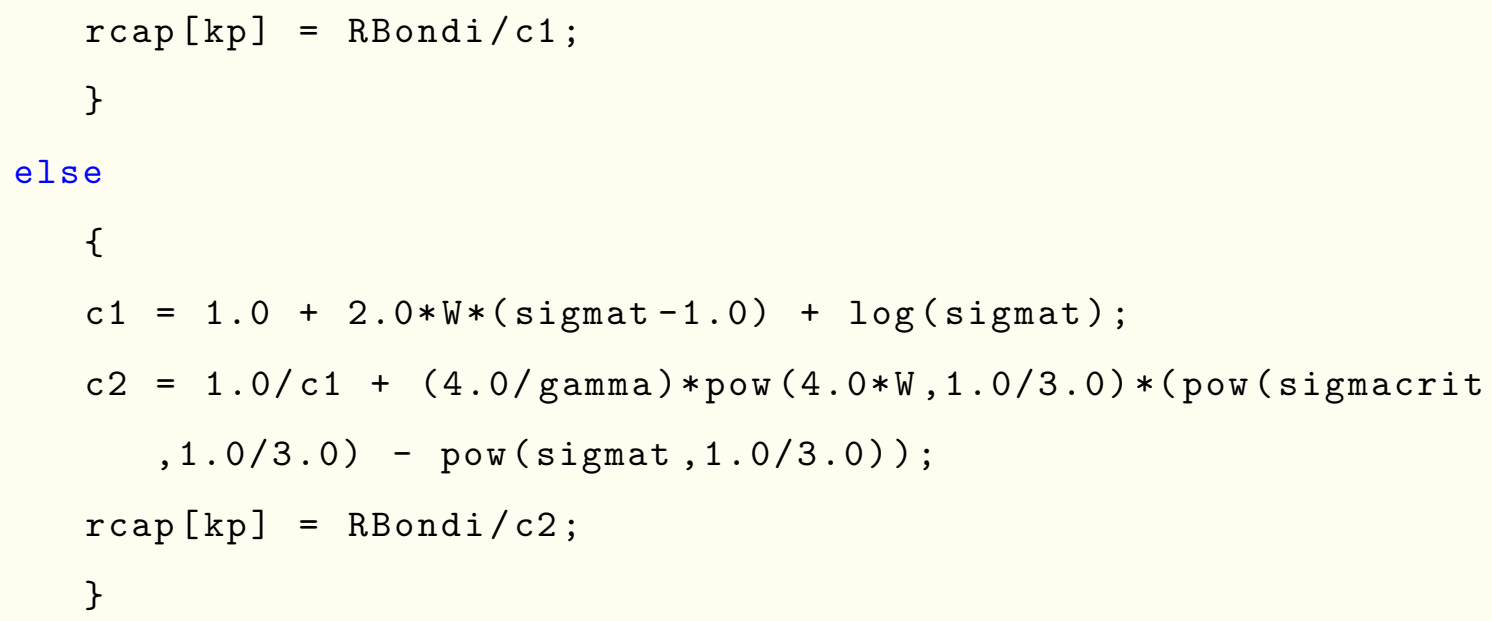




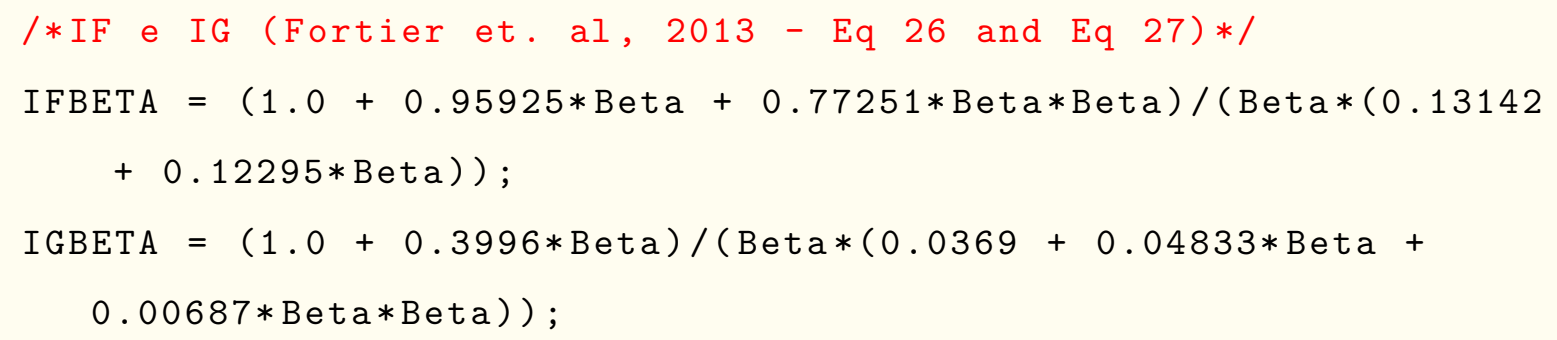




\section{B.14.1 Comentários gerais}

Essa função é responsável pelo esvaziamento da zona de alimentação, dada pela equação (linhas 80 a 100):

$$
\Sigma_{\mathrm{m}}=\Sigma_{\mathrm{m}(0)}-\frac{\dot{M}_{\text {core }} d t}{2 \pi a b R_{\mathrm{H}}} .
$$

O restante da função segue um procedimento similar ao descrito no apêndice B.2. No entanto, nessa função utiliza-se o raio de captura para cálculo das taxas de acreção (linhas 291 a 293) ao invés do raio geométrico do núcleo.

Nesta tese, seguiremos o modelo de Ormel e Kobayashi (2012) no qual se utiliza um envelope radioativo de baixa opacidade e aproximações para a estrutura do envelope planetário. Assim, o raio de captura, $R_{\text {cap }}$, é dado por (linhas 261 a 271):

$$
R_{\text {cap }} \approx R_{\mathrm{B}}\left\{\begin{array}{l}
{\left[1+\frac{2 W_{\text {neb }}\left(\sigma_{a}-1\right)+\log \sigma_{a}}{\gamma}\right]^{-1}, \quad\left(1 \leqslant \sigma_{a} \leqslant \sigma_{1}\right),} \\
{\left[\frac{1}{x_{1}}+\frac{4\left(W_{\text {neb }}\right)^{1 / 3}}{\gamma}\left(\sigma_{a}^{1 / 3}-\sigma_{1}^{1 / 3}\right)\right]^{-1}, \quad\left(\sigma_{a}>\sigma_{1}\right),}
\end{array}\right.
$$

onde $R_{\mathrm{B}}=G M_{\mathrm{p}} / \gamma c_{\mathrm{s}}^{2}(\operatorname{com} \gamma=1.4)$ é o raio de Bondi do planeta (linha 256) e $\sigma_{a}=\rho_{a} / \rho_{\text {gas }}$ (linha 254) é a razão da densidade requerida para captura da partícula e a densidade do gás. De acordo com Ormel e Kobayashi (2012), podemos escrever:

$$
\sigma_{a}=\frac{\left(6+e^{2}\right) r_{\mathrm{p}} \rho_{\mathrm{m}}}{9 R_{\mathrm{H}}}
$$

onde $e$ é a excentricidade do planetesimal, $r_{\mathrm{p}}$ o raio do planetesimal, $\rho_{\mathrm{m}}$ a densidade volumétrica do planetesimal e $R_{\mathrm{H}}$ o raio de Hill do planeta.

A grandeza $\sigma_{1}=1 / 5 W_{\text {neb }}$ (linha 259) é uma grandeza adimensional que define uma transição entre regimes de pressão para o gás (ver Ormel e Kobayashi (2012)) e $x_{1}=$ $R_{1} / R_{\mathrm{B}}=1+2 W_{\text {neb }}\left(\sigma_{1}-1\right)+\log \sigma_{1}$ (linha 268) é um parâmetro de normalização do raio. O parâmetro que define a estrutura da atmosfera do envelope é $W_{\text {neb }}$, definido por (linha 258):

$$
W_{\mathrm{neb}}=\frac{3 \kappa_{\mathrm{B}} L_{c}}{64 \pi \sigma_{\mathrm{sb}}} \frac{P_{\mathrm{gas}}}{G M_{\mathrm{core}} T_{\mathrm{gas}}^{4}}
$$


onde $\kappa_{\mathrm{B}}$ é a constante de Boltzmann, $\sigma_{\mathrm{sb}}$ a constante de Stefan-Boltzman, $P_{\text {gas }}$ a pressão

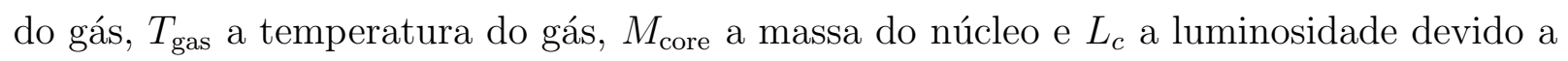
acreção de planetesimais, dada por (linha 255):

$$
L_{c}=\left(\frac{G M_{\text {core }}}{R_{\text {core }}}\right) \dot{M}_{\text {core }},
$$

onde $\dot{M}_{\text {core }}$ é a taxa de acreção de sólidos.

O raio de captura não pode ser maior que o raio de Hill do planeta e menor que o raio geométrico do núcleo (linhas 273 e 274). Algumas variáveis tiveram que ser acrescentadas ao código para o cálculo do raio de captura como a velocidade do som e a pressão (linhas 229 a 243), a densidade volumétrica do gás (linhas 222 a 227) e a temperatura (linha 257).

Outra característica importante é que o núcleo não pode crescer indefinidamente, existe uma massa limite a partir do qual o espalhamento dos planetesimais não permite que este núcleo acrete planetesimais, essa condição é obtida pela equação (linha 301):

$$
M_{e s c}=\frac{2 M_{\star} R_{\mathrm{core}}}{\sqrt{\left(f_{c a p}\right) r}},
$$

onde $f_{\text {cap }}=0.1$.

\section{B.15 Arquivo computeaccretionsolidsequilibrium.c}

\section{B.15.1 Transcrição do código}

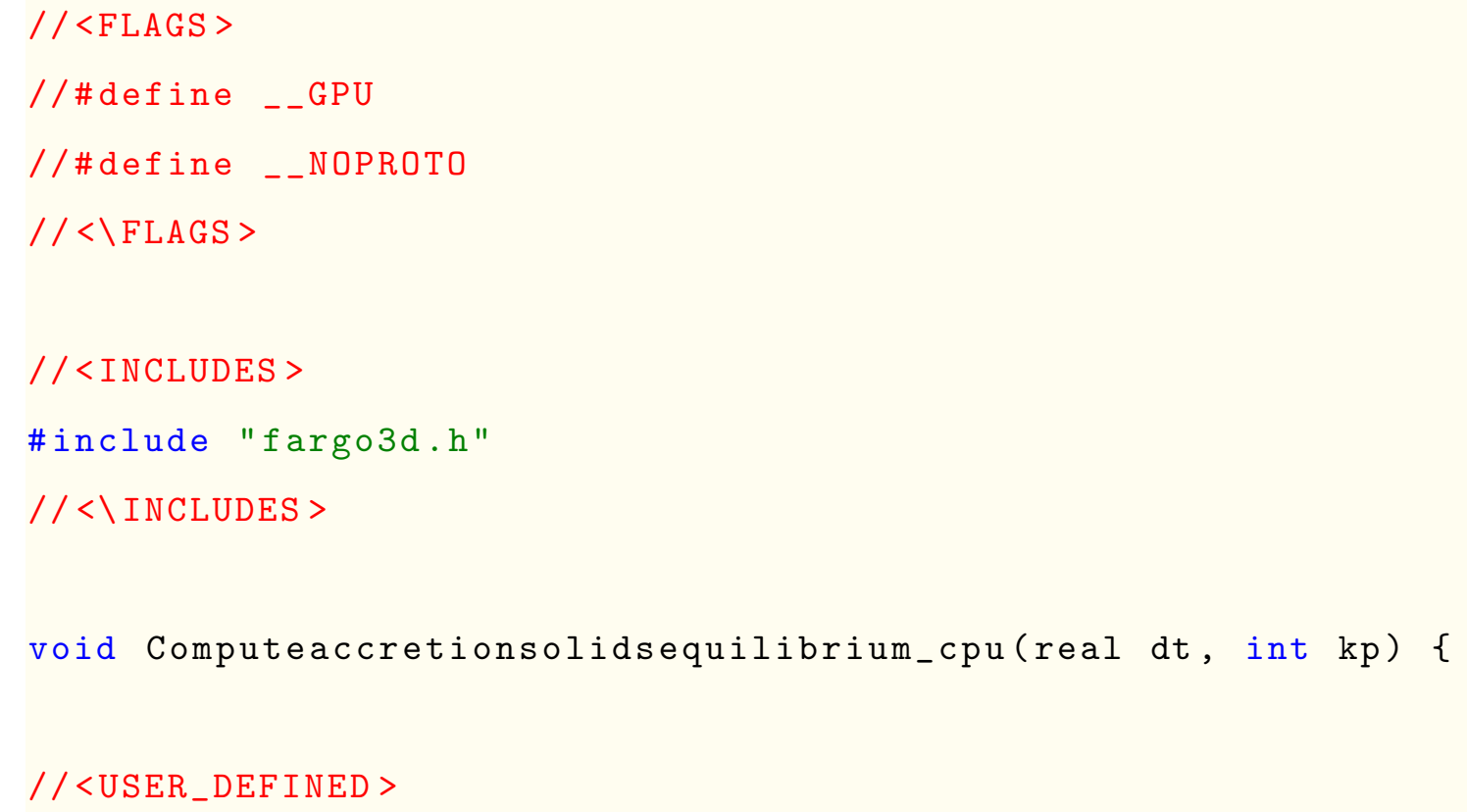




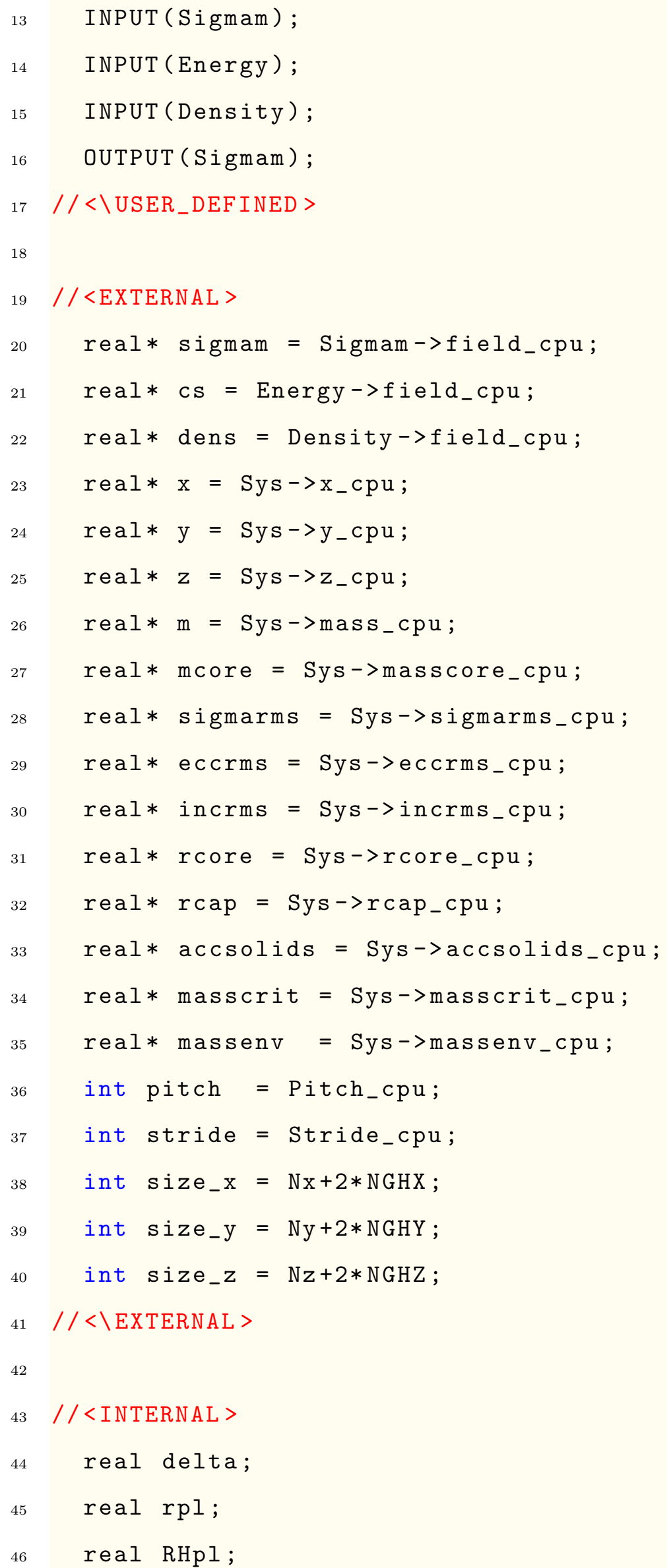




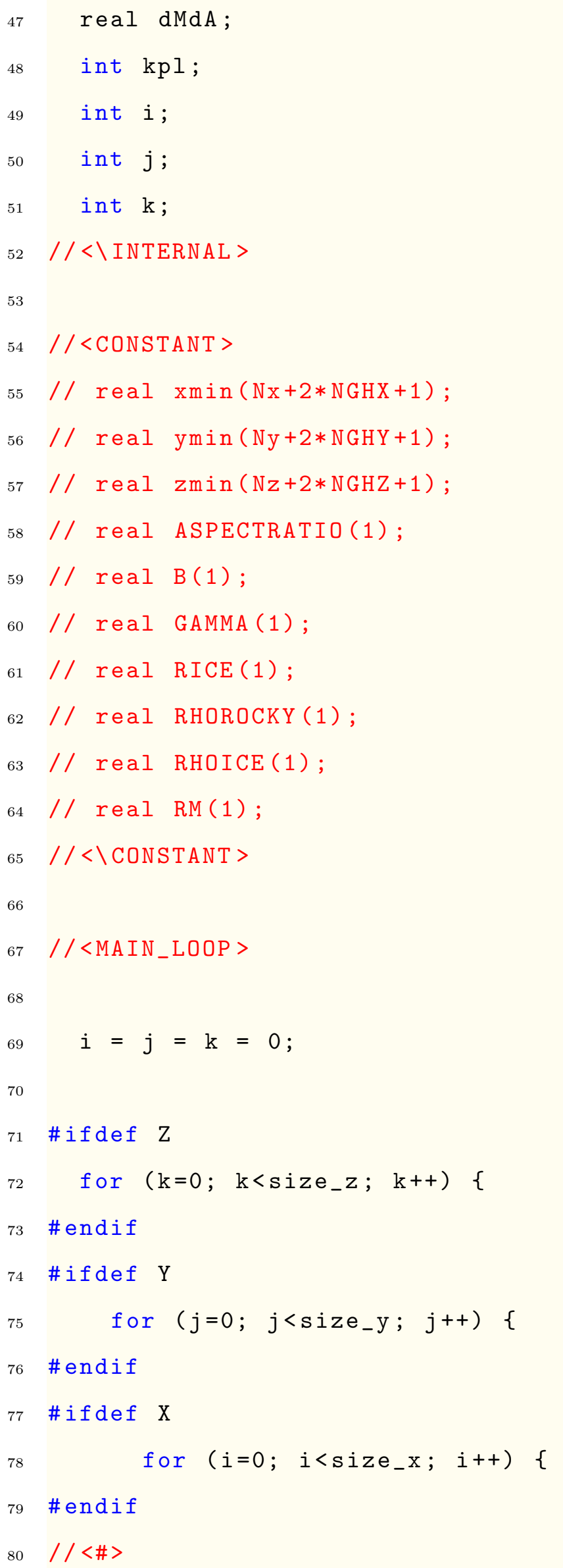




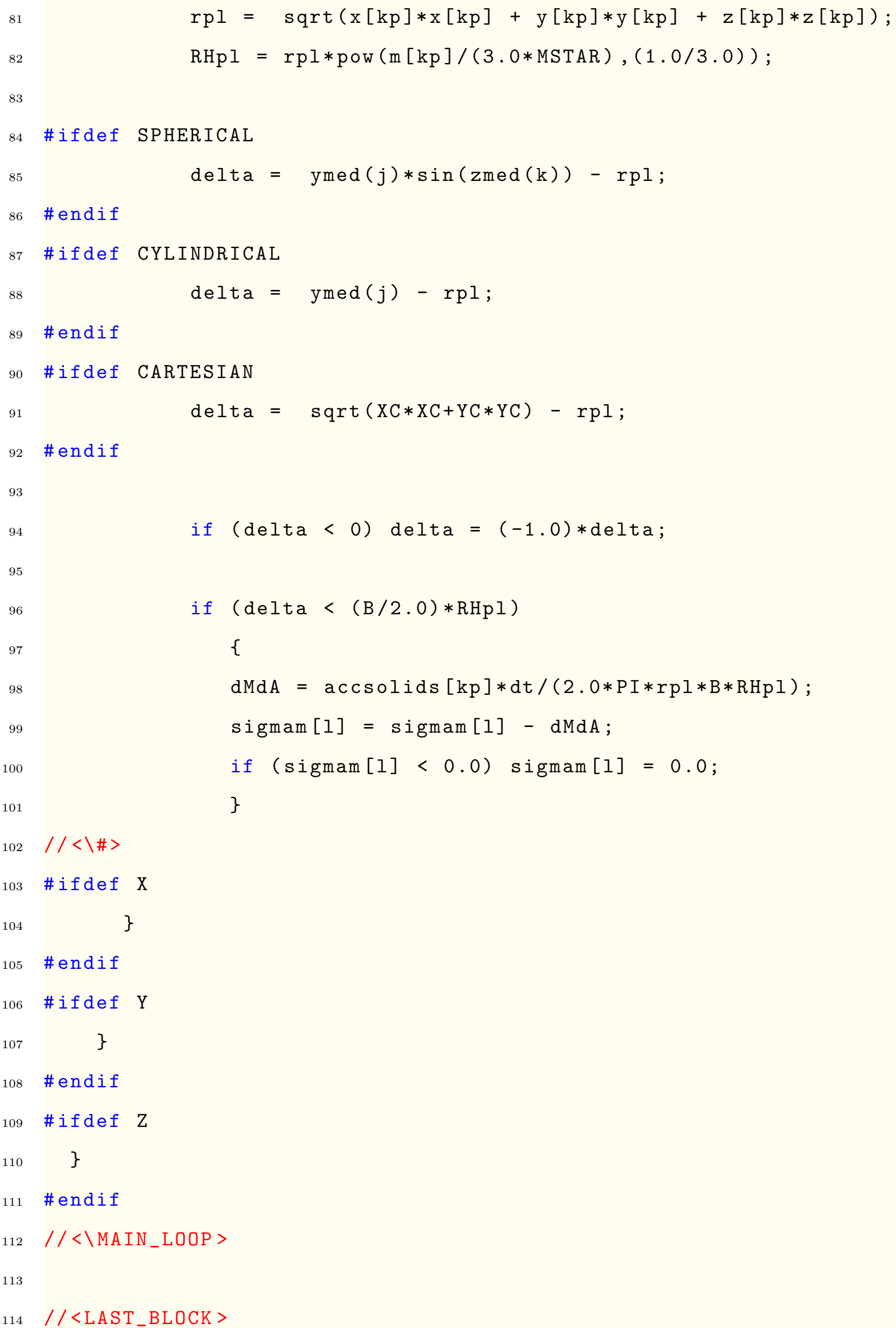


115

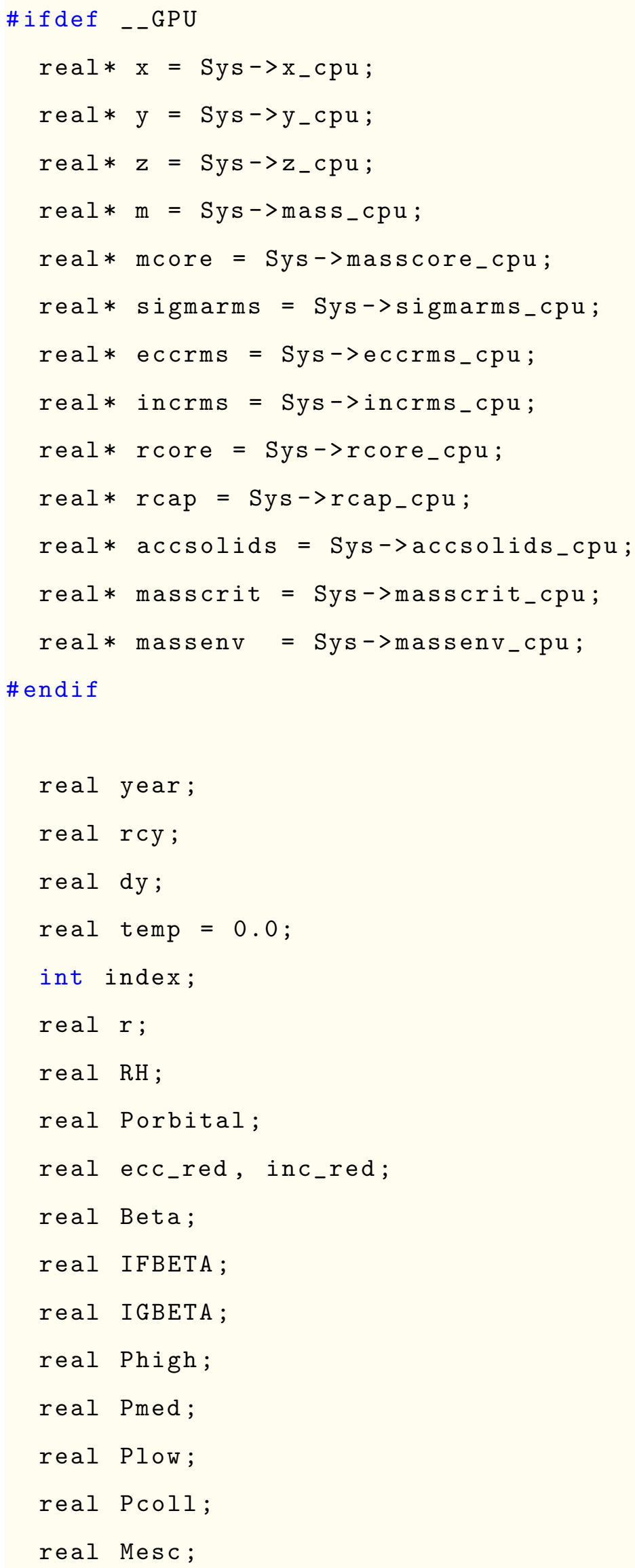




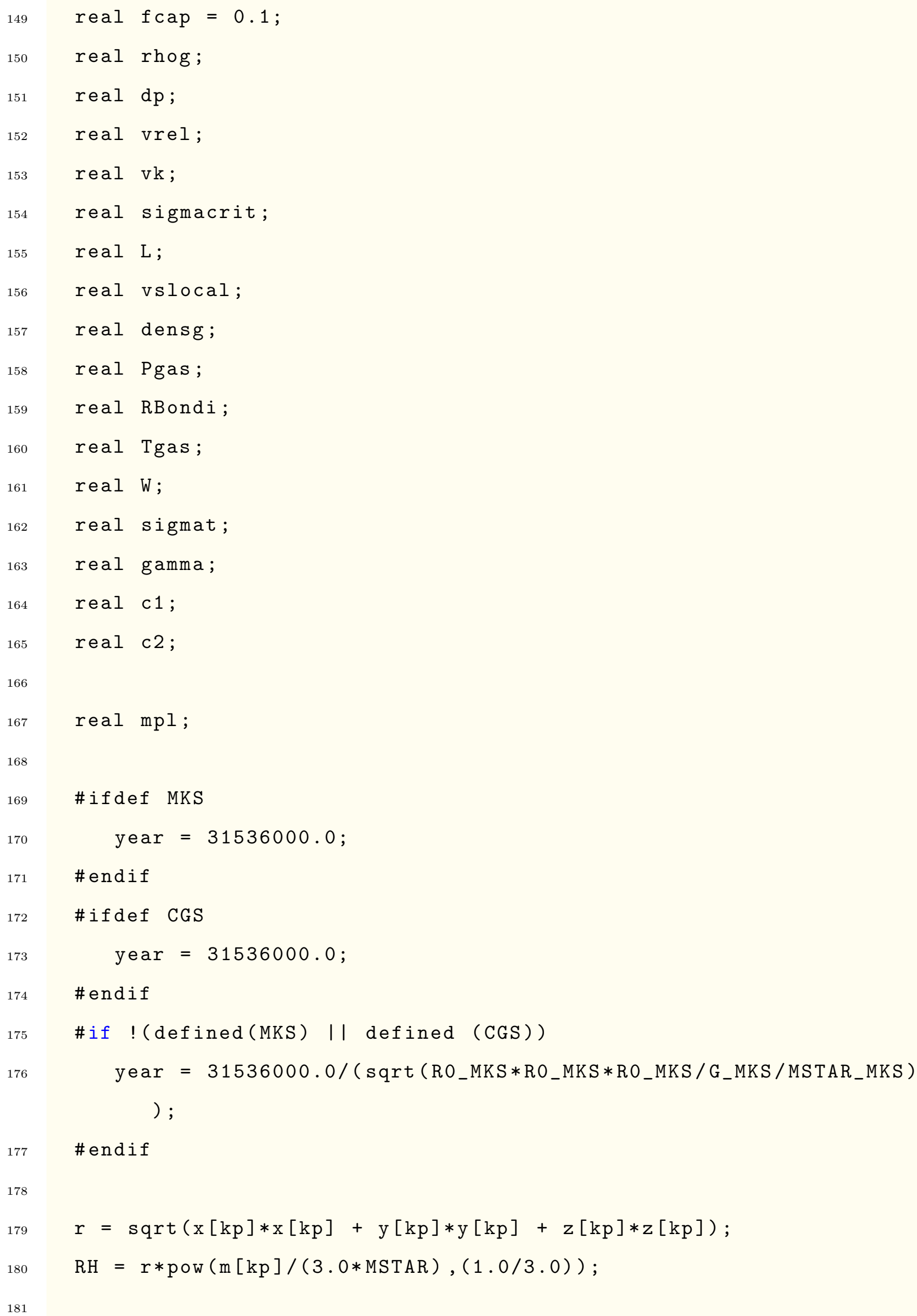




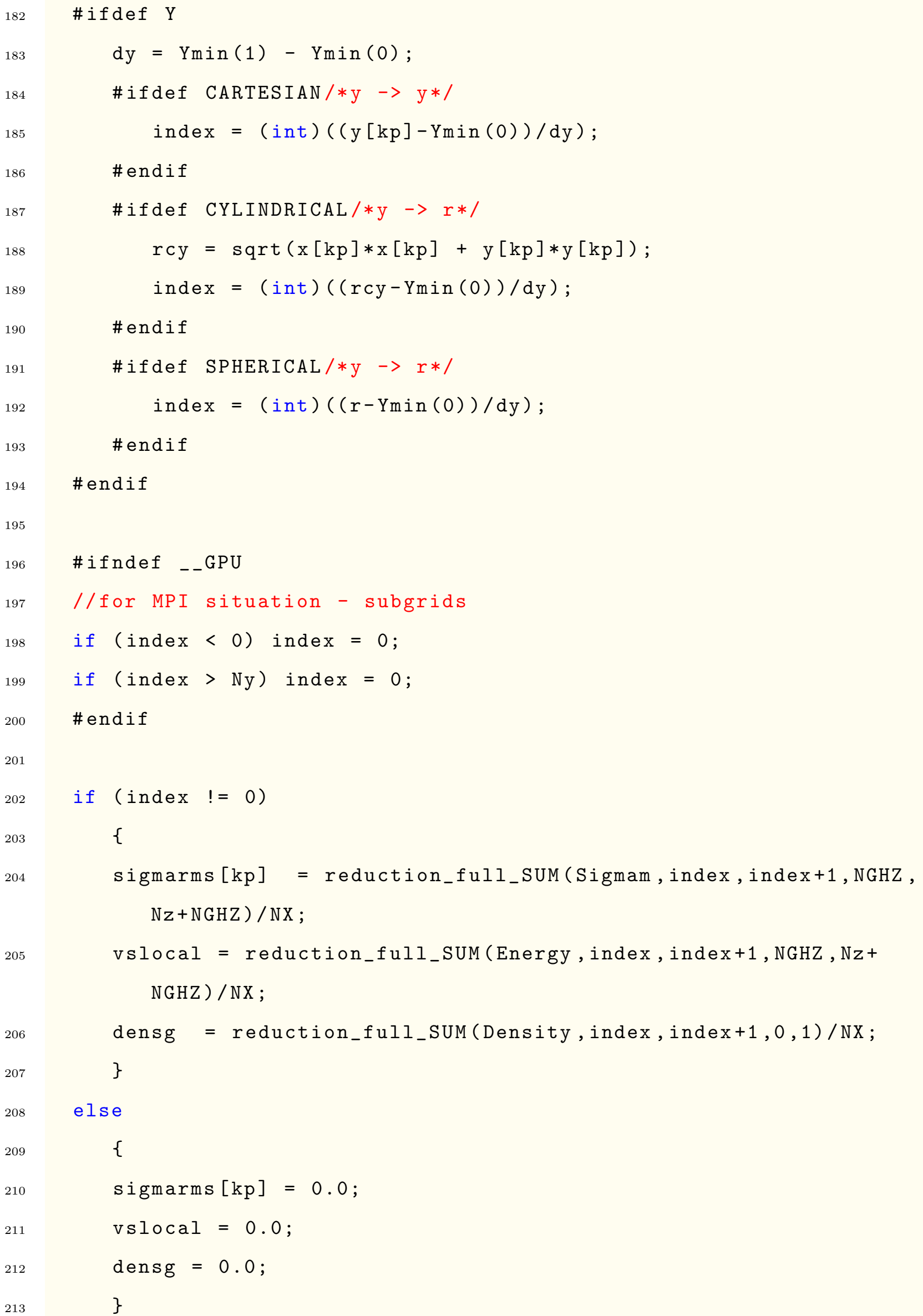




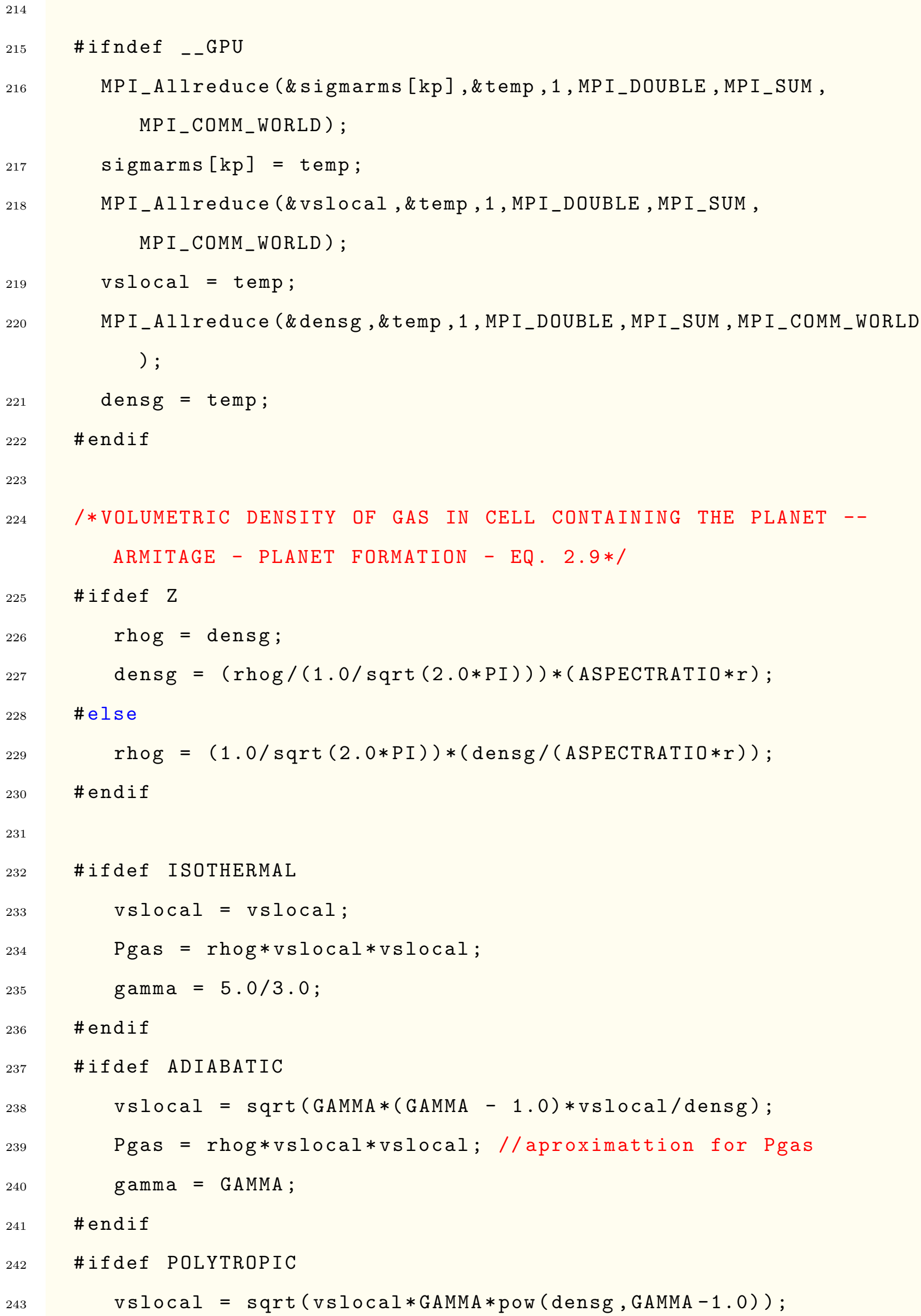


Pgas = rhog*vslocal*vslocal; //aproximattion for Pgas gamma $=$ GAMMA;

\#endif

$/ *$ RADIUS OF CORE*/

rcore $[\mathrm{kp}]=$ pow $(3.0 * \operatorname{mcore}[\mathrm{kp}] /(4.0 * \mathrm{PI} * \mathrm{RHOM}), 1.0 / 3.0)$;

/*RADIUS OF CAPTURE*/

if $(r<$ RICE) dp = RHOROCKY; //after line ice

else dp = RHOICE; //before line ice

$\mathrm{vk}=\operatorname{sqrt}(\mathrm{G} * \operatorname{MSTAR} / \mathrm{r}) ;$

$/ / \operatorname{vrel}=\operatorname{vk} * \operatorname{sqrt}(5.0 *$ eccrms $[\mathrm{kp}] *$ eccrms $[\mathrm{kp}] / 8.0+1.0 *$ incrms $[\mathrm{kp}] *$ incrms $[\mathrm{kp}] / 2.0)$;

$/ /$ sigmacrit $=(\mathrm{dp} * \mathrm{RM} * \operatorname{vrel} * \operatorname{vrel}) /(3.0 * \mathrm{G} * \operatorname{mcore}[\mathrm{kp}] * \mathrm{rhog})$;

sigmacrit $=((6.0+\operatorname{eccrms}[\mathrm{kp}] * \operatorname{eccrms}[\mathrm{kp}] *(\mathrm{RH} / \mathrm{r}) *(\mathrm{RH} / \mathrm{r})) * \mathrm{RM} * \mathrm{dp})$ / ( $9.0 * \mathrm{RH}) / \mathrm{rhog}$;

$\mathrm{L}=(\mathrm{G} * \mathrm{mcore}[\mathrm{kp}] / \operatorname{rcore}[\mathrm{kp}]) * \operatorname{accsolids}[\mathrm{kp}]$;

RBondi $=(G * m[\mathrm{kp}] /($ gamma*vslocal*vslocal $))$;

Tgas $=($ vslocal*vslocal)/R_MU;

$\mathrm{W}=(3.0 * \mathrm{KE} * \mathrm{~L} * \mathrm{Pgas}) /(64.0 * \mathrm{PI} * \mathrm{STEFANK} * \mathrm{G} * \mathrm{mcore}[\mathrm{kp}] *$ pow $(\mathrm{Tgas}, 4.0)) ;$ sigmat $=(1.0 /(5.0 * \mathrm{~W}))$;

if ( sigmacrit < sigmat)

\{

$c 1=1.0+(2.0 * W *($ sigmacrit -1.0$)+\log ($ sigmacrit $)) /($ gamma $)$ ;

$\operatorname{rcap}[\mathrm{kp}]=$ RBondi/c1;

\}

else

\{

$c 1=1.0+2.0 * W *($ sigmat -1.0$)+\log ($ sigmat $) ;$

$c 2=1.0 / \mathrm{c} 1+(4.0 /$ gamma $) *$ pow $(4.0 * \mathrm{~W}, 1.0 / 3.0) *($ pow $($ sigmacrit $, 1.0 / 3.0)$ - pow (sigmat, 1.0/3.0));

$\mathrm{rcap}[\mathrm{kp}]=$ RBondi/c2; 


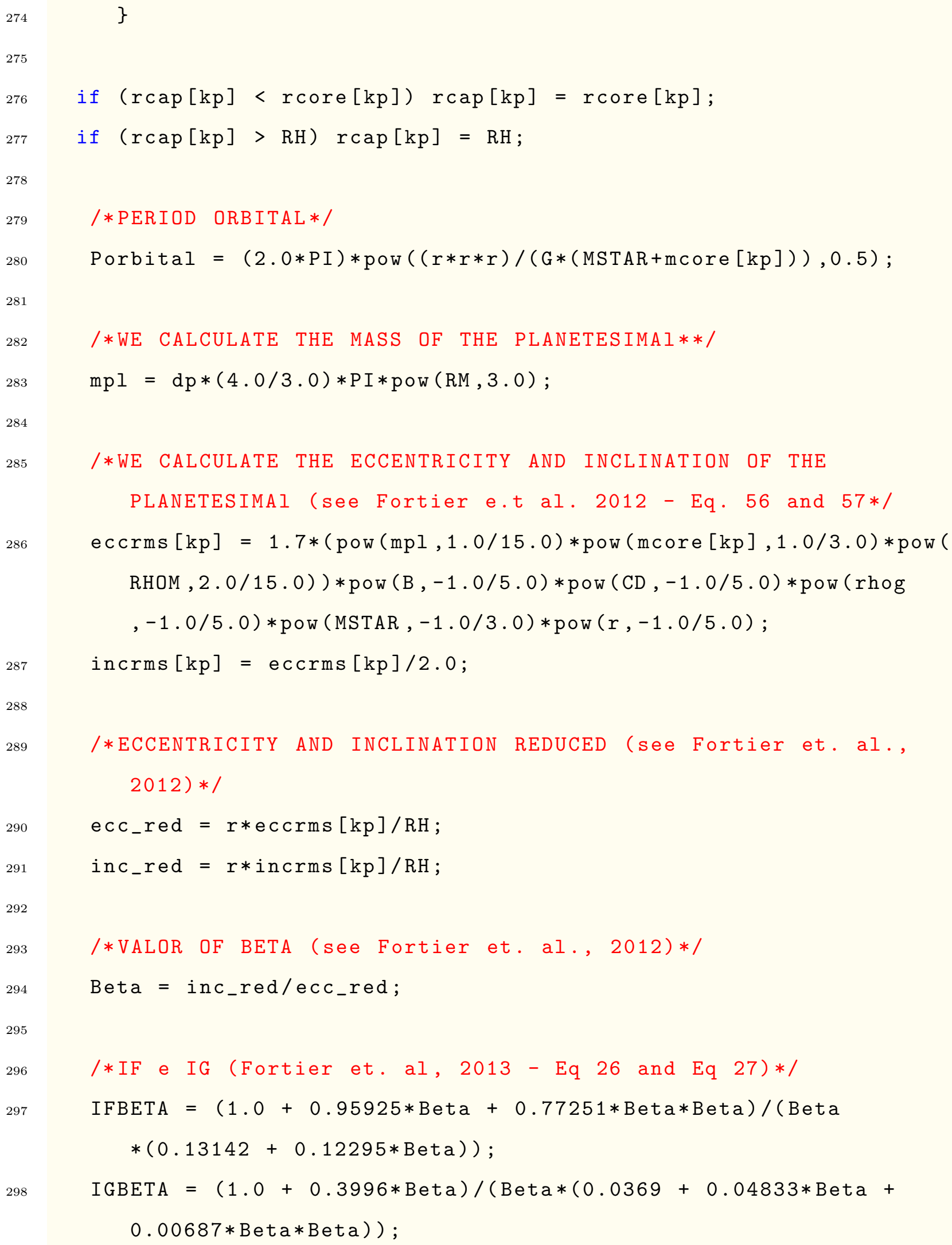




\section{B.15.2 Comentários gerais}

Essa função é responsável pelo esvaziamento da zona de alimentação, dada pela equação (linhas 65 a 84$)$ :

$$
\Sigma_{\mathrm{m}}=\Sigma_{\mathrm{m}(0)}-\frac{\dot{M}_{\mathrm{core}} d t}{2 \pi a b R_{\mathrm{H}}}
$$

O restante da função segue um procedimento similar ao descrito no apêndice B.3. No 
entanto, nessa função utiliza-se o raio de captura para cálculo das taxas de acreção (linhas 301 a 303) ao invés do raio geométrico do núcleo. O procedimento segue o mesmo padrão descrito no apêndice B.14.

\section{B.16 Arquivo accretiongas.c}

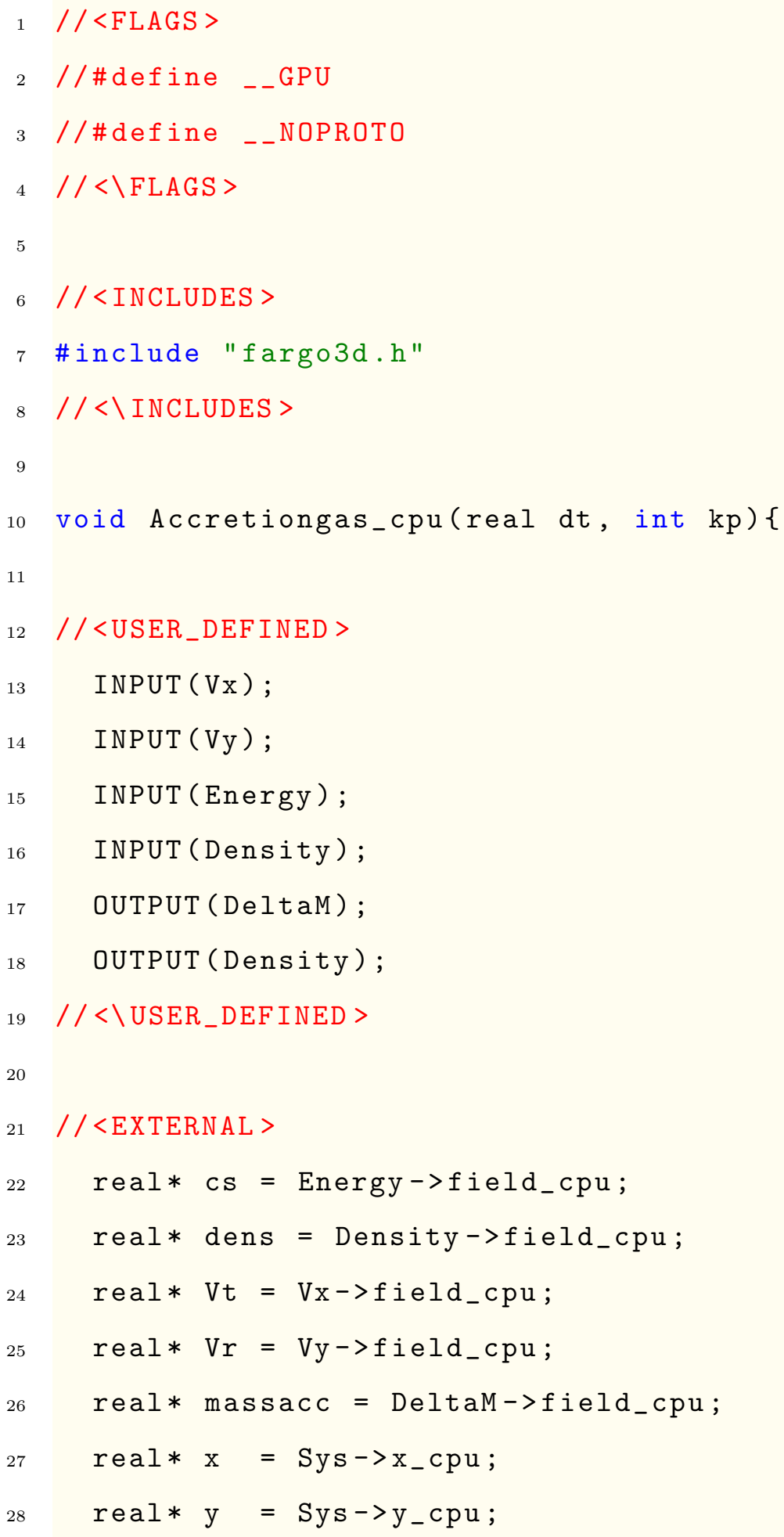




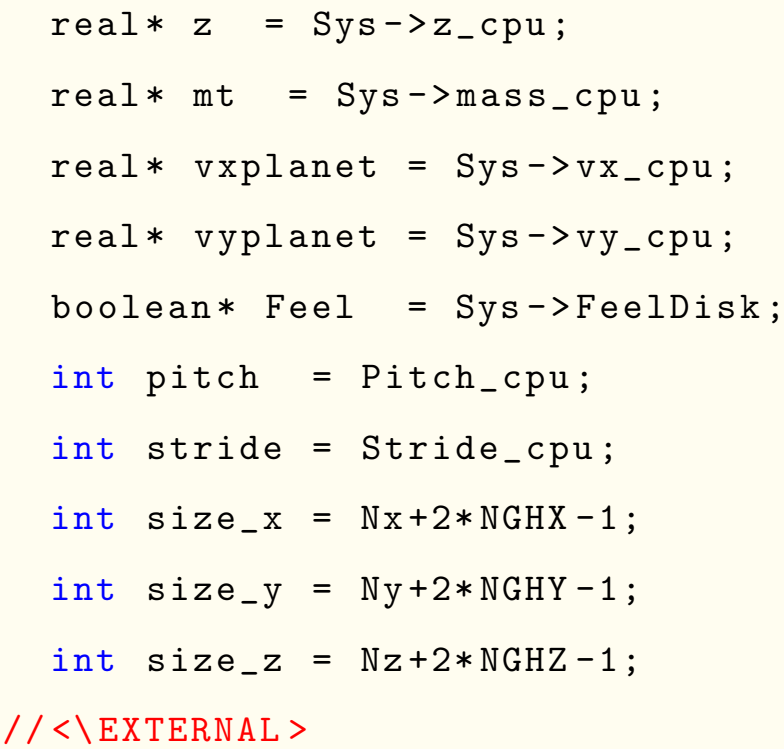




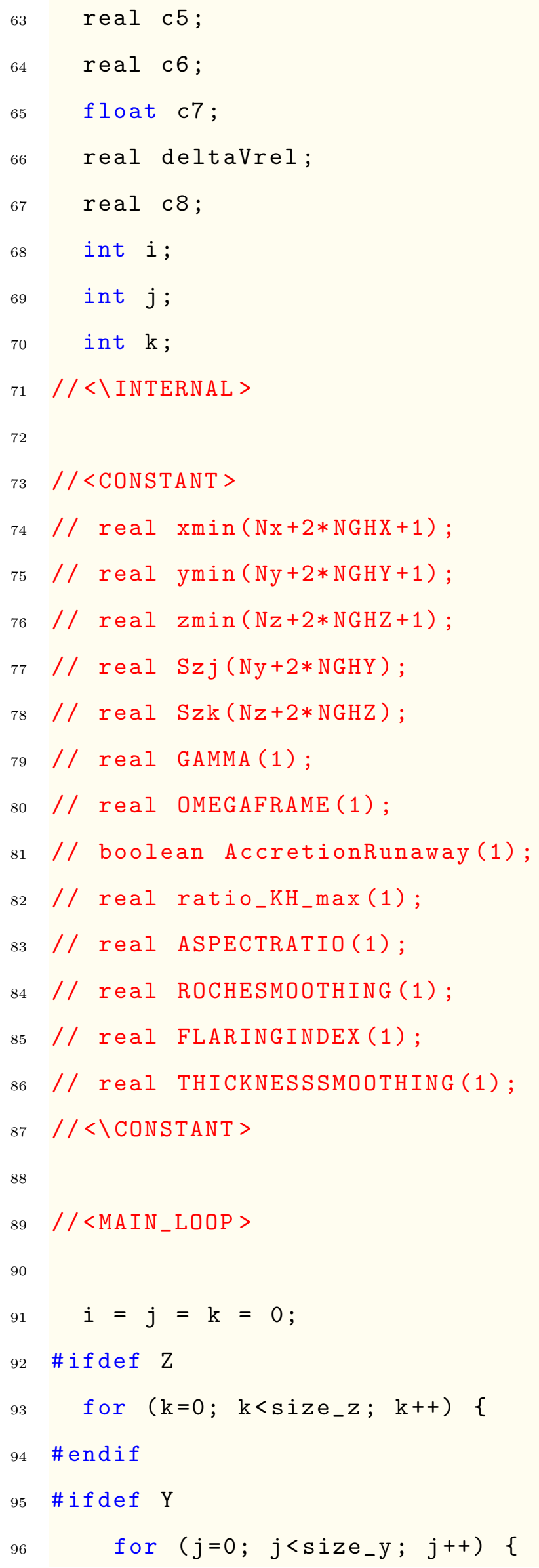




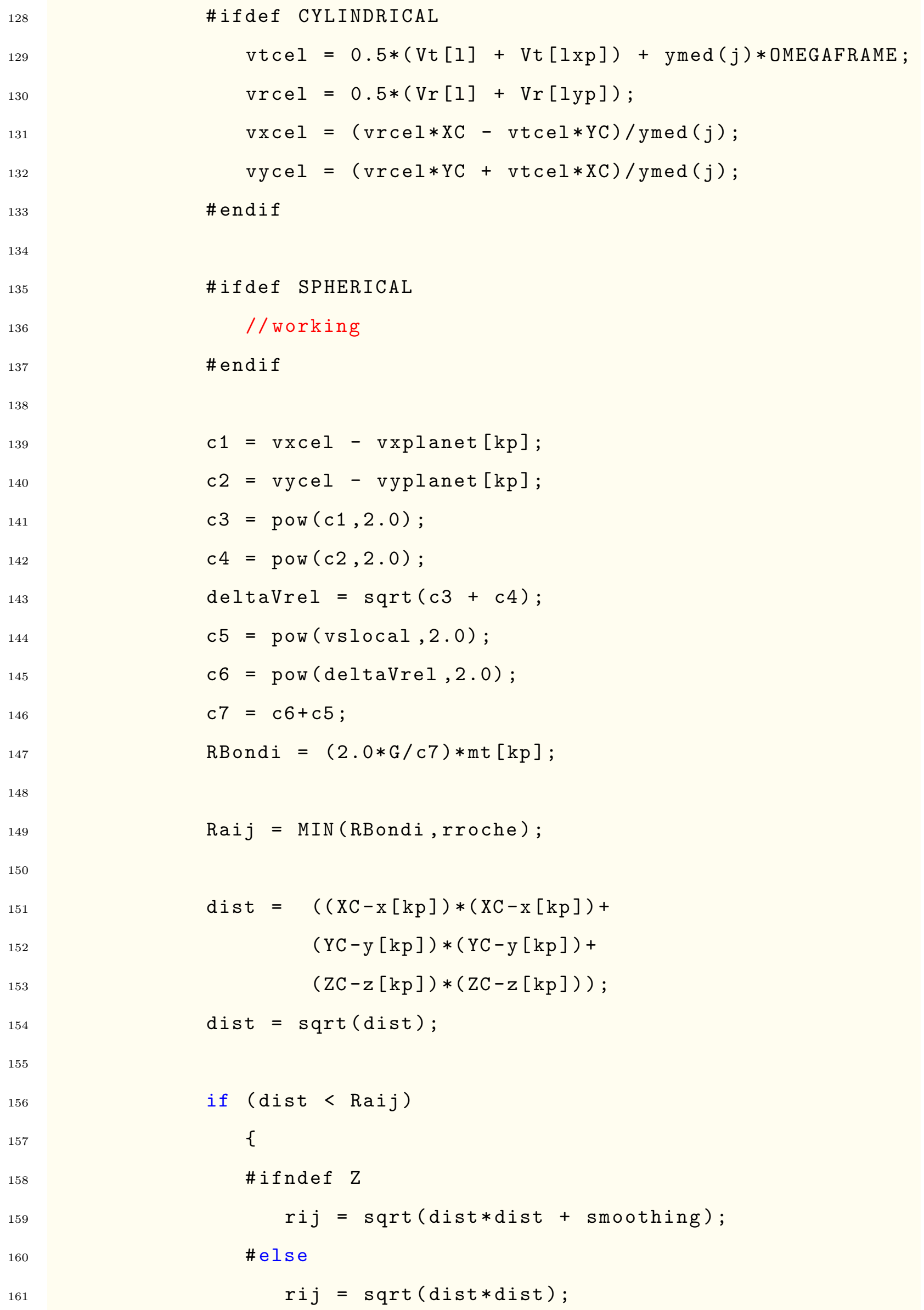




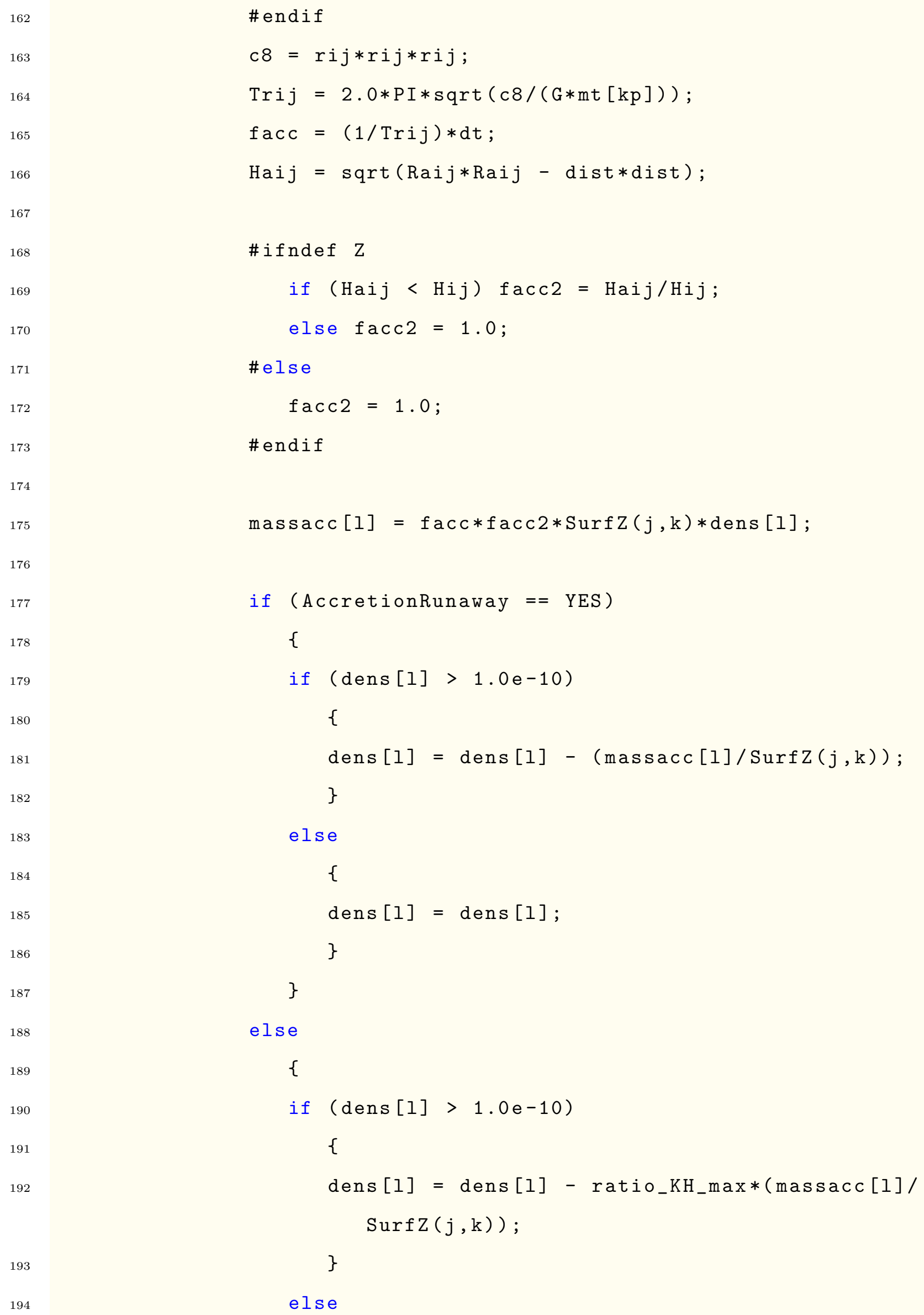

\#endif

$c 8=r i j * r i j * r i j ;$

$\operatorname{Tr} i j=2.0 * P I * \operatorname{sqrt}(\mathrm{c} 8 /(\mathrm{G} * \mathrm{mt}[\mathrm{kp}]))$;

$f a c c=(1 / \operatorname{Tr} i j) * d t ;$

Haij $=\operatorname{sqrt}(\operatorname{Raij} *$ Raij - dist*dist);

$\#$ ifndef $Z$

if $(\mathrm{Haij}<\mathrm{Hij})$ facc2 $=\mathrm{Haij} / \mathrm{Hij}$;

else facc2 $=1.0$;

\# else

$f \mathrm{acc} 2=1.0$;

\#endif

$\operatorname{massacc}[1]=f \operatorname{acc} * f \operatorname{acc} 2 * \operatorname{SurfZ}(j, \mathrm{k}) * \operatorname{dens}[1] ;$

if (AccretionRunaway $==$ YES)

\{

if (dens [l] $>1.0 e-10)$

\{ $\operatorname{dens}[1]=\operatorname{dens}[1]-(\operatorname{massacc}[1] / \operatorname{SurfZ}(j, k))$; \}

else

\{

$\operatorname{dens}[1]=\operatorname{dens}[1]$;

\}

\}

else

\{

if (dens $[1]>1.0 e-10)$

\{

$\operatorname{dens}[1]=\operatorname{dens}[1]-\operatorname{ratio}$ KH_max $_{-} *(\operatorname{massacc}[1] /$ $\operatorname{SurfZ}(j, k))$;

\}

else 


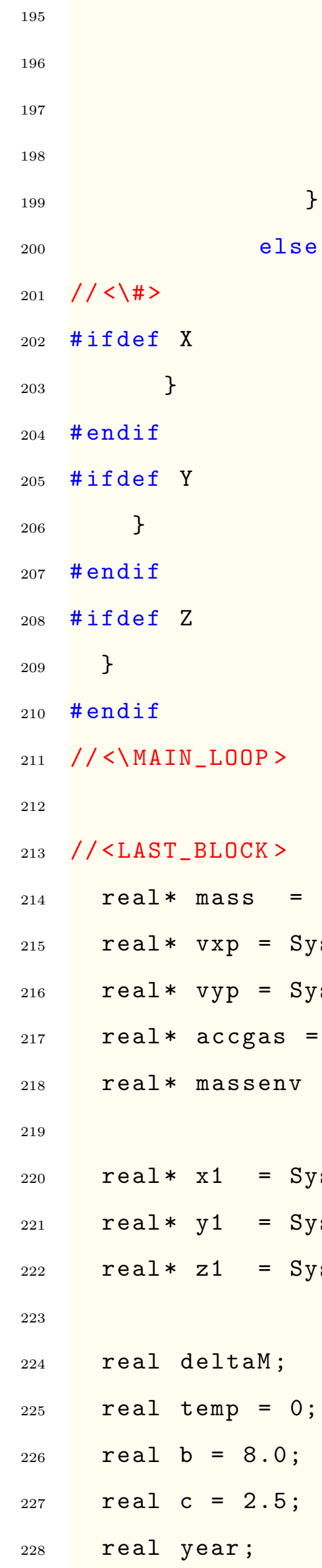

195

196

197

198

199

200

$$
201
$$

203$$
204
$$$$
205
$$

206

207

$$
210
$$$$
212
$$$$
213
$$$$
214
$$$$
215
$$$$
216
$$$$
217
$$$$
218
$$$$
219
$$$$
220
$$$$
221
$$$$
222
$$$$
223
$$$$
224 \text { real deltaM; }
$$$$
225 \text { real temp }=0 \text {; }
$$$$
226 \text { real b }=8.0 \text {; }
$$$$
227 \text { real } c=2.5 \text {; }
$$$$
228 \text { real year; }
$$

208

209

$$
211
$$




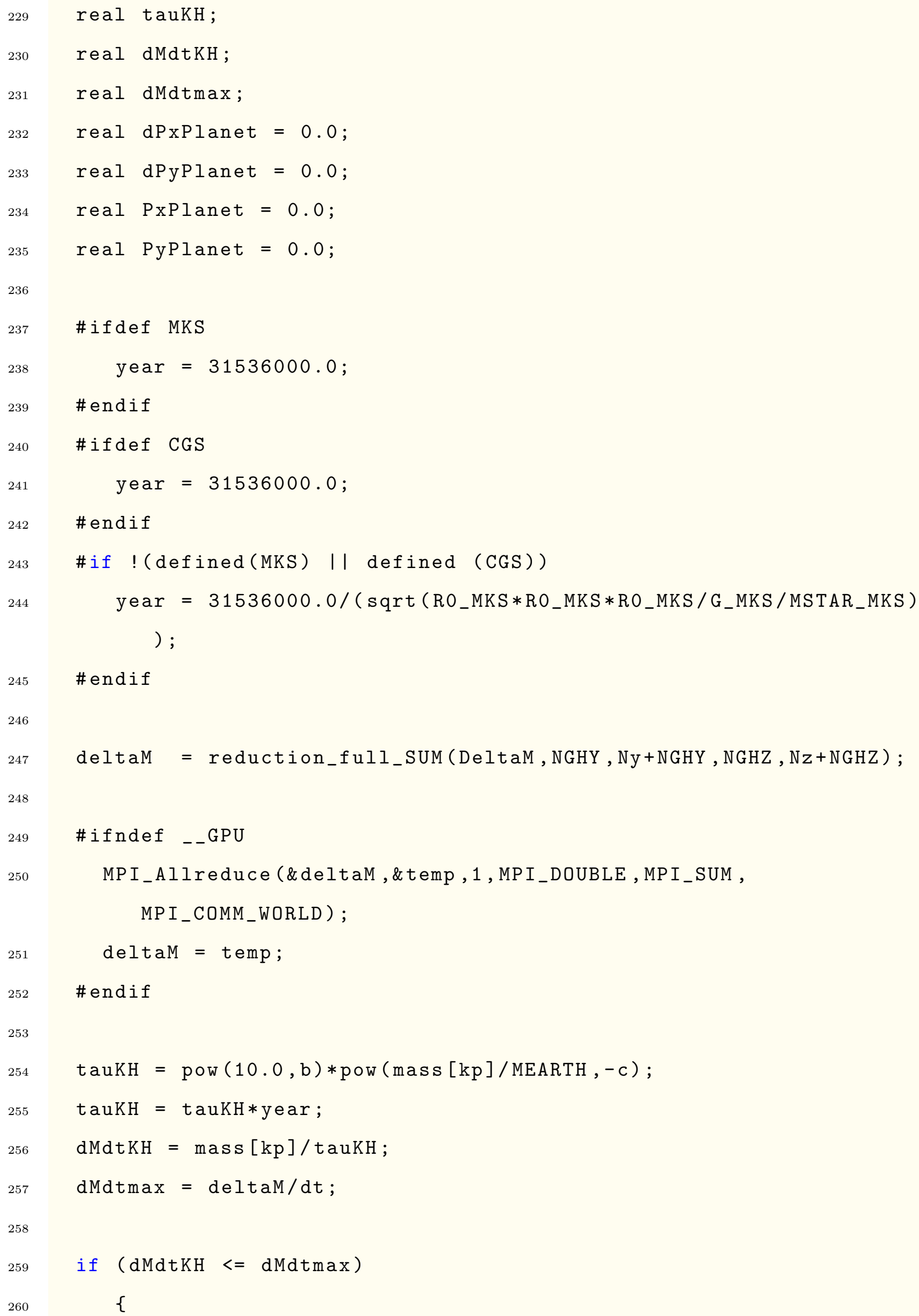




\section{B.16.1 Comentários gerais}

Essa função é responsável pela acreção de gás. Iniciada a acreção de gás, o envelope do protoplaneta contrai no tempo de escala de Kelvin-Helmholtz, obtida por Ikoma et al. (2000), e é dada por (linha 254 e 255):

$$
\tau_{\mathrm{KH}} \simeq 10^{b}\left(\frac{M_{\mathrm{p}}}{\mathrm{M}_{\otimes}}\right)^{-c}\left(\frac{\kappa}{1 \mathrm{~cm}^{2} \mathrm{~g}^{-1}}\right) \text { anos }
$$

seguindo (Ida e Lin, 2004b), adotamos o valor $b \simeq 8$ e $c \simeq 2.5$. Esses valores dependem da opacidade, que neste trabalho foi tomada como $\kappa \sim 1 \mathrm{~cm}^{2} \mathrm{~g}^{-1}$.

Obtido esse parâmetro, o programa calcula a taxa de acreção de Kelvin-Helmholtz (linha 256), dada por:

$$
\dot{M}_{\mathrm{KH}}=\frac{M_{\mathrm{p}}}{\tau_{\mathrm{KH}}} .
$$

Em seguida, compara o valor obtido com o valor da taxa no regime de runamay (linha 259 a 270), logo:

$$
\dot{M}_{\text {gas }}=\min \left(\dot{M}_{\text {run }}, \dot{M}_{\mathrm{KH}}\right)
$$


a taxa de acreção, $\dot{M}_{\text {run }}$, no regime de runamay, é dada pela equação 5.21 e é obtida nas linhas 102 a 201 e nas linhas 248 a 253. Para melhor entendimento do modelo de gás no regime de runaway, recomendamos a leitura da seção 5.4 . 
Anexo

Artigo publicado 


\title{
Adapting a gas accretion scenario for migrating planets in FARGO3D
}

\author{
L. A. DePaula, ${ }^{1 \star}$ T. A. Michtchenko, ${ }^{1}$ \\ ${ }^{1}$ Instituto Astronômico, Geofísico e Ciência astmosféricas, \\ Universidade de São Paulo, Rua do Matão 1226, 05508-900 São Paulo, Brazil
}

Accepted 2018 November 6. Received 2018 November 3; in original form 2018 August 8

\begin{abstract}
FARGO3D has been proposed to investigate numerically the gravitational interaction of the planet with the gas disc, providing original outcomes. However, FARGO3D does not consider the gas accretion of the planet that may affect the planetary migration process. Thus, the aim of this paper is to include a model for the gas accretion in the FARGO3D code. For this task, we choose Russell's scheme, which is an adaptation of Kley's model for the gas accretion onto migrating planets. Initially, we study the influence of the gas accretion onto the planet on type II migration of giant planets. For this purpose, we follow the evolution of the planets in a two-dimensional locally isothermal disc with a specific accretion rate and different values of viscosity and planetary mass considering two scenarios. In the first, the gas mass is withdrawn from the disc and is not added to the planet. In the second the planets migrate, while their masses grow due to the gas accretion. Then, we extend our study to estimate the time needed for a low mass planet to open a gap in the gas disc, and compare its value with the characteristic time of type I migration.
\end{abstract}

Key words: Protoplanetary discs - Planet disc interaction - Planet formation

\section{INTRODUCTION}

According to the classical theory of planetary formation, giant planets form in outer regions of the protoplanetary disc where there is enough material available (Lissauer 1993; Pollack et al. 1996). However, a large number of giant planets with very short period orbits, known as "hot Jupiters", has been discovered (e.g. Udry \& Santos 2007). One of the mechanisms, proposed to explain the locations of such planets, is the planetary migration resulting from the gravitational interaction of the planet with the gas disc (Masset 2000; Benítez-Llambay et al. 2011; Kley \& Nelson 2012; Baruteau \& Masset 2013; Baruteau \& Papaloizou 2013). Indeed, this interaction leads to an exchange of the angular momentum between the disc and the planets, changing their orbital parameters and resulting, in general, in the reduction of the planet's semiaxes and damped eccentricities (Goldreich \& Tremaine 1980; Ward 1986; Meyer-Vernet \& Sicardy 1987; Lin \& Papaloizou 1993; Ward 1997).

Several numerical codes have been employed to investigate the gravitational interaction of the planet with the gas disc, such as NIRVANA (Ziegler 1998) and FARGO (Masset 2000), among others. However, the majority of the codes does not consider gas accretion onto the planet or deal with

^ E-mail: luiz.paula@usp.br simplified models. This is due to the fact that the accretion process depends on several aspects of the disc structure and on a variety of physical processes and their consideration increases significantly computational costs. Therefore, little is known about how the accretion process affects the local structure around the planet, and, consequently, how it affects the planetary migration. Moreover, according to the classical theory of planetary formation, the rate of the gas accretion onto the planet also depends on the mass of the planet. In fact, for low mass planets, the gas accretion process is regulated by the Kelvin-Helmholtz contraction of the planet's gas envelope. On the other hand, as the mass increases, the hydrostatic equilibrium breaks up and, as a consequence, the planet enters in a runaway accretion regime, at which the planet's mass increases very fast.

There are two main migration regimes known as type I and II migration. Type I migration occurs for low-mass planets $\left(\lesssim 50 \mathrm{M}_{\text {Earth }}\right)$, whose interaction with the disc is weak enough to leave the disc structure almost unperturbed. This type of migration can be approximated analytically by the linear regime (Meyer-Vernet \& Sicardy 1987), when the total torque on the planet due to the gas is defined by the combined effects of the Lindblad and corotation resonances (Ogilvie \& Lubow 2006). Goldreich \& Tremaine (1980) were the first to formulate the disc-planet interaction and derive formulae for the migration process. Later, Tanaka et al. (2002) extended the linear regime of excitation to three- 
dimensional isothermal discs and recalculated the torques of the Lindblad and corotation resonances.

On the other hand, type II migration occurs for highmass planets $\left(>0.5 \mathrm{M}_{\mathrm{J}}\right)$. In this regime, a planet opens an annular gap, within which the disc surface density is reduced substantially from its unperturbed value; as a consequence, the gas in this region contributes less to the torque on the planet, thus reducing the amount of total torque of the system (Bryden \& Lin 1999; Ida \& Lin 2004). The gap is responsible for a coupling between the orbital migration of the planet and the viscous evolution of the protoplanetary disc. So, in the case when the gas does not cross the gap, the planet migrates inward in a timescale determined by the disc's viscosity (Lin \& Papaloizou 1986; Ward 1997). However, studies show that the gas can cross the gap via horseshoe orbits, implying that the rate of migrates are different than those of the viscous evolution of the disc (Edgar 2004; Dürmann \& Kley 2015).

The calculation of the migration rate of the planets of intermediate mass is complicated because this process cannot be fitted by neither the type I nor the type II migration, thus this issue still remain open (Armitage 2010).

Numerical simulations allow us to investigate how the accretion of gas onto the planet affects the flow of gas in the gap, modifying the planet's migration rate. For example, Nelson et al. (2000), using the method originally described by Kley (1999) for gas accretion of the planet, have found that the orbital migration of massive planets is always inwards and that the planet reaches the central star after $10^{4}$ initial orbital periods, regardless of the fact that the planet is accreting mass or not. Later, Dürmann \& Kley (2017), adding some refinements for the gas accretion to the same model, have shown that a fast migrating planet is able to accrete more gas than a slowly migrating planet. Moreover, they showed that the amount of gas crossing the gap changes during the migration process as the migration slows down.

This work investigates type II migration considering the model for gas accretion presented in Russell (2011) and adapting it to suit the FARGO3D code (Benítez-Llambay et al. 2015). Indeed, the FARGO3D code does not include a model for gas accretion, although, this process can affect the planetary migration. Following Russell (2011), we use a timescale of gas accretion that considers the orbital period of the gas around the planet. Additionally, we using the minimum value between the Bondi radius and the Hill radius. Finally, we introduce a gas accretion rate to deal with small planets, using the Kelvin-Helmholtz contraction time scale for planet's gas envelope. In particular, we investigate the influence of Russell's gas accretion model on the type II migration, and the time for a low mass planet to open a significant gap in the disc.

This manuscript is organized as follows. In Sect. 2, we describe the gas accretion model and introduce the numerical model for the disc in Sect. 3. In Sect. 4, we discuss how the gas accretion model affects the migration of giant planets and compare our results with those reported in Dürmann \& Kley (2015) and Dürmann \& Kley (2017). In Sect. 5 , we investigate the time it takes for a accreting planet with initial mass $\simeq 20 \mathrm{M}_{\text {Earth }}$, on a fixed orbit, to open a gap in the gas disc. Finally, we discuss the results in Sect. 6 .

\section{GAS ACCRETION SCENARIO}

Kley (1999) was one of the first works to introduce a model for gas accretion to a planet forming in the disc. Russell (2011) modified the model including Bondi's radius for gas accretion zone, effects of the disc height, Kelvin-Helmholtz gravitational contraction time scale, among others. The calculation of the Bondi's radius is a condition for the calculation of the gas accretion zone. Bondi's radius determines the region around the massive body immersed in the gas cloud, from which the body captures the gas. By definition, in this region, the resulting (thermal + relative to the body) velocity of the gas is smaller than the escape velocity of the gas (Bondi 1952). This condition provides that

$R_{B_{i j}}=\frac{2 G M_{\mathrm{p}}}{c_{\mathrm{s}}^{2}+\Delta v_{i j}^{2}}$,

where $\Delta v_{i j}$ is the module of the relative velocity between the planet and gas residing in cell $(i, j), G$ is the gravitational constant and $M_{\mathrm{p}}$ is the mass of planet. In the FARGO3D code, $c_{\mathrm{s}}$ is computed at the center of each cell and, for isothermal discs, its field is constant in time and given by the initial conditions (Benítez-Llambay et al. 2015), namely, $c_{\mathrm{s}}=h \Omega_{\mathrm{k}} r$, where $h=0.05$ is the aspect ratio of the disc, $\Omega_{\mathrm{k}}$ is the Keplerian angular velocity, and $r$ is the distance between the center of the star and the center of the cell.

The radius of the accretion zone of the planet, $R_{a_{i j}}$, is then determined by the condition

$R_{a_{i j}}=\min \left(R_{B_{i j}}, R_{\mathrm{H}}\right)$,

where $R_{\mathrm{H}}$ is the Hill radius of the planet given by

$R_{\mathrm{H}}=a\left(\frac{M_{\mathrm{p}}}{3 M_{\star}}\right)^{1 / 2}$,

with $a$ and $M_{\star}$ denoting the semimajor axis of the planet and the mass of the star, respectively. Defined in this way, $R_{a_{i j}}$ determines a minimum distance at which a cell should be from the planet, to be considered within the accretion region of the planet. If the distance from the cell to the planet $r_{i j}$ is smaller than $R_{a_{i j}}$, then the gas will be removed from this cell during accretion.

The mass of gas removed from a cell with position $[i, j]$ inside the accretion zone in a particular time step $d t$ (intrinsic time of the hydrodynamic code), is calculated as

$\delta m_{i j}=f_{i j} \Sigma_{i j} A_{i j} d t$,

where $\Sigma_{i j}$ is the cell surface density, $A_{i j}$ is the cell surface area and $f_{i j}$ is the frequency with which the gas is removed from the cell, defined by

$f_{i j}=\frac{1}{2 \pi} \sqrt{\frac{G M_{\mathrm{p}}}{r_{i j}^{3}}}$,

where $r_{i j}$ is the distance between the cell and the planet. Thus, the total mass, $\Delta m_{n}$, removed from all accreting cells per nth time-step, is a sum

$\Delta m_{n}=\sum_{i, j} \delta m_{i j}$ 
and the mass of planet is then increased by this amount.

The linear momentum is also transferred from the gas to the planet during accretion. However, according to results obtained by Dürmann \& Kley (2017), this process does not change significantly the migration rate of the planet. So, in this paper, we choose to work only with the increase in planetary mass.

The application of the Bondi's radius to calculate the accretion zone results in a dynamic accretion rate, which varies around the planet. The model is adaptable for the runaway regime for gas accretion of giant planets. On the other hand, low mass planets are outside the runaway regime and, as shown in Russell (2011), do not accrete mass in a rate beyond the Kelvin-Helmholtz contraction time scale. Indeed, the Kelvin-Helmholtz gravitational contraction time scale, $\tau_{\mathrm{KH}}$, represents the characteristic growth time of a planet's gas envelope. Ikoma et al. (2000) found that $\tau_{\mathrm{KH}}$ is strongly dependent on the planetary mass and is expressed approximately as

$\tau_{\mathrm{KH}} \simeq 10^{b}\left(\frac{M_{\mathrm{p}}}{M_{\star}}\right)^{-c}\left(\frac{\kappa}{1 \mathrm{~cm}^{2} \mathrm{~g}^{-1}}\right) \mathrm{yr}$,

where $\kappa$ is the grain opacity with power index $b=8$ and $c=2.5$. In the present work, however, we adopt an approach used in Ida \& Lin (2004), setting $\kappa=1.0 \mathrm{~cm}^{2} \mathrm{~g}^{-1}$, which gives

$\tau_{\mathrm{KH}} \simeq 10^{8}\left(\frac{M_{\mathrm{p}}}{M_{\star}}\right)^{-2.5} \mathrm{yr}$.

This expression gives an approximate growth time of the gas envelope for a planet with low mass.

According to Russell (2011), the rate which limits gas accretion onto the planet is determined by the minimum between the potential gas accretion rate $\left(\dot{M}_{\mathrm{U}}\right)$ and the KelvinHelmholtz gas accretion rate $\left(\dot{M}_{\mathrm{KH}}\right)$ for a particular time step $d t$ (intrinsic time of the hydrodynamic code):

$\dot{M}=\min \left(\dot{M}_{\mathrm{U}}, \dot{M}_{\mathrm{KH}}\right)=\min \left(\frac{\Delta m_{n}}{d t}, \frac{M_{\mathrm{p}}}{\tau_{\mathrm{KH}}}\right)$,

where $\tau_{\mathrm{KH}}$ is given by Eq. 8 and $\Delta m_{n}$ by the Eq. 6 .

The accretion rate given by Eq. 9 determines the ratio of gas removed from the cells within the planet's accretion zone. The ratio of gas accretion, $\mu$, is:

$\mu=\frac{\dot{M}_{\mathrm{KH}}}{\dot{M}_{\mathrm{U}}}$,

where $\mu \leqslant 1$. The mass removed from each cell in the planet's accretion zone is reduced by $\mu$. Thus,

$\delta m_{i j}=\mu f_{i j} \Sigma_{i j} A_{i j}$.

This equation implies that, if $\mu<1, \dot{M}_{\mathrm{KH}}<\dot{M}_{\mathrm{U}}$, and, consequently, the Kelvin-Helmholtz rate limits the gas accretion. Otherwise, $\mu=1$ and the accretion of gas occurs in the runaway regime.

In summary, unlike the scenario described in Kley (1999), the model described by Russel allows us to work with the accretion mechanism for small planetary masses using the Kelvin-Helmholtz contraction time scale for planet's gas envelope. Besides that, it is possible to adapt the size of the accretion zone taking into account the radius of Bondi. In addition, Russell's model uses, for the runaway regime, a timescale of gas accretion that considers the orbital period of the gas around the planet that results in a dynamic range of accretion time scales for each cell where gas is accreted.

In this work, Russel's model described above has been adapted in FARGO3D, for use in GPU programming.

\section{NUMERICAL SETUP}

To reduce high computational costs, we apply the hydrodynamic code FARGO3D (Benítez-Llambay et al. 2015) in the $2 \mathrm{D}$ regime in our simulations. The advantage of using FARGO3D in 2D setup, instead of using its predecessor FARGO, is that FARGO3D allows GPU computation, thus reducing computational time. The application of the threedimensional model to gas accretion study is left for future works.

In order to compare results, we choose setup parameters similar to those adopted for the NIRVANA code in Dürmann \& Kley (2015). Assuming a thin gas disc, with typical vertical height $(H)$ much smaller than its radius, we introduce a $2 \mathrm{D}$ approximation of the problem. The disc is considered to be locally isothermal, with viscosity defined by the parameter $\alpha$ from Shakura \& Sunyaev (1973). The star, with $M_{\star}=1 \mathrm{M}_{\odot}$, is located at the origin of a cylindrical coordinate system, while the disc extends from 1.56 to $15.6 \mathrm{au}$ (0.3 to 3.0 in code units). The resolution of the disc is fixed at $582 \times 1346$ cells equally spaced and no significant differences $(<5 \%)$ in the final position of the planet and the migration time have been found using higher resolutions. The planet of mass $M_{\mathrm{p}}$ is placed initially on a circular orbit at a distance of $\simeq 5.2$ ua, that corresponds to $r=1.0$ code units.

Following Dürmann \& Kley (2017), we work with a steady accretion flow through the disc, that is, with the constant local accretion rate $\dot{m}$. In this situation, the radial and angular components of the velocity of gas, $v_{\mathrm{r}}$ and $v_{\theta}$, respectively, are given by (Dürmann \& Kley 2015):

$v_{\mathrm{r}}=-\frac{3}{2} \alpha h^{2} r \Omega_{\mathrm{K}}, \quad v_{\theta}=\sqrt{1-\frac{3 h^{2}}{2}} r \Omega_{\mathrm{K}}$,

where $\Omega_{\mathrm{K}}=\sqrt{G M_{\star} / r^{3}}$ is the Keplerian orbital frequency of the gas at the position $r$ and the parameter $h$ corresponds to the relative disc thickness and has constant value $h=$ $H / r=0.05$. The surface density of the disc is given by (Dürmann \& Kley 2015):

$\Sigma=\frac{\dot{m}}{3 \pi \alpha h^{2} \sqrt{\left(G M_{\star}\right)}} r^{-1 / 2}=\Sigma_{0} r^{-1 / 2}$,

where $\Sigma_{0}$ is the superficial density at $r=1$ code units. These equations can be obtained for stationary accretion disks with constant accretion rate.

Table 1 shows the parameter space used in our simulations. Throughout the paper we will refer to the disc defined by the of parameters $(\alpha, q, \dot{m})=\left(0.003,0.001,10^{-7} \frac{\mathrm{M}_{\star}}{\text { year }}\right)$ as the standard disc, with $q=M_{\mathrm{p}} / M_{\star}$. It is worth mentioning that in the FARGO3D code the initial profile of the 
Table 1. Space of parameters. The values of $\alpha$ and $q(q=$ $\left.M_{\mathrm{p}} / M_{\star}\right)$ are dimensionless. We define a standard parameter set as $(\alpha, q, \dot{m})=\left(0.003,0.001,10^{-7} \frac{\mathrm{M}_{\star}}{\text { year }}\right)$.

\begin{tabular}{ccc}
\hline \hline$\alpha$ & $q$ & $\dot{m}\left(\frac{\mathrm{M}_{\star}}{\text { year }}\right)$ \\
\hline 0.001 & 0.0002 & $1 \times 10^{-9}$ \\
0.003 & 0.0005 & $1 \times 10^{-8}$ \\
0.01 & 0.001 & $1 \times 10^{-7}$ \\
\hline
\end{tabular}

Table 2. Values for $\Sigma_{0}$ in $\mathrm{kg} \cdot \mathrm{m}^{-2}$ for each set of parameters.

\begin{tabular}{cccc}
\hline \hline$\alpha \backslash \dot{m}$ & $1 \times 10^{-7} \frac{\mathrm{M}_{\star}}{\text { year }}$ & $1 \times 10^{-8} \frac{\mathrm{M}_{\star}}{\text { year }}$ & $1 \times 10^{-9} \frac{\mathrm{M}_{\star}}{\text { year }}$ \\
\hline & & & \\
0.001 & 2626.3 & 262.63 & 26.263 \\
0.003 & 8743.4 & 874.34 & 87.434 \\
0.010 & 2626.3 & 262.63 & 26.263 \\
\hline
\end{tabular}

surface density of the disc is obtained through the free parameters for the disk aspect ratio $(h=0.05)$, the flare of the $\operatorname{disc}(\gamma=0)$ and the surface density in $r=1\left(\Sigma_{0}\right)$. Table 2 displays the values of $\Sigma_{0}$ obtained for each parameter set $(\alpha, \dot{m})$ according to Eq. 13 . The values are in $\mathrm{kg} \cdot \mathrm{m}^{-2}$.

We modify the FARGO3D code in such a way that the torque on the planet due to the gas is reduced when the gas is inside a region with radius equal to $0.8 R_{\mathrm{H}}$ around the planet. Following Dürmann \& Kley (2017), we use a Fermilike tapering function the given by

$f_{\text {taper }}\left(r_{\text {cell }}\right)=\frac{1}{1+\exp \left(-\frac{r_{\text {cell }-0.8 R_{\mathrm{H}}}}{0.8 R_{\mathrm{H}}}\right)}$,

where $r_{\text {cell }}$ is the distance of the cell to the planet and $R_{\mathrm{H}}$ is the planet's Hill radius.

For comparison purpose, we choose the same boundary conditions used by Dürmann \& Kley (2015). So, we disable the damping of the surface density in the FARGO3D code, to avoid accumulation of gas at the inner boundary and allow gas to flow freely as desired.

\section{GIANT PLANET MIGRATION}

In order to investigate how Russell's accretion model (Russell 2011) affects the type II migration, we analyse two scenarios for the migration of giant planets. In the first scenario (Sec. 4.1), the planets do not grow during migration, that is, the gas mass is withdrawn from the disc and is not added to the planet. In the second scenario (Sec. 4.2), the planets migrate, while their masses grow due the gas accretion.

First, we need to know how the gas accretion of the planet affects the profile of the gap, also as the flow of gas through the gap opened by the planet modifying the torque on the planet. Additionally, we analyse the rate of planetary migration for different values of the disc viscosity. In this work we have three conditions for the viscosity of the disc, we use the term low viscosity when $\alpha=0.001$, medium viscosity when $\alpha=0.003$ and high viscosity when $\alpha=0.01$.

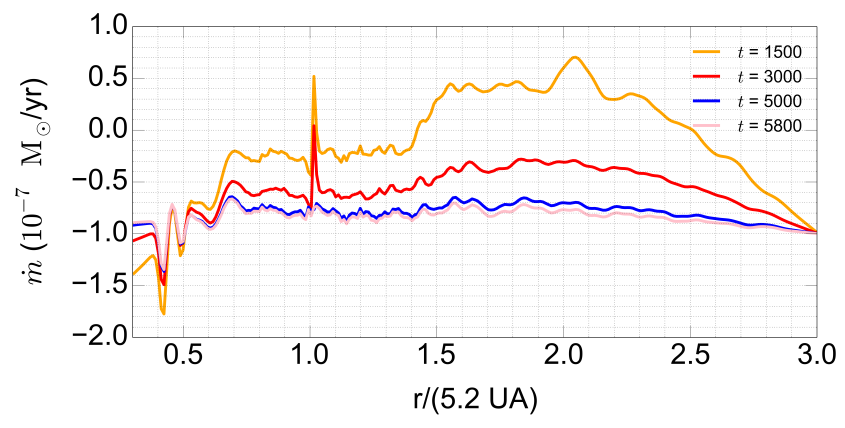

Figure 1. Profiles of the local accretion rate obtained for the standard parameter set $(\alpha, q, \dot{m})=\left(0.003,0.001,10^{-7} \frac{\mathrm{M}_{\star}}{\text { year }}\right)$, with a planet at $r=1$. The profiles are shown at four different instants after the beginning of the calculation. Time is dimensionless and is defined in terms of the number of orbits of the planet fixed at $r=1$ code units.

These analyses require the gas disc to be in equilibrium. Thus, following the approach of Dürmann \& Kley (2015), we calculate the time needed for the disc to reach the steady state. Figure 1 shows the profiles of $\dot{m}(r)$ as a function of the radius of the disc after different time periods, calculated for the planet of $1.0 \mathrm{M}_{\mathrm{J}}$ fixed at $r=1$ code units. To calculate the local accretion rate, we include a specific subroutine in the FARGO3D code, which integrates the azimuthal mass fluxes produced by the code.

As seen in Figure 1, although the profile of the accretion rate does not attain a constant value, it converges to a nearly flat function between 5000 and 5800 orbital periods of the disc. Thus, we can assume that the disc reaches equilibrium state after 5000 orbits and adopt this value as a standard timespan.

Figure 2 shows the azimuthally averaged surface density for non-accreting (solid lines) and accreting (dashed lines) planets, obtained after 5000 orbital periods of the disc, for the three values of planetary masses and three different viscosity regimes used in our simulations. As expected, we observe the completely developed gaps in all cases. The gaps are increasing in depth with the increasing planet mass and the decreasing viscosity of the disc. The regions of overdensity at the positions of the planets $(r=1$ code units) appear in the case when accretion processes are not considered (solid lines). This is due to the accumulation of gas around the non-accreting planet, treated as a point in the hydrodynamic mesh; when the gas accretion into the planet is taken into account, this artefact disappears (dashed lines). Finally, we have performed the same simulations for different accretion rates of the disc, $\left(10^{-8} \mathrm{M}_{\star} \mathrm{yr}^{-1}\right.$ and $\left.10^{-9} \mathrm{M}_{\star} \mathrm{yr}^{-1}\right)$, but we have not observed any significant difference; the same behaviour is reported for the NIRVANA code in Dürmann \& Kley (2015).

\subsection{Migrating planets without growth}

Soon after the gas disc reaches equilibrium, the planets are allowed to migrate. We followed the migration tracks of planets for the parameter sets shown in Table 1. The measurements were performed for accreting and non-accreting planets during 1200 orbital periods of the disc; in the accreting 

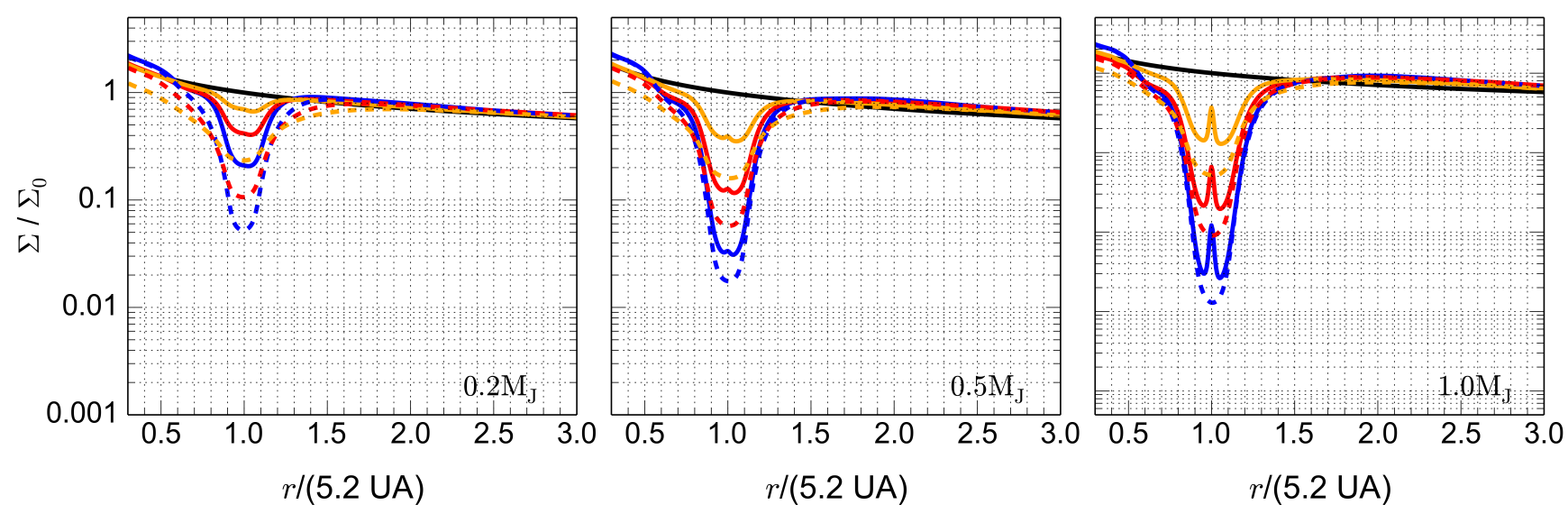

Figure 2. Azimuthally averaged surface density for non-accreting (solid line) and accreting (dashed line) planets for different values of the planet mass (left: $\simeq 0.2 \mathrm{M}_{\mathrm{J}}$ or $q=0.0002$, middle: $\simeq 0.5 \mathrm{M}_{\mathrm{J}}$ or $q=0.0005$ and right: $\simeq 1 \mathrm{M}_{\mathrm{J}}$ or $q=0.001$ ). The blue lines corresponds to $\alpha=0.001$, the red lines to $\alpha=0.003$ and orange lines $\alpha=0.010$. The black line indicates the initial density at the beginning of the simulation without planet.

case, the mass withdrawn from the disc was not added to the planet.

The migration tracks obtained are shown Fig. 3, where the parameters of the standard set are changed one-by-one, in order to analyse the behaviour of the planet. We show the dependence of the rate of migration on the viscosity of the disc in the left frame of Fig. 3. In the case of high viscosity $(\alpha=0.015)$, there is a notable difference between the behaviour of accreting (dashed line) and non-accreting (solid line) planets. With decreasing $\alpha$, the difference also decreases and we note no difference in the case of low viscosity $(\alpha=0.001)$.

The middle frame of Fig. 3 shows that the behaviour of the planet for different accretion rate of disc is only slightly different for accreting (dashed line) and non-accreting (solid lines) planets.

According to the right frame of Fig. 3, the effect of accretion process is much more significant for low-mass planets. This is due to the fact that it accelerates the opening of the gap in a region where the gravitational effect of the planet is less intense.

As shown in Fig. 3, in general, the orbital decay of the planet is slower for accreting planets than for non-accreting planets. This difference is less significant with the increase of the planetary mass (right frame) and for the decreasing accretion rate of disc (middle frame). This is due to the fact that the density along the disc decreases with the decrease of the rate of accretion (see Eq. 13); as a consequence, the total mass of the disc also decreases. Moreover, the gas mass in the nearby region of the planet also decreases when planets are accreting. In fact, this decrease in the gas mass near the planet causes the effect of the torque on the planet to decrease, thus, large planets in low mass discs have a smaller effect on their migratory process due to gas accretion. Similar results were obtained by Dürmann \& Kley (2015) using a different model for gas accretion.

It should be noted that some simulations were excluded from our analysis. This is the case when the planets escape from the gap, what occurs for the non-accreting planets with the masses of $0.2 \mathrm{M}_{\mathrm{J}}$ and $0.5 \mathrm{M}_{\mathrm{J}}$, in the low $(\alpha=0.001)$ and medium $(\alpha=0.003)$ viscosity regime. This also occurs for the planet with the mass of $0.2 \mathrm{M}_{\mathrm{J}}$ for accreting planets in all viscosity regimes considered.

In what follows, we analyse how the gas accretion model influences both the gap profile and the mass fluxes in the gap.

\subsubsection{Gap profiles for accreting and non-accreting planets}

The gap created by the planet in the disc has a significant impact on the migration process because the decreasing superficial density of gas in the gap region reduces the contribution to the torque on the planet (Dürmann \& Kley 2015).

Figure 4 shows the time evolution of the gaps created by non-accreting planets (left panel) and accreting planets (right panel). We compare the plots when the planet is in the same radial position, consequently, time is different in both plots. Looking at the planet at given positions helps to better understand the difference in local physical processes. For accreting planets, we note a larger lost of mass at the inner border of the disc due to the boundary conditions. When the planet is far away from the inner border of the disc, this effect does not influence on the profile of the gap. A similar analysis was done for different parameter sets from Table 1 and the conclusion made is that effect is stronger in the higher viscosity regime and for lower accretion rate of disc.

Figure 5 shows the local disc structure in the gap region obtained for the standard parameter set. The gap profile suffers no significant changes during the migration process of accreting and non-accreting planets. In addition, in Fig. 5 , we observe that the density bump (mass concentration around the position of the planet) is eliminated in the case of accreting planets. This feature remains during planetary migration and the same effect can be observed for different values of the planetary mass and accretion rate of the disc.

Considering different values of the disc mass (i.e., accretion rate of the disc), we have found that, for fixed $\alpha$ value, the gap structure near the planet does not change considerably, in both cases of accreting and non-accreting 

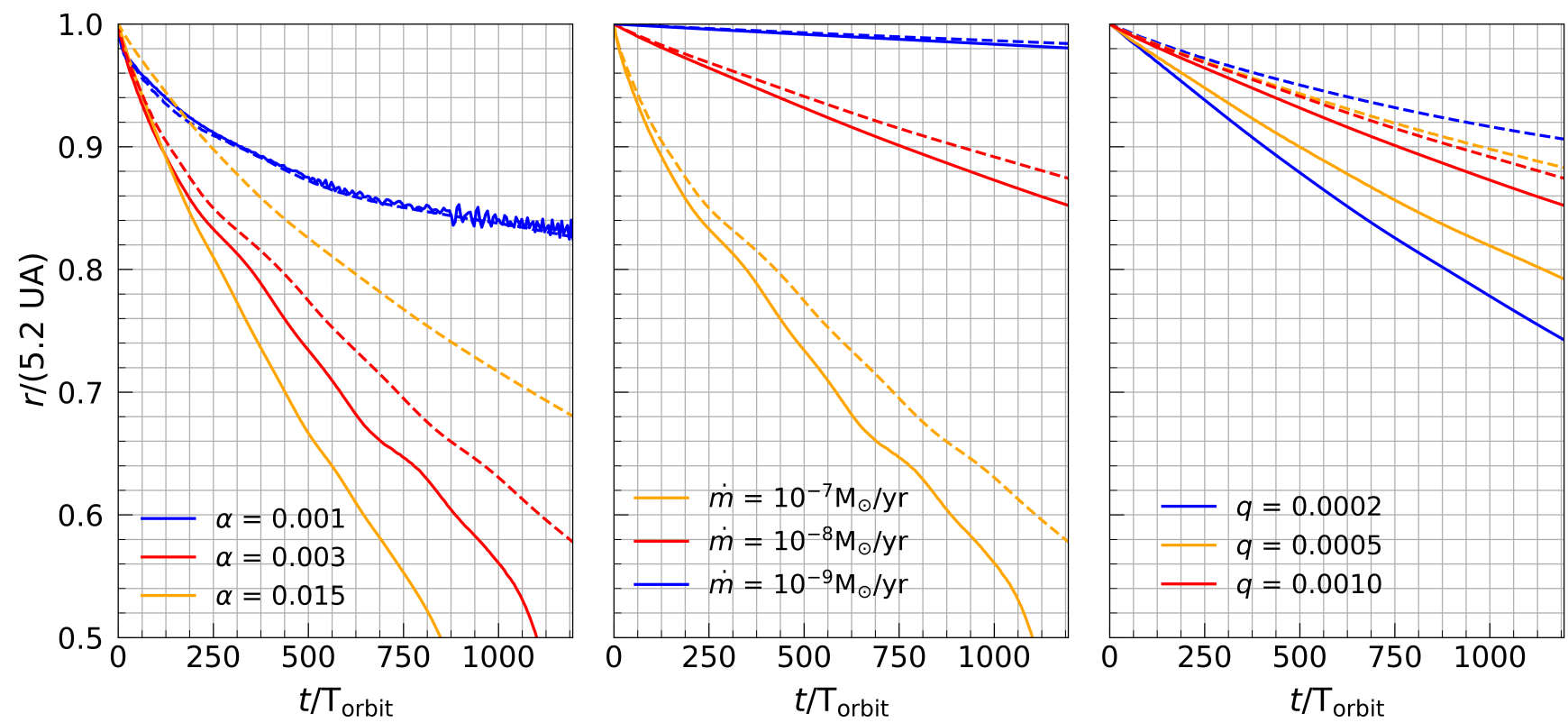

Figure 3. Planet migration tracks for different model parameters. In the left frame we have a planet mass of $\simeq 1 \mathrm{M}_{\mathrm{J}}($ or $q=0.001$ ) on a disc with accretion rate $10^{-7} \mathrm{M}_{\odot} / \mathrm{yr}$ for different viscosity values (blue: $\alpha=0.001$, red: $\alpha=0.003$ and orange: $\alpha=0.015$ ). In the central frame we have a planet mass of $\simeq 1 \mathrm{M}_{\mathrm{J}}$ (or $q=0.001$ ) on a disc with $\alpha=0.003$ and different accretion rates (orange: $10^{-7} \mathrm{M}_{\odot} / \mathrm{yr}$, red: $10^{-8} \mathrm{M}_{\odot} / \mathrm{yr}$ and blue: $10^{-9} \mathrm{M}_{\odot} / \mathrm{yr}$ ). In the right frame we have different planetary masses (blue: $\simeq 0.2 \mathrm{M}_{\mathrm{J}}$ or $q=0.0002$, orange: $\simeq 0.5 \mathrm{M}_{\mathrm{J}}$ or $q=0.0005$ and red: $\simeq 1.0 \mathrm{M}_{\mathrm{J}}$ or $\left.q=0.001\right)$ in a disc with $\alpha=0.003$ and accretion rate $10^{-8} \mathrm{M}_{\odot} / \mathrm{yr}$. The solid line is for non-accreting planets, and the dashed line for accreting planets.

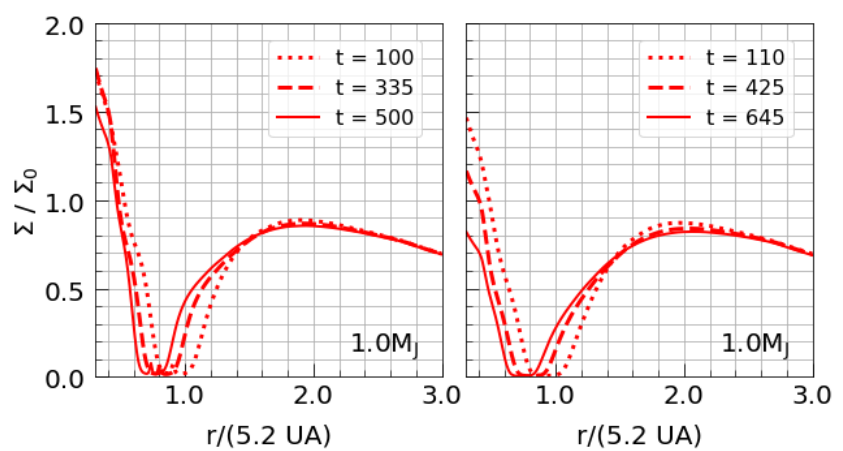

Figure 4. Global gap profiles obtained for the standard parameter set, at three different times during planet migration. The left frame corresponds to non-accreting planets, while the right frame corresponds to accreting planets.

planets. These results agree with the results obtained with the NIRVANA code in Dürmann \& Kley (2015), where only non-accreting planets were investigated.

In summary, for accreting planets, our results show that, despite the accretion of gas generating deeper gaps, the gas accretion does not alter significantly the gap profile around the migrating planet provided that the gap is established.

\subsubsection{Flow across the gap for accreting and non-accreting planets}

Figure 6 shows the averaged azimuthal torques, which act on non-accreting (left panel) and accreting (right panel) planets, in their close vicinity. The torques were calculated for
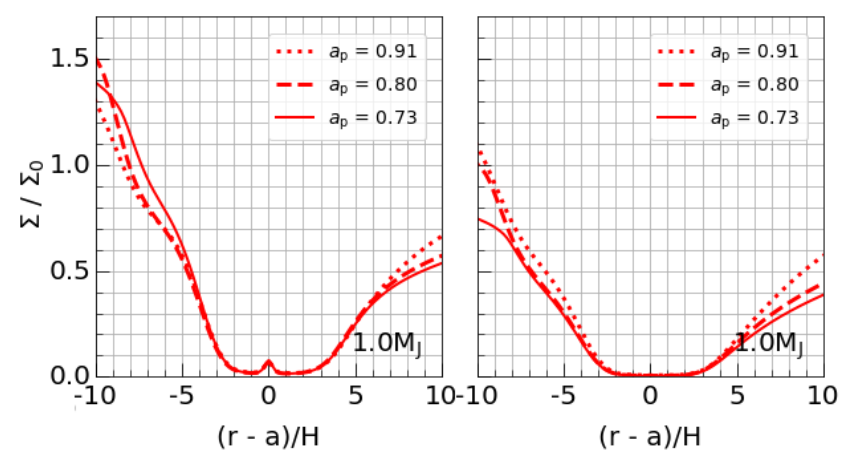

Figure 5. Gap profiles obtained for the standard parameter set, at different positions of the planet in the disc during its migration path. The gap is re-scaled using the local disc scale height, $H$, at the position of the planet. The curves correspond directly to those shown in Fig. 4. The left frame corresponds to non-accreting planets, while the right frame corresponds to accreting planets.

the standard parameter set. The magnitude of each torque is normalized with respect to the maximum value obtained along the radial distance. In both cases, the torques are stabilised in a few hundred orbits and reach the highest values in the vicinity of the planet (from -5 to +5 in the $x$-axis in Fig. 6). For both accreting and non-accreting planets, the plots shows that the torques depend only slightly on the position of the planet in the disc.

Additionally, Fig. 6 shows that the torque produced by the internal disc is proportionally stronger (of the order of $10 \%$ ) for accreting planets than for non-accreting planets. The similar behaviour was observed in the low viscosity 

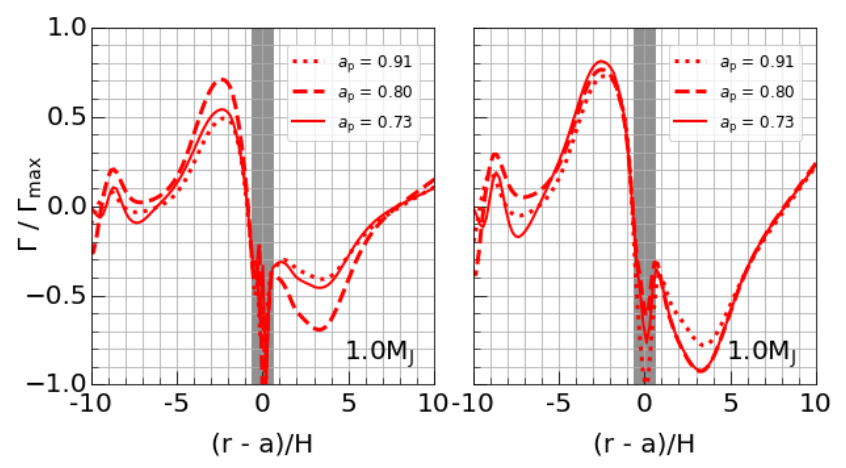

Figure 6. Normalized torques for the same model as in Fig. 5, at the same times and respective positions. The left frame corresponds to non-accreting planets, while the right frame corresponds to accreting planets. The gray area is the attenuated region within the Hill radius.

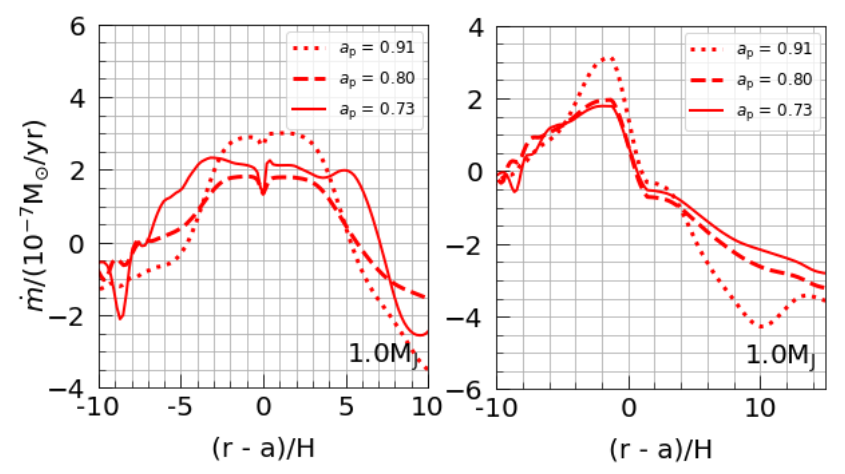

Figure 7. Azimuthally averaged local accretion rate, $\dot{m}(r)$, at different positions of the planet during the migration of the planet for the same model as in Fig. 5.

regime. In the case of the high viscosity regime, we have noticed a positive torque which was closer to the accreting planets. The gray area in Fig. 6 shows the region of attenuation defined by Eq. 14. For accreting planets, the torque within this region is smaller that is related to the decreasing mass due to the gas accretion by the planet.

In Fig. 7, we show the mass accretion rate in the neighbourhood of the planet, $\dot{m}(r)$, at different positions of the migrating planet, for non-accreting (left frame) and accreting (right frame) planets. For non-accreting planets (left panel), there is a large positive flow (contrary to the movement of the planet), which arises due to the fact that the migration velocity of the planet is higher than the viscous accretion speed. The same behaviour was observed in the case of low viscosity regime. On the other hand, in the high viscosity regime, with low accretion rates for the disk, we have found some cases for which the gas flow is negative in the region close to the planetary gap. In this cases the migration velocity of the planet is lower that the viscous speed. These results are very similar to those obtained by Dürmann \& Kley (2015) for NIRVANA code, for nonaccreting planets.

For accreting planets (Fig. 7 right), we note a sharp fall of the gas flow in the accretion region. This is due to the fact that the planet is treated as a massive point in the hy- drodynamic mesh, despite that the mass is withdrawn from the disc in the accretion region around the planet. Analysing the mass flow around the planet in the case of high viscosity regime, we have noted that the fall of the gas flow is sharper due to the fact that the gas mass near the planet is smaller in this case. The observed asymmetry of the gas flow in the case of the accreting planet results in a distribution of gas around the planet, which is different from that around the non-accreting planet. As a consequence, the differential torque is smaller for accreting planets when compared to that for non-accreting planets.

Finally, in the case of low accretion rate of the disc and the high viscosity regime, the positive torque due to the internal disc is proportionally higher in regions close to the planet than in the case of the medium viscosity regime. However, the effect of attenuation of torques on the planet given by Eq. 14 does not allow the reverse migration of accreting planets.

\subsection{Migrating planets with mass growth}

In this section we analyze the growth of a planet with the initial mass of $\simeq 1 \mathrm{M}_{\mathrm{J}}$. Since, in this case, we do not need to wait for the disc to attain the equilibrium state, we allow the planet to start migrating after only 300 orbits, which is the time necessary to the disc stabilize in the planet's presence. In the first 300 orbits, the planet is fixed on circular orbit, the gas is removed from the disc and the mass of the planet is kept constant.

To understand the influence of the planetary mass increase on the planet's migration process, we compare different scenarios of gas accretion onto the planet. In the first scenario, described in Kley (1999), the accretion rate is adjusted by the parameter $k_{a}$, which is a factor of increase or decrease of accretion. The second scenario corresponds to Russel's model (Russell 2011) described in Sect. 2. Two cases are observed: in case $\mathbf{R}$, the mass is removed from the disc, but does not added to the planet, while in case RA the mass is removed and subsequently added to the planet. The linear moment of the accreted gas is not added to the planet, since its change does not interfere significantly on the resulting process (Dürmann \& Kley 2017). Finally, for the sake of comparison, we include a model $\mathbf{N}$, which does not consider for gas accretion, thus no mass is removed from the disc by the planet.

The time evolution of the semimajor axis of the planet with initial mass equal to $\simeq 1 \mathrm{M}_{\mathrm{J}}$, in the different scenarios, is shown in Fig. 8. Comparing the $\mathbf{N}$ model (black curve) with the $\mathbf{R}$ (blue curve) and RA (cyan curve) models, we can observe that the removal of mass from the region around the planet decreases significantly the migration rate. Moreover, when the removed mass is added to the planet, the planetary inertia increases and, consequently, the the migration rate decreases. The decay of the semimajor axis in the model RA follows closely Kley's model with larger value of the parameter $k_{a}=2.0$. According to Dürmann \& Kley (2017), this value is a saturated upper limit of the accretion rate.

The growth of the planetary mass initially with $\simeq 1 \mathrm{M}_{\mathrm{J}}$ is shown in Fig. 9, where the continuous cyan curve corresponds to Russell's model RA, while the dashed curves correspond to Kley's model, with different values of the parameter $k_{a}$. We observe that, according to the model RA, 


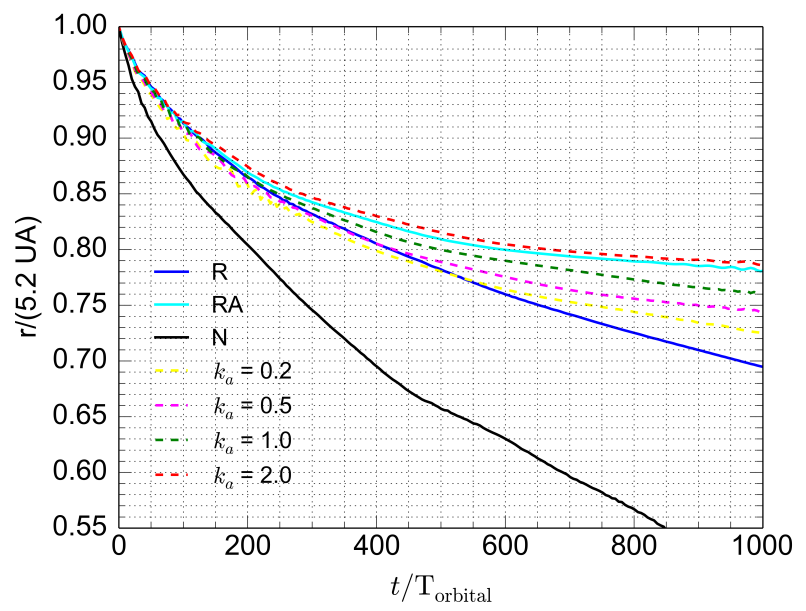

Figure 8. Orbital decay of a planet with initial mass equal to $\simeq 1 \mathrm{M}_{\mathrm{J}}$. Model $\mathrm{N}$ : no matter is removed from the gas disc. Model $\mathbf{R}$ : the gass is removed, without be added to the planet. Model RA: the gas is removed according to Russell's approach (2011) and added to the planet. Kley's approach (1999) is used with the different values of the parameter $k_{a}, 0.2,0.5,1.0$ and 2.0, when the mass is added to the planet.

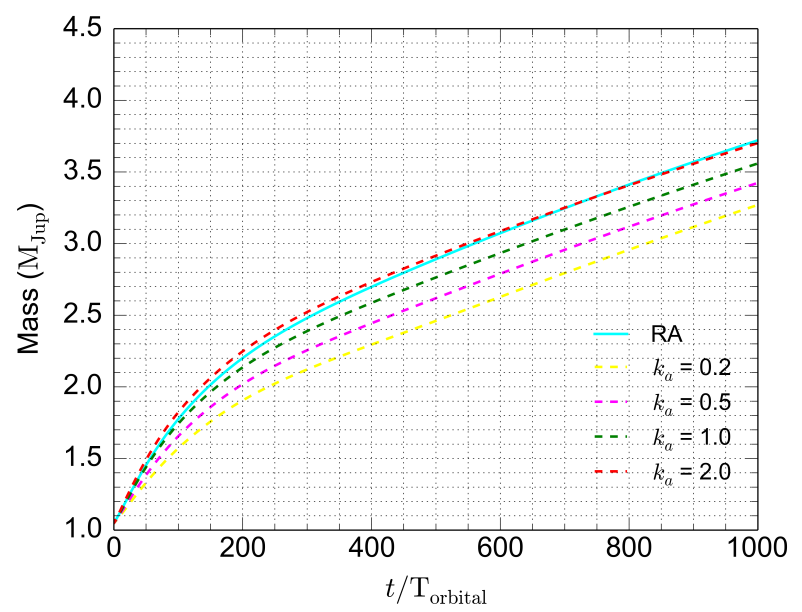

Figure 9. Growth of a planet with initial mass equal to $1 \mathrm{M}_{\mathrm{J}}$. In the model RA the gas is removed according to Russell's approach (2011) and added to the planet. In the model with $k_{a}=0.2,0.5$, 1.0 and 2.0 the mass is removed using Kley's approach (1999) and the mass too is added to the planet.

the planet reaches the mass of more than $3.5 \mathrm{M}_{J}$ in 1000 orbits, which is very similar to what is observed using Kley's model with $k_{a}=2.0$. This shows that, indeed, the runaway regime for gas accretion in Russell (2011) is equivalent to the model in Kley (1999) for high accretion rates.

The surface density of the gas around the planet when the planet crosses $r=0.85 R_{0}$, is shown in Fig. 10, for the same models presented in Fig. 8. As expected, the gap is deeper when the planetary mass is higher at that instant, that happens for higher gas accretion rates. According to Fig. 9, the larger values of the mass correspond to the scenarios RA and $k_{a}=2.0$. Also, the higher accretion rates are

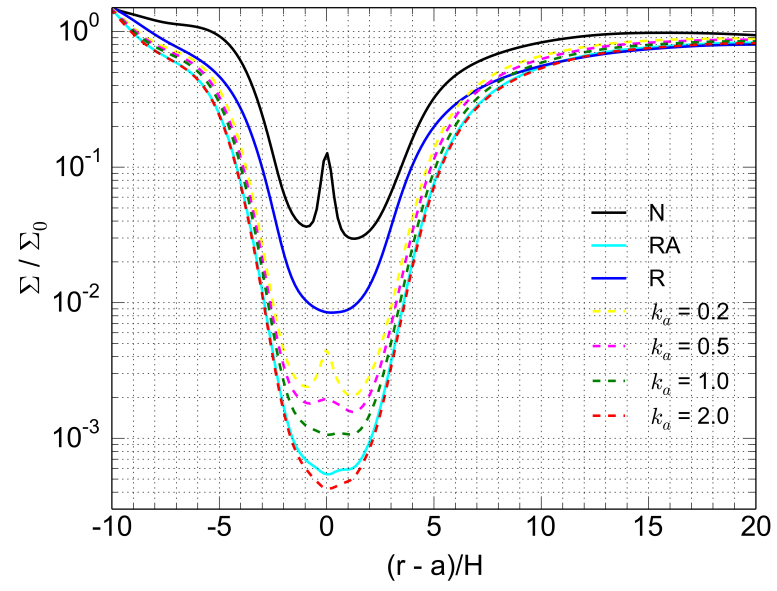

Figure 10. Surface density profile close to the planet for the different models of accretion when the planet has reached $r=$ $0.85 R_{0}$. Model $\mathbf{R}$ : the gass is removed, without be added to the planet. Model RA: the gas is removed according to Russell's approach (2011) and added to the planet. Kley's approach (1999) is used with the different values of the parameter $k_{a}, 0.2,0.5,1.0$ and 2.0, when the mass is added to the planet.

responsible for the decreasing of the overdensity effect in the vicinity of the planet. Once again, we notice that the result obtained for the runaway regime with model RA is very similar to that obtained with $k_{a}=2.0$.

Fig. 11 shows gas accretion rates for a growing giant planet. The behavior for the gas accretion rate in runaway regime is qualitatively very similar to the one obtained by Mordasini et al. (2012), that uses a more complex model for gas accretion. However, in our model the planet can migrate and the disc model is different, so the results can not be compared in quantitative terms. A more detailed analysis that includes an adiabatic disk will be carried out in future works.

The results obtained show that Russell's model (Russell 2011) and Kley's model (Kley 1999) provide similar results when work with the giant planets in the runaway regime for gas accretion. However, the model in Kley (1999) is not adapted to simulate the accretion of the low mass planets, because it does not account for the Kelvin-Helmholtz scale. In contrast, Russell's model can be used to investigate the growth of the low mass planets since it adopts this approach.

\section{GROWTH OF LOW MASS PLANETS}

In order to study the accretion process in the case of low mass planets, we place a planet of mass $\simeq 20 \mathrm{M}_{\text {Earth }}$ in a fixed orbit ( $r=1$ code units) and analyze the increase of the planetary mass using the model for gas accretion described in section 2.

Figure 12 shows the in situ growth of the planet in the disc described by the standard parameter set from Table 1. We observe that initially the planetary mass increases monotonously and slowly, but this process accelerates significantly when the planet enters in the runaway regime. This occurs after approximately 1800 orbits, when the plan- 


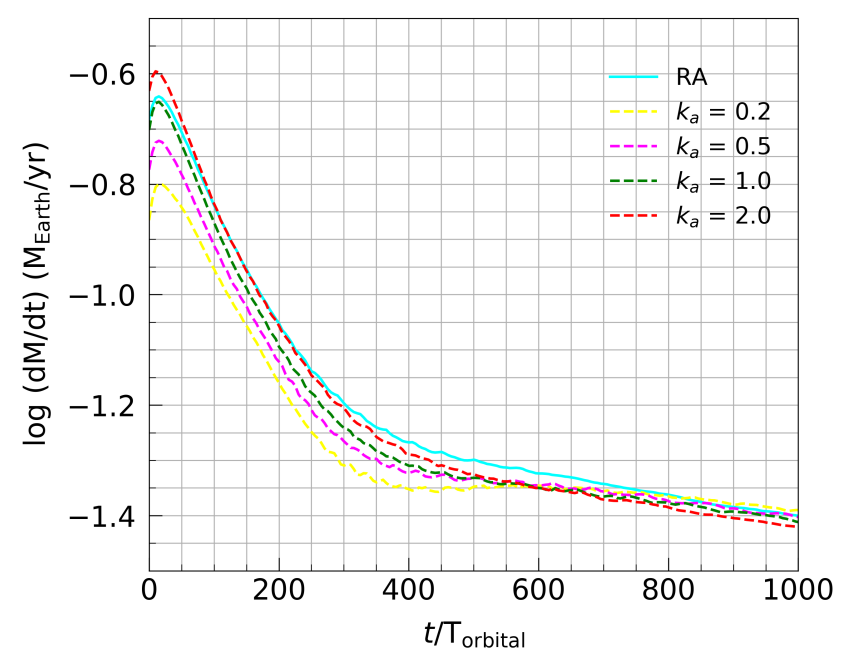

Figure 11. Gas accretion rates as a function of time. Model RA: the gas is removed according to Russell's approach (2011) and added to the planet. Kley's approach (1999) is used with the different values of the parameter $k_{a}, 0.2,0.5,1.0$ and 2.0, when the mass is added to the planet.

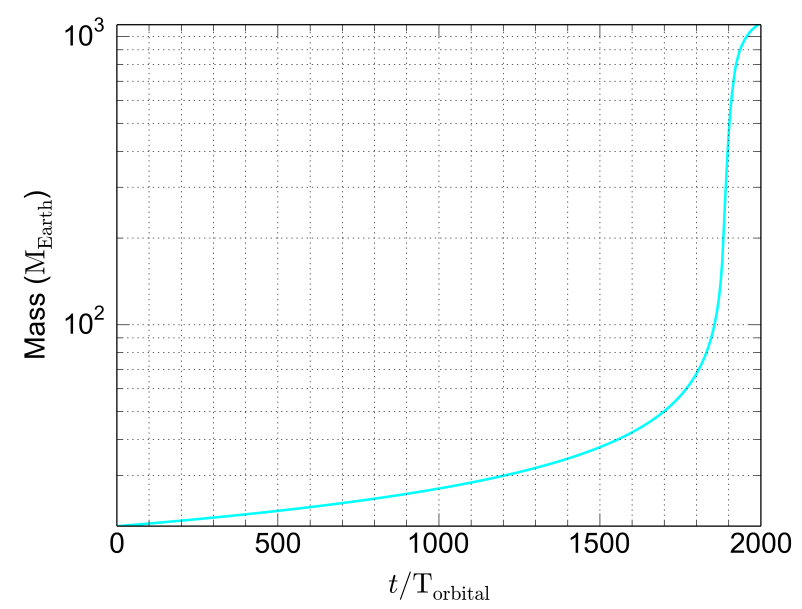

Figure 12. In situ formation of initial mass planet $\simeq 20 \mathrm{M}_{\text {Earth }}$ at $r=1$ code units using the model for gas accretion described in section 2 .

etary mass reaches $\sim 0.2 \mathrm{M}_{\mathrm{J}}$, this behaviour is in agreement with other models for gas accretion (Alibert et al. 2005; Fortier et al. 2013). It should be noted that any model which considers only runaway accretion regime, would not be able to reproduce this behaviour, since, in this case, the formation time would be very short. The runaway accretion decreases the time for the planet to establish type II migration, since the gas along the planetary orbit is quickly exhausted.

Fig. 13 shows gas accretion rates for the planet fixed in $r=1$ code units. The behavior for the gas accretion rate is similar to the one obtained by Mordasini et al. (2012), that uses a more complex model for gas accretion. The only difference observed is the scale of the accretion rate, which is due to the fact that our model for the gas disk has a much higher surface density, thus resulting in higher accretion rates. In Mordasini et al. (2012) it is also possible to

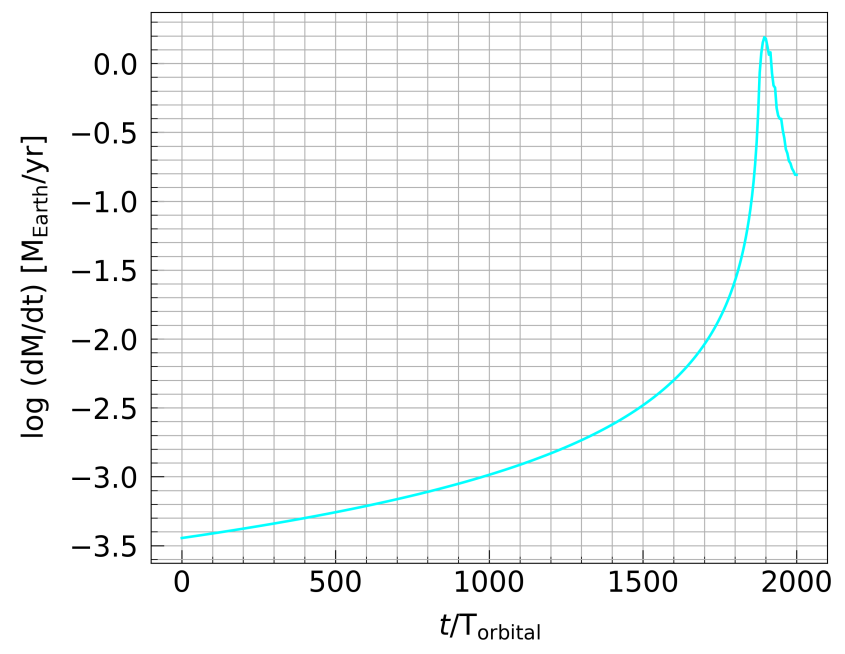

Figure 13. Gas accretion rates as a function of time for the situ formation of initial mass planet $\simeq 20 \mathrm{M}_{\text {Earth }}$ at $r=1$ code units using the model for gas accretion described in section 2 .

find a complete scenario that includes the formation of the solid core. Here, we already start with a mass of $\simeq 20 \mathrm{M}_{\text {Earth }}$. A complete scenario including a solid accretion model within the FARGO3D is under development and will be analyzed in future work.

We analyze the effect of gas accretion on the movement of the gas around the planet by performing a streamline analysis, shown in Fig. 14. In Fig. 14a, we observe that, at the beginning of the accretion process, the accreted gas comes from regions near the planet. Moreover, we notice a high gas density region around the planet. In Fig. 14b, the gravitational perturbations due to the planet tend to clear the gas along the planetary orbit, at the same time increasing the gas density in the region close to the planet. The accretion rate of gas is still too slow to decrease the gas density close to the planet. As the planetary mass increases, the gas mass tends to accumulate in the spiral arms. The mass transfer from the outer disc to the inner disc in the region close to the planet is still small.

In Fig. 14c, the planet starts to accrete the gas in the runaway regime; we see the mass depletion in the region around the planet, and the gas density around the planet tends to decrease. Following, the planet begins to accrete gas from the connection of the inner disc with the outer disc. In Fig. 14d, we see a stronger mass transfer between the inner and outer disc. The gas tends to surround the planet and the high rate of gas accretion tends to clear the nearby region of the planet. Finally, in Fig. 14e, an amount of gas surrounds the planet, where it is accreted to the planets, while the rest of the gas is accelerated by the planet and driven to the inner disc. Thus, we can observe an intense mass flow between the inner and outer discs.

In summary, much of the mass during the early stages of accretion comes from regions along the orbit of the planet. However, with the increase of the planetary mass and the clearing of the orbital region, a connection between the inner and outer discs is established, from where the mass is accreted now. In any case, despite the accretion of gas, the time needed for the planet to clear its orbit is still very long. Thus, type I migration would be sufficient to drive the 

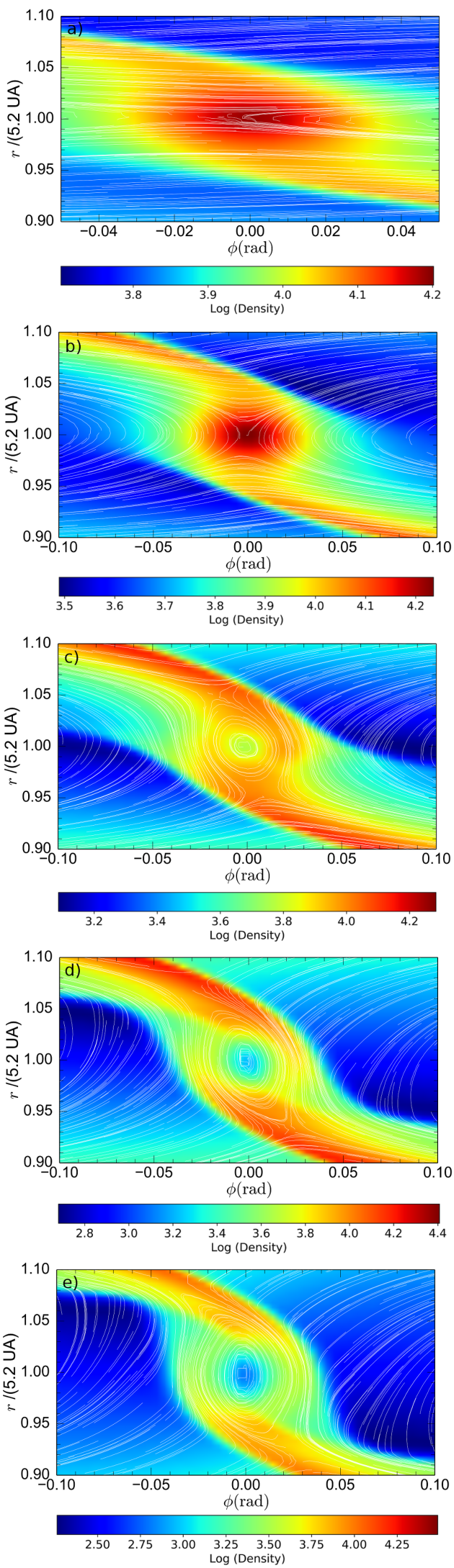

Figure 14. The grid mesh colored with the log of the superficial density (in $\mathrm{kg} / \mathrm{m}^{2}$ ) and with the streamlines in the planet's frame. $(\mathrm{A}) \simeq 30 \mathrm{M}_{\text {Earth }}(t=1210$ orbits $),(\mathrm{B}) \simeq 0.2 \mathrm{M}_{\mathrm{J}}(t=1800$ orbits $)$, $(\mathrm{C}) \simeq 0.5 \mathrm{M}_{\mathrm{J}}(t=1880$ orbits $),(\mathrm{D}) \simeq 1.2 \mathrm{M}_{\mathrm{J}}(t=1895$ orbits $)$ and $(\mathrm{E}) \simeq 2.0 \mathrm{M}_{\mathrm{J}}(t=1910$ orbits $)$. planets close to the star until the planet enters a type II migratory process.

In the model investigated in the paper, the gas accretion process for low-mass planets does not depend substantially on the position of the planet in the disc. It should be stressed that we do not consider solid core growth due to accretion of planetesimals that is a process which is strongly dependent on the density of solids along the disc. Therefore, it is necessary to consider accretion of solids to increase the rate of mass accretion. In addition, the accretion rate of solids is important in determining the critical mass for which gas accretion begins (Ikoma et al. 2000). A model for accretion of solids will be elaborated in future work.

\section{CONCLUSIONS}

In this work we studied the migration of massive planets in locally isothermal disc in equilibrium using the FARGO3D code. Initially, the position of the planet was fixed and the structure of the gap was analyzed for different values of the planetary mass and disc viscosity (Fig. 2). We obtained that the depth of the gap increases with planet mass and reduces with increasing viscosity. This result is in agreement with that obtained by Dürmann \& Kley (2015) using the NIRVANA code for non-accreting planets. For accreting planets, the gaps are deeper, while the overdensity regions close to the planets are vanishing. The results above are independent of the initial accretion rate of the disc.

Analyzing the flux through the gap during the migration process, we observe rapid inward migration in the case when the planet decays faster than the typical viscous inward drift of the disc material. We find that, for smaller disc mass and higher viscosity, the planet decays more slowly than the typical viscous inward drift of the disc material.

In this paper, we performed simulations for both nonaccreting planets and accreting planets. In latter case, we adapt a model for gas accretion from Russell (2011), to calculate the rate of accretion. Our main goal is to use a more rigorous and robust gas accretion scheme that is valid and consistent for a larger range of planetary masses. In this model, the size of the accretion zone is obtained taking into account the planet's Bondi radius and the Hill radius; in this way, physical characteristics of the disc, such as its thermal velocity, become important to determine which cells belong to the accretion region. The timescales involved in accreting gas onto a planet are also calculated cell-by-cell using the orbital period about the planet instead of the predefined orbital period in the predecessor code. This modification allows us to obtain an accretion rate in the runaway regime that is closer to the Bondi accretion limit.

Also, we take into account the Kelvin-Helmholtz collapse time-scale in approximation of the planet's gas accretion rate for small masses. This modification allows us to study the gas accretion process for planets which have not yet reached the runaway regime.

As expected, the reduced mass in the vicinity of the planet reduces migration rate for accreting planets. The difference in the values of the migration rates becomes less significant with the increase of the planetary mass (Fig. 3, right) and with the decrease of disc accretion rate (Fig. 3, center). Also, the effect of the gas accretion is more signifi- 
cant in higher viscosity regimes (Fig. 3, left). In fact, in low viscous discs, the mass tends to accumulate faster in the regions around the planet and accretion can not account for cleaning the region in order to change significantly the differential torque. Minor planetary masses are more affected from the accretion process, because the smaller the mass of the planet, the smaller the gravitational effect that prevents the mass from entering the gap, therefore, the process of accretion tends to clean the region of the planet favoring the appearance of the planetary gap.

In this work, we study only $2 \mathrm{D}$ discs. For massive planets, the averaged gap profile is identical for $2 \mathrm{D}$ and $3 \mathrm{D}$ discs and we may expect very similar effects for the planetary migration. Nevertheless, it may be interesting to perform 3D simulations and analyze the migration properties because little is known yet about the mechanism of gas accretion in the $3 \mathrm{D}$ case.

The size of the accretion zone depends on the thermal velocity of the gas. Recent works show the importance of considering the thermodynamical effects involved in the gas accretion process. Changes in entropy can change the luminosity and the geometry of the accretion zone, thus modifying the gas accretion rate of the planet. Recent 3D hydrodynamic simulations show that supersonic shock fronts are important for analyzing the thermodynamics of the accretion process (Marley et al. 2007; Szulágyi \& Mordasini 2017). Thus, in future works, it would be interesting to explore the changes that radiative discs could provoke in the accretion zone. Models with larger numerical resolutions would be needed in this case.

We test the model of gas accretion for the runaway regime by considering a $1 \mathrm{M}_{\mathrm{J}}$ mass planet migrating towards the star and accreting mass during its motion. We note that the runaway regime corresponds to that used by Kley (1999) for parameter $k_{a}=2.0$. This agrees with the expected result given that the accretion of gas is close to the saturated regime for this parameter.

Also, we simulated the growth of a low mass planet fixed at position $r=1$ code units and we evaluated the time to enter the runaway regime and open the gap needed for type II migration. We found a time of approximately 1800 orbits, which is very high considering the rapid migration of type I. Thus, the planet would fall in the star before being able to open the gap. However, this has to be yet further investigated. In fact, new parameters for the gas disc may reveal a faster gap opening process, specially on heat transfer discs. In addition, a complete model that includes the accretion of planetesimals could give us an indication of when the gas accretion process begins. These factors will be explored in future work.

\section{ACKNOWLEDGEMENTS}

The authors are grateful to P. Benítez-Llambay for meaningful discussions and suggestions. This work was supported by FAPESP (Brazil) through the grants 2014/00492-3. This work has used the computing facilities of the Laboratory of Astroinformatics (IAG/USP, NAT/Unicsul), that were purchased thanks to the Brazilian agency FAPESP (grant 2009/54006-4) and the INCT-A. 


\section{REFERENCES}

Alibert Y., Mordasini C., Benz W., Winisdoerffer C., 2005, A\&A, 434, 343

Armitage P. J., 2010, Astrophysics of Planet Formation

Baruteau C., Masset F., 2013, in Souchay J., Mathis S., Tokieda T., eds, Lecture Notes in Physics, Berlin Springer Verlag Vol. 861,

Lecture Notes in Physics, Berlin Springer Verlag. p. 201 (arXiv:1203.3294), doi:10.1007/978-3-642-32961-6_6

Baruteau C., Papaloizou J. C. B., 2013, ApJ, 778, 7

Benítez-Llambay P., Masset F., Beaugé C., 2011, A\&A, 528, A2

Benítez-Llambay P., Masset F., Koenigsberger G., Szulágyi J., 2015, Nature, 520, 63

Bondi H., 1952, MNRAS, 112, 195

Bryden G., Lin D. N. C., 1999, in Bulletin of the American Astronomical Society. p. 1130

Dürmann C., Kley W., 2015, A\&A, 574, A52

Dürmann C., Kley W., 2017, A\&A, 598, A80

Edgar R., 2004, New Astron. Rev., 48, 843

Fortier A., Alibert Y., Carron F., Benz W., Dittkrist K.-M., 2013, A\&A, 549, A44

Goldreich P., Tremaine S., 1980, ApJ, 241, 425

Ida S., Lin D. N. C., 2004, ApJ, 604, 388

Ikoma M., Nakazawa K., Emori H., 2000, ApJ, 537, 1013

Kley W., 1999, MNRAS, 303, 696

Kley W., Nelson R. P., 2012, ARA\&A, 50, 211

Lin D. N. C., Papaloizou J., 1986, ApJ, 309, 846

Lin D. N. C., Papaloizou J. C. B., 1993, in Levy E. H., Lunine J. I., eds, Protostars and Planets III. pp $749-835$

Lissauer J. J., 1993, ARA\&A, 31, 129

Marley M. S., Fortney J. J., Hubickyj O., Bodenheimer P., Lissauer J. J., 2007, ApJ, 655, 541

Masset F., 2000, A\&AS, 141, 165

Meyer-Vernet N., Sicardy B., 1987, Icarus, 69, 157

Mordasini C., Alibert Y., Georgy C., Dittkrist K.-M., Klahr H., Henning T., 2012, A\&A, 547, A112

Nelson R. P., Papaloizou J. C. B., Masset F., Kley W., 2000, MNRAS, 318, 18

Ogilvie G. I., Lubow S. H., 2006, MNRAS, 370, 784

Pollack J. B., Hubickyj O., Bodenheimer P., Lissauer J. J., Podolak M., Greenzweig Y., 1996, Icarus, 124,62

Russell J. L., 2011, PhD thesis, Canada: Univerty of Guelph, https://atrium.lib.uoguelph.ca/xmlui/bitstream/ handle/10214/3212/thesis.pdf?sequence $=11$

Shakura N. I., Sunyaev R. A., 1973, A\&A, 24, 337

Szulágyi J., Mordasini C., 2017, Monthly Notices of the Royal Astronomical Society: Letters, 465, L64

Tanaka H., Takeuchi T., Ward W. R., 2002, ApJ, 565, 1257

Udry S., Santos N. C., 2007, ARA\&A, 45, 397

Ward W. R., 1986, Icarus, 67, 164

Ward W. R., 1997, Icarus, 126, 261

Ziegler U., 1998, Computer Physics Communications, 109, 111 